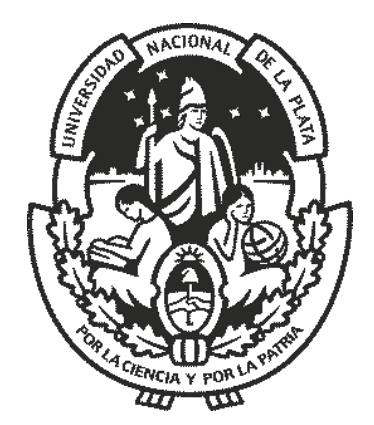

\title{
UNIVERSIDAD NACIONAL DE LA PLATA
}

FACULTAD DE CIENCIAS EXACTAS

DEPARTAMENTO DE QUIMMICA

Trabajo de Tesis Doctoral

PULPAS DE FRUTOS PATAGONICOS: PROCESOS, CONSERVACIÓN Y DESARROLLO DE ALIMENTOS FUNCIONALES

Carolina Antonella Paulino

Director: Dr. Antonio De Michelis

Asesora académica: Dra. Alicia Chaves 
El presente trabajo de Tesis Doctoral, para optar al título de Doctor de la Facultad de Ciencias Exactas de la Universidad Nacional de La Plata, fue realizado en la Facultad de Ciencias y Tecnología de los Alimentos, Universidad Nacional del Comahue, bajo la dirección del Dr. Antonio De Michelis.

Villa Regina, Mayo de 2017 
A mis padres
A Guille, Gino y Nacho 


\section{Agradecimientos}

A mi director, Antonio De Michelis por su apoyo y confianza para realizar este trabajo, por su comprensión tanto en el aspecto laboral como humano y por permitirme trabajar con absoluta libertad pero con un apoyo constante.

A mi asesora, Alicia Chaves, por su colaboración y predisposición, muchas gracias.

A Mónica Ochoa por guiarme en el camino de la investigación y compartir millones de momentos durante estos años de trabajo. Por su predisposición, su apoyo incondicional, su colaboración y experiencia, por su amistad y por estar cuando la necesité en momentos en que el tiempo apremiaba. Gracias Moni, te quiero!

De forma especial quiero agradecer a Alicia Kesseler, por acompañarme en mis primeros pasos en el camino de la investigación y docencia, por su predisposición para enseñarme, por su amistad. Fue fundamental para mí su colaboración y tiempo dedicado, le estaré eternamente agradecida.

A la Educación Pública y Gratuita. A la Universidad Nacional de Comahue y Universidad Nacional de la Plata por permitirme realizar mi formación de grado y post-grado. A la Agencia Nacional de Promoción Científica y Tecnológica por haberme otorgado la beca que me permitió realizar este trabajo.

A la Facultad de Ciencias y Tecnología de los Alimentos por la calidad de la enseñanza recibida y por permitirme realizar el trabajo de mi investigación en sus laboratorios. A todos sus integrantes, gracias.

A Silvi, Lore y Graciela, por estar siempre al pie del cañón compartiendo triunfos y derrotas, por ser incondicionales, las quiero amigas.

Al grupo de las chicas de la FACTA, porque además de compartir el trabajo, compartimos mates, festejos y charlas. Gracias por su amistad.

Un agradecimiento muy significativo $(p<0,0001)$ a Valentín Tassile, por ayudarme con los temas de estadística y su permanente disposición antes mis consultas. 
A Daniela Rodríguez, por su colaboración en las cosas de cada día, su predisposición a ayudarme en lo que necesité, por los momentos compartidos, por el buen humor que contagia.

A Walter, Susana, Melina, Soledad, Andrés, Florencia, Mara e Ivanna que de distintas maneras me enseñaron y ayudaron en este trabajo, por su compañerismo.

A mis compañeros de las cátedras de Introducción a la Química y Química Orgánica (María Elena, Ivanna, Esther, Mario, Andrés, Facundo), por escucharme y acompañarme siempre, por su amistad.

A mis amigas (Naty, Romi, Vicky, Cris, Noris y Sabri), por las energías de todos los días, por acompañarme siempre.

A Beatriz y Ricardo, mis papás, por todo el esfuerzo que hicieron siempre para que pudiera completar mis estudios, por su confianza y apoyo, y aunque mamá no pueda leer esto, sé que en algún lugar sonreirá feliz.

A mis hermanos, Rodolfo y Luciano, por su amor y compartir conmigo cada momento, por alentarme a seguir.

A Rossy, por estar siempre en cada paso que doy, te amo tía.

A Carlos y Ana, mis suegros, por ayudarme siempre que lo necesito, por su cariño constante.

Al amor de mi vida, Guillermo, por la contención invalorable, por ir siempre juntos a la par, por los abrazos y palabras en los tiempos críticos, por su amor.

A Gino e lgnacio, mis bombones, que llegaron en esta etapa de la vida para sumar música y alegría con sus risas y ocurrencias, los amo hijos.

A mi familia toda, por su apoyo y contención.

Como dijo Isaac Newton: "Si he llegado a ver más lejos que los demás, es porque me he sentado sobre los hombros de gigantes".

GRACIAS TOTALES! 


\section{RESUMEN}

El objetivo general del presente trabajo fue el estudio integral de pulpas de frutas patagónicas, los productos con ellas formulados, los procesos aplicados y la estabilidad frente a distintos métodos de conservación.

Se trabajó con seis matrices de origen patagónico: zarzamora, frambuesa, guinda, arándano, rosa mosqueta y cassis. Las cuatro primeras se utilizaron como pulpas, analizándose las propiedades fisicoquímicas y funcionales en estado fresco. Rosa mosqueta y cassis se deshidrataron y se añadieron en polvo como ingredientes funcionales.

Como primera instancia (capítulo I) se probaron diferentes solventes y temperaturas para la extracción de compuestos bioactivos, seleccionando la mejor combinación entre mayores concentraciones obtenidas y menor toxicidad del solvente utilizado.

En el capítulo Il se realizó una caracterización completa desde el punto de vista nutricional y funcional de las diferentes matrices a utilizar para la preparación de las pulpas y/o productos.

En el capítulo III, se analizó el efecto de los procesos de pulpado, escaldado y pasteurizado sobre los compuestos bioactivos (fenoles totales, flavonoides, antocianinas monoméricas, ácido ascórbico), poder antirradicalario y el color superficial de zarzamora, frambuesa, arándano y guinda.

En el capítulo IV, se estudió el almacenamiento, durante un año, de las pulpas en dos condiciones diferentes: envasadas al vacío y conservadas en condiciones de freezer $\left(-18^{\circ} \mathrm{C}\right)$ y envasadas en viales de vidrio, pasteurizadas y conservadas a temperatura ambiente en condiciones de luz y oscuridad.

En el capítulo $\mathbf{V}$ se planteó el desarrollo de alimentos funcionales en base a las pulpas y polvos de frutos patagónicos estudiados, por lo cual se prepararon pulpas mezclas y mermeladas con o sin el agregado de polvo de rosa mosqueta o cassis a fin de potenciar sus características funcionales.

Las frutas estudiadas se diferencian en general por su atractivo color, bajo contenido graso y el aporte de fibra alimentaria, principalmente en frambuesa y zarzamora. En cuanto a compuestos bioactivos y poder antirradicalario se destacan guinda y arándano con los mayores valores. Zarzamora y arándano 
contribuyen además con un elevado contenido de antocianinas monoméricas, lo que impacta directamente en el color superficial.

Los resultados presentados otorgan herramientas útiles al momento de la selección de la tecnología de procesamiento más adecuada para la obtención de pulpas y polvos de frutas finas patagónicos estables.

Durante la conservación de pulpas congeladas, en general, las pérdidas de los compuestos bioactivos estudiados no superaron el $30 \%$, además de mantener un nivel alto de pigmentos y un color atractivo. En pulpas pasteurizadas almacenadas a temperatura ambiente en condiciones de luz y oscuridad, las pulpas de arándano presentaron y conservaron los mayores niveles de compuestos bioactivos, poder antirradicalario (PA) y estabilidad del color. Frambuesa y guinda fueron las matrices con mayores pérdidas de compuestos bioactivos y PA.

El agregado de rosa mosqueta deshidratada o cassis para mejorar el contenido de ácido ascórbico en los productos (pulpas mezcla y mermeladas) fue satisfactorio ya que se conservó una concentración importante del compuesto en los productos finales. A su vez, esta adición fue favorable para mantener los compuestos bioactivos y el poder antirradicalario en valores altos.

El estudio y combinación de pulpas y polvos de frutos patagónicos permitieron obtener productos de base frutal, de apariencia general agradable, ricos en antioxidantes y cuyas propiedades bioactivas se mantuvieron estables durante los procesos térmicos, pretratamientos y el almacenamiento.

Palabras claves: zarzamora, guinda, frambuesa, arándano, rosa mosqueta, cassis, pulpas, mermeladas, procesos térmicos, conservación, compuestos bioactivos, color. 


\section{ABREVIATURAS}

\begin{tabular}{|c|c|c|c|}
\hline AA & Ácido ascórbico & GAE & Ácido gálico equivalentes \\
\hline AC & Acetona & GLU & Glucosa \\
\hline ACP & Análisis componentes principales & GRAS & Generalmente reconocido como seguro \\
\hline ACY & Antocianinas monoméricas & G-Z & Guinda - Zarzamora \\
\hline AD & Agua destilada & HDL & Lipoproteínas de alta densidad \\
\hline ADN & Ácido desoxirribonucleico & HMF & 5-hidroximetil-furfural \\
\hline A-F & Arándano-Frambuesa & ICP-MS & $\begin{array}{l}\text { Espectrometría de masas con plasma } \\
\text { acoplado inductivamente }\end{array}$ \\
\hline ANOVA & Análisis de varianza & IDA & Índice de degradación de antocianinas \\
\hline AOAC & Association Of Analytical Communities & IDF & Fibra dietaria insoluble \\
\hline ARN & Ácido ribonucleico & IDR & Ingesta diaria recomendada \\
\hline BHT & Butil-hidroxi-tolueno & INTA & $\begin{array}{l}\text { Instituto Nacional de Tecnología } \\
\text { Agropecuaria }\end{array}$ \\
\hline C & Cassis & IQF & Individual quick frozen \\
\hline CAA & Código Alimentario Argentino & $\mathbf{I R}$ & Ingesta recomendada \\
\hline CE & Catequina equivalente & ME & Metanol \\
\hline CL & Ánalisis de cluster & MEAC & Metanol acidificado \\
\hline CP & Color polimérico & NLEA & $\begin{array}{l}\text { Acta de Educación y Etiquetado } \\
\text { Nutricional }\end{array}$ \\
\hline CTEP & $\begin{array}{l}\text { Cooperación Transfronteriza España- } \\
\text { Portugal }\end{array}$ & OMS & Organización Mundial de la Salud \\
\hline DGC & Di Rienzo-Guzmán-Casanoves & ONU & Organización de las Naciones Unidas \\
\hline DPPH & 1,1-difenil-2-picrilhidracilo & PA & Poder antirradicalario \\
\hline EC50 & Concentración efectiva media & PAST & Pasteurizado \\
\hline EDTA & Ácido etilendiaminotetraacético & PULP & Pulpado \\
\hline ERBR & Especies reactivas de bromo & PET & Tereftalato de polietileno \\
\hline ERCL & Especies reactivas de cloro & $\mathrm{pH}$ & $\begin{array}{l}\text { logaritmo negativo de la concentración } \\
\text { de iones hidrógeno }\end{array}$ \\
\hline ERN & Especies reactivas de nitrógeno & PPO & Polifenoloxidasa \\
\hline ERO & Especies reactivas de oxígeno & PR & Poder Reductor \\
\hline ESC & Escaldado & PRM & Productos de la reacción de Maillard \\
\hline ET & Etanol & $\mathbf{R L}$ & Radical libre \\
\hline ETAC & Etanol acidificado & RMD & Rosa mosqueta deshidratada \\
\hline FAO & Food and Agricultural Organization & SAGPYA & $\begin{array}{l}\text { Secretaría de Ganadería, Pesca y } \\
\text { Alimentos }\end{array}$ \\
\hline FBBB & Fast Blue BB & SD & Desvío estándar \\
\hline \multirow[t]{2}{*}{ FC } & Folin Ciocalteu & SDF & Fibra dietaria soluble \\
\hline & & SSD & Sistema de soporte de decisiones \\
\hline FDA & Food and Droug Administration & SSR & Sólidos solubles refractométricos \\
\hline $\mathbf{F F}$ & Fruta fresca & TBHQ & terbutil-hidroquinona \\
\hline FOS & Fructooligosacáridos & TDF & Fibra dietaria total \\
\hline FRAP & Ferric Reducing Ability of Plasma & T-T-T & Tiempo-temperatura-tolerancia \\
\hline FRMD & Frambuesa-Rosa mosqueta deshidratada & UPGMA & $\begin{array}{l}\text { Agrupamiento de pares -media aritmética } \\
\text { no ponderada }\end{array}$ \\
\hline FRUC & Fructanos & UV & Indicador de radiación ultravioleta \\
\hline
\end{tabular}




\section{ESQUEMA GENERAL DEL TRABAJO}

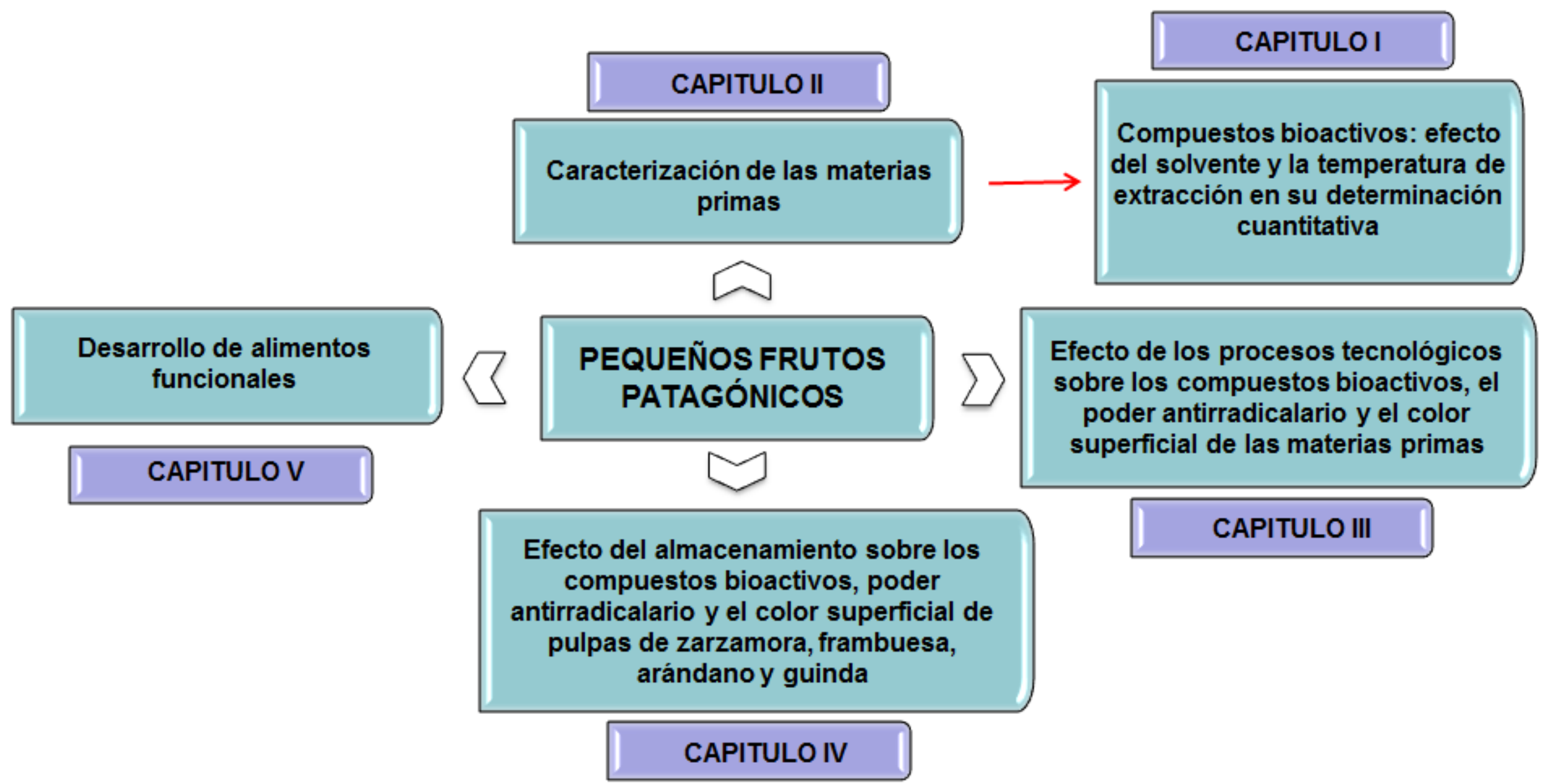




\section{INDICE}

\section{ANTECEDENTES}

1. IMPORTANCIA DEL PROBLEMA

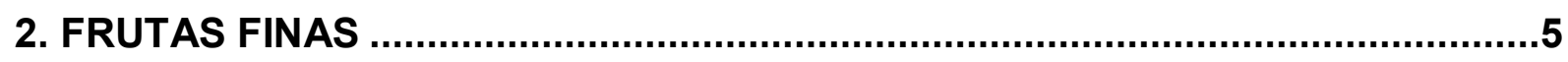

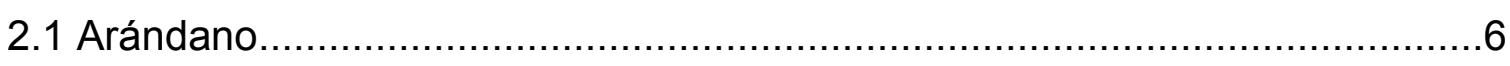

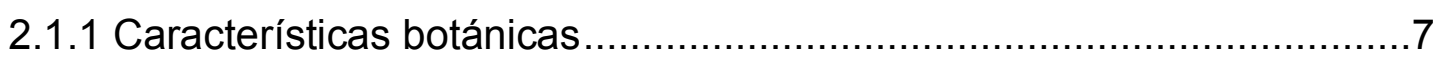

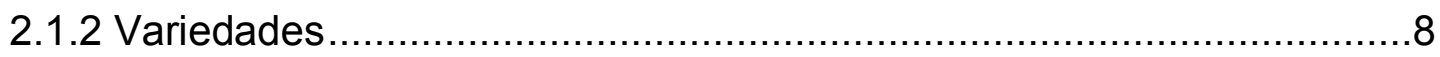

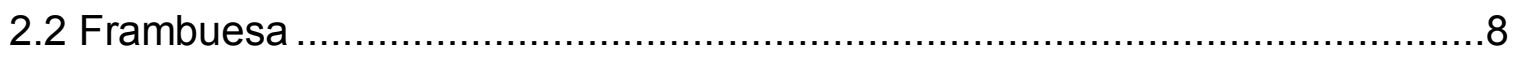

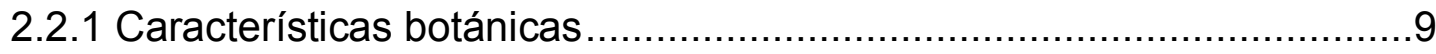

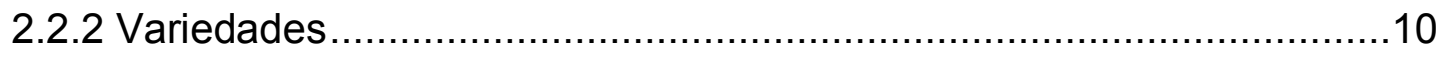

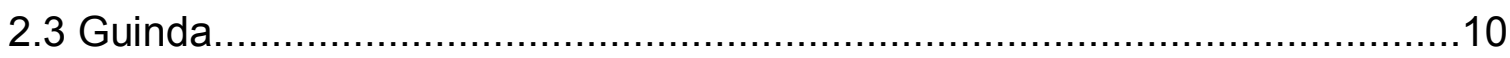

2.3.1 Características botánicas ............................................................

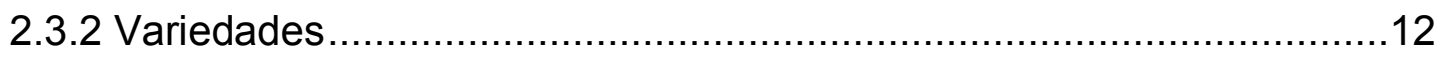

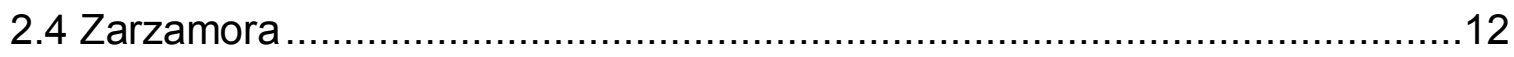

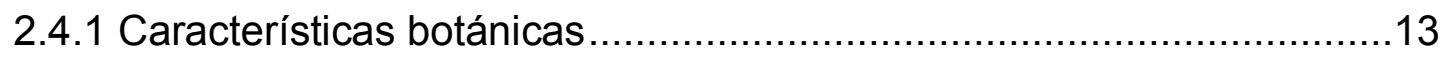

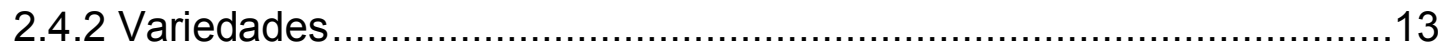

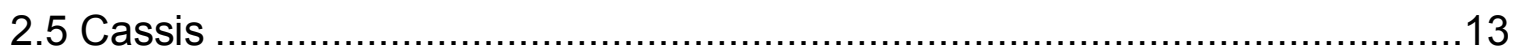

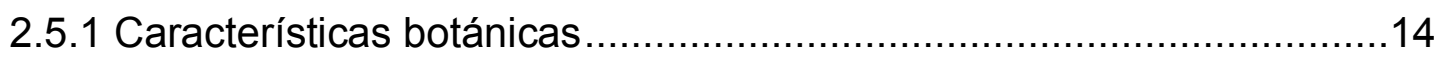

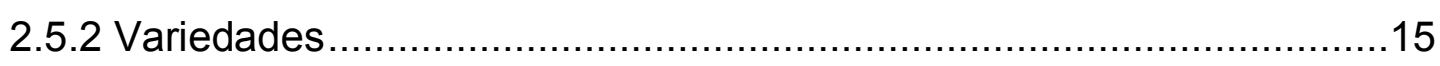

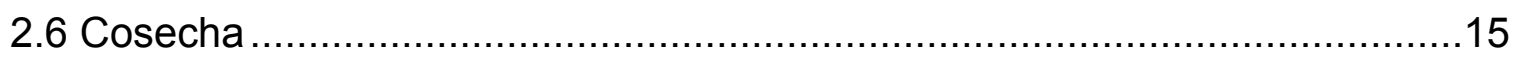

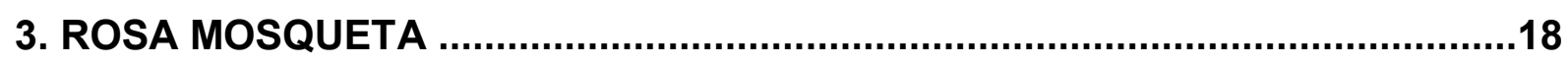

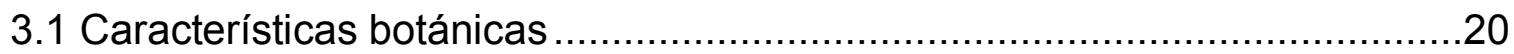

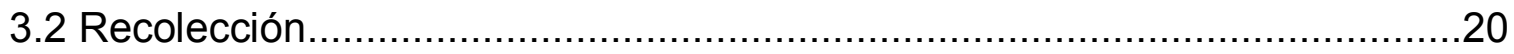

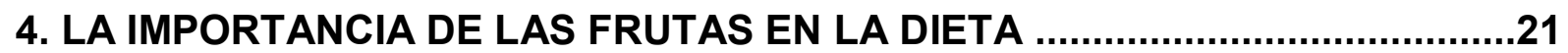

5. RADICALES LIBRES Y ESPECIES REACTIVAS DEL OXIGENO …................22

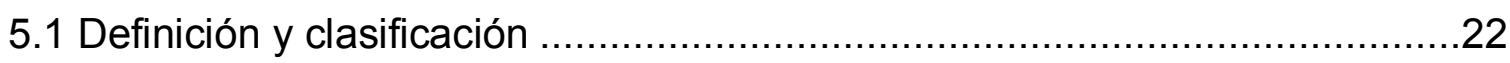

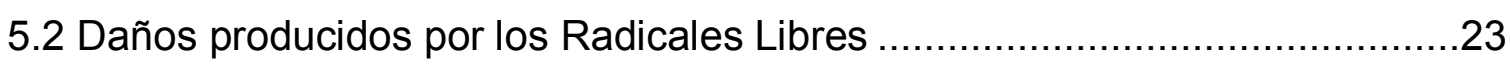

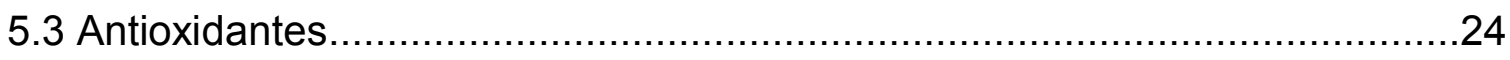

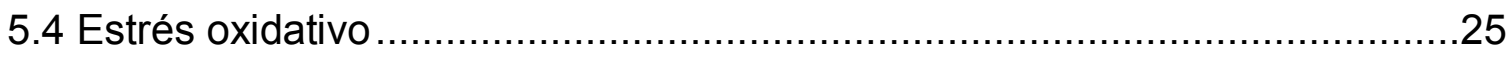

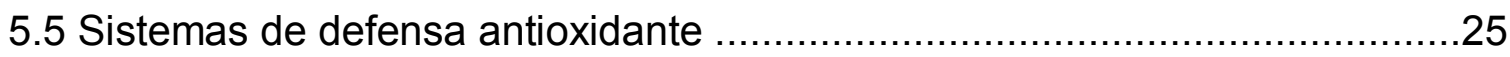

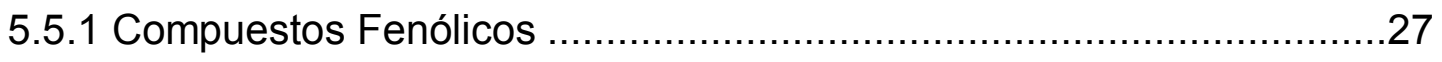




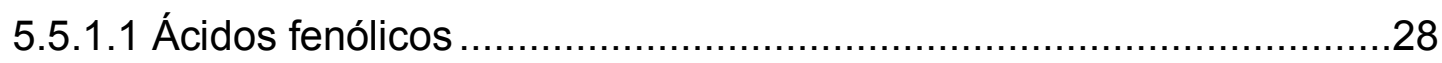

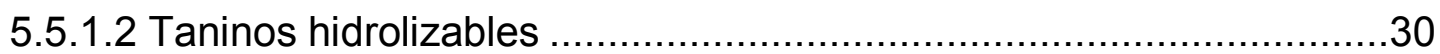

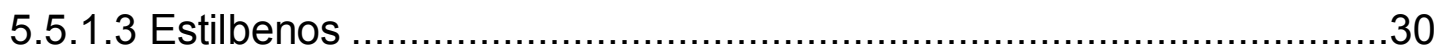

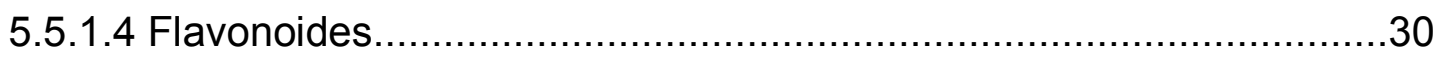

5.5.2 Actividad antioxidante de los compuestos fenólicos........................32

5.5.3 Las frutas rojas como fuente de compuestos fenólicos .............................33

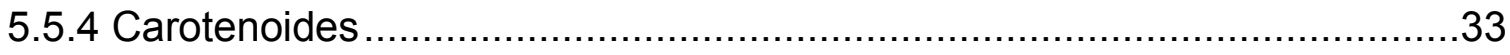

5.5.4.1 Actividad antioxidante de los carotenoides ……....................................34

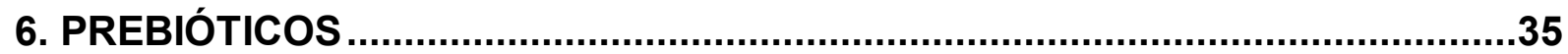

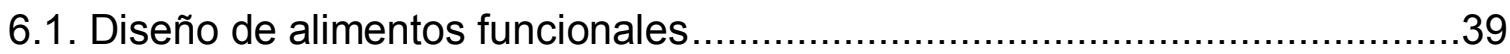

7. ALIMENTOS FUNCIONALES

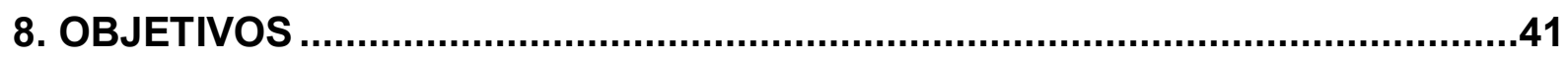

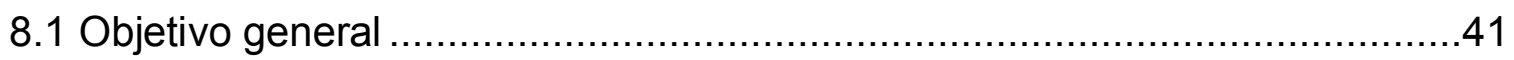

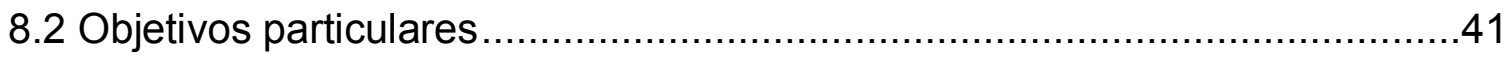

9. REFERENCIAS

\section{CAPÍTULO I}

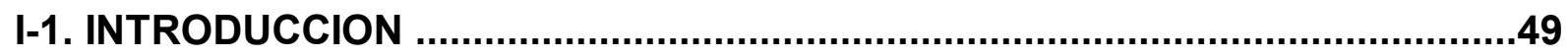

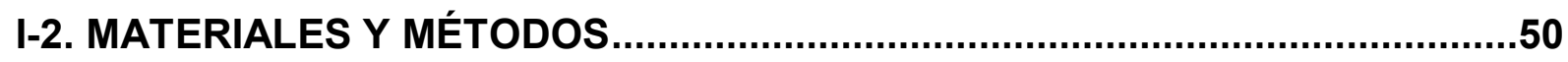

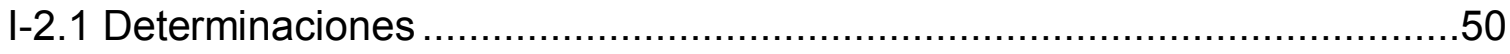

I-2.2 Diseño experimental y análisis estadístico..............................................52

I-2.2.1 Efecto del solvente de extracción ................................................52

I-2.2.2 Efecto de la temperatura de extracción ..........................................52

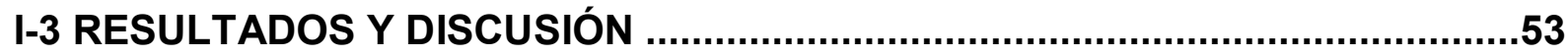

I-3.1 Solvente de extracción: análisis de componentes principales ...................53

I-3.1.1 Confirmación inferencial a través de un análisis de varianza ............58

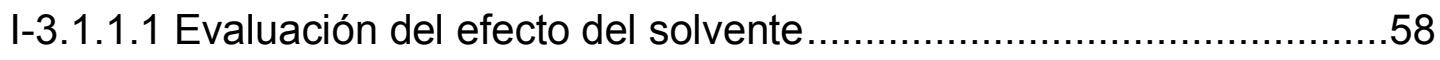

I-3.1.1.2 Contenido de compuestos bioactivos y poder antirradicalario ........61

I-3.2 Temperatura de extracción: análisis de componentes principales...............63

I-3.2.1 Confirmación inferencial a través de un análisis de varianza ............69

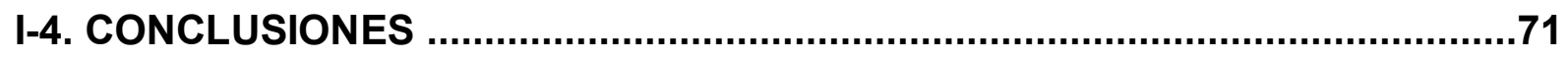

I-5. REFERENCIAS 


\section{CAPITULO II}

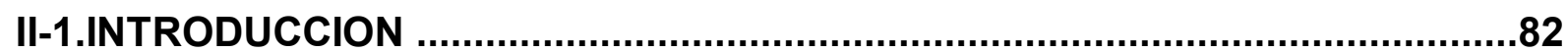

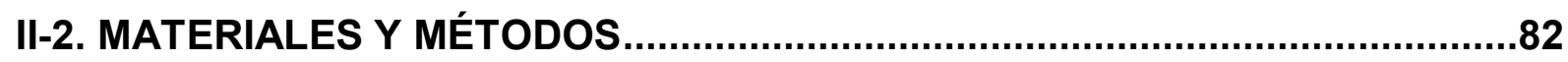

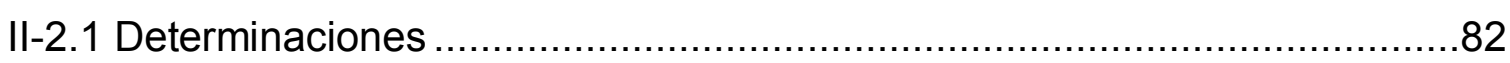

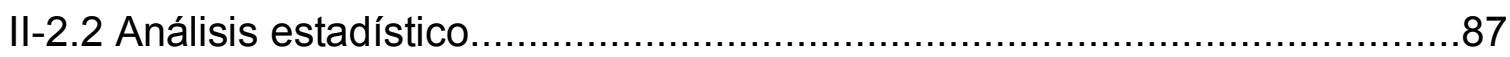

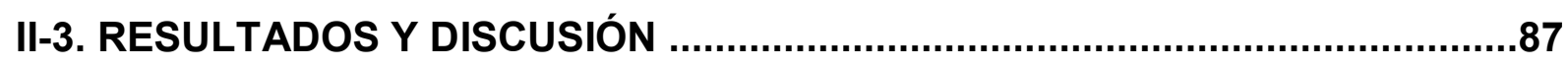

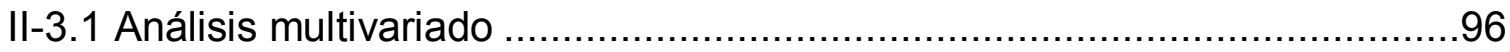

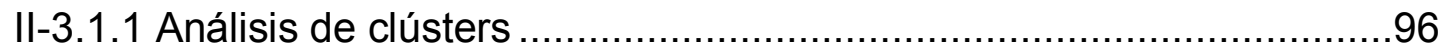

II-3.1.2 Análisis de componentes principales ...........................................

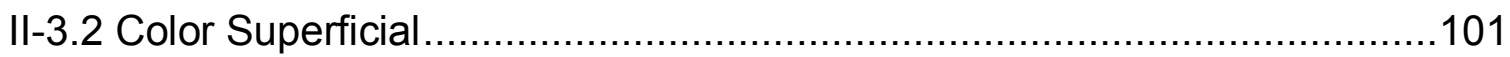

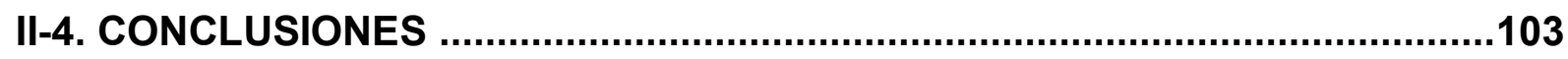

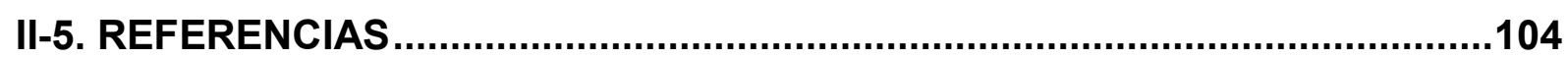

\section{CAPITULO III}

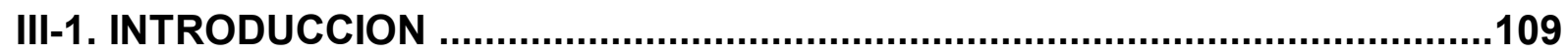

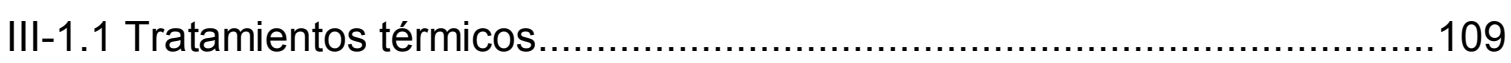

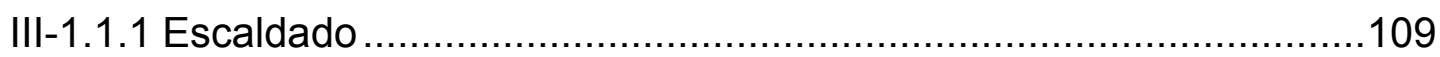

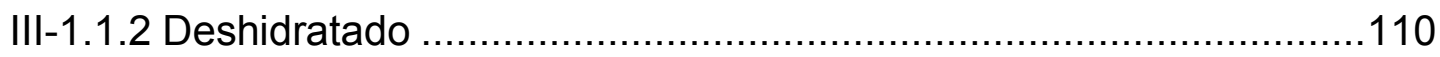

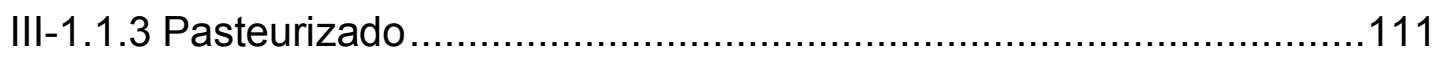

III-1.1.4 Tratamientos térmicos y propiedades antioxidantes ......................112

III-2. MATERIALES Y MÉTODOS .................................................................113

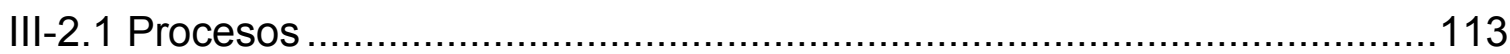

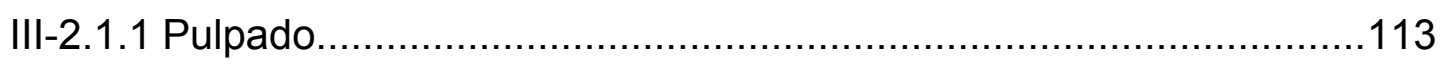

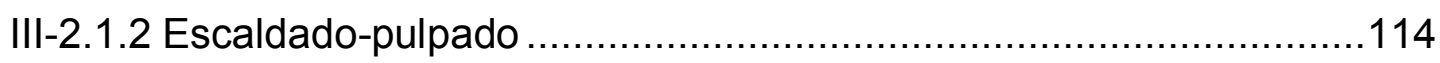

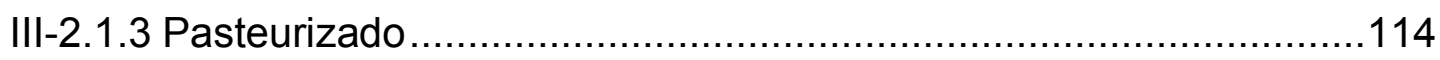

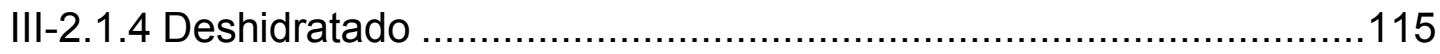

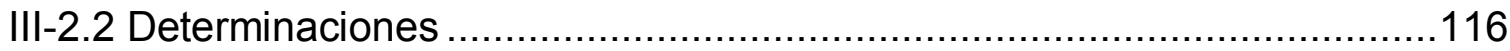

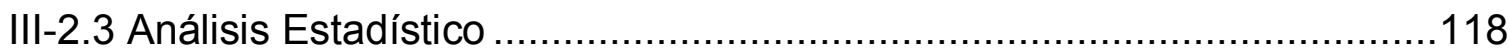

III-3. RESULTADOS Y DISCUSIÓN ……......................................................118

III-3.1 Efecto de los procesos: pulpado, escaldado y pasteurizado...................118

III-3.1.1 Fenoles totales, flavonoides y poder antirradicalario .....................118

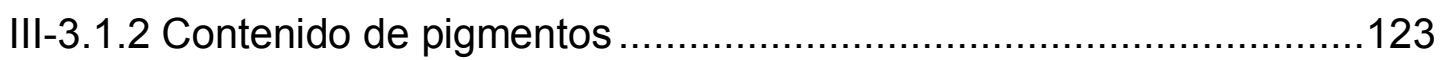


III-3.1.3 Color superficial 129

III-3.2 Efecto del proceso de deshidratación 136

III-3.2.1 Fenoles totales, flavonoides, ácido ascórbico y poder antirradicalario

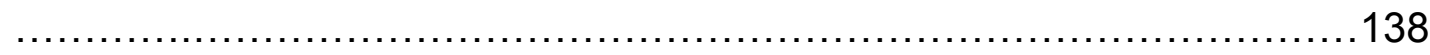

III-3.2.2 Contenido de pigmentos ..................................................... 140

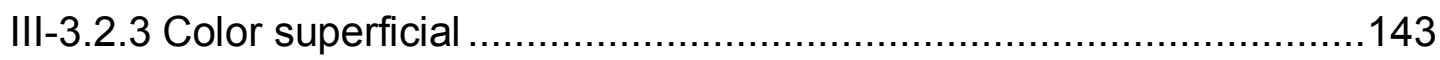

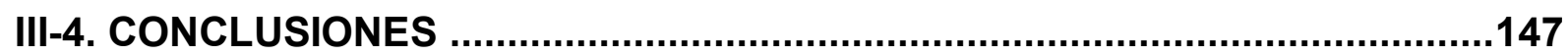

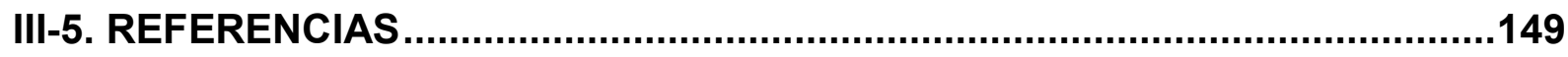

\section{CAPITULO IV}

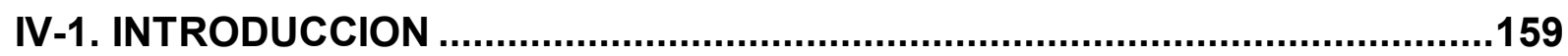

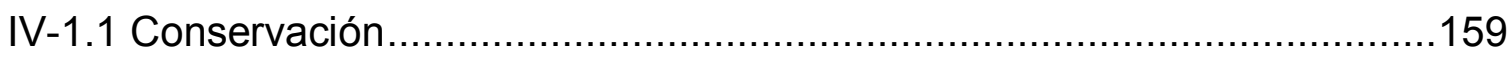

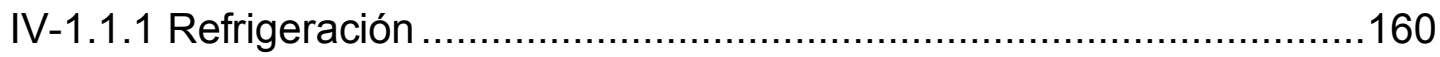

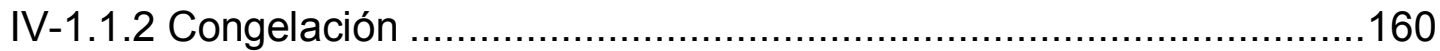

IV-1.2 Factores que afectan la conservación durante el almacenamiento .........160

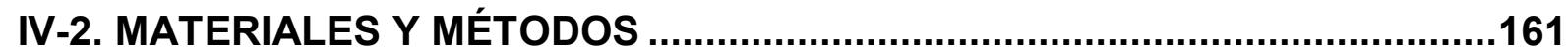

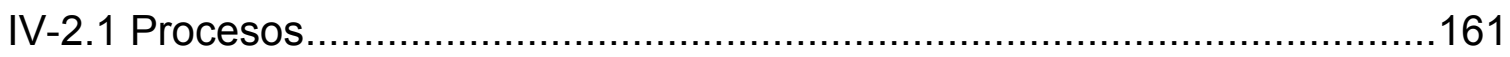

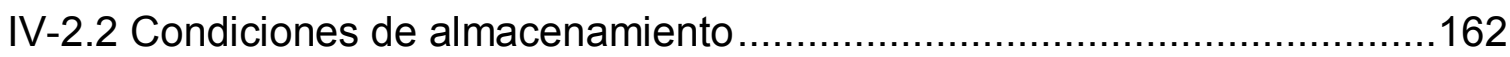

IV-2.2.1 Almacenamiento Luz/Oscuridad ......................................................162

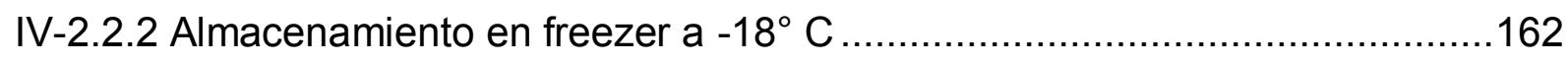

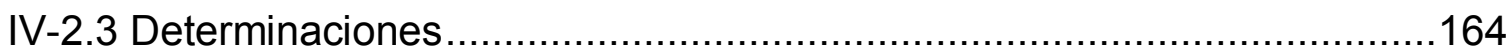

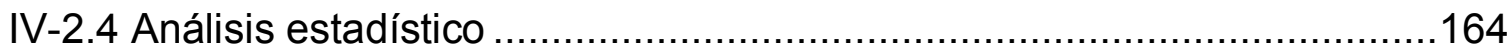

IV-2.4.1 Almacenamiento en freezer a $-18^{\circ}$............................................164

IV-2.4.2 Almacenamiento Luz/Oscuridad...............................................164

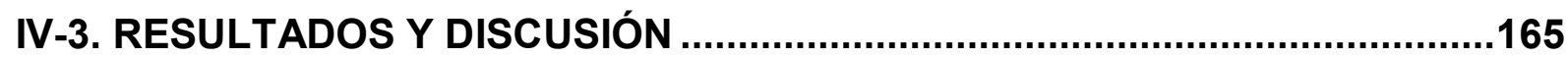

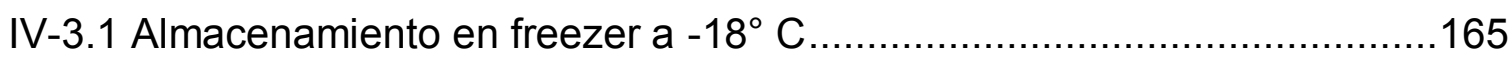

IV-3.1.1 Fenoles totales, flavonoides y poder antirradicalario.....................165

IV-3.1.2 Contenido de pigmentos.......................................................171

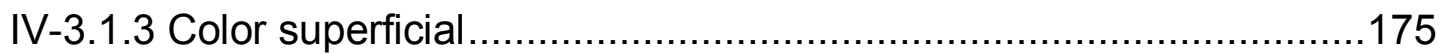

IV-3.2 Almacenamiento a temperatura ambiente en condiciones de luzoscuridad............................................................... 178

IV-3.2.1 Fenoles totales, flavonoides y poder antirradicalario....................178 
IV-3.2.2 Contenido de pigmentos 189

IV-3.2.3 Color superficial. 194

IV-4. CONCLUSIONES .202

IV-5. REFERENCIAS .206

\section{CAPITULO V}

V-1. INTRODUCCION .212

V-1.1 Diseño de alimentos funcionales 213

V-2. MATERIALES Y MÉTODOS .214

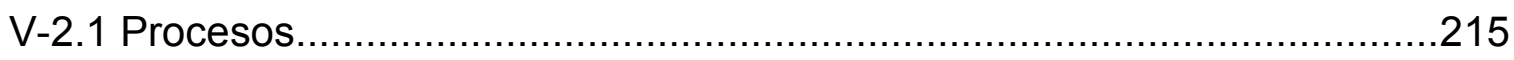

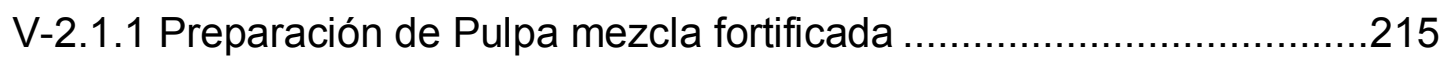

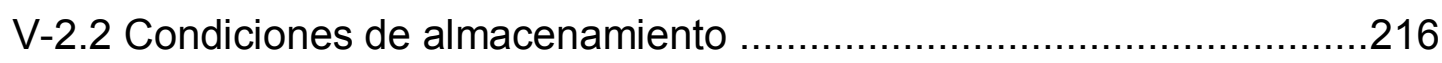

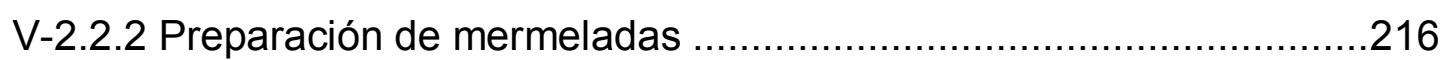

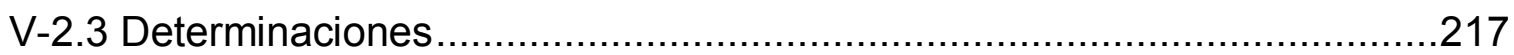

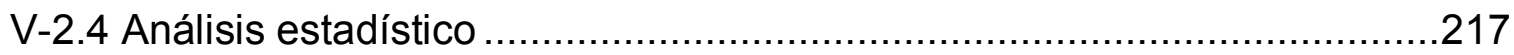

V-2.4.1 Proceso de elaboración de mermelada .......................................217

V-2.4.2 Almacenamiento Luz/Oscuridad de pulpas mezclas fortificadas ....218

V-3. RESULTADOS Y DISCUSIÓN .218

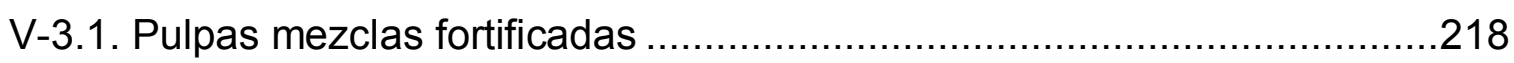

V-3.1.1 Elaboración de pulpas mezcla fortificadas ..................................218

V-3.1.1.1 Fenoles totales, flavonoides, ácido ascórbico y p. antirradicalario 218

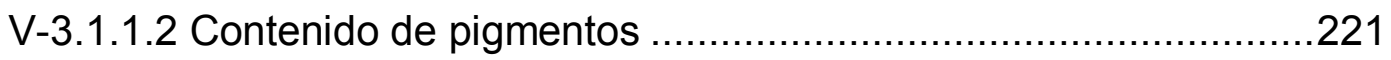

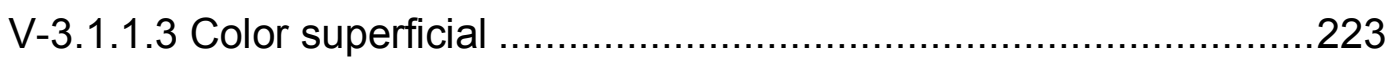

V-3.1.2 Almacenamiento de pulpas mezcla fortificadas............................224

V-3.1.2.1 Fenoles totales, flavonoides, ácido ascórbico y p.antirradicalario .224

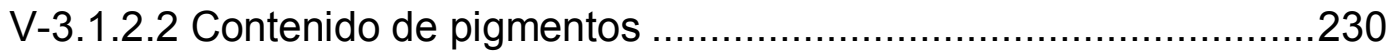

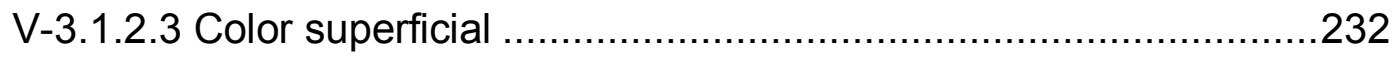

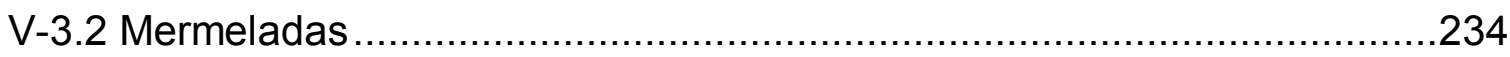

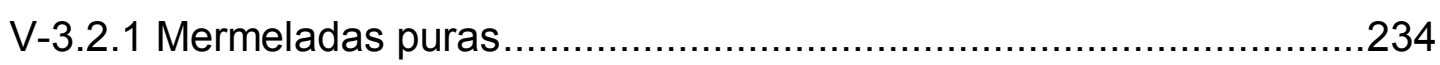


V-3.2.1.1 Fenoles totales, flavonoides, ácido ascórbico y p. antirradicalario .234

V-3.2.1.2 Contenido de pigmentos 238

V-3.2.1.3 Color superficial 239

V-3.2.2 Mermeladas fortificadas 241

V-3.2.2.1 Fenoles totales, flavonoides, ácido ascórbico y p. antirradicalario .241

V-3.2.2.2 Contenido de pigmentos 243

V-3.2.2.3 Color superficial 245

V-4. CONCLUSIONES .247

\section{ANEXO}

A-1. INTRODUCCION .259

A-2. MATERIALES Y MÉTODOS ..............................................................260

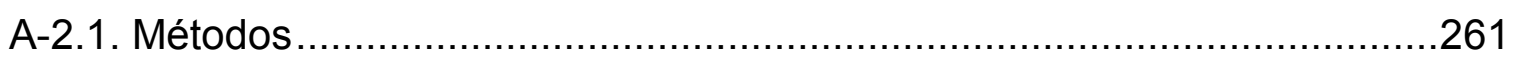

A-2.2 Análisis estadístico ............................................................261

A-3. RESULTADOS Y DISCUSIÓN ...............................................................261

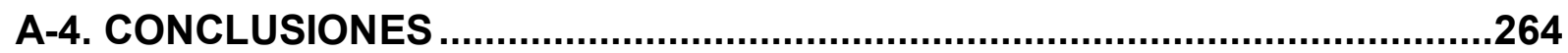

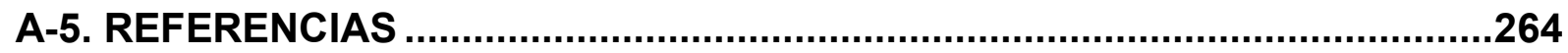





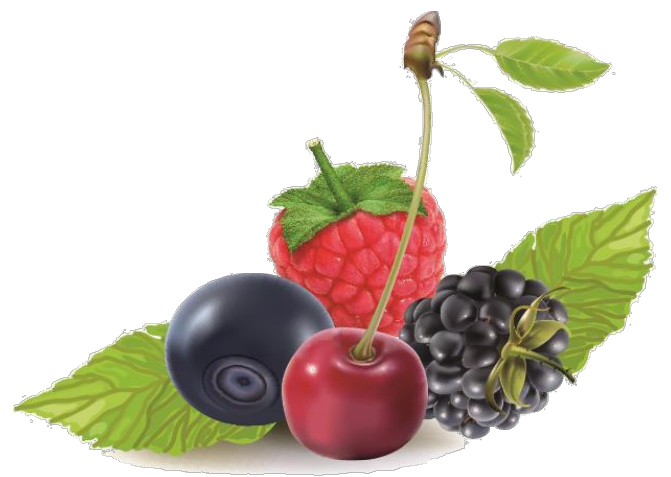

ANTECEDENTES 


\section{IMPORTANCIA DEL PROBLEMA}

Argentina se ha ubicado tradicionalmente como un país con enorme capacidad para producir alimentos. Según Lódola y col. (2010) distintos factores tales como modificaciones sufridas por los mercados internacionales, evolución de los precios de los alimentos, cambios tecnológicos y de organización a nivel de país y un excelente incremento de la producción y la exportación han hecho revalorizar el papel de Argentina como productor y oferente de alimentos a nivel internacional.

Si se analizan las exportaciones argentinas en el rubro agroalimentos surge claramente que más de la mitad de las exportaciones corresponden a productos de primera transformación, seguidos por los productos sin transformación y finalmente, con menos de un $15 \%$ de incidencia, por los productos de segunda transformación. Esto hace que Argentina tenga una mayor participación en las exportaciones mundiales en la categoría de productos no transformados y de primera transformación, siendo mínima su participación en productos de segunda transformación (Rebizo y Tejada Rodríguez, 2011).

En el Plan Argentina Innovadora 2020 uno de los cuatro sectores específicos seleccionados para trabajar desde el punto de vista científico, tecnológico e industrial es el de las Frutas Finas por su alta importancia regional y posibilidades de expansión.

Al presente, la cadena posee un desarrollo relativamente reducido, pero ha evolucionado desde el punto de vista económico en forma dinámica y posee un fuerte impacto en las regiones geográficas donde se localiza. Resultan escasas las estadísticas oficiales actualizadas de producción de estos cultivos, por lo cual las estimaciones acerca de cada especie en particular conllevan siempre un apreciable rango de error. En 2007, esta cadena aportó $1 \%$ al valor agregado agroalimentario, exportó por 91,8 millones de US\$; de los cuales más de un $64 \%$ correspondió a arándanos frescos y el resto a jaleas y mermeladas; y generó unos 4000 puestos de trabajo que equivalen al $2 \%$ del total de empleos correspondientes a la totalidad de las cadenas agroalimentarias (Lódola y col. 2010; Ribizo y Tejada Rodríguez 2011). 
En la Patagonia abundan materias primas de origen vegetal que son alimentos en sí mismas o que serían potenciales precursores de nuevos alimentos. Sumado a esto, es una región con una cultura ya instalada en la producción de alimentos diferenciados, de alto valor agregado, normalmente elaborados por pequeños emprendimientos comerciales con importante generación de puestos de trabajo. sector de las frutas finas posee la particularidad de englobar dos grupos de cultivos diferentes: berries (frambuesas, moras, grosellas y arándanos) y cherries (guinda y cereza), y además actividades de recolección de frutos silvestres como la rosa mosqueta. Si bien constituyen producciones intensivas en mano de obra y capital, que generan alta rentabilidad en pequeñas superficies, las características de perecibilidad de estas frutas imponen cuidados y requerimientos específicos, tanto en la post-cosecha como en el transporte de las mismas.

Más del $70 \%$ de la superficie cultivada de frutas finas, con una superficie de 1359 ha y más de 300 productores, se concentra en territorio patagónico: la Comarca Andina del Paralelo $42^{\circ}$ que abarca localidades de Río Negro (El Bolsón) y de Chubut (El Hoyo, Lago Puelo y Epuyén) (ver figura 1); El Valle Inferior del Río Chubut; El Alto Valle del Río Negro (Villa Regina, General Roca, Allen y Cipolletti) y Neuquén (Plottier, Senillosa, San Martín de los Andes) y Santa Cruz (Los Antiguos). La Comarca Andina del paralelo $42^{\circ}$ es la región que concentra la mayor superficie cultivada (excepto en arándano), dado que son producciones que se adaptan bien en áreas climáticas con veranos frescos; por esa razón, los valles cordilleranos son ideales. La excepción es el Alto Valle del Rio Negro, donde el excesivo calor genera algunos problemas con los groselleros en general; en la frambuesa decrece algo la calidad, mientras que la cereza encuentra condiciones superiores (Martinez, 2007). 


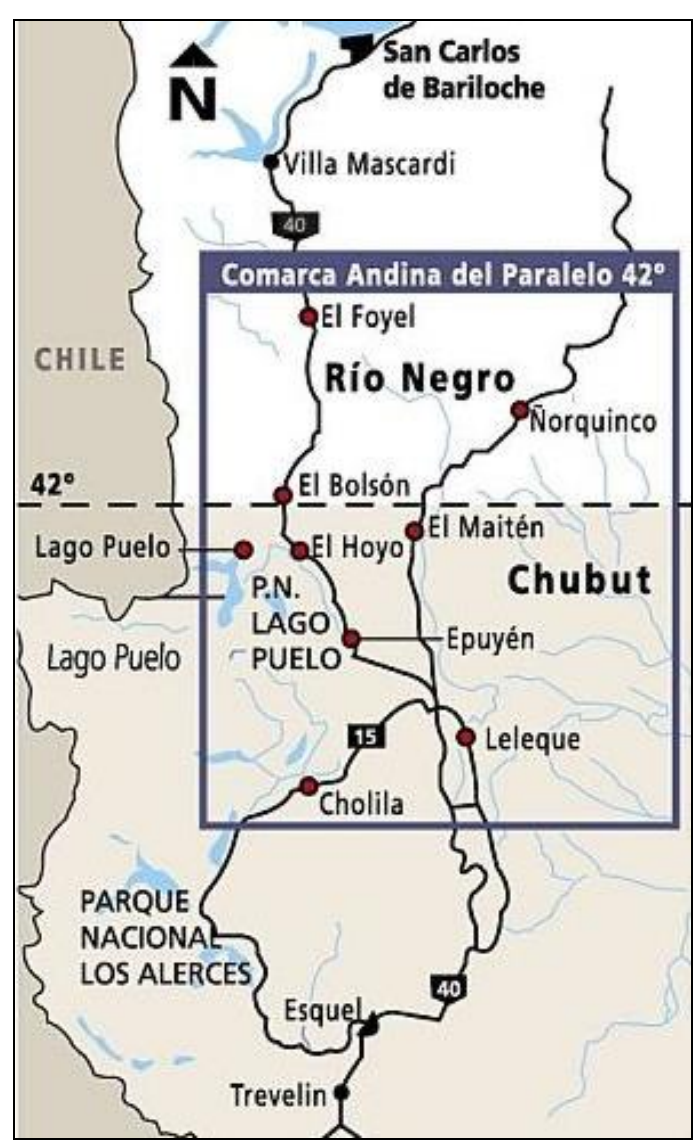

Figura 1. Mapa de la Comarca Andina del Paralelo 42 (Fuente: SSD, 2008)

La menor incidencia de este sector en el mercado interno se debe, por un lado, a la falta de hábitos de consumo por parte de la población argentina, y por otro a la baja capacidad del sector para generar productos frescos y procesados a precios accesibles. En general se ofrecen productos sin transformación a los que se les ha aplicado alguna mejora, como por ejemplo los frutos seleccionados y empacados en estado fresco y congelado y productos de primera transformación como conservas, licores, jaleas y mermeladas (Argentina Innovadora 2020, 2012).

Actualmente, de toda la producción de la Comarca Andina del Paralelo $42^{\circ}$ (1.500.000 kg en 2015), un $70 \%$ se destina a la industria debido a su corto período de conservación y a los serios problemas de logística para los frutos frescos que aún posee nuestro país, correspondiendo $700.000 \mathrm{~kg}$ a frambuesa, $450.000 \mathrm{~kg} \mathrm{a}$ zarzamora, $150.000 \mathrm{~kg}$ a cereza y guinda, $60.000 \mathrm{~kg}$ a frutilla y $140.000 \mathrm{~kg}$ al resto (grosella negra, grosella roja, uva espina, arándano, etc) (INTA AER El Bolsón, 2015, comunicación personal). 
Si bien la experiencia del sector en emprender procesos de agregado de valor al fruto fresco es buena, con estas materias primas se podrían elaborar una amplia gama de nuevos productos, con alto valor agregado y propiedades funcionales, tales como: frutos deshidratados, pulpas pasteurizadas, pulpas concentradas, bebidas saborizadas, mezclas secas para té, barras de cereal, jugos con bacterias próbioticas, quesos blandos con frutas finas, etc. Asimismo en los distintos grados de producción y procesamiento se aplicarían diversos tipos de tecnologías, ya desarrolladas pero no optimizadas aún para este grupo.

La positiva evolución de la producción de frutas finas así como el creciente interés por parte de los actores de esta cadena agroalimentaria en contar con un foro productivo sectorial impulsó que, a principios del año 2006, la ex Secretaria de Agricultura, Ganadería, Pesca y Alimentos de la Nación (SAGPyA), convocara a la primera reunión para fundar el Foro Federal de Frutas Finas, el cual quedó formalmente constituido por medio de la Resolución 281/08. El accionar permanente del Foro, desde su creación hasta el presente, ha contribuido a definir el perfil y los objetivos del sector productor de frutas finas en la Argentina.

A través de este órgano, integrado por las entidades públicas y privadas representativas del sector, se ha logrado generar un ámbito de trabajo y discusión que permite consensuar criterios, prioridades y acciones, tendientes a aumentar la competitividad de la cadena.

El Foro analizó los factores limitantes para la producción y transformación de las frutas finas en la Comarca del Paralelo $42^{\circ}$, confirmando dentro de las problemáticas: información insuficiente; escasa mano de obra para cosecha; baja capacidad instalada de frío y de empaque; escaso agregado de valor; insuficiente oferta de frambuesa para la industria local y una baja competitividad de la industria dulcera (Bruzone, 2009).

\section{FRUTAS FINAS}

El grupo de "frutas finas" comprende un conjunto de especies caracterizadas por su reducido tamaño, en comparación con las frutas pomáceas (manzana, pera) o las cítricas. Esta denominación se vincula al aspecto comercial y no al botánico. 
Dentro del grupo, se incluyen al menos dos subgrupos:

a) Berries, de sabores agridulces y rápida perecibilidad:

- Frutillas (Fragaria chiloensis e híbridos).

- Frambuesa roja (Rubus idaeus).

- Moras y Zarzamoras (híbridos del género Rubus)

- Arándanos (Vaccinium corymbosum, la de mayor interés comercial).

- Grosellas: Grosella Blanca o Uva Espina (Ribes grossularia), Grosella Negra o Cassis (Ribes nigrum) y Grosella Roja o Corinto (Ribes rubrum).

b) Cherries, frutos menores de las frutas de carozos: Cereza (Prunus avium) y Guinda (Prunus cerasus) (Bruzzone, 2004).

El Código Alimentario Argentino, en su Artículo 888 del capítulo XI (alimentos vegetales) en la última modificatoria del año 2013, creó el grupo "bayas y otras frutas pequeñas" para incluir a frutos, que si bien son muy diversos, comparten las características de poseer un tamaño reducido. Se encuentran incluidas frutas como la uva, el mistol, la mora, distintas frutas silvestres (sauco, calafate, maqui, murra, piquillín, rosa mosqueta, zarzaparrilla, frutilla silvestre) y todos los berries (frutilla, arándano, frambuesa, mora y zarzamora, grosellas), aunque no se encuentran incluidas las cherries (Código Alimentario Argentino, 2016).

\subsection{Arándano}

El arándano es un arbusto frutal nativo de América del Norte (Estados Unidos y Canadá), donde ha sido mejorado genéticamente y producido comercialmente para el consumo en fresco e industrialización (Kalt y MacDonal, 1996). Pertenecen a la familia de la Ericáceas, y la especie de mayor interés comercial es la Vaccinium corymbosum.

Son cultivados en países del hemisferio norte, principalmente en Europa y Estados Unidos, pero su consumo se ha expandido notablemente en áreas no tradicionales, (tales como Chile, Argentina y Uruguay) debido a que son considerados como una fuente natural de longevidad, por los nutrientes que contiene. 
En la figura 2 se puede observar la planta, el fruto y la flor del arándano.
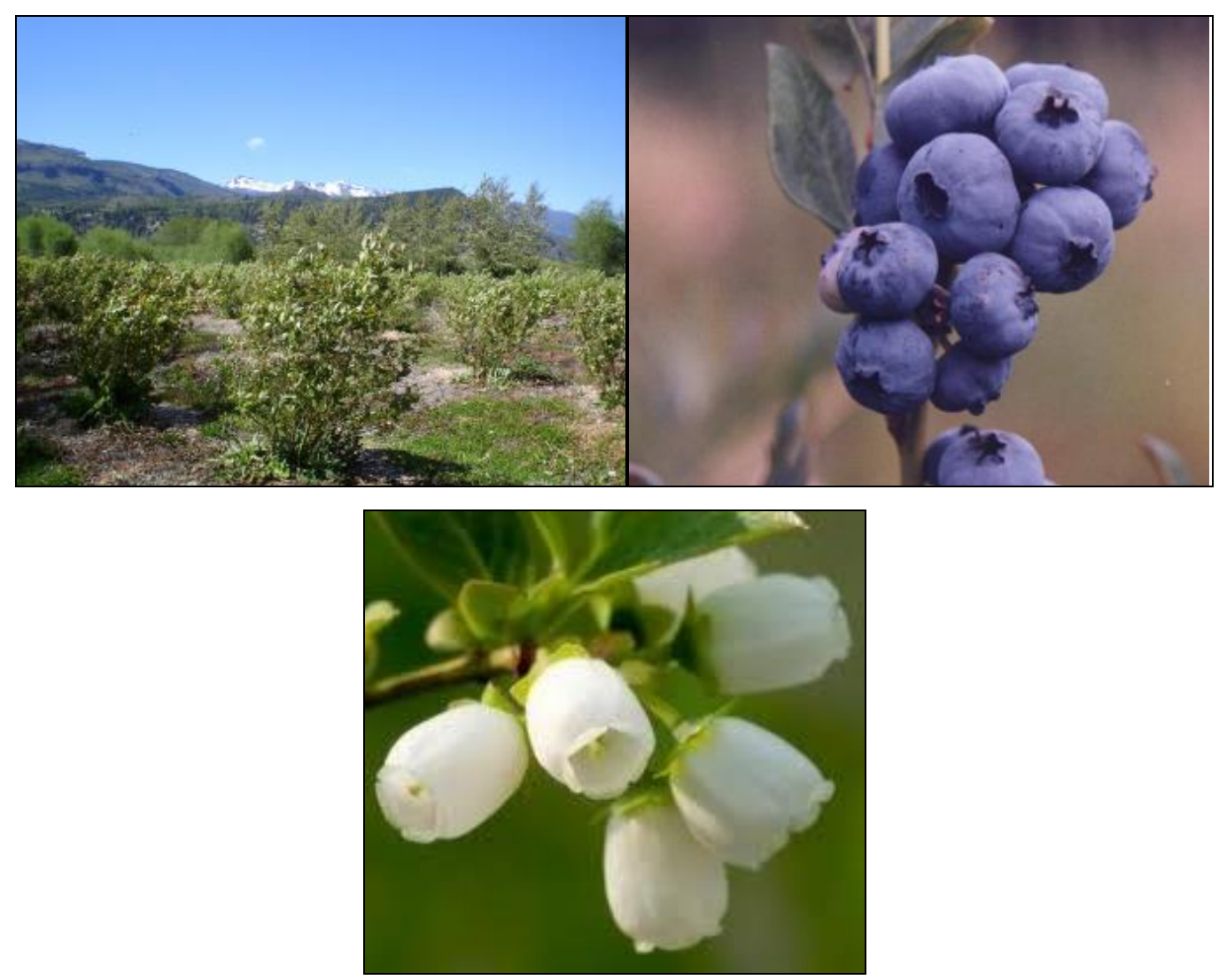

Figura 2. Planta, fruto y flor del arándano (Fuente: Martínez y De Michelis, 2011)

\subsubsection{Características botánicas}

Son arbustos que, dependiendo de la especie, alcanzan alturas que van desde unos pocos centímetros hasta varios metros.

Sus hojas son simples y caedizas, su forma varía de ovalada a lanceolada, se distribuyen en forma alterna a lo largo de la ramilla, los estomas están ubicados exclusivamente en el revés de las hojas en densidades de hasta 300 por $\mathrm{mm}^{2}$.

Las flores se producen en inflorescencias (racimos) generalmente axilares, poseen corola blanca o rosada, las que se diferencian en las yemas terminales de las ramillas cuando se detiene el crecimiento vegetativo al inicio del otoño.

El fruto es una baya casi esférica tamaño de 0,7 a $1,5 \mathrm{~cm}$ de diámetro, nace en racimos, es blanco al principio y a medida que va madurando se torna rojizo-purpura 
para convertirse en azul cuando está completamente maduro (en algunas variedades permanece rojizo). La epidermis del fruto está provista de secreciones cerosas (pruina), que le dan a éste una terminación muy atractiva similar a otras especies frutales como por ejemplo las del género Prunus (Eck y Childers, 1989).

El sistema radicular es superficial, fibroso y de poca extensión no cuenta con pelos radiculares de modo que son las raíces jóvenes las que efectúan principalmente la labor de absorción.

\subsubsection{Variedades}

La mayoría de los arándanos que se cultivan son especies americanas, esto se debe a la migración de las especies europeas hacia el continente americano, desarrollándose nuevas variedades a partir de cruzas. Las principales son:

- Arándanos Rojos (Vaccinium macrocarpon): también llamados "cranberry" en inglés, de pulpa blanca, seca, astringente y amarga. Dentro de este grupo encontramos las variedades: Pilgrim, Stevens, Beckwith, Gregelyski y Ben Lear Bergmann.

- Arándanos azules: generalmente, se agrupan en dos grandes clases: de mata baja o "arándanos enanos" y de mata alta o "arándanos gigantes". En la terminología norteamericana se les denomina respectivamente, como "lowbush blueberry" y "highbush blueberry". A su vez los árandanos highbush se clasifican según su requerimiento de frío en alto y bajo.

Las variedades comprendidas dentro de los arándanos azules enanos son: Northland, Northblue, Tophat, Northsky, Northcountry, entre otras. Mientras que dentro de los arándanos gigantes hallamos: Bluetta, Earliblue, Duke, Polaris, Bluecorp, Nui, Reka, Northblue, Draper, Berkeley, Legacy, Jersey, Lateblue, Darrow, Elliot, Aurora, entre otras. La especie conocida como "rabbiteye" o arándano "ojo de conejo" también se encuentra dentro de los highbush con variedades como Vernon, Alapaha, Powderblue, Rahi, Tifblue, Ochlockone, Maru, Centra Blue, Columbus, entre otras (Palomares, 2010).

\subsection{Frambuesa}

El frambueso rojo o europeo procede del monte Ida, en Grecia, de donde se extendió a Italia, a los Países Bajos, a Inglaterra y luego a América. 
En la figura 3 se puede observar la planta, el fruto y la flor de la frambuesa.
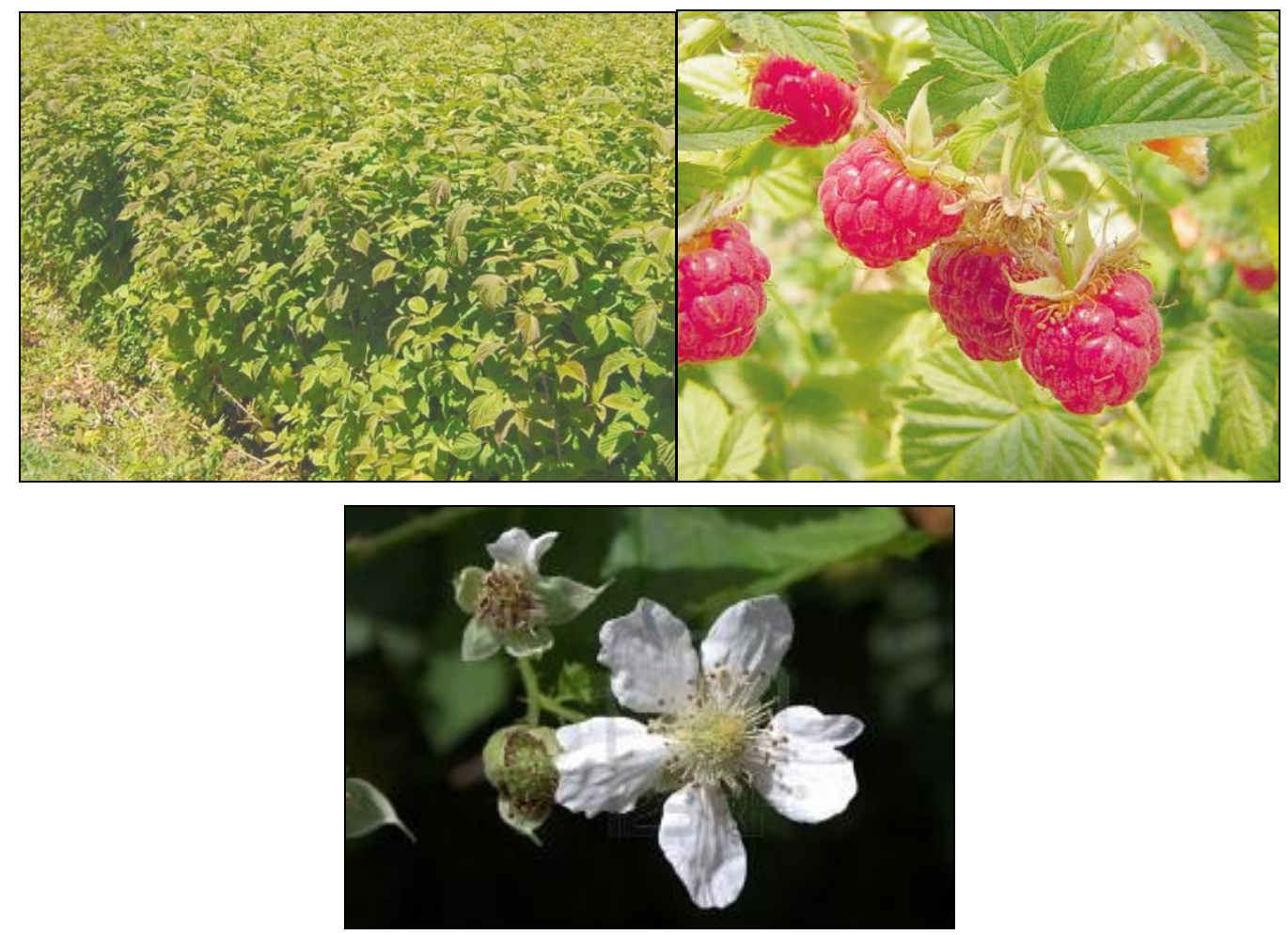

Figura 3. Planta, fruto y flor de la frambuesa (Fuente: Martínez y De Michelis, 2011)

\subsubsection{Características botánicas}

Es un arbusto perenne con su estructura aérea bienal, ya que la caña muere al fructificar al segundo año. Durante los primeros años los retoños se desarrollan tanto de yemas vegetativas de las raíces como de la base de los tallos de las cañas; a medida que la planta envejece la mayoría proviene de la base de las cañas.

Las hojas son compuestas, alternas formadas por 5 a 7 folíolos aserrados soportados por un largo pedúnculo. El color de las hojas es verde en su cara superior y gris plateado en el revés debido a la presencia de vellosidad algodonosa; la lámina de la hoja está surcada por nervaduras muy evidentes que hacen su superficie más o menos arrugada. Éste es un carácter varietal distintivo.

Sus flores son hermafroditas, corolas compuestas por 5 pequeños pétalos blancos caducos y poco vistosos; cáliz grueso formado por cinco sépalos en forma de estrella que permanece soldado al receptáculo floral. 
A partir del ovario de cada pistilo fecundado se originan pequeñas drupas reunidas y adheridas flojamente en el receptáculo elevado.

Posee la particularidad de adquirir coloración rojiza aún en las partes sombreadas de la planta (Martínez y De Michelis, 2011).

\subsubsection{Variedades}

Las variedades de frambuesa en general responden en forma diferente según el ambiente en que se cultiven, pero mantienen ciertas características que le son típicas. Se dividen en dos grupos:

- Reflorecientes o remontantes. Sus frutos son pequeños, poco perfumados, poco azucarados y de baja calidad comercial. Dentro de este grupo encontramos las variedades: Heritage, Ruby y Autumn Bliss.

- No reflorecientes o no remontantes. Sus frutos son más apreciados por ser más gruesos, dulces y perfumados. Con objeto industrial se cultivan solamente las variedades de fruto rojo. Dentro de este grupo encontramos las variedades: Schöeneman, Glen Clova, Meecker, Tulameen, Willamette, Himbo Queen, Rucanta y Ambar (Martínez y De Michelis, 2011).

\subsection{Guinda}

Las guindas pertenecen a la familia Rosaceae, Su denominación científica es Prunus cerasus $L$. El origen ha sido trazado en la región de los mares Negro y Caspio como también el de la especie relacionada, y tal vez predecesora, $P$. fructicosa Pall (Ochoa, 2011).

En la figura 4 se puede observar la planta, el fruto y la flor del guindo. 

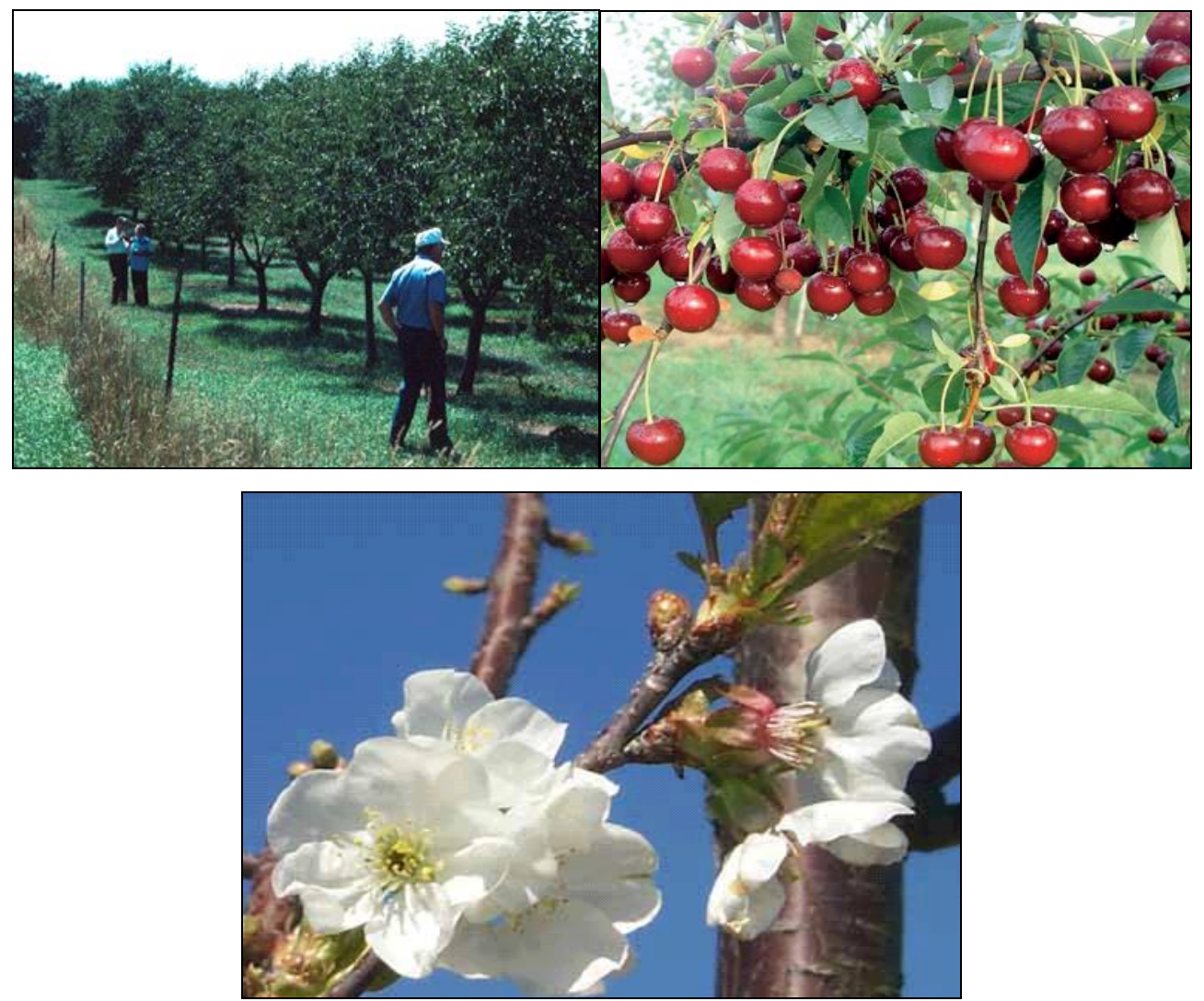

Figura 4. Planta, fruto y flor del guindo (Fuente: Ochoa, 2011)

\subsubsection{Características botánicas}

El guindo es un árbol de tamaño mediano con una forma redondeada. Sus hojas son elípticas con extremidades agudas y bordes suavemente aserrados, con largos pecíolos.

Las flores son blancas con largos pedicelos; son autofértiles y la posición del ovario es media con un hipanto distintivo, característico de los frutales de carozo. Los brotes de la inflorescencia de la guinda producen generalmente 2-4 flores. Sin embargo, muchos nacen lateralmente en la madera del año. Las guindas son las de mas tarde floración entre las frutas de carozo.

El fruto es una drupa de 1,25 a $3 \mathrm{~cm}$ de diámetro, redondo, con el pedúnculo largo unido. Son generalmente rojo brillante, y están expuestos a poca variación de color. La producción comienza al 3er o 4to año y su vida productiva es relativamente corta, de 20 a 25 años (Ochoa, 2011). 


\subsubsection{Variedades}

Las variedades de Guinda se dividen en dos tipos: Amarelle que son las que presentan jugos claros (Montmorency y Meteor) y Morello que son las que presentan jugos rojo oscuro (Northstar, Schattenmorelle, English morello y Balaton).

Montmorency es en gran medida la variedad más cultivada en el mundo y es la mejor guinda para procesar (Ochoa, 2011).

\subsection{Zarzamora}

Existen tres tipos principales de zarzamoras de diferentes orígenes: los hexaploides de la costa oeste de América del Norte, los tetraploides de la costa este de América del Norte, y los tetraploides de origen europeo.

En la figura 5 se puede observar el fruto, la planta y la flor de la zarzamora.
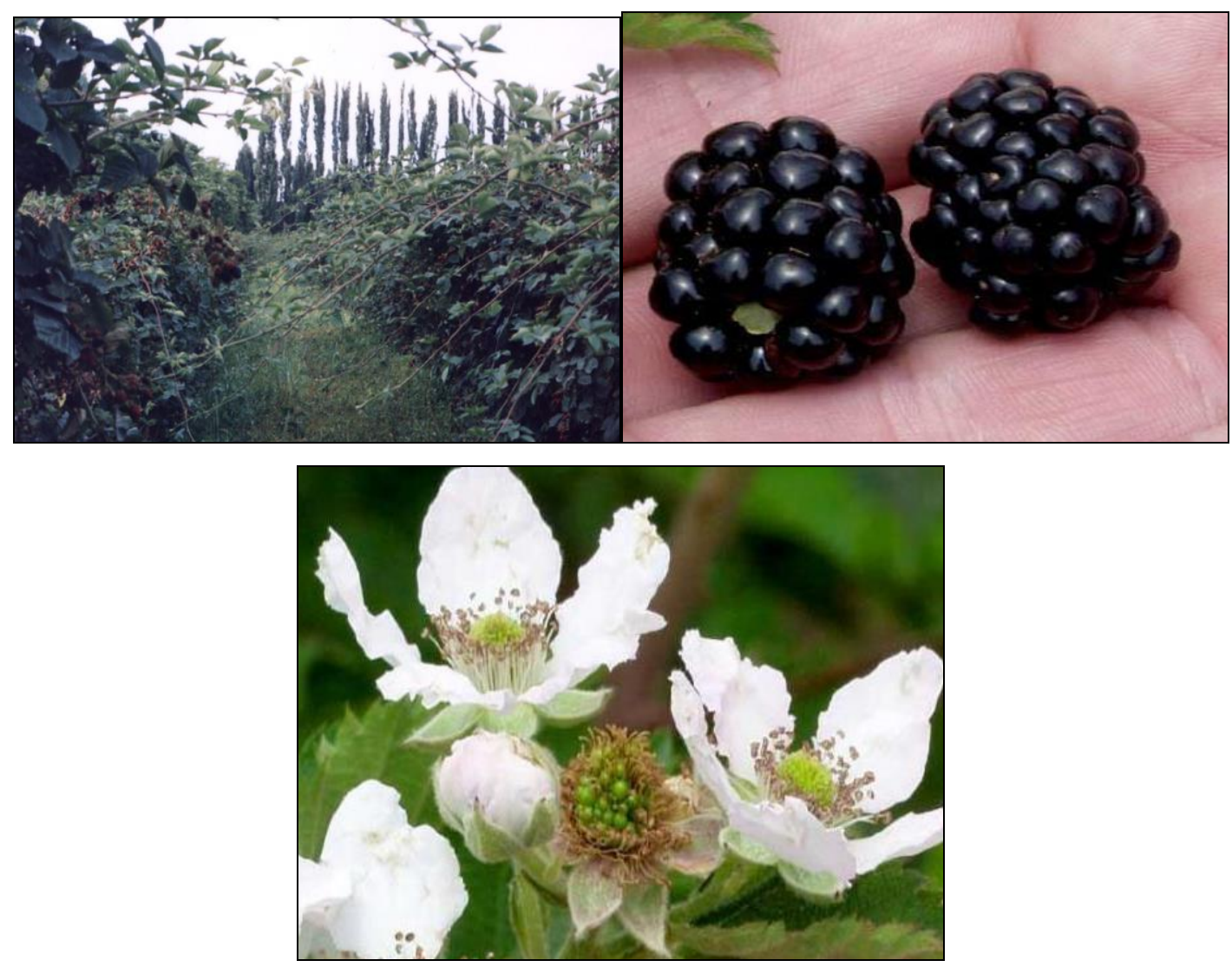

Figura 5. Planta, fruto y flor de la zarzamora (Fuente: Martínez y De Michelis, 2011) 


\subsubsection{Características botánicas}

Son arbustos perennes con su sistema radicular muy fibroso y superficial. Presentan el sistema radicular más potente y profundo de todos los berries. Sus tallos son erectos o semierectos, bienales (algunos trienales). Las hojas son trifoliadas (tres lóbulos) y algunas pentafoliadas.

Las flores están agrupadas en racimos, son autofértiles. Su fruto es una polidrupa, siempre negro y sin vellosidad, brillante. Posee un rango de maduración prolongado.

En general, en todas las variedades probadas en la Comarca Andina del Paralelo 42 el primer racimo se quema por helada y brota una yema secundaria que da una cosecha no completa y más tardía.

Se diferencian de la frambuesa principalmente en que:

a) Son arbustos perennifolios de tallos más gruesos y presentan espinas más grandes y curvas hacia la parte inferior (existen híbridos sin espinas). Las hojas se presentan iguales pero de hasta tres folíolos y del mismo color en ambas caras.

b) El receptáculo queda inserto al momento de cosechar, obteniendo un fruto lleno.

c) El fruto es un poco más grande que la frambuesa, según el estado de maduración se presentan dos colores, estos van desde el morado-rojizo hasta un color granate muy oscuro que tiende al negro. Éstos últimos son los que están listos para ser cosechados (Martínez y De Michelis, 2011).

\subsubsection{Variedades}

Dentro de las variedades de zarzamora encontramos: Black Satin, Dirksen Thornless, Thornfree, Thornless Evergreen y Theodor Reimers (Martínez y De Michelis, 2011).

\subsection{Cassis}

Pertenece al género Ribes (Ribes nigrum), es una de las especies de mayor importancia comercial en la actualidad junto al Corinto (Ribes rubrum) y la Uva espina (Ribes Uva Crispa). Hay de 140 a 160 especies de Ribes, Todas originarias 
del hemisferio norte de las regiones frías. Se encuentran en Europa, Asia y Norteamérica, derivando las especies cultivadas de cruzamientos y mejoramientos (Riadigos y Adrion, 1993).

En la figura 6 se puede observar el fruto, la planta y la flor del cassis.
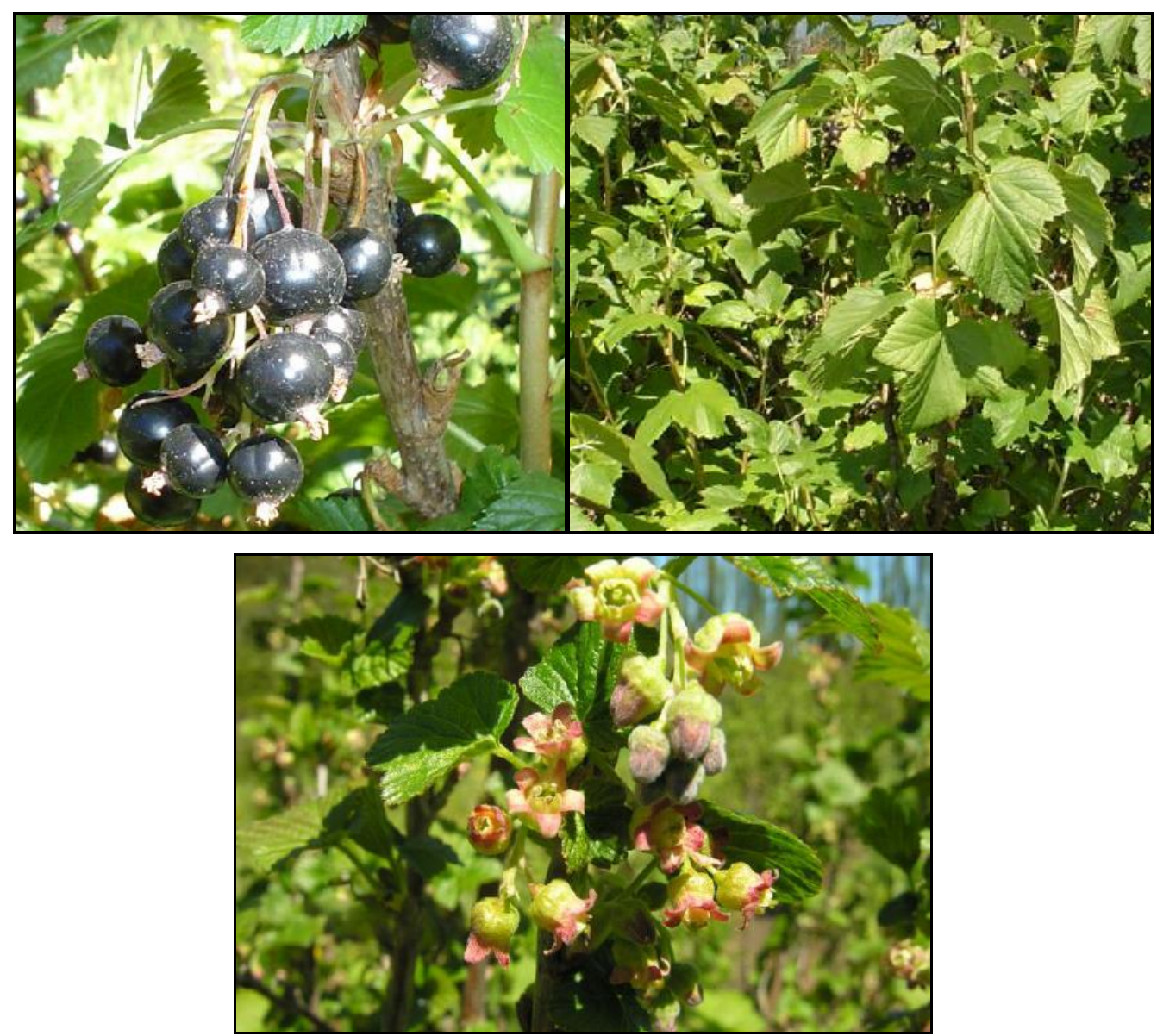

Figura 6. Planta, fruto y flor del cassis (Fuente: Riadigos y Adrion, 1993)

\subsubsection{Características botánicas}

Pertenecen a la familia de las Saxifragáceas. Son arbustos perennes, muy longevos. Su sistema radicular es de naturaleza fibrosa, muy ramificado, con un gran número de raíces delgadas. El mayor volumen de raíces se encuentra en los primeros $60 \mathrm{~cm}$.

Su forma arbustiva alcanza la mayor altura para las grosellas, pudiendo llegar en suelos fértiles hasta 1,60 metros. Sus hojas son palmadas, lobuladas de 6 a $8 \mathrm{~cm}$ de 
ancho dependiendo de su variedad y la presencia de aceites esenciales le otorga un aroma inconfundible.

Sus flores están agrupadas en racimos, son hermafroditas y auto fértiles, salvo en algunas variedades en que se pueden encontrar flores masculinas y femeninas sobre una misma planta o flores hermafroditas que no se autofecundan debiendo intercalarse en las plantaciones variedades polinizadoras.

Fructifican en forma de baya de 0,5 a $1 \mathrm{~cm}$ de diámetro, globosas, color negro o morado. Las yemas florales en los cassis siempre se desarrollan sobre los tallos anuales (de la última temporada).

Las flores son muy pequeñas, alrededor de $0,5 \mathrm{~cm}$. A pesar del gran porcentaje de variedades autofértiles, es muy importante la calidad de la polinización y la fecundación cruzada que provocan las abejas. Las lluvias y viento en período de floración dan racimos de menor calidad (pocos frutos y de distinto tamaño dentro del mismo racimo). Las heladas en dicho período provocan un efecto semejante y en algunos casos por la precocidad con que florecen pueden afectarse severamente la cosecha (Riadigos y Adrion, 1993).

\subsubsection{Variedades}

En la región de la Comarca Andina del Paralelo $42^{\circ}$, las variedades de cassis presentes son: Noir de Bourgogne, Gian de Boskoop, Burga, Royal de Naples, Troll, Titania, Silvergieters, Schwarze y Rosenthals (Riadigos y Adrion, 1993). Los viveros locales actualmente están trabajando Silvergieters y Titania.

\subsection{Cosecha}

Para los berries, el período de cosecha en nuestro país comprende desde fines de noviembre hasta principios de enero. En las variedades remontantes (frambuesa) se presenta su segunda cosecha en febrero-marzo y puede prolongarse hasta abrilmayo, según las condiciones del clima. El índice de cosecha es el color y la facilidad de desprendimiento del fruto de su receptáculo (frambuesa), aun cuando esté firme y brillante. En el caso del cassis, si bien puede haber caída de frutos por sobremaduración o pérdida de peso y arrugamiento de frutos más avanzados, la 
cosecha puede extenderse aproximadamente unos 15 días, se cosecha por racimo cortándolo desde la base. Este es el punto de exigencia diferente con frambuesa y zarzamoras, donde la cosecha es escalonada y se extraen los frutos individualmente.

La cosecha está a cargo de trabajadores temporarios, que realizan la labor de manera manual. Las formas de recolección en el campo pueden ser directas o indirectas.

La directa consiste en el empleo de trabajadores de mayor experiencia capaces de reconocer los frutos para exportación (por la variedad de tonos dentro del mismo color de maduración, y por ser frutos muy sensibles a la manipulación durante la recolección). La cosecha indirecta permite volver a filtrar los frutos que serán exportados (aunque se pierda mayor cantidad de frutos que en la cosecha directa) y desechar aquellos que están en malas condiciones (ya sea por estado de maduración o que sufran cualquier alteración de tipo estética).

En el caso de las frambuesas y cassis se practican ambas tendencias. En los cultivos de moras y arándanos se realiza mayormente la cosecha directa (directo al envase final) ya que aparte de la capacitación que pueda tener el cosechador, la fruta correcta es muy diferenciable de la que esta inmadura, por el color y porque el fruto maduro es menos frágil y más firme al tacto.

Se aconseja limitar la recolección a las horas más frescas de la mañana. La fruta, que debe ser firme, debe mantenerse poco tiempo en la mano; debiéndose colocar inmediatamente en el envase de comercialización y no mezclarla con fruta sobremadura, con mohos o dañada. Los berries frescos se comercializan en envases de Tereftalato de polietileno (PET) de aproximadamente $170 \mathrm{~g}$ ("clamshells") empacados en cajas planas de cartón. En el caso del cassis, hay que evitar cosechar hojas y palillos de la planta para facilitar la posterior limpieza y despalillado y se utilizan envases de cosecha lo más plano posible para evitar acumulación y pérdidas por aplastamiento. Es frecuente utilizar bandejas de madera de no más de $5 \mathrm{~cm}$ de altura con fondos y laterales recubiertos con papel o las 
bandejas Wenco y cargadas con uno o dos kg como máximo. En el caso de cosecha para industria también se utilizan baldes (Riadigos y Adrion, 1993).

El producto congelado se envasa en bolsas de polietileno (80-100 micrones) contenidas en cajas de cartón corrugado de $10 \mathrm{Kg}$ (Masdeu, 2004).

En la figura 7 se puede observar la secuencia de cosecha y clasificación de la frambuesa.
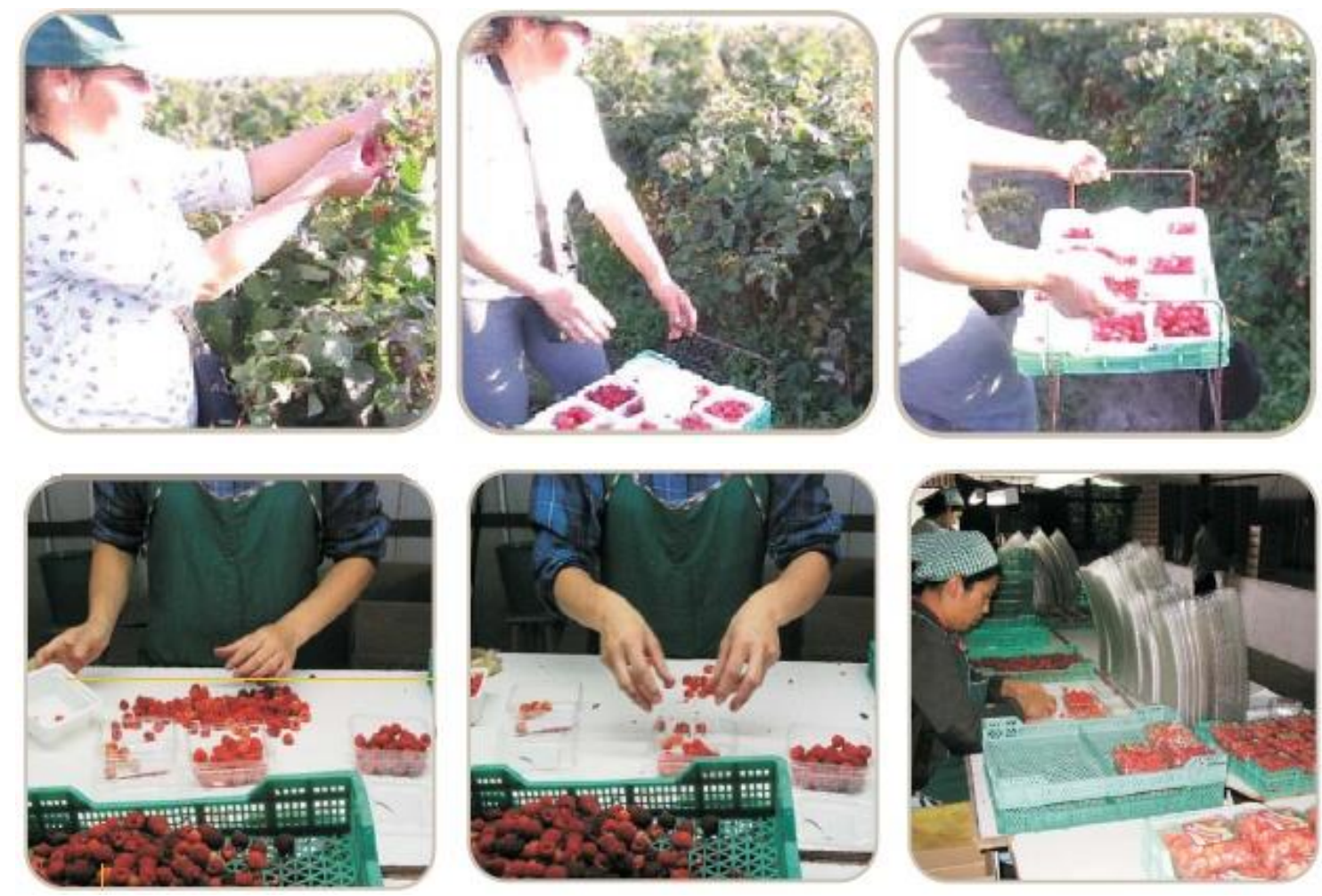

Figura 7. Secuencia de cosecha y clasificación de frambuesa (Fuente: Masdeu, 2004)

Para el caso de la guinda, aquellas destinadas a proceso se sacuden de los árboles cuando están maduras. Se requieren dos máquinas: un agitador del tronco, que toma el tronco y sacude el árbol, y un armazón colector que recoge y concentra la fruta sacudida sobre una cinta transportadora. Un árbol entero se cosecha en cuestión de segundos. 
Cerca de dos semanas antes de cosechar se coloca un compuesto que libera etileno, para reducir la fuerza que se debe ejercer para el desprendimiento de la fruta, y para aumentar el porcentaje de la fruta cosechada. A menudo los troncos de los árboles son dañados por el agitador.

Las guindas tienen muy corta vida y deben ser manejadas cuidadosamente para reducir el moretoneado y el pardeamiento. Las frutas destinadas a proceso son volcadas inmediatamente en un baño de agua fría ni bien son cosechadas. Se transportan a las plantas industriales y son procesadas en pocas horas desde la cosecha (Ochoa, 2011).

En la figura 8 se puede apreciar el agitador unido al tronco listo para sacudir, la cinta transportadora y las guindas volcadas en agua fría al final de la recolección.
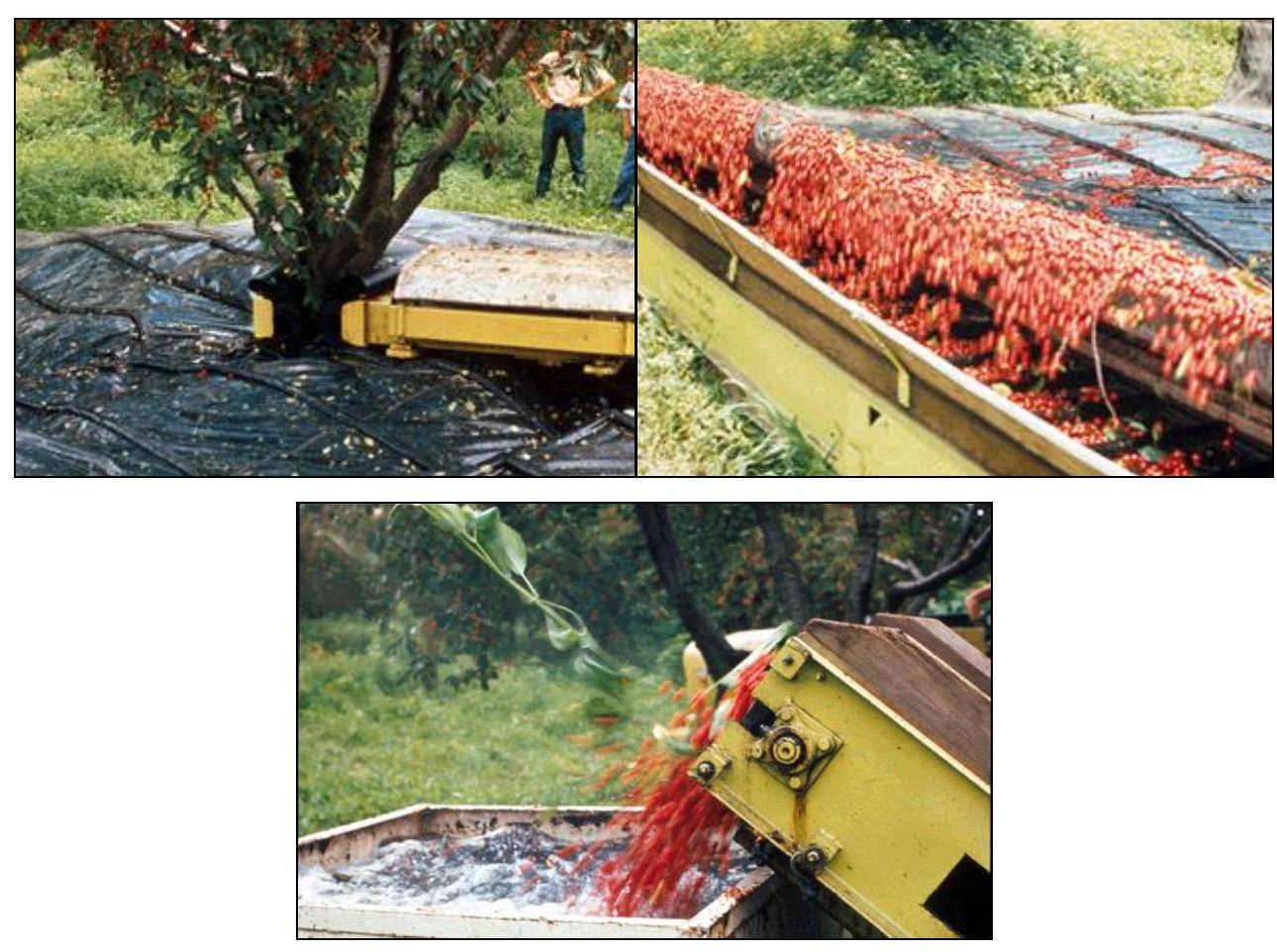

Figura 8. Secuencia de cosecha de guinda (Fuente: Ochoa, 2011)

\section{ROSA MOSQUETA}

La rosa mosqueta es una especie arbustiva, originaria de Europa Central, Polonia, Balcanes, Hungría, Rusia, El Cáucaso, India y África, que fue introducida en Argentina a través de Chile, país al que fue llevada por los conquistadores. 
Esta rosácea silvestre, ha invadido grandes extensiones de tierras de las regiones andino-patagónicas de Argentina, el valle central longitudinal de las regiones VIII, IX y X de Chile y sectores aislados del Perú. En estos países ha sido calificada como una maleza arbustiva de vigoroso crecimiento, ya que ocupa agresivamente terrenos aptos para la actividad agrícola y ganadera.

Actualmente gracias a la demanda de productos industriales y artesanales fabricados a base a la pulpa del fruto o la semilla de esta planta, puede considerarse como un producto forestal no maderero.

Pertenece a la familia de las Rosáceas con 122 géneros y unas 3400 especies; abarca la mayoría de los árboles y arbustos frutales de las regiones templadas. EI género Rosa que incluye más de 100 especies, se encuentra representada en Argentina fundamentalmente por tres de ellas, las cuales están englobadas dentro del nombre común "rosa mosqueta", estas son: Rosa rubiginosa, Rosa canina y Rosa moschata (Caro, 2007).

En la figura 9 se puede observar el fruto, la planta y la flor de la rosa mosqueta.
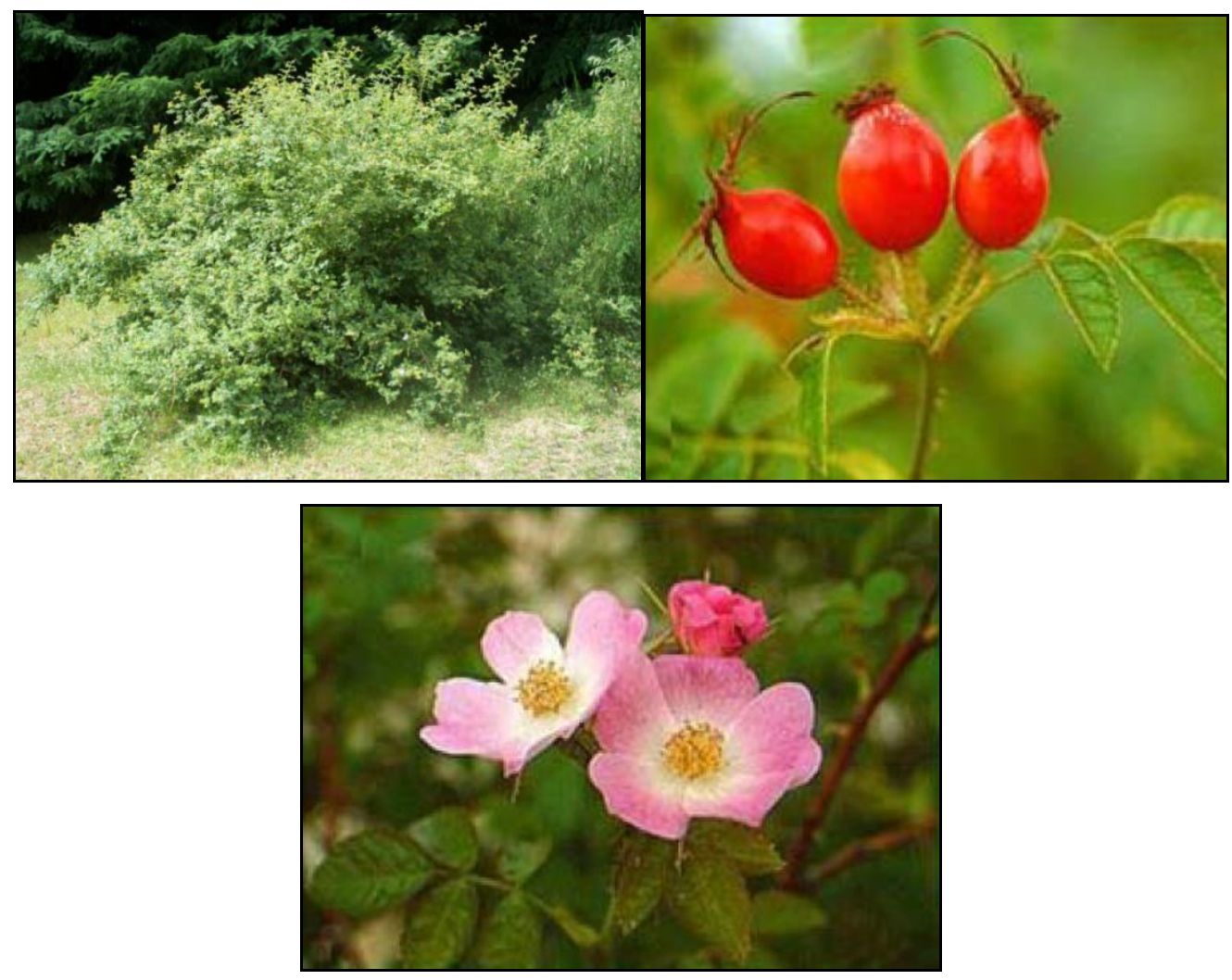

Figura 9. Planta, fruto y flor de la rosa mosqueta (Fuente: Caro, 2007) 


\subsection{Características botánicas}

En general, la rosa mosqueta se presenta como un arbusto de ramas delgadas y muy espinosas, de 0,5 a 1,2 m de altura en $R$. rubiginosa, 1,9 a 3,5 m en $R$. canina y 1 a $2,5 \mathrm{~m}$ en $R$. moschata. Tiene una raíz pivotante de 1 a $1,5 \mathrm{~m}$ de profundidad, con una masa radical superficial que puede emitir retoños o tallos largos y erectos.

Sus hojas son alternas y compuestas de 3 a 7 foliolos, de borde aserrado. Sus flores se presentan solitarias o agrupadas $R$. canina y $R$. rubiginosa y, agrupadas en corimbos (7-8) con 10 a 15 flores cada uno en R. moschata. Son rosadas o blancas, de tres a cinco centímetros de diámetro. Ambos sexos se encuentran en la misma flor. El número de flores por rama depende de dos factores: del vigor de la planta y de la edad del tallo en que se desarrolla. En un tallo de dos años se desarrolla una flor central rodeada de tres pedúnculos más largos que poseen de una a tres flores cada uno. Por debajo de este racimo floral, se presenta una nueva flor solitaria. Los racimos florales de las ramillas laterales portan inflorescencias cada vez más simples hasta emitir una sola flor. Los tallos de tres o cuatro años dan flores sólo en las ramillas laterales y en número escaso.

Sus frutos vulgarmente se denominan escaramujos, son de color rojo anaranjado a rojo intenso según su grado de maduración, de 12 a $15 \mathrm{~mm}$ y presentan un utrículo suculento (pulpa) con núculas (semillas) y pelos epidérmicos dentro del mismo (Caro, 2007).

\subsection{Recolección}

En una plantación nueva la producción comienza al tercer año con un rendimiento promedio de $800-1.500$ gramos de fruta por planta, aumentando a 25 Kg por planta en plena producción.

De acuerdo a la especie, existen dos tipos de colorido de fruto de rosa mosqueta: rojo y anaranjado. Si se está cosechando para la exportación, es conveniente cosechar separadamente estos dos tipos, para obtener un producto homogéneo de exportación. Sin embargo si la recolección es para la fabricación de mermeladas, jaleas y o té, esta clasificación y separación en la cosecha no es 
necesaria. El fruto posee una maduración escalonada. Un buen índice de madurez del fruto es el color, que depende de la variedad que se esté cosechando.

Se debe evitar recolectar los frutos cuando estén sobremaduros pues fermentan rápidamente. La cosecha se realiza en forma manual o con implementos (ver figura 10). La primera es la que realizan generalmente las personas poco experimentadas, con rendimientos cercanos a los $50 \mathrm{Kg} / \mathrm{día}$. La cosecha con implementos (por ejemplo el rastrillo pequeño que se observa en la fotografía) la realizan personas más experimentadas, con la que es posible encontrar rendimientos cercanos los 100 $\mathrm{kg} / \mathrm{día}$. La desventaja de este método de cosecha con implementos es que deteriora la calidad del fruto, sin embargo esto es compensado por el mayor volumen cosechado por hora (Caro, 2007).

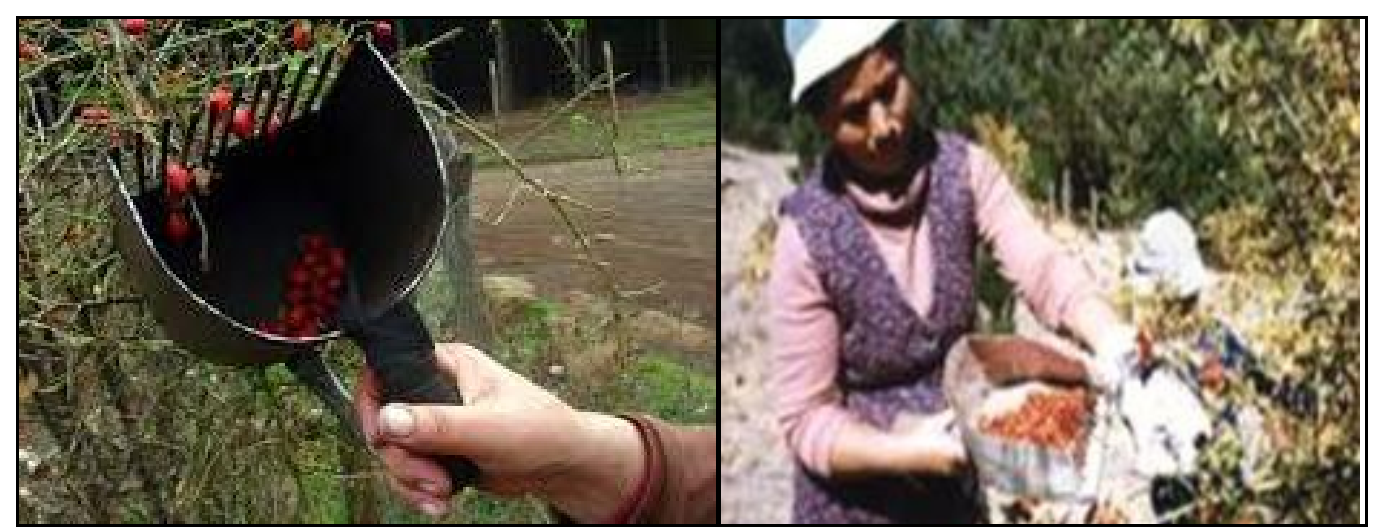

Figura 10. Recolección de rosa mosqueta (Fuente: Caro, 2007)

\section{LA IMPORTANCIA DE LAS FRUTAS EN LA DIETA}

Existe una creciente tendencia de asociación de la alimentación con el estado de salud de la persona (Aguilera Garca y col., 2010); si bien la función principal de la dieta es aportar los nutrientes para satisfacer las necesidades nutricionales del organismo, cada vez hay más pruebas científicas que apoyan la hipótesis de que algunos alimentos tienen el efecto de mejorar las condiciones físicas y mentales, así como de reducir el riesgo de contraer ciertas enfermedades (CTEP, 2010). Las frutas finas de cultivo y las silvestres de la Patagonia argentina forman parte de este selecto grupo, cuya ingesta permite hacer frente a los cambios producidos por la presencia, en exceso, de radicales libres y especies reactivas del oxígeno 
generando un desequilibrio entre ellos y la acción de los antioxidantes, que desencadena un cuadro conocido como estrés oxidativo.

\section{RADICALES LIBRES Y ESPECIES REACTIVAS DEL OXIGENO}

\subsection{Definición y clasificación}

Los radicales libres $(R L)$ son moléculas que en su estructura atómica presentan un electrón no apareado, pueden existir de forma independiente y que, debido a la inestabilidad de su configuración electrónica, son generalmente muy reactivos. Esta reactividad es la base de su toxicidad y de su corta vida media (Boots y col., 2008).

La generación de RL no se ha de relacionar siempre con su toxicidad debido a que la función que desarrollan presenta dos caras opuestas, por un lado actúan como mediadores y reguladores a concentraciones fisiológicas, mientras que a concentraciones elevadas pueden actuar como potentes oxidantes citotóxicos.

En los sistemas vivos se generan muchos tipos de radicales libres, siendo los más conocidos los radicales del oxígeno. Se utiliza el término Especies Reactivas del Oxígeno (ERO) como nombre colectivo para referirse a las especies derivadas del oxígeno, incluyendo tanto los derivados radicales como los no radicales, que son agentes oxidantes y/o fácilmente convertibles en radicales (la presencia de un "•" en una especie reactiva indica que ésta posee un electrón no apareado, es decir, que es un radical). De forma análoga existen Especies Reactivas del Nitrógeno (ERN), del Cloro (ERCl) y del Bromo (ERBr) (Halliwell, 1996). En la tabla 1 se presentan las principales especies reactivas del oxígeno (ERO).

Tabla 1. Nomenclatura de las principales especies reactivas del oxígeno

\begin{tabular}{|ll|ll|}
\hline \multicolumn{2}{|c|}{ Radicales } & \multicolumn{2}{c|}{ No Radicales } \\
\hline Hidroxilo & $\mathrm{OH}$ & Peróxidos orgánicos & $\mathrm{ROOH}$ \\
Alcóxido & $\mathrm{RO}$ & Oxígeno singlete & $\mathrm{O}_{2}$ \\
Hidroperoxilo & $\mathrm{HOO}$ & Peróxido de hidrógeno & $\mathrm{H}_{2} \mathrm{O}_{2}$ \\
Superóxido & $\mathrm{O}_{2} \cdot$ & Ácido hipocloroso & $\mathrm{HClO}$ \\
Peroxilo & $\mathrm{ROO}$ & Ácido nitroso & $\mathrm{HNO}_{2}$
\end{tabular}




\begin{tabular}{|c|c|c|c|}
\hline Óxido Nítrico & NO & Catión nitrilo & $\mathrm{NO}_{2}^{+}$ \\
\hline \multirow[t]{5}{*}{ Dióxido de nitrógeno } & $\mathrm{NO}_{2}$ & Peroxinitrilo & $\mathrm{ONOO}^{-}$ \\
\hline & & Ácido peroxinitroso & $\mathrm{ONOOH}$ \\
\hline & & Alquil peroxinitritos & ROONO \\
\hline & & Ozono & $\mathrm{O}_{3}$ \\
\hline & & & $\mathrm{HBrO}$ \\
\hline
\end{tabular}

Fuente: Halliwell y Whiteman (2004)

Nuestro organismo está expuesto a una gran variedad de ERO que pueden generarse a partir de fuentes endógenas, relacionadas con el metabolismo del oxígeno y con las diversas reacciones de defensa de nuestro sistema inmunitario, o de fuentes exógenas, como el tabaco, la contaminación del aire, la radiación UV, el ozono y ciertos medicamentos. Aunque la exposición a los ERO procedentes de fuentes exógenas sea extremadamente elevada, la exposición a fuentes endógenas es mucho más importante y extensa, debido a que es un proceso que se produce de forma continua en las células de nuestro organismo a lo largo de la vida (Kohen, 1999).

\subsection{Daños producidos por los Radicales Libres}

Cuando el organismo se ve desbordado por un exceso de RL, prácticamente cualquier estructura biológica que lo integra (ADN, ARN, proteínas, carbohidratos y lípidos) puede convertirse en diana de la acción de estas especies reactivas y resultar dañada. El daño causado por el ataque de ERO puede originar lesiones en el ADN, pérdida de función de enzimas, incremento de la permeabilidad celular, disrupción de la señalización en la célula y, en ocasiones, muerte celular por necrosis o apoptosis. Por este motivo, es común relacionar el daño provocado por las diversas especies reactivas con la fisiopatología de varias enfermedades como el cáncer, la diabetes y enfermedades pulmonares como la enfermedad pulmonar obstructiva crónica y la sarcoidosis (García Alonso y col., 2002).

Es importante destacar que no todas las especies reactivas presentan la misma capacidad de reacción o son igual de reactivas. Ciertos compuestos como el $\mathrm{H}_{2} \mathrm{O}_{2}$, 
$\mathrm{O}_{2}$ • y NO•, reaccionan de forma relativamente selectiva con sólo ciertas moléculas biológicas in vivo, mientras que el radical $\cdot \mathrm{OH}$ es altamente reactivo, ya que reacciona instantáneamente con cualquier molécula que encuentra. Otra característica que diferencia a los ERO es el sitio donde actúan; los radicales libres reaccionan casi al instante en el lugar de su formación debido a su elevada reactividad, mientras que los ERO no radicalarios, como el $\mathrm{H}_{2} \mathrm{O}_{2}$, pueden atravesar membranas biológicas y extender así su campo de acción y su posible toxicidad a zonas alejadas de su lugar de formación y durante períodos de tiempo más largos.

A pesar de que los $\mathrm{RL}$ son conocidos básicamente por sus efectos dañinos sobre el organismo, se debe puntualizar que la generación de $R L$ no se relaciona siempre con toxicidad y daño, ya que estas moléculas desarrollan funciones fisiológicas cruciales para el correcto funcionamiento del cuerpo humano $\mathrm{y}$, aunque parezca contradictorio, nuestras células necesitan estar rodeadas de un cierto ambiente oxidativo para poder existir y desarrollarse. Los RL participan activamente en diversas funciones celulares como la activación génica, el crecimiento celular, la modulación de diversas reacciones químicas y el control de la homeostasis (regulando los procesos de fosforilación de enzimas y factores de trascripción); pero las "buenas acciones" de los RL no acaban aquí; gracias a ellos es posible la relajación muscular y la dilatación de los vasos sanguíneos (NO•); actúan en el control de la presión sanguínea y forman parte del mecanismo de defensa llevado a cabo por las células fagocíticas contra agentes infecciosos (Casadevall, 2009).

\subsection{Antioxidantes}

Hemos visto que inherente al metabolismo aeróbico se produce la generación constante de especies reactivas, radicalarias y no radicalarias, que, aunque contribuyen a funciones básicas del organismo como señalización redox o acciones defensa, pueden producir daños a nivel del ADN y del funcionamiento celular.

Para prevenir y proteger a los componentes celulares del daño inducido por los radicales libres, ERO y otras especies reactivas, los organismos aerobios han desarrollado un elaborado mecanismo de defensa, el llamado sistema de defensa antioxidante (Casadevall, 2009). 
Halliwell y Gutteridge (1995) definieron "antioxidante" como "cualquier sustancia que, cuando está presente a bajas concentraciones respecto a las de un sustrato oxidable, retrasa o previene significativamente la oxidación de este sustrato"

\subsection{Estrés oxidativo}

Un desequilibrio entre la producción de radicales libres y la acción de los antioxidantes desencadena un cuadro de cambios fisiológicos y bioquímicos conocido como estrés oxidativo.

Este estrés oxidativo puede darse tanto por un exceso de producción de RL y ERO como por un problema o alteración en el sistema de defensa antioxidante. Podría definirse como "el daño biomolecular causado por el ataque de especies reactivas sobre los constituyentes de los organismos vivos". Este daño oxidativo tiene como blanco todo tipo de moléculas biológicas, incluyendo lípidos, proteínas, hidratos de carbono y ADN, hecho que conduce a fenómenos de peroxidación lipídica, oxidación y fragmentación de proteínas e hidratos de carbono, mutagénesis, carcinogénesis y lesión de las membranas celulares.

El estrés oxidativo y el daño que produce habitualmente se han relacionado con el proceso de envejecimiento (asociado a la acumulación de componentes celulares oxidados como ácidos nucleicos, proteínas y lípidos). Actualmente se consideran un factor clave en el desarrollo de diversas enfermedades crónicas y desórdenes neurodegenerativos relacionados con la edad como el Alzheimer o el Parkinson (Casadevall, 2009).

\subsection{Sistemas de defensa antioxidante}

Los sistemas antioxidantes o mecanismos de defensa que ha desarrollado el organismo para protegerse de los diversos "ataques" oxidativos, pueden clasificarse en función de su origen en sistemas antioxidantes endógenos, enzimáticos y no enzimáticos, y sistemas antioxidantes exógenos, que se adquieren a través de la dieta. 
Los nutrientes básicos que ingerimos a través de la dieta (proteínas, lípidos, vitaminas y minerales) ayudan a los mecanismos de defensa internos contra todas las oxidaciones no deseadas, por ejemplo:

-Proteínas: un déficit de proteínas en la dieta provocaría una disminución en el aporte de aminoácidos como glutamina, cisteína y arginina, constituyentes de las enzimas antioxidantes, lo que causaría una sobre producción de radicales libres por disminución de estas enzimas.

- Lípidos: la ingesta de ácidos grasos $\omega-3$ disminuye el riesgo de sufrir enfermedades cardiovasculares, ya que parecen actuar como inhibidores de la producción de radicales libres aumentando la expresión de genes antioxidantes.

- Vitaminas: ciertas vitaminas inhiben la producción de NO• y otras actúan como secuestradoras de ERO y reguladoras de la actividad de las enzimas antioxidantes. Destacan la vitamina $E$ ( $\alpha$-tocoferol), que inhibe la formación de ERO inducida por radicales lipídicos y protege a la célula de la peroxidación lipídica y la vitamina $\mathrm{C}$ (ácido ascórbico), una eficaz secuestradora de ERO.

- Minerales: actúan como cofactores de muchas enzimas que participan en la eliminación de radicales libres (Casadevall, 2009).

- Además de todos estos nutrientes básicos, a través de la dieta obtenemos también una de las principales fuentes de antioxidantes exógenos, las llamadas sustancias fitoquímicas, que son compuestos procedentes del reino vegetal de estructura química y propiedades muy variadas, que juegan un papel importante en el mantenimiento del equilibrio redox y en disminuir la incidencia del daño producido por los radicales libres, por lo que actualmente se consideran altamente beneficiosos para la salud.

Gran cantidad de alimentos de origen vegetal contienen extractos con compuestos con actividad antioxidante, por ejemplo, el té verde, el vino tinto o las frutas, especialmente los berries. 


\subsubsection{Compuestos Fenólicos}

Los compuestos fenólicos constituyen una de las principales clases de metabolitos secundarios de las plantas, donde desempeñan diversas funciones fisiológicas, entre otras, intervienen en su crecimiento y reproducción y en procesos defensivos frente a patógenos, predadores o radiación ultravioleta. Los compuestos fenólicos presentan un anillo benceno hidroxilado como elemento común en sus estructuras moleculares, las cuales pueden incluir grupos funcionales como ésteres, metil ésteres, glicósidos, etc. (Martínez-Valverde y col., 2000; Duthie y Crozier, 2000). Aunque existe una gran variedad de compuestos fenólicos en las plantas (se conocen más de 8000 ), la mayor parte de ellos tienen como origen metabólico común la ruta del ácido siquímico y el metabolismo de los fenilpropanoides (Robards y col., 1999). Las distintas familias de compuestos fenólicos se caracterizan principalmente por el número de átomos de carbono de su esqueleto básico molecular.

- Ácidos cinámicos $\left(\mathrm{C}_{6}-\mathrm{C}_{3}\right)$

- Ácidos benzoicos $\left(\mathrm{C}_{6}-\mathrm{C}_{1} \circ \mathrm{C}_{6}-\mathrm{C}_{2}\right)$

- Flavonoides $\left(\mathrm{C}_{6}-\mathrm{C}_{3}-\mathrm{C}_{6}\right)$

- Proantocianidinas o taninos condensados $\left(\left(\mathrm{C}_{6}-\mathrm{C}_{3}-\mathrm{C}_{6}\right)_{n}\right)$

- Estilbenos $\left(\mathrm{C}_{6}-\mathrm{C}_{2}-\mathrm{C}_{6}\right)$

- Cumarinas $\left(\mathrm{C}_{6}-\mathrm{C}_{3}\right)$

- Lignanos $\left(\mathrm{C}_{6}-\mathrm{C}_{3}-\mathrm{C}_{3}-\mathrm{C}_{6}\right)$

- Ligninas $\left(\left(\mathrm{C}_{6}-\mathrm{C}_{3}\right)_{\mathrm{n}}\right)$

Así, los compuestos fenólicos comprenden desde moléculas simples como los ácidos benzoicos hasta polímeros complejos como las ligninas. Los compuestos fenólicos están presentes en todo el reino vegetal. Sus cantidades y tipos varían en función de la especie botánica, variedad y parte de la planta considerada (frutos, semillas, hojas, tallos, etc.). Influyen además las horas de exposición solar, grado de madurez, condiciones de cultivo, procesado y almacenamiento de los frutos. En los alimentos, los compuestos fenólicos habitualmente se presentan conjugados con azúcares como la glucosa, galactosa, arabinosa, ramnosa, xilosa, o los ácidos 
glucurónico y galacturónico. También pueden unirse a ácidos carboxílicos, ácidos orgánicos, aminas y lípidos (Duthie y col., 2003).

La actividad antioxidante de los compuestos fenólicos se atribuye a su facilidad para ceder átomos de hidrógeno de un grupo hidroxilo aromático a un radical libre y a la posibilidad de deslocalización de cargas en el sistema de dobles enlaces del anillo aromático (Duthie y col., 2003).

Los compuestos fenólicos poseen además una estructura química ideal para captar iones metálicos (principalmente hierro y cobre) y por tanto para inhibir la formación de radicales libres a través de reacciones de Fenton (Rice-Evans y col., 1997). Son también inhibidores de enzimas prooxidantes, como cicloxigenasa, lipooxigenasa y xantina oxidasa. Además de las propiedades antioxidantes anteriormente descriptas, a estos compuestos se les atribuyen actividades biológicas beneficiosas para salud. Entre estas destacan sus efectos vasodilatadores, anticarcinogénicos, antiinflamatorios, bactericidas, estimuladores de la respuesta inmune, antialérgicos, antivirales y efectos estrogénicos. (Cao y col., 1997). A continuación se describen los principales grupos de compuestos fenólicos presentes en los alimentos vegetales.

\subsubsection{1 Ácidos fenólicos}

Los ácidos fenólicos (figura 11) son abundantes en los alimentos. Los más frecuentes son el ácido cafeíco, y en menor medida el ácido ferúlico, que se encuentra asociado a la fibra dietética mediante la formación de enlaces éster con la hemicelulosa. El ácido cafeíco también se encuentra esterificado, principalmente con el ácido quínico, dando lugar al ácido clorogénico, que está presente en el café, y en muchas frutas y verduras (Scalbert y Williamson, 2000). Se pueden diferenciar dos grupos principales de ácidos fenólicos, los ácidos benzoicos y los ácidos cinámicos. 
<smiles>[R]c1cc(C(=O)O)cc([R])c1[R]</smiles>

Ácidos benzoicos

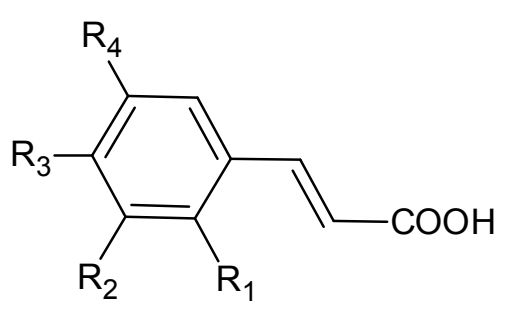

Ácidos Cinámicos

\begin{tabular}{|c|c|c|c|c|c|c|c|c|}
\hline Ácido & $\mathrm{R}_{1}$ & $\mathrm{R}_{2}$ & $\mathrm{R}_{3}$ & Ácido & $\mathrm{R}_{1}$ & $\mathrm{R}_{2}$ & $\mathrm{R}_{3}$ & $\mathrm{R}_{4}$ \\
\hline Gálico & $\mathrm{OH}$ & $\mathrm{OH}$ & $\mathrm{OH}$ & Ferúlico & $\mathrm{H}$ & $\mathrm{H}$ & $\mathrm{OH}$ & $\mathrm{OCH}_{3}$ \\
\hline Protocatéquico & $\mathrm{H}$ & $\mathrm{OH}$ & $\mathrm{OH}$ & $\begin{array}{l}\text { p- } \\
\text { cumárico }\end{array}$ & $\mathrm{H}$ & $\mathrm{H}$ & $\mathrm{OH}$ & $\mathrm{H}$ \\
\hline Vaníllico & $\mathrm{H}$ & $\mathrm{OH}$ & $\mathrm{OCH}_{3}$ & Cafeíco & $\mathrm{H}$ & $\mathrm{H}$ & $\mathrm{OH}$ & $\mathrm{OH}$ \\
\hline Siríngico & $\mathrm{OCH}_{3}$ & $\mathrm{OH}$ & $\mathrm{OCH}_{3}$ & Sinápico & $\mathrm{H}$ & $\mathrm{OCH}_{3}$ & $\mathrm{OH}$ & $\mathrm{OCH}_{3}$ \\
\hline
\end{tabular}

Figura 11. Estructura química de los ácidos fenólicos (Fuente: García Alonso y col., 2002)

Los ácidos benzoicos o derivados del ácido hidroxibenzoico, tienen una estructura básica $\mathrm{C}_{6}-\mathrm{C}_{1}$. Los principales son los ácidos gálico, salicílico, $\mathrm{p}$ hidroxibenzoico, protocatéquico, vaníllico y siríngico, estos cuatro últimos se consideran universales ya que forman parte de las ligninas. Generalmente se presentan de forma conjugada en los vegetales, aunque pueden ser detectados en forma libre en algunas frutas o tras su liberación como consecuencia del procesado. El ácido gálico se puede encontrar conjugado como tal o como sus dímeros (ácido elágico), trímeros (ácido tergálico) o tetrámeros (ácido galágico), los dos últimos menos frecuentes. Los ácidos gálico y elágico son componentes esenciales de los taninos hidrolizables, como por ejemplo los elagitaninos de frutillas, frambuesas y zarzamoras. Generalmente los contenidos en estos ácidos son bajos a excepción de las frutas rojas (Manach y col., 2004).

Los ácidos cinámicos o derivados del ácido hidroxicinámico, están ampliamente distribuidos como conjugados en materias vegetales, incluyendo muchos alimentos y bebidas. Entre ellas, los berries constituyen una fuente importante de estos compuestos. Salvo en el caso de alimentos procesados, raramente se encuentran como ácidos libres y de forma predominante aparecen esterificados con ácido 
quínico, tartárico o glucosa. Los más comunes son los ácidos cafeico, ferúlico, sinápico y p-cumárico.

El contenido en ácidos fenólicos de algunos berries se presenta en la tabla 2.

Tabla 2. Contenido en $\mathrm{mg} / \mathrm{Kg}$ de ácidos fenólicos totales en frutas rojas.

\begin{tabular}{|l|c|c|}
\hline \multicolumn{1}{|c|}{ Fruta } & Ácidos benzoicos & Ácidos cinámicos \\
\hline Zarzamora & $80-270^{1}$ & $15^{2}$ \\
\hline Frambuesa & $60-100^{1}$ & $3^{2}$ \\
\hline Cereza & $2,5^{2}$ & $180-1150^{1}$ \\
\hline Grosella & $40-130^{1}$ & $133^{3}$ \\
\hline Frutilla & $20-90^{1}$ & $19-27^{2}$ \\
\hline Arándano & $15^{3}$ & $2000-2200^{1}$ \\
\hline
\end{tabular}

Fuente: ${ }^{1}$ Manach y col. (2004), ${ }^{2}$ Heinonen y col. (1998b), ${ }^{3}$ Phenol-Explorer (2017)

\subsubsection{Taninos hidrolizables}

Los taninos hidrolizables resultan de la esterificación de los ácidos gálico y elágico. Se distinguen 2 grupos principales; los galotaninos, que son frecuentes en frutas como el mango, y los elagitaninos, característicos de frutas rojas como las frutillas, frambuesas y zarzamoras (Clifford y Scalbert, 2000).

\subsubsection{Estilbenos}

Los estilbenos tienen un esqueleto básico de 14 carbonos $\left(\mathrm{C}_{6}-\mathrm{C}_{2}-\mathrm{C}_{6}\right)$ y su distribución en alimentos vegetales no es muy amplia (Scalbert y Williamson, 2000). Los estilbenos con mayor interés nutricional son el resveratrol $(3,5,4$ 'trihidroxiestilbeno) y el piceido (resveratrol-3-O-b-D-glucósido), presentes en uvas y vinos.

\subsubsection{Flavonoides}

Los flavonoides constituyen el grupo de compuestos fenólicos más diverso y ampliamente distribuido en las plantas. Su estructura básica, el flaván, (figura 12) 
consta de dos grupos fenilo ( $\mathrm{A}$ y $\mathrm{B}$ ) unidos por un puente de tres carbonos que forma un anillo heterocíclico oxigenado (anillo C) (Manach y col., 2004).

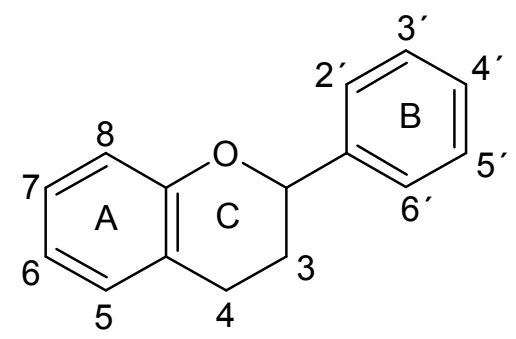

Figura 12. Estructura química del flaván

En función de los grados de oxidación e insaturación del anillo heterocíclico se pueden diferenciar varias clases de flavonoides y dentro de cada clase se pueden establecer diferencias en base a la naturaleza y número de los sustituyentes unidos a los anillos (Robards y col., 1999). La presencia o ausencia de un grupo hidroxilo unido a la posición 3 determina la subdivisión en las dos clases principales de flavonoides: los 3-hidroxi flavonoides (flavonoles, flavanoles, flavan-3,4-dioles, antocianidinas, proantocianidinas o taninos condensados) y los flavonoides no hidroxilados en posición 3 (flavonas, isoflavonas, flavanonas). La mayoría de los tejidos de las plantas (principalmente en hoja y fruto) pueden sintetizar flavonoides, los cuales se presentan en forma de glicósidos. Las agliconas de los flavonoles y flavonas no se encuentran en el vegetal fresco pero pueden presentarse como consecuencia del proceso.

Las antocianidinas tienen la estructura básica del catión flavilio. Seis antocianidinas son importantes en los alimentos; cianidina, delfinidina, peonidina, pelargonidina, petunidina y malvidina, contribuyendo a la coloración de numerosas frutas. En los vegetales frescos, generalmente se encuentran unidas a azúcares dando lugar a los antocianos o antocianinas, que son responsables de los colores azules, púrpuras, rojos y matices intermedios de estas coloraciones de frutas rojas como cerezas, ciruelas, frutillas, frambuesas, zarzamoras, uvas y grosellas (Clifford, 2000; Scalbert y Williamson, 2000). Los azúcares más comunes son; glucosa, galactosa, ramnosa y arabinosa, normalmente unidos a la posición 3 o a las posiciones 3 y 5 , generando diglicósidos (Clifford, 2000). También se encuentran 
disacáridos de glucosa (soforósidos), de ramnosa y glucosa (rutinósidos), de xilosa y glucosa y trisacáridos (Clifford, 2000).

Las antocianinas más comunes en las frutas son los 3-monoglucósidos de cianidina, delfinidina, peonidina, pelargonidina y petunidina, la cianidina-3galactósido y la cianidina-3-arabinósido (Robards y col., 1999).

\subsubsection{Actividad antioxidante de los compuestos fenólicos}

La actividad antioxidante de los compuestos fenólicos se ve determinada por su estructura química, por lo que existen grandes diferencias en la efectividad como antioxidantes entre los distintos grupos de compuestos. Los compuestos fenólicos pueden actuar como antioxidantes mediante dos mecanismos principales (RiceEvans y col., 1997):

- Como captadores de radicales libres. Los compuestos fenólicos pueden actuar como donantes de hidrógeno o electrones en reacciones de terminación que rompen el ciclo de generación de nuevos radicales libres, deteniendo las reacciones en cadena.

- Como quelantes de metales. Esta acción requiere la presencia de grupos hidroxilos cercanos en el anillo aromático. De este modo, los o-dihidroxifenoles son secuestradores efectivos de iones metálicos e inhiben la generación de radicales libres.

El número y posición de grupos hidroxilo, el grado de polimerización o la presencia de azúcares unidos determinarán propiedades de los compuestos fenólicos tales como la solubilidad y la tendencia a ceder electrones o átomos de hidrógeno.

El grado de polimerización de los compuestos fenólicos tiene un marcado efecto sobre la actividad antioxidante. Así, los compuestos poliméricos son más potentes como antioxidantes que los monómeros. Por ejemplo, los taninos son más efectivos frente a los radicales peroxilo que los fenoles simples. La actividad para captar $\mathrm{O}_{2}$ aumenta con el grado de polimerización de los flavanoles y los dímeros de ácido 
ferúlico inhiben la peroxidación lipídica en mayor extensión que los monómeros (Moure y col., 2001).

\subsubsection{Las frutas rojas como fuente de compuestos fenólicos}

Las frutas, incluidos los berries, constituyen una de las principales fuentes de compuestos fenólicos en la dieta. En ellas es frecuente encontrar derivados de los ácidos hidroxibenzoicos e hidroxicinámicos, antocianinas, flavonoles, catequinas, y taninos condensados e hidrolizables (Macheix y col., 1990). La mayoría de estos compuestos permanecen en productos elaborados a base de frutas y berries (Heinonen y col., 1998b), como por ejemplo jugos, pulpas, mermeladas, jaleas, gelatinas, etc. (Häkkinen y col., 2000; Zafrilla y col., 2001).

\subsubsection{Carotenoides}

Los carotenoides son pigmentos liposolubles responsables de los colores amarillos, anaranjados y rojos que presentan los alimentos, las plantas (frutos, tallos, flores y hojas) y algunos animales invertebrados marinos.

Se clasifican en dos grupos: carotenos y xantofilas. Los carotenos solo contienen carbono e hidrogeno ( $\beta$-caroteno, licopeno, etc.), mientras que las xantofilas contienen además oxigeno (por ejemplo la luteína). En general, en sus extremos pueden ser lineales o cíclicos; por lo tanto diferentes combinaciones de estas características estructurales ha llevado a detectar más 600 carotenoides en plantas (Britton, 1995).

El caroteno más comúnmente encontrado es el $\beta$-caroteno y normalmente constituye entre el 25 al $30 \%$, del contenido total de carotenoides en las plantas. Dentro de las xantofilas, la luteína es la más abundante (40-45 \%).

Las frutas y vegetales poseen diferencias cualitativas y cuantitativas en la composición de sus carotenoides; dichas diferencias se deben a factores como la zona de cultivo, la variedad, el estado de madurez, las condiciones de cosecha y de almacenamiento, entre otras (Rodríguez Amaya y Kimura, 2004). 
Varios estudios epidemiológicos han demostrado una relación entre el alto consumo de las frutas y vegetales, y una disminución en el riesgo de contraer enfermedades degenerativas como el cáncer, enfermedades cardiovasculares y degeneración macular, debido principalmente a la presencia de compuestos con actividad antioxidante (Su y col., 2002).

Estos compuestos junto con las antocianinas y clorofilas, son los pigmentos vegetales de mayor distribución en la naturaleza. Algunos de los carotenoides presente en los alimentos son precursores de la vitamina $A$, como es el caso del $\beta$ caroteno y otros carotenoides que poseen anillo $\beta$ no sustituido, dicha vitamina es importante en el proceso de la visión, mantenimiento epitelial, secreción de la mucosa y reproducción (Rodríguez Amaya y Kimura, 2004).

\subsubsection{Actividad antioxidante de los carotenoides}

En estudios realizados in vitro, se ha comprobado que los carotenoides son potentes antioxidantes capaces de secuestrar diversos radicales libres. La actividad antioxidante de estos pigmentos depende de una serie de factores, como su estructura química (tamaño, número de sustituyentes, configuración cis o trans, etc), su concentración, la presión parcial de oxígeno o su interacción con otros antioxidantes, sobre todo las vitaminas C y E (Meléndez-Martínez, 2004).

Los carotenoides tienen la capacidad de inactivar algunas especies de moléculas en estado de excitación electrónica principalmente las debidas a reacciones fotosensibles. Como se sabe, la luz puede convertir moléculas a una forma electrónicamente excitada de vida corta, pero que pueden interactuar con otras de su misma especie para formar una molécula estable. Esta última es la que puede reaccionar con una gran variedad de moléculas para iniciar las reacciones fotoquímicas (Rodríguez Amaya, 1999).

Se ha demostrado que los carotenoides son muy efectivos para la inactivación del oxígeno singulete, evitando el daño fotoxidativo iniciado por esta molécula reactiva capaz de iniciar la peroxidación de lípidos al reaccionar con ácidos grasos saturados; de inactivar proteínas y enzimas al reaccionar con aminoácidos como 
metionina, histidina, triptófano o tirosina o bien de oxidar residuos de guanina en el ADN o ARN. (Sánchez y col., 1999; Young y Lowe, 2001).

\section{PREBIÓTICOS}

El intestino grueso contiene una variedad de especies de bacterias que son benéficas: Bifidobacterium, Eubacterium y Lactobacillus y perjudiciales: Clostridium, Shigella y Veillonella. Aunque esta generalización da probablemente una visión demasiado simple de la microbiología del intestino, es un concepto de trabajo factible para el desarrollo de ingredientes de alimentos funcionales para que permitan modular la composición de las colonias microbianas (Roberfroid, 2001). En este contexto el concepto prebiótico, se define como un ingrediente activo no digerible que afecta benéficamente al huésped por la estimulación selectiva del crecimiento y/o activación del metabolismo de una o un número limitado de bacterias en el colon mejorando intrínsecamente la salud del huésped (Gibson y Roberfroid, 1995).

Dentro de los ingredientes activos con potencial actividad prebiótica se encuentran los fructanos. Roberfroid (2005) ha resumido las posibles funciones fisiológicas como prebióticos que pueden tener los fructanos; dentro de las cuales se destacan su efecto benéfico en la disponibilidad de minerales, el fortalecimiento de los mecanismos de defensa, el mejoramiento del metabolismo de lípidos, así como la prevención de ciertas enfermedades.

La estructura fundamental de los fructanos es un esqueleto de unidades de fructosa unidas entre sí por enlaces glucosídicos $\beta(2 \rightarrow 1)$ y/o $ß(2 \rightarrow 6)$. Es frecuente encontrar, adicionalmente, una molécula de glucosa al inicio de la cadena de cada fructano (Niness, 1999). Existen diversos tipos de fructanos en la naturaleza, pero desde un punto de vista nutricional y de uso en la industria alimentaria se reconocen a los fructooligosacáridos (FOS) y a la inulina como los más importantes.

La inulina y los FOS no tienen una composición química definida ya que ambos son, en realidad, una mezcla de fructanos de diferente tamaño. Debido a que las moléculas de fructosa se unen exclusivamente por enlaces $\beta(2 \rightarrow 1)$, estos fructanos adquieren una conformación espacial semejante a cadenas lineales. La diferencia 
entre los FOS y la inulina radica en el número de moléculas de fructosa que tienen estas cadenas. En la inulina, este número varía entre 2 y 60 , mientras que en los FOS, que tienen cadenas más pequeñas, el número varía entre 2 y 10 (Niness, 1999). Esto significa que a los FOS se les puede considerar como un subgrupo de la inulina.

\section{ALIMENTOS FUNCIONALES}

Los fitoquímicos están presentes en forma natural en muchas frutas y verduras. Por tal razón, se están desarrollando nuevos alimentos con base frutihortícola denominados funcionales, considerados como aquellos que se consumen dentro de una dieta normal y que contienen compuestos biológicamente activos con propiedades benéficas para la salud científicamente comprobadas (CTEP, 2010).

El concepto de alimento funcional a menudo se cita como una nueva área que emerge de la ciencia y nutrición de los alimentos; sin embargo, este concepto se basa en los avances en el conocimiento y la evolución de la nutrición que ocurrieron en el siglo XX (Menrad, 2003). Durante dicho siglo la desnutrición y las deficiencias en los alimentos procesados era la mayor preocupación, comenzando a tener gran auge, el interés en los alimentos modificados para corregir problemas públicos asociados a la salud. En la mayoría de las situaciones los investigadores se han preguntado cómo el alimento se puede modificar o formular para tener efectos fisiológicos o nutrimentales específicos que mejoren la salud (Schneeman, 2000).

Los alimentos funcionales son aquéllos que contienen ingrediente(s) activo(s), los cuales benefician a una o un número limitado de funciones en el cuerpo proporcionando bienestar y salud en la reducción del riesgo de una enfermedad (Roberfroid, 2000) o aquel alimento que tiene un efecto fisiológico más allá de su efecto tradicional (Clydesdale, 1997).

La documentación de la existencia de los alimentos funcionales comenzó en el año 1000 A.C., en China. En Asia existe una larga tradición que atribuye propiedades curativas o terapéuticas a los alimentos y hierbas. No obstante, esto había pertenecido hasta hace poco tiempo a la esfera de la "medicina no tradicional", no documentada por una sólida investigación científica. La creencia de que el alimento está íntimamente ligado a una salud óptima tampoco es un concepto nuevo 
en Occidente, basta con recordar la frase propuesta por Hipócrates: "que la alimentación sea tu única medicina y que la medicina sea tu alimentación" (Rossi, 2007).

En 1984, el concepto de alimento funcional fue propuesto por científicos japoneses estudiando la relación entre nutrición, satisfacción sensorial, fortificación y modulación de sistemas fisiológicos. En la actualidad se engloban bajo el nombre de "Alimentos para Uso Dietético Específico" (Food for Specific Health Use FOSHU). El gobierno japonés construyó alegaciones sanitarias encaminadas a mejorar con su consumo la salud de la población (Rossi, 2007).

En Estados Unidos, en 1990 se instauró el Acta de Educación y Etiquetado Nutricional (NLEA), pero recién se cumplió totalmente en 1994 cuando se emplearon ingredientes para los cuales la Administración de Alimentos y Drogas de los Estados Unidos (FDA) tenía evidencia científica de la correlación entre el producto y la prevención de ciertas enfermedades, sin embargo los alimentos funcionales son una nueva categoría indefinida y es definida como un ingrediente activo " $X$ " seguro (GRAS) o como un aditivo similar a un suplemento alimenticio (Rossi, 2007).

Según Roberfroid (2002), el término alimento funcional hace referencia a productos alimenticios que deben consumirse dentro de la dieta habitual para conseguir efectos beneficiosos que van más allá de los requerimientos nutricionales tradicionales, mejorando el estado general de salud y/o reduciendo el riesgo de enfermedad.

Los componentes de los alimentos funcionales pueden ser probióticos, prebióticos o macronutrientes (Bellisle y col., 1998).

De los productos de diseño que se encuentran actualmente en el mercado, el mayor porcentaje fundamenta su funcionalidad en alguno de los siguientes componentes activos:

- Los fitoquímicos, los cuales fueron explicados con anterioridad. 
- Los fitoestrógenos, moléculas de origen vegetal con una estructura química similar a los estrógenos. Los más estudiados son las isoflavonas (presentes en soja y sus derivados, lentejas y arvejas) y los lignanos (se encuentran fundamentalmente en semillas de lino).

- Los ácidos grasos poliinsaturados tipo $\omega-3$, presentes principalmente en aceites de pescado, semillas y frutos secos parecen jugar un papel relevante como agentes antiinflamatorios, anti arrítmicos y protectores a nivel cardiovascular.

- El ácido oleico ( $\omega-9)$ presente en el aceite de oliva, es el más importante de los ácidos grasos monoinsaturados. Favorece la reducción de triglicéridos y del colesterol total, y es una de las pocas sustancias conocidas con capacidad de inducir la elevación del HDL (lipoproteína de alta densidad).

- Las bacterias probióticas (bifidobacterias y lactobacilos), que se encuentran generalmente en productos lácteos fermentados, modifican favorablemente el balance de la microflora intestinal, inhiben el crecimiento de bacterias nocivas, favorecen la digestión, potencian la función inmunológica y aumentan la resistencia a las infecciones.

- La fibra dietética que corresponde a aquellas sustancias de origen vegetal, en su mayor parte hidratos de carbono, no digeridas por las enzimas humanas y que pueden ser parcialmente fermentadas por bacterias colónicas. Se clasifica en soluble e insoluble. La fibra insoluble engloba a la celulosa, hemicelulosa y lignina. Como acciones funcionales se le atribuyen: el incremento del bolo fecal y el estímulo de la motilidad intestinal; la mayor necesidad de masticado, el aumento de la excreción de ácidos biliares y propiedades antioxidantes e hipocolesterolemiantes. La fibra soluble está representada fundamentalmente por pectinas, gomas, mucilagos y algunas hemicelulosas; su principal característica es la capacidad para atrapar agua y formar geles viscosos, lo que determina su poder laxante. En términos generales, la insoluble predomina en los cereales enteros, y la soluble en frutas, vegetales y tubérculos. Algunos componentes de la fibra son prebióticos (Alderete, 2006). 
El aumento de la preocupación con relación a la dieta y el mayor conocimiento de las influencias de los alimentos funcionales sobre la salud, hicieron que las industrias desarrollaran cada vez más nuevos productos. El tamaño del mercado global de este tipo de alimentos ha venido creciendo en forma sostenida. Así, la industria de la salud y el bienestar creció un $2,2 \%$ en 2013 , llegando a USD 750 mil millones. Con respecto al tamaño de valor de mercado, Estados Unidos lidera de lejos la lista de los 20 principales, seguido por China, Japón y mercados emergentes como Brasil y México. Pero en crecimiento, los emergentes ganan terreno, con China liderando y donde Brasil, Rusia y México se encuentran entre los cinco principales países de 2013. Además, al 2019 se espera que los mercados emergentes generen el $86 \%$ de las nuevas ventas, con crecimientos significativos en la venta de alimentos funcionales y naturales, que formarán el núcleo de la demanda del consumidor (Prospectiva 2020, 2014). El principal factor que contribuye al rápido aumento de este mercado es la apreciación de que, por lo menos, cerca de un sexto de las causas de muerte están relacionadas con la dieta y que si se la mejora se puede aumentar la expectativa y la calidad de vida de la población (Bellisle y col., 1998).

Una categoría de los alimentos funcionales que tiene gran interés de la población, la industria alimentaria y la comunidad científica son los ingredientes probióticos y prebióticos los cuales, pueden modificar positivamente los procesos fisiológicos y biológicos en la nutrición o como auxiliar en el tratamiento de ciertas patologías humanas (Roberfroid, 2001).

\subsection{Diseño de alimentos funcionales}

Un alimento puede hacerse funcional siguiendo alguna de las siguientes estrategias o sus combinaciones (Roberfroid, 2002):

1.Eliminando componentes perjudiciales presentes en el alimento (e.j. alergenos).

2. Incrementando la concentración de un componente presente de forma natural en el alimento hasta unos niveles en que pueda inducir los beneficios esperados (e.j. fortificación con micronutrientes) o incrementando la concentración de una sustancia no nutritiva hasta niveles en que se conoce su efecto beneficioso. 
3. Añadiendo un componente que no está presente de forma natural en el alimento, pero cuyos efectos beneficiosos son reconocidos (e.j. prebióticos, antioxidantes no vitamínicos).

4. Sustituyendo un componente, generalmente un macronutriente (e.j. grasas), cuyo consumo excesivo tenga efectos perjudiciales por un componente de reconocido efecto beneficioso (e.j. inulina).

5. Incrementando la biodisponibilidad o estabilidad de un componente que se sepa que es capaz de producir un efecto funcional o reducir un potencial riesgo de enfermedad del propio alimento.

Una de las áreas más prometedoras para el desarrollo de alimentos funcionales se fundamenta en la posibilidad de modular los sistemas redox y antioxidantes del organismo (Roberfroid, 2002). Por esta razón, en la actualidad muchos alimentos funcionales tienen como finalidad incrementar el aporte de antioxidantes naturales en la dieta. En este contexto, la adición de extractos vegetales ricos en compuestos fenólicos ha sido propuesta como una estrategia factible para el desarrollo de alimentos funcionales con una actividad antioxidante incrementada (Larrosa y col., 2002). De hecho, en el campo del desarrollo de nuevos ingredientes se está produciendo un aumento en la producción de este tipo de extractos vegetales en los cuales los compuestos bioactivos son aislados y concentrados para su uso como suplementos, alimentos nutracéuticos o como ingredientes en la elaboración de alimentos funcionales (Psczcola, 2003).

No obstante, una alternativa natural a la adición de estos extractos o del propio compuesto activo previamente aislado, podría ser la selección de materias primas ricas en el principio activo cuyos niveles se desean incrementar. En este sentido se podría trabajar con frutas finas (de cultivo y silvestres), que proveerían una elevada actividad antioxidante, colores atractivos (debido a las antocianinas y carotenoides), elevadas concentraciones de ácido ascórbico (por ejemplo en el caso de la rosa mosqueta y el cassis). 


\section{OBJETIVOS}

\subsection{Objetivo general}

Formulación de productos en base a pulpas de frutos patagónicos, con o sin el agregado de otros ingredientes que permitan aumentar la funcionalidad y el valor nutritivo. Evaluación de la estabilidad frente a distintos métodos de conservación.

\subsection{Objetivos particulares}

- Caracterización de principios activos y estudio de propiedades que confieran funcionalidad a los distintos frutos patagónicos. Estandarización de la metodología a aplicar en las matrices utilizadas.

- Formulación y estudio, de las pulpas de frutos patagónicos, con o sin el agregado de aditivos, a fin de lograr un alimento o ingrediente funcional.

- Estudio de la estabilidad de las pulpas durante su conservación por distintos métodos.

- Formulación y estudio de nuevos productos elaborados que permitan el agregado de valor, sobre las materias primas patagónicas, debido a su transformación en alimentos funcionales.

\section{REFERENCIAS}

- Aguilera Garca, C.; Barberá Mateos, J.; Díaz, L. 2010. Alimentos Funcionales: aproximación a una nueva alimentación. Instituto de Nutrición y trastornos alimentarios, Madrid, España.

- Alderete, J. 2006. Consolidación de una tendencia. Revista Alimentos Argentinos, $n^{\circ}$ 34, p. 17-21. Dirección Nacional de Alimentos, Ministerio de Agroindustria. Presidencia de la Nación Argentina.

- Argentina Innovadora 2020. 2012. Núcleo socio-productivo estratégico. Procesamiento de alimentos. Documento de referencia. Plan Nacional de Ciencia, Tecnología e Innovación Productiva. Ministerio de Ciencia, Tecnología e Innovación Productiva. Presidencia de la Nación Argentina.

- Bellisle, R.; Diploc, A.; Hornstra, G. 1998. Functional Foods Science in Europe. British Journal of Nutrition. Vol. 80, suplemento 1, p. 190-193. 
- Boots, A.; Haenen, G.; Bast, A. 2008. Health effects of quercitin: from antioxidant to nutraceutical. Journal of Pharmacology. Vol. 585, n 2-3, p. 325-337.

- Britton, G. 1995. Structure and properties of carotenoids in relation to function. The Faseb Journal. Vol. 9, no 15, p. 1551-1558.

- Bruzone, I. 2004. Frutas Finas en los Valles Cordilleranos Patagónicos. Revista Alimentos Argentinos. № 24, p. 36-38.

- Bruzone, I. 2009. Foro Federal de Frutas Finas: Tiempos de madurez. Revista Alimentos Argentinos. № 42, p. 62-64.

- Cao, G.; Sofic, E.; Prior, R. 1997. Antioxidant and proxidant behaviour of flavonoids. Structureactivity relationships. Free Radical Biology \& Medicine. Vol. 22, n० 5 , p. 749-760.

- Caro, J. 2007. Comparación entre un método enzimático y uno colorimétrico en la determinación de ácido ascórbico en Rosa Mosqueta. Universidad Nacional del Comahue. Memoria para optar al título de Técnico en Control e Higiene de los Alimentos.

- Casadevall, V. 2009. Caracterización de derivados polifenólicos obtenidos de fuentes naturales. Universidad de Barcelona, España. Memoria para optar por el título de Doctor de la Universidad de Barcelona.

- Clifford, M.; Scalbert, A. 2000. Ellagitannins: Nature, occurrence and dietary burden. Journal Science Food Agricultural. Vol. 80, nº 7, p. 1118-1125.

- Clifford, M. 2000. Anthocyanins: Nature, occurrence and dietary burden. Journal Science Food Agricultural. Vol. 80, nº 7, p. 1063-1072.

- Clydesdale, F. 1997. A Proposal for the Establishment of Scientific Criteria for Health Claims for Functional Foods. Nutrition Reviews. Vol. 55, nº 12, p. 413-422.

- Código Alimentario Argentino. 2016. Artículo 888 del capítulo XI. http://www.anmat.gov.ar/alimentos/normativas alimentos caa.asp. Fecha de acceso: noviembre de 2016.

- Cooperación Transfronteriza España-Portugal (CTEP). 2010. Alimentos funcionales: función cognitiva y comportamiento. Manual Proyecto BIOEMPRENDE. Disponible on-line: http://www.bioemprende.eu (fecha de acceso: noviembre 2014).

- Duthie, G.; Crozier, A. 2000. Plant-derived phenolic antioxidants. Current opinion in clinical nutrition and metabolic care. Vol. 11, $n^{\circ} 6$, p. 447-51. 
- Duthie, G.; Gardner, P.; Kyle, J. 2003. Plant polyphenols: are they the new magic bullet?. Journal Nutrition Society. Vol. 62, n 3, p. 599-603

- Eck, P.; Childers, N. 1989. Blueberry Culture. Rutgers University Press. New Brunswick, New Jersey, p. 94-110.

- García Alonso, F.; Periago, M.; Vidal-Guevara, M.; Cantos E. 2002. Evaluación de las propiedades antioxidantes en concentrados de uva y frutas rojas. Análisis Veterinarios. Vol. 18, p. 103-114.

- Gibson, G.; Roberfroid, M. 1995. Dietary Modulation of the human colonic microflora: introducing the concept of prebiotics. Journal of Clinical Nutrition. Vol. $125, n^{\circ} 6$, p. 1401-1412.

- Häkkinen, S.; Kärenlampi S.; Mykkänen H.; Törrönen A. 2000. Influence of domestic processing and storage on flavonol contents in berries. Journal of Agricultural and Food Chemistry. Vol. 48, n 7, p. 2960-2965.

- Halliwell, B.; Gutteridge, J. 1995. The definition and measurement of antioxidants in biological systems. Free Radical Biology Medicinal. Vol. 18, $n^{\circ} 1, p$. 125-126.

- Halliwell, B. 1996. Oxidative stress, nutrition and health. Experimental strategies for optimization of nutritional antioxidant intake in humans. Free Radical Research. Vol. 25, n 1, p. 57-74.

- Halliwell, B. y Whiteman M. 2004. Measuring reactive species and oxidative damage in vivo and in cell culture: how should you do it and what do the results mean?. Journal of Pharmacology. Vol 142, $n^{\circ} 2$, p. 231-255.

- Heinonen, M.; Lehtonen P.; Hopia A. 1998a. Antioxidant activity of berry and fruit wines and liquors. Journal of Agricultural and Food Chemistry. Vol. 46, $n^{\circ} 1, p$. 25-31.

- Heinonen, M.; Meyer A.; Frankel E. 1998b. Antioxidant activity of berry phenolics on human low-density lipoprotein and liposome oxidation. Journal of Agricultural and Food Chemistry. Vol. 46, no 10, p. 4107-4112.

- INTA AER El Bolson. 2015. Comunicación escrita del Dr. De Michelis Antonio.

- Kalt, W.; MacDonald, E. (1996). Chemical Composition of Lowbush Blueberry Cultivars. Journal of American Society Horticulture Science. Vol. 12, n 1, p. 142 146. 
- Kohen, R. 1999. Skin antioxidants: their role in aging and in oxidative stress New approaches for their evaluation. Biomedical Pharmacother. Vol. 53, n 4, p. 181 192.

- Larrosa, M.; Llorach, R.; Espín, J.; Tomás-Barberán, F. 2002. Increase of antioxidant activity of tomato juice upon functionalization with vegetable by product extracts. Lebensmittel-Wissenschaft Und-Tech. Vol. 35, n² 2, p. 532-542.

- Lódola, A.; Brigo, R.; Morra, F. 2010. Mapa de cadenas agroalimentarias de Argentina. En "Cambios estructurales en las actividades agropecuarias. De lo primario a las cadenas globales de valor". Colección Documentos de Proyectos. Comisión Económica para América Latina y el Caribe, pg. 53 - 78.

- Macheix, J.; Fleuriet A.; Billot J. 1990. Fruit phenolics. Boca Raton, Florida, USA. CRC Press, p. 378-382.

- Manach, C.; Scalbert, A.; Morand, C.; Rémésy, C.; Jiménez L. 2004. Polyphenols: food sources and bioavailability. American Journal of Clinical Nutrition. Vol. 79, nº 5 , p. 727-747.

- Martínez-Valverde, I.; Periago, M., Ros G. 2000.Significado nutricional de los compuestos fenólicos en la dieta. Archivos Latinoamericanos de Nutrición. Vol. 50, $\mathrm{n}^{\circ} 1$, p. 5-18.

- Martinez, E. 2007. Frutas finas en la Región Andina Patagónica.Entrevista para el sitio web Fruticultura Sur. Recuperado el 25/09/2010. Disponible en: http://fruticulturasur.com/fichaNota.php?articulold=475.

- Martinez, E.; De Michelis, A. 2011. Cultivo, Cosecha, Post-cosecha inmediata y elaboración de Frambuesas, Moras e Híbridos. Ediciones del INTA.

- Masdeu, I. 2004. Herramientas para la cosecha de berries. Universidad de Chile. Facultad de arquitectura y urbanismo diseño. Memoria para optar al título de Diseñador Industrial.

- Meléndez Martínez, A.; Vicario Romero, I. y Mira, H. 2004. Importancia nutricional de los pigmentos carotenoides. Archivos latinoamericanos de nutrición. Vol. 54, n², p. 149-154.

- Menrad, K. 2003. Market and Marketing of Functional Food in Europe. Journal of Food Engineer. Vol. 56, n² 2, p. 181-188. 
- $\quad$ Moure, A.; Cruz, J.; Franco, D.; Domínguez, J.; Sineiro, J.; Domínguez, H.; Núñez, M.; Parajó, J. 2001. Natural antioxidants from residual sources. Food Chemistry. Vol. 72, nº 2, p. 145-171.

- Niness, K. 1999. Inulin and oligofructose: What are they?. Journal of Nutrition. Vol. 129, no 7, p. 1402S-1406S

- Ochoa, M. 2011. Estudio del deterioro químico de guindas durante la deshidratación. Universidad Nacional de Bahía Blanca, Argentina. Memoria para optar por el título de Doctor en Ciencias Químicas de la Universidad Nacional de Bahía Blanca.

- Palomares, J. 2010. Los frutos del bosque o pequeños frutos en la Cornisa Cantábrica: el Arándano. Gobierno de Cantabria. Consejería de Desarrollo Rural, Ganadería, Pesca y Biodiversidad.

- Phenol-Explorer. 2017. Database on polyphenols content in foods. http://phenol-explorer.eu. Fecha de acceso: febrero 2017

- Prospectiva 2020. 2014. Mercado Mundial De Los Superfoods: Tendencias, Perspectivas y Análisis de Casos. Informe $N^{\circ}$ LXXXI. GDB Network

- Pszczola, D. 2003. Getting more fruits and vegetables into foods. Food Technology. Vol. 57, no 1, p. 52-63.

- Rebizo, M.; Tejada Rodríguez, A. 2011. Balance de inserción internacional de las cadenas agroindustriales argentinas. Documento de Proyecto $n^{\circ} 52$. Colección Documentos de Proyectos. Comisión Económica para América Latina y el Caribe, PROSAP, Ministerio de Agricultura, Ganadería y Pesca, pg. 5 - 219.

- Riadigos, E.; Adrion, P. 1993. Cultivo de grosellas. Cassis, Corinto, Uva espina. AER INTA El Bolsón, EEA Bariloche.

- Rice-Evans, C.; Miller, N.; Paganga, G. 1997. Antioxidant properties of phenolic compounds. Trends Plant Science. Vol. 2, no 4, p. 152-159.

- Robards, K.; Prentzler, P.; Tucker, G.; Swatsitang, P.; Glover, W. 1999. Phenolic compounds and their role in oxidative processes in fruits. Journal of Food Chemistry. Vol. 66, nº 4, p. 401-43.

- Roberfroid, M. 2000. Concepts and strategy of functional food science: the European perspective. American Journal of Clinical Nutrition. Vol. 71, $\mathrm{n}^{\circ} 6, \mathrm{p}$. 1660S-1664S. 
- $\quad$ Roberfroid, M. 2001. Prebiotics: preferential substrates for specific germs? American Journal of Clinical Nutrition. (Supplement). Vol. 73, nº 2, p. 406s-409s.

- Roberfroid, M. 2002. Global view on functional foods: European perspectives. Journal of British Nutrition. Vol. 88, suplemento 2, p. S133-S138.

- Roberfroid, M. 2005. Inulin-Type Fructans: Functional Food Ingredients. Boca Raton, Florida, USA. CRC Press

- Rodríguez Amaya, D. 1999. Carotenoides y preparación de alimentos: La retención de los Carotenoides Provitamina A en alimentos preparados, procesados y almacenados. Agencia para el Desarrollo Internacional de los Estados Unidos. Washington, D.C.: OMNI/USAID.

- Rodríguez Amaya, D.; Kimura, M. 2004. Harvestplus Handbook for Carotenoid Analysis. Harvestplus Technical Monograph series 2.

- Rossi, R. 2007. El poder de las sustancias bioactivas. Revista Énfasis Alimentación Latinoamérica. FLC. Año XIII, № 7, p. 18-19.

- Sánchez, A.; Flores-Cotera, L.; Langley, E.; Martin, R.; Maldonado, G.; Sánchez, S. 1999. Carotenoides: estructuras, función, biosíntesis, regulación y aplicaciones. Revista Latinoamericana de Microbiología, México. Vol. 41, n 3, p. 175-192.

- Schneeman, B. 2000. Relationship of Food, Nutrition, and Health. In: Essentials of Functional Foods. Eds. Schmidl, M.; Labuza, T. Aspen Publication. Gaithersburg, Maryland, USA.

- SSD. 2008. Sistema de Soporte de Decisiones para la producción agrícola de los valles cordilleranos patagónicos. INTA - EEA Bariloche, versión en CD

- Su, Q.; Rowley, K.; Balazs, N. 2002. Carotenoids: separation methods applicable to biological samples. Journal of Chromatography B. Vol. 781, $n^{\circ} 1-2, p$. 393-418.

- Wang, H.; Cao, G.; Prior, R. 1996. Total antioxidant capacity of fruits. Journal of Agricultural and Food Chemistry. Vol. 44, nº 3, p. 701- 705

- Young, A. y Lowe, G. 2001. Antioxidant and Prooxidant propierties of carotenoids. Archives of biochemistry and biophysics. Vol. 385, n 1, p. 20-7.

- Scalbert, A.; Williamson, G. 2000. Dietary intake and bioavailability of polyphenols. Journal of British Nutrition. Vol. 130, no 8, p.2073-2085. 
- Zafrilla, P.; Ferreres, F.; Tomás-Barberán F. 2001. Effect of processing and storage on the antioxidant ellagic acid derivatives and flavonoids of red raspberry (Rubus idaeus) jams. Journal of Agricultural and Food Chemistry. Vol. 49, n ${ }^{\circ} 8, p$. 3651-3655. 


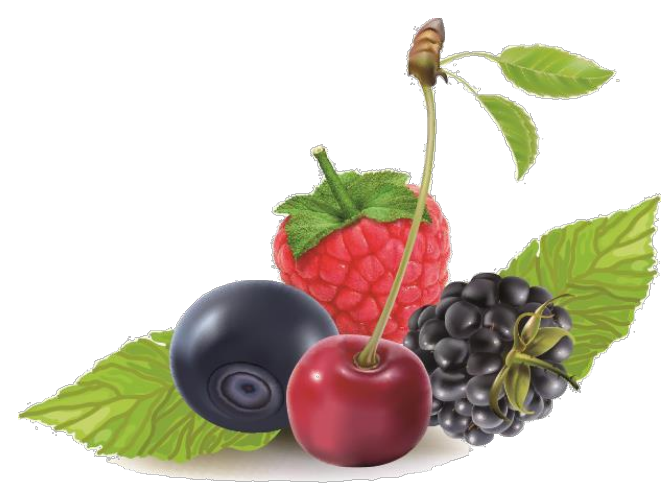

CAPÍTULO I

Compuestos bioactivos: efecto del solvente y la temperatura de extracción en su determinación cuantitativa 


\section{I-1. INTRODUCCION}

Diversas técnicas de extracción han sido desarrolladas para obtener fitoquímicos a partir de matrices vegetales, ante la carencia de una metodología única y estándar (Smith, 2003; Pinelo y col., 2005; Wang y Weller, 2006; Sasidharan y col., 2011). Este es un paso muy importante para el aislamiento, identificación y posterior uso de estos componentes y en la bibliografía se dispone de variada información sobre la extracción y el análisis de los compuestos bioactivos de materiales derivados de plantas, incluyendo frutas, verduras, vinos, café, té, hierbas, cereales y leguminosas (Balasundram y col., 2006; Luthria y Pastor-Corrales, 2006; Naczk y Shahidi, 2006).

La extracción por solvente (Baydar y col., 2004; Bucić-Kojić y col., 2007) y con fluidos supercríticos (Bleve y col., 2008; Nahar y Sarker, 2005) son las técnicas más comúnmente utilizadas. El primero, es un procedimiento secuencial y sistemático, llevado a cabo utilizando un disolvente orgánico acuoso para extraerlos. Este método tradicional abarca a su vez dos posibilidades: extracción líquido-líquido o sólido-líquido y la literatura menciona diferentes solventes de extracción para fitoquímicos a partir de productos frescos, tales como metanol, etanol, acetona, propanol, acetato de etilo y dimetilformamida, con o sin el agregado de agua y/o ácido (Antolovich y col., 2000; Luthria y col., 2006).

La extracción sólido-líquido, o lixiviación se define como un fenómeno de transporte de masa en el que los sólidos contenidos en una matriz sólida migran a un disolvente puesto en contacto con ella. Estos fenómenos de transporte se pueden mejorar mediante cambios en los gradientes de concentración, coeficientes de difusión o aumento de temperatura (Corrales y col., 2009).

La eficiencia de extracción es habitualmente una función de las condiciones del proceso. Hallazgos previos han informado de la influencia de algunas variables (temperatura, tiempo de contacto, proporción sólido-solvente, etc.) sobre los rendimientos de diversos productos naturales como cáscaras de almendra, subproductos de uva y manzana, hojas de Henna, semillas de mango y cassis (Rubilar y col., 2003; Pinelo y col, 2004; Uma y col, 2010; Dorta y col., 2013; Cacace y Mazza, 2003). El papel positivo o negativo de cada factor en la transferencia de masa del proceso no siempre es obvia; las características químicas del solvente, la composición y estructura diversa de los productos naturales aseguran que cada 
sistema matriz-disolvente muestre un comportamiento diferente, que no se puede predecir (Naczk y Shahidi, 2006).

Desde el punto de vista de producción a escala comercial, la técnica de extracción seleccionada debe ser versátil, de bajo costo, simple de aplicar, y segura para el personal de operación (Wu y Chappell, 2008).

En la primera parte de esta investigación, se buscó alcanzar las mejores condiciones para la extracción de los compuestos bioactivos, para ello se estandarizaron los factores referidos a la extracción (temperatura, tamaño de partícula, tiempo y cantidad de extracciones) a excepción del solvente y luego, una vez seleccionado el grupo de solventes con mejores aptitudes, se procedió a evaluar dos temperaturas. La selección de los sistemas se hizo sobre la base de su eficiencia reportada en la extracción de fenoles totales, flavonoides, poder antirradicalario y antocianinas de la matriz de la muestra fresca.

\section{I-2. MATERIALES Y MÉTODOS}

Las frutas (temporada enero-marzo de 2010) fueron cosechadas por productores de la zona de la Comarca Andina del Paralelo 42 (El Bolsón, Río Negro, Argentina) en su punto de madurez óptimo y enviadas inmediatamente a Villa Regina, donde se conservaron en heladera a $5^{\circ} \mathrm{C}$ hasta su utilización.

Se realizó un muestreo aleatorio simple, se descartaron aquellos frutos que presentaban síntomas de avanzado estado de madurez.

\section{I-2.1 Determinaciones}

- Extracción. Las frutas frescas (FF) se pulparon mediante batidora de inmersión. Se pesaron entre 2 y $5 \mathrm{~g}$ de pulpa, se añadieron $20 \mathrm{~mL}$ de solvente y se colocó en un baño termostatizado con agitación (modelo Dubnoff) a $37^{\circ} \mathrm{C}$ durante 30 minutos. Luego se filtró mediante vacío y el residuo se extrajo nuevamente con otros $20 \mathrm{ml}$ de solvente. Esta operación se repitió dos veces más. Finalmente los extractos reunidos se llevaron a $100 \mathrm{~mL}$ con agua destilada. Los extractos y todas las determinaciones se realizaron por triplicado.

Se utilizaron nueve sistemas de extracción: agua destilada, soluciones acuosas de metanol, etanol y acetona al $50 \%$ y $70 \%$, solución al $1 \%$ de $\mathrm{HCl}$ en metanol y en etanol (AD; ME 50\%; ME 70\%; ET 50\%; ET 70\%; AC 50\%; AC 70\%; MEAC y ETAC respectivamente). 
- Fenoles totales. La concentración de fenoles totales (FT) se midió por el método descrito por Swain y Hillis (1959) con algunas modificaciones. Se adicionó a una alícuota de $50 \mu \mathrm{L}$ de extracto, $1500 \mu \mathrm{L}$ de agua destilada y $100 \mu \mathrm{L}$ del reactivo Folin-Ciocalteu $1 \mathrm{~N}$. Se agitó con vortex y a los 3 minutos se adicionó $300 \mu \mathrm{L}$ de $\mathrm{Na}_{2} \mathrm{CO}_{3}$ al $20 \%$. Se incubó 30 minutos a $40^{\circ} \mathrm{C}$. Las lecturas de absorbancia fueron realizadas con un espectrofotómetro Metrolab 1700 a 765 nm, contra un estándar externo de Ácido Gálico (mg/L). Los resultados finales se expresaron como mg Ácido Gálico equivalente/100g producto.

- Flavonoides. Se determinaron los flavonoides totales (Fv) por el método de formación de complejo con $\mathrm{AlCl}_{3}$, contra un estándar externo de catequina (mg/L). Una alicuota del extracto se mezcló con $300 \mu \mathrm{L} \mathrm{NaNO}{ }_{2} 5 \%$. Luego de 5 min se añaden $300 \mu \mathrm{L} \mathrm{AlCl}_{3} 10 \%$ y finalmente, luego de $6 \mathrm{~min}, 2 \mathrm{~mL} \mathrm{NaOH} 1 \mathrm{~N}$. Se lleva a $10 \mathrm{~mL}$ con agua destilada. Las lecturas de absorbancia fueron realizadas con un espectrofotómetro Metrolab 1700 a $510 \mathrm{~nm}$. Los resultados finales se expresaron como mg catequina equivalente/100g producto (Zhishen y col., 1999).

- Poder antirradical. El poder antirradical (PA) fue analizado empleando el radical estable 1,1-difenil-2-picrilhidracilo (DPPH) en metanol (Brand-Williams y col., 1995). El grado de decoloración de la solución indicó la eficiencia antioxidante de la sustancia agregada. Se mezcló $3 \mathrm{~mL}$ de solución de DPPH en metanol (40ppm) con diferentes alícuotas de muestra, ajustadas de modo de consumir entre 30 a $70 \%$ del radical, completando el volumen final de $100 \mu \mathrm{L}$ con agua destilada. Luego de 90 min se midió el cambio de absorbancia a $515 \mathrm{~nm}$ en un espectrofotómetro Metrolab 1700. La cantidad de antioxidante (mg de producto) necesario para disminuir la concentración inicial de DPPH al 50\% se denominó EC50 y para mayor simplicidad se definió el poder antirradical como $1 / \mathrm{EC}_{50}(1 / \mathrm{mg}$ de producto): esto significa que a mayor capacidad antioxidante, más efectivo es el producto como antioxidante.

- Antocianinas Monoméricas. Se determinaron las antocianinas monoméricas (ACY) mediante el método de pH diferencial reportado por Wrolstad (2001). La antocianina experimenta una transformación reversible en función del $\mathrm{pH}$ manifestado por cambio en la absorbancia. La forma oxonium predomina a pH 1 y el hemiacetal a pH 4.5. Una alícuota de $1 \mathrm{ml}$ del extracto se llevó a pH 1,0 con el agregado de $4 \mathrm{ml}$ de una solución buffer cloruro de potasio 0,025 M. Se procedió de la misma forma con otra alícuota del extracto que se llevó a pH 4,5 utilizando un buffer acetato de sodio $0,4 \mathrm{M}$. Se dejaron en reposo a temperatura ambiente al 
resguardo de la luz durante 15 minutos y se procedió a medir la absorbancia a 510 nm (máxima longitud de onda donde absorben los pigmentos antociánicos) y $700 \mathrm{~nm}$ (para eliminar absorbancia dada por turbidez). Se utilizó un espectrofotómetro Metrolab UV 1700. Los resultados finales se expresaron como miligramos de cianidina-3-glucósido por cada 100 gramos de producto (mg cianidina-3-glu/100 g FF).

\section{I-2.2 Diseño experimental y análisis estadístico}

Se utilizó el programa estadístico Infostat v. 2012 (Di Rienzo y col., 2012).

\section{I-2.2.1 Efecto del solvente de extracción}

Se analizaron los datos usando una técnica de análisis multivariado: el análisis de componentes principales (ACP), con el fin de lograr la agrupación de las muestras según los criterios elegidos.

Luego, a fin de confirmar inferencialmente los resultados, se aplicó un diseño factorial completamente aleatorizado a dos vías, donde los factores analizados fueron fruta y tipo de solvente. Se chequearon los supuestos de homocedasticidad de varianza, normalidad y aleatoriedad de los residuales. El análisis se desestimó ya que la interacción resultó significativa, para un nivel de significancia $\alpha=0,05$, lo que opaca los efectos principales, invalidando el análisis. Por esta razón se procedió a aplicar un diseño completamente aleatorizado para cada fruta, siendo las variables respuesta: contenido de fenoles totales, flavonoides totales, poder antirradical y antocianinas monoméricas. Los resultados obtenidos se analizaron mediante un análisis de varianza para un nivel de significancia $\alpha=0,05$ y se empleó la prueba de DGC (Di Rienzo, Guzmán, Casanoves) para la comparación de medias, ya que la misma permite crear grupos homogéneos excluyentes.

\section{I-2.2.2 Efecto de la temperatura de extracción}

Nuevamente en primera instancia se analizaron los datos usando el análisis de componentes principales.

Luego, a fin de confirmar inferencialmente los resultados, se aplicó un diseño factorial completamente aleatorizado a dos vías, donde los factores analizados fueron temperatura y tipo de solvente con partición por fruta, siendo las variables respuesta: contenido de fenoles totales, flavonoides, poder antirradical y 
antocianinas. Se chequearon los supuestos de homocedasticidad de varianza, normalidad y aleatoriedad de los residuales. Los resultados obtenidos se analizaron mediante un análisis de varianza para un nivel de significancia $\alpha=0,05$ y se empleó la prueba de DGC (Di Rienzo, Guzmán, Casanoves).

\section{I-3 RESULTADOS Y DISCUSIÓN}

Los datos que se analizaron corresponden a cuatro frutas con tres repeticiones por fruta y variable. Se ingresaron las muestras asignándoles códigos para su identificación (1, 2 o 3 ya que las determinaciones se realizaron por triplicado).

\section{I-3.1 Solvente de extracción: análisis de componentes principales}

El ACP permite analizar la estructura de los datos proyectándolos en el hiperespacio reducido, definido por las primeras componentes principales significativas, facilitando considerablemente el análisis y reduciendo costos (Rojas y col., 2007). Cada componente principal se expresa como una combinación lineal de las variables originales.

Estas nuevas componentes principales resumen en dos dimensiones la mayor parte de la variabilidad de un gran número de variables. Las componentes principales sucesivas corresponden a porcentajes cada vez menores de la varianza total.

En las figuras l-1, I-2, I-3 y l-4 se presentan los resultados de las dos primeras componentes para cada una de las matrices, y se observó que las muestras pueden agruparse en tres conglomerados diferenciados entre sí. Además se procedió a realizar la proyección de las variables en el plano anterior. 


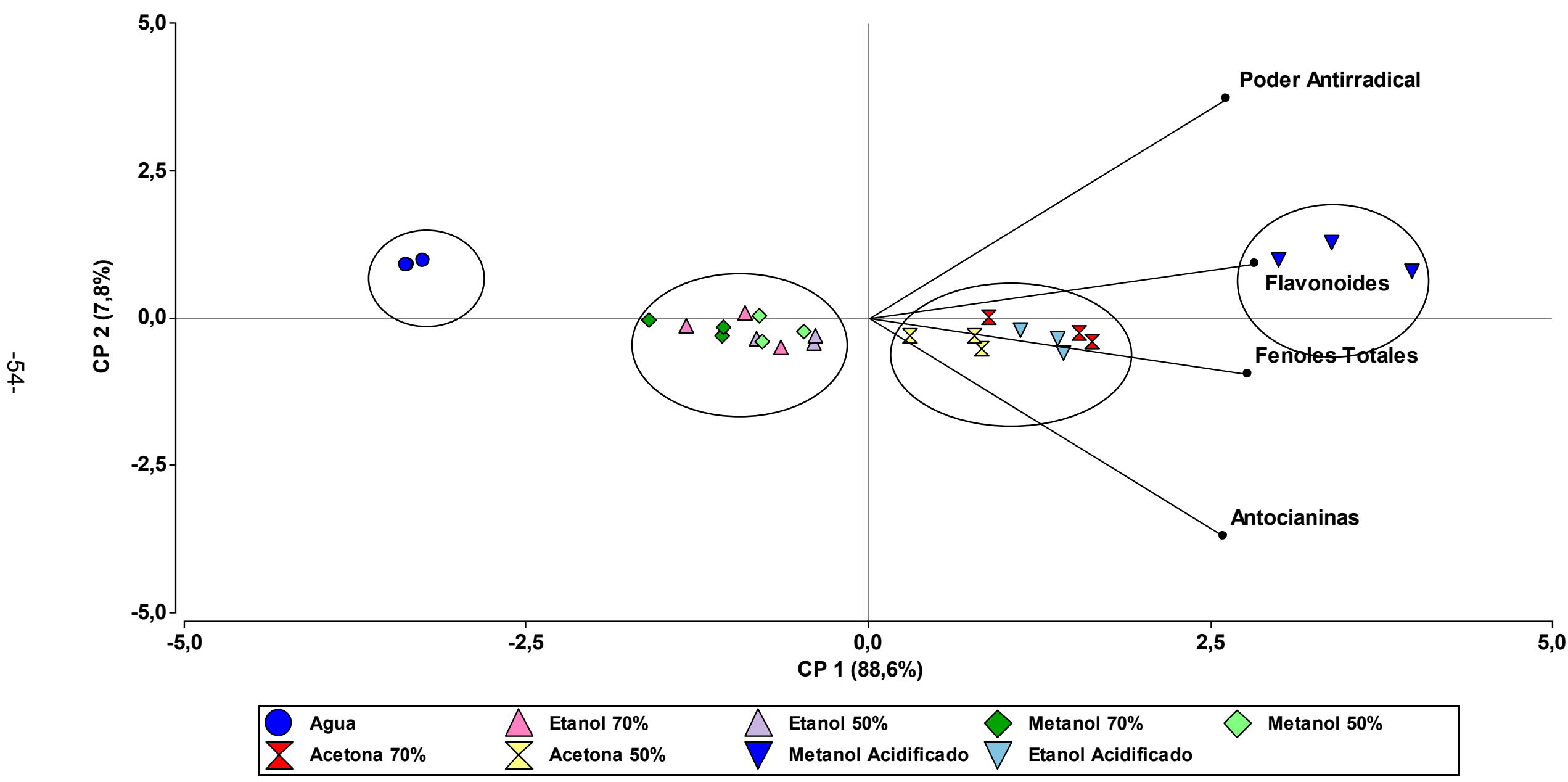

Figura I-1. ACP y proyección de las variables para la matriz arándano. Nota: Las agrupaciones entre muestras indicadas en la figura fueron obtenidas mediante un análisis de cluster. 


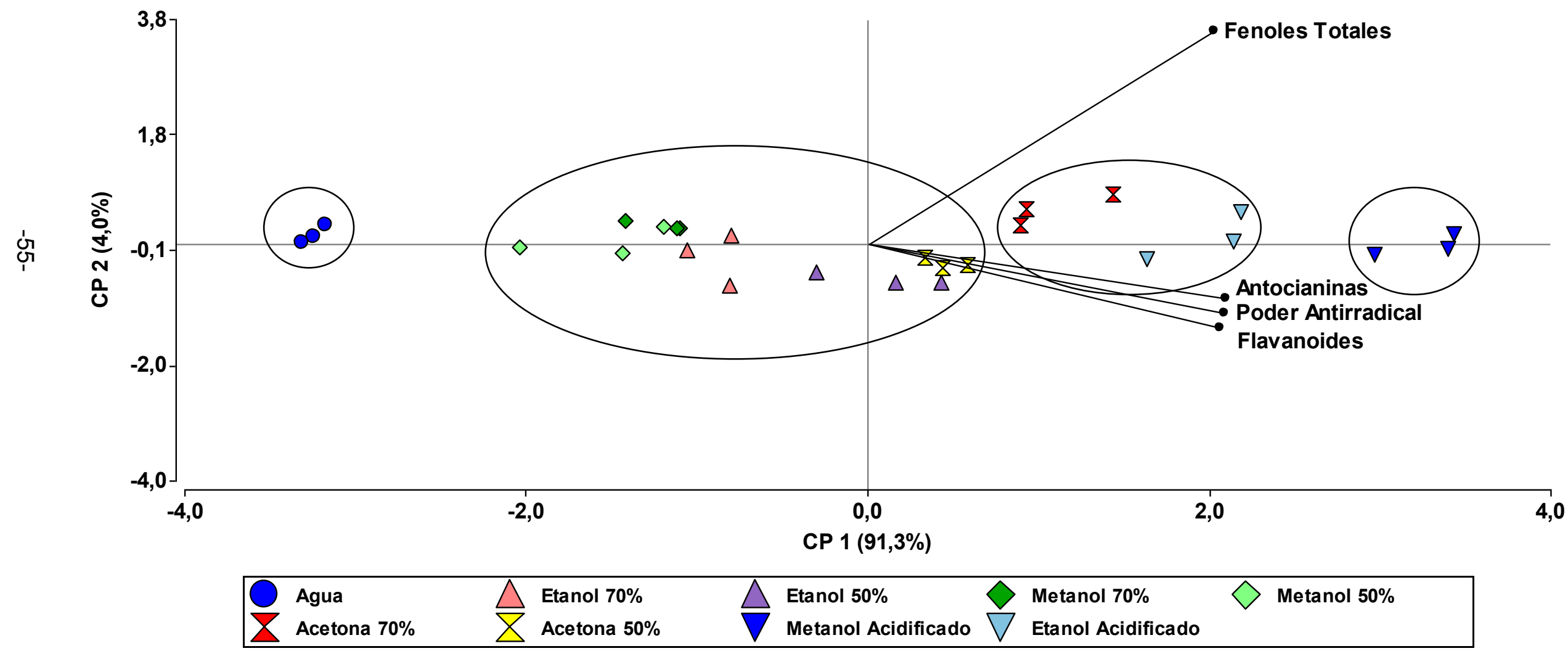

Figura I-2. ACP y proyección de las variables para la matriz frambuesa. Nota: Las agrupaciones entre muestras indicadas en la figura fueron obtenidas mediante un análisis de cluster. 


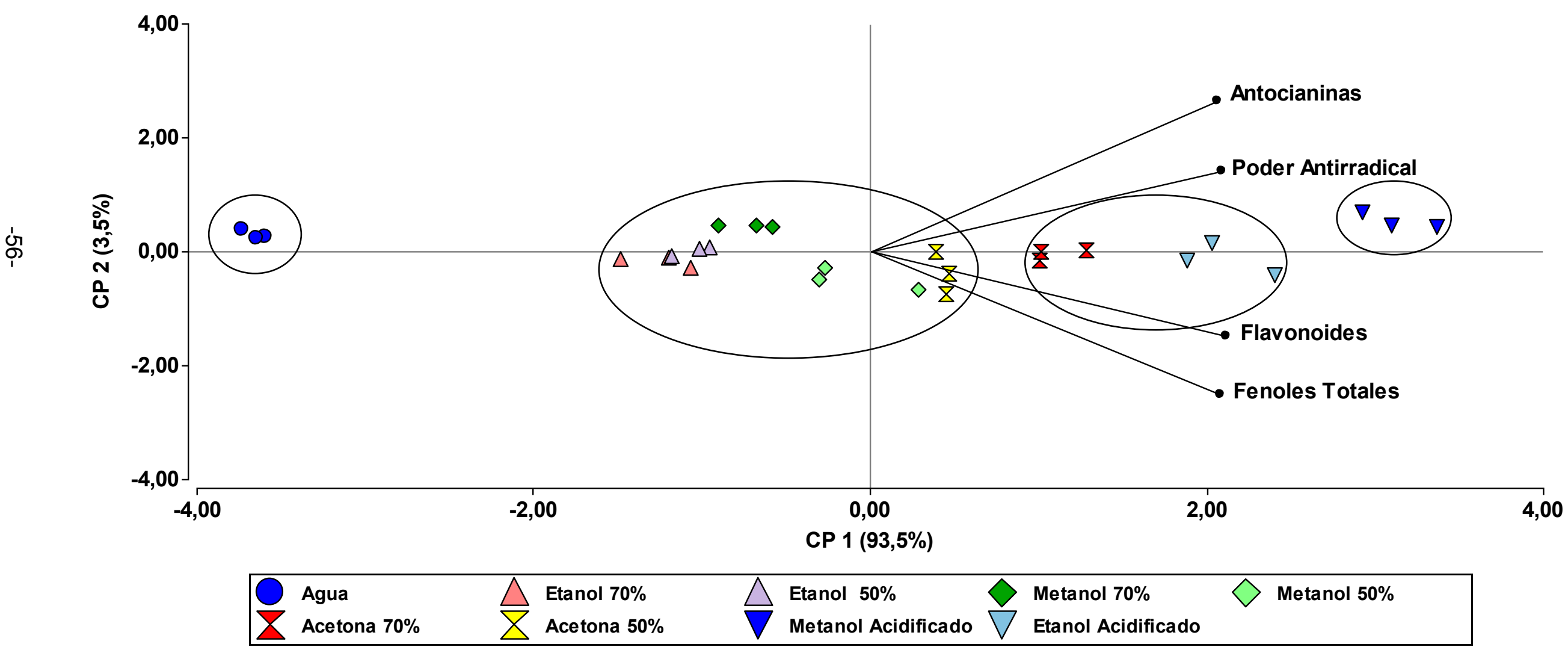

Figura I-3. ACP y proyección de las variables para la matriz guinda. Nota: Las agrupaciones entre muestras indicadas en la figura fueron obtenidas mediante un análisis de cluster. 


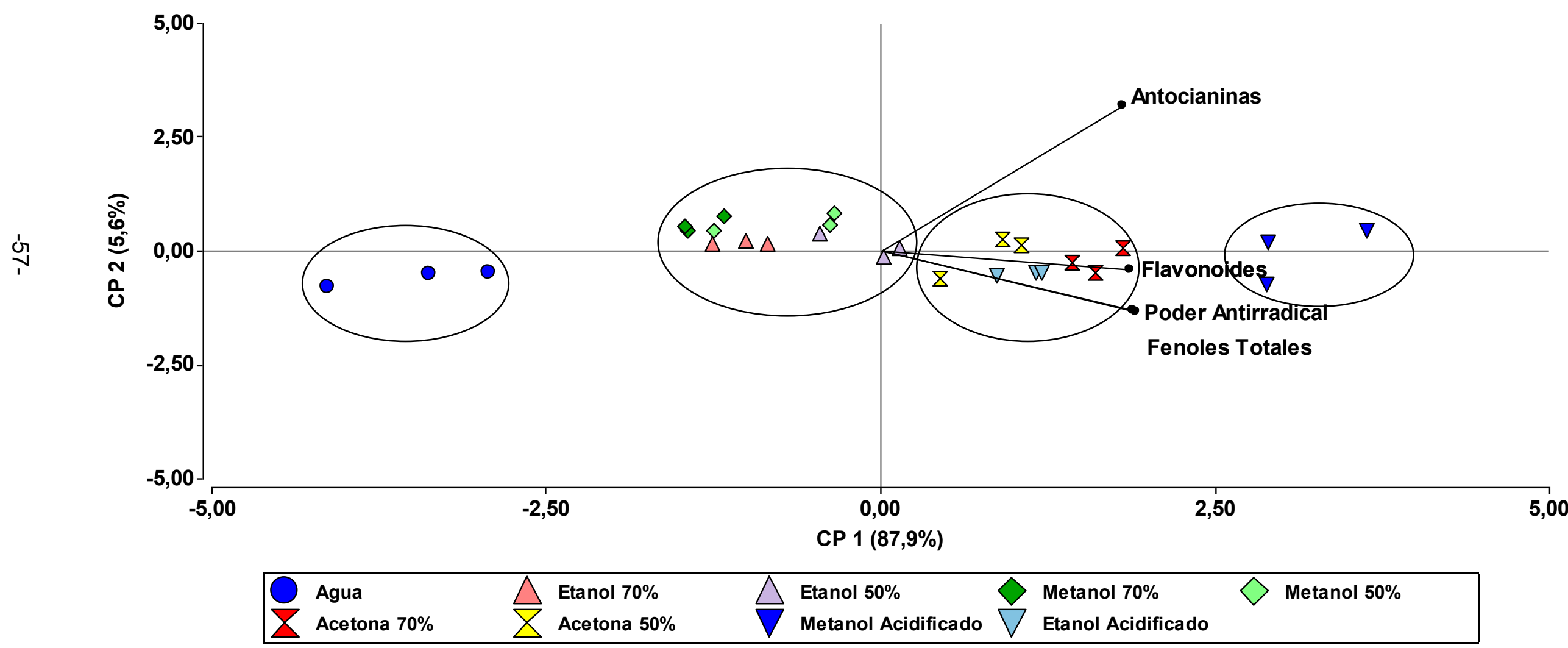

Figura I-4. ACP y proyección de las variables para la matriz zarzamora. Nota: Las agrupaciones entre muestras indicadas en la figura fueron obtenidas mediante un análisis de cluster. 
A través de las figuras se puede resumir la estructura de datos descritos por las variables cuantitativas determinadas. En todos los casos se denota que la primera componente explicó entre el 88 y $94 \%$ de la información, por lo cual es válido analizar el sentido y dirección de los vectores solamente en esa componente.

En las cuatro matrices y para todas las variables analizadas el metanol acidificado fue el solvente que permitió una mejor extracción de los fitoquímicos, seguido por un grupo que abarcaba etanol acidificado y dos concentraciones de acetona (50 y $70 \%$ ). En el caso particular de frambuesa, el solvente etanol $50 \%$ también podría considerarse dentro del grupo anterior, lo que confirma que la selección del disolvente dependerá del tipo de muestra y de la naturaleza de los compuestos que se desean extraer. En todos los casos el solvente más ineficiente para la extracción resultó el agua destilada, lo que concuerda con lo hallado por Sulaiman y col. (2011) en la extracción de fenoles totales y antioxidantes de 37 especies de vegetales crudos.

\section{I-3.1.1 Confirmación inferencial a través de un análisis de varianza}

\section{I-3.1.1.1 Evaluación del efecto del solvente}

Se realizó un análisis de varianza para confirmar inferencialmente las conclusiones descriptivas que se desprenden del análisis de componentes principales.

En la tabla I-1 se muestra el contenido de FT, Fv, PA y ACY en los distintos extractos para las cuatro frutas. 
Tabla I-1. Valores de los compuestos bioactivos en las frutas analizadas con los distintos solventes a $37^{\circ} \mathrm{C}$

\begin{tabular}{|c|c|c|c|c|c|c|c|c|c|c|c|c|c|c|c|c|}
\hline \multirow[t]{2}{*}{ Solvente } & \multicolumn{4}{|c|}{ Guinda } & \multicolumn{4}{|c|}{ Zarzamora } & \multicolumn{4}{|c|}{ Arandano } & \multicolumn{4}{|c|}{ Frambuesa } \\
\hline & FT & $\mathrm{Fv}$ & PA & $\overline{A C Y}$ & FT & $\mathrm{Fv}$ & PA & ACY & FT & $\overline{\mathrm{Fv}}$ & PA & ACY & $\overline{\text { FT }}$ & $\overline{\mathrm{Fv}}$ & PA & $\overline{A C Y}$ \\
\hline Agua Destilada & $141 \pm 15^{\circ}$ & $65 \pm 4^{E}$ & $0,45 \pm 0,04^{G}$ & $5 \pm 1^{F}$ & $268 \pm 14^{\circ}$ & $58 \pm 5^{c}$ & $0,69 \pm 0,02^{F}$ & $92 \pm 8^{c}$ & $164 \pm 3^{D}$ & $54 \pm 2^{D}$ & $0,31 \pm 0,03^{G}$ & $19 \pm 1^{\sigma}$ & $130 \pm 7^{c}$ & $22 \pm 1^{D}$ & $0,33 \pm 0,01^{F}$ & $10 \pm 1^{F}$ \\
\hline $\begin{array}{l}\text { Etanol (\%) } \\
50\end{array}$ & $338+11^{\mathrm{c}}$ & $174+4^{\circ}$ & $0.94+0.01=$ & $19+2^{\mathrm{E}}$ & $355+20^{\mathrm{c}}$ & $88+3^{\mathrm{B}}$ & $104+0.04^{\mathrm{D}}$ & $134+2^{\mathrm{B}}$ & $244+13^{c}$ & $84+7^{c}$ & $0.49+0.02^{ \pm}$ & $52+1^{\mathrm{B}}$ & $170+6^{B}$ & $34+4^{B}$ & $0.62+0.03^{\mathrm{B}}$ & $30+2^{\mathrm{c}}$ \\
\hline 70 & $333 \pm 8^{c}$ & $179 \pm 23^{\circ}$ & $0,81 \pm 0,01^{r}$ & $18 \pm 1^{\mathrm{E}}$ & $327 \pm 10^{\mathrm{D}}$ & $80 \pm 4^{\text {B }}$ & $0,97 \pm 0,02$ & $127 \pm 2^{\text {B }}$ & $240 \pm 23^{c}$ & $81 \pm 7^{c}$ & $0,43 \pm 0,01^{r}$ & $45 \pm 5^{\mathrm{C}}$ & $165 \pm 15^{B}$ & $33 \pm 3^{\text {в }}$ & $0,52 \pm 0,04^{\mathrm{c}}$ & $22 \pm 2^{\mathrm{E}}$ \\
\hline Metanol (\%) & & & & & & & & & & & & & & & & \\
\hline 50 & $418 \pm 31^{B}$ & $229 \pm 23^{\mathrm{C}}$ & $1,24 \pm 0,06^{\mathrm{D}}$ & $18 \pm 2^{\mathrm{E}}$ & $317 \pm 23^{\circ}$ & $85 \pm 4^{\mathrm{B}}$ & $1 \pm 0,01^{\mathrm{E}}$ & $131 \pm 7^{\text {B }}$ & $254 \pm 12^{\mathrm{C}}$ & $80 \pm 6^{c}$ & $0,49 \pm 0,01^{\mathrm{E}}$ & $48 \pm 4^{\mathrm{C}}$ & $159 \pm 16^{\mathrm{B}}$ & $27 \pm 3^{\mathrm{c}}$ & $0,41 \pm 0,03^{\mathrm{E}}$ & $24 \pm 2^{\circ}$ \\
\hline 70 & $288 \pm 3^{c}$ & $187 \pm 15^{\mathrm{D}}$ & $1,31 \pm 0,03^{\mathrm{D}}$ & $20 \pm 1^{\mathrm{E}}$ & $324 \pm 6^{\mathrm{V}}$ & $66 \pm 1^{\mathrm{c}}$ & $0,99 \pm 0,01^{\mathrm{E}}$ & $134 \pm 4^{\text {B }}$ & $226 \pm 17^{\mathrm{C}}$ & $73 \pm 6^{\mathrm{C}}$ & $0,44 \pm 0,01^{\digamma}$ & $45 \pm 2^{\mathrm{C}}$ & $178 \pm 1^{\mathrm{B}}$ & $30 \pm 1^{\mathrm{c}}$ & $0,47 \pm 0,04^{\mathrm{D}}$ & $19 \pm 0^{\mathrm{E}}$ \\
\hline Acetona (\%) & & & & & & & & & & & & & & & & \\
\hline 50 & $467 \pm 53^{B}$ & $237 \pm 10^{\mathrm{C}}$ & $1,24 \pm 0,01^{\mathrm{D}}$ & $25 \pm 3^{\mathrm{D}}$ & $401 \pm 10^{B}$ & $87 \pm 2^{B}$ & $1,37 \pm 0,02^{\mathrm{C}}$ & $142 \pm 10^{B}$ & $305 \pm 29^{B}$ & $104 \pm 5^{B}$ & $0,57 \pm 0,02^{\mathrm{D}}$ & $55 \pm 3^{B}$ & $188 \pm 3^{\text {B }}$ & $36 \pm 2^{B}$ & $0,63 \pm 0,01^{\mathrm{B}}$ & $32 \pm 1^{\mathrm{c}}$ \\
\hline 70 & $463 \pm 16^{\mathrm{B}}$ & $264 \pm 21^{\mathrm{B}}$ & $1,55 \pm 0,08^{\mathrm{C}}$ & $29 \pm 1^{\mathrm{C}}$ & $403 \pm 11^{\mathrm{B}}$ & $101 \pm 2^{A}$ & $1,56 \pm 0,01^{\mathrm{B}}$ & $145 \pm 5^{\text {B }}$ & $334 \pm 13^{A}$ & $116 \pm 6^{\mathrm{B}}$ & $0,67 \pm 0,02^{\mathrm{C}}$ & $56 \pm 4^{\mathrm{B}}$ & $235 \pm 15^{\mathrm{A}}$ & $35 \pm 1^{\mathrm{B}}$ & $0,65 \pm 0,02^{\mathrm{B}}$ & $34 \pm 1^{\mathrm{c}}$ \\
\hline Metanol Acidificado & $579 \pm 31^{A}$ & $312 \pm 12^{\mathrm{A}}$ & $1,96 \pm 0,05^{A}$ & $48 \pm 2^{A}$ & $439 \pm 19^{A}$ & $102 \pm 5^{A}$ & $2,08 \pm 0,01^{A}$ & $165 \pm 12^{A}$ & $357 \pm 37^{A}$ & $144 \pm 7^{A}$ & $1,26 \pm 0,08^{A}$ & $64 \pm 4^{\mathrm{A}}$ & $258 \pm 11^{\mathrm{A}}$ & $46 \pm 1^{A}$ & $0,84 \pm 0,02^{A}$ & $44 \pm 4^{\mathrm{A}}$ \\
\hline Etanol Acidificado & $538 \pm 29^{A}$ & $299 \pm 22^{A}$ & $1,86 \pm 0,02^{B}$ & $33 \pm 3^{B}$ & $395 \pm 3^{\mathrm{B}}$ & $94 \pm 3^{A}$ & $1,55 \pm 0,07^{\mathrm{B}}$ & $136 \pm 2^{B}$ & $312 \pm 3^{B}$ & $108 \pm 2^{\mathrm{C}}$ & $0,71 \pm 0,01^{\text {в }}$ & $62 \pm 4^{A}$ & $238 \pm 21^{A}$ & $45 \pm 1^{A}$ & $0,65 \pm 0,00^{\mathrm{B}}$ & $38 \pm 3^{\mathrm{B}}$ \\
\hline
\end{tabular}

Los valores represetan la media $(n=3) \pm S D$. Medias con una letra común por columna no son significativamente diferentes $(p<=0,05)$ 
Como surge de la tabla l-1 guinda es la matriz que presenta mayor contenido de FT y Fv, mientras que los mayores valores de PA y ACY se obtuvieron para zarzamora.

A través del análisis de componentes principales y varianza, se destaca el metanol acidificado como el mejor solvente de extracción para todas las frutas y variables; seguido por un grupo que comprende etanol acidificado y dos concentraciones de acetona (50 y 70\%). Esto podría deberse a que en estos frutos rojos intensamente coloreados las antocianinas constituyen un importante grupo dentro de los compuestos bioactivos (Heinonen y Meyer, 2002) que es sabido se extraen mejor con solventes acidificados. Según Moore y col. (1982) para una mayor extracción y estabilidad de compuestos como las antocianinas y proantocianidinas se utiliza normalmente metanol acidificado ya que destruye las membranas celulares permitiendo una mejor extracción de este tipo de compuestos.

En la bibliografía, los métodos más comunes de extracción utilizan metanol y etanol acidificado como extractantes (Amr y Al-Tamimi, 2007; Awika y col., 2005; Caridi y col., 2007; Lapornik y col., 2005); y además destacan el metanol como el solvente más eficiente (Kapasakalidis y col., 2006); de hecho para extraer antocianinas de la pulpa de uva, se encontró que la extracción con metanol fue un $20 \%$ más eficiente que con etanol y un $73 \%$ más efectiva que con agua (Castañeda Ovando y col., 2009). A estos datos se suma el hecho de la industria alimenticia prefiere el etanol por sobre el metanol debido a la toxicidad de este último.

Dorta y col. (2013) han observado que los solventes de alta polaridad son más efectivos en la recuperación de compuestos antioxidantes que los solventes no polares y que condiciones ácidas, como $\mathrm{pH} 3$ favorecen la recuperación de fenoles. También Oreopoulou (2003) informa que la extracción alcohólica de productos de uva es más efectiva en condiciones ácidas con pH alrededor de 3-3,5 ya que la hidrólisis de los enlaces glucosídicos no sería indeseable sino que permitiría aumentar la actividad antioxidante de algunos compuestos. Vatai y col. (2009) informa que la utilización de etanol acidificado permitió la extracción de 30 a $40 \%$ más de fenoles totales de sauco. Por otra parte, también se demostró que acetonaagua (70:30) es el mejor solvente para extraer proantocianidinas de arándanos (Prior, 2001). Las mezclas acetona-agua con alto \% de acetona han sido muy efectivas para extraer fenoles de las matrices proteicas ya que degradan los complejos polifenol-proteínas (Dorta y col., 2013). 
Los solventes como el acetato de etilo, acetona y cloroformo se utilizan para las formas de compuestos fenólicos menos polares y altamente metoxiladas (muy comunes en la piel de las frutas) (González-Montelongo y col., 2010).

Sulaiman y col. (2011) estudiaron el efecto de los solventes en la extracción de fenoles totales y antioxidantes de 37 especies de vegetales crudos y si bien no utilizaron solventes acidificados, hallaron que acetona-agua 70:30 fue el mejor solvente para extraer fenoles totales de 24 especies, para extraer flavonoides de 22 especies y que 27 especies mostraron los mayores valores de PA en dicho extracto, al mismo tiempo informaron que el agua destilada fue el solvente más ineficiente para extraer compuestos fenólicos. Se podría inferir que esto se debe a la oxidación de los fenoles totales por la polifenol oxidasa, activa en el medio acuoso, mientras que en los extractos de metanol, etanol y acetona la enzima se encuentra inactiva, además la temperatura de $37^{\circ} \mathrm{C}$ durante la extracción favorece la actividad enzimática, por ello los extractos acuosos presentaron un amarronamiento que no se observó en los otros.

Las condiciones de extracción y la selección de los disolventes dependerán del tipo de muestra y de la naturaleza de los compuestos que se desean extraer. Así, Shahidi y col. (1991) y Naczk y col. (1992) encontraron que la extracción en dos pasos secuenciales con acetona al $70 \%$ era suficiente para la extracción de taninos. Deshpande y Cheryan (1985) publicaron que el tiempo óptimo de extracción de fenoles totales era de 50 a 60 minutos. Otro aspecto a tener en cuenta es la relación peso de muestra a volumen de solvente. Comúnmente se utiliza 1:1 y 1:10, sin embargo mayores relaciones como 1:20 a 1:100 han dado mejores resultados (Dorta y col., 2013). En este trabajo se utilizó una proporción 1:20 en frambuesa y guinda y 1:50 en arándano y zarzamora, matrices caracterizadas por presentar mayor concentración de ACY.

\section{I-3.1.1.2 Contenido de compuestos bioactivos y poder antirradicalario}

Resulta difícil hacer una comparación directa entre la concentración de fitoquímicos hallada con la informada por otros autores, ya que además de que las condiciones de cultivo afectan significativamente la síntesis de diversos compuestos, la cosecha de frutos rojos es a menudo subjetiva pues se suele tener en cuenta solo el color como atributo principal. Sumado a esto, las condiciones de extracción generalmente son diferentes (solventes, tiempo de extracción, temperatura, etc.). 
Aun así se pueden observar varios trabajos que reportan el alto contenido en fenoles totales de guindas (228 a $407 \mathrm{mg} \mathrm{GAE} / 100 \mathrm{~g} \mathrm{FF}$ ) y su gran capacidad antioxidante frente a otras frutas (Chaovanalikit y Wrolstad, 2004; Kim y PadillaZakour, 2004; Kirakosyan y col., 2009; Piljac-Žegarac y Šamec, 2011; Vinson, 1998). Los fenoles totales de guinda incluyen flavonoides (antocianinas, flavan-3ol y flavonoles) y derivados del ácido hidroxicinamico (especialmente catequina y epicatequina) (Heinonen y col., 1998; Gonçalves y col., 2004; Veres y col., 2008). Wang y col. (1999) hallaron compuestos en guindas Montmorency que tienen capacidad antioxidante comparable a terbutil-hidroquinona (TBHQ) y butil-hidroxitolueno (BHT). En cuanto a los valores de antocianinas, se han reportaron valores desde 20 a 67 mg/100 g fruta fresca (Savic y col., 1985; Wang y col., 1997; Kim y Padilla-Zakour, 2004; Ochoa, 2011).

Los berries, grupo dentro del cual se hallan el arándano, la zarzamora y la frambuesa, constituyen un grupo destacado por su contenido en compuestos bioactivos y capacidad antioxidante, intensificado cuando estos presentan un fuerte color purpura (Kanner y col., 1994; Kalt y col. 1999; Kähkönen y col., 1999; Moyer y col. 2002; Sellappan y col. 2002; Borowska y Szajdek, 2003; Benvenutti y col. 2004).

En zarzamora se han informado valores para FT de 322 a 644 mg GAE/ 100g FF (Heinonen y col. 1998; Sellappan y col., 2002; Ali y col., 2011; Guerrero C. y col., 2010; Jimenez-Garcia y col., 2012; Szajdek y Borowska, 2008) y para Fv de 56 y 276 mg CE/100g FF (Marinova y col., 2005; Jimenez-Garcia y col., 2012). En cuanto a las antocianinas, los valores reportados oscilan entre 133 y $153 \mathrm{mg}$ cianidina-3glu/100 g FF (Wang y Lin, 2000; Pantelidis y col., 2007).

Por otra parte, el arándano ha mostrado ser un muy buen antioxidante debido en parte a su alto contenido en antocianinas, hidroxicinamatos y proantocianidinas (Heinonen y Meyer, 2002). Se han informado valores de FT desde 181 a $671 \mathrm{mg}$ GAE/100g FF (Vinson, 1998; Prior y col. 1998; Sellappan y col., 2002; Marinova y col. 2005; Guerrero C. y col., 2010; Szajdek y Borowska, 2008), y para Fv 50 y 191 mg CE/100g FF (Jimenez-Garcia y col., 2012; Marinova y col., 2005). Para las antocianinas, las concentraciones reportadas oscilan entre 63 y $331 \mathrm{mg}$ cianidina-3glu/100 g FF (Prior y col., 1998; Ehlenfeldt y Prior, 2001; Connor y col., 2002).

La frambuesa es un fruto que presenta una alta capacidad de captación de radicales libres y contiene numerosos compuestos bioactivos con beneficios potenciales para la salud. Contiene alrededor de tres veces más ácido elágico que 
las nueces y nueces (Daniel y col., 1989; Maas y col., 1991). Además del ácido elágico libre se han hallado dos elagitaninos en cantidades significativas, que pueden contribuir significativamente a la actividad antioxidante y propiedades vasodilatadoras de las frambuesas (Mullen y col., 2002). Un mayor contenido de fenoles totales, flavonoides y antocianinas en frambuesas contribuyen a su mayor actividad antioxidante (Liu y col., 2002; Wang y Lin, 2000). Se han reportado valores de FT en el rango de 114 a 349 mg GAE/100g FF (De Ancos y col., 2000; Marinova y col., 2005; Anttonen y Karjalainen, 2005; Proteggente y col., 2002). Para Fv los valores informados en la bibliografía oscilan entre 26 y $60 \mathrm{mg}$ CE/100g FF (JimenezGarcia y col., 2012; Marinova y col., 2005). Para antocianinas los valores tabulados se hallan entre 20 y 118 mg cianidina-3-glu/100 g FF (Torre y Barritt, 1977; Haffner y col., 2002; Anttonen y Karjalainen, 2005).

\section{I-3.2 Temperatura de extracción: análisis de componentes principales}

Respecto a la temperatura se ha observado que la extracción a temperaturas elevadas afecta la estabilidad de los compuestos fenólicos, debido a la degradación enzimática y química y a las pérdidas causadas por la volatilización y la descomposición térmica (González-Montelongo y col., 2010). Es un importante parámetro a ser optimizado con el fin de minimizar el costo energético del proceso (Spigno y col., 2007). Muchos autores están de acuerdo en el hecho de que un aumento en la temperatura de extracción aumenta la solubilidad y el coeficiente de difusión para cualquier compuesto, no sólo bioactivos; sin embargo más allá de un cierto valor crítico, los fítoquímicos se pueden desnaturalizar (Spigno y De Faveri, 2007; Pinelo y col., 2005; Yilmaz y Toledo, 2006).

Cacace y Mazza (2003) concluyen que en la extracción con etanol al 95\% para cassis la temperatura crítica estaba alrededor de los $35^{\circ} \mathrm{C}$ y que por encima de los $45^{\circ} \mathrm{C}$ la disminución de antocianinas es muy marcada. Uma y col. (2010) establecen para hoja de Henna la temperatura óptima de extracción de $39,6^{\circ} \mathrm{C}$ y concluyen que por encima de los $55^{\circ} \mathrm{C}$ la degradación de fenoles totales supera el $41 \%$.

En vista de las referencias bibliográficas que indican el efecto negativo de las altas temperaturas, con el grupo de solventes que lograron una extracción superior a $37^{\circ} \mathrm{C}$ (MEAC, ETAC, AC 50\% y AC 70\%) se procedió a repetir la extracción a temperatura ambiente $\left(20^{\circ} \mathrm{C}\right)$, manteniendo tiempo de extracción y relación peso de muestra a volumen de solvente, para las variables FT, Fv, PA y ACY. 
En las figuras I-9, I-10, I-11 y l-12 se puede observar el contenido de FT, Fv, PA y ACY para las cuatro matrices en estudio. Se aplicó un análisis de componentes principales como criterio meramente descriptivo, y se denotó la mayor extracción, en todos los casos, al aumentar la temperatura. Nuevamente la primera componente explicó más del $75 \%$ de la información, por lo cual es válido analizar el sentido y dirección de los vectores solamente en esa componente. 


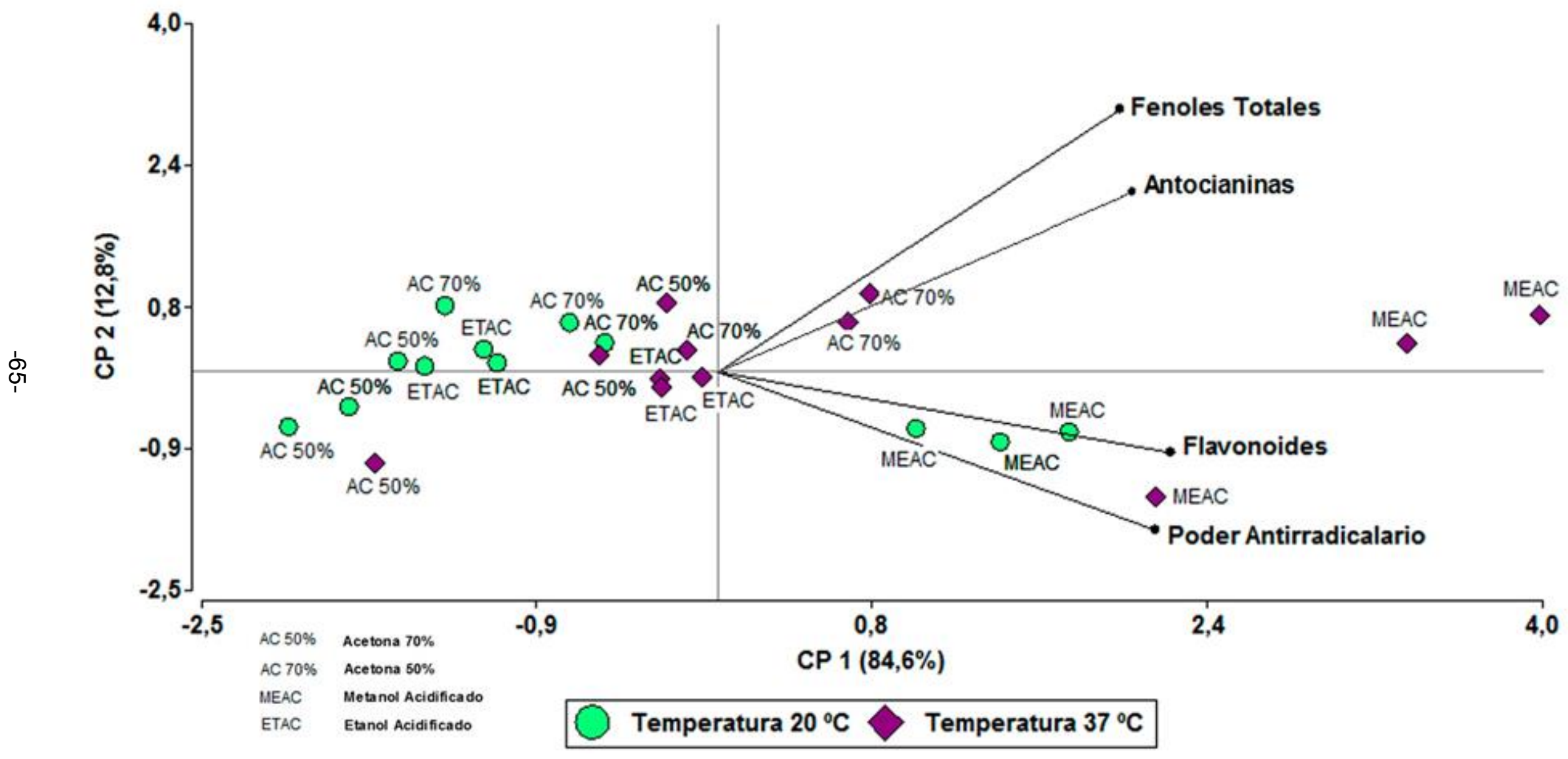

Figura 1-9. Proyección de las variables en el plano para la matriz arándano. Efecto temperatura 


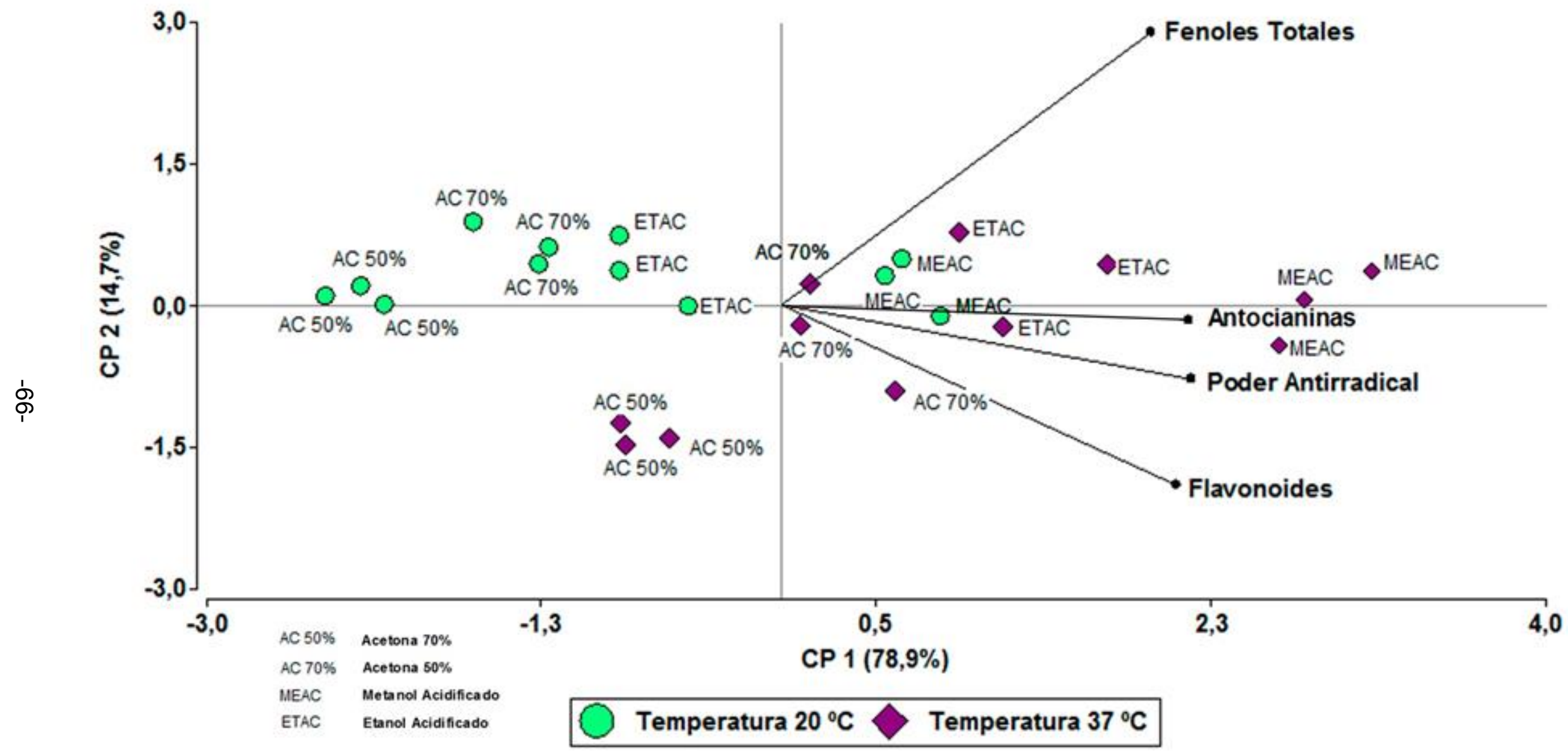

Figura I-10. Proyección de las variables en el plano para la matriz frambuesa. Efecto temperatura 


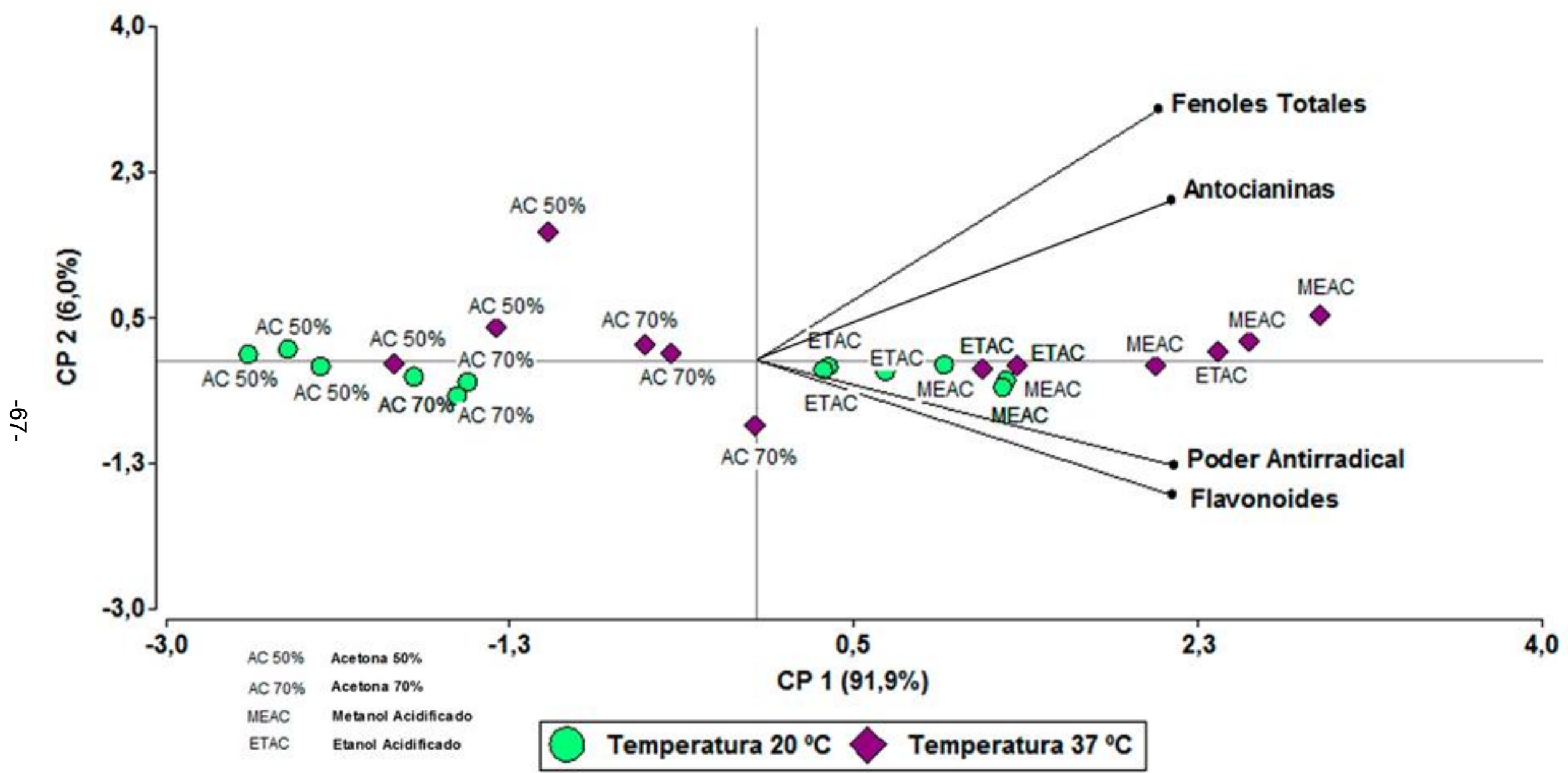

Figura I-11. Proyección de las variables en el plano para la matriz guinda. Efecto temperatura 


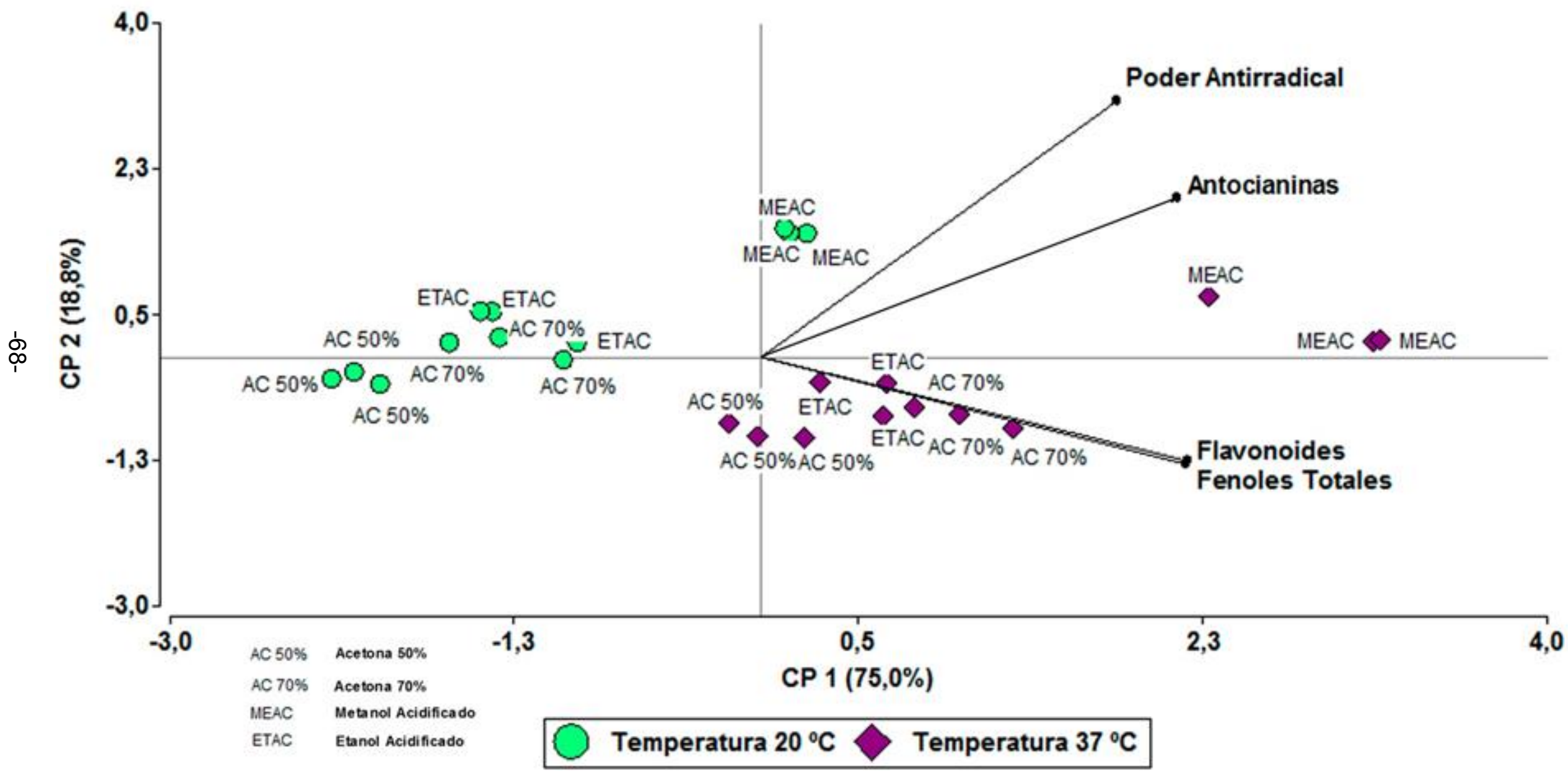

Figura I-12. Proyección de las variables en el plano para la matriz zarzamora. Efecto temperatura 


\section{I-3.2.1 Confirmación inferencial a través de un análisis de varianza}

A continuación se realizó un análisis de varianza para confirmar inferencialmente las conclusiones descriptivas que se desprenden del análisis de componentes principales. En la tabla l-2 se pueden observar los valores medios para las variables cuantificadas en las condiciones del estudio. 
Tabla I-2. Valores de los compuestos bioactivos en las frutas analizadas considerando solventes y temperaturas

\begin{tabular}{|c|c|c|c|c|c|c|c|c|c|c|c|c|c|c|c|c|}
\hline \multirow{2}{*}{ Solvente } & \multicolumn{4}{|c|}{ Guinda } & \multicolumn{4}{|c|}{ Zarzamora } & \multicolumn{4}{|c|}{ Arandano } & \multicolumn{4}{|c|}{ Frambuesa } \\
\hline & FT & Fv & PA & $\overline{A C Y}$ & FT & Fv & PA & $\overline{A C Y}$ & FT & Fv & PA & ACY & FT & Fv & PA & ACY \\
\hline \multicolumn{17}{|l|}{ Acetona 50\% } \\
\hline $20^{\circ} \mathrm{C}$ & $404 \pm 6^{\mathrm{B}}$ & $226 \pm 7^{\mathrm{c}}$ & $1,15 \pm 0,06^{\mathrm{D}}$ & $20 \pm 2^{\mathrm{B}}$ & $365 \pm 9^{\mathrm{B}}$ & $66 \pm 3^{c}$ & $1,23 \pm 0,03^{\mathrm{D}}$ & $125 \pm 2^{A}$ & $287 \pm 12^{\text {B }}$ & $91 \pm 2^{\mathrm{c}}$ & $0,50 \pm 0,04^{\mathrm{D}}$ & $50 \pm 1^{\mathrm{A}}$ & $198 \pm 3^{c}$ & $22 \pm 2^{B}$ & $0,50 \pm 0,01^{\mathrm{c}}$ & $20 \pm 3^{\text {B }}$ \\
\hline $37^{\circ} \mathrm{C}$ & $467 \pm 53^{\mathrm{D}}$ & $237 \pm 10^{F}$ & $1,24 \pm 0,01^{H}$ & $25 \pm 3^{D}$ & $401 \pm 10^{\mathrm{D}}$ & $87 \pm 2^{\mathrm{F}}$ & $1,37 \pm 0,02^{\mathrm{H}}$ & $142 \pm 10^{\mathrm{D}}$ & $305 \pm 29^{C}$ & $104 \pm 5^{F}$ & $0,57 \pm 0,02{ }^{\mathrm{H}}$ & $55 \pm 3^{c}$ & $188 \pm 3^{F}$ & $36 \pm 2^{\mathrm{D}}$ & $0,63 \pm 0,01^{\mathrm{F}}$ & $32 \pm 1^{\mathrm{D}}$ \\
\hline \multicolumn{17}{|l|}{ Acetona $70 \%$} \\
\hline $20^{\circ} \mathrm{C}$ & $414 \pm 5^{B}$ & $244 \pm 5^{B}$ & $1,34 \pm 0,06^{\mathrm{C}}$ & $23 \pm 3^{\text {B }}$ & $363 \pm 5^{B}$ & $75 \pm 4^{A}$ & $1,43 \pm 0,04^{\mathrm{C}}$ & $118 \pm 2^{\text {в }}$ & $316 \pm 2^{A}$ & $101 \pm 10^{B}$ & $0,49 \pm 0,05^{\mathrm{C}}$ & $46 \pm 2^{A}$ & $218 \pm 2^{B}$ & $23 \pm 2^{\mathrm{B}}$ & $0,55 \pm 0,04^{\mathrm{B}}$ & $22 \pm 3^{\mathrm{B}}$ \\
\hline $37^{\circ} \mathrm{C}$ & $463 \pm 16^{\mathrm{D}}$ & $264 \pm 21^{\mathrm{E}}$ & $1,55 \pm 0,08^{\mathrm{G}}$ & $29 \pm 1^{\mathrm{D}}$ & $403 \pm 11^{\mathrm{D}}$ & $101 \pm 2^{D}$ & $1,56 \pm 0,01^{\mathrm{G}}$ & $145 \pm 10^{\mathrm{D}}$ & $334 \pm 13^{\mathrm{C}}$ & $116 \pm 6^{\mathrm{E}}$ & $0,67 \pm 0,02^{\mathrm{G}}$ & $56 \pm 4^{\mathrm{c}}$ & $235 \pm 15^{\mathrm{E}}$ & $35 \pm 1^{\mathrm{D}}$ & $0,65 \pm 0,02^{\mathrm{E}}$ & $34 \pm 1^{\mathrm{D}}$ \\
\hline \multicolumn{17}{|c|}{ Metanol Acidificado } \\
\hline $20^{\circ} \mathrm{C}$ & $513 \pm 3^{A}$ & $296 \pm 8^{A}$ & $1,78 \pm 0,04^{\mathrm{A}}$ & $45 \pm 3^{A}$ & $373 \pm 8^{A}$ & $81 \pm 3^{A}$ & $1,97 \pm 0,01^{\mathrm{A}}$ & $132 \pm 1^{A}$ & $321 \pm 4^{\mathrm{A}}$ & $127 \pm 7^{\mathrm{A}}$ & $1,05 \pm 0,08^{A}$ & $50 \pm 2^{A}$ & $234 \pm 4^{\mathrm{A}}$ & $33 \pm 3^{A}$ & $0,72 \pm 0,01^{A}$ & $27 \pm 2^{A}$ \\
\hline $37^{\circ} \mathrm{C}$ & $579 \pm 31^{\mathrm{C}}$ & $312 \pm 12^{\mathrm{D}}$ & $1,96 \pm 0,05^{\mathrm{E}}$ & $58 \pm 2^{\mathrm{C}}$ & $439 \pm 19^{\mathrm{C}}$ & $102 \pm 5^{\mathrm{D}}$ & $2,08 \pm 0,01^{\mathrm{E}}$ & $165 \pm 12^{\mathrm{C}}$ & $357 \pm 37^{\mathrm{C}}$ & $144 \pm 7^{\mathrm{D}}$ & $1,26 \pm 0,08^{\mathrm{E}}$ & $64 \pm 4^{\mathrm{B}}$ & $258 \pm 11^{\mathrm{D}}$ & $46 \pm 1^{\mathrm{C}}$ & $0,84 \pm 0,01^{\mathrm{D}}$ & $44 \pm 4^{\mathrm{C}}$ \\
\hline \multicolumn{17}{|c|}{ Etanol Acidificado } \\
\hline $20^{\circ} \mathrm{C}$ & $493 \pm 5^{A}$ & $282 \pm 6^{A}$ & $1,64 \pm 0,02^{\mathrm{B}}$ & $29 \pm 4^{\mathrm{B}}$ & $366 \pm 8^{B}$ & $72 \pm 3^{\mathrm{B}}$ & $1,51 \pm 0,02^{\mathrm{B}}$ & $129 \pm 3^{A}$ & $305 \pm 4^{\mathrm{B}}$ & $93 \pm 5^{\mathrm{c}}$ & $0,57 \pm 0,03^{\mathrm{B}}$ & $48 \pm 3^{A}$ & $224 \pm 4^{B}$ & $31 \pm 4^{\mathrm{A}}$ & $0,55 \pm 0,01^{\mathrm{B}}$ & $31 \pm 2^{A}$ \\
\hline $37^{\circ} \mathrm{C}$ & $538 \pm 29^{C}$ & $299 \pm 22^{D}$ & $1,86 \pm 0,02^{F}$ & $33 \pm 3^{\mathrm{D}}$ & $395 \pm 3^{D}$ & $94 \pm 3^{\mathrm{E}}$ & $1,55 \pm 0,07^{\mathrm{F}}$ & $136 \pm 2^{\mathrm{D}}$ & $312 \pm 3^{D}$ & $108 \pm 2^{F}$ & $0,71 \pm 0,00^{F}$ & $62 \pm 4^{\mathrm{B}}$ & $238 \pm 21^{\mathrm{E}}$ & $45 \pm 1^{\mathrm{C}}$ & $0,65 \pm 0,00^{\mathrm{E}}$ & $38 \pm 3^{c}$ \\
\hline
\end{tabular}

Los valores represetan la media $(n=3) \pm S D$. Medias con una letra común por columna no son significativamente diferentes $(p<=0,05)$ 
A través del análisis de componentes principales y varianza, se evidenciaron diferencias significativas $(p \leq 0,05)$ entre ambas temperaturas. El mejor solvente de extracción dentro de este grupo fue, en todos los casos, el metanol acidificado; que incluso a $20^{\circ} \mathrm{C}$ extrajo aún mejor que otros solventes a $37^{\circ} \mathrm{C}$.

La extracción a $37^{\circ} \mathrm{C}$ mejoró entre un 5 a un $11 \%$ las concentraciones de compuestos bioactivos y poder antirradical para guinda; un 5 a un $21 \%$ para zarzamora; 10 a $22 \%$ para arándano y 9 a $39 \%$ para frambuesa.

\section{I-4. CONCLUSIONES}

Según los resultados obtenidos se puede concluir que el mejor sistema de extracción para los compuestos bioactivos analizados en guinda, zarzamora, frambuesa y arándano resultó ser el metanol acidificado y en contrapartida el más ineficiente el agua destilada. En cuanto a temperatura, a $37^{\circ} \mathrm{C}$ la concentración de los fitoquímicos extraídos en todas las matrices fue superior que a $20^{\circ} \mathrm{C}$. La variación desigual del resto de los solventes dentro de cada matriz refleja el importante papel que ésta juega al momento de realizar la extracción, por lo cual siempre será necesario realizar una evaluación previa del efecto de los solventes y las condiciones de extracción antes de abordar el estudio de una nueva fruta si no se cuenta con bibliografía específica.

Considerando la toxicidad del metanol y teniendo en cuenta que dentro del conglomerando siguiente de alta extracción se encontraban el etanol y la acetona (en sus dos concentraciones), se decidió para estudios posteriores utilizar solución al $1 \%$ de $\mathrm{HCl}$ en etanol como extractante y como temperatura $37^{\circ} \mathrm{C}$.

\section{I-5. REFERENCIAS}

- Ali, L.; Svensson, B.; Alsanius, B. y Olsson, M. 2011. Late season harvest and storage of Rubus berries-Major antioxidant and sugar levels. Scientia Horticulturae. Vol. 129 , no. 3, p. 376-381

- Alothman, M.; Bhat, R.; Karim, A. 2009. Antioxidant capacity and phenolic content of selected tropical fruits from Malaysia, extracted with different solvents. Food Chemistry. Vol. 115, no. 3, p. 785-788. 
- Amr, A. y Al-Tamimi, E. 2007. Stability of the crude extracts of Ranunculus asiaticus anthocyanins and their use as food colourants. Journal of Food Science and Technology. Vol. 42, nº, p. 985-991.

- Antolovich, M., Prenzler, P., Robards, K. Y Ryan, D. 2000. Sample preparation in the determination of phenolic compounds in fruits. The Analyst. Vol. 125, $n^{\circ} .5, p$. 989-1009.

- Anttonen, M.; Karjalainen, R. 2005. Environmental and genetic variation of phenolic compounds in red raspberry. Journal of Food Composition and Analysis. Vol. $18, n^{\circ} 8$, p. $759-769$.

- Awika, J.; Rooney, L. y Waniska, R. 2005. Anthocyanins from black sorghum and their antioxidant properties. Food Chemistry. Vol. 90, n 1-2, p. 293-301.

- Balasundram, N., Tan, Y.A., Sambanthamurthi, R., Sundram, K. y Samman, S. 2005. Antioxidant properties of palm fruit extracts. Asia Pacific Journal of Clinical Nutrition. Vol. 4, nº 4, p. 319-324.

- Baydar, N., Ozkan, G., y Sagdic, O. 2004. Total phenolic contents and antibacterial activities of grape (Vitis vinifera L.) extracts. Food Chemistry. Vol. 15, $n^{\circ}$ 5, p. 335-339.

- Benvenuti, S.; Pellati, F.; Melegari, M. y Bertelli, D. 2004. Polyphenols, anthocyanins, ascorbic acid, and radical scavenging activity of rubus, ribes, and aronia. Journal of Food Science. Vol. 69, n 3, p. 164-169

- Bleve, M., Ciurlia, L., Erroi, E., Lionetto, G., Longoc, L., Rescioa, L. 2008. An innovative method for the purification of anthocyanins from grape skin extracts by using liquid and sub-critical carbon dioxide. Separation and Purification Technology Vol. 64, nº 2, p. 192-197.

- Borowska, J.; Szajdek A. 2003. Antioxidant activity of berry fruits and beverages. Polish Journal of Natural Science. Vol. 14, p. 521-528

- Brand-Williams, W.; Cuvelier, M.E. y Berset, C. Use of a free radical method to evaluate antioxidant activity. LWT - Food Science and Technology, 1995, vol. 28, no. 1, p. 25-30.

- Bucić-Kojić, A.; Planinić, M.; Srećko, T., Bilić, M.; y Velić, D. 2007. Study of solid- liquid extraction kinetics of total polyphenols from grape seeds. Journal of Food Engineering, 81, 236-242. 
- Cacace, J. y Mazza, G. 2003. Optimization of extraction of anthocyanins from black currants with aqueous ethanol. Journal of Food Science. Vol. 68, no 1, p. $240-$ 248.

- Caridi, D.; Trenerry, V.; Rochfort, S.; Duong, S.; Laugher, D. y Jones, R. 2007. Profiling and quantifying quercetin glucosides in onion (Allium cepa L.) varieties using capillary zone electrophoresis and high performance liquid chromatography. Food Chemistry. Vol. 105, n² 2, p. 691-699.

- Castañeda-Ovando, A.; Pacheco-Hernández, L.; Páez-Hernández, M.; Rodríguez J. y Galán-Vidal, C. 2009. Chemical studies of anthocyanins: A review. Food Chemistry. Vol. 113, n 4, p. 859-871.

- Connor, A.; Luby, J.; Hancock, J.; Berkheimer, S.; Hanson, E. 2002. Changes in fruit antioxidant activity among blueberry cultivars during cold-temperature storage. Journal of Agricultural and Food Chemistry. Vol. 50, n 4, p. 893-898.

- Corrales, M.; Fernández García, A.; Butz, P.; y Tauscher, B. 2009. Extraction of anthocyanins from grape skins assisted by high hydrostatic pressure. Journal of Food Engineering. Vol. 90, nº 4, p. 415-421.

- Chaovanalikit, A. y Wrolstad, R. 2004. Total Anthocyanins and total Phenolics of fresh and processed cherries and their antioxidant properties. Journal of Food Science. Vol. 69, no. 1, p. FCT67-FCT72.

- Daniel, E.; Krupnick, A.; Heur, Y.; Blinzler, J.; Nims, R.; Stoner, G. 1989. Extraction, stability and, quantitation of ellagicac id in various fruits and nuts. Journal of Food Composition and Analysis. Vol. 2, p. 338-349.

- De Ancos, B.; González, E.; Cano, M. 2000. Ellagic acid, vitamin C, and total phenolic contents and radical scavenging capacity affected by freezing and frozen storage in raspberry fruit. Journal of Agricultural and Food Chemistry. Vol. 48, $n^{\circ} 10$, p. $4565-4570$.

- Deshpande, S. y Cheryan, M. 1985. Evaluation of Vanillin assay for Tannin analysis of dry beans. Journal of Food Science. Vol. 50, no. 4, p. 905-910.

- Di Rienzo, J.; Casanoves, F.; Balzarini, M.; González, L.; Tablada, M. y Robledo, C. 2012. Software InfoStat versión 2012. Argentina: Grupo InfoStat, FCA, U.N.C., Arg. 
- Dorta, E.; Lobo, M. y González, M. 2013. Optimization of factors affecting extraction of antioxidants from Mango seed. Food and Bioprocess Technology. Vol. 6, no. 4, p. 1067-1081.

- Ehlenfeldt, M. y Prior, R. 2001. Oxygen radical absorbance capacity (ORAC) and phenolic and anthocyanin concentrations in fruit and leaf tissues of highbush blueberry. Journal of Agricultural and Food Chemistry. Vol. 49, n 5, p. 2222-2227.

- Everitt, B. 1980. Cluster Analysis. Halsted Press. Nueva York. USA.

- Gonçalves, B.; Landbo, A.; Knudsen, D.; Silva, A.; Moutinho-Pereira, J.; Rosa, E.; Meyer, A. 2004. Effect of Ripeness and Postharvest Storage on the Phenolic Profiles of Cherries ( Prunus avium L.). Journal of Agricultural and Food Chemistry. Vol.52, no 3, p. 523-530.

- González-Montelongo, R.; Gloria Lobo, M. y González, M. 2010. Antioxidant activity in banana peel extracts: Testing extraction conditions and related bioactive compounds. Food Chemistry. Vol. 119, no. 3, p. 1030-1039.

- Guerrero C.; Ciampi P.; Castilla C.; Medel S.; Schalchli S.; Hormazabalu., E.; Bensch T. y Alberdi L. 2010. Antioxidant capacity, anthocyanins, and total phenols of wild and cultivated berries in Chile. Chilean Journal of Agricultural Research. Vol. 70, no. 1 , p. 537-544.

- Haffner, K.; Rosenfeld, H.; Skrede, G.; Wang, L. 2002. Quality of red raspberry Rubus idaeus L. cultivars after storage in controlled and normal atmospheres. Postharvest Biology and Technology. Vol. 24, n 3, p. 279-289.

- Heinonen, I.; Meyer, A. y Frankel, E. 1998. Antioxidant activity of berry Phenolics on human low-density Lipoprotein and Liposome Oxidation. Journal of Agricultural and Food Chemistry. Vol. 46, no. 10, p. 4107-4112.

- Heinonen, I. y Meyer, A. 2002. Antioxidants in fruits, berries and vegetables. En: JONGEN. Fruit and Vegetable Processing. Woodhead Publishing/CRC Press, $p$. 23-51.

- Jimenez-Garcia, S.; Guevara-Gonzalez, R.; Miranda-Lopez, R.; FeregrinoPerez, A.; Torres-Pacheco, I. y Vazquez-Cruz, M. 2012. Functional properties and quality characteristics of bioactive compounds in berries: Biochemistry, biotechnology, and genomics. Food Research International. Vol. Article in press. 
- Kähkönen, M.; Hopia, A.; Vuorela, H.; Rauha, J.; Pihlaja, K.; Kujala, T. y Heinonen, M. 1999. Antioxidant activity of plant extracts containing phenolic compounds. Journal of Agricultural and Food Chemistry. Vol. 47, no. 10, p. 39543962.

- Kalt, W.; Forney, C.; Martin, A.; Prior R. 1999. Antioxidant capacity, vitamin C, phenolics and anthocyanins after fresh storage of small fruits. Journal of Agricultural and Food Chemistry. Vol. 47, n 11, p. 4638-44.

- Kanner, J.; Frankel, E.; Granit, R; German, B.; Kinsella J. 1994. Natural antioxidants in grapes and wines. Journal of Agricultural and Food Chemistry. Vol. $42, \mathrm{n}^{\circ} 1$, p. 64-69.

- Kapasakalidis, P.; Rastall, R. y Gordon, M. 2006. Extraction of polyphenols from processed black currant (Ribes nigrum L.) residues. Journal of Agricultural and Food Chemistry. Vol. 54, no 11, p. 4016-4021.

- Kim, D.; y Padilla-Zakour, O. 2004. Jam processing effect on phenolics and antioxidant capacity in Anthocyanin-rich Fruits: Cherry, Plum, and Raspberry. Journal of Food Science. Vol. 69, no. 9, p. S395-S400

- Kirakosyan, A.; Seymour, E.; Llanes, D.; Kaufman, P. y Bolling, S. 2009. Chemical profile and antioxidant capacities of tart cherry products. Food Chemistry. Vol. 115 , no. 1 , p. 20-25.

- Lapornik, B.; Prosek, M. y Golc, W. 2005. Comparison of extracts prepared from plant by-products using different solvents and extraction time. Journal of Food Engineering. Vol. 71, $\mathrm{n}^{\circ}$ 2, p. 214-222.

- Liu, M.; Li, X.; Weber, C.; Lee, C.; Brown, J.; Liu, R. 2002. Antioxidant and antiproliferative activities of raspberries. Journal of Agricultural and Food Chemistry. Vol. 50, n 10, p. 2926-2930.

- Luthria, D., Mukhopadhyay, S. y Kwansa, A. 2006. A systematic approach for extraction of phenolic compounds using parsley (Petroselinum crispum) flakes as model substrate. Journal of the Science of Food and Agriculture. Vol. 86, $n^{\circ}$. 9, p. $1350-1358$.

- Luthria, D., y Pastor-Corrales, M. (2006). Phenolic acids content of 15 dry edible bean (Phaseolus vulgaris L.) varieties. Journal of Food Composition and Analysis. Vol. 19, n²-3, p. 205-211. 
- Maas, J.; Galletta, G.; Stoner, G. 1991. Ellagic acid, an anticarcinogen in fruits, especially in strawberries: a review. HortScience. Vol. 26, p. 10-14.

- Marinova, D.; Ribarova, F. y Atanassova M. 2005. Total phenolics and total flavonoids in Bulgarian fruits and vegetables. Journal of the University of Chemical Technology and Metallurgy. Vol. 40, n 3, p. 255-260.

- Moore, A.; Francis, F. y Clydesdale, F. 1982. Changes in chromatographic profile of anthocyanins of red onion during extraction. Journal Food Protection. Vol. 45, no. 1, p. 738.

- Moyer, R.; Hummer, K.; Finn C.; Frei B.; Wrolstad R. 2002. Anthocyanins, phenolics, and antioxidant capacity in diverse small fruits: Vaccinium, Rubus, and Ribes. Journal of Agricultural and Food Chemistry. Vol. 50, n 3, p. 519-525.

- Mullen, W.; McGinn, J.; Lean, M.; MacLean, M.; Gardner, P.; Duthie, G.; Yokota, T.; Crozier, A. 2002. Ellagitannins, flavonoids, and other phenolics in red raspberries and their contribution to antioxidant capacity and vasorelaxation properties. Journal of Agricultural and Food Chemistry. Vol. 50, no 18, p. 5191-5196.

- Naczk, M.; Shahidi, F. y Sullivan, A. 1992. Recovery of rapeseed tannins by various solvent systems. Food Chemistry. Vol. 45, no. 1, p. 51-54.

- Naczk, M. y Shahidi, F. 2006. Phenolics in cereals, fruits and vegetables: Occurrence, extraction and analysis. Journal of Pharmaceutical and Biomedical Analysis. Vol. 41, no. 5, p. 1523-1542.

- Nahar, L.; y Sarker, S. 2005. Supercritical fluid extraction. Natural Products Isolation. Vol. 20, Capitulo no 3, p. 47-76.

- Ochoa, M. 2011. Estudio del deterioro químico de guindas durante la deshidratación. Universidad Nacional de Bahía Blanca, Argentina. Memoria para optar por el título de Doctor en Ciencias Químicas de la Universidad Nacional de Bahía Blanca.

- Oreopoulou, V. 2003. Extraction of Natural Antioxidants. En: LIADAKIS Y TZIA. Extraction Optimization in Food Engineering. Marcel Dekker, Inc./CRC Press, vol. 128.

- Pantelidis, G.; Vasilakakis, M.; Manganaris, G.; Diamantidis G. 2007. Antioxidant capacity, phenol, anthocyanin and ascorbic acid contents in raspberries, blackberries, red currants, gooseberries and Cornelian cherries. Food Chemistry. Vol. 102, nº 3, p. 777-783. 
- Piljac-Žegarac, J. y Šamec, D. 2011. Antioxidant stability of small fruits in postharvest storage at room and refrigerator temperatures. Food Research International. Vol. 44, no. 1, p. 345-350.

- Pinelo, M.; Rubilar, M.; Sineiro, J. y Nunez, M. J. (2004). Extraction of antioxidant phenolics from almond hulls (Prunus amygdalus) and pine sawdust (Pinus pinaster). Food Chemistry, 85, 267-273.

- Pinelo, M., Del Fabbro, P., Manzocco, L., Nunez, M. J. y Nicoli, M. C. 2005. Optimization of continuous phenol extraction from Vitis vinifera byproducts. Food Chemistry. Vol. 92, n 1, p. 109-117.

- Prior, R.; Cao, G.; Martin, A.; Sofic, E.; McEwen, J.; O'Brien, C.; Lischner, N.; Ehlenfeldt, M.; Kalt, W.; Krewer, G.; Mainland, C. 1998. Antioxidant capacity as influenced by total phenolic and anthocyanin content, maturity, and variety of Vaccinium species. Journal of Agricultural and Food Chemistry. Vol. 46, no 7, p. 2686-2693.

- Prior, R.; Lazarus, S.; Cao, G.; Muccitelli, H.; Hammerstone, J. 2001. Identification of Procyanidins and Anthocyanins in Blueberries and Cranberries (Vaccinium Spp.) Using High-Performance Liquid Chromatography/Mass Spectrometry. Journal of Agricultural and Food Chemistry. Vol. 49, n ${ }^{\circ} 3$, p. 12701276.

- Proteggente, A.; Pannala, A.; Paganga, G.; Van Buren, L.; Wagner, E.; Wiseman, S.; Van De Put F.; Dacombe, C. 2002. The antioxidant activity of regularly consumed fruit and vegetables reflects their phenolic and vitamin $\mathrm{C}$ composition. Free Radical Research. Vol. 36, n² 2, p. 217-233.

- Rojas, C.; Alvarado, J.; Ballabio, D.; Todeshini, R. y Tripaldi, P. 2007. Análisis multivariante de propiedades físicas y químicas de aceites y grasas vegetales del Ecuador. Facultad de Ciencias y Tecnología. Universidad del Azuay. Ecuador.

- Rubilar, M.; Pinelo, M.; Franco, D.; Sineiro, J.; y Nunez, M. 2003. Residuos agroindustriales como fuente de antioxidantes. Afinidad. Vol. 60, p. 153-160.

- Sasidharan, S., Chen, Y., Saravanan, D., Sundram, K.M., Latha, Y.L., 2011. Extraction, isolation and characterization of bioactive compounds from plants' extracts. African Journal of Traditional Complementary and Alternative Medicines. Vol. 8, no 1, p. 1-10. 
- Savic, M. 1985. Quantitative analysis of anthocyanins in sour cherry cultivars. En: Anthocyanins in Fruits, Vegetables, and Grain, Mazza, G. y Miniati, E. CRC, Press, Boca Raton, Florida.

- Sellappan, S.; Akoh, C.; Krewer, G. 2002. Phenolic compounds and antioxidant capacity of Georgia-grown blueberries and blackberries. Journal of Agricultural and Food Chemistry. Vol. 50, n 8, p. 2432-2438.

- Shahidi, F.; Naczk, M.; Pegg, R. y Synowiecki, J. 1991. Chemical composition and nutritional value of processing discards of cod (Gadus morhua). Food Chemistry. Vol. 42, no. 2, p. 145-151.

- Smith, R.M. 2003. Before the injection-modern methods of sample preparation for separation techniques. Journal of Chromatography. Vol. 1000, $\mathrm{n}^{\circ} 1-$ 2, p. 3-27.

- Spigno, G.; Tramelli, L.; Marco de Faveri, D. 2007. Effects of extraction time, temperature and solvent on concentration and antioxidant activity of grape marc phenolics. Journal of Food Engineering. Vol. 81, nº 11, p. 200-208.

- Spigno, G.; y De Faveri, D. 2007. Antioxidants from grape stalks and marc: influence of extraction procedure on yield, purity and antioxidant power of the extracts. Journal of Food Engineering. Vol. 78, n 3, p. 793-801.

- Sulaiman, S.; Sajak, A.; Ooi, K.; Supriatno y Seow, E. 2011. Effect of solvents in extracting polyphenols and antioxidants of selected raw vegetables. Journal of Food Composition and Analysis. Vol. 24, no. 4-5, p. 506-515.

- Sun, T.; Powers, J. y Tang, J. 2007. Evaluation of the antioxidant activity of asparagus, broccoli and their juices. Food Chemistry. Vol. 105, no. 1, p. 101-106.

- Swain, T. y Hillis, W. 1959. The phenolic constituents of Prunus domestica. I.-The quantitative analysis of phenolic constituents. Journal of the Science of Food and Agriculture. Vol. 10, no. 1, p. 63-68.

- Szajdek, A. y Borowska, E. 2008. Bioactive compounds and health-promoting properties of berry fruits: A review. Plant Foods for Human Nutrition. Vol. 63, no. 4, p. 147-156.

- Torre, L. y Barritt, B. 1977. Quantitative evaluation of Rubus fruit anthocyanin pigments. Journal of Food Science. Vol. 42, n² 2, p. 488-490. 
- Uma, D.; Ho, C. y Wan Aida W. 2010. Optimization of Extraction Parameters of Total Phenolic Compounds from Henna (Lawsonia inermis) Leaves. Sains Malaysiana. Vol. 39, n 1, p. 119-128.

- Vatai, T., Škerget, M. y Knez, Ž. 2009. Extraction of phenolic compounds from elder berry and different grape marc varieties using organic solvents and/or supercritical carbon dioxide. Journal of Food Engineering. Vol. 90, no. 2, p. 246-254.

- Veres, Z.; Holb, I.; Nyeki, J.; Szabo, Z.; Szabo, T.; Remenyik, J. 2008. Antioxidant and anthocyanin contents of sour cherry cultivars. Acta Horticulturae (ISHS). Vol. 795, p. 787-792.

- Vinson, J. 1998. Flavonoids in foods as in vitro and in vivo antioxidants. Advances in Experimental Medicine and Biology. Vol. 439, p. 151-164.

- Wang, H.; Nair, M.; lezzoni, A.; Strasburg, G.; Booren, A.; Gray, I. 1997. Quantification and Characterization of Anthocyanins in Balaton Tart Cherries. Journal of Agricultural Food Chemistry. Vol. 45, nº 7, p. 2556-2560.

- Wang, H.; Nair, M.; Strasburg, G.; Booren, A. y Gray, J. 1999. Antioxidant polyphenols from tart cherries (Prunus cerasus). Journal of Agricultural and Food Chemistry. Vol. 47, no. 3, p. 840-844.

- Wang, S. y Lin, H. 2000. Antioxidant activity in fruits and leaves of blackberry, raspberry, and strawberry varies with cultivar and developmental stage. Journal of Agricultural and Food Chemistry. Vol. 48, n² 2, p. 140-146.

- Wang, L., Weller, C.L. 2006. Recent advances in extraction of nutraceuticals from plants. Trends in Food Science \& Technology. Vol. 17, n 6, p. 300-312.

- Wrolstad, R. 2001. Color and Pigment Analyses in Fruit Products. Station Bulletin 624, Agricultural Experiment Station, Oregon State University, Corvallis: 117.

- Wu, S.; Chappell, J. 2008. Metabolic engineering of natural products in plants; tools of the trade and challenges for the future. Curr Opin Biotechnol. Vol. 19, $n^{\circ} 2$, p. $145-52$.

- Yilmaz, Y. y Toledo, R. 2006. Oxygen radical absorbance capacities of grape/wine industry byproducts and effect of solvent type on extraction of grape seed polyphenols. Journal of Food Composition and Analysis. Vol. 19, no 1, p. 41-44. 
- Zhishen, J.; Mengcheng, T. y Jianming, W. 1999. The determination of flavonoid contents in mulberry and their scavenging effects on superoxide radicals. Food Chemistry. Vol. 64, no. 4, p. 555-559. 


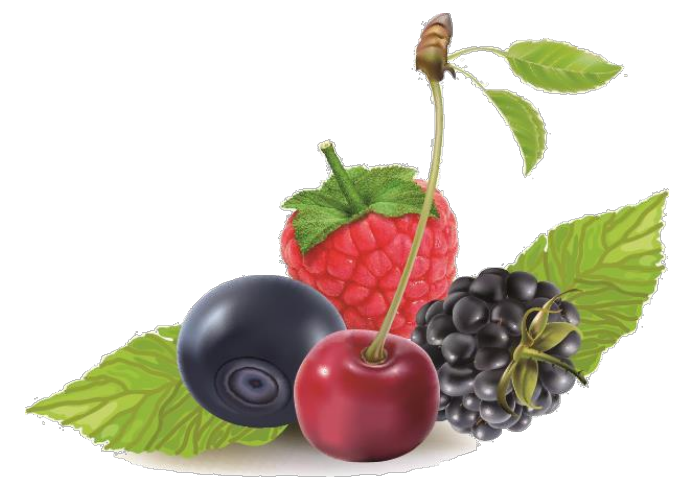

CAPITULO II

Caracterización de las materias primas 


\section{II-1.INTRODUCCION}

En esta tesis se trabajó con frutas finas obtenidas de productores de la zona de la Comarca Andina del Paralelo 42 (Río Negro, Argentina). Las variedades utilizadas fueron frambuesa var. Tulameen, zarzamoras var. Thornfree, guindas var. Montmorency y arándanos var. Elliot.

Si bien en la bibliografía disponible pueden hallarse valores de referencia de los parámetros estudiados en esta tesis, factores tales como las condiciones de cultivo, zona geográfica y clima influyen en la composición final de las materias primas, por lo cual es necesario realizar una caracterización fisicoquímica detallada de las matrices a utilizar y así aportar, además, datos inexistentes a nivel nacional.

\section{II-2. MATERIALES Y MÉTODOS}

Las frutas fueron cosechadas por productores de la zona de la Comarca Andina del Paralelo 42 en su punto de madurez óptimo y enviadas inmediatamente a Villa Regina, donde se conservaron en heladera a $5^{\circ} \mathrm{C}$ hasta su utilización.

Se realizó un muestreo aleatorio simple, se descartaron aquellos frutos que presentaban síntomas de avanzado estado de madurez. Todos los extractos y las determinaciones se realizaron por triplicado.

\section{II-2.1 Determinaciones}

Se realizaron las siguientes determinaciones:

- Contenido de humedad. Se determinó en base al método AOAC 920.151. Frutos frescos se procesaron con un homogeneizador y $5 \mathrm{~g}$ de la pulpa resultante se colocaron en cápsulas de porcelana con arena, previamente taradas en balanza analítica. Dichos recipientes se dispusieron en estufa de vacío a $70^{\circ} \mathrm{C}$, hasta pesada constante, calculándose el residuo por diferencia de peso.

- Sólidos solubles refractométricos (SSR). Se determinó según el método 932.12 de la AOAC, utilizando un refractómetro ABBE, marca ATAGO tipo 1. Los frutos frescos se procesaron con un homogeneizador y la pulpa se colocó sobre un filtro de tela (voile) a fin de facilitar la separación de los sólidos del jugo obtenido, sobre el cual se realizó la medición.

- Contenido de cenizas. Se determinó en base al método AOAC 940.26. La muestra previamente deshidratada se colocó en crisoles de porcelana y se 
carbonizó. Dichos recipientes se dispusieron en una mufla a $525^{\circ} \mathrm{C}$, hasta pesada constante, calculándose el residuo de la calcinación por diferencia de peso.

- Contenido de grasas. Se determinó a través del método de Soxhlet (extracción directa) AOAC 954.02. La muestra anhidra se extrajo con éter de petróleo y luego se determinó gravimétricamente el extracto seco, después que se eliminó el solvente.

- Determinación del contenido de proteínas totales. Se determinó en base al método de Kjeldahl (ORION, 1984). La sustancia a investigar se sometió a un tratamiento con ácido sulfúrico concentrado en presencia de una mezcla catalizadora formada por sulfato de mercurio y sulfato de potasio. Del sulfato amónico formado se libera el amoníaco por tratamiento con una solución de hidróxido de sodio, ioduro de sodio y EDTA. La medida del amoníaco se realizó con electrodo sensible al gas amoníaco, modelo 95-12 marca Orion. Se utilizó el factor 6,25 para la conversión del nitrógeno proteico a proteína.

- pH y acidez titulable. Frutos frescos se procesaron con un homogeneizador y $5 \mathrm{~g}$ de la pulpa resultante se suspendieron en $100 \mathrm{ml}$ de agua destilada hervida. Se midió el pH del homogenato según el método 981.12 de la AOAC, utilizando un analizador de iones marca Orion, modelo EA 940 y un electrodo combinado de $\mathrm{pH}$. Por otra parte, la acidez se determinó según el método 942.15 de la AOAC, titulando con $\mathrm{NaOH} 0,1 \mathrm{M}$ hasta $\mathrm{pH} 8,1$. La acidez se expresó como gramos de ácido cítrico anhidro por cada 100 gramos de fruta fresca (g ácido cítrico anhidro/100 g producto).

- Contenido de carotenoides totales. Se determinó por el método descripto por Rodríguez Amaya y Kimura (2004). La muestra se extrajo con acetona a temperatura ambiente, luego se realizó una partición con éter de petróleo, se llevó a sequedad en rotavapor Buchi RE 111 y el extracto seco se retomó con $4 \mathrm{ml}$ de etanol absoluto. Los resultados se expresan como microgramos de luteína por cada 100 gramos de fruta fresca ( $\mu$ g luteína/100 g producto).

- Extracción de azúcares. Se tomó $1 \mathrm{~g}$ de muestra, se añadieron $10 \mathrm{ml}$ de solución de etanol absoluto y se colocaron en un baño termostático con agitación (modelo Dubnoff) a $25{ }^{\circ} \mathrm{C}$ durante 30 minutos. Luego se filtró mediante vacío y el residuo se volvió a extraer con otros $10 \mathrm{ml}$ de solvente. Los extractos reunidos se llevaron a $25 \mathrm{ml}$ con agua destilada. De la solución anterior se tomó $1 \mathrm{ml}$ y finalmente se llevó a $50 \mathrm{ml}$ con agua destilada. 
- Azúcares reductores (AR). Se determinó en base al método microcolorimétrico de Nelson-Somogyi modificado por Castellanos (1995). Se adicionó a una alícuota de $0,5 \mathrm{ml}$ de extracto alcohólico, $0,5 \mathrm{ml}$ de reactivo de cobre. Se incubó en agua hirviendo durante 40 minutos y luego se enfriaron los tubos en agua corriente durante 5 minutos. Se añadió $0,5 \mathrm{ml}$ de reactivo de arsenomolibdato, se mezcló y llevó a $5 \mathrm{ml}$ finales con agua destilada. Las lecturas de absorbancia fueron realizadas con un espectrofotómetro Metrolab 1700 a $610 \mathrm{~nm}$, contra un estándar externo de Glucosa (mg/l). Los resultados finales se expresaron como gramos de Glucosa por cada 100 gramos de fruta fresca (g GLU/100g producto).

- Azúcares totales (AT). Se determinó en base al método de Antrona (Southgate, 1976). Se adicionó a una alícuota de $200 \mu \mathrm{l}$ de extracto alcohólico, $2 \mathrm{ml}$ de reactivo de antrona. Se incubó en agua hirviendo durante 15 minutos y luego se enfriaron los tubos a temperatura ambiente, en oscuridad, durante 5 minutos. Las lecturas de absorbancia fueron realizadas con un espectrofotómetro Metrolab 1700 a $620 \mathrm{~nm}$, contra un estándar externo de Glucosa $(\mathrm{mg} / \mathrm{l})$. Los resultados finales se expresaron como gramos de Glucosa por cada 100 gramos de fruta fresca (g GLU/100g producto).

- Extracción de compuestos bioactivos. Se realizó según la metodología explicada en el Capítulo I, sección 2.1; utilizando como solvente de extracción solución al $1 \%$ de $\mathrm{HCl}$ en etanol y temperatura de $37^{\circ} \mathrm{C}$.

- Fenoles totales (FT). Se realizó según la metodología explicada en el Capítulo I, sección I-2.1.

- Flavonoides (Fv). Se realizó según la metodología explicada en el Capítulo I, sección I-2.1.

- Poder Reductor (PR). Fue analizado por el método de Benzie y Strain (1996) para determinar la capacidad del plasma sanguíneo para reducir iones férricos ("Ferric Reducing Ability of Plasma", FRAP). El ensayo FRAP mide directamente la capacidad de los antioxidantes para reducir un complejo de Fe (III) con una tripiridiltriazina, la 2,4,6-tris(2-piridil)-s-triazina (TPTZ), al correspondiente complejo de $\mathrm{Fe}$ (II) en medio ácido. El color azul resultante puede medirse espectrofotométricamente a $593 \mathrm{~nm}$ y se considera que está directamente relacionado con la capacidad reductora total de los antioxidantes dadores de electrones presentes en la muestra ensayada. Los resultados finales se expresaron como microgramos de $\mathrm{Fe}^{+2}$ por gramo de fruta fresca ( $\mu \mathrm{g} \mathrm{Fe} \mathrm{F}^{+2} / \mathrm{g}$ producto). 
- Antocianinas. Se realizó según la metodología explicada en el Capítulo I, sección I-2.1.

- Extracción de Fructanos. Frutos frescos se procesaron con un homogeneizador y $1 \mathrm{~g}$ de la pulpa resultante se dispersó en $80 \mathrm{ml}$ de agua destilada a $80^{\circ} \mathrm{C}$ y se agitó por 15 minutos, manteniendo la temperatura constante a fin de solubilizar los fructanos de la muestra. Se homogenizó, se dejó enfriar a temperatura ambiente y finalmente se trasvasó cuantitativamente a un matraz de $100 \mathrm{ml}$, ajustando el volumen con agua destilada. Antes de realizar las determinaciones, las muestras se calentaron nuevamente a $80^{\circ} \mathrm{C}$ y se filtraron mediante vacío.

- Fructanos Totales. Se determinó según el método 999.03 y 32.32 de la AOAC, utilizando un kit enzimático provisto por Megazyme. Los productos se someten a una extracción con agua caliente. Alícuotas de ese extracto se tratan con una sacarasa, para hidrolizar sacarosa a glucosa y fructosa, y con una mezcla de amilasas, para hidrolizar el almidón a glucosa. Todos los azúcares reductores se reducen a polialcoholes con borohidruro alcalino. Los fructanos se hidrolizan a fructosa y glucosa con una fructanasa y los azúcares se determinan por colorimetría, mediante una reacción con hidracina del ácido p-hidroxibenzoico, leyendo absorbancia a $410 \mathrm{~nm}$. Los resultados finales se expresaron como miligramos de fructanos por cada 100 gramos de fruta fresca (mg FRUC/100 g producto).

- Poder Antirradical (PA). Se realizó según la metodología explicada en el Capítulo I, sección I-2.1.

- Ácido Ascórbico Total. Esta determinación fue realizada por HPLC, según el método AOAC Collaborative Protocol, Brause, IFU Analytical Commision (1998). Se utilizó una columna tipo $\mathrm{C}_{18}$ en fase reversa. La fase móvil fue $\mathrm{KH}_{2} \mathrm{PO}_{4}(0.5 \%, \mathrm{~m} / \mathrm{v})$, $\mathrm{pH} 2.5$, con ditiotreitol (DTT) $(0.1 \%, \mathrm{~m} / \mathrm{v})$. Se utilizaron 5 estándares de calibración de ácido ascórbico y se aseguraron tiempos de retención estables. Se midió la respuesta máxima a $254 \mathrm{~nm}$ utilizando un detector de arreglo de diodos. Los resultados se informaron como miligramos de ácido ascórbico total por cada kilogramo de producto (mg Ascórbico Total/ Kg producto).

- Fibra Dietaria Total. Se determinó según el método 991.43 de la AOAC. La muestra seca se sometió a digestión enzimática con $\alpha$-amilasa termoestable, proteasa y amiloglucosidasa. La fibra dietética insoluble (IDF) se filtró, y luego el 
residuo se lavó con agua destilada caliente. La solución combinada de filtrado y lavados de agua se precipitó con etanol para la determinación de fibra dietética soluble (SDF). Luego el precipitado se filtró y se secó. Ambos residuos, IDF y SDF, se corrigieron por proteína, ceniza y blanco, para el cálculo final de los valores SDF e IDF. Para la determinación de fibra dietética total, la SDF se precipitó con etanol, y luego se filtró, secó y pesó. El valor de fibra dietética total (TDF) se corrigió por el contenido de proteína y ceniza. Las proteínas y cenizas se realizaron según los métodos descriptos en los apartados anteriores.

- Color superficial. El color se evaluó con los parámetros triestímulo del espacio de color CIELAB utilizando un fotocolorímetro Minolta modelo CR 400 (Konica Minolta Sensing Inc, Osaka, Japon), con iluminante $\mathrm{C}$ y $2^{\circ}$ de ángulo de observador. El instrumento se estandarizó con una placa de cerámica blanca $\left(L^{*}=95,55 ; a^{*}=-0,10\right.$ y $\left.b^{*}=+2,69\right)$. En el caso de las frutas frescas, se colocaron varios frutos en una caja de Petri de $100 \mathrm{~mm}$ de diámetro y la medición de color (en diez puntos diferentes) se realizó en el momento en que se verificó la descongelación de los mismos. Las pulpas obtenidas en las distintas condiciones, se dispusieron en viales de $5 \mathrm{ml}$ para la medición de color. En todos los casos, se registraron los parámetros $L^{*}, a^{*}, b^{*}$ del espacio CIELAB. $L^{*}$ indica luminosidad, que se representa en una escala que toma valores entre 0 y 100 , correspondientes a negro y blanco respectivamente. El parámetro $a^{*}$ indica cromaticidad sobre un eje que va del verde (-) al rojo (+), mientras que el parámetro $b^{*}$ indica cromaticidad sobre un eje que va del azul (-) al amarillo (+). A partir de estos valores numéricos se calcularon las funciones de color "Chroma" y "ángulo de tono" (hue) usando las siguientes ecuaciones:

$$
\begin{gathered}
\text { hue }=\arctan \left(b^{*} / a^{*}\right) \\
\text { Chroma }=\left(\mathrm{a}^{*^{2}}+\mathrm{b}^{*^{2}}\right)^{1 / 2}
\end{gathered}
$$

Se calculó también la función "cambio global de color" ( $\Delta \mathrm{E})$, utilizando la ecuación:

$$
\Delta \mathrm{E}=\sqrt{\left(\Delta \mathrm{L}^{*}\right)^{2}+\left(\Delta \mathrm{a}^{*}\right)^{2}+\left(\Delta \mathrm{b}^{*}\right)^{2}}
$$

Donde, 


$$
\begin{aligned}
& \Delta L^{*}=\left(\bar{L}_{0}^{*}-L^{*}\right) \\
& \Delta a^{*}=\left(\bar{a}_{0}^{*}-a^{*}\right) \\
& \Delta b^{*}=\left(\bar{b}_{0}^{*}-b^{*}\right) \\
& \bar{L}_{0}^{*}, \bar{a}_{0}^{*}, \bar{b}_{0}^{*}, \text { son los valores medios triestímulo de la muestra control. }
\end{aligned}
$$

- Minerales. Se determinaron Sodio, Potasio, Calcio, Cinc y Hierro por Espectrometría de Masas con fuente de Plasma de Acoplamiento Inductivo (ICPMS).

\section{II-2.2 Análisis estadístico}

Los datos se analizaron usando técnicas de análisis multivariado mediante el análisis de cluster $(\mathrm{CL})$ y de componentes principales (ACP), con el fin de lograr la agrupación de las muestras según los criterios elegidos. Corresponden a cuatro frutas con tres repeticiones por fruta y variable. Se ingresaron las muestras asignándoles códigos para su identificación (1, 2 o 3 ya que las determinaciones se realizaron por triplicado). El análisis de clúster se llevó a cabo mediante una agrupación de tipo jerárquico, con criterio de encadenamiento UPGMA (Método aritmético de pares no ponderados) y una distancia euclídea.

El ACP permite representar los datos originales (individuos y variables) en un espacio de dimensión inferior del espacio original, facilitando considerablemente el análisis y reduciendo costos. Cada componente principal se expresa como una combinación lineal de las variables originales

Se utilizó el programa estadístico Infostat v. 2012. (Di Rienzo y col., 2012).

\section{II-3. RESULTADOS Y DISCUSIÓN}

En las Tablas II-1, II-2, II-3 y II-4 se presentan resultados de la caracterización de la fruta fresca de seis cosechas diferentes (año 2009 al 2014), indicando para cada caso máximo, mínimo y promedio. Algunas determinaciones, por razones presupuestarias, no se realizaron todos los años. 
Tabla II-1. Caracterización de frutos frescos de frambuesa

\begin{tabular}{|c|c|c|c|}
\hline \multirow{2}{*}{ DETERMINACIÓN } & \multicolumn{3}{|c|}{ FRAMBUESA } \\
\hline & Mínimo & Promedio & Máximo \\
\hline Humedad (\%) & 84,72 & 86,04 & 87,10 \\
\hline $\operatorname{SSR}\left({ }^{\circ} \mathrm{Bx}\right)$ & 9,5 & 11,7 & 14,5 \\
\hline $\mathrm{pH}$ & 2,61 & 2,94 & 3,22 \\
\hline Cenizas (\%) & 1,90 & 2,33 & 2,90 \\
\hline Acidez Titulable $^{(\mathrm{a})}$ & 1,62 & 1,93 & 2,25 \\
\hline Proteínas Totales (\%) & 1,11 & 1,18 & 1,24 \\
\hline Grasas (\%) & 0,24 & 0,28 & 0,31 \\
\hline Azúcares Reductores ${ }^{(b)}$ & 2,3 & 2,6 & 2,9 \\
\hline Azúcares Totales ${ }^{(c)}$ & 10,26 & 11,44 & 12,50 \\
\hline Carotenos $^{(\mathrm{d})}$ & 562 & 576 & 594 \\
\hline Fenoles Totales ${ }^{(\mathrm{e})}$ & 134 & 192 & 258 \\
\hline Flavonoides $^{(\mathrm{f})}$ & 26 & 37 & 46 \\
\hline Ácido Ascórbico Total ${ }^{(\mathrm{g})}$ & 213 & 340 & 467 \\
\hline Antocianinas $^{(\mathrm{h})}$ & 30 & 43 & 68 \\
\hline Fructanos Totales $^{(\mathrm{i})}$ & 13 & 16 & 21 \\
\hline Poder Antirradical ${ }^{(j)}$ & 0,47 & 0,65 & $\overline{1,14}$ \\
\hline Poder Reductor (k) & 19 & 27 & 38 \\
\hline Fibra Dietaria Total ${ }^{(I)}$ & 5,45 & 5,83 & 7,40 \\
\hline Color superficial: $L^{*}$ & 27,33 & 29,59 & 32,17 \\
\hline Color superficial: $a^{*}$ & 25,37 & 26,66 & 28,49 \\
\hline Color superficial: b* & 10,99 & 12,42 & 14,04 \\
\hline Calcio $^{(\mathrm{m})}$ & 183 & 210 & 410 \\
\hline Hierro $^{(m)}$ & 5,8 & 6,2 & 9,0 \\
\hline Cinc $^{(m)}$ & 2,3 & 3,1 & 3,6 \\
\hline
\end{tabular}




\begin{tabular}{|l|r|r|r|} 
Sodio $^{(m)}$ & 10 & 12 & 15 \\
\hline Potasio $^{(m)}$ & 1788 & 1874 & 2200 \\
\hline
\end{tabular}

(a)g de ácido cítrico anhidro/100 g de FF, (b) g de GLU/100 g FF, (c) g de GLU/100 g de FF, (d) $\mu \mathrm{g}$ de luteína/100 gramos de FF, (e) mg GAE/100g de FF, (f) mg CE/100 g de FF, (g) mg ascórbico Total/ Kg FF, (h) mg cianidina-3-glu/100 g FF, (i) mg FRUC/100 g de FF, (j) $\mathrm{mg}^{-1}$ de tejido fresco, (k) $\mu \mathrm{g} \mathrm{Fe}+2 / \mathrm{g} \mathrm{FF}$, (I) g de fibra/ $100 \mathrm{~g} \mathrm{FF},(\mathrm{m}) \mathrm{mg} / \mathrm{kg}$ de FF.

Tabla II-2. Caracterización de frutos frescos de guinda

\begin{tabular}{|c|c|c|c|}
\hline \multirow{2}{*}{ DETERMINACIÓN } & \multicolumn{3}{|c|}{ GUINDA } \\
\hline & Mínimo & Promedio & Máximo \\
\hline Humedad (\%) & 77,50 & 80,46 & 86,68 \\
\hline $\operatorname{SSR}\left({ }^{\circ} \mathrm{Bx}\right)$ & 17,0 & 19,3 & 22,5 \\
\hline $\mathrm{pH}$ & 3,10 & 3,39 & 3,57 \\
\hline Cenizas (\%) & 2,30 & 2,41 & 2,46 \\
\hline Acidez Titulable ${ }^{(a)}$ & 1,52 & 1,80 & 1,99 \\
\hline Proteínas Totales (\%) & 0,76 & 0,78 & 0,80 \\
\hline Grasas (\%) & 0,24 & 0,25 & 0,27 \\
\hline Azúcares Reductores ${ }^{(b)}$ & 7,60 & 9,04 & 10,51 \\
\hline Azúcares Totales ${ }^{(c)}$ & 13,50 & 15,36 & 16,72 \\
\hline Carotenos $^{(\mathrm{d})}$ & 463 & 475 & 497 \\
\hline Fenoles Totales ${ }^{(\mathrm{e})}$ & 487 & 558 & 732 \\
\hline Flavonoides $^{(\mathrm{f})}$ & 192 & 281 & 335 \\
\hline Ácido Ascórbico Total ${ }^{(\mathrm{g})}$ & 94 & 115 & 136 \\
\hline Antocianinas $^{(\mathrm{h})}$ & 23 & 36 & 58 \\
\hline Fructanos Totales $^{(\mathrm{i})}$ & 98 & 101 & 106 \\
\hline Poder Antirradical ${ }^{(j)}$ & 0,52 & 0,99 & 1,87 \\
\hline Poder Reductor ${ }^{(k)}$ & 36 & 42 & 47 \\
\hline Fibra Dietaria Total ${ }^{(\mathrm{I})}$ & 1,5 & 1,8 & 2,1 \\
\hline
\end{tabular}




\begin{tabular}{|l|r|r|r|}
${\text { Color superficial: } L^{*}}^{*} 19,92$ & 21,98 & 22,91 \\
\hline${\text { Color superficial: } a^{*}}^{*} 14,79$ & 17,8 & 19,18 \\
\hline${\text { Color superficial: } b^{*}}^{*}$ & 5,22 & 7,18 & 8,81 \\
\hline Calcio $^{(m)}$ & 160 & 190 & 230 \\
\hline Hierro $^{(m)}$ & 3,2 & 3,5 & 4,0 \\
\hline Cinc $^{(m)}$ & 0,5 & 0,7 & 1,0 \\
\hline Sodio $^{(m)}$ & 10 & 18 & 30 \\
\hline Potasio $^{(m)}$ & 1730 & 3200 & 4149 \\
\hline
\end{tabular}

(a)g de ácido cítrico anhidro/100 g de FF, (b) g de GLU/100 g FF, (c) g de GLU/100 g de FF, (d) $\mu \mathrm{g}$ de luteína/100 gramos de FF, (e) mg GAE/100g de FF, (f) mg CE/100 g de FF, (g) mg ascórbico Total/ Kg FF, (h) mg cianidina-3-glu/100 g FF, (i) mg FRUC/100 g de FF, (j) $\mathrm{mg}^{-1}$ de tejido fresco, (k) $\mu \mathrm{g} \mathrm{Fe}+2 / \mathrm{g} \mathrm{FF}$, (I) g de fibra/ $100 \mathrm{~g} \mathrm{FF},(\mathrm{m}) \mathrm{mg} / \mathrm{kg}$ de FF.

Tabla II-3. Caracterización de frutos frescos de arándano

\begin{tabular}{|c|c|c|c|}
\hline \multirow{2}{*}{ DETERMINACIÓN } & \multicolumn{3}{|c|}{ ARANDANO } \\
\hline & Mínimo & Promedio & Máximo \\
\hline Humedad (\%) & 77,50 & 83,27 & 86,90 \\
\hline $\operatorname{SSR}\left({ }^{\circ} \mathrm{Bx}\right)$ & 9,5 & 12,3 & 14,5 \\
\hline $\mathrm{pH}$ & 2,8 & 3,1 & 3,9 \\
\hline Cenizas (\%) & 1,32 & 1,70 & 1,99 \\
\hline Acidez Titulable ${ }^{(a)}$ & 0,48 & 1,27 & 2,03 \\
\hline Proteínas Totales (\%) & 0,84 & 0,87 & 0,90 \\
\hline Grasas (\%) & 0,30 & 0,36 & 0,41 \\
\hline Azúcares Reductores ${ }^{(b)}$ & 4,90 & 5,89 & 6,87 \\
\hline Azúcares Totales ${ }^{(\mathrm{c})}$ & 10,64 & 11,61 & 12,5 \\
\hline Carotenos $^{(d)}$ & 338 & 356 & 393 \\
\hline Fenoles Totales ${ }^{(e)}$ & 310 & 463 & 782 \\
\hline Flavonoides $^{(\mathrm{f})}$ & 90 & 154 & 281 \\
\hline Ácido Ascórbico Total ${ }^{(\mathrm{g})}$ & 130 & 195 & 260 \\
\hline
\end{tabular}




\begin{tabular}{|l|r|r|r|} 
Antocianinas $^{(\mathrm{h})}$ & 58 & 153 & 277 \\
\hline Fructanos Totales $^{(\mathrm{i})}$ & 70 & 78 & 98 \\
\hline Poder Antirradical $^{(\mathrm{j})}$ & 0,70 & 1,25 & 1,87 \\
\hline Poder Reductor $^{(\mathrm{k})}$ & 24 & 32 & 37 \\
\hline Fibra Dietaria Total $^{(\mathrm{l})}$ & 3,73 & 3,99 & 4,25 \\
\hline${\text { Color superficial: } \mathrm{L}^{*}}^{*}$ & 17,35 & 19,18 & 22,00 \\
\hline${\text { Color superficial: } \mathrm{a}^{*}}^{*}$ & 6,27 & 8,26 & 8,93 \\
\hline${\text { Color superficial: } \mathrm{b}^{*}}^{*}$ & 1,37 & 1,86 & 2,21 \\
\hline Calcio $^{(\mathrm{m})}$ & 60 & 120 & 210 \\
\hline Hierro $^{(\mathrm{m})}$ & 1,7 & 2,3 & 5,0 \\
\hline Cinc $^{(\mathrm{m})}$ & 1,1 & 1,4 & 1,6 \\
\hline Sodio $^{(\mathrm{m})}$ & 10 & 25 & 42 \\
\hline Potasio $^{(\mathrm{m})}$ & 890 & 960 & 1128 \\
\hline
\end{tabular}

(a)g de ácido cítrico anhidro/100 g de FF, (b) g de GLU/100 g FF, (c) g de GLU/100 g de FF, (d) $\mu \mathrm{g}$ de luteína/100 gramos de FF, (e) mg GAE/100g de FF, (f) mg CE/100 g de FF, (g) mg ascórbico Total/ Kg FF, (h) $\mathrm{mg}$ cianidina-3-glu/100 g FF, (i) mg FRUC/100 g de FF, (j) $\mathrm{mg}^{-1}$ de tejido fresco, (k) $\mu \mathrm{g} \mathrm{Fe}+2 / \mathrm{g} \mathrm{FF}$, (I) $\mathrm{g}$ de fibra/ $100 \mathrm{~g} \mathrm{FF},(\mathrm{m}) \mathrm{mg} / \mathrm{kg}$ de FF.

Tabla Il-4. Caracterización de frutos frescos de zarzamora

\begin{tabular}{|l|r|r|r|}
\hline \multirow{2}{*}{ DETERMINACIÓN } & \multicolumn{3}{|c|}{ ZARZAMORA } \\
\cline { 2 - 4 } & \multicolumn{1}{|c|}{ Mínimo } & Promedio & \multicolumn{1}{c|}{ Máximo } \\
\hline Humedad (\%) & 86,60 & 87,82 & 88,61 \\
\hline SSR ( $\left.{ }^{\circ} \mathrm{Bx}\right)$ & 6,0 & 9,6 & 12,5 \\
\hline $\mathrm{pH}$ & 2,75 & 3,40 & 4,20 \\
\hline Cenizas (\%) & 2,43 & 2,58 & 2,88 \\
\hline Acidez Titulable (a) & 0,73 & 1,12 & 0,92 \\
\hline Proteínas Totales (\%) & 1,18 & 1,19 & 1,21 \\
\hline Grasas (\%) & 0,43 & 0,52 & 0,62 \\
\hline
\end{tabular}




\begin{tabular}{|l|r|r|r|} 
Azúcares Reductores $^{(\mathrm{b})}$ & 2,10 & 2,76 & 3,20 \\
\hline Azúcares Totales $^{(\mathrm{c})}$ & 6,19 & 8,03 & 9,87 \\
\hline Carotenos $^{(\mathrm{d})}$ & 445 & 555 & 691 \\
\hline Fenoles Totales $^{(\mathrm{e})}$ & 259 & 319 & 398 \\
\hline Flavonoides $^{(\mathrm{f})}$ & 45 & 67 & 97 \\
\hline Ácido Ascórbico Total $^{(\mathrm{g})}$ & 148 & 296 & 444 \\
\hline Antocianinas $^{(\mathrm{h})}$ & 81 & 141 & 182 \\
\hline Fructanos Totales $^{(\mathrm{i})}$ & 30 & 33 & 35 \\
\hline Poder Antirradical $^{(\mathrm{j})}$ & 0,46 & 1,14 & 1,70 \\
\hline Poder Reductor $^{(\mathrm{k})}$ & 14 & 25 & 39 \\
\hline Fibra Dietaria Total $^{(\mathrm{l})}$ & 5,43 & 5,52 & 5,60 \\
\hline${\text { Color superficial: } \mathrm{L}^{*}}^{*}$ & 14,76 & 18,68 & 21,03 \\
\hline${\text { Color superficial: }{ }^{*}}^{*}$ & 1,31 & 1,65 & 2,48 \\
\hline${\text { Color superficial: }{ }^{*}}^{*}$ & 0 & 0,03 & 0,16 \\
\hline Calcio $^{(\mathrm{m})}$ & 280 & 301 & 320 \\
\hline Hierro $^{(\mathrm{m})}$ & 9,0 & 9,2 & 9,9 \\
\hline Cinc $^{(\mathrm{m})}$ & 1,7 & 3,2 & 4,3 \\
\hline Sodio $^{(\mathrm{m})}$ & 10 & 13 & 15 \\
\hline Potasio $^{(\mathrm{m})}$ & 1525 & 1700 \\
\hline
\end{tabular}

(a)g de ácido cítrico anhidro/100 g de FF, (b) $g$ de GLU/100 g FF, (c) g de GLU/100 g de FF, (d) $\mu \mathrm{g}$ de luteína/100 gramos de FF, (e) mg GAE/100g de FF, (f) mg CE/100 g de FF, (g) mg ascórbico Total/ Kg FF, (h) mg cianidina-3-glu/100 g FF, (i) mg FRUC/100 g de FF, (j) $\mathrm{mg}^{-1}$ de tejido fresco, (k) $\mu \mathrm{g} \mathrm{Fe}+2 / \mathrm{g} \mathrm{FF}$, (I) g de fibra/ $100 \mathrm{~g} \mathrm{FF},(\mathrm{m}) \mathrm{mg} / \mathrm{kg}$ de FF.

A los fines de realizar un análisis detallado de la composición, se toma la temporada 2013 de referencia, indicándose los valores de las variables en la Tabla 5. La elección de esta temporada por sobre las demás radica en el hecho de que este año efectivamente se realizaron todas las determinaciones indicadas. 
Tabla II-5. Caracterización de frutos frescos de frambuesa, zarzamora, guinda y arándano temporada 2013

\begin{tabular}{|c|c|c|c|c|}
\hline DETERMINACIÓN & FRAMBUESA & ZARZAMORA & GUINDA & ARANDANO \\
\hline Humedad (\%) & $86,2 \pm 0,1$ & $87,6 \pm 0,6$ & $79,5 \pm 0,1$ & $83,2 \pm 1,2$ \\
\hline $\operatorname{SSR}\left({ }^{\circ} \mathrm{Bx}\right)$ & $11,67 \pm 0,76$ & $9,83 \pm 0,29$ & $18,97 \pm 0,57$ & $12,80 \pm 0,26$ \\
\hline $\mathrm{pH}$ & $2,83 \pm 0,19$ & $3,10 \pm 0,00$ & $3,48 \pm 0,05$ & $2,85 \pm 0,04$ \\
\hline Cenizas (\%) & $2,71 \pm 0,18$ & $2,70 \pm 0,17$ & $2,39 \pm 0,08$ & $1,44 \pm 0,13$ \\
\hline Acidez Titulable ${ }^{(a)}$ & $2,08 \pm 0,10$ & $1,19 \pm 0,10$ & $1,98 \pm 0,02$ & $1,62 \pm 0,01$ \\
\hline Proteínas Totales (\%) & $1,14 \pm 0,03$ & $1,20 \pm 0,01$ & $0,77 \pm 0,01$ & $0,88 \pm 0,01$ \\
\hline Grasas (\%) & $0,24 \pm 0,01$ & $0,44 \pm 0,01$ & $0,26 \pm 0,01$ & $0,31 \pm 0,02$ \\
\hline Azúcares Reductores ${ }^{(b)}$ & $2,40 \pm 0,10$ & $3,22 \pm 0,04$ & $7,73 \pm 0,15$ & $5,00 \pm 0,10$ \\
\hline Azúcares Totales ${ }^{(\mathrm{c})}$ & $11 \pm 1$ & $10 \pm 0$ & $14 \pm 0$ & $11 \pm 0$ \\
\hline Carotenos $^{(\mathrm{d})}$ & $576 \pm 16$ & $450 \pm 6$ & $478 \pm 19$ & $358 \pm 31$ \\
\hline Fenoles Totales $^{(\mathrm{e})}$ & $174 \pm 16$ & $299 \pm 8$ & $500 \pm 13$ & $372 \pm 26$ \\
\hline Flavonoides $^{(\mathrm{f})}$ & $38 \pm 3$ & $71 \pm 5$ & $327 \pm 8$ & $93 \pm 4$ \\
\hline Ácido Ascórbico Total ${ }^{(\mathrm{g})}$ & $467 \pm 0$ & $444 \pm 0$ & $136 \pm 0$ & $260 \pm 0$ \\
\hline Antocianinas $^{(h)}$ & $40 \pm 1$ & $180 \pm 2$ & $24 \pm 2$ & $111 \pm 3$ \\
\hline Fructanos Totales $^{(\mathrm{i})}$ & $13 \pm 0$ & $35 \pm 0$ & $102 \pm 4$ & $85 \pm 15$ \\
\hline Poder Antirradical ${ }^{(j)}$ & $0,48 \pm 0,03$ & $0,79 \pm 0,03$ & $0,70 \pm 0,01$ & $0,79 \pm 0,05$ \\
\hline Poder Reductor ${ }^{(\mathrm{k})}$ & $34 \pm 4$ & $14 \pm 0$ & $40 \pm 4$ & $26 \pm 2$ \\
\hline Fibra Dietaria Total ${ }^{(\mathrm{l})}$ & $5,72 \pm 0,28$ & $5,54 \pm 0,10$ & $1,50 \pm 0,20$ & $3,72 \pm 0,10$ \\
\hline Color superficial: L* & $28,17 \pm 1,14$ & $18,73 \pm 1,64$ & $21,64 \pm 1,49$ & $21,26 \pm 0,84$ \\
\hline Color superficial: $a^{*}$ & $26,94 \pm 0,90$ & $1,65 \pm 0,15$ & $17,30 \pm 2,30$ & $6,61 \pm 0,35$ \\
\hline Color superficial: b* & $12,91 \pm 0,76$ & $0,05 \pm 0,01$ & $7,19 \pm 0,84$ & $1,46 \pm 0,09$ \\
\hline Calcio $^{(m)}$ & $200 \pm 15$ & $287 \pm 8$ & $202 \pm 4$ & $208 \pm 2$ \\
\hline Hierro $^{(m)}$ & $5,9 \pm 0,1$ & $9,3 \pm 0,3$ & $3,8 \pm 0,3$ & $4,9 \pm 0,1$ \\
\hline
\end{tabular}




\begin{tabular}{|l|r|r|r|r|} 
Cinc $^{(m)}$ & $2,3 \pm 0,3$ & $1,9 \pm 0,2$ & $0,5 \pm 0,1$ & $1,1 \pm 0,1$ \\
\hline Sodio $^{(m)}$ & $10 \pm 0$ & $10 \pm 1$ & $10 \pm 2$ & $11 \pm 1$ \\
\hline Potasio $^{(m)}$ & $1892 \pm 180$ & $1458 \pm 5$ & $4079 \pm 76$ & $1129 \pm 4$ \\
\hline
\end{tabular}

Los valores representan la media ( $\mathrm{n}=3) \pm \mathrm{SD}(\mathrm{a}) \mathrm{g}$ de ácido cítrico anhidro/100 g de FF, (b) g de GLU/100 g $\mathrm{FF}$, (c) g de GLU/100 g de FF, (d) $\mu \mathrm{g}$ de luteína/100 gramos de FF, (e) mg GAE/100g de FF, (f) mg CE/100 g de $\mathrm{FF}$, (g) mg ascórbico Total/ Kg FF, (h) mg cianidina-3-glu/100 g FF, (i) mg FRUC/100 g de FF, (j) mg ${ }^{-1}$ de tejido fresco, (k) $\mu \mathrm{g} \mathrm{Fe}+2 / \mathrm{g} \mathrm{FF}$, (l) g de fibra/ $100 \mathrm{~g} \mathrm{FF,} \mathrm{(m)} \mathrm{mg/} \mathrm{kg} \mathrm{de} \mathrm{FF.}$

En la composición química general de las frutas, cabe destacar su elevado contenido acuoso y su casi inapreciable contenido graso, así como el hecho de ser buenas fuentes de vitamina $\mathrm{C}$ y carotenos y elementos minerales. Su contenido de proteínas es bajo y dentro de su fracción hidrocarbonada hay que señalar el aporte de fibra alimentaria. Todo ello hace que su consumo contribuya para conseguir una alimentación sana y equilibrada.

El agua es el componente mayoritario de las frutas frescas y su contenido depende de la disponibilidad de la misma por parte del tejido vegetal en el momento de efectuarse la recolección, de modo, que su contenido acuoso puede verse afectado por las oscilaciones diarias de temperatura, condiciones del suelo, etc. En estas frutas, el contenido oscila entre el $70 \%$ y $90 \%$ del peso total del fruto, lo que dificulta la conservación de estos alimentos durante un largo tiempo, haciéndolos un sustrato susceptible de contaminación fúngica.

Las proteínas totales en las frutas estudiadas representaron alrededor del $1 \%$ de su peso fresco, lo cual se condice con lo descripto por Wills y col. (1984), constituyendo una fuente escasa de proteína y otras sustancias nitrogenadas (Primo Yúfera, 1998). La mayor parte de ellas desempeñan papeles funcionales y no de reserva como ocurre en los cereales y los frutos secos; además muchas son enzimas (Wills y col., 1999).

El contenido de lípidos es bajo, lo cual es esperable para las frutas carnosas (Olarte, 2007). Una dieta sin exceso de grasa y con predominio de las grasas de origen vegetal se considera un factor positivo en la lucha contra las enfermedades coronarias; siendo ésta una de las razones por las que se recomienda incluir las frutas y hortalizas en la dieta (Wills y col., 1999).

Por otra parte es importante destacar que todas las matrices presentan una acidez marcada, lo cual influiría favorablemente durante el procesado, ya que 
ayudaría a evitar el pardeamiento enzimático y durante la conservación, porque favorecería la retención del color.

Los valores de sólidos solubles refractométricos coinciden con los hallados en la bibliografía para guinda (Ochoa, 2011), arándano (Dinamarca y col., 1986), frambuesa y zarzamora (Martínez y De Michelis, 2011).

Los frutos con mayor contenido de fenoles totales, flavonoides y poder antirradical fueron guinda y arándano. Cabe destacar que en el caso de PA, zarzamora iguala el valor alcanzado por arándano, lo que se atribuye a la elevada concentración de antocianinas en estas matrices, ya que, estos compuestos contribuyen al PA.

Los valores encontrados para la concentración de antocianinas tienen un sentido lógico si se analiza que las matrices que presentan los colores más intensos (zarzamora y arándano) también presentan los valores más elevados. Además se asemejan a los reportados por la bibliografía para frambuesa, arándano, zarzamora (Agnieszka y Borowska, 2008) y guinda (Ochoa, 2011).

Los métodos de evaluación DPPH (determinación del poder antirradical - PA) y FRAP (determinación del poder reductor - PR) registran mecanismos distintos de actividad antioxidante, mientras que el primero está relacionado con la capacidad de transferir átomos de hidrogeno fenólicos, el segundo mide la capacidad reductora del extracto. El poder reductor no sigue exactamente el mismo comportamiento del poder antirradical, esto se debe a la menor selectividad del método FRAP (Rodríguez y col., 2009).

Las concentraciones de carotenoides, expresados como luteína, halladas en los berries superan en un 40 a un $60 \%$ los valores presentados por Marinova y Ribarova (2006). En el caso de guinda, la concentración triplica los valores reportados por Ferretti y col., 2010. La composición de carotenoides en frutas y hortalizas es muy compleja y variable, con diferencias, incluso en los carotenoides mayoritarios. Por lo general, factores como variedad, estado de madurez y sitio geográfico de producción influyen de manera significativa. En este último caso, temperaturas elevadas y una mayor exposición a la luz solar pueden generar un aumento de la carotenogénesis en las frutas (Rodríguez-Amaya y Kimura, 2004).

En cuanto a la concentración de fructanos totales, los valores obtenidos se encuentran por debajo de lo informado por Jovanovic-Malinovska y col. (2014) con excepción de la matriz zarzomora, aunque los autores mencionados no discriminan las variedades utilizadas. Puede haber varias razones para este tipo de discrepancia 
ya que muchos factores afectan los niveles de oligosacáridos en los alimentos , incluyendo variedad, madurez, variación estacional, clima, procedimiento de extracción, tiempo y temperatura de almacenamiento, así como el método de análisis para la determinación (Wilson y col., 2004; Kocsis y col., 2007). Madrigal y Sangronis (2007) reportaron que a pH menores de 4 , los enlaces tipo $\beta$ de las unidades de fructosa, tanto en la inulina como en la oligofructosa, se hidrolizan con la consecuente formación de fructosa. Las frutas finas patagónicas se consideran alimentos ácidos, ya que presentan pHs en el rango 2,8 - 3,5; lo que impacta de modo negativo en la concentración de fructanos totales.

Agnieszka y Borowska (2008) reportaron datos de contenido de ácido ascórbico total en varios berries, informando valores inferiores a los registrados en el presente trabajo. En cuanto a guinda la concentración hallada se condice con lo reportado por Ochoa (2011). El contenido en estas frutas viene determinado por varios factores, entre ellos, especies, variedad, condiciones climáticas, zona de cosecha y condiciones de almacenamiento.

\section{II-3.1 Análisis multivariado}

\section{II-3.1.1 Análisis de clústers}

Los clúster obtenidos en la figura II-1 permiten evaluar las agrupaciones entre muestras, conservando la información contenida en las veintitrés variables de entrada (los datos correspondientes a color superficial se evaluaron de forma separada). En este sentido, un elevado valor de la distancia entre dos individuos nos indica un alto grado de disimilaridad entre ellos. 


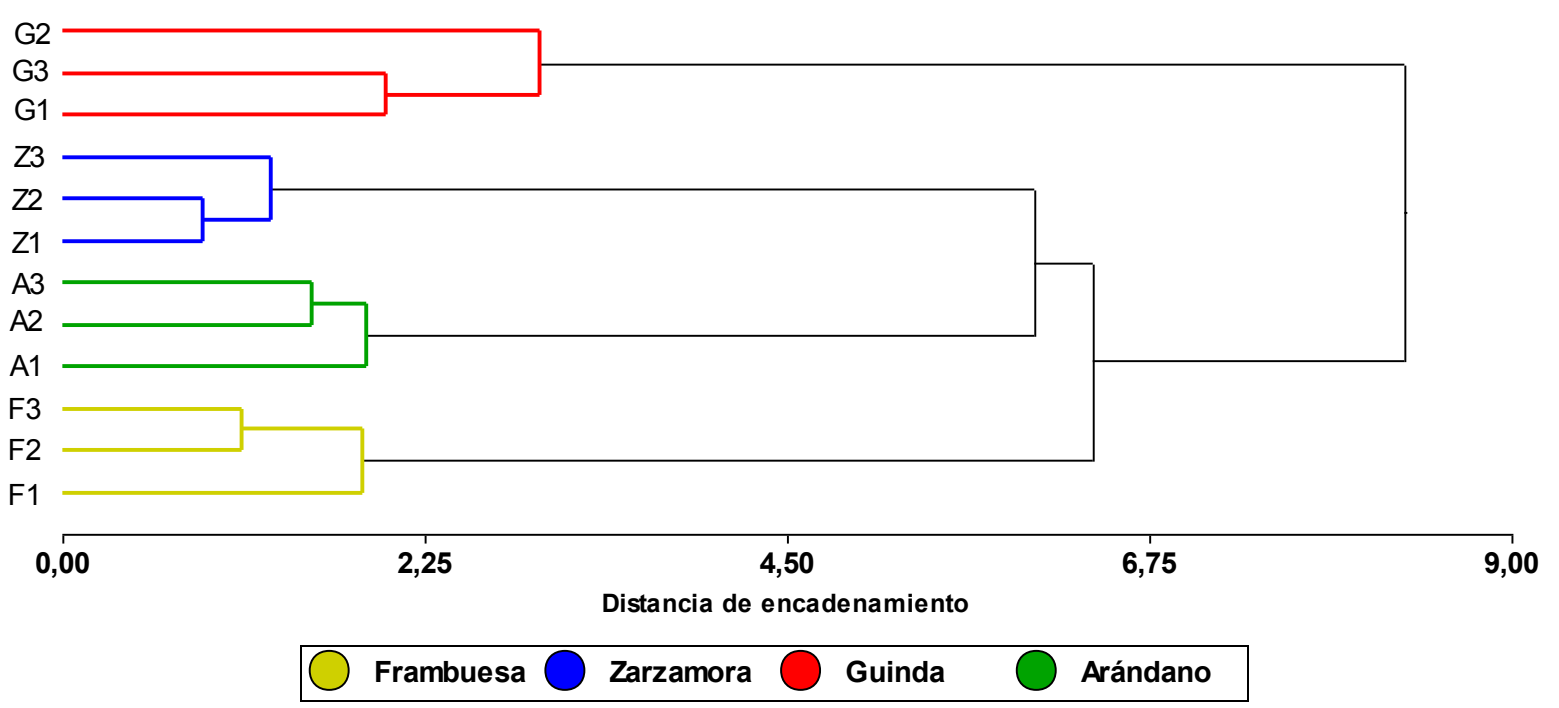

Figura II-1. Dendrograma por observaciones

Se puede observar en la figura que la primera agrupación se generó entre miembros de la misma especie y a continuación entre grupos similares; uno constituido por berries: frambuesa, arándano y zarzamora; y con una mayor distancia de encadenamiento se une la guinda, fruta de carozo que pertenece al grupo de los cherries.

Además, zarzamora y arándano conforman los grupos más similares, quizás por sus altos contenidos de antocianinas que se traducen en sus intensos colores.

\section{II-3.1.2 Análisis de componentes principales}

En la figura II-2 se presentan los resultados de las dos primeras componentes, y se observa que las muestras están agrupadas formando cuatro grupos diferenciados entre sí. Estas agrupaciones se realizan teniendo en cuenta la proximidad de los puntos y coinciden con las encontradas en el análisis de cluster. 


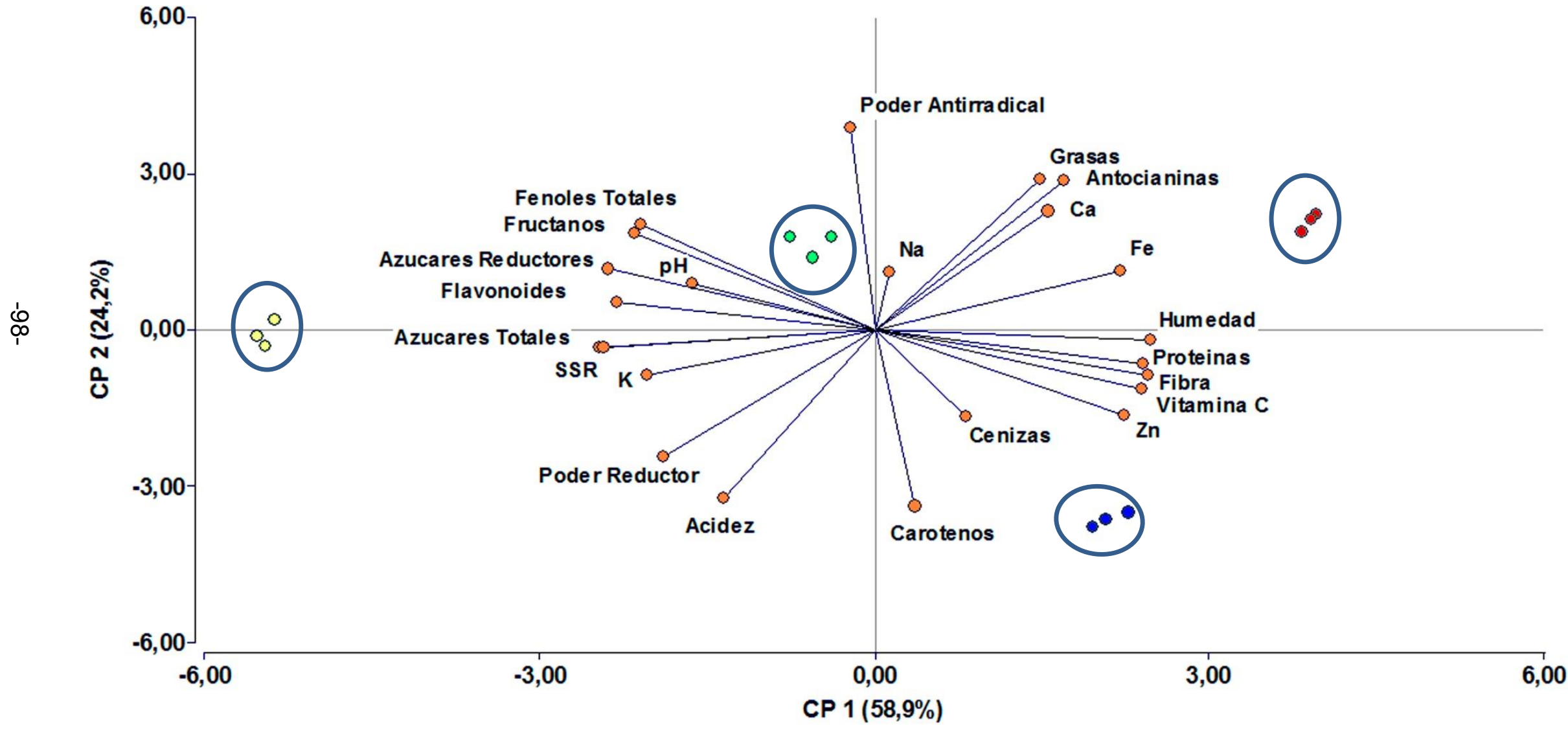

Frambuesa Guinda $\bigcirc$ Arandano $\bigcirc$ Zarzamora

Figura II-2. Proyección de las variables en el plano. Nota: Las agrupaciones entre muestras indicadas en la figura fueron obtenidas mediante un análisis de cluster. 
A través de la figura II-2 podemos resumir la estructura de datos descritos por las variables cuantitativas determinadas en las tablas anteriores. La dirección y sentido de los vectores verifican los datos anteriormente analizados, por ejemplo:

- el vector contenido de antocianinas tiene un sentido lógico si se analiza que sobre el cuadrante positivo de la componente 2 se hallan las matrices que presentan los colores más intensos (zarzamora y arándano);

- el poder reductor no sigue exactamente el mismo comportamiento del poder antirradical, esto se debe a la menor selectividad del método FRAP;

- en la concentración de fructanos totales, si bien el bajo $\mathrm{pH}$ de la frutas impacta de modo negativo, el vector respeta el mismo sentido y dirección que los correspondientes a azúcares totales y reductores;

- las matrices guinda y arándano presentan el mayor contenido de fenoles totales, flavonoides y poder antirradical. Notar que la proyección de la matriz sobre el vector se realiza de forma perpendicular, es decir en el caso de estas variables la concentración aumenta de izquierda a derecha.

- El contenido de fibra aumenta de izquierda a derecha, destacando al género Rubus (frambuesa y zarzamora) con los mayores valores, cercanos a $6 \mathrm{~g} / 100 \mathrm{~g}$ de fruta fresca, cantidad que establece el Código Alimentario Argentino (en el capítulo V) como límite inferior para poder rotular un alimento con la leyenda "Alto Contenido de fibra".

- En cuanto a hierro y cinc los valores hallados para todas las matrices son bajos, comparando con aquellos alimentos que se consideran de referencia por sus elevadas concentraciones (ver tablas II-6 y II-7). Además, en el caso de los elementos minerales resulta particularmente difícil concluir respecto de las recomendaciones sobre la ingesta diaria, debido a que su biodisponibilidad (el porcentaje de nutriente capaz de ser absorbido y disponible para ser almacenado), se ve influenciada por diversos factores, como por ejemplo en el caso de hierro y cinc por el contenido de fenoles totales que tienden a reducir la biodisponibilidad. Estudios en ratas demostraron que los fenoles totales forman complejos insolubles con el hierro y el zinc que precipitan y por lo tanto no pueden dializar (Dergal, 2006; Binaghi y col., 2007). 
Tabla II-6. Contenido en hierro de algunos alimentos

\begin{tabular}{|l|c|}
\hline \multicolumn{1}{|c|}{ Alimento } & Contenido de Fe (mg/100 g) \\
\hline Hígado porcino & $15-23$ \\
\hline Legumbres & $7-8$ \\
\hline Cereales & $7-18$ \\
\hline Moluscos bivalvos & $8-24$ \\
\hline Pescados & $3-7$ \\
\hline Frutos secos & $2-4$ \\
\hline Carne de ternera & $2-3$ \\
\hline Espinaca-Acelga & $3-4$ \\
\hline
\end{tabular}

Fuente: Tabla de composición de alimentos de Centroamérica, 2007.

Tabla II-7. Contenido en cinc de algunos alimentos

\begin{tabular}{|l|c|}
\hline \multicolumn{1}{|c|}{ Alimento } & Contenido de $\mathbf{Z n}$ (mg/100 g) \\
\hline Moluscos bivalvos & $180-200$ \\
\hline Germen de trigo tostado & $17-20$ \\
\hline Hígado de ternera & $12-13$ \\
\hline Carne de ternera & $10-15$ \\
\hline Semillas de calabaza & $10-12$ \\
\hline Semillas de sandía & $8-10$ \\
\hline Chocolate negro & $9-10$ \\
\hline Cacao en polvo & $6-7$ \\
\hline Maní & $6-7$ \\
\hline
\end{tabular}

Fuente: Tabla de composición de alimentos de Centroamérica, 2007. 
- La concentración de potasio aumenta de derecha a izquierda destacándose la guinda con los valores más elevados. Considerando que la Organización Mundial de la Salud recomienda un consumo mínimo, por día en un adulto, de $3510 \mathrm{mg}$ de potasio provenientes de alimentos, esta matriz presenta una fuente importante de potasio a través de una fuente no tradicional (Organización Mundial de la Salud, 2012).

\section{II-3.2 Color Superficial}

El color puede ser descripto a través de la luminosidad y la cromaticidad.

La luminosidad es el atributo que permite clasificar a una superficie de color como equivalente a la sensación producida por un elemento gris en la escala desde el blanco al negro.

La cromaticidad involucra dos características que son la longitud de onda dominante y la pureza. La primera corresponde a la sensación de color llamada matiz y la última a la saturación (figura II-3).

El matiz o tinte (hue) es el atributo que permite identificar al rojo, verde, amarillo o a un intermedio. Un valor de hue $=0^{\circ}$ representa un color rojo púrpura, $90^{\circ}$ amarillo; $180^{\circ}$ verde azulado y $270^{\circ}$ azul

La saturación (Chroma) es una propiedad de la superficie coloreada que da la diferencia de color respecto al gris de igual luminosidad.

$\Delta \mathrm{E}$ es la variación global del color respecto a un patrón o referencia.

En cuanto al análisis del color superficial, se presentan los resultados como $L^{*}$, $a^{*}$ y $b^{*}$ y sus conversiones a Chroma y Hue, ya que las tres primeras, no son variables independientes (Francis, 1980). 


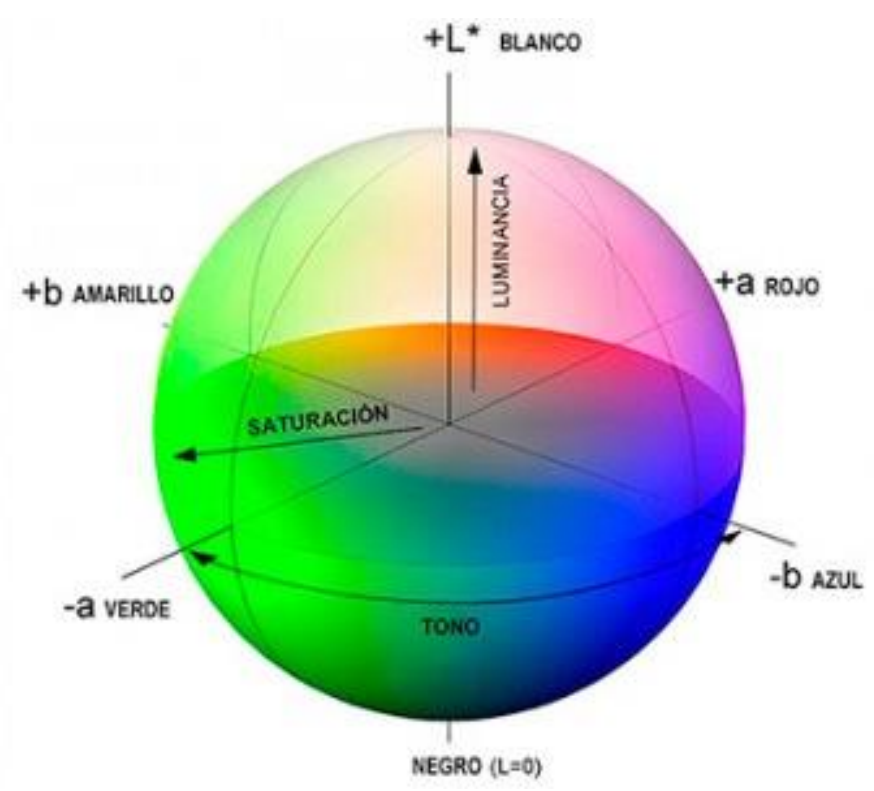

Figura II-3. Parámetros analizados en color superficial.

En la tabla II-8 se presentan los valores de color superficial correspondiente a las frutas frescas.

Tabla II-8. Color superficial en frutas frescas

\begin{tabular}{|c|c|r|r|r|r|}
\hline & $\mathbf{L}^{*}$ & \multicolumn{1}{c|}{$\mathbf{a}^{*}$} & $\mathbf{b}^{*}$ & hue & \multicolumn{1}{c|}{ Chroma } \\
\hline Frambuesa & $28,17 \pm 1,14$ & $26,94 \pm 0,90$ & $12,91 \pm 0,76$ & $25,59 \pm 0,95$ & $29,88 \pm 1,06$ \\
\hline Zarzamora & $18,73 \pm 1,64$ & $1,65 \pm 0,15$ & $0,05 \pm 0,01$ & $1,86 \pm 0,23$ & $1,65 \pm 0,15$ \\
\hline Guinda & $27,17 \pm 0,87$ & $14,56 \pm 2,17$ & $4,03 \pm 1,04$ & $15,26 \pm 1,68$ & $15,11 \pm 2,36$ \\
\hline Arándano & $36,46 \pm 2,85$ & $0,28 \pm 0,25$ & $-5,99 \pm 0,93$ & $272,89 \pm 3,23$ & $6,00 \pm 0,92$ \\
\hline
\end{tabular}

Los valores representan la media $(n=20) \pm S D$. Medias con una letra común por columna no son significativamente diferentes $(p \leq 0,05)$

Guinda, Frambuesa y Zarzamora presentan un matiz correspondiente al primer cuadrante. Tanto en frambuesa como guinda esto se traduce en colores rojizosanaranjados con mayor luminosidad en el primer caso, lo que impacta en la viveza del rojo final que presenta la matriz. Los frutos de zarzamora son más oscuros, con predominancia de púrpuras. En el caso de arándano, presenta un valor de ángulo hue correspondiente al cuarto cuadrante, es decir tonalidades azules. En la figura 
II-4, se puede observar un diagrama de color que se construye en función de las coordenadas cromáticas $a^{*}$ y $b^{*}$, donde la saturación $\left(C^{*}\right)$ se incrementa desde el centro (valor 0 ) hacia la periferia, la luminosidad se indica en la escala a la derecha $y$ hue $\left(h^{*}\right)$ indica el tono del producto. Ejemplo: la letra $A$ en el diagrama se corresponde con los parámetros de color del arándano fresco $\left(a^{*}=0,28 \pm 0,25 ; b^{*}=\right.$ $5,99 \pm 0,93$, hue $=272,89 \pm 3,23$ y Chroma $=6,00 \pm 0,92$ ).

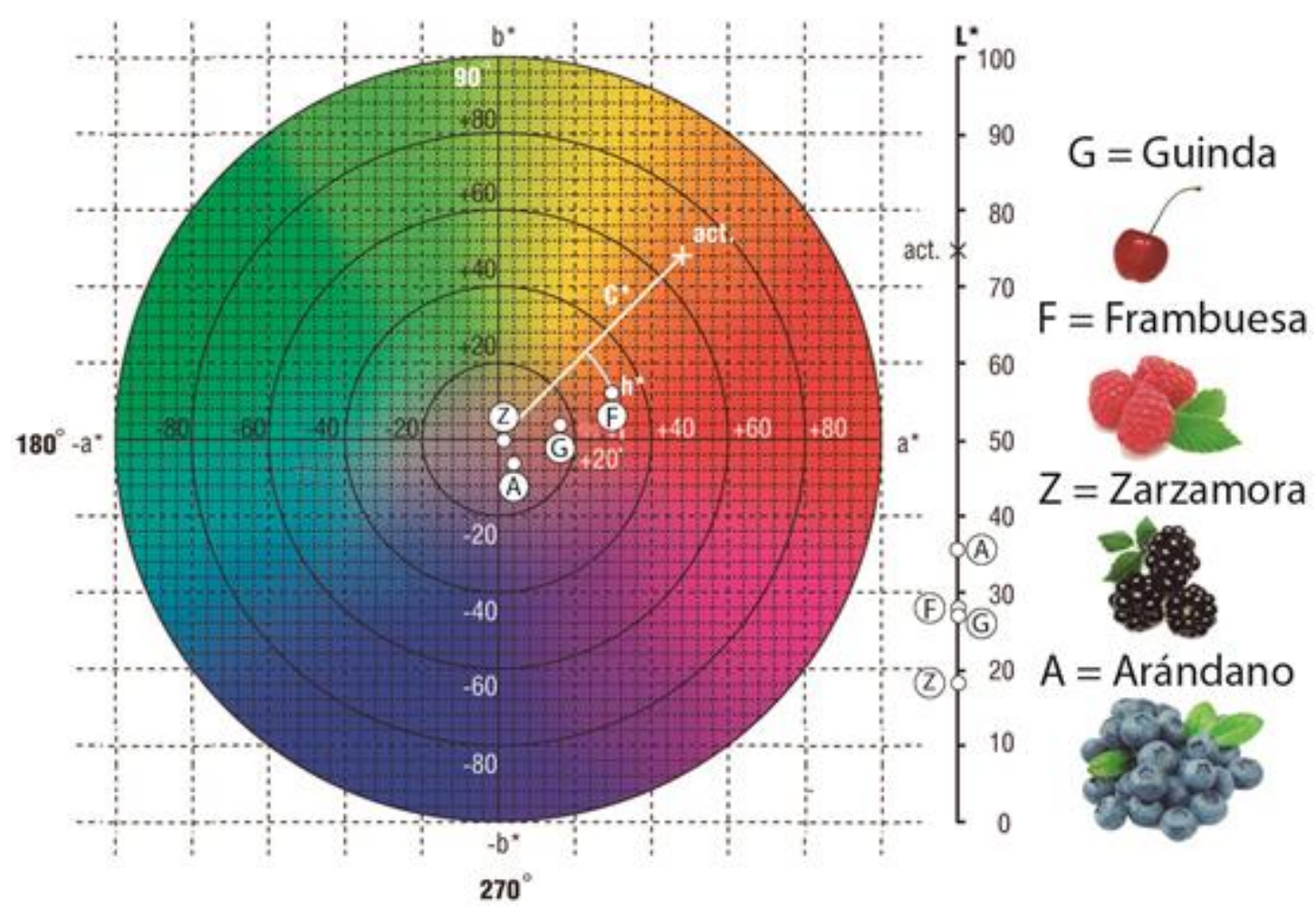

Figura II-4. Color superficial en frutas frescas. . Nota: el disco de color central se corresponde con un valor de $\mathrm{L}^{*}=50$

\section{II-4. CONCLUSIONES}

Las frutas estudiadas se destacan en general por su atractivo color, elevado contenido acuoso y bajo contenido graso y proteico. Dentro de su fracción hidrocarbonada hay que señalar el aporte de fibra alimentaria, principalmente en frambuesa y zarzamora. Toda ellas, exhiben una marcada acidez lo que podría influir positivamente durante el procesado y la conservación y, si bien, el aporte en cuanto a compuestos biactivos y poder antirradicalario es interesante, se destacan guinda y arándano con los mayores valores. Zarzamora y arándano contribuyen 
además con un elevado contenido de antocianinas monoméricas, lo que impacta directamente en el color superficial.

Estos resultados indican que las matrices serían, desde el punto de vista de su funcionalidad, una buena alternativa para la prevención de ciertas enfermedades asociadas al estrés oxidativo. El empleo de pulpas de estos frutos como ingredientes en las proporciones adecuadas, podría favorecer el desarrollo de alimentos funcionales ricos en compuestos fenólicos y con una elevada actividad antioxidante. Además, el hecho de ser elaborados de forma natural a partir de frutas de colores atractivos podría favorecer la aceptación del producto final por parte del consumidor.

\section{II-5. REFERENCIAS}

- Agnieszka, S.; Borowska, E. 2008. Bioactive Compounds and HealthPromoting Properties of Berry Fruits: A Review. Journal of Plant Foods Human Nutrition. Vol. 63, n 4, p. 147-156.

- Association of Official Analytical Chemistry (1990). Official Methods of Analysis of the AOAC. 15th Edition Washington D.C.

- Association of Official Analytical Chemistry (1998). Collaborative Protocol, Brause, IFU Analytical Commision. Edition Washington D.C.

- Benzie, I.; Strain, J. 1996. Ferric reducing ability of plasma (FRAP) as a measure of antioxidant power: The FRAP assay. Journal of Analytical Biochemistry. Vol. 239, $\mathrm{n}^{\circ} 1$, p. 70-76

- Binaghi, M.; López, L.; Ronayne de Ferrer, P. y Valencia, M. 2007. Evaluación de la influencia de distintos componentes de la dieta sobre la biodisponibilidad potencial de minerales en alimentos complementarios. Revista chilena de nutrición. Vol. 34, no 1, p. 56-60.

- Brand-Williams, W.; Cuvelier, M.E. y Berset, C. 1995. Use of a free radical method to evaluate antioxidant activity. LWT - Food Science and Technology, vol. 28 , no. 1 , p. $25-30$.

- Castellanos, O. 1995. Proyecto de investigación sobre la relación entre las particularidades bioquímicas (enzimáticas) de la interacción del hongo Beauveria bassiana y la broca del café con el grado de patogenicidad del hongo. Universidad de La Salle, p. 8-9. 
- Código Alimentario Argentino. 2016. Administración Nacional de Medicamentos, Alimentos y Tecnología Médica (ANMAT). http://www.anmat.gov.ar/ fecha de acceso: abril 2016.

- Dergal, S. 2006. Capítulo 6. Química de los alimentos. Cuarta edición. Ed. Pearson Educación, Mexico.

- Dinamarca, P.; Poblete, R.; Sánchez, A. 1986. Aspectos técnico-económicos en la producción de berries. Publicación técnica $N^{\circ}$ 16. Santiago de Chile, Fundación Chile, Departamento Agroindustrial.

- Ferretti, G.; Bacchetti, T.; Belleggia , A. y Neri, D. 2010. Cherry Antioxidants: From Farm to Table. Molecules. Vol. 15, p. 6993-7005.

- Jovanovic-Malinovska, R.; Kuzmanova, S.; Winkelhausen, E. 2014. Oligosaccharide Profile in Fruits and Vegetables as Sources of Prebiotics and Functional Foods. International Journal of Food Properties. Vol. 17, n ${ }^{\circ}$, p. 949965.

- Kocsis, L.; Liebhard, P.; Praznik,W. 2007. Effect of seasonal changes on content and profile of soluble carbohydrates in tubers of different varieties of Jerusalem artichoke (Helianthus tuberosus L.). Journal of Agricultural and Food Chemistry. Vol. 55, p. 9401-9408.

- Madrigal, L.; Sangronis, E. 2007. La inulina y derivados como ingredientes claves en alimentos funcionales. Archivos Latinoamericanos de Nutrición. Vol. 57, $n^{\circ}$ 4, p. 387-396.

- Marinova, D.; Ribarova, F. 2006. HPLC determination of carotenoids in Bulgarian berries. Journal of Food Composition and Analysis. Vol. 20, p. 370-374.

- Martinez, E.; De Michelis, A. 2011. Cultivo, Cosecha, Post-cosecha inmediata y elaboración de Frambuesas, Moras e Híbridos. Ediciones del INTA.

- Ochoa, M. 2011. Estudio del deterioro químico de guindas durante la deshidratación. Universidad Nacional del Sur, Argentina. Memoria para optar al título de Doctor en Ciencias Químicas de la Universidad Nacional del Sur.

- Olarte, G. 2007. Obtención y conservación de pulpa de frutas. Instituto de Ciencia y Tecnología de Alimentos. Universidad Nacional de Colombia.

- Organización Mundial de la Salud. 2012. Guideline: Potassium intake for adults and children. WHO Library Cataloguing-in-Publication Data. Ginebra, Suiza. 
- ORION Research Incorporated. 1984. Guide to Food and Beverage Analysis, p. 19-21.

- Primo Yúfera, E. 1998. Química de los Alimentos. Editorial Síntesis S.A. Madrid, España.

- Rodríguez Amaya, D.; Kimura, M. 2004. Harvestplus Handbook for Carotenoid Analysis. Harvestplus Technical Monograph series 2.

- Rodríguez, L.; Lopez, L.; García, M. 2009. Determinación de la composición química y actividad antioxidante en distintos estados de madurez de frutas de consumo habitual en Colombia, mora (Rubus Glaucus B.), maracuyá (Passiflora Edulis S.), guayaba (Psidium Guajava L.) y Papayuela (Carica Cundinamarcensis J.). Facultad de Ciencias Naturales. Universidad Jorge Tadeo Lozano. Bogotá, Colombia.

- Rojas, C.; Alvarado, J.; Ballabio, D.; Todeshini, R. y Tripaldi, P. 2007. Análisis multivariante de propiedades físicas y químicas de aceites y grasas vegetales del Ecuador. Facultad de Ciencias y Tecnología. Universidad del Azuay. Ecuador.

- Swain, T. y Hillis, W. 1959. The phenolic constituents of Prunus domestica. I.-The quantitative analysis of phenolic constituents. Journal of the Science of Food and Agriculture. Vol. 10, no. 1, p. 63-68.

- Southgate, D. 1976. Determination of food carbohydrates. Molecular, Nutrition \& Food Research. Vol. 21, nº 9, p. 835.

- Tabla de composición de alimentos de Centroamérica. 2007. INCAP. Ed. Menchú, M. y Méndez, H. 2da. Edición. ISBN: 99922-880-2-7. Guatemala.

- Wilson, R.G.; Smith, J.A.; Yonts, C.D. 2004. Chicory root yield and carbohydrate composition is influenced by cultivar, planting, and harvest date. Crop Science. Vol. 44, p. 748-752.

- Wills, R.; Lee, H.; McGlasson, B. y Graham, D. 1984. Fisiología y Manipulación de Frutas y Hortalizas Postrecolección. Editorial Acribia, Zaragoza, p. 230.

- Wills, R.; McGlasson, B.; Graham, D.; Joyce, D. 1999. Introducción a la fisiología y manipulación postcosecha de frutas, hortalizas y plantas ornamentales. Acribia, S.A. Zaragoza, p. 170. 
- Wrolstad, R. 2001. Color and Pigment Analyses in Fruit Products. Station Bulletin 624. Agricultural Experiment Station. Oregon State University, Corvallis, p. $1-17$.

- Zhishen, J.; Mengcheng, T. y Jianming, W. 1999. The determination of flavonoid contents in mulberry and their scavenging effects on superoxide radicals. Food Chemistry. Vol. 64, no. 4, p. 555-559. 


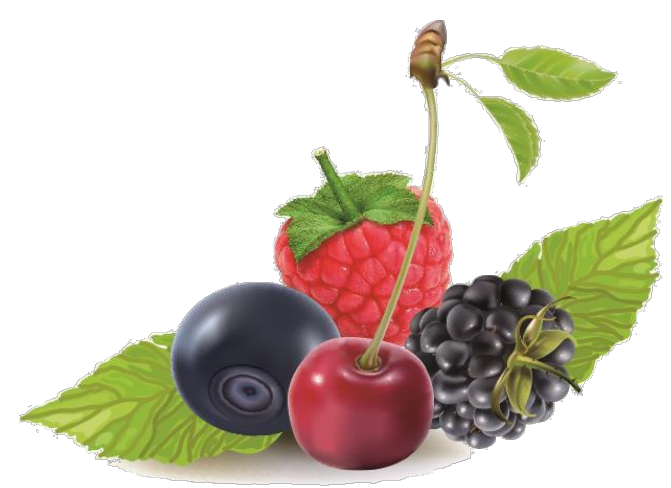

CAPITULO III

Efecto de los procesos tecnológicos sobre los compuestos bioactivos, el poder antirradicalario y el color superficial de las materias primas 


\section{III-1. INTRODUCCION}

La tendencia actual de los consumidores a adquirir alimentos con alta calidad, valor nutritivo y funcional está haciendo que las industrias de procesado desarrollen tecnologías capaces de combinar estas propiedades con la innegociable seguridad alimentaria.

Debido al carácter estacional de las frutas finas (de cultivo y silvestres) es importante determinar cómo los procesos tecnológicos afectan la concentración de los compuestos bioactivos, el poder antirradicalario y el color superficial para cada materia prima. Dentro de la denominación "compuestos bioactivos" se incluye a los fenoles totales, flavonoides, antocianinas y ácido ascórbico.

En muchos alimentos la esterilización, pasteurización, deshidratación, así como también el almacenamiento prolongado pueden traducirse en una pérdida importante de compuestos bioactivos (Jonsson, 1991), aunque no siempre son responsables de una disminución en las propiedades antioxidantes de los alimentos sino que en algunos casos, estos factores pueden inducir la formación de nuevos compuestos con estas propiedades, que mantienen o incluso aumentan el potencial antioxidante de los alimentos en general (Lerici y col., 1997; Nicoli y col., 1997a).

\section{III-1.1 Tratamientos térmicos}

El tratamiento térmico es la tecnología de proceso, que garantiza la seguridad microbiológica de los productos, más utilizada en la industria alimentaria. Se basa fundamentalmente en la generación de calor fuera del producto a calentar, por diversos métodos, y su transferencia al mismo a través de los mecanismos de conducción y convección (Pereira y Vicente, 2010).

De los tratamientos térmicos disponibles, se citan los utilizados en este trabajo: escaldado, pasteurización y deshidratación.

\section{III-1.1.1 Escaldado}

El escaldado, o sea la exposición de las piezas de fruta a altas temperaturas durante unos pocos minutos, es una operación de control crítica en el procesamiento de frutas autoestables. En métodos tradicionales de conservación, la función principal de este tratamiento es pasivar y/o destruir las enzimas que podrían deteriorar las hortalizas y las frutas. Pero en estas técnicas de procesamiento mínimo, el escaldado tiene también el importante rol de reducir la carga microbiana 
inicial mediante la inactivación de microorganismos sensibles al calor, remueve aromas y sabores indeseables, fija el color y ablanda la fruta para facilitar el pelado y el posterior pulpado de la fruta (Díaz de Tablante y col., 1993; Tapia y col., 1996). Las temperaturas utilizadas son letales para las levaduras, la mayoría de los hongos y los microorganismos aeróbicos. Así se ha encontrado que el escaldado reduce la carga microbiana entre un 60 y un 99 \% (Alzamora y col., 1995). Además este tratamiento tiene un efecto sensibilizante sobre los microorganismos sobrevivientes, los que se vuelven menos resistentes al estrés impuesto por la reducción de $\mathrm{pH}$ y de actividad del agua, y por la presencia de sorbatos, sulfitos $\mathrm{u}$ otros antimicrobianos. El escaldado puede realizarse en agua caliente, en ebullición o en vapor de agua saturado. Este último método es preferible, ya que permite la retención de propiedades nutricionales (principalmente vitaminas solubles en agua) y sensoriales (principalmente textura) (Vidales y col., 1998; Alzamora y col., 2000).

\section{III-1.1.2 Deshidratado}

La deshidratación de frutas y hortalizas es uno de los métodos más antiguos y más utilizados para su conservación, cuyo objetivo es eliminar agua de su composición hasta niveles que lo tornen estable en condiciones ambientales normales. Con el deshidratado se aumenta la vida de anaquel de los alimentos mediante la reducción de la actividad de agua, lo que inhibe el crecimiento microbiano y la actividad de las enzimas. La reducción del peso y volumen en el secado también reduce los costos de transporte y almacenamiento (Cao y col., 2003).

La calidad del producto puede ser fuertemente afectada por las condiciones de secado. Una temperatura elevada y un largo tiempo de proceso asociados pueden generar daño por calor $\mathrm{y}$, si ocurre, afectan negativamente las características organolépticas y el valor nutricional del producto (Vullioud y col., 2006).

Los cambios de color en los alimentos afectan la apariencia, y pueden ser un indicador de la pérdida de propiedades nutricionales y funcionales (Wrolstad y col. 2005). Las frutas deshidratadas se consideran altamente estables, sin embargo, sufren importantes modificaciones en las características cromáticas durante los procesos de secado, humidificación y almacenamiento (Uddin y col., 2002). En la tabla III-1 se muestran los principales factores que aportan a los cambios de color durante el secado convectivo: el contenido de pigmentos, las reacciones de Maillard 
y el pardeamiento enzimático (Marty-Audouin y col., 1999). Además, también juegan un rol importante durante el procesamiento la temperatura de secado y el $\mathrm{pH}$.

Tabla III-1. Factores que contribuyen a cambios de color durante el secado

\begin{tabular}{|c|c|c|}
\hline Componente & Compuestos & Efecto de la deshidratación \\
\hline \multirow{4}{*}{ Pigmentos Naturales } & Clorofila & $\begin{array}{l}\text { Cambia del color verde al amarillo o } \\
\text { rojo }\end{array}$ \\
\hline & Carotenoides & Oxidación de carotenoides \\
\hline & Antocianinas & Estable a bajos valores de $\mathrm{pH}$ \\
\hline & Betalainas & $\begin{array}{l}\text { Muy sensible al } \mathrm{pH} \text {, se degradan a } \\
\text { pigmentos marrones a } \mathrm{pH} \text { neutro }\end{array}$ \\
\hline \multicolumn{3}{|c|}{ Reacciones } \\
\hline Maillard & $\begin{array}{l}\text { Azúcares } \\
\text { reductores, } \\
\text { aminoácidos, } \\
\text { proteínas }\end{array}$ & $\begin{array}{l}\text { Formación de pigmentos de color } \\
\text { marrón o negro, melanoidinas y otros } \\
\text { compuestos aromáticos }\end{array}$ \\
\hline Pardeamiento enzimático & $\begin{array}{l}\text { Compuestos } \\
\text { fenólicos }\end{array}$ & $\begin{array}{l}\text { Transformación de compuestos } \\
\text { fenólicos a polímeros de color negro o } \\
\text { marrón }\end{array}$ \\
\hline
\end{tabular}

Fuente: Hii y Law, 2010.

\section{III-1.1.3 Pasteurizado}

Consiste en la aplicación de un tratamiento térmico relativamente suave (temperaturas generalmente iguales o inferiores a $100{ }^{\circ} \mathrm{C}$ ), pero suficiente para eliminar los microorganismos productores de enfermedades, presentes en los alimentos. La pasteurización inactiva la mayor parte de las formas vegetativas de los microorganismos, pero no sus formas esporuladas, por lo que constituye un proceso adecuado para la conservación a corto tiempo. Además, ayuda a la inactivación de las enzimas que pueden causar deterioro en los alimentos. (Mafarf, 1994; Ordoñez y col., 1998) 


\section{III-1.1.4 Tratamientos térmicos y propiedades antioxidantes}

Los alimentos pueden ser objeto de algunos cambios químicos durante el tratamiento térmico. Uno de ellos es el pardeamiento no enzimático que incluye los fenómenos de caramelización, degradación de ácido ascórbico o de polifenoles oxidados y/o la interacción de proteínas o aminas con hidratos de carbono; esta última es denominada reacción de Maillard (Fennema, 2010). Lo que caracteriza a estas reacciones, es que en todas ellas intervienen grupos carbonilo llamados "activos" provenientes principalmente de azúcares reductores. Son muchos los factores que afectan a las reacciones de pardeamiento no enzimático. Un aumento de la temperatura tiene un efecto acelerador sobre la formación de color. Esto se debe a que el calor favorece cada una de las etapas de la reacción. Un factor importante a tener en cuenta es que la temperatura además tiene efecto sobre otras reacciones paralelas a las de pardeamiento, en las que se pueden generar grupos reactivos que participan en las reacciones de formación de color.

El desarrollo de la reacción de Maillard en condiciones de acidez y/o altas temperaturas conduce a la degradación de los azucares y luego a la formación de productos intermedios como furfural y HMF (5-hidroximetil-furfural) (Pérez-Locas y Yaylayan, 2010). El furfural se condensa fácilmente con las antocianinas, formando compuestos poliméricos pardos. Esta reacción es muy dependiente de la temperatura y se acelera por la presencia de oxígeno (Fennema, 2010; Es-Safi y col., 2003). Se cree que los productos de la reacción de Maillard (PRM) actúan como antioxidantes. Por lo tanto, las pérdidas de los antioxidantes naturales durante el calentamiento podrían ser minimizadas o compensadas por la formación de los PRM (Manzocco y col., 2001; Nicoli y col., 1997b).

Las propiedades antioxidantes de los PRM son fuertemente afectadas por las características físico-químicas de los sistemas y por las condiciones de procesamiento. Sustancias como fenoles, ácido ascórbico, otros compuestos carbonilos, (aunque se formen en las reacciones oxidativas) también pueden tomar parte en la reacción de Maillard (Manzocco y col., 2001).

El pardeamiento no enzimático prevalece en las etapas posteriores de la elaboración de alimentos, en el almacenamiento y envejecimiento de los productos derivados de frutas (Es-Safi y col., 2003).

El objetivo de este capítulo fue el estudio del efecto de los procesos tecnológicos sobre los compuestos bioactivos (fenoles totales, flavonoides, 
antocianinas, ácido ascórbico), el poder antirradicalario y el color superficial de las materias primas relacionadas con la estabilidad funcional de las frutas finas.

\section{III-2. MATERIALES Y MÉTODOS}

Las frutas fueron cosechadas por productores de la zona de la Comarca Andina del Paralelo 42, en su punto de madurez óptimo, y enviadas inmediatamente a Villa Regina, donde se conservaron en heladera a $5^{\circ} \mathrm{C}$ hasta su utilización.

Se realizó un muestreo aleatorio simple, se descartaron aquellos frutos que presentaban síntomas de avanzado estado de madurez.

Las variedades utilizadas fueron: frambuesa var. Tulameen, zarzamora var. Thornfree, guindas var. Montmorency, arándanos var. Elliot, cassis var. Silvergrietten y Rosa Mosqueta silvestre var. Rosa eglanteria.

Para las determinaciones en fresco los frutos se cortaron con ayuda de un bisturí. Los extractos y las determinaciones se realizaron por triplicado

\section{III-2.1 Procesos}

Los frutos frescos fueron sometidos a las siguientes operaciones y procesos:

\section{III-2.1.1 Pulpado}

Aplicado a frambuesa, zarzamora y arándano. Las frutas se pulparon mediante batidora de inmersión (fotografías III-1 y III-2) en condiciones de presión y temperatura atmosféricas (en presencia de luz y oxígeno) conservándose a $-18^{\circ} \mathrm{C}$ hasta su utilización.

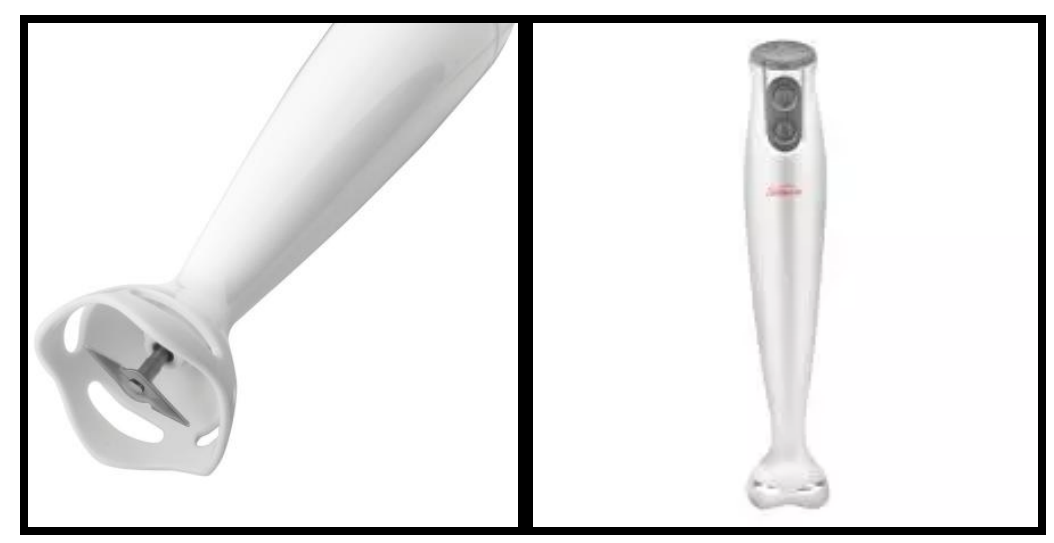

Fotografías III-1 y III-2. Batidora de inmersión utilizada para pulpar las frutas frescas 
En el caso de guinda el pulpado de la matriz fresca no se realizó, ya que se contaba con información previa recopilada por nuestro grupo de investigación, respecto al pronto pardeamiento de la pulpa, lo cual genera cambios desfavorables en el color superficial. Esta matriz solamente se trabajó escaldada (Ochoa, 2011).

\section{III-2.1.2 Escaldado-pulpado}

Se aplicó a guinda y arándano y se siguió la metodología reportada por Ochoa (2011). Antes de realizar la operación de pulpado, se tomaron 200 gramos de fruta fresca entera y se sumergieron en $600 \mathrm{ml}$ de agua hirviendo $\left(98^{\circ} \mathrm{C}\right)$ por 2 minutos (fotografías III-3 y III-4), cumplido el tiempo se enfriaron sumergiéndolas en agua helada y se secaron con papel absorbente. El escaldado no se aplicó en todas las matrices disponibles ya que las pertenecientes al género Rubus (frambuesa y zarzamora) presentan alta sensibilidad en el manejo en fresco, por lo que la aplicación de un proceso de estas características produciría un gran deterioro.

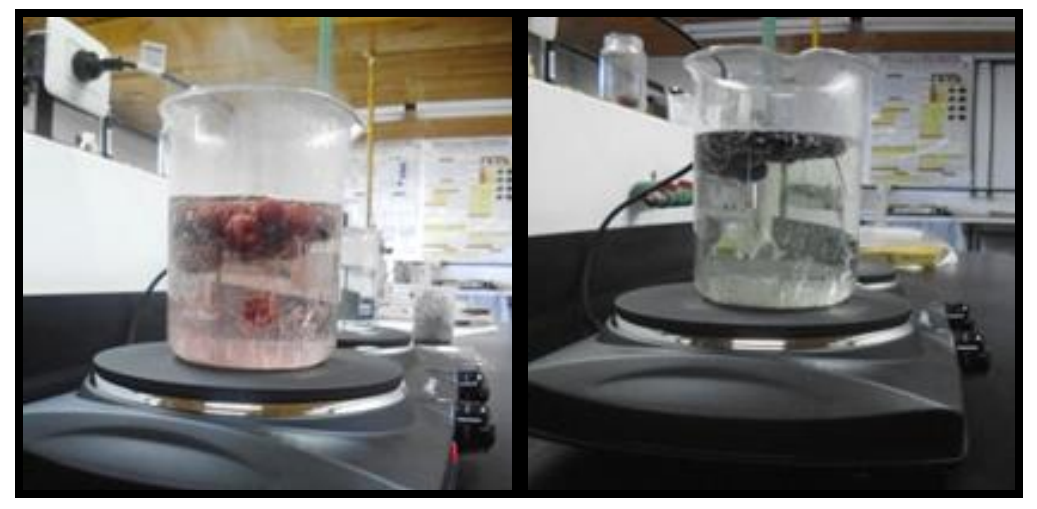

Fotografías III-3 y III-4. Proceso de escaldado de guinda y arándano

\section{III-2.1.3 Pasteurizado}

Las pulpas resultantes (frambuesa, zarzamora, arándano sin escaldar y escaldado, guinda escaldada) se envasaron en viales de vidrio, sellados con precintos metálicos y se pasteurizaron en baño termostatizado marca Thermo Scientific a $98^{\circ} \mathrm{C}$ durante 10 minutos. Se escogió este par temperatura-tiempo ya que, la enzima peroxidasa (la cual puede estar presente en las matrices analizadas) es termorresistente y se la involucra en la degradación de flavonoides (Schreier y Miller, 1985). Luego del tratamiento térmico, se dejaron enfriar los viales sobre mesada a temperatura ambiente (fotografía III-5). 


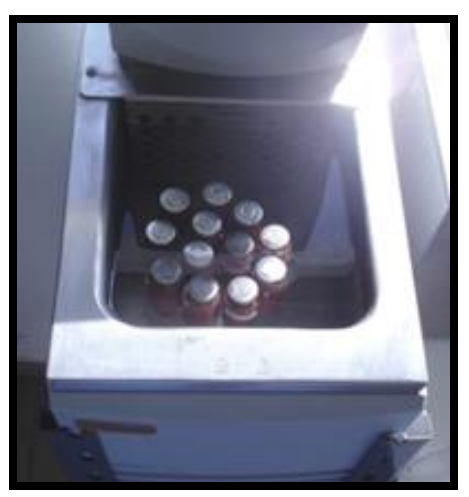

Fotografía III-5. Proceso de pasteurización de las pulpas

\section{III-2.1.4 Deshidratado}

Aplicado a frutos frescos de rosa mosqueta y cassis. En el caso de la rosa mosqueta, se realizaron tres punciones ecuatoriales en la superficie de los frutos (Ohaco Dominguez, 2012) antes de someterlos al secado. Los frutos de rosa mosqueta y casis se colocaron en un secadero piloto con circulación de aire caliente (esquema III-1) a temperatura constante de $70^{\circ} \mathrm{C}$ y velocidad de aire de $3 \mathrm{~m} / \mathrm{s}$, hasta una humedad final de $9 \%$ para rosa mosqueta y $12 \%$ para cassis. Una vez deshidratados, los frutos fueron pulverizados mediante un molinillo marca CoolBrand, y se homogeneizó el tamaño del polvo obtenido con un tamiz de 18 mesh. 


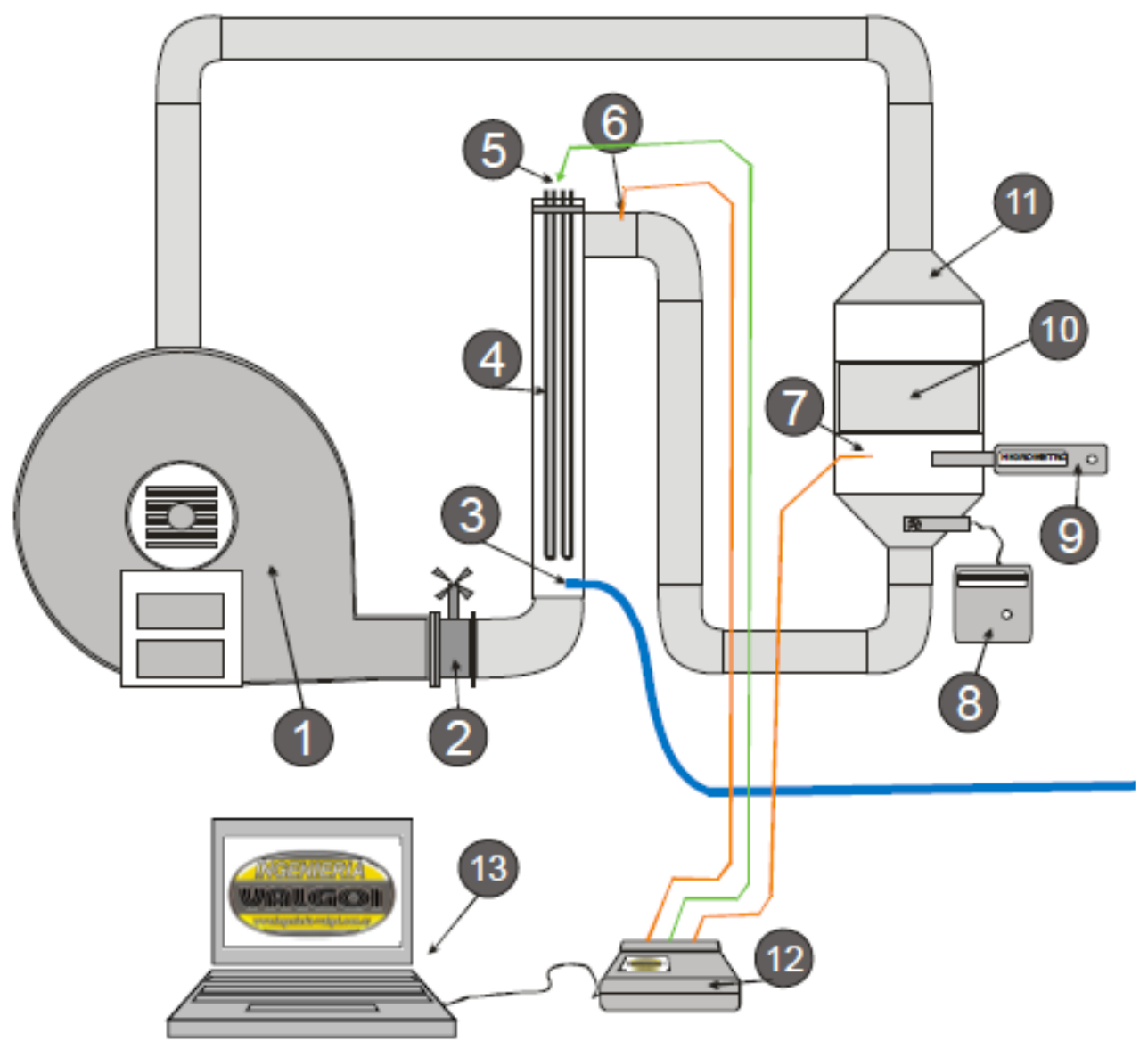

Esquema III-1. Equipo experimental de secado. 1: Ventilador; 2: Regulador de velocidad del aire; 3 : Circuito de humectación del aire; cámara de secado; 4: Intercambiador de calor eléctrico; 5: Circuito eléctrico regulador de la potencia de calefacción eléctrica; 6 : Sensor de temperatura de bulbo seco del aire; 7: Sensor de temperatura de bulbo seco del aire a la entrada de la bandeja de portamuestra; 8: Anemómetro; 9: Higrómetro; 10: Dispositivo porta-bandeja con muestra a secar; 11: Cámara de secado; 12: Controlador automático de temperatura del aire de secado y 13: Equipo de recepción de datos. Fuente: Ohaco Dominguez (2012)

\section{III-2.2 Determinaciones}

- Extracción de compuestos bioactivos. Se realizó según la metodología explicada en el Capítulo I, sección I-2.1; utilizando como solvente de extracción solución al $1 \%$ de $\mathrm{HCl}$ en etanol y temperatura de $37^{\circ} \mathrm{C}$.

- Fenoles totales (FT). Se realizó según la metodología explicada en el Capítulo I, sección I-2.1.

- Flavonoides (Fv). Se realizó según la metodología explicada en el Capítulo I, sección I-2.1.

- Poder Antirradical (PA). Se realizó según la metodología explicada en el Capítulo I, sección I-2.1. 
- Antocianinas (ACY). Se realizó según la metodología explicada en el Capítulo I, sección I-2.1.

- Porcentaje de Color Polimérico (\% CP). Se determinó utilizando el método del bisulfito (Giusti y Wrolstad, 2005). Las muestras blanqueadas con bisulfito se obtuvieron mediante la adición de 0,2 $\mathrm{ml}$ de una solución al $20 \%$ de metabisulfito de potasio a $2,8 \mathrm{ml}$ de cada extracto. Las muestras control se obtuvieron mediante la adición de agua en lugar de la solución de metabisulfito de potasio. Las lecturas de absorbancia de ambas muestras (control y blanqueadas) se realizaron a $420 \mathrm{~nm}(\lambda$ de detección de compuestos pardos) y a $510 \mathrm{~nm}$ ( $\lambda$ máxima de la antocianina). También se realizaron lecturas de absorbancia a $700 \mathrm{~nm}$ para corregir la turbidez por lo que dichos valores fueron sustraídos. Se utilizó un espectrofotómetro UV/Vis, modelo 1700. El porcentaje de color polimérico ( $\% \mathrm{CP}$ ) es un indicador de la presencia de pigmentos polimerizados; incluye a los complejos taninos-antocianinas y los compuestos pardos.

- Índice de degradación de antocianinas (IDA). Se determinó siguiendo el procedimiento propuesto por Fuleki y Francis (1968). El índice de degradación es indicativo de la proporción de antocianinas degradadas en la muestra. Consiste en hacer el cociente entre el contenido de antocianinas totales (degradadas y no degradadas) calculadas por el método de $\mathrm{pH}$ simple (absorbancia medida a $\mathrm{pH}$ 1) y el contenido de antocianinas monoméricas (no degradadas) utilizando el método de $\mathrm{pH}$ diferencial.

- Ácido Ascórbico Total (AA). Se realizó según la metodología explicada en el Capítulo II, sección II-2.1.

- Color superficial. Se realizó según la metodología explicada en el Capítulo II, sección II-2.1.

En el caso puntual de la determinación de fenoles totales en productos que contengan alta concentración de ácido ascórbico (ver anexo), como la rosa mosqueta y el cassis, se utilizó la sal de diazonio Fast Blue BB, ya que FolinCiocolteau presenta alta respuesta a las concentraciones de ácido ascórbico (antioxidante no fenólico).

- Fenoles Totales por Fast Blue: Se utilizó el método descripto por Medina (2011) con algunas modificaciones. Se transfirieron $2 \mathrm{ml}$ de extracto a un tubo de ensayo, y en él se adicionaron: una alícuota de $200 \mu \mathrm{l}$ de solución al $1 \%$ de reactivo de Fast Blue BB en metanol, y $200 \mu \mathrm{l}$ de $\mathrm{NaOH}$ al 5\%. Luego de 60 minutos de 
incubación en oscuridad a temperatura ambiente, se procedió a realizar la lectura de absorbancia a $420 \mathrm{~nm}$ con un espectrofotómetro Shimadzu UV-1800. Para la curva de calibrado se utilizó el mismo estándar externo que en la determinación de fenoles por Folin Ciocalteu (ácido gálico p.a. Biopack). Los resultados finales se expresaron como mg Ácido Gálico equivalente/100g producto.

\section{III-2.3 Análisis Estadístico}

Para evaluar el efecto del proceso sobre los fenoles totales, flavonoides, ácido ascórbico, antocianinas monoméricas, poder antirradicalario y color superficial, se aplicó un diseño completamente aleatorizado. Los resultados se analizaron mediante análisis de varianza (ANOVA) para un nivel de significancia $\alpha=0,05$ y se empleó la prueba de DGC (Di Rienzo, Guzmán, Casanoves) para la comparación de medias. Se utilizó el programa estadístico Infostat v. 2012. (Di Rienzo y col., 2012).

\section{III-3. RESULTADOS Y DISCUSIÓN}

\section{III-3.1 Efecto de los procesos: pulpado, escaldado y pasteurizado}

\section{III-3.1.1 Fenoles totales, flavonoides y poder antirradicalario}

Diversos estudios realizados sobre berries y cherries han demostrado que los diferentes procesos aplicados pueden afectar la calidad nutricional y funcional en este tipo de alimentos, lo que se refleja en cambios en las concentraciones de fitoquímicos específicos (fenoles, flavonoides, antocianinas, etc.). En esta sección se analiza la retención de compuestos bioactivos y del poder antirradicalario luego de la aplicación de los diferentes tratamientos. En la tabla III-2 se puede observar el efecto de los procesos sobre los FT, Fv y PA de zarzamora.

Tabla III-2. Efecto de los procesos sobre los FT, Fv y PA de zarzamora

\begin{tabular}{|l|ccc|}
\hline & FT & Fv & PA \\
\hline Fresco & $301 \pm 7^{\mathrm{B}}$ & $65 \pm 1^{\mathrm{b}}$ & $1,75 \pm 0,01^{\mathrm{B}^{*}}$ \\
Pulpado & $284 \pm 1^{\mathrm{B}}$ & $60 \pm 2^{\mathrm{b}}$ & $1,67 \pm 0,02 \mathrm{C}^{*}$ \\
Pasteurizado & $377 \pm 15^{\mathrm{A}}$ & $77 \pm 4^{\mathrm{a}}$ & $1,84 \pm 0,02 \mathrm{~A}^{\mathrm{A}^{*}}$ \\
\hline
\end{tabular}

FT: fenoles totales (mg GAE/100 g), Fv: flavonoides (mg CE/100 g), PA: poder antirradical $\left(\mathrm{mg}^{-1}\right)$. Los valores representan la media $(n=3) \pm S D$. Medias con una letra común por columna no son significativamente diferentes $(p \leq 0,05)$ 
Por la aplicación del proceso de pulpado se registró una disminución en el PA del $5 \%$. No se hallaron diferencias significativas $(p \leq 0,05)$ para FT y Fv. La aplicación del proceso de pasteurizado genera un aumento en la concentración de los principios activos en la pulpa: $33 \%$ FT, $28 \%$ Fv y $10 \%$ PA.

En la tabla III-3 se puede observar el efecto de los procesos sobre los FT, Fv y PA de frambuesa.

Tabla III-3. Efecto de los procesos sobre los FT, Fv y PA de frambuesa

\begin{tabular}{|l|ccc|}
\hline & FT & Fv & PA \\
\hline Fresco & $188 \pm 3^{\mathrm{B}}$ & $35 \pm 1^{\mathrm{a}}$ & $1,65 \pm 0,01^{\mathrm{A}^{*}}$ \\
Pulpado & $173 \pm 3^{\mathrm{C}}$ & $31 \pm 2^{\mathrm{b}}$ & $1,33 \pm 0,01^{\mathrm{B}^{*}}$ \\
Pasteurizado & $210 \pm 10^{\mathrm{A}}$ & $37 \pm 1^{\mathrm{a}}$ & $1,70 \pm 0,04^{\mathrm{A}^{*}}$ \\
\hline
\end{tabular}

FT: fenoles totales (mg GAE/100 g), Fv: flavonoides (mg CE/100 g), PA: poder antirradical $\left(\mathrm{mg}^{-1}\right)$. Los valores representan la media $(n=3) \pm S D$. Medias con una letra común por columna no son significativamente diferentes $(p \leq 0,05)$

Nuevamente se registran diferencias significativas $(p \leq 0,05)$ por la aplicación del proceso pulpado. Las pérdidas para FT fueron del $8 \%$, mientras que flavonoides y poder antirradical fueron las variables más afectadas, con un 11 y 19\% respectivamente. Del análisis de los valores para pulpa pasteurizada se desprende un aumento del $21 \%$ para FT, $19 \%$ para Fv y $28 \%$ para PA, en referencia al pulpado, pero no se presentan diferencias significativas $(p \leq 0,05)$ en el contenido de Fv y PA respecto a la matriz fresca.

En la tabla III-4 se puede observar el efecto de la aplicación de distintos procesos sobre los FT, Fv y PA de arándano sin escaldar. 
Tabla III-4. Efecto de los procesos sobre los FT, Fv y PA de arándano sin escaldar

\begin{tabular}{|l|ccc|}
\hline & FT & Fv & PA \\
\hline Fresco & $506 \pm 29^{\mathrm{A}}$ & $204 \pm 9^{\mathrm{a}}$ & $2,59 \pm 0,12^{\mathrm{A}^{*}}$ \\
Pulpado & $436 \pm 9^{\mathrm{B}}$ & $179 \pm 2^{\mathrm{b}}$ & $2,00 \pm 0,06^{\mathrm{B}^{*}}$ \\
Pasteurizado & $465 \pm 3^{\mathrm{B}}$ & $193 \pm 2^{\mathrm{a}}$ & $1,99 \pm 0,09^{\mathrm{B}^{*}}$ \\
\hline
\end{tabular}

FT: fenoles totales (mg GAE/100 g), Fv: flavonoides (mg CE/100 g), PA: poder antirradical $\left(\mathrm{mg}^{-1}\right)$. Los valores representan la media $(n=3) \pm S D$. Medias con una letra común por columna no son significativamente diferentes $(p \leq 0,05)$

En este caso, por la aplicación del proceso de pulpado, se registraron las mayores pérdidas, $14 \%$ para FT, $12 \%$ en el caso de Fv y finalmente $23 \%$ para PA. El pasteurizado incrementó un $8 \%$ la concentración de Fv en la pulpa, llevando la concentración nuevamente a los valores que presentó la matriz fresca, pero no presenta diferencias significativas $(p \leq 0,05)$ en el contenido de FT y PA de la pulpa.

Durante el proceso de pulpado, en general, las matrices presentaron una disminución en los parámetros, debido a la oxidación por efecto de la incorporación de aire en la pulpa, lo que constituye un serio inconveniente en el procesamiento de frutas (Cheftel y col., 1980; Camacho y Sanabria, 2005).

Kalt y col. (2000) registraron el efecto de la introducción de oxígeno en muestras de zumo de arándano sin pasteurizar. Las muestras fueron colocadas en viales, completamente llenos y hasta la mitad, y luego sacudidas. En los viales que tenían poco espacio de cabeza que contenía oxígeno, no hubo pérdidas significativas en el contenido fenólico total y la capacidad antioxidante después de 6 horas, mientras que en los de mayor espacio de cabeza, se registraron disminuciones del $30 \%$ y $46 \%$, respectivamente, durante el mismo período. El oxígeno ha sido reportado como un factor importante en la desestabilización de los compuestos bioactivos en los productos procesados (Francis y Markakis, 1989).

Las tres frutas sin escaldar, frambuesa, zarzamora y arándano, presentaron un incremento en los FT, Fv y PA frente a la condición de pasteurizado en respuesta a un aumento en la extractabilidad debido al factor temperatura y a la inhibición de las 
enzimas oxidativas nativas de las matrices (Peleg y col., 1991; Nicoli y col., 2004; Kalt y col. 2000; Dewanto y col., 2002; Jeong y col. 2004).

El incremento del poder antirradicalario podría deberse a la generación y acumulación de antioxidantes del tipo Maillard. Se ha reportado que los compuestos derivados de la reacción de Maillard presentan distintos grados de actividad antioxidante dependiendo de su origen (Kim y col., 1986), lo que ha sido comprobado no sólo en sistemas modelo, sino también en alimentos (Wijewickreme y col., 1999; Anese y col., 1999).

La condensación de los productos de la oxidación de los polifenoles determina la formación de procianidinas con estructuras aromáticas más grandes y mayor capacidad antioxidante (Nicoli y col., 2000). Además, el hecho de que los polifenoles poliméricos sean más potentes como antioxidantes que los monómericos (Moure y col., 2001), podría explicar la mayor actividad antiradicalaria de las frutas en estas condiciones.

En el caso de guinda primero se realizó un escaldado de la fruta entera y posteriormente se aplicaron los procesos de pulpado y pasteurización, los valores hallados se muestran en la tabla III-5.

Tabla III-5. Efecto del pulpado y pasteurizado sobre los FT, Fv y PA de guinda escaldada

\begin{tabular}{|l|ccc|}
\hline & FT & Fv & PA \\
\hline Fresco & $500 \pm 13^{\mathrm{B}}$ & $342 \pm 5^{\mathrm{b}}$ & $0,73 \pm 0,05^{\mathrm{B}^{*}}$ \\
Esc. + Pulp. & $573 \pm 21^{\mathrm{A}}$ & $353 \pm 1^{\mathrm{a}}$ & $1,13 \pm 0,02^{\mathrm{A}^{*}}$ \\
Esc. + Pulp. + Past. & $554 \pm 33^{\mathrm{A}}$ & $356 \pm 2^{\mathrm{a}}$ & $1,05 \pm 0,06^{\mathrm{A}^{*}}$ \\
\hline
\end{tabular}

FT: fenoles totales (mg GAE/100 g), Fv: flavonoides (mg CE/100 g), PA: poder antirradical $\left(\mathrm{mg}^{-1}\right)$. Esc.: escaldado, Pulp.: pulpado, Past.: pauteurizado Los valores representan la media $(n=3) \pm S D$. Medias con una letra común por columna no son significativamente diferentes $(p \leq$ $0,05)$

La pulpa de guinda escaldada presentó un incremento del $15 \%$ en FT y $55 \%$ en PA frente a la condición de fresco. La aplicación del proceso de pasteurizado no 
genero diferencias significativas $(p \leq 0,05)$ respecto a los valores hallados para FT, Fv y PA de la pulpa escaldada.

En la tabla III-6 se presentan los resultados para arándano, pero en este caso realizando un escaldado de los frutos frescos previo al pulpado.

Tabla III-6. Efecto del pulpado y pasteurizado sobre los FT, Fv y PA de arándano escaldado

\begin{tabular}{|l|ccc|}
\hline & FT & Fv & PA \\
\hline Fresco & $506 \pm 29^{\mathrm{B}}$ & $204 \pm 9^{\mathrm{a}}$ & $2,79 \pm 0,12^{\mathrm{A}^{*}}$ \\
Esc. + Pulp. & $580 \pm 18^{\mathrm{A}}$ & $222 \pm 3^{\mathrm{a}}$ & $2,86 \pm 0,03^{\mathrm{A}^{*}}$ \\
Esc. + Pulp. + Past. & $591 \pm 5^{\mathrm{A}}$ & $217 \pm 8^{\mathrm{a}}$ & $2,74 \pm 0,08^{\mathrm{A}^{*}}$ \\
\hline
\end{tabular}

FT: fenoles totales (mg GAE/100 g), Fv: flavonoides (mg CE/100 g), PA: poder antirradical $\left(\mathrm{mg}^{-1}\right)$. Esc.: escaldado, Pulp.: pulpado, Past.: pauteurizado Los valores representan la media $(n=3) \pm S D$. Medias con una letra común por columna no son significativamente diferentes $(p \leq 0,05)$

La pulpa de arándano escaldado, al igual que guinda, presentó un aumento del $15 \%$ en la concentración de FT. No se hallaron diferencias significativas $(p \leq 0,05)$ en Fv ni en PA por la aplicación del proceso de escaldado. La pulpa escaldada pasteurizada tampoco presentó diferencias significativas $(p \leq 0,05)$ en ninguna de las variables cuantificadas respecto a la pulpa escaldada.

En el caso del escaldado previo, puedo observarse el efecto beneficioso del pretratamiento sobre ambas matrices, ya que permitió incrementar los valores de FT, Fv y PA. Esto se atribuye a la inactivación de enzimas oxidativas nativas en la fruta (Skrede y col., 2000) y además a que los tratamientos térmicos mejoran la permeabilidad de las células pigmentadas del pericarpio (Brambilla y col. 2008), produciendo cambios en la extractabilidad, liberando con mayor facilidad compuestos polifenólicos y flavonoides en relación a los de las materias primas originales (Peleg y col., 1991 y Kalt y col. 2000).

Al haber aplicado previamente un proceso que involucra altas temperaturas, el efecto del pasteurizado no fue tan marcado en arándano escaldado como en aquel donde no se aplicó el pretratamiento. 
El mayor contenido en los parámetros evaluados en fresco lo obtuvo el arándano, seguido por la guinda, la zarzamora y finalmente la frambuesa.

\section{III-3.1.2 Contenido de pigmentos}

En berries y cherries, las antocianinas monoméricas son, en gran medida, los pigmentos responsables del color observado y dependiendo de las condiciones de proceso aplicadas, pueden reaccionar con otros compuestos, degradarse, o polimerizarse, conduciendo a distintas variaciones en las tonalidades e intensidades del color observado.

En la tabla III-7 se muestra el contenido de antocianinas monoméricas, porcentaje de color polimérico e índice de degradación de antocianinas (IDA) en zarzamora.

El IDA propuesto por Fuleki y Francis (1968), indica la proporción de antocianinas degradadas en la muestra, basándose en el principio de que las mediciones obtenidas a pH 1,0 incluyen la absorción debida a los productos degradadados y no degradados, mientras que la diferencia en la absorción entre el $\mathrm{pH} 1,0$ y 4,5 se deberá únicamente a las antocianinas no degradadas.

Tabla III-7. Efecto de los procesos sobre la concentración de antocianinas monoméricas y \% de color polimérico en zarzamora

\begin{tabular}{|l|ccc|}
\hline & ACY & $\%$ CP & IDA \\
\hline Fresco & $182 \pm 4^{\mathrm{A}}$ & $2 \pm 0^{\mathrm{C}}$ & $1,05 \pm 0,02^{\mathrm{C}^{*}}$ \\
Pulpado & $162 \pm 6^{\mathrm{B}}$ & $5 \pm 1^{\mathrm{b}}$ & $1,13 \pm 0,01^{\mathrm{B}^{*}}$ \\
Pasteurizado & $133 \pm 4^{\mathrm{C}}$ & $16 \pm 1^{\mathrm{a}}$ & $1,21 \pm 0,01^{\mathrm{A}^{*}}$ \\
\hline
\end{tabular}

ACY: antocianinas monoméricas ( $\mathrm{mg}$ cianidina-3-glu/100 g), \%CP: porcentaje de color polimérico, IDA: índice de degradación de antocianinas. Los valores representan la media $(n=3)$ \pm SD. Medias con una letra común por columna no son significativamente diferentes $(p \leq 0,05)$

Ambos procesos redujeron el contenido de antocianinas monoméricas, $11 \%$ en el caso del pulpado y $27 \%$ para la operación pasteurizado.

El IDA junto al porcentaje de color polimérico \%CP son parámetros que representan la degradación de los pigmentos antociánicos. El \%CP indica cuanto del color percibido se debe a los compuestos derivados de las antocianinas. Las 
antocianinas poliméricas no sufren un cambio reversible de color con el cambio de $\mathrm{pH}$ y no se pueden combinar con el bisulfito para formar un aducto de ácido sulfónico incoloro, debido a que el carbono de la posición 4 de la molécula de antocianina no está disponible, por encontrarse unido covalentemente a otro compuesto fenólico (Wrolstad y col., 2005). En este caso, ambos procesos elevaron el \%CP: 2,5 veces en el pulpado y 8 veces en el pasteurizado. El valor del IDA, en la muestra fresca, fue mayor que 1 lo que hace suponer que ocurrió una degradación durante la preparación de la muestra o en la etapa de extracción de pigmentos (quizás debida a la presencia de oxígeno durante la molienda de la fruta). Se hallaron diferencias estadísticas significativas $(p \leq 0,05)$ entre los valores de IDA para la condiciones fresco, pulpado y pasteurizado; siendo mayor la degradación durante este último proceso.

En el caso de frambuesa, los valores se presentan en la tabla III-8. La tendencia para ambas variables respeta el patrón marcado para zarzamora (descenso de la concentración de ACY y aumento de \% CP).

Tabla III-8. Efecto de los procesos sobre la concentración de antocianinas monoméricas y \% de color polimérico en frambuesa

\begin{tabular}{|l|ccc|}
\hline & ACY & $\%$ CP & IDA \\
\hline Fresco & $46 \pm 3^{\mathrm{A}}$ & $15 \pm 1^{\mathrm{C}}$ & $1,20 \pm 0,02^{\mathrm{C}^{*}}$ \\
Pulpado & $40 \pm 2^{\mathrm{B}}$ & $22 \pm 3^{\mathrm{b}}$ & $1,27 \pm 0,02^{\mathrm{B}^{*}}$ \\
Pasteurizado & $34 \pm 1^{\mathrm{C}}$ & $36 \pm 2^{\mathrm{a}}$ & $1,38 \pm 0,02^{\mathrm{A}^{*}}$ \\
\hline
\end{tabular}

ACY: antocianinas monoméricas (mg cianidina-3-glu/100 g), \%CP: porcentaje de color polimérico, IDA: índice de degradación de antocianinas. Los valores representan la media $(n=3)$ \pm SD. Medias con una letra común por columna no son significativamente diferentes $(p \leq 0,05)$

Las antocianinas monoméricas sufrieron una degradación del $13 \%$ y $26 \%$ debido a la aplicación de los procesos de pulpado y pasteurizado respectivamente. Además se notó un aumento en el \%CP de 2,4 veces al final del pasteurizado. El IDA nuevamente dio superior a 1 para la frambuesa fresca y se incrementó un 6 y 15\% en el pulpado y pasteurizado respectivamente. 
Para arándano sin escaldado previo, la pérdida de antocianinas monoméricas fue aún mayor, reportando un $26 \%$ de pérdida en el pulpado y un $35 \%$ en el pasteurizado, valores que se desprenden de los datos que se presentan en la tabla III-9.

Tabla III-9. Efecto de los procesos sobre la concentración de antocianinas monoméricas y \% de color polimérico en arándano sin escaldar

\begin{tabular}{|l|ccc|}
\hline & ACY & $\%$ CP & IDA \\
\hline Fresco & $150 \pm 4^{\mathrm{A}}$ & $4 \pm 1^{\mathrm{b}}$ & $1,01 \pm 0,01^{\mathrm{C}}$ \\
Pulpado & $111 \pm 3^{\mathrm{B}}$ & $10 \pm 2^{\mathrm{a}}$ & $1,12 \pm 0,01^{\mathrm{B}^{*}}$ \\
Pasteurizado & $98 \pm 4^{\mathrm{C}}$ & $13 \pm 4^{\mathrm{a}}$ & $1,16 \pm 0,01^{\mathrm{A}^{*}}$ \\
\hline
\end{tabular}

ACY: antocianinas monoméricas ( $\mathrm{mg}$ cianidina-3-glu/100 g), \%CP: porcentaje de color polimérico, IDA: índice de degradación de antocianinas. Los valores representan la media $(n=3)$ $\pm S D$. Medias con una letra común por columna no son significativamente diferentes $(p \leq 0,05)$

El porcentaje de color polimérico se incrementó 2,5 veces en el pulpado y 3,2 en el pasteurizado, aunque no se hallaron diferencias estadísticas entre ambas condiciones $(p \leq 0,05)$. El valor del IDA para la fruta fresca indicó que no había pigmentos degradados, pero luego del pulpado y pasteurizado se incrementó un 12 y $15 \%$ respectivamente.

En general, las tres matrices presentaron una disminución en las ACY por efecto del pulpado. El oxígeno desempeña un papel vital en los procesos de degradación de las antocianinas. Su presencia puede acelerar la degradación ya sea a través de un mecanismo oxidativo directo y/o a través de la acción de enzimas oxidantes (Jackman y col., 1987; Fennema, 2010). En presencia de oxígeno, enzimas tales como polifenoloxidasas catalizan la oxidación del ácido clorogénico en la correspondiente o-quinona (clorogenoquinona). Esta quinona reacciona con antocianinas para formar productos de condensación marrones (Kader y col., 1999). Estos mismos autores propusieron, al trabajar con soluciones modelo de sustratos purificados, que la cianidina-3-glucosido (antocianina orto-difenólica mayoritaria en zarzamora) se degrada por un mecanismo de oxidación acoplado, involucrando a la o-quinona generada enzimáticamente con regeneración parcial del co-sustrato odifenólico (el ácido clorogénico). Estas observaciones confirman que la PPO juega 
un rol fundamental en la degradación de las ACY (Kader y col., 1997; WescheEbeling y Montgomery, 1990; Skrede y col., 2000).

En muestras de jugo de arándano sin pasteurizar analizadas por Kalt y col. (2000) el efecto de la introducción de oxígeno generó una disminución del $76 \%$ de las ACY.

Según Patras y col. (2010), el calor es un factor que puede acelerar la destrucción de los pigmentos antociánicos, lo cual ha sido corroborado en el presente trabajo, donde, durante el proceso térmico de pasteurización e independientemente de la matriz, se han registrado mayores pérdidas de ACY en comparación con aquellos procesos que no involucran aumento de temperatura.

Se observó un deterioro de ACY causado por el tratamiento térmico que llevó a la transformación de ACY monoméricas en poliméricas con el consecuente aumento del \% CP. Se evidenció que la pulpa de arándano sin escaldar es más sensible al efecto de la pasteurización que la de zarzamora y frambuesa.

La degradación de las antocianinas por aplicación de procesos térmicos está íntimamente relacionada con el número de azúcares unidos a una determinada aglicona, presentando la mayor estabilidad los tri y diglucósidos de cianidina (Ochoa, 2010).

Rommel y col., (1990) comprobaron que la cianidina-3-glucósido, desaparece completamente durante la fermentación, por ello, como las antocianinas de frambuesa contienen di y triglicósidos predominantemente, se cree que esto contribuye a la mayor estabilidad del color de los vinos de frambuesa comparados con los de frutilla o zarzamora que contienen predominantemente monoglicósidos. Esta es, probablemente, la explicación de la mayor estabilidad de las ACY de frambuesa frente a las otras matrices.

A continuación, en la tabla III-10, se muestran los datos correspondientes a guinda, donde se realizó un escaldado del fruto entero, previo a la aplicación de los demás procesos. 
Tabla III-10. Efecto de los procesos sobre la concentración de antocianinas monoméricas y \% de color polimérico en guinda escaldada

\begin{tabular}{|l|ccc|}
\hline & ACY & $\%$ CP & IDA \\
\hline Fresco & $24 \pm 3^{\mathrm{A}}$ & $36 \pm 6^{\mathrm{b}}$ & $1,29 \pm 0,04^{\mathrm{A}^{*}}$ \\
Esc. + Pulp. & $24 \pm 1^{\mathrm{A}}$ & $42 \pm 4^{\mathrm{b}}$ & $1,36 \pm 0,05^{\mathrm{A}}$ \\
Esc. + Pulp. + Past. & $19 \pm 1^{\mathrm{B}}$ & $49 \pm 4^{\mathrm{a}}$ & $1,47 \pm 0,04^{\mathrm{A}^{*}}$ \\
\hline
\end{tabular}

ACY: antocianinas monoméricas (mg cianidina-3-glu/100 g), \%CP: porcentaje de color polimérico, IDA: Índice de degradación de antocianinas. Esc.: escaldado, Pulp.: pulpado, Past.: pauteurizado Los valores representan la media $(n=3) \pm$ SD. Medias con una letra común por columna no son significativamente diferentes $(p \leq 0,05)$

El escaldado previo en guinda permitió que el proceso de pulpado no tenga diferencias significativas $(p \leq 0,05)$ en la concentración de ACY ni en el \% CP e IDA con respecto a la fruta fresca. En el pasteurizado de pulpa de guinda escaldada se registró una disminución del $21 \%$ para las ACY y un aumento en el \% CP del 36\%. EI IDA en el pasteurizado tampoco presentó diferencias significativas $(p \leq 0,05)$ con los procesos anteriores.

Rubinskiene y col. (2005) demostraron que la cianidina-3-rutinósido exhibió la mayor estabilidad frente a un tratamiento térmico de $95^{\circ} \mathrm{C}$ en cassis. Éste es el pigmento mayoritario en guinda con un 87,6\% (Ochoa, 2011; Dekasos, 1970 y Stinzing y col., 2006).

En arándano escaldado, se registraron menores pérdidas en comparación con los valores hallados para la misma matriz sin el pretratamiento. Los valores se presentan en la tabla III-11. 
Tabla III-11. Efecto de los procesos sobre la concentración de antocianinas monoméricas y \% de color polimérico en arándano escaldado

\begin{tabular}{|l|ccc|}
\hline & ACY & \%CP & IDA \\
\hline Fresco & $150 \pm 4^{\mathrm{A}}$ & $4 \pm 1^{\mathrm{b}}$ & $1,01 \pm 0,01^{\mathrm{B}^{*}}$ \\
Esc. + Pulp. & $145 \pm 7^{\mathrm{A}}$ & $11 \pm 1^{\mathrm{a}}$ & $1,10 \pm 0,01^{\mathrm{A}}$ \\
Esc. + Pulp. + Past. & $147 \pm 4^{\mathrm{A}}$ & $11 \pm 4^{\mathrm{a}}$ & $1,12 \pm 0,00^{\mathrm{A}}$ \\
\hline
\end{tabular}

ACY: antocianinas monoméricas (mg cianidina-3-glu/100 g), \%CP: porcentaje de color polimérico, IDA: Índice de degradación de antocianinas. Esc.: escaldado, Pulp.: pulpado, Past.: pauteurizado Los valores representan la media $(n=3) \pm S D$. Medias con una letra común por columna no son significativamente diferentes $(p \leq 0,05)$

Los valores hallados para la concentración de ACY no presentaron diferencias significativas $(p \leq 0,05)$ con la fruta fresca $(p \leq 0,05)$. Se favoreció la retención de antocianinas $(97 \%$ con escaldado previo frente a un $74 \%$ en la condición sin escaldar), lo cual se condice con lo hallado por Rossi y col. (2003) y Lee y col. (2002) para la misma matriz. El pretratamiento de escaldado previo a la molienda de berries resultó efectivo para mejorar la estabilidad y la recuperación de compuestos fenólicos bioactivos (Rossi y col., 2003). Los IDA en la matriz escaldada fueron menores que en la que no se aplicó el pretratamiento.

Al igual que otros polifenoles, las antocianinas se degradan enzimáticamente en presencia de polifenoloxidasa. Esta enzima puede ser inactivada por calentamiento suave y, por lo tanto, algunos autores han informado de que la inclusión de una etapa de escaldado puede tener un efecto positivo sobre la retención de antocianinas. Por ejemplo, Skrede y col. (2000) demostraron que la adición de un extracto de pulpa de arándano escaldado al jugo de arándano no permite la degradación de las antocianinas, mientras que la adición de un extracto no escaldado causó una pérdida del $50 \%$ de las antocianinas.

A modo de resumen la tabla III-12 engloba los resultados obtenidos respecto del efecto de los procesos sobre los FT, Fv, PA, ACY, \%CP e IDA en las diferentes matrices. 
Tabla III-12. Resumen del efecto de los procesos sobre los compuestos bioactivos de zarzamora, frambuesa, arándano y guinda

\begin{tabular}{|c|c|c|c|c|c|c|}
\hline \multirow{2}{*}{ MA TRIZ } & \multicolumn{6}{|c|}{ DETERMINACIÓN } \\
\hline & FT & Fv & PA & $\mathrm{ACY}$ & $\% \mathrm{CP}$ & IDA \\
\hline & & & ZARZAMORA & & & \\
\hline Fresco & $301 \pm 7$ & $65 \pm 1$ & $1,75 \pm 0,01$ & $182 \pm 4$ & $2 \pm 0$ & $1,05 \pm 0,02$ \\
\hline Pulpado & $284 \pm 1$ & $60 \pm 2$ & $1,67 \pm 0,02$ & $162 \pm 6$ & $5 \pm 1$ & $1,13 \pm 0,01$ \\
\hline \multirow[t]{2}{*}{ Pasteurizado } & $377 \pm 15$ & $77 \pm 4$ & $1,84 \pm 0,02$ & $133 \pm 4$ & $16 \pm 1$ & $1,21 \pm 0,01$ \\
\hline & & & FRAMBUESA & & & \\
\hline Fresco & $188 \pm 3$ & $35 \pm 1$ & $1,65 \pm 0,01$ & $46 \pm 3$ & $15 \pm 1$ & $1,20 \pm 0,02$ \\
\hline Pulpado & $173 \pm 3$ & $31 \pm 2$ & $1,33 \pm 0,01$ & $40 \pm 2$ & $22 \pm 3$ & $1,27 \pm 0,02$ \\
\hline \multirow[t]{2}{*}{ Pasteurizado } & $210 \pm 10$ & $37 \pm 1$ & $1,70 \pm 0,04$ & $34 \pm 1$ & $36 \pm 2$ & $1,38 \pm 0,02$ \\
\hline & & & ARANDANO & & & \\
\hline Fresco & $506 \pm 29$ & $204 \pm 9$ & $2,59 \pm 0,12$ & $150 \pm 4$ & $4 \pm 1$ & $1,01 \pm 0,01$ \\
\hline Pulpado & $436 \pm 9$ & $179 \pm 2$ & $2,00 \pm 0,06$ & $111 \pm 3$ & $10 \pm 2$ & $1,12 \pm 0,01$ \\
\hline Pasteurizado & $465 \pm 3$ & $193 \pm 2$ & $1,99 \pm 0,09$ & $98 \pm 4$ & $13 \pm 4$ & $1,16 \pm 0,01$ \\
\hline Escaldado + Pulpado & $580 \pm 18$ & $222 \pm 3$ & $2,86 \pm 0,03$ & $145 \pm 7$ & $11 \pm 1$ & $1,10 \pm 0,01$ \\
\hline \multirow[t]{2}{*}{ Escaldado + Pasteurizado } & $591 \pm 5$ & $217 \pm 8$ & $2,74 \pm 0,08$ & $147 \pm 4$ & $11 \pm 4$ & $1,12 \pm 0,00$ \\
\hline & \multicolumn{6}{|c|}{ GUINDA } \\
\hline Fresco & $500 \pm 13$ & $342 \pm 5$ & $0,73 \pm 0,05$ & $24 \pm 3$ & $36 \pm 6$ & $1,29 \pm 0,04$ \\
\hline Escaldado + Pulpado & $573 \pm 21$ & $353 \pm 1$ & $1,13 \pm 0,02$ & $24 \pm 1$ & $42 \pm 4$ & $1,36 \pm 0,05$ \\
\hline Escaldado + Pasteurizado & $554 \pm 33$ & $356 \pm 2$ & $1,05 \pm 0,06$ & $19 \pm 1$ & $49 \pm 4$ & $1,47 \pm 0,04$ \\
\hline
\end{tabular}

\section{III-3.1.3 Color superficial}

Los cambios de color en los productos alimenticios afectan la apariencia, y pueden ser un indicador de la pérdida de propiedades nutricionales y funcionales y de la severidad de los procesos aplicados (Wrolstad y col., 2005). Las frutas sufren importantes modificaciones en las características cromáticas durante los procesos y el almacenamiento (Uddin y col., 2002) y ellas pueden relacionarse con la concentración y degradación de pigmentos en esas condiciones. Los pigmentos antociánicos son altamente inestables y de fácil degradación durante el procesamiento y el almacenamiento de las frutas, lo cual puede tener un impacto muy significativo sobre la calidad del color (Wrolstad y col., 2005).

En la tabla III-13 se presentan las coordenadas cromáticas correspondientes a la matriz zarzamora. 
Tabla III-13. Funciones de color: luminosidad, ángulo de tono, saturación y cambio global de color en zarzamora

\begin{tabular}{|l|cccc|}
\hline & $\mathbf{L}^{*}$ & hue & Chroma & $\Delta \mathrm{E}$ \\
\hline Fresco & $33,86 \pm 3,49^{\mathrm{A}}$ & $358,65 \pm 0,61^{\mathrm{b}}$ & $1,49 \pm 0,25^{\mathrm{B}^{*}}$ & ---- \\
Pulpado & $18,68 \pm 2,26^{\mathrm{C}}$ & $1,51 \pm 3,55^{\mathrm{b}}$ & $1,65 \pm 0,40^{\mathrm{B}^{*}}$ & $15,19 \pm 2,25$ \\
Pasteurizado & $20,86 \pm 0,72^{\mathrm{B}}$ & $15,79 \pm 0,25^{\mathrm{a}}$ & $10,39 \pm 0,69^{\mathrm{A}^{*}}$ & $15,82 \pm 0,20$ \\
\hline
\end{tabular}

$\mathrm{L}^{*}$ : luminosidad, hue: ángulo de tono, Chroma: saturación, $\Delta \mathrm{E}$ : cambio global de color. Los valores representan la media $(n=6) \pm S D$. Medias con una letra común por columna no son significativamente diferentes $(p \leq 0,05)$

Las zarzamoras frescas presentaron un color púrpura brillante (figura III-1) debido principalmente a la presencia de antocianinas. Por lo tanto, es esperable que el color superficial cambie debido a la disminución de estos pigmentos causada por los diferentes procesos aplicados. Se procedió al cálculo de $\Delta \mathrm{E}$ tomando como referencia la muestra fresca, lo cual permitió visualizar un gran cambio global del color en la matriz por aplicación de los dos procesos.
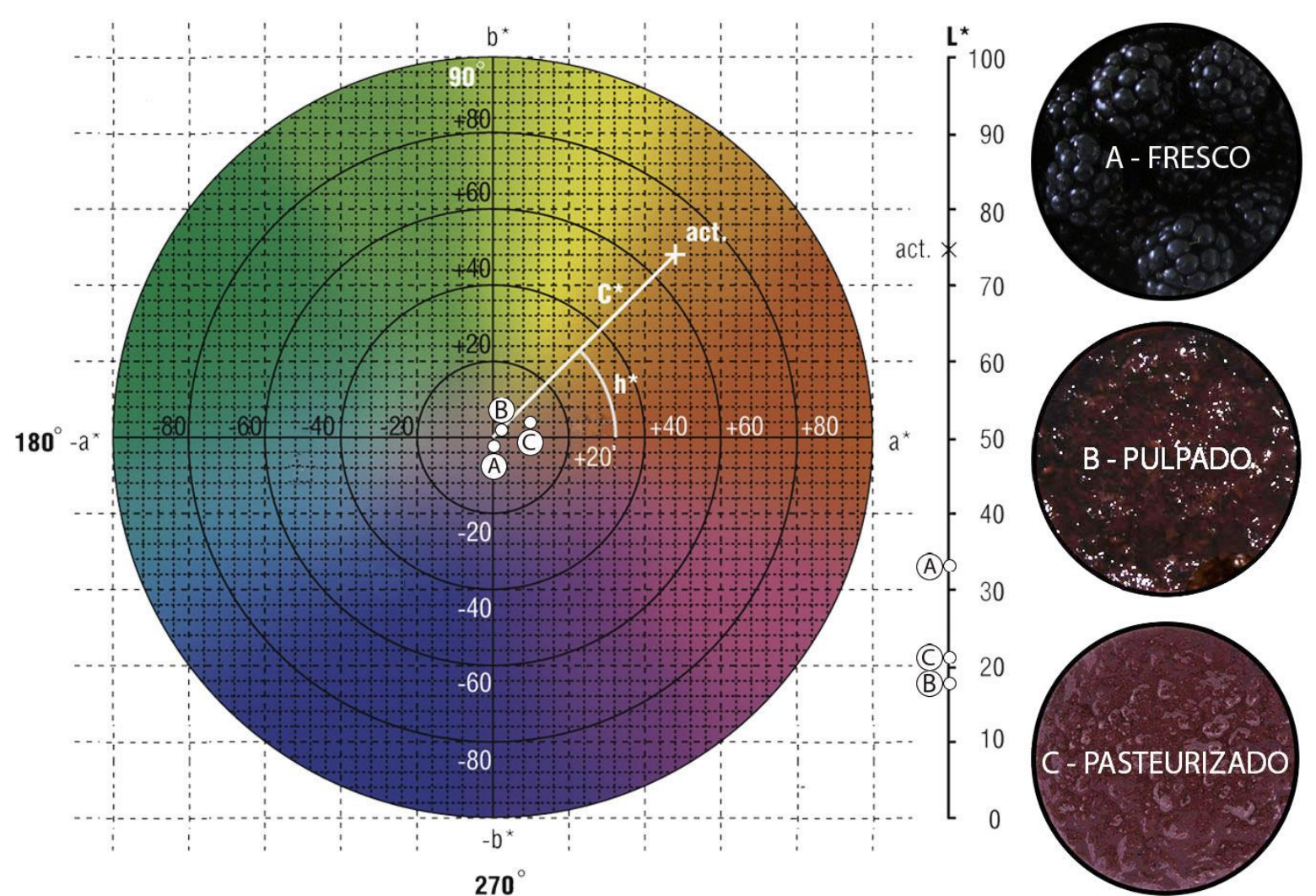

Figura III-1. Diagrama de color para zarzamora fresca y los productos obtenidos de la aplicación de procesos. Nota: el disco de color central se corresponde con un valor de $L^{*}=50$ 
Observando los valores del ángulo de tono, se divisó que la matriz fresca y la pulpada presentaron un color púrpura-violáceo, mientras que por aplicación del proceso de pasteurizado el color viró hacia tonalidades levemente más rojizas. Comparando el color obtenido en el pasteurizado con la zarzamora fresca, se podría pensar en el fenómeno de copigmentación (asociación de antocianinas monoméricas y polifenoles) que disminuye los valores de luminosidad e incrementa la intensidad, lo cual también repercute en un aumento del \% CP en detrimento de la concentración de antocianinas monoméricas (tabla III-7).

Las coordenadas de color para frambuesa fresca y los productos obtenidos por su procesamiento se presentan en la tabla III-14.

Tabla III-14. Funciones de color: luminosidad, ángulo de tono, saturación y cambio global de color en frambuesa

\begin{tabular}{|l|cccc|}
\hline & $\mathrm{L}^{*}$ & hue & Chroma & $\Delta \mathrm{E}$ \\
\hline Fresco & $37,67 \pm 1,53^{\mathrm{A}}$ & $25,67 \pm 2,74^{\mathrm{a}}$ & $37,75 \pm 0,29^{\mathrm{A}^{*}}$ & --- \\
Pulpado & $28,06 \pm 2,83^{\mathrm{B}}$ & $24,88 \pm 2,50^{\mathrm{a}}$ & $29,04 \pm 0,84^{\mathrm{B}^{*}}$ & $12,02 \pm 1,06$ \\
Pasteurizado & $31,14 \pm 1,01^{\mathrm{B}}$ & $25,05 \pm 0,96^{\mathrm{a}}$ & $29,81 \pm 1,68^{\mathrm{B}^{*}}$ & $10,27 \pm 1,95$ \\
\hline
\end{tabular}

L*: luminosidad, hue: ángulo de tono, Chroma: saturación, $\Delta \mathrm{E}$ : cambio global de color. Los valores representan la media $(n=6) \pm S D$. Medias con una letra común por columna no son significativamente diferentes $(p \leq 0,05)$

No se hallaron diferencias estadísticas significativas $(p \leq 0,05)$ en el ángulo de tono para las tres condiciones, pero al comparar las coordenadas colorimétricas correspondientes a fruta fresca y los procesos de pulpado y pasteurizado, surgieron diferencias en cuanto a luminosidad y saturación, es decir, si bien estábamos en presencia de colores rojos, éste fue más intenso y brillante en el caso de la fruta fresca (figura III-2). Los valores para el cambio global de color $(\Delta \mathrm{E})$ fueron menores que los registrados para zarzamora, pero de igual modo importantes, influenciados principalmente por el gran cambio en la luminosidad de las muestras.

Los valores registrados para la matriz fresca se encuentran dentro del rango informado por Çekiç, y Özgen (2010) para frambuesa Tulameen. Bononi y col. (2006), para la misma variedad, registraron valores menores en los tres parámetros colorimétricos $\left(L^{*}, a^{*} y b^{*}\right)$, pero factores tales como las condiciones de cultivo, zona 
geográfica y clima influyen en la composición final de las materias primas y por ende en el color expresado.

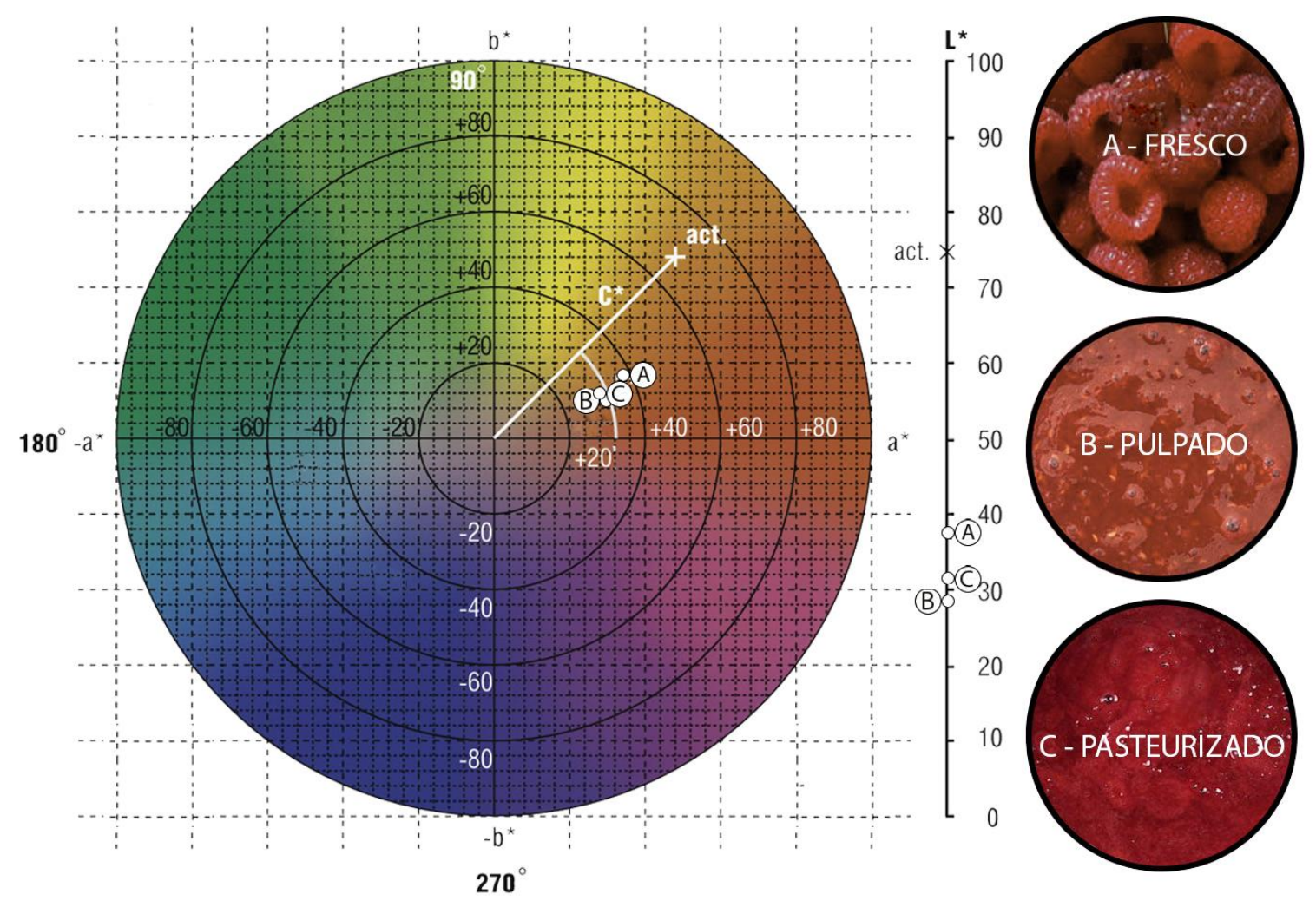

Figura III-2. Diagrama de color para frambuesa fresca y los productos obtenidos de la aplicación de procesos. Nota: el disco de color central se corresponde con un valor de $L^{*}=50$

En la tabla III-15 se presentan los valores de los parámetros colorimétricos para arándano sin escaldar.

Tabla III-15. Funciones de color: luminosidad, ángulo de tono, saturación y cambio global de color en arándano sin escaldar

\begin{tabular}{|l|cccc|}
\hline & $\mathrm{L}^{*}$ & hue & Chroma & $\Delta \mathrm{E}$ \\
\hline Fresco & $36,46 \pm 2,85^{\mathrm{A}}$ & $272,97 \pm 2,88^{\mathrm{a}}$ & $6,00 \pm 0,92^{\mathrm{A}^{*}}$ & ---- \\
Pulpado & $19,66 \pm 1,14^{\mathrm{B}}$ & $1,33 \pm 0,29^{\mathrm{a}}$ & $1,56 \pm 0,15^{\mathrm{B}^{*}}$ & $17,90 \pm 1,05$ \\
Pasteurizado & $20,92 \pm 0,58^{\mathrm{B}}$ & $10,27 \pm 0,39^{\text {a }}$ & $8,07 \pm 0,31^{\mathrm{B}^{*}}$ & $18,86 \pm 0,31$ \\
\hline
\end{tabular}

$\mathrm{L}^{*}$ : luminosidad, hue: ángulo de tono, Chroma: saturación, $\Delta \mathrm{E}$ : cambio global de color. Los valores representan la media $(n=6) \pm S D$. Medias con una letra común por columna no son significativamente diferentes $(p \leq 0,05)$ 
El fruto fresco de arándano presentó un color azul intenso, lo cual se traduce en un ángulo de tono correspondiente al cuarto cuadrante (hue $>270^{\circ}$ ). El proceso de pulpado provocó un corrimiento hacia tonalidades púrpuras por homogenización de cáscara y pulpa (figura III-3), que además afecta la saturación del color. El posterior pasteurizado modifica aún más el ángulo, llevándolo a zonas con mayor presencia de rojos (hue $>10^{\circ}$ ), pero aumentando su intensidad (figura III-3).

La presencia de estas tres tonalidades (azul, púrpura y roja) en el color superficial impacta directamente sobre el valor de $\Delta \mathrm{E}$, el cual alcanzó elevados valores.

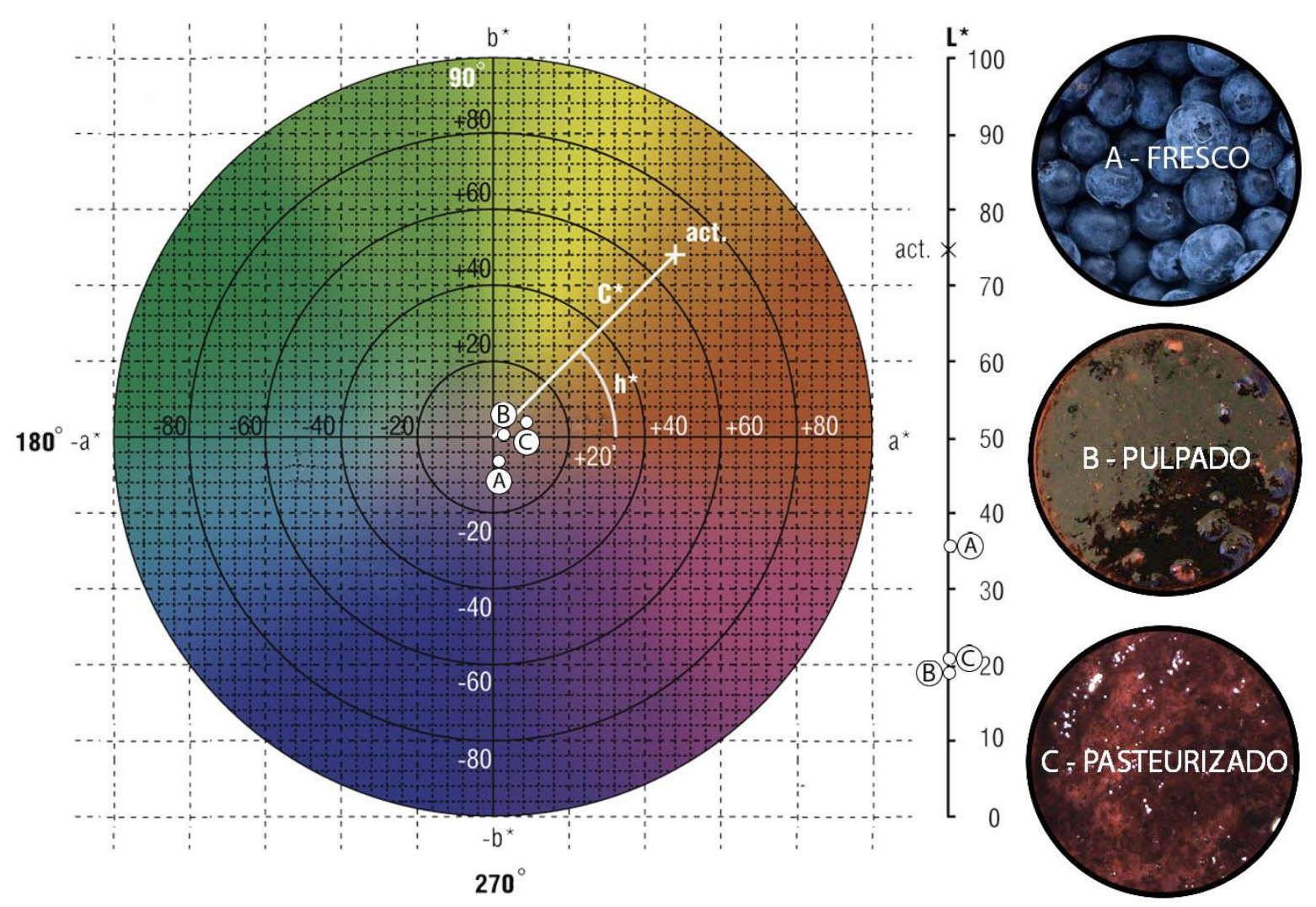

Figura III-3. Diagrama de color para arándano sin escaldar fresco y los productos obtenidos de la aplicación de procesos. Nota: el disco de color central se corresponde con un valor de $L^{*}=50$

En las tres matrices sin pretratamiento de escaldado (zarzamora, frambuesa y arándano) se produjo, durante el pulpado, una disminución importante de la luminosidad, que vuelve a aumentar en el pasteurizado, sin llegar a reponer su valor inicial. Nicoli y col. (2000) explican que la condensación de los productos de la 
oxidación de los polifenoles determina la formación de procianidinas con estructuras aromáticas más grandes, lo que se traduce en el oscurecimiento de las pulpas.

El escaldado previo de guinda y arándano permitió reducir el grado de pardeamiento de las frutas por inhibición de la acción enzimática lo que se evidenció por valores más altos de luminosidad (tablas III-16 y III-17).

Tabla III-16. Funciones de color: luminosidad, ángulo de tono, saturación y cambio global de color en guinda escaldada

\begin{tabular}{|l|cccc|}
\hline & L* $^{*}$ & hue & Chroma & $\Delta \mathrm{E}$ \\
\hline Fresco & $27,17 \pm 0,87^{\mathrm{C}}$ & $15,30 \pm 1,65^{\mathrm{C}}$ & $15,11 \pm 2,37^{\mathrm{D}^{*}}$ & ---- \\
Escaldado & $42,26 \pm 2,91^{\mathrm{A}}$ & $22,40 \pm 0,30^{\mathrm{b}}$ & $20,93 \pm 4,25^{\mathrm{C}^{*}}$ & $16,50 \pm 4,18$ \\
Esc. + Pulp. & $33,69 \pm 0,29^{\mathrm{B}}$ & $25,66 \pm 0,55^{\mathrm{a}}$ & $29,46 \pm 0,26^{\mathrm{A}^{*}}$ & $16,20 \pm 0,34$ \\
Esc. + Pulp. + Past. & $33,00 \pm 1,06^{\mathrm{B}}$ & $25,14 \pm 0,60^{\mathrm{a}}$ & $26,99 \pm 0,67^{\mathrm{B}^{*}}$ & $13,68 \pm 1,10$ \\
\hline
\end{tabular}

L*: luminosidad, hue: ángulo de tono, Chroma: saturación, $\Delta \mathrm{E}$ : cambio global de color. Esc.: escaldado, Pulp.: pulpado, Past.: pauteurizado Los valores representan la media $(n=6) \pm S D$. Medias con una letra común por columna no son significativamente diferentes $(p \leq 0,05)$

El color de la guinda fresca se ubicó en la zona de rojo-púrpura (hue > 15), el proceso de escaldado cambió fuertemente el color moviéndolo hacia un rojo más puro, Chroma aumentó significativamente, es decir se intensificó el color, lo que por supuesto se manifiestó en un gran cambio global del color $(\Delta \mathrm{E}=16,5)$. Analizando el efecto del pulpado y pasteurizado se observó que hue, si bien se modificó en $3^{\circ}$, continuó en la zona correspondiente a la tonalidad rojiza-anaranjada y aumentó Chroma, lo que implica una mayor intensidad del color (figura III-4). 

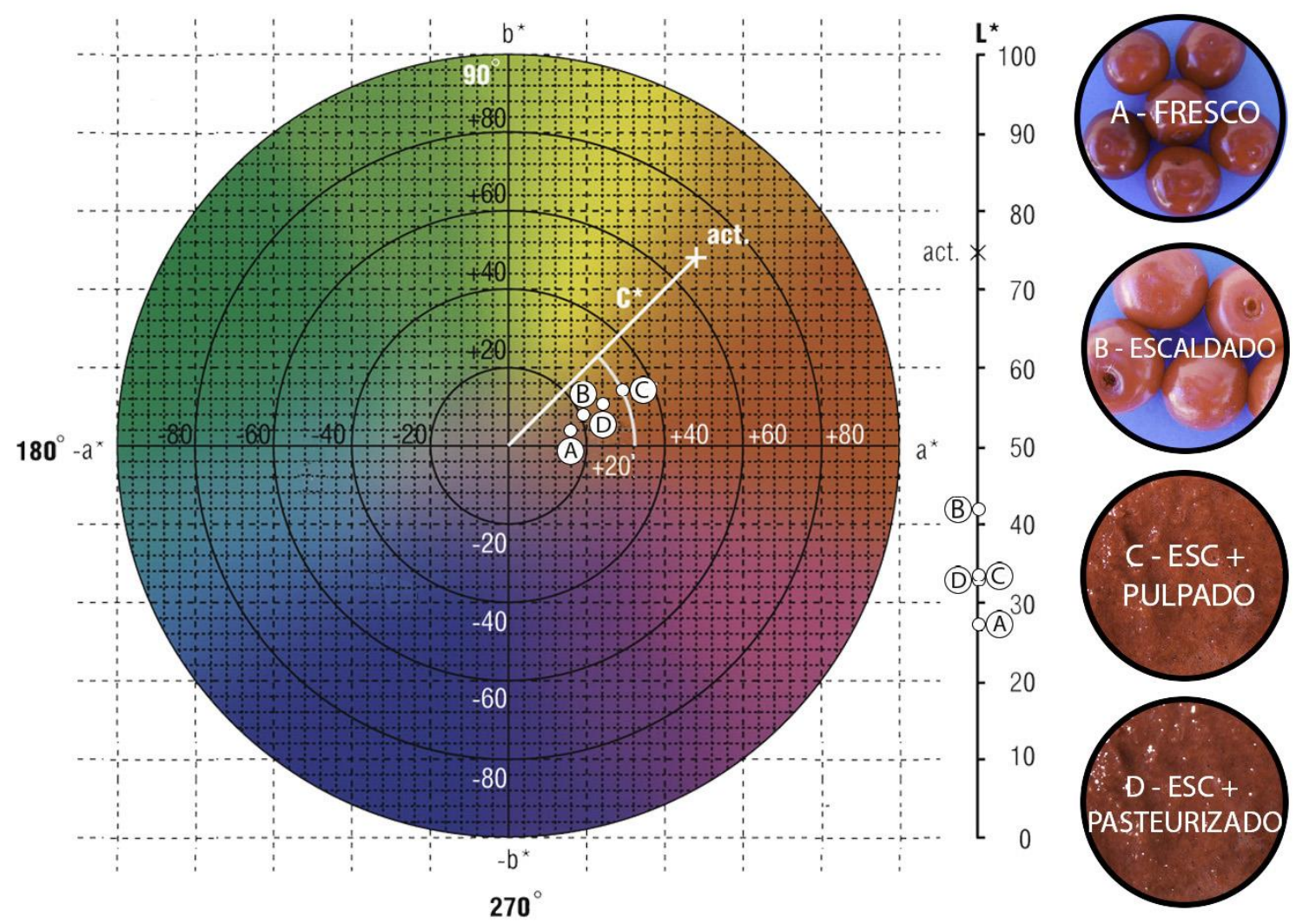

Figura III-4. Diagrama de color para guinda fresca y los productos obtenidos de la aplicación de procesos. Nota: el disco de color central se corresponde con un valor de $L^{*}=50$

Las funciones de color obtenidas por los procesos aplicados sobre arándano escaldado se muestran en la tabla III-17.

Tabla III-17. Funciones de color: luminosidad, ángulo de tono, saturación y cambio global de color en arándano escaldado

\begin{tabular}{|l|cccc|}
\hline & L* $^{*}$ & hue & Chroma & $\Delta E$ \\
\hline Fresco & $36,46 \pm 2,85^{\mathrm{B}}$ & $272,97 \pm 2,88^{\mathrm{a}}$ & $6,00 \pm 0,92^{\mathrm{B}^{*}}$ & ---- \\
Escaldado & $38,01 \pm 0,26^{\mathrm{A}}$ & $16,94 \pm 0,40^{\mathrm{b}}$ & $4,51 \pm 2,10^{\mathrm{C}^{*}}$ & $20,67 \pm 0,81$ \\
Esc. + Pulp. & $19,19 \pm 2,03^{\mathrm{C}}$ & $12,50 \pm 0,89^{\mathrm{c}}$ & $8,41 \pm 1,87^{\mathrm{A}^{*}}$ & $12,54 \pm 0,56$ \\
Esc. + Pulp. + Past. & $19,60 \pm 2,81^{\mathrm{C}}$ & $10,40 \pm 2,35^{\mathrm{c}}$ & $8,79 \pm 2,02^{\mathrm{A}^{*}}$ & $20,47 \pm 1,27$ \\
\hline
\end{tabular}

: : luminosidad, hue: ángulo de tono, Chroma: saturación, $\Delta \mathrm{E}$ : cambio global de color. Esc.: escaldado,

Pulp.: pulpado, Past.: pauteurizado Los valores representan la media $(n=6) \pm S D$. Medias con una letra común por columna no son significativamente diferentes $(p \leq 0,05)$ 
Observando en la tabla los valores de hue, se manifiestó nuevamente que la fruta fresca es azul; y el color viró hacia los púrpuras-rojizos cuando la misma es escaldada, (figura III-5) es decir con un importante componente rojo, lo que implica un gran de cambio global del color $(\Delta E=20,67)$. La pulpa pasteurizada es similar a la escaldada, de color púrpura intenso y no se presentaron diferencias estadísticas significativas $(p \leq 0,05)$ para la luminosidad, ángulo de tono y saturación.
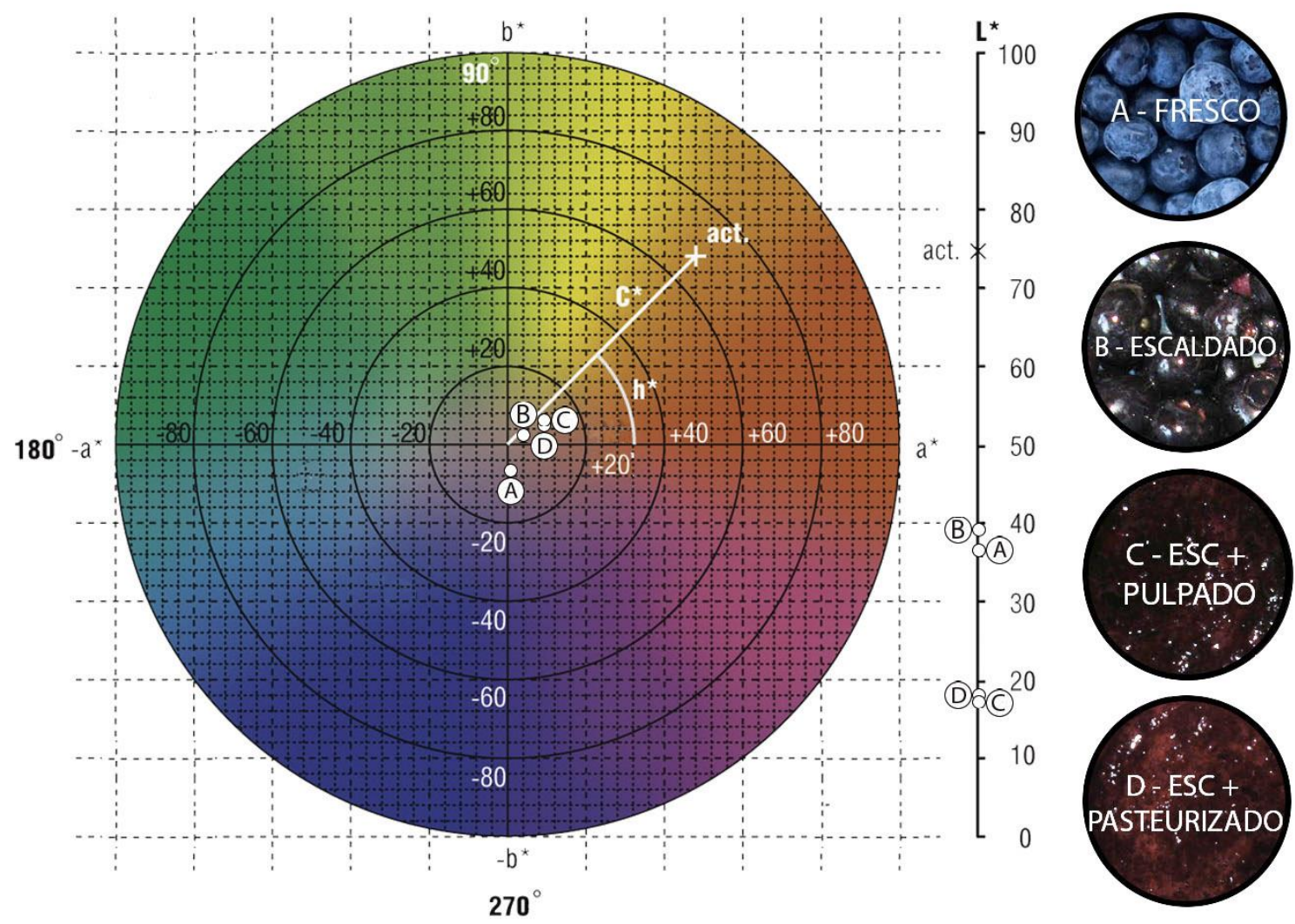

Figura III-5. Diagrama de color para arándano fresco y los productos obtenidos de la aplicación de procesos. Nota: el disco de color central se corresponde con un valor de $L^{*}=50$

\section{III-3.2 Efecto del proceso de deshidratación}

La rosa mosqueta y el cassis fueron las dos matrices seleccionadas para ser deshidratadas y luego añadidas en forma de polvo sobre los distintos productos formulados a fin de elevar la concentración de ácido ascórbico original.

Se seleccionó este proceso ya que los frutos de rosa mosqueta, según puede observase en la fotografía III-6, son complejos y poseen en su parte externa restos de la infloración y pelos epidérmicos cuya separación manual es muy engorrosa, de alto costo y que traen gran cantidad de problemas durante la separación por 
pulpado. Debido a que este proceso involucra altas temperaturas lo cual influye negativamente sobre la concentración final de ácido ascórbico.

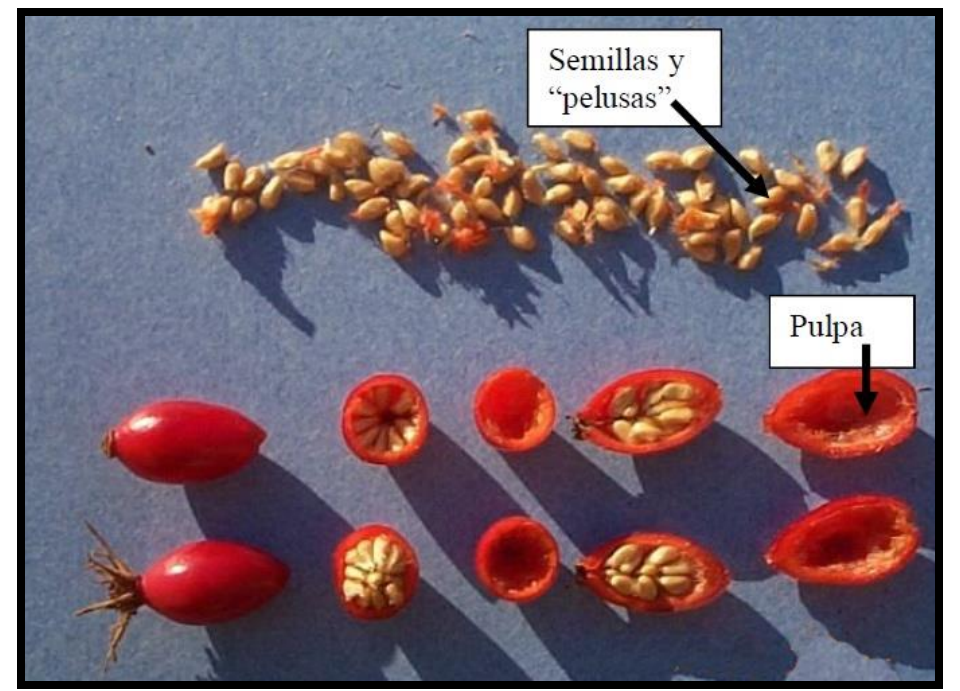

Fotografía III-6. Detalles del fruto de la rosa mosqueta.

Los frutos de cassis se presentan en forma de "racimos" y también poseen en su parte externa restos de infloración, lo cual dificulta su manejo en fresco y el proceso de pulpado (fotografía III-7).

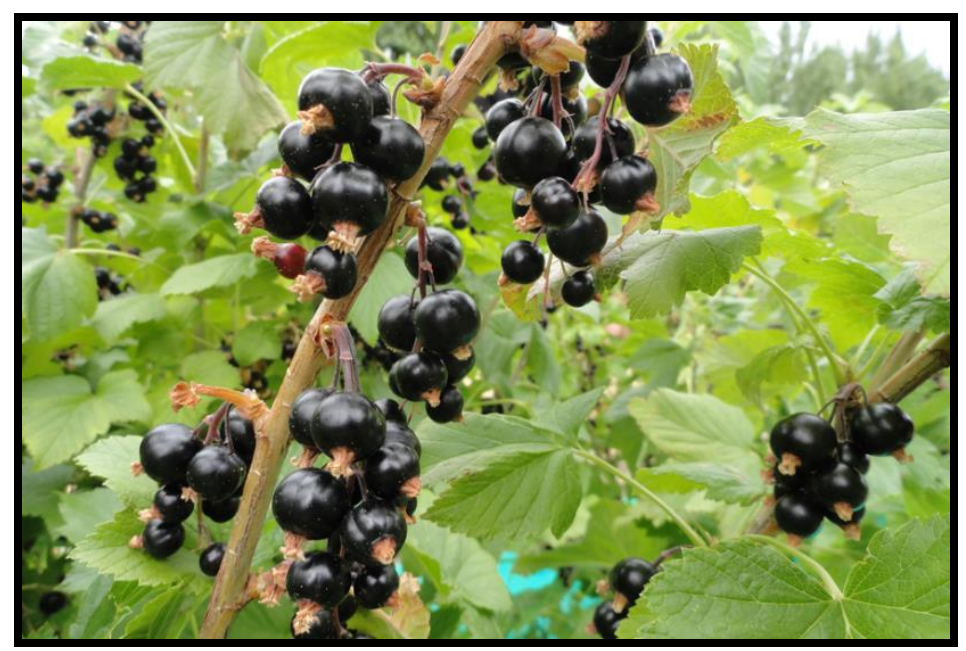

Fotografía III-7. Frutos de cassis.

En el caso de la rosa mosqueta se aplicaron tres punciones ecuatoriales en cada fruto como pretratamiento físico, a fin producir un daño mecánico sobre la piel de los frutos, lo que produce grietas en la capa impermeable facilitando la llegada de humedad desde el interior hacia la superficie del fruto y reduciendo el tiempo total de 
secado a 4 horas en las condiciones ya detalladas en la sección III-2.1 (Ohaco Dominguez, 2012).

\section{III-3.2.1 Fenoles totales, flavonoides, ácido ascórbico y poder antirradicalario}

En la tabla III-18 se presentan los valores correspondientes a compuestos bioactivos y poder antirradicalario de rosa mosqueta fresca y deshidratada.

Tabla III-18. Efecto de la deshidratación sobre los fenoles totales, flavonoides, ácido ascórbico y poder antirradical de rosa mosqueta

\begin{tabular}{|l|cccc|}
\hline & FT & Fv & PA & AA \\
\hline Fresco & $6450 \pm 129^{\mathrm{B}}$ & $1904 \pm 109^{\mathrm{b}}$ & $17,38 \pm 0,51^{\mathrm{B}^{*}}$ & $9845 \pm 56^{\mathrm{A}^{\prime \prime}}$ \\
Deshidratado & $8063 \pm 418^{\mathrm{A}}$ & $2463 \pm 195^{\mathrm{a}}$ & $19,86 \pm 0,73^{\mathrm{A}^{*}}$ & $7184 \pm 93^{\mathrm{B} "}$ \\
\hline
\end{tabular}

FT: fenoles totales (mg GAE/100 g ms), Fv: flavonoides (mg CE/100 g ms), PA: poder antirradical $\left(\mathrm{mg}^{-1} \mathrm{~ms}\right), A A$ : ácido ascórbico $(\mathrm{mg} / \mathrm{kg} \mathrm{ms})$. Los valores representan la media $(n=3)$ \pm SD. Medias con una letra común por columna no son significativamente diferentes $(p \leq 0,05)$

El proceso de deshidratación aumentó el contenido de FT, Fv y PA en un 25\%, $29 \%$ y $14 \%$ respectivamente en comparación con los frutos frescos. En cuanto al contenido de ácido ascórbico se registró una disminución del $27 \%$ en el polvo final obtenido.

A continuación, en la tabla III-19, se puede observar el efecto del deshidratado sobre los valores de fenoles totales, flavonoides, ácido ascórbico y poder antirradical en cassis.

Tabla III-19. Efecto de la deshidratación sobre los fenoles totales, flavonoides, ácido ascórbico y poder antirradical de cassis

\begin{tabular}{|l|cccc|}
\hline & FT & Fv & PA & AA \\
\hline Fresco & $2473 \pm 87^{\mathrm{B}}$ & $1874 \pm 42^{\mathrm{b}}$ & $8,05 \pm 0,30^{\mathrm{B}^{*}}$ & $1260 \pm 26^{\mathrm{a} "}$ \\
Deshidratado & $2934 \pm 110^{\mathrm{A}}$ & $2197 \pm 64^{\mathrm{a}}$ & $9,76 \pm 0,29^{\mathrm{A}^{*}}$ & $900 \pm 45^{\mathrm{b} "}$ \\
\hline
\end{tabular}

FT: fenoles totales (mg GAE/100 g ms), Fv: flavonoides (mg CE/100 g ms), PA: poder antirradical $\left(\mathrm{mg}^{-1} \mathrm{~ms}\right), \mathrm{AA}$ : ácido ascórbico $(\mathrm{mg} / \mathrm{kg} \mathrm{ms})$. Los valores representan la media $(\mathrm{n}=3)$ \pm SD. Medias con una letra común por columna no son significativamente diferentes $(p \leq 0,05)$ 
Nuevamente se nota un aumento de los FT, Fv y PA en el producto deshidratado del $19 \%, 17 \%$ y $21 \%$ respectivamente. El contenido de ácido ascórbico en el deshidratado disminuyó un $29 \%$ en el polvo final obtenido.

Las frutas obtenidas por secado convectivo presentaron mayor contenido de FT, Fv y PA. Resultados similares fueron reportados por Franceschinis y col., (2015) para cerezas Lapins, donde el contenido de fenoles totales se incrementó un $30 \%$. En concordancia con estos resultados, Que y col., (2008) en su estudio sobre el contenido fenólico y la actividad antioxidante en zapallo deshidratado, informaron un contenido de FT 4,6 veces superior en secado por aire caliente. Estos autores consideran que el incremento de polifenoles se consigue a partir de precursores por reacciones de interconversión de tipo no enzimático favorecidas por la aplicación de de calor durante el secado. Por otro lado, el incremento del poder antirradicalario podría deberse, a la generación y acumulación de productos de la hidrólisis de polifenoles y antioxidantes del tipo Maillard (Fennema, 2010; Manzocco y col., 2001; Tuohy y col., 2006; Torres y col.; 2015).

Espinoza y col., (2015) informaron un aumento considerable (5 veces más) de flavonoides en membrillo respecto a la muestra original, cuando se trabaja a temperaturas entre 55 y $65{ }^{\circ} \mathrm{C}$ y tiempos entre 160 y 220 minutos. Resultados similares, de mayores contenidos de compuestos bioactivos al aumentar las temperaturas de secado de aire convectivo, también se han reportado en el café (Nicoli y col., 1997a; Sanchez-Gonzalez y col., 2005) y en polvos de semilla de mango (Soong y Barlow, 2004). Esto probablemente podría ser debido a la formación de sustancias fenólicas durante el proceso de secado a $60{ }^{\circ} \mathrm{C}$ en una estufa de aire convectivo.

Piga y col. (2003) realizaron un estudio sobre la influencia de la temperatura del aire de secado sobre los compuestos fenólicos y la actividad antioxidante de las ciruelas pasas. Sus resultados indicaron que el secado a alta temperatura destruyó las antocianinas y redujo significativamente los flavonoides y el ácido ascórbico. El análisis es, sin embargo, más complejo cuando se estudian las propiedades funcionales de los alimentos secos ya que durante el procesamiento los polifenoles, en su etapa intermedia de oxidación, pueden tener una mayor potencia antioxidante que inicialmente y los tratamientos a alta temperatura pueden causar la formación de nuevos compuestos, o degradación de componentes, que tienen una mayor actividad antioxidante. 
El ácido ascórbico es uno de los nutrientes presente en frutas y hortalizas más sensibles a la temperatura, pH y luz. De hecho, operaciones como el cortado, o pelado, sin aplicación de calor, implican pérdidas considerables (Peinado Pardo, 2011). La pérdida se debe básicamente a la degradación química que sufre dicho componente debido a la oxidación promovida por la enzima ascorbato oxidasa (Zanoni y col., 1999). Por otro lado, la ruptura de la compartamentalización acelera su destrucción, ya que se facilita el acceso del oxígeno a la matriz vegetal. En los frutos perforados (como los de la rosa mosqueta) se estima que la degradación del ácido ascórbico se debe fundamentalmente a una reacción oxidativa ya que se ve aumentada la superficie de exposición al oxígeno, fenómeno que se observa al comienzo de la deshidratación. Este efecto se contrarresta a medida que evoluciona el secado pues la presencia de esos canales abiertos mecánicamente permite una rápida eliminación del agua y, como consecuencia, se reducen las posibilidades de una degradación química al disminuir la posibilidad de movimiento de los reactivos en un medio que posee bajo contenido de agua. Pirone y col., 2007 y Márquez y col, 2006, han reportado que $70^{\circ} \mathrm{C}$ es la temperatura óptima para el secado ya que permite acortar los tiempos de secado y retener altos contenidos ácido ascórbico.

El contenido final de ácido ascórbico en ambas matrices, a pesar de la degradación sufrida por el proceso de deshidratación, es comparativamente alto frente a otros frutos ricos en dicho nutriente. Por ejemplo, 10 gramos de polvo de rosa mosqueta, que podría añadirse a productos tales como pulpas, helados, infusiones o yogures aportaría el $160 \%$ de la ingesta recomendada por el Código Alimentario Argentino (Res. GMC No46/03, Cap. 5). En el caso del polvo de cassis, 10 gramos se corresponderían con el $20 \%$ de la IR para esta vitamina.

\section{III-3.2.2 Contenido de pigmentos}

En frutos de rosa mosqueta el profundo color anaranjado o rojo es sinónimo de alto contenido de carotenoides que como se sabe, algunos son precursores de vitamina A y responsables además de gran parte de la actividad nutricional y biológica que presenta este fruto silvestre. Según Diez y col. (2008) en la matriz fresca, recolectada en la zona de El Bolsón, se han identificado y cuantificado: carotenoides totales $2570 \mathrm{mg} / \mathrm{kg}$ de los cuales alrededor del $77 \%$ corresponde a licopeno y el $12 \%$ a $\beta$-caroteno. 
En la figura III-6 se presentan los valores obtenidos de carotenos totales en fruto fresco y deshidratado (8,3\% humedad), expresados en base seca.

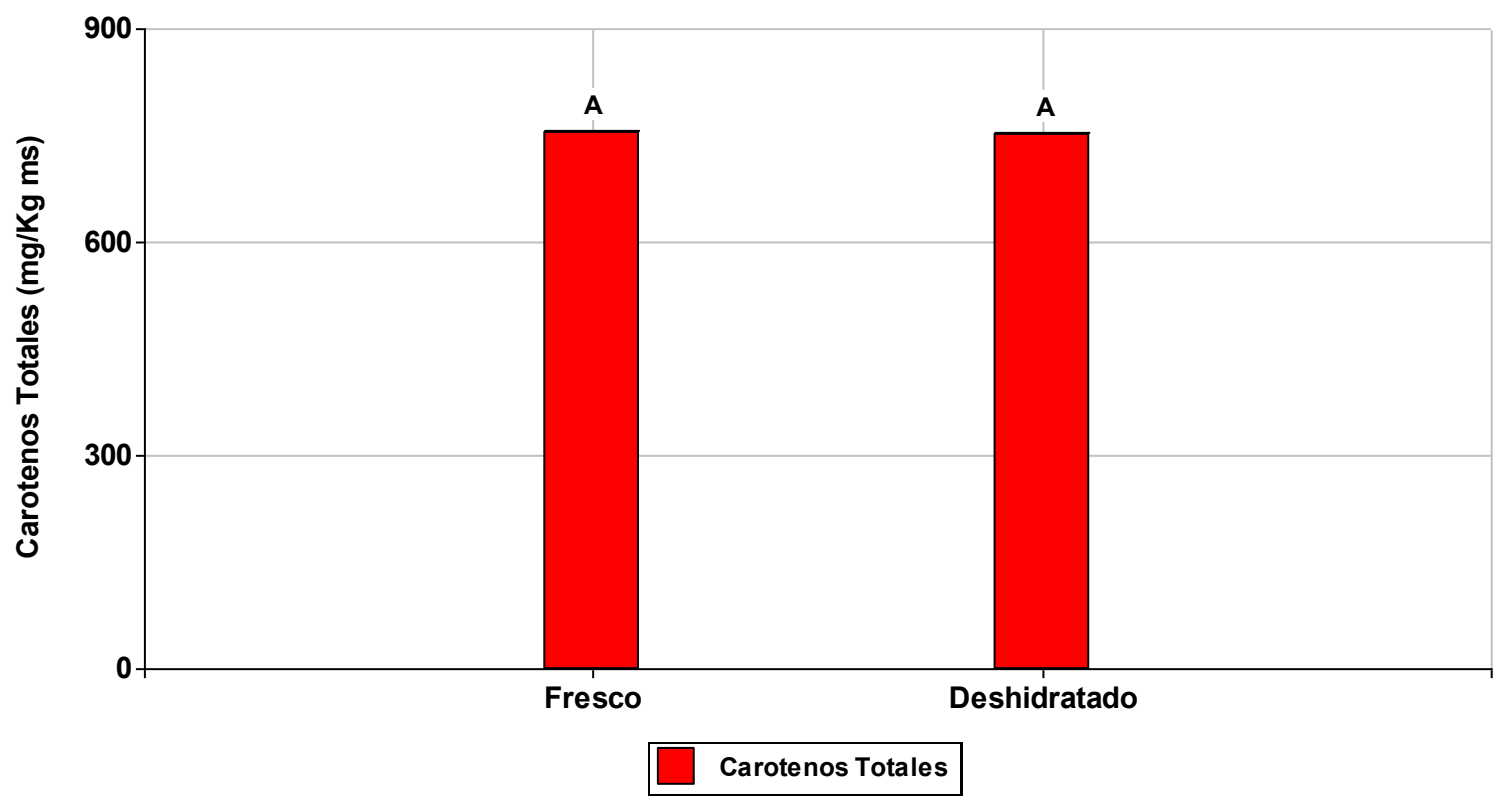

Figura III-6. Contenido de carotenos totales en frutos frescos y deshidratados de rosa mosqueta. Nota: la altura de la barra indica el valor medio. Las barras de error expresan el error estándar.

En la cuantificación de carotenos totales se obtuvo un valor de $754,2 \mathrm{mg} / \mathrm{kg}$ en fruto fresco de rosa mosqueta, el cual es comparable con valores encontrados en la bibliografía (Márquez, 2003; Hornero-Méndez y Mínguez- Mosquera, 2000). No se encontraron diferencias significativas $(p \leq 0,05)$ entre los valores promedio de carotenos entre la muestra fresca y las muestras perforadas y deshidratadas a $70^{\circ} \mathrm{C}$ ( $p \leq 0,05)$. Comparando los resultados de fruto fresco y deshidratado, se pudo observar que los carotenos no son afectados por la aplicación de aire caliente en la temperatura bajo estudio, ya que el porcentaje de retención en los frutos deshidratados es muy elevado (99,7 \%). Esto concuerda con lo reportado por Márquez (2003), quien estudió la evolución de carotenos durante el secado de frutos de rosa mosqueta. Se puede inferir que el método de secado bajo las condiciones de operación fue satisfactorio para la conservación de estos nutrientes. Según algunos autores la eliminación de agua hasta un nivel de aproximadamente $12 \%$ hace que las sales cuprosas y el ácido ascórbico se concentren, estableciendo 
así un medio reductor, y consecuentemente, un sistema antioxidante que protege a los carotenos.

En cassis, como en el resto de los berries, nuevamente las antocianinas monoméricas son, en gran medida, los pigmentos responsables del color observado. En la tabla III-20 se presentan las concentraciones de antocianinas monoméricas, $\% \mathrm{CP}$ e IDA en fruto fresco y deshidratado (12\% humedad), expresados en base seca.

Tabla III-20. Contenido de antocianinas monoméricas, índice de degradación de antocianinas y porcentaje de color polimérico en frutos de cassis.

\begin{tabular}{|l|ccc|}
\hline & ACY & \%CP & IDA \\
\hline Fresco & $707 \pm 5^{\mathrm{A}}$ & $6 \pm 2^{\mathrm{b}}$ & $0,93 \pm 0,09 \mathrm{~A}^{*}$ \\
Deshidratado & $392 \pm 20^{\mathrm{B}}$ & $6 \pm 1^{\mathrm{b}}$ & $1,11 \pm 0,08^{\mathrm{A}^{*}}$ \\
\hline
\end{tabular}

ACY: antocianinas monoméricas (mg cianidina-3-glu/100g ms), \%CP: porcentaje de color polimérico, IDA: índice de degradación de antocianinas. Los valores representan la media $(n=3) \pm S D$. Medias con una letra común por columna no son significativamente diferentes $(p \leq 0,05)$

Luego de la deshidratación se registra una pérdida del $45 \%$ de las antocianinas monoméricas. Este resultado era esperable, ya que numerosas investigaciones (Poei-Langton y Wrolstad, 1981; Garzón, 1998; Garzón y Wrolstad, 2002; De Rosso y Mercadante, 2007) han demostrado que la interacción entre las antocianinas y el ácido ascórbico produciría la destrucción de ambos compuestos, probablemente por la formación de peróxido de hidrógeno durante la oxidación del ácido ascórbico (Fennema, 2010). Las pérdidas se producen tanto en condiciones aeróbicas como anaeróbicas (Poei-Langton y Wrolstad, 1981).

Resultados similares fueron reportados por Forni y col. (1993) donde el 50\% de antocianinas se perdieron durante el tratamiento térmico de cerezas. Stojanovic y Silva (2007) indicaron una disminución del contenido de antocianinas de arándanos deshidratados por corriente de aire de un $69 \%$, en comparación con frescos. A altas temperaturas de secado, aumenta la producción de furfural y 5-hidroximetil-furfural (HMF), productos intermediarios de la reacción de Maillard cuando la misma ocurre a pH ácido (Pérez-Locas y Yaylayan, 2010). Teniendo en cuenta el pH del cassis 
fresco $(3,3 \pm 0,1)$, estos compuestos intermediarios podrían haberse formado durante las condiciones de secado convectivo.

Además, cabe resaltar que la presencia de furfural puede acelerar $y / o$ inducir la polimerización de los flavonoides y las antocianinas (Es-Safi y col., 2000; Stojanovic y Silva, 2007).

En cuanto a valores publicados para el índice de degradación de antocianinas, Michalczyk y col. (2009) indicaron para distintos berries (frutilla, frambuesa y arándano) secados a $40{ }^{\circ} \mathrm{C}$, valores superiores a los determinados en este trabajo, en un intervalo entre 1,3-1,8. El valor de IDA obtenido en la muestra fresca se encuadra dentro del rango esperado, ya que es menor a 1, es decir, no contiene pigmentos degradados. No se hallaron diferencias estadísticas significativas $(p \leq 0,05)$ entre los valores de IDA y \%CP para las condiciones fresco y deshidratado, lo cual nos lleva a inferir que un muy bajo porcentaje de ACY se ha polimerizado, es decir, durante el secado se degradan por otras rutas alternativas ya sean químicas o enzimáticas. Michalczyk y col. (2009) recomiendan establecer un IDA límite a partir del cual la degradación sea tan significativa que el producto deba ser descartado.

\section{III-3.2.3 Color superficial}

En la deshidratación es esperable que los colores se intensifiquen debido a la concentración de los pigmentos dada por la pérdida de agua. Además, el desarrollo de pardeamiento y la polimerización de pigmentos que pueden ocurrir a causa del proceso también pueden contribuir a los cambios de color observados

En la tabla III-21 se presentan los valores de las coordenadas cromáticas para rosa mosqueta sometida al proceso de deshidratación. 
Tabla III-21. Funciones de color: luminosidad, ángulo de tono, saturación y cambio global de color en rosa mosqueta

\begin{tabular}{|l|cccc|}
\hline & $\mathrm{L}^{*}$ & hue & Chroma & $\Delta \mathrm{E}$ \\
\hline Fresco & $36,94 \pm 1,41^{\mathrm{B}}$ & $39,34 \pm 0,93^{\mathrm{b}}$ & $49,80 \pm 2,00^{\mathrm{A}^{*}}$ & ---- \\
Entero Deshidratado & $30,99 \pm 0,98^{\mathrm{C}}$ & $28,21 \pm 0,37^{\mathrm{c}}$ & $29,89 \pm 1,18^{\mathrm{B}^{*}}$ & $24,42 \pm 1,34$ \\
Polvo & $49,47 \pm 0,55^{\mathrm{C}}$ & $66,70 \pm 0,23^{\mathrm{a}}$ & $27,44 \pm 1,03^{\mathrm{C}^{*}}$ & $32,83 \pm 0,41$ \\
\hline
\end{tabular}

$\mathrm{L}^{*}$ : luminosidad, hue: ángulo de tono, Chroma: saturación, $\Delta \mathrm{E}$ : cambio global de color. Los valores representan la media $(n=6) \pm S D$. Medias con una letra común por columna no son significativamente diferentes $(p \leq 0,05)$

Los frutos frescos presentaron un color rojo-anaranjado (figura III-7) muy intenso. Por efecto de la deshidratación, disminuyó el parámetro $a^{*}\left(a^{*}\right.$ fresco $=38,52 \pm$ 2,$07 ; a^{*}$ deshidratado $\left.=26,34 \pm 0,96\right)$ y el parámetro $b^{*}\left(b^{*}{ }_{\text {fresco }}=31,55 \pm 0,63 ; b^{*}\right.$ deshidratado $=14,13 \pm 0,71$ ), que representan (en valores positivos) los rojos y amarillos respectivamente, lo cual impactó sobre el ángulo de tono que se desplazó hacia menores valores y apreciándose visualmente como una tendencia hacia los marrones. La mayor diferencia entre ambas condiciones radica en la saturación del color observado, donde la muestra deshidratada presenta el menor valor (figura III7).

Estos frutos experimentaron cambios macroestructurales hacia una contracción volumétrica que no es acompañada por su cutícula cerosa y se traduce en una superficie rugosa que posee diferente capacidad de reflejar la luz, lo cual impacta sobre $L^{*}$ (figura III-7). Diferentes autores han informado que las disminuciones en los valores de $L^{*}$ se correlacionaron bien con los aumentos en el pardeamiento de los alimentos (Jiménez y col., 1994; Negi y Roy, 2000). 


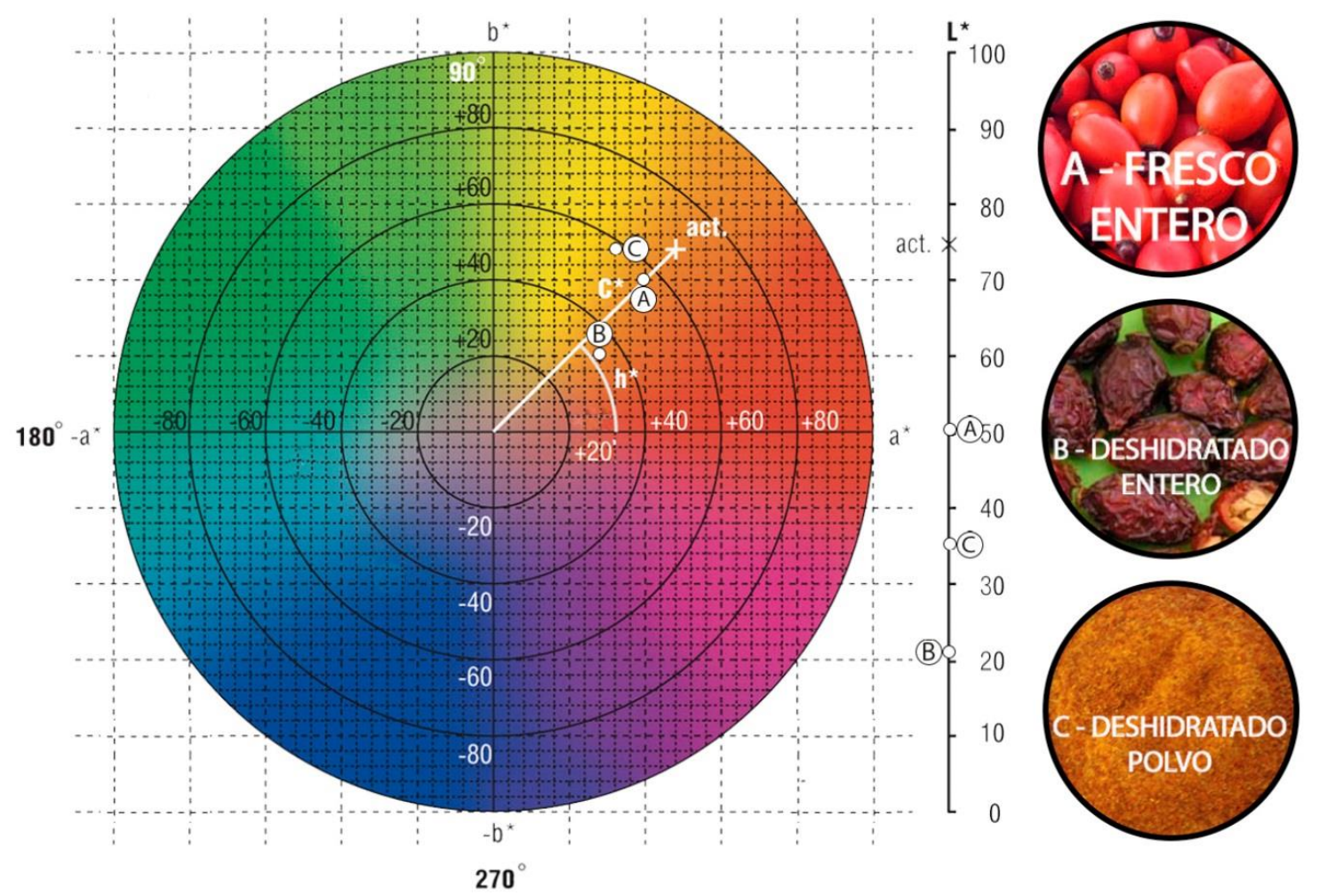

Figura III-7. Diagrama de color para rosa mosqueta fresca y los productos obtenidos de la deshidratación. Nota: el disco de color central se corresponde con un valor de

$$
L^{*}=50
$$

En cuanto al polvo obtenido de la molienda del fruto deshidratado, se observó valores significativamente mayores $(p \leq 0,05)$ de luminosidad, indicando un aspecto más pálido. Resultados similares para polvo de páprika fueron reportados por Topuz y col., 2009. El ángulo de tono aumentó significativamente $(p \leq 0,05)$ hacia tonalidades amarillentas-anaranjadas (figura III-7).

El mayor cambio global del color, en relación a la muestra fresca, lo presentó el polvo de rosa mosqueta (tabla III-21).

Los frutos de cassis también se sometieron al proceso de deshidratación y los resultados obtenidos se muestran en la tabla III-22. 
Tabla III-22. Funciones de color: luminosidad, ángulo de tono, saturación y cambio global de color en cassis

\begin{tabular}{|l|cccc|}
\hline & $\mathrm{L}^{*}$ & hue & Chroma & $\Delta \mathrm{E}$ \\
\hline Fresco & $18,53 \pm 0,43^{\mathrm{A}}$ & $358,15 \pm 0,91^{\mathrm{a}}$ & $3,11 \pm 0,83^{\mathrm{A}^{*}}$ & ---- \\
Entero Deshidratado & $19,99 \pm 0,46^{\mathrm{A}}$ & $7,55 \pm 0,17^{\mathrm{c}}$ & $2,18 \pm 0,08^{\mathrm{B}^{*}}$ & $2,12 \pm 0,25$ \\
Polvo & $18,36 \pm 1,00^{\mathrm{A}}$ & $25,46 \pm 0,22^{\mathrm{b}}$ & $12,51 \pm 0,84^{\mathrm{C}^{*}}$ & $9,19 \pm 0,86$ \\
\hline
\end{tabular}

L*: luminosidad, hue: ángulo de tono, Chroma: saturación, $\Delta \mathrm{E}$ : cambio global de color. Los valores representan la media $(n=6) \pm S D$. Medias con una letra común por columna no son significativamente diferentes $(p \leq 0,05)$

Los frutos frescos de cassis presentaron un color púrpura-violáceo intenso debido a la alta concentración de antocianinas de la matriz (Moyer y col., 2002). Si bien durante el proceso de deshidratación, se registró una pérdida importante de antocianinas monoméricas (tabla III-20), este factor no impactó severamente sobre el cambio global de color $(\Delta \mathrm{E}=2,12 \pm 0,25)$, como así tampoco sobre el parámetro $a^{*}\left(a^{*}\right.$ fresco $=3,10 \pm 0,83 ; a^{*}$ deshidratado $\left.=2,16 \pm 0,08\right)$. El proceso de deshidratación provocó un corrimiento en hue de aproximadamente $10^{\circ}$, pero aun manteniendo la baja saturación, lo cual situó a la matriz en la zona de las tonalidades púrpuras (figura III-8).

La molienda del fruto deshidratado elevó el valor del parámetro $\mathrm{a}^{*}\left(\mathrm{a}^{*}\right.$ deshidratado $=$ $\left.2,16 \pm 0,08, a^{*}{ }_{\text {polvo }}=11,30 \pm 0,74\right)$, repercutiendo de manera significativa $(p \leq 0,05)$ sobre el ángulo de tono y la saturación y nos permite obtener un polvo púrpurarojizo (figura III-8). 


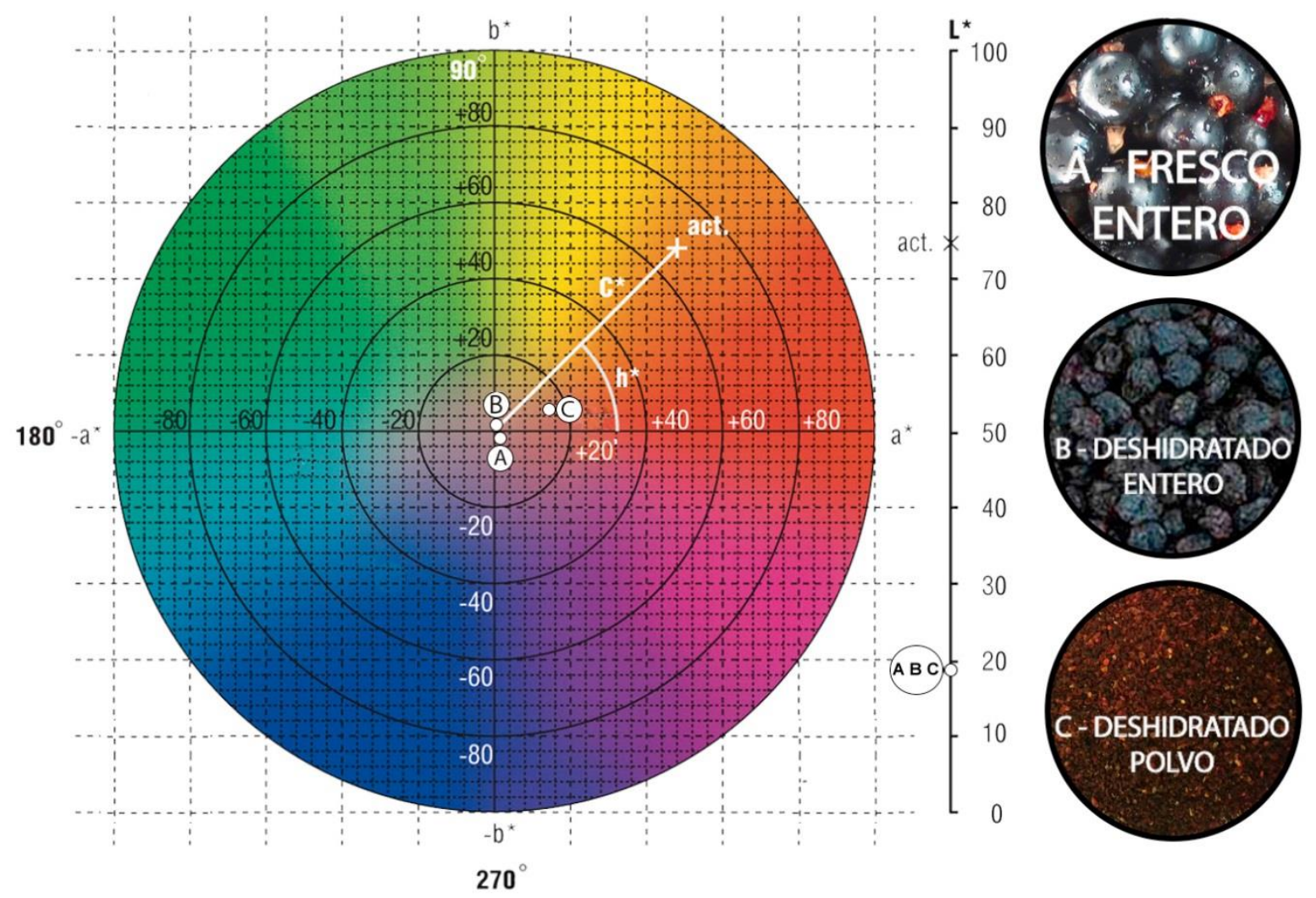

Figura III-8. Diagrama de color para cassis fresco y los productos obtenidos de la deshidratación. Nota: el disco de color central se corresponde con un valor de $L^{*}=50$

\section{III-4. CONCLUSIONES}

En cuanto a fenoles totales, flavonoides y poder antirradicalario:

- El proceso de pulpado disminuyó significativamente $(p \leq 0,05)$ las concentraciones de todos los compuestos bioactivos y el PA en zarzamora, frambuesa y arándano sin escaldar, debido a la incorporación de aire en la pulpa.

- El proceso de pasteurizado aumentó significativamente $(p \leq 0,05)$ los valores en zarzamora, frambuesa y arándano sin escaldar, en relación al pulpado, producto de un aumento de la extractabilidad por efecto de temperatura e inhibición de enzimas oxidativas nativas.

- El proceso de escaldado de arándano y guinda aumentó significativamente $(p \leq 0,05)$ la concentración de FT, Fv y PA de la pulpa respecto a fruta fresca; denotando el efecto beneficioso de la aplicación del pretratamiento.

- El pasteurizado, en matrices escaldadas, no generó cambios significativos en ninguna de las variables cuantificadas respecto al pulpado. 
- La deshidratación de rosa mosqueta y cassis, aumentó significativamente ( $\mathrm{s}$ $0,05)$ la concentración de FT, Fv y PA e impacta de modo negativo $(p \leq 0,05)$, sobre la concentración de ácido ascórbico.

- El elevado contenido de fenoles totales, flavonoides, ácido ascórbico y poder antirradicalario que presentan los polvos los convierten en excelentes aditivos para aumentar la funcionalidad de diversos alimentos.

\section{En cuanto a evaluación de color y contenido de pigmentos:}

- Durante el pulpado y pasteurización de zarzamora, frambuesa y arándano sin escaldar, se observó una disminución significativa $(p \leq 0,05)$ e importante de las antocianinas monómericas que se polimerizaron con el consiguiente aumento de \% CP e IDA.

- La concentración de ACY en guinda fue la menos afectada por los procesos aplicados.

- El escaldado previo en arándano, minimizó las pérdidas de antocianinas monoméricas en comparación con la misma matriz sin pretratamiento.

- La concentración de carotenos de rosa mosqueta no fue significativamente $(p \leq 0,05)$ afectada por la aplicación de aire caliente a $70^{\circ} \mathrm{C}$.

- En cassis, se registró una pérdida de ACY muy marcada $(45 \%, p \leq 0,05)$, debido a la interacción entre las antocianinas y el ácido ascórbico.

- Las matrices sometidas a los procesos de pulpado y pasteurizado tuvieron un significativo $(p \leq 0,05)$ cambio global de color, pero mantuvieron sus tonalidades dentro de los púrpuras-rojizos (el ángulo de saturación varió entre 270 y $25^{\circ}$ ), es decir, colores atractivos que facilitan la aceptación por parte de los consumidores.

- El proceso de deshidratación afectó significativamente $(p \leq 0,05)$ el color superficial en rosa mosqueta, permitiendo obtener un polvo amarrillento-anaranjado.

- El proceso de deshidratación en cassis permitió obtener un polvo de color violáceo atractivo sin generar drásticos cambios globales de color.

- La oxidación de las antocianinas fue más significativa en la muestra deshidratada (cassis) en comparación con las pulpas de otros frutos finos, debido al elevado contenido de ácido ascórbico de esa matriz.

- El polvo de cassis fue el producto que menor cambio global de color presentó de todas las matrices analizadas. 


\section{Conclusión general}

Los resultados presentados otorgan herramientas útiles al momento de la selección de la tecnología de procesamiento más adecuada para la obtención de pulpas y polvos de frutas finas patagónicos, ya sea para consumo directo o para la incorporación a otros alimentos preparados como yogures, mermeladas, infusiones, postres, etc, a fin de transformarlos en alimentos funcionales, por su alto contenido en compuestos bioactivos, ácido ascórbico, poder antirradical, de muy atractivos colores.

\section{III-5. REFERENCIAS}

- Anese, M.; Manzocco, L.; Nicolo, M.; Lerici, C. 1999. Antioxidant properties of tomato juice as affected by heating. Journal of the Science of Food and Agriculture. Vol. 79, p. 750-754.

- Alzamora, S.; Cerrutti, P.; Guerrero, S. y López-Malo, A. 1995. Minimally processed fruits by combined methods. Food preservation by moisture control: fundamentals and applications, Eds.Technomics A., Design of Minimal Processing Technologies for Publishing, Lancaster, Pennsylvania, p. 463-492.

- Alzamora, S.; Castro, M.; Vidales, S.; Nieto, A. y Salvatori, D. 2000. The role of tissue microstructure in the textural characteristics of minimally processed fruits. In S. M. Alzamora, S. Tapia, \& A. Lopez-Malo (Eds.), Minimally processed fruits and vegetables (p. 153-171). Maryland: Aspen Publishers Inc

- Bononi, M.; Andreoli, G.; Granelli, G.; Eccher, T. y Tateo, F. 2006. Cyanidin volumetric indexand chromaticity coordinates ratio to characterize red raspberry (Rubus idaeus). International Journal of Food Sciences and Nutrition. Vol. 57, n 5-6, p. 369-375.

- Brambilla, A.; Lo Scalzo, R.; Bertolo, G. y Torreggiani, D. 2008. SteamBlanched Highbush Blueberry (Vaccinium corymbosum L.) Juice: Phenolic Profile and Antioxidant Capacity in Relation to Cultivar Selection. Journal of Agricultural and Food Chemistry. Vol. 56, p. 2643-2648.

- Camacho, G. y Sanabria, G. 2005. Alternativas de procesamiento y transformación para la uchuva. En: Avances en cultivo, poscosecha y exportación de 
la uchuva Physalis peruviana L. en Colombia. Universidad Nacional de Colombia con el Auspicio del Ministerio de Agricultura y Desarrollo Rural. Bogotá, p 191-203.

- Cao W.; Nishiyama Y. y Koide S. 2003. Thin-layer drying of maitake mushroom analysed with a simplified model. Biosystems Engineering. Vol. 85, p. 331-337.

- Çekiç, Ç. y Özgen, M. 2010. Comparison of antioxidant capacity and phytochemical properties of wild and cultivated red raspberries (Rubus idaeusn L.). Journal of Food Composition and Analysis. Vol. 23, n 6, p. 540-544.

- Cheftel, J.; López, F.; Desnuelle, P. y Cheftel, H. 1980. Introducción a la bioquímica y tecnología de los alimentos. Acribia. España.

- Código Alimentario Argentino. 2016. Resolución GMC №46/03, Capítulo 5. http://www.anmat.gov.ar/alimentos/normativas_alimentos_caa.asp.Fecha de acceso: noviembre de 2016

- Jonsson, L. 1991. Thermal degradation of carotenoids and influence on their physiological functions. Nutritional and Toxicological Consequences of Food Processing. New York: Plenum Press, p. 75-82

- Dekazos, E. 1970. Anthocyanin pigments in red tart cherries. Journal of Food Science. Vol. 35, p. 237-241.

- De Rosso, V. y Mercadante, A. 2007. The high ascorbic acid content is the main cause of the low stability of anthocyanin extracts from acerola. Food Chemistry. Vol. 103, no 3, p. 935-943.

- Dewanto, V.; Wu, X.; Adom, K. y Liu, R. 2002. Thermal processing enhances the nutritional value of tomatoes by increasing total antioxidant activities. Journal Agricultural Food Chemistry. Vol. 50, p. 3010.

- Díaz de Tablante, R.; Tapia, M.; Montenegro, G. y González, I. 1993. Desarrollo de productos de mango y papaya de alta humedad por métodos combinados CYTED-D "Preservación de frutas a granel por métodos combinados". Boletin Interno $N^{\circ} 1$, p. 5-21.

- Diez, S.; Kesseler, A.; Pirone, B. 2008. Pigmentos en Frutos de Rosa Mosqueta: Efectos de la Deshidratación. Proceeding del XXVII Congreso Argentino de Química. Facultad de Bioquímica, Química y Farmacia (UNTucuman) Asociación Química Argentina 
- Espinoza, M.; Gómez, E.; Aguilar, J.; Cabanillas, J.; Santa, M.; Rodríguez, I. y Siche, R. 2015. Aprovechamiento de los residuos del membrillo (Cydonia oblonga L.) como fuente de compuestos bioactivos. Agroindustrial Science. Vol. 5, $n^{\circ} 2$, p. 133141.

- Es-Safi, N.; Cheynier, V. y Moutounet, M. 2003. Implication of phenolic reactions in food organoleptic properties. Journal of Food Composition and Analysis. Vol. 16, p. $535-553$.

- Fennema, O. 2010. Química de los Alimentos (3ra ed.) Zaragoza (España). Editorial Acribia, S.A

- Forni, E.; Polesello, A. y Torregiani, D. 1993. Changes in anthocyanins in cherries (Prunus avium) during osmodehydration, pasteurization and storage. Food Chemistry. Vol. 48, p. 295-299

- Franceschinis, L.; Sette, P.; Schebor, C. y Salvatori, D. 2015. Color and bioactive compounds characteristics on dehydrated sweet cherry products. Food and Bioprocess Technology: An International Journal. Vol. 8, nº 5, p. 935-1168.

- Francis, F. 1980. Color quality evaluation of horticultural crops. HortScience. Vol. 15, p. 14-15.

- Francis, F. y Markakis, P. 1989. Food colorants: anthocyanins. Critical Reviews in Food Science \& Nutrition. Vol. 28, nº 4, p. 273-314.

- Fuleki, T.; Francis, F. 1968. Quantitative methods for anthocyanins. Determination of total anthocyanins and degradation index for cranberry juice. Journal of Food Science. Vol. 33, n 78-83.

- Garzón, G. 1998. The Stability of Pelargonidin-based Anthocyanins in Natural and Model Systems. Thesis for the degree of Doctor of Philosophy in Food Science and Technology. Submitted to Oregon State University.

- Garzón, G. y Wrolstad, R. 2002. Comparison of the Stability of Pelargonidinbased Anthocyanins in Strawberry Juice and Concentrate. Journal of Food Science. Vol. 67, n 4, p. 1288-1299.

- Giusti, M. y Wrolstad, R. 2005. Characterization and measurement of anthocyanins by UV-visible spectroscopy. Unit F1.2. In: Handbook of food analytical chemistry, vol. 2: pigments, colorants, flavors, texture, and bioactive food components (p. 19-23). New York: John Wiley \& Sons Inc. 
- Hii, C.; Law, C. 2010. Product Quality Evolution During Drying of Foods, Vegetables and Fruits, en Jangam, S.V; Law, C.L y Mujumdar, A.S. (Eds.), Drying of Foods, Vegetables and Fruits, The University of Nottingham, Malasya. Vol. 1, p. 125 -145 .

- Hornero-Mendez D. y Mınguez-Mosquera, M. 2000. Carotenoid Pigments in Rosa mosqueta Hips, an Alternative Carotenoid Source for Foods. Journal of Agricultural Food Chemistry. Vol. 48, nº 3, p. 825-828.

- Jackman, R.; Yada, R.; Tung, M. y Speers, R. 1987. Anthocyanins as food colorants: a review. Journal Food Biochemistry. Vol. 11, p. 201.

- Jeong, S.; Kim, S.; Kim, D.; Jo, S.; Nam, K.; Ahn, D. y Lee, S. 2004. Effect of heat treatment on the antioxidant activity of extracts from citrus peels. Journal of agricultural and food chemistry, Vol. 52, n²11, p. 3389-3393.

- Jiménes, M.; Mateo, J.; Huerta, T.; Mateo, R. 1994. Influence of the storage conditions on some physiochemical and mycological parameters of honey. Journal of the Science of Food and Agriculture. Vol. 64, n 1, p. 67-74.

- Kader, F.; Rovel, B.; Girardin, M. y Metche, M. 1997. Mechanism of browning in fresh highbush blueberry fruit (Vaccinium corymbosum L.): role of blueberry polyphenol oxidase, chlorogenic acid and anthocyanins. Journal Sciencie Food Agricultural. Vol. 74, p. 31.

- Kader, F.; Irmouli, M.; Nicolas, J. y Metche, M. 1999. Degradation of cyanidin by caffeic acid o-quinone. Determination stiochiomety and characterization of degraded products. Journal of Agricultural and Food Chemistry. Vol. 47, p. 46254630.

- Kalt, W.; McDonald, J. y Donner, H. 2000. Anthocyanins, phenolics, and antioxidant capacity of processed lowbush blueberry products, Journal of Food Science. Vol. 65, p. 390.

- Kim, S.; Hayase, F. y Kato, H. 1986. Desmutagenic effects of melanoidins against amino acid and protein pyrolysates. Journal of Agricultural and Food Chemistry. Vol. 34, p. 354-358.

- Lee, J.; Durst, R. y Wrolstad, R. 2002. Impact of juice processing on blueberry anthocyanins and polyphenolics: comparison of two pretreatments. Journal of Food Science. Vol. 67, p. 1660-1666. 
- Lerici, C.; Manzocco, L.; Anese, M. y Nicoli, M. 1997. Cambiamenti del potere antiossidante in alimenti sottoposti a processi di trasformazione e conservazione. Industrie Alimentari. Vol. 36, p. 977-982.

- Mafarf, P. 1994. En Ingeniería Industrial Alimentaria Volumen 1: Procesos físicos de conservación. Ed. Acribia. Zaragoza-España.

- Manzocco, L.; Calligaris, S.; Mastrocola, D.; Nicoli, M. y Lerici, C. 2001. Review of non-enzymatic browning and antioxidant capacity in processed foods. Trends in Food Science and Technology. Vol. 11, p. 340-346.

- Márquez. 2003. Deshidratación de frutos no tradicionales. Rosa mosqueta. Memoria para optar por el título de Doctor Universitario en Ciencia e Ingeniería de los Alimentos de la Universidad Politécnica de Valencia. España

- Márquez C.; De Michelis A.; Giner S. 2006. Drying kinetics of rose hip fruits (Rosa eglanteria L.). Journal of Food Eng. Vol. 77, p. 566-574.

- Marty-Audouin, C.; Lebert, A. y Rocha-Mier, T. 1999. Influence of drying on the color of plant products. Developments in drying: food dehydration. Vol. 1, p. 207234.

- Medina, M. 2011. Simple and rapid method for the analysis of phenolic compounds in beverages and grains. Journal of Agricultural and Food Chemistry. Vol. 59, p. 1565-1571.

- Michalczyk, M., Ryszard, M. y Matuszak, I. 2009. The effect of air-drying, freezedrying and storage on the quality and antioxidant activity of some selected berries. Journal of Food Processing and Preservation. Vol. 33, p. 11-21.

- Moure, A.; Cruz, J.; Franco, D.; Dominguez, J.; Sineiro, J.; Dominguez, H.; Nuñez, M.; Parajó, J. 2001. Natural antioxidants from residual sources. Food Chemistry. Vol. 72, p. 145-171.

- Moyer, R.; Hummer, K.; Finn, C.; Frei, B. y Wrolstad, R. 2002 Anthocyanins, phenolics, and antioxidant capacity in diverse small fruits: Vaccinium, Rubus, and Ribes. Journal Agricultural Food Chemistry. Vol. 50, p. 519-525.

- Negi, P.; Roy, S. 2000. Effect of blanching and drying methods on $\beta$-carotene, ascorbic acid and chlorophyll retention of leafy vegetables. LWT-Food Science and Technology. Vol. 33, n4), p. 295-298. 
- Nicoli, M.; Anese, M.; Manzocco, L. y Lerici C. 1997a. Antioxidant properties of coffee brews in relation to the roasting degree. LWT-Food Science and Technology. Vol. 30, p. 292-297.

- Nicoli, M.; Anese, M.; Parpinel, M.; Franceschi, S. y Lerici C. 1997b. Loss and or formation of antioxidants during food processing and storage. Cancer Letters. Vol. 114 , p. $71-74$

- Nicoli, M.; Calligaris, S. y Manzocco, L. 2000. Effect of enzymatic and chemical oxidation on the antioxidant capacity of catechin model system and apple derivatives. Journal of Agriculture and Food Chemistry. Vol. 48, p. 4576-4580.

- Nicoli, M.; Anese, M. y Parpinel, M. 2004. Influence of processing on the antioxidant properties of fruit and vegetables. Trends Food Science Technology. Vol. $10, n^{\circ} 94$.

- Ochoa, M. 2011. Estudio del deterioro químico de guindas durante la deshidratación. Universidad Nacional de Bahía Blanca, Argentina. Memoria para optar por el título de Doctor en Ciencias Químicas de la Universidad Nacional de Bahía Blanca.

- Ohaco Domínguez, E. 2012. Modelos del producto para optimizar equipos de secado convectivo para frutos de rosa mosqueta en términos de los tiempos del proceso y la calidad final del producto. Universidad Nacional de Bahía Blanca, Argentina. Memoria para optar por el título de Doctor en Ciencia y Tecnología de los Alimentos de la Universidad Nacional de Bahía Blanca.

- Ordónez, J.; Cambero, M; García, M.; Garcia de Fernando, G.; De la Hoz, L. y Selgas, M. 1998. Componentes de los Alimentos y Procesos. Ed. Ordóñez. Vol. I, p. 284-289

- Patras, A.; Brunton, N.; O'Donnell, C.; Tiwari, B. 2010. Effect of thermal processing on anthocyanin stability in foods; mechanisms and kinetics of degradation. Trends in Food Science \& Technology. Vol. 21, p. 3-11.

- Peleg, H.; Naim, M.; Rouseff, R. y Zehavi, U. 1991. Distribution of bound and free polyphenolic acids in oranges (Citrus sinensis) and grapefruit (Citrus paradise). Journal of the Sciencie Food and Agriculture. Vol. 57, p. 417-426.

- Peinado Pardo, I. 2011. Influencia de las condiciones de deshidratación en los niveles de compuestos con actividad antioxidante del tomate cherry. Memoria para 
optar por el título de Máster Universitario en Ciencia e Ingeniería de los Alimentos de la Universidad Politécnica de Valencia. España

- Pereira, R. y Vicente, A. 2010. Environmental impact of novel thermal and non-thermal technologies in food processing. Food Research International. Vol. 43, $\mathrm{n}^{\circ} 7$, p. $1936-1943$.

- Perez-Locas, C.; Yaylayan, V. 2010. The Maillard reaction and food quality deterioration. In Chemical Deterioration and Physical Instability of Food and Beverages. P. 72-75. Boca Ratón, Florida, USA: Woodhead Publishing Limited and CRC Press.

- Piga, A.; Del Caro, A. y Corda, G. 2003. From plums to prunes: influence of drying parameters on polyphenols and antioxidant activity. Journal of Agricultural and Food Chemistry. Vol. 51, $\mathrm{n}^{\circ} 12$, p. 3675-3681.

- Pirone B.; Ochoa M.; Kesseler A. y De Michelis A. 2007. Chemical characterization and evolution of ascorbic acid concentration during dehydration of rosehip (Rosa eglanteria) fruits. American Journal of Food Technology. Vol. 2, $n^{\circ} 5$, p. 377-387.

- Poei-Langston, M. y Wrolstad, R. 1981. Color degradation in an ascorbic acid-anthocyanin-flavonol model system. Journal of Food Science. Vol. 46, p. 12181222.

- Que, F.; Mao, L.; Fang, X. y Wu, T. 2008. Comparison of hot air-drying and freezedrying on the physicochemical properties and antioxidant activities of pumpkin (Cucurbita moschata Duch.) flours. International Journal of Food Science \& Technology. Vol. 43, p. 1195-1201.

- Rommel, A.; Heatherbell, D. y Wrolstad, R. 1990. Red Raspberry Juice and Wine: Effect of Processing and Storage on Anthocyanin Pigment Composition, Color and Appearance. Journal of Food Sciencie. Vol. 55, nº 4, p. 1011-1017.

- Rossi, M.; Giussani, E.; Morelli, R.; Lo Scalzo, R.; Nani, R. y Torreggiani, D. 2003. Effect of fruit blanching on phenolics and radical scavenging activity of highbush blueberry juice. Food Research International. Vol. 36, p. 999-1005.

- Rubinskiene, M.; Viskelis, P.; Jasutiene, I.; Viskeliene, R. y Bobinas, C. 2005. Impact of various factors on the composition and stability of black currant anthocyanins. Food Research International. Vol. 38, p. 867-871 
- Sánchez-González, I.; Jiménez-Escrig, A. y Saura-Calixto, F. 2005. In vitro antioxidant activity of coffees brewed using different procedures (Italian, espresso and filter). Food Chemistry. Vol. 90, n ${ }^{\circ}$ 1, p. 133-139.

- Schreier, P. y Miller E. 1985. Studies on flavonol degradation by peroxidase (donor: $\mathrm{H}_{2} \mathrm{O}_{2}$-oxidoreductase, EC1.11.1.7): Part 2-Quercetin. Food Chemistry. . Vol. $18, n^{\circ} 4$, p. 301-317.

- Skrede, G.; Wrolstad, R.; Durst, R. 2000. Changes in Anthocyanins and Polyphenolics during Juice Processing of Highbush Blueberries (Vaccinium corymbosum L.). Journal of Food Science. Vol. 65, n 2, p. 357-364.

- Soong, Y. y Barlow, P. 2004. Antioxidant activity and phenolic content of selected fruit seeds. Food Chemistry. Vol. 88, no 3, p. 411-417.

- Stintzing, F.; Trichterborn, J. y Carle, R. 2006. Characterisation of anthocyanin-betalain mixtures for food colouring by chromatic and HPLC-DAD-MS analyses. Food Chemistry. Vol. 94, p. 296-309.

- Stojanovic, J.; Silva, J. 2007. Influence of osmotic concentration, continuous high frequency ultrasound and dehydration on antioxidants, colour and chemical properties of rabbiteye blueberries. Food Chemistry. Vol. 101, p. 898-906.

- Tapia M.; Alzamora S. y Chanes J. 1996. Combination of preservation factors applied to minimal processing of foods. Critical Revision Food Science Nutrition. Vol. 36, n6, p. 629-659.

- Topuz, A.; Feng, H. y Kushad, M. 2009. The effect of drying method and storage on color characteristics of paprika. LWT-Food Science and Technology. Vol. 42, no 10, p. 1667-1673.

- Torres, C.; Romero, L. y Diaz, R. 2015. Quality and sensory attributes of apple and quince leathers made without preservatives and with enhanced antioxidant activity. LWT-Food Science and Technology. Vol. 62, nº 2, p. 996-1003.

- Tuohy, K.; Hinton, D.; Davies, S.; Crabbe, M.; Gibson, G. y Ames, J. 2006. Metabolism of Maillard reaction products by the human gut microbiota-implications for health. Molecular nutrition \& food research. Vol. 50, no 9, p. 847-857.

- Uddin, M.; Hawlader, M.; Ding, L. y Mujumdar, A. 2002. Degradation of ascorbic acid in dried guava during storage. Journal of Food Engineering. Vol. 51, p. 21-26. 
- Vidales, S.; Castro, M. y Alzamora, S. 1998. The structure-texture relationship of blanched glucose impregnated strawberries. Food science and technology international. Vol. 4, p. 169-178.

- Vullioud M.; Márquez C. y De Michelis A. 2006. Equilibrium sorption isotherms and isosteric heat of rose hip fruits (Rosa eglanteria). International Journal of Food Properties. Vol. 9, p. 823-833.

- Wesche-Ebeling, P. y Montgomery, M. 1990. Strawberry polyphenoloxidase: its role in anthocyanin degradation. Journal of Food Science. Vol. 55, p. 731-745.

- Wijewickreme, A.; Krejpcio, Z. y Kitts, D. (1999). Hydroxyl Scavenging Activity of Glucose, Fructose, and Ribose-Lysine Model Maillard Products. Journal of Food Science. Vol. 64, no 3, p. 457-461.

- Wrolstad, R.; Durst, R.; Lee, J. 2005. Tracking color and pigment changes in anthocyanin products. Trends in Food Science \& Technology. Vol. 16, p. 423-428.

- Zanoni, B.; Peri, C.; Nani, R. y Lavelli, V. 1999. Oxidative heat damage of tomato halves as affected by drying. Food Research International. Vol. 31, p. 395401. 


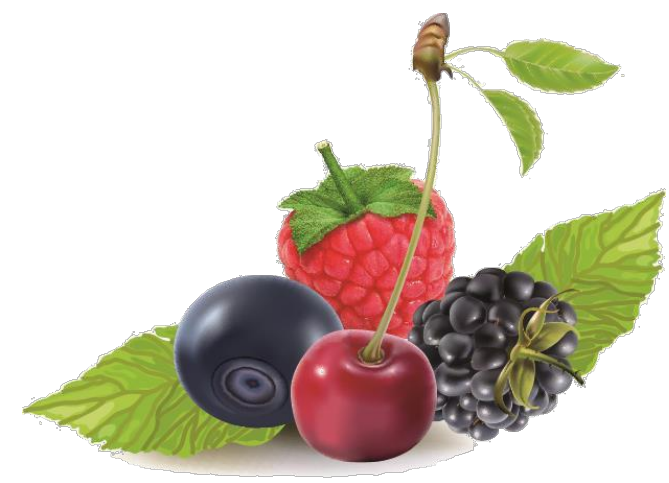

CAPITULO IV

Efecto del almacenamiento sobre los compuestos bioactivos, poder antirradicalario y el color superficial de pulpas de zarzamora, frambuesa, arándano y guinda 


\section{IV-1. INTRODUCCION}

Debido a su carácter estacional, las frutas finas (de cultivo y silvestres) están disponibles por un corto periodo de tiempo para consumo en fresco, por lo que resulta importante evaluar alternativas de almacenamiento y métodos de procesamiento que permitan extender su período de vida útil, preservando al máximo las características de calidad de la fruta fresca original.

Durante las operaciones de acondicionamiento, procesamiento $y$ almacenamiento se producen cambios que afectan a las propiedades nutritivas y funcionales de estos alimentos. Por esta razón, en este trabajo se ha incluido la evaluación de los compuestos bioactivos y el color superficial luego de la aplicación de los procesos tecnológicos (Capítulo III) y durante el almacenamiento, período en el cual pueden volverse inestables con el consecuente deterioro de la calidad inicial.

El uso de las pulpas como ingredientes en la elaboración de distintos productos (néctares, mermeladas, salsas, helados, yogures, alimentos infantiles, etc) presenta una serie de ventajas frente al método tradicional de utilizar la fruta fresca como materia prima, ya que permite la reducción de costos de almacenamiento por reducción de volumen y de transporte, como así también ampliar el tiempo de conservación (Osorio Mora, 2008).

\section{IV-1.1 Conservación}

La conservación de alimentos puede realizarse por procedimientos químicos (modificando la composición de los productos) o físicos (por la acción de determinados factores externos). Los métodos actuales de conservación permiten influir adecuadamente sobre la actividad enzimática y el curso de los procesos fisicoquímicos que alteran los productos, limitando o anulando por completo la actividad de los microorganismos (Gónzalez, 2011).

Dentro de los métodos de conservación, una subclasificación permite distinguir, de acuerdo a las condiciones de temperatura aplicadas, procesos de preservación por calor y frío. Entre los primeros encontramos, principalmente, los estudiados en el capítulo III; mientras que refrigeración y congelación se destacan como aquellos donde la baja temperatura es el factor común. 


\section{IV-1.1.1 Refrigeración}

Típicamente las temperaturas de refrigeración están comprendidas entre el punto de congelación del alimento $\left(-1^{\circ} \mathrm{C}\right)$ y unos $10^{\circ} \mathrm{C}$. Mediante el descenso de la temperatura se aumenta la vida útil del producto fresco o procesado por la disminución de la proliferación de microorganismos, la actividad metabólica de tejido y reacciones químicas o bioquímicas de deterioro. (Mafart, 1994; Ordoñez y col., 1998)

\section{IV-1.1.2 Congelación}

El poder conservador de este método se debe a la casi total eliminación del agua líquida por transformación en hielo obstaculizando la actividad microbiológica, enzimática, y a la reducción de la actividad biológica por el descenso de la temperatura que generalmente se lleva hasta un valor entre -10 y $-20^{\circ} \mathrm{C}$. Cuando la congelación y el almacenamiento se realizan adecuadamente, las características organolépticas del alimento y su valor nutritivo se afectan de manera reducida con el paso del tiempo.

La pérdida de cualidades en alimentos congelados es un proceso gradual, los cambios son lentos, acumulativos e irreversibles. La mayoría de los productos congelados tienen una vida media de varios meses. (Mafart, 1994; Ordoñez y col., 1998).

\section{IV-1.2 Factores que afectan la conservación durante el almacenamiento}

El almacenamiento de los alimentos constituye una de las etapas críticas en la industria de forma general, ya que, durante el mismo hay una pérdida gradual y acumulativa de la calidad con respecto al tiempo (IIR, 1986).

Las temperaturas de almacenamiento, sus fluctuaciones y los tiempos de anaquel son los factores principales que afectan la calidad del producto y estos se conocen como factores TTT (tiempo-temperatura-tolerancia). La vida de anaquel de casi todos los alimentos congelados, incluyendo los berries, se incrementa al disminuir las temperaturas al menos entre -18 a $-40{ }^{\circ} \mathrm{C}$ (Gómez-Sánchez y col., 2007).

Además de los factores temperatura y tiempo, también la presencia de oxígeno y luz afectan la calidad final del producto almacenado. En el primer caso debido a la oxidación por efecto de la incorporación de aire en la pulpa, lo que constituye un 
serio inconveniente en el procesamiento de frutas (Cheftel y col., 1980; Camacho y Sanabria, 2005).

El envasado que tiende a excluir el aire desde el tejido de la fruta es uno de los métodos más utilizados para matrices vegetales. El reemplazo del oxígeno por azúcares o gas inerte y/o el uso de vacío y películas impermeables se utiliza para prevenir y retardar el oscurecimiento y otros cambios de color (Gradziel, 1988; Venning y col., 1989, Kallio y col., 1986).

En cuanto a la luz, numerosos autores han reportado el efecto dañino de este parámetro sobre los compuestos bioactivos y el color superficial (Klein y Kurilich, 2000; Chandler y Schwartz, 1987; Jackman y Smith, 1996; Carlsen y Stapelfeldt, 1997; Inami y col., 1996; Kalt y col., 1993).

El objetivo de este capítulo fue estudiar la evolución de los compuestos bioactivos, el poder antirradicalario y el color superficial durante el almacenamiento de las pulpas, por un período de un año, bajo dos condiciones de conservación: pasteurizado (en ausencia y presencia de luz a temperatura ambiente) y congelado (en freezer a $-18^{\circ} \mathrm{C}$ ).

\section{IV-2. MATERIALES Y MÉTODOS}

Las frutas fueron cosechadas por productores de la zona de la Comarca Andina del Paralelo 42 en su punto de madurez óptimo y enviadas inmediatamente a Villa Regina, donde se conservaron en heladera a $5^{\circ} \mathrm{C}$ hasta su utilización.

Se realizó un muestreo aleatorio simple, se descartaron aquellos frutos que presentaban síntomas de avanzado estado de madurez.

Las variedades utilizadas fueron: frambuesa var. Tulameen, zarzamora var. Thornfree, guindas var. Montmorency y arándanos var. Elliot. Los extractos y las determinaciones se realizaron por triplicado

\section{IV-2.1 Procesos}

Las frutas fueron sometidas a los procesos establecidos en el capítulo III-2.1: pulpado (zarzamora y frambuesa) y escaldado-pulpado (arándano y guinda). El total de pulpa, por matriz, se dividió en dos fracciones: una se envasó en viales de vidrio, sellados con precintos metálicos y se pasteurizó según lo detallado en capítulo III2.1; y la segunda se colocó en placas de Petri descartables de $60 \mathrm{~mm}$ de diámetro, 
las cuales se barrieron con nitrógeno y se envasaron al vacío con una envasadora marca Oster Foodsaver V2240 (fotografía IV-1).

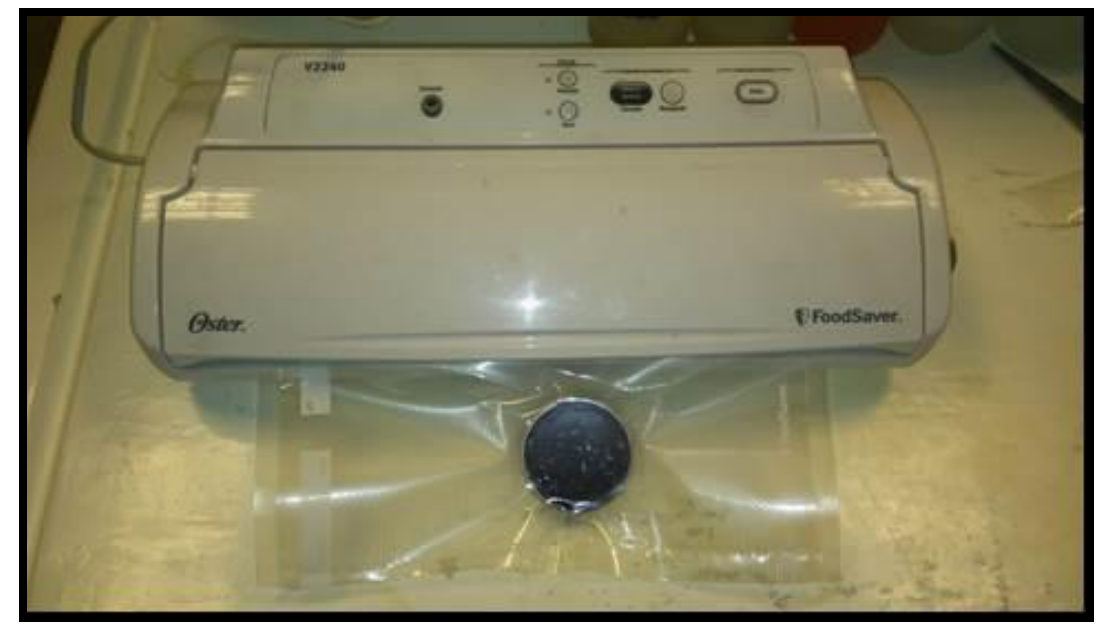

Fotografía IV-1. Proceso de envasado al vacío de pulpa de arándano escaldado

\section{IV-2.2 Condiciones de almacenamiento}

\section{IV-2.2.1 Almacenamiento Luz/Oscuridad}

Las pulpas pasteurizadas envasadas en viales de vidrio se almacenaron a temperatura ambiente $\left(25^{\circ} \mathrm{C}\right)$ en condiciones de anaquel (luz) y en oscuridad durante 12 meses, tomándose muestras al azar para llevar a cabo el seguimiento en la concentración de los compuestos estudiados. Los tiempos establecidos para extracción de muestras fueron (en días): 15, 30, 45, 60, 90, 120, 150, 180, 240, 300, 360.

\section{IV-2.2.2 Almacenamiento en freezer a $-18^{\circ} \mathrm{C}$}

Las placas con pulpa envasadas al vacío fueron congeladas y almacenadas a $18^{\circ} \mathrm{C}$ en freezer durante 12 meses. Se tomaron muestras al azar cada 30 días para llevar a cabo el seguimiento en la concentración de los compuestos estudiados. Los tiempos establecidos para extracción de muestras fueron (en días): 30, 60, 90, 120, $150,180,240,300,360$.

En los esquemas IV-1 y IV-2 se presenta un resumen de los procesos y condiciones de almacenamiento aplicados. 


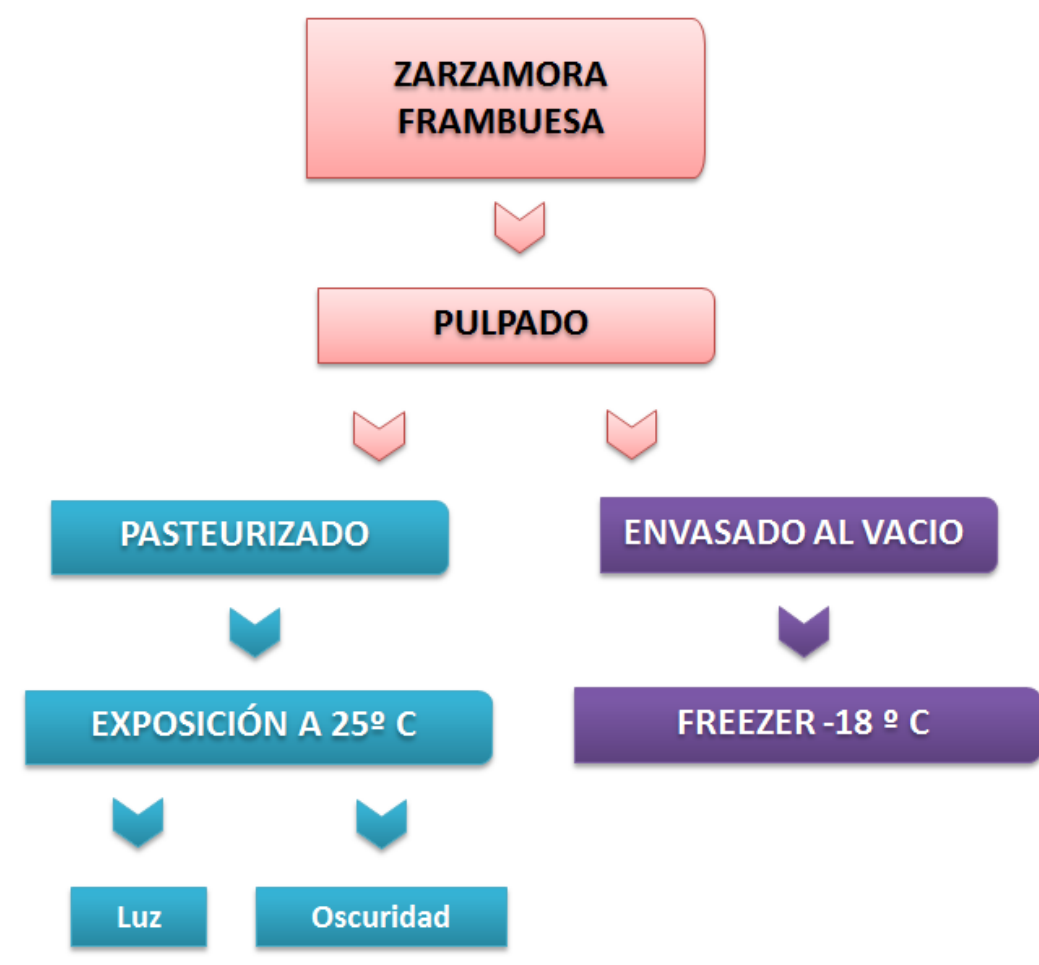

Esquema IV-1. Procesos y condiciones de almacenamiento aplicados a zarzamora y frambuesa.
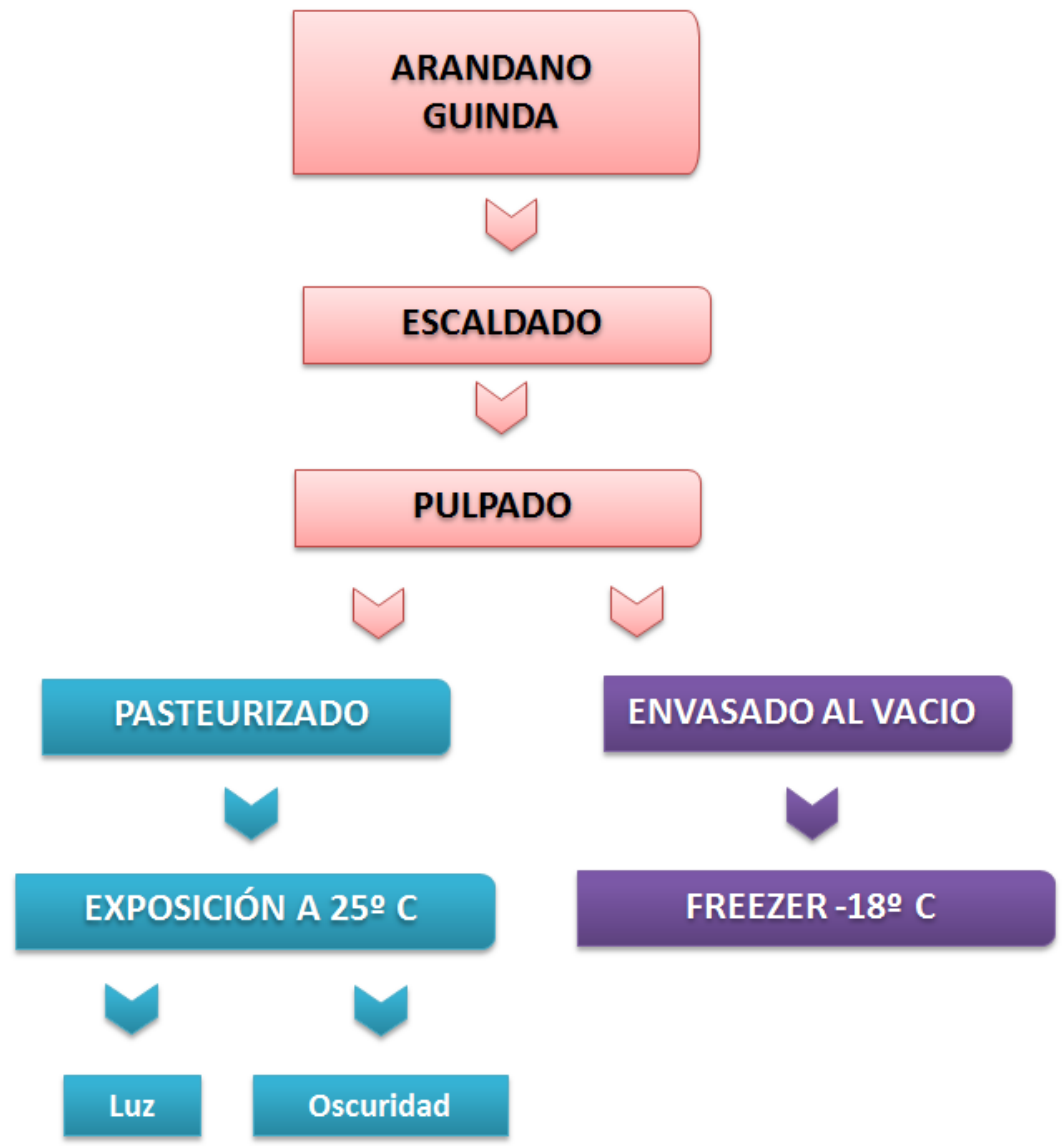

Esquema IV-2. Procesos y condiciones de almacenamiento aplicados a guinda y arándano. 


\section{IV-2.3 Determinaciones}

- Extracción de compuestos bioactivos. Se realizó según la metodología explicada en el Capítulo I, sección I-2.1; utilizando como solvente de extracción solución al $1 \%$ de $\mathrm{HCl}$ en etanol y temperatura de $37^{\circ} \mathrm{C}$.

- Fenoles totales (FT). Se realizó según la metodología explicada en el Capítulo I, sección I-2.1.

- Flavonoides (Fv). Se realizó según la metodología explicada en el Capítulo I, sección I-2.1.

- Poder Antirradical (PA). Se realizó según la metodología explicada en el Capítulo I, sección I-2.1.

- Antocianinas (ACY). Se realizó según la metodología explicada en el Capítulo I, sección I-2.1.

- Porcentaje de Color Polimérico (\% CP). Se realizó según la metodología explicada en el Capítulo III, sección III-2.2.

- Índice de degradación de antocianinas (IDA). Se realizó según la metodología explicada en el Capítulo III, sección III-2.2.

- Ácido Ascórbico Total (AA). Se realizó según la metodología explicada en el Capítulo II, sección II-2.1.

- Color superficial. Se realizó según la metodología explicada en el Capítulo II, sección II-2.1.

\section{IV-2.4 Análisis estadístico}

\section{IV-2.4.1 Almacenamiento en freezer a $-18^{\circ} \mathrm{C}$}

Para estudiar el efecto del almacenamiento en congelado sobre los compuestos bioactivos, poder antirradicalario y color superficial, se aplicó un diseño completamente aleatorizado. Los resultados se evaluaron mediante análisis de varianza (ANOVA) para un nivel de significancia $\alpha=0,05$ y se empleó la prueba de DGC (Di Rienzo, Guzmán, Casanoves) para la comparación de medias. Se utilizó el programa estadístico Infostat v. 2012. (Di Rienzo y col., 2012).

\section{IV-2.4.2 Almacenamiento Luz/Oscuridad}

En una primera instancia se aplicó un diseño factorial a dos vías (tiempo y tratamiento luz/oscuridad) completamente aleatorizado donde se encontró que para la mayoría de las variables hay interacción, por lo que a los efectos de evaluar el 
tratamiento (luz/oscuridad) se consideró el último punto de medición con un nivel de significancia del $\alpha=0,05$.

A los efectos de evaluar el tiempo de conservación y para todos los tratamientos se realizó un análisis de varianza (ANOVA) acompañado de contraste de tendencias (lineal y cuadrática) con un nivel de significancia $\alpha=0,05$. Se empleó la prueba de DGC (Di Rienzo, Guzmán, Casanoves) para la comparación de medias. Se utilizó el programa estadístico Infostat v. 2012. (Di Rienzo y col., 2012).

\section{IV-3. RESULTADOS Y DISCUSIÓN}

La biodisponibilidad de los fitoquímicos está influenciada por la matriz y la microestructura de los alimentos en los que se encuentran, las condiciones de almacenamiento (luz, oxígeno y temperatura) y el procesamiento térmico al que están sometidos (Parada y Aguilera, 2007). Como consecuencia, el conocimiento del contenido y la estabilidad de éstos en las frutas bajo estudio durante el almacenamiento es esencial para determinar su funcionalidad.

\section{IV-3.1 Almacenamiento en freezer a $-18^{\circ} \mathrm{C}$}

\section{IV-3.1.1 Fenoles totales, flavonoides y poder antirradicalario}

El contenido de fenoles totales, flavonoides y poder antirradicalario en las pulpas congeladas almacenadas durante un año se muestra en la tabla IV-1. 
Tabla IV-1. Efecto del almacenamiento en congelado sobre los FT, Fv y PA de zarzamora, frambuesa, arándano y guinda

\begin{tabular}{|c|c|c|c|c|c|c|c|c|c|c|}
\hline \multirow{2}{*}{ Fruta } & \multirow{2}{*}{ Control } & \multicolumn{9}{|c|}{ Alm acenam iento Congelado (m eses) } \\
\hline & & 1 & 2 & 3 & 4 & 5 & 6 & 8 & 10 & 12 \\
\hline \multicolumn{11}{|c|}{ Fenoles Totales (FT) } \\
\hline Zarzamora & $460 \pm 3^{A}$ & $452 \pm 8^{A}$ & $427 \pm 19^{B}$ & $393 \pm 17^{c}$ & $351 \pm 16^{\mathrm{D}}$ & $360 \pm 14^{\circ}$ & $334 \pm 12^{D}$ & $352 \pm 15^{D}$ & $370 \pm 17^{\circ}$ & $331 \pm 18^{D}$ \\
\hline Fram buesa & $219 \pm 12^{A}$ & $233 \pm 9^{A}$ & $222 \pm 6^{A}$ & $209 \pm 5^{\mathrm{B}}$ & $210 \pm 10^{\mathrm{B}}$ & $201+ \pm 8^{B}$ & $200 \pm 10^{B}$ & $181 \pm 6^{c}$ & $173 \pm 9^{c}$ & $168 \pm 7^{c}$ \\
\hline A ránd ano & $596 \pm 10^{A}$ & $616 \pm 3^{A}$ & $526 \pm 18^{\mathrm{B}}$ & $463 \pm 14^{c}$ & $466 \pm 19^{c}$ & $473+ \pm 18^{C}$ & $475 \pm 5^{c}$ & $472 \pm 20^{c}$ & $479 \pm 21^{c}$ & $465 \pm 20^{c}$ \\
\hline Guinda & $585 \pm 9^{A}$ & $593 \pm 12^{A}$ & $581 \pm 7^{A}$ & $485 \pm 21^{B}$ & $437 \pm 9^{c}$ & $446+ \pm 7^{c}$ & $440 \pm 10^{c}$ & $426 \pm 18^{c}$ & $490 \pm 18^{\mathrm{B}}$ & $483 \pm 12^{B}$ \\
\hline \multicolumn{11}{|c|}{ Flavonoides (Fv) } \\
\hline Zarzamora & $70 \pm 4^{\mathrm{a}}$ & $63 \pm 7^{\mathrm{a}}$ & $56 \pm 3^{b}$ & $58 \pm 4^{b}$ & $64 \pm 3^{\mathrm{a}}$ & $64 \pm 2^{a}$ & $54 \pm 7^{\circ}$ & $56 \pm 2^{b}$ & $58 \pm 5^{b}$ & $67 \pm 1^{\mathrm{s}}$ \\
\hline Fram buesa & $42 \pm 3^{a}$ & $34 \pm 2^{b}$ & $32 \pm 1^{b}$ & $34 \pm 2^{b}$ & $37 \pm 2^{b}$ & $38 \pm 1^{b}$ & $33 \pm 3^{b}$ & $35 \pm 5^{b}$ & $36 \pm 1^{b}$ & $41 \pm 6^{\mathrm{a}}$ \\
\hline A rándano & $210 \pm 8^{a}$ & $195 \pm 9^{\mathrm{s}}$ & $198 \pm 11^{\mathrm{a}}$ & $196 \pm 12^{a}$ & $173 \pm 15^{b}$ & $181 \pm 7^{b}$ & $170 \pm 5^{b}$ & $160 \pm 5^{b}$ & $157 \pm 7^{b}$ & $165 \pm 4^{b}$ \\
\hline Guinda & $320 \pm 7^{a}$ & $313 \pm 13^{a}$ & $291 \pm 4^{b}$ & $281 \pm 3^{b}$ & $268 \pm 8^{\circ}$ & $265 \pm 5^{\circ}$ & $255 \pm 8^{\circ}$ & $257 \pm 3^{\circ}$ & $250 \pm 11^{\circ}$ & $267 \pm 17^{\circ}$ \\
\hline \multicolumn{11}{|c|}{ Poder Antirradicalario (PA) } \\
\hline Zarzamora & $1,75 \pm 0,01^{\mathrm{c}^{*}}$ & $1,45 \pm 0,09^{D^{*}}$ & $1,47 \pm 0,02^{D^{*}}$ & $1,54 \pm 0,09^{D^{*}}$ & $1,55 \pm 0,04^{D^{*}}$ & $1,60 \pm 0,05^{D^{-}}$ & $1,86 \pm 0,01^{\mathrm{B}^{*}}$ & $1,99 \pm 0,06^{\mathrm{A}^{*}}$ & $1,68 \pm 0,03^{c^{*}}$ & $1,68 \pm 0,14^{\mathrm{c}^{-}}$ \\
\hline Fram buesa & $1,33 \pm 0,01^{\mathrm{A}^{*}}$ & $0,68 \pm 0,02^{\mathrm{B}^{*}}$ & $0,50 \pm 0,02^{c^{-}}$ & $0,57 \pm 0,02^{\mathrm{C}^{*}}$ & $0,54 \pm 0,02^{c^{-}}$ & $0,55 \pm 0,04^{c^{-}}$ & $0,52 \pm 0,02^{c^{-}}$ & $0,52 \pm 0,01^{\mathrm{c}^{-}}$ & $0,53 \pm 0,01^{\mathrm{c}^{-}}$ & $0,56 \pm 0,03^{c^{-}}$ \\
\hline A rándano & $1,99 \pm 0,05^{\mathrm{A}^{*}}$ & $1,58 \pm 0,08^{\mathrm{E}^{*}}$ & $1,49 \pm 0,05^{\mathrm{c}^{*}}$ & $1,45 \pm 0,04^{\mathrm{C}^{*}}$ & $1,45 \pm 0,05^{\mathrm{c}^{-}}$ & $1,46 \pm 0,06^{\mathrm{C}^{-}}$ & $1,44 \pm 0,03^{\mathrm{c}^{-}}$ & $1,47 \pm 0,02^{\mathrm{C}^{*}}$ & $1,66 \pm 0,07^{\mathrm{E}^{*}}$ & $1,58 \pm 0,03^{\mathrm{B}^{*}}$ \\
\hline Guinda & $0,80 \pm 0,07^{\mathrm{A}^{*}}$ & $0,57 \pm 0,01^{c^{*}}$ & $0,53 \pm 0,02^{\mathrm{C}^{-}}$ & $0,57 \pm 0,01^{\mathrm{c}^{-}}$ & $0,56 \pm 0,02^{\mathrm{c}^{-}}$ & $0,64 \pm 0,04^{\mathrm{B}^{*}}$ & $0,53 \pm 0,02^{\mathrm{c}^{-}}$ & $0,60 \pm 0,02^{\mathrm{C}^{*}}$ & $0,61 \pm 0,03^{c^{*}}$ & $0,59 \pm 0,02^{\mathrm{c}^{-}}$ \\
\hline
\end{tabular}

FT: fenoles totales ( $\mathrm{mg} \mathrm{GAE} / 100 \mathrm{~g}$ ), Fv: flavonoides ( $\mathrm{mg} \mathrm{CE} / 100 \mathrm{~g}$ ), PA: poder antirradical $\left(\mathrm{mg}^{-1}\right)$. Los valores representan la media $(\mathrm{n}=3) \pm \mathrm{SD}$. Medias con una letra común por fila no son significativamente diferentes $(p<=0,05)$ 
A los fines de poder realizar un análisis comparativo para estimar tendencias, se procedió al cálculo del porcentaje de retención de los compuestos bioactivos y el poder antirradicalario, en el tiempo, considerando las cuatro matrices bajo estudio (figuras IV-1, IV-2 y IV-3).

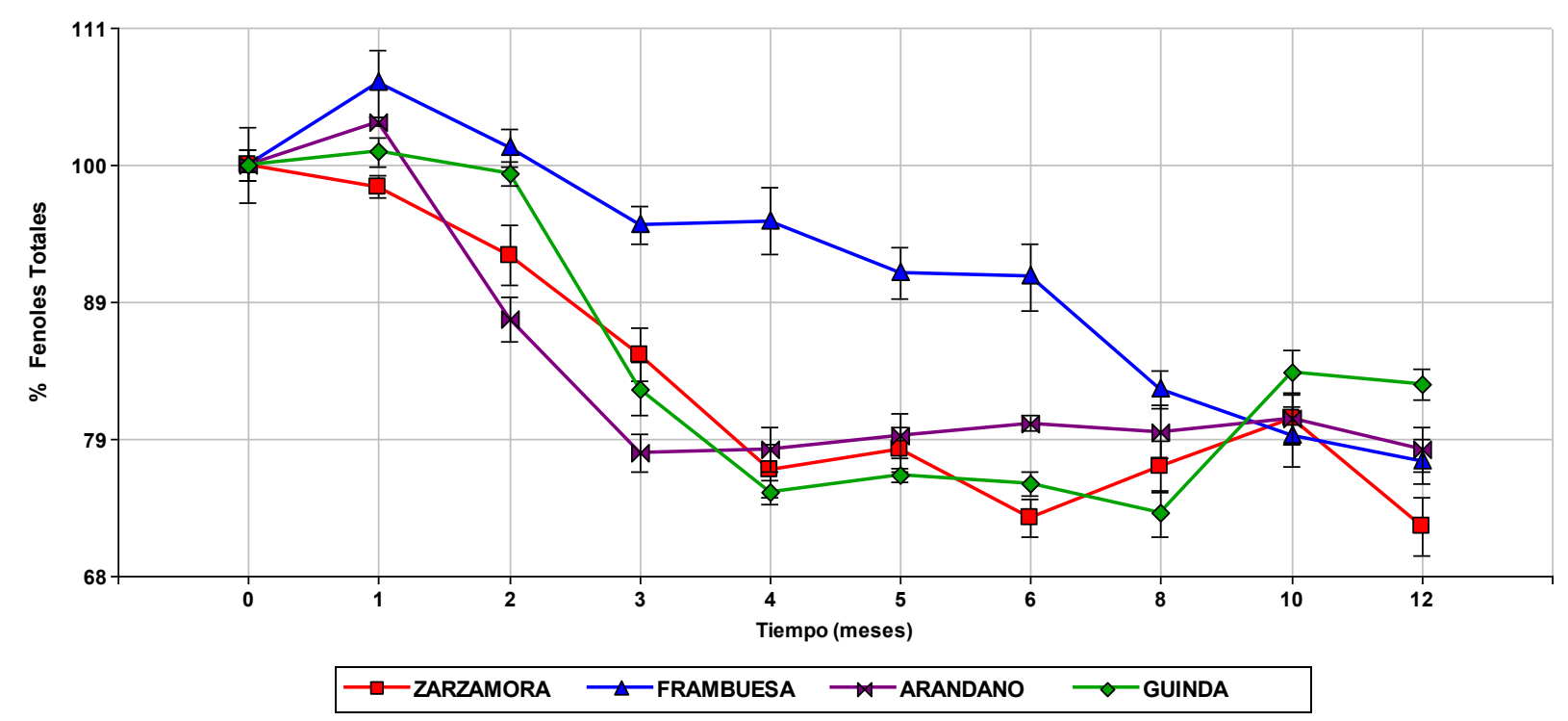

Figura IV-1. Porcentaje de fenoles totales a lo largo del tiempo de almacenamiento congelado. Nota: la altura del punto indica el valor medio. Las barras de error expresan el error estándar.

El contenido de fenoles totales disminuyó a lo largo del almacenamiento congelado para las cuatro pulpas estudiadas. Las principales diferencias radicaron en las cinéticas de disminución ya que, para zarzamora y arándano se registró a partir de los 30 días de almacenamiento un decaimiento significativo (pérdida entre 10 y 15\%), mientras que en guinda recién luego de 60 días la concentración disminuyó un 17\%. Los fenoles totales de frambuesa presentaron la mayor estabilidad en los primeros 6 meses con una retención del $95 \%$. Luego del año de almacenamiento todas las matrices retuvieron entre un 70 y $87 \%$ de los fenoles totales

Bunea y col. (2008) concluyeron en su estudio sobre fenoles totales de espinaca que, si bien, el almacenamiento puede afectar negativamente la cantidad total de compuestos fenólicos, algunos de los fenoles simples pueden aumentar su concentración como resultado de la descomposición de estructuras supramoleculares que los contienen, lo cual podría explicar la presencia de oscilaciones en las curvas de las figura IV-1. 
Türkben y col. (2010) evaluaron el efecto del congelado y almacenamiento, durante 6 meses, en freezer sobre ácido elágico, principal ácido fenólico presente en frambuesa y zarzamora (Rommel y Wrolstad, 1993; Häkkinen y col. 1999a, b) y denotaron una pérdida marcada que depende de la variedad estudiada: $49-50 \%$ en frambuesa (var. Aksu y Heritage respectivamente) y 28 , 32 y $66 \%$ en zarzamora (var. Jumbo, Chester y Bursa 2 respectivamente). Concluyen que esa disminución podría estar relacionada con la liberación de la PPO (responsable de la oxidación de los polifenoles a quinonas) ligada a la pared celular cuando se produce la disrupción de la misma por congelación.

El aumento en la concentración del sistema enzimático fue corroborado por De Ancos y col. (2000), quienes reportaron un incremento de la PPO, luego de un año, de $34 \%$ y $19 \%$ en frambuesas var. Heritage y Rubí. La disminución del contenido de fenoles totales $(23 \%)$ en frambuesas var. Zeva informado por estos autores para el mismo período de tiempo se condice con lo hallado en la presente investigación.

Poiana y col. (2010) informaron disminuciones significativas en la concentración de $\mathrm{FT}$ en berries almacenados a $-18{ }^{\circ} \mathrm{C}$ durante 10 meses: $28 \%$ en arándano, $42 \%$ en zarzamora y $47 \%$ en frambuesa; en todos los casos los valores fueron superiores a los obtenidos en este trabajo (20\% para zarzamora y arándano y $21 \%$ para frambuesa), quizás debido al hecho de que estos autores trabajan con fruta entera, mientras que en esta sección se analizó fruta ya procesada.

En la figura IV-2 se presenta la evolución del porcentaje de flavonoides en las cuatro matrices a lo largo del almacenamiento congelado durante un año 


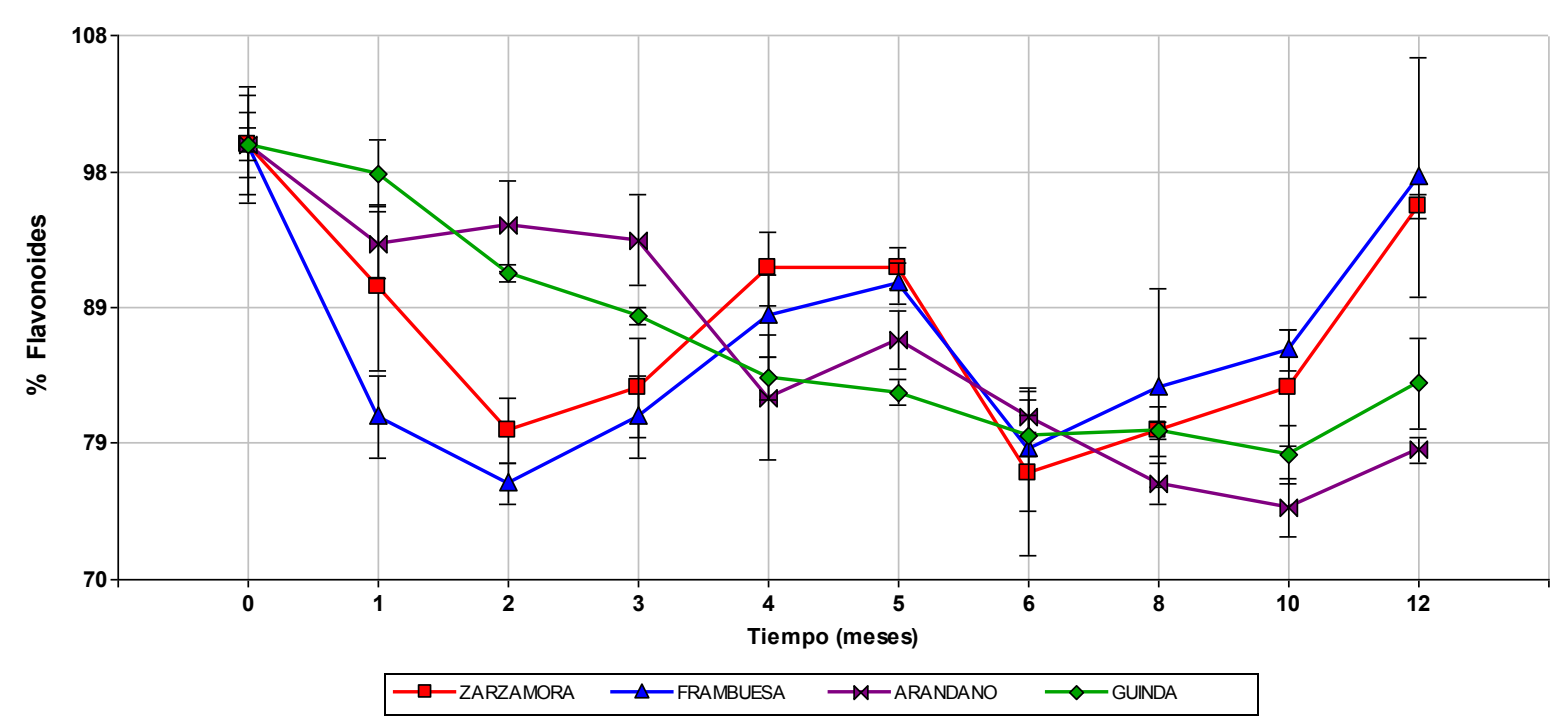

Figura IV-2. Porcentaje de flavonoides a lo largo del tiempo de almacenamiento congelado. Nota: la altura del punto indica el valor medio. Las barras de error expresan el error estándar.

Para esta variable no se hallaron diferencias significativas $(p \leq 0,05)$ en zarzamora y frambuesa, y se destaca que ambas matrices, que pertenecen al género Rubus, presentaron el mismo comportamiento en el tiempo. En arándano y guinda se observaron disminuciones en la concentración, a lo largo del año de almacenamiento, del $21 \%$ y $17 \%$ respectivamente.

Häkkinen y col. (2000) realizaron un estudio sobre el procesamiento doméstico y almacenamiento de berries en el cual cuantificaron flavonoides individuales (quercetina, kampferol y mirecetina) y destacaron el efecto protector de la vitamina $\mathrm{C}$ sobre estos compuestos en matrices con alto contenido, como frambuesa y cassis. Además reportaron el variado comportamiento de cada uno de los flavonoides cuantificados; concluyendo que mirecetina y kaempferol son más susceptibles al almacenamiento congelado que quercetina.

Según Poiana y col. (2010) es probable que la disminución significativa de flavonoides se deba al contenido de agua no congelada. La actividad y la velocidad de las reacciones enzimáticas alcanzan valores máximos en las capas de agua líquida en frutas congeladas. Tal vez, este fenómeno contribuya a la modificación de compuestos químicos, incluyendo sustancias biológicamente activas. En los productos congelados las reacciones 
enzimáticas son lentas, pero no se encuentran completamente bloqueadas. En general, la actividad de las enzimas en los berries congelados está ligada a la presencia de agua no congelada. A una temperatura de $-18^{\circ} \mathrm{C}$, en las matrices congeladas, el contenido de agua líquida representa aproximadamente el $11 \%$ del agua total.

Además, después de la congelación, los solutos pueden estar sobresaturados en la fase no congelada. Con el tiempo, estos solutos pueden cristalizar o precipitar y cambiar las cantidades relativas y concentraciones reales. Por lo tanto, la fuerza iónica y el pH pueden cambiar debido a las proporciones cambiantes de los componentes del buffer. Estos factores también afectan la estabilidad, provocando cambios en las características de las moléculas en solución (Kobs, 1997).

La evolución del poder antirradical en las frutas durante el almacenamiento congeladas se muestra en la figura IV-3. De las matrices bajo estudio, la frambuesa fue la que presentó mayores variaciones, con una pérdida del $58 \%$ del poder antirradicalario, seguida por guinda (26\%) y arándano (21\%). En zarzamora no se hallaron diferencias significativas $(p \leq 0,05)$ al finalizar el año almacenamiento $\mathrm{a}-18^{\circ} \mathrm{C}$.

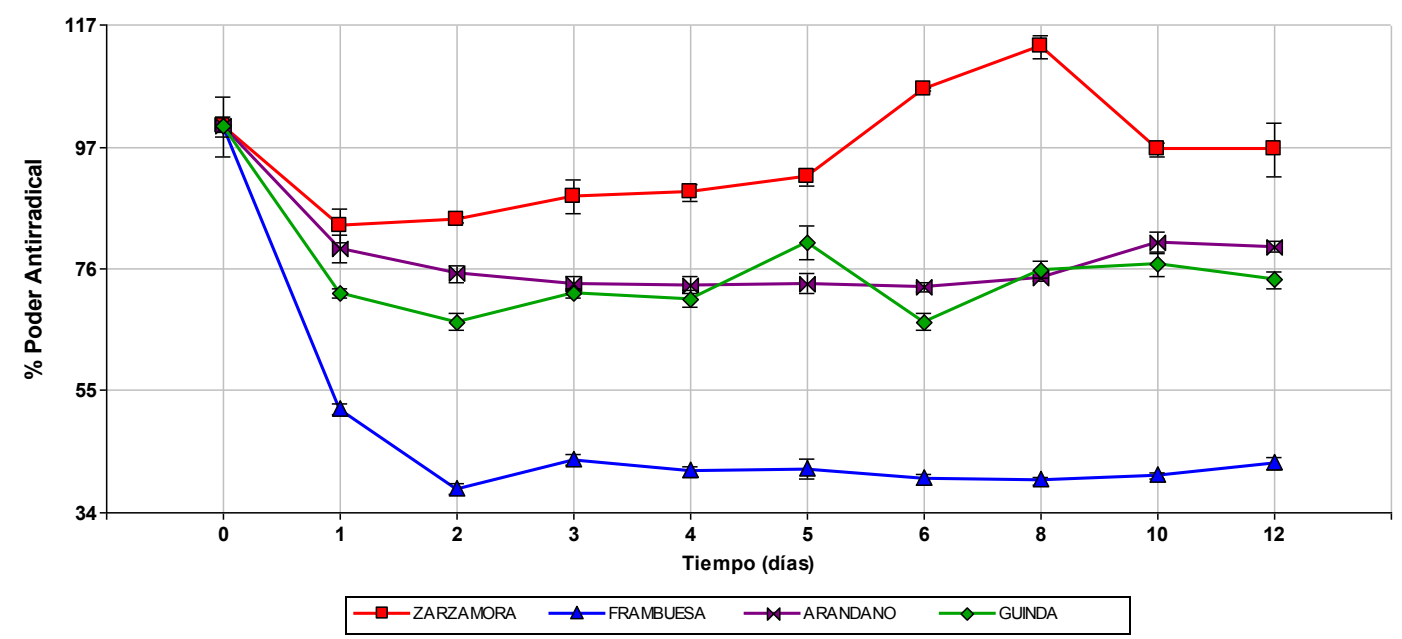

Figura IV-3. Porcentaje de poder antirradicalario a lo largo del tiempo de almacenamiento congelado. Nota: la altura del punto indica el valor medio. Las barras de error expresan el error estándar. 
Varios autores han reportado la disminución del poder antirradical durante el almacenamiento congelado de berries y cherries (De Ancos, 2000; Poiana, 2010; Chaovanalikit y Wrolstad, 2004), concluyendo que el porcentaje de retención final dependerá de la especie y dentro de ella las distintas variedades también tienen influencia.

Además, se recomienda considerar las condiciones en la cual se realice el almacenamiento y los extractos. Por ejemplo Zhao, (2007) estudió las fluctuaciones de temperatura del equipo de frio, y concluyó que los gradientes de temperatura dentro de un producto durante el almacenamiento congelado pueden resultar en la migración de la humedad con el consecuente cambio en la concentración de las sustancias. Scibisz y Mitek (2007) observaron el impacto del método de descongelación (temperatura ambiente y refrigeración) informando fluctuaciones en la concentración de pigmentos entre ambas condiciones.

\section{IV-3.1.2 Contenido de pigmentos}

En la tabla IV-2 se presentan los datos para la concentración de ACY, \% CP e IDA a lo largo de un año de almacenamiento para las pulpas de zarzamora, frambuesa, arándano y guinda.

Las antocianinas monoméricas, presentaron muy buenos porcentajes de retención a lo largo de los 12 meses de almacenamiento (figura IV-4) siendo zarzamora y guinda las frutas más afectadas con solo un $14 \%$ de pérdida. En frambuesa y arándano no se registraron diferencias significativas $(p \leq 0,05)$ a lo largo del año de almacenamiento para la concentración de ACY. 
Tabla IV-2. Efecto del almacenamiento congelado sobre ACY, \% CP e IDA de zarzamora, frambuesa, arándano y guinda

\begin{tabular}{|c|c|c|c|c|c|c|c|c|c|c|}
\hline \multirow{2}{*}{ Fruta } & \multirow{2}{*}{ Control } & \multicolumn{9}{|c|}{ Alm acenam iento Congelado (m eses) } \\
\hline & & 1 & 2 & 3 & 4 & 5 & 6 & 8 & 10 & 12 \\
\hline \multicolumn{11}{|c|}{ Antocianinas ( $A C Y$ ) } \\
\hline Fram buesa & $46 \pm 3^{A}$ & $47 \pm 1^{A}$ & $42 \pm 3^{A}$ & $41 \pm 3^{A}$ & $43 \pm 2^{A}$ & $42 \pm 2^{A}$ & $44 \pm 1^{A}$ & $43 \pm 2^{A}$ & $44 \pm 2^{A}$ & $45 \pm 2^{A}$ \\
\hline Arándano & $172 \pm 10^{\mathrm{A}}$ & $172 \pm 9^{A}$ & $164 \pm 6^{A}$ & $166 \pm 2^{A}$ & $166 \pm 3^{\mathrm{A}}$ & $164+ \pm 5^{\mathrm{A}}$ & $173 \pm 4^{\mathrm{A}}$ & $167 \pm 3^{\mathrm{A}}$ & $176 \pm 4^{\mathrm{A}}$ & $168 \pm 4^{A}$ \\
\hline Zarzam ora & $20 \pm 2^{\mathrm{s}}$ & $19 \pm 2^{a}$ & $19 \pm 3^{\mathrm{a}}$ & $21 \pm 1^{\mathrm{s}}$ & $20 \pm 0^{3}$ & $22 \pm 2^{3}$ & $19 \pm 1^{\mathrm{a}}$ & $18 \pm 2^{a}$ & $20 \pm 1^{\mathrm{s}}$ & $20 \pm 2^{3}$ \\
\hline Fram buesa & $34 \pm 0^{3}$ & $34 \pm 5^{3}$ & $36 \pm 1^{\mathrm{a}}$ & $35 \pm 2^{s}$ & $32 \pm 0^{s}$ & $31 \pm 3^{\mathrm{s}}$ & $32 \pm 2^{a}$ & $33 \pm 2^{a}$ & $32 \pm 2^{a}$ & $33 \pm 2^{a}$ \\
\hline A rándano & $13 \pm 2^{a}$ & $12 \pm 1^{\mathrm{a}}$ & $12 \pm 1^{\mathrm{s}}$ & $11 \pm 2^{a}$ & $12 \pm 1^{\mathrm{a}}$ & $12 \pm 2^{\mathrm{a}}$ & $12 \pm 1^{\mathrm{a}}$ & $13 \pm 1^{\mathrm{a}}$ & $14 \pm 2^{a}$ & $14 \pm 2^{a}$ \\
\hline Guinda & $24 \pm 3^{\mathrm{a}}$ & $23 \pm 1^{\mathrm{a}}$ & $25 \pm 1^{\mathrm{s}}$ & $26 \pm 0^{3}$ & $26 \pm 2^{\mathrm{s}}$ & $27 \pm 1^{\mathrm{a}}$ & $25 \pm 3^{\mathrm{a}}$ & $26 \pm 1^{a}$ & $24 \pm 3^{a}$ & $25 \pm 3^{9}$ \\
\hline Guinda & $1,32 \pm 0,06^{\mathrm{B}^{*}}$ & $1,27 \pm 0,01 \mathrm{\Xi}^{*}$ & $1,36 \pm 0,02^{A^{*}}$ & $1,37 \pm 0,01^{\mathrm{A}^{*}}$ & $1,31 \pm 0,00^{\boldsymbol{\theta}^{*}}$ & $1,37 \pm 0,02^{\mathrm{A}^{*}}$ & $1,30 \pm 0,03^{\mathrm{E}^{*}}$ & $1,32 \pm 0,03^{\mathrm{E}^{*}}$ & $1,30 \pm 0,05^{\mathrm{B}^{*}}$ & $1,24 \pm 0,03^{\text {}}$ \\
\hline
\end{tabular}

ACY: antocianinas monoméricas ( $\mathrm{mg}$ cianidina-3-glu/100 $\mathrm{ms}$ ), \%CP: porcentaje de color polimérico, IDA: índice de degradación de antocianinas. Los valores representan la media ( $\mathrm{n}=3$ ) $\pm \mathrm{SD}$. Medias con una letra común por fila no son significativamente diferentes $(p<=0,05)$ 


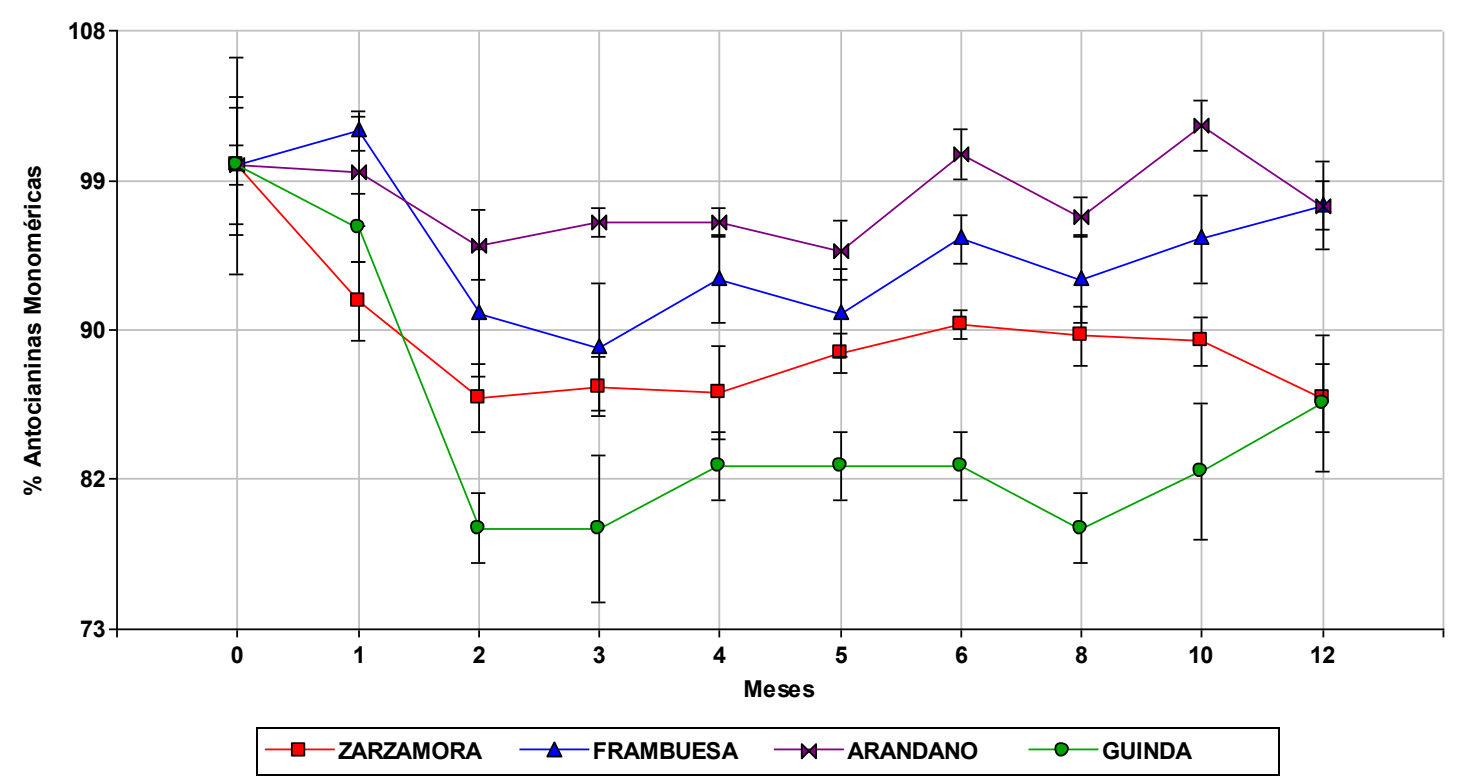

Figura IV-4. Porcentaje de ACY en las pulpas estudiadas durante el almacenamiento congelado. Nota: la altura del punto indica el valor medio. Las barras de error expresan el error estándar.

El porcentaje de color polimérico es otro parámetro que representa la degradación de los pigmentos antociánicos, e indica cuanto del color percibido se debe a los compuestos derivados de las antocianinas. La evolución del \% $\mathrm{CP}$ se presenta en la figura IV-5. Ninguna de las matrices presentó diferencias significativas $(p \leq 0,05)$ en el tiempo de almacenamiento, lo cual es consistente con el comportamiento de las ACY. Los mayores valores los presentó frambuesa, seguido por guinda, zarzamora y finalmente arándano

Los \% CP de tiempo cero pueden responder a la formación de complejos de los pigmentos con otros polifenoles, pudiendo incluir a los compuestos pardos producidos por vía enzimática debido a la descompartimentalización llevada a cabo durante el procesamiento de la muestra. Varios estudios, sobre distintos productos (pulpa de frambuesa, cerezas y frutillas enlatadas, productos a base de frambuesa negra, productos procesados de arándanos) en los que se analizó el procesado junto al almacenamiento, han demostrado que a medida que se produce un descenso en el contenido de antocianinas monoméricas el porcentaje de color polimérico se ve incrementado (Ochoa y col. 1999; Chaovanalkit y Wrolstad, 2004; Ngo y col. 2007; Brownmiller y col., 2008). 


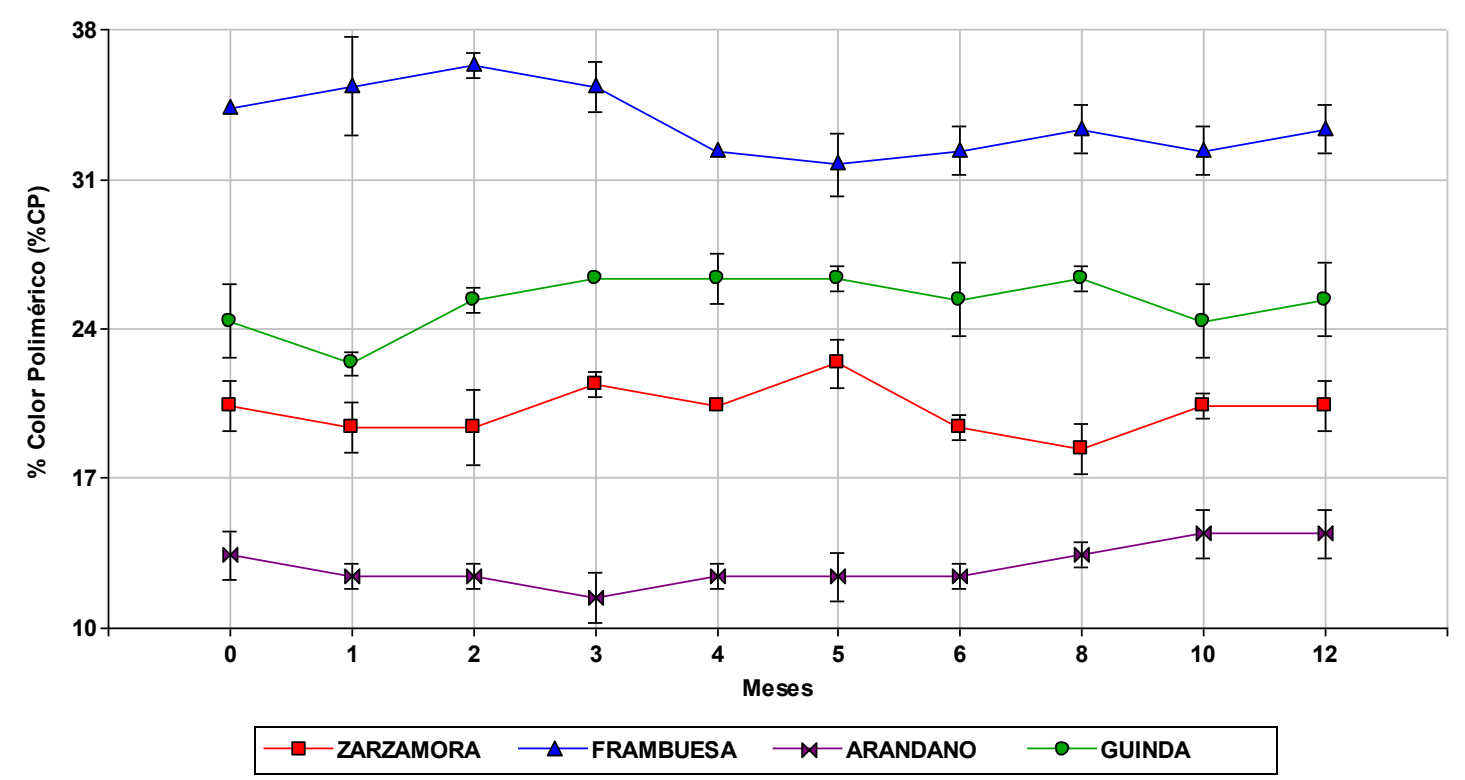

Figura IV-5. Porcentaje de CP en las pulpas estudiadas durante el almacenamiento congelado. Nota: la altura del punto indica el valor medio. Las barras de error expresan el error estándar.

El índice de degradación de antocianinas (IDA) es indicativo de la proporción de antocianinas degradadas en la muestra y sus valores a lo largo del almacenamiento se muestran en la figura IV-6.

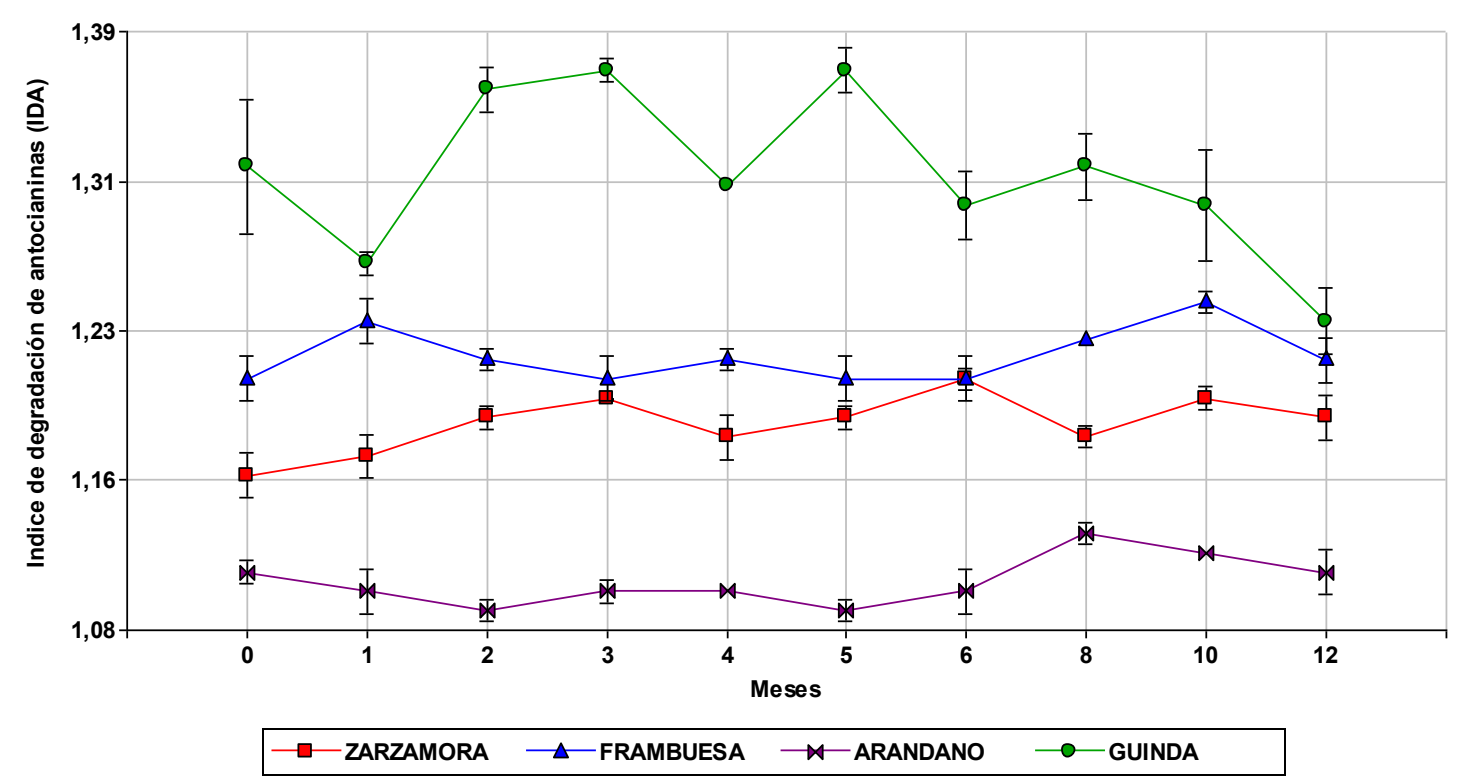

Figura IV-6. Índice de degradación de ACY en las pulpas estudiadas durante el almacenamiento congelado. Nota: la altura del punto indica el valor medio. Las barras de error expresan el error estándar. 
Teniendo en cuenta que el índice se basa en el principio de que las mediciones obtenidas a pH 1,0 incluyen la absorción total de los pigmentos, mientras que la diferencia en la absorción entre el $\mathrm{pH} 1,0$ y 4,5 se debe únicamente a las antocianinas no degradadas, las muestras que no contienen pigmento degradado u otros compuestos pardos deberían dar valores de IDA cercanos a la unidad.

Solamente para zarzamora se registró un aumento del 2,5\% entre el IDA correspondiente al valor inicial y luego del almacenamiento congelado por un año.

En guinda, si bien no se registraron cambios significativos $(p \leq 0,05)$, los valores para el índice a tiempo cero fueron los más elevados, lo cual indicaría una mayor proporción de antocianinas degradadas, debido probablemente a la pérdida de pigmentos durante la preparación de la muestra o en la etapa de extracción para el análisis.

\section{IV-3.1.3 Color superficial}

Los datos iniciales y finales de la luminosidad, ángulo de tono y saturación de las pulpas congeladas se presentan en la tabla IV-3.

Tabla IV-3. Funciones de color en las matrices bajo estudio durante el almacenamiento congelado

\begin{tabular}{|c|c|ccc|}
\hline Fruta & $\begin{array}{c}\text { Tiempo } \\
\text { (meses) }\end{array}$ & $\mathrm{L}^{*}$ & hue & Chroma \\
\hline \multirow{2}{*}{ Zarzamora } & $\mathbf{0}$ & $21,61 \pm 1,38^{\mathrm{A}}$ & $16,36 \pm 1,25^{\mathrm{b}}$ & $7,07 \pm 0,63^{\mathrm{B}^{*}}$ \\
& $\mathbf{1 2}$ & $19,89 \pm 1,35^{\mathrm{A}}$ & $18,63 \pm 0,59^{\mathrm{a}}$ & $9,27 \pm 0,87^{\mathrm{A}^{*}}$ \\
\hline \multirow{2}{*}{ Frambuesa } & $\mathbf{0}$ & $20,97 \pm 0,38^{\mathrm{C}}$ & $25,11 \pm 0,65^{\mathrm{C}}$ & $30,54 \pm 0,54^{\mathrm{C}}$ \\
& $\mathbf{1 2}$ & $29,98 \pm 0,43^{\mathrm{B}}$ & $25,99 \pm 0,36^{\mathrm{C}}$ & $29,81 \pm 0,62^{\mathrm{C}^{*}}$ \\
\hline \multirow{2}{*}{ Arándano } & $\mathbf{0}$ & $20,92 \pm 0,58^{\mathrm{D}}$ & $10,27 \pm 0,58^{\mathrm{e}}$ & $8,07 \pm 0,61^{\mathrm{D}^{*}}$ \\
& $\mathbf{1 2}$ & $20,52 \pm 0,89^{\mathrm{D}}$ & $12,34 \pm 0,73^{\mathrm{d}}$ & $9,32 \pm 0,26^{\mathrm{D}^{*}}$ \\
\hline \multirow{2}{*}{ Guinda } & $\mathbf{0}$ & $28,04 \pm 0,68^{\mathrm{E}}$ & $28,27 \pm 1,09^{\mathrm{f}}$ & $29,11 \pm 1,71^{\mathrm{E}^{*}}$ \\
& $\mathbf{1 2}$ & $19,89 \pm 1,35^{\mathrm{F}}$ & $20,84 \pm 0,70^{\mathrm{g}}$ & $7,37 \pm 0,92^{\mathrm{F}^{*}}$ \\
\hline
\end{tabular}

L*: luminosidad, hue: ángulo de tono, Chroma: saturación. Los valores representan la media $(n=6) \pm S D$. Medias con una letra común por columna y por fruta no son significativamente diferentes $(p \leq 0,05)$ 
A los fines de evaluar el cambio global de color en las muestras se determinó, a lo largo del almacenamiento, los valores de $\Delta \mathrm{E}$ (figura IV-7).

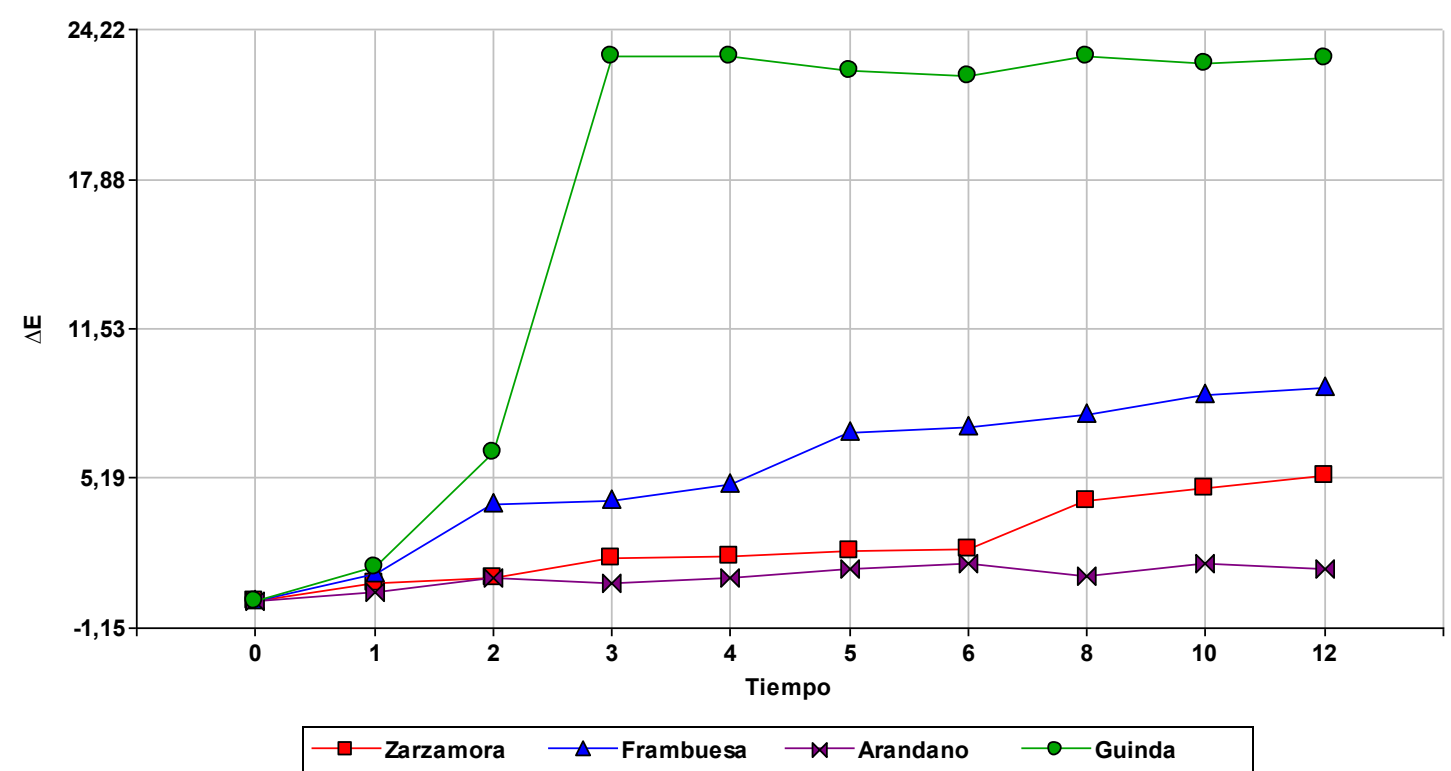

Figura IV-7. Cambio global de color en pulpas congeladas por 12 meses. Nota: la altura del punto indica el valor medio. Las barras de error expresan el error estándar.

En arándano, la variación de color superficial, en la pulpa, fue prácticamente imperceptible a lo largo del año de almacenamiento $(\Delta \mathrm{E}=1,35)$, hallando sólo diferencias significativas $(p \leq 0,05)$ para el ángulo hue, que si bien varió dos grados, se mantuvo dentro de las tonalidades púrpuras-rojizas, sin modificar su intensidad (fotografía IV-2)

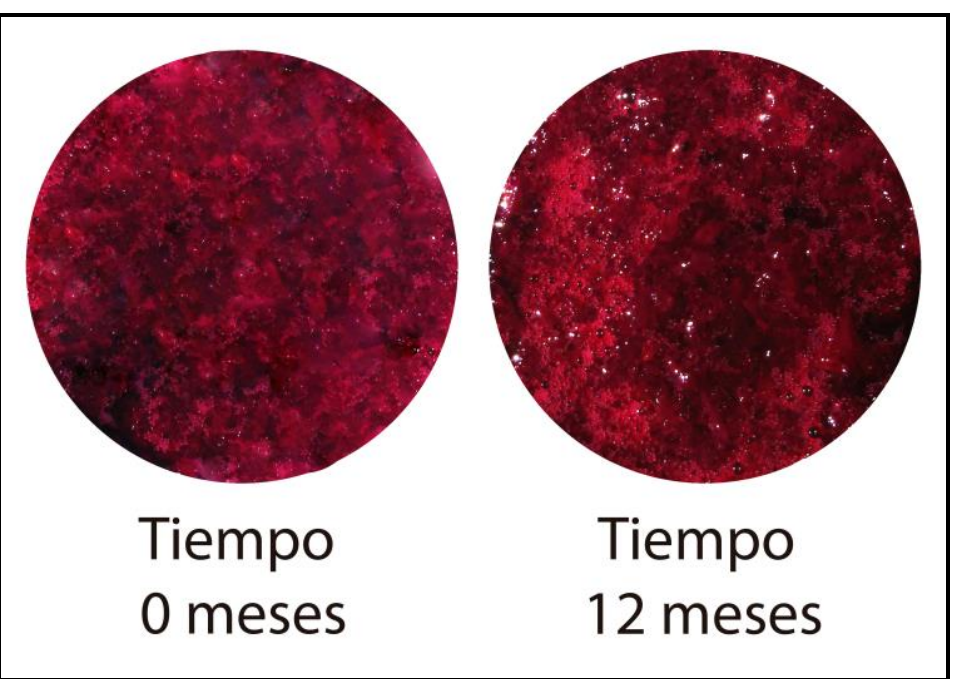

Fotografía IV-2. Pulpa de arándano - almacenamiento congelado 
La pulpa de zarzamora presentó una variación $(\Delta \mathrm{E}=5,28)$ de cinco puntos con respecto al tiempo cero, disminuyendo su luminosidad e incrementando el ángulo hue y la saturación, es decir, su color se desplazó hacia los rojos pero sin perder el atractivo (fotografía IV-3)

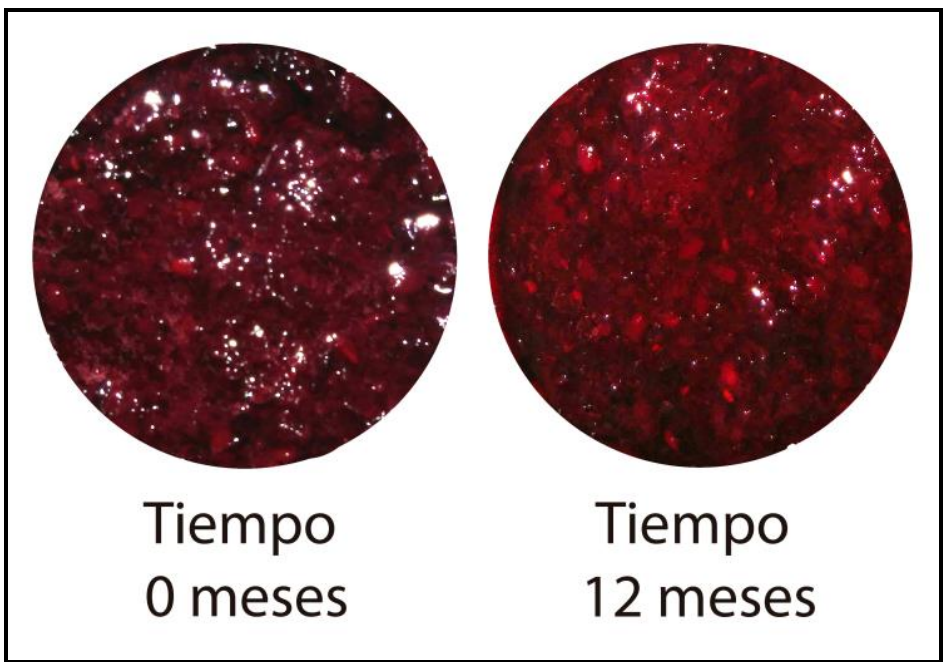

Fotografía IV-3. Pulpa de zarzamora - almacenamiento congelado

El color final de la pulpa de frambuesa almacenada a $-20^{\circ} \mathrm{C}$ durante un año fue un rojo intenso, más luminoso que el de la muestra original. $L^{*}$ fue el único parámetro en el cual se hallaron diferencias significativas $(p \leq 0,05)$ lo cual impactó sobre el cambio global del color $(\Delta \mathrm{E}=9,05)$ (fotografía IV-4).

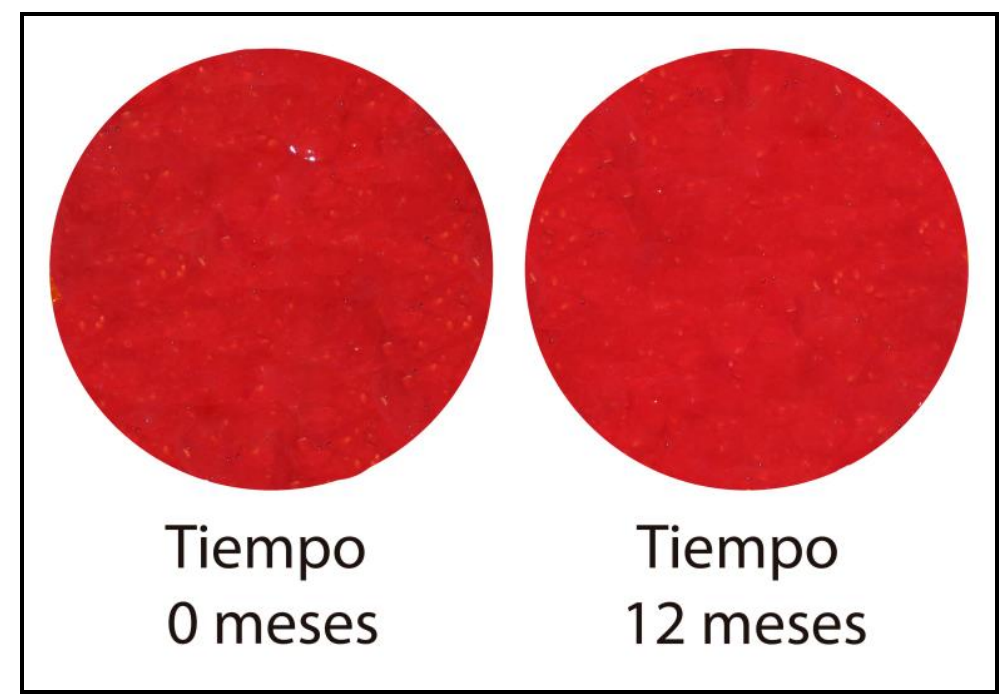

Fotografía IV-4. Pulpa de frambuesa - almacenamiento congelado 
La matriz que mayor $\Delta \mathrm{E}$ presentó $(\Delta \mathrm{E}=23,01)$ fue la pulpa congelada de guinda, con cambios visuales muy notorios a partir de los 60 días. Hubo una pérdida muy marcada de luminosidad, de rojos $\left(a^{*}{ }_{\text {control }}=25,62 \pm 1,25 ; a^{*}{ }_{\text {anual }}=\right.$ $7,24 \pm 0,50)$ y amarillos $\left(b^{*}{ }_{\text {control }}=13,81 \pm 1,28 ; b^{*}\right.$ anual $=2,62 \pm 0,26$ ), que provocó un corrimiento en hue y Chroma, expresando un color rosa pálido (fotografía IV-5).

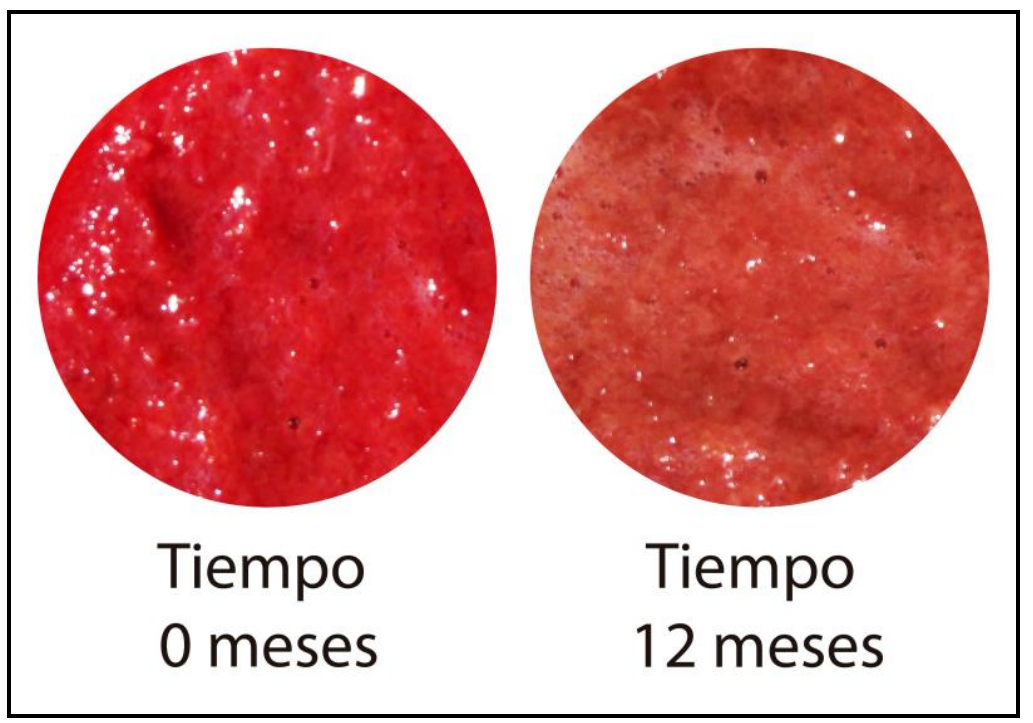

Fotografía IV-5. Pulpa de guinda - almacenamiento congelado

\section{IV-3.2 Almacenamiento a temperatura ambiente en condiciones de luz- oscuridad}

\section{IV-3.2.1 Fenoles totales, flavonoides y poder antirradicalario}

La utilización de las pulpas, como alimentos funcionales o como ingredientes para nuevos productos, requiere el conocimiento de la estabilidad en el tiempo, con el fin de adaptarlas a las condiciones de uso durante la elaboración, el envasado y la distribución. En particular, los compuestos bioactivos presentan alta susceptibilidad a diversos factores químicos y físicos. Por lo tanto, es necesario evaluar la estabilidad de estas pulpas durante el almacenamiento a temperatura ambiente en presencia o ausencia de luz.

En la tabla IV-4 se informan las concentraciones en los compuestos bioactivos analizados en la pulpa de zarzamora control y luego de doce meses de almacenamiento en condiciones de luz y oscuridad. Solo se observó disminución significativa de FT respecto a la pulpa en el tiempo cero. 
Tabla IV-4. Valores de los FT, Fv y PA en pulpa de zarzamora en las condiciones ensayadas

\begin{tabular}{|c|c|ccc|}
\hline $\begin{array}{c}\text { Meses de } \\
\text { almacenamiento }\end{array}$ & Tratamiento & FT & Fv & PA \\
\hline $\mathbf{0}$ & Control & $378 \pm 13^{\mathrm{A}}$ & $59 \pm 2^{\mathrm{a}}$ & $0,64 \pm 0,05^{\mathrm{A}^{*}}$ \\
$\mathbf{1 2}$ & Luz & $315 \pm 15^{\mathrm{B}}$ & $55 \pm 4^{\mathrm{b}}$ & $0,64 \pm 0,03^{\mathrm{A}^{*}}$ \\
$\mathbf{1 2}$ & Oscuridad & $314 \pm 7^{\mathrm{B}}$ & $54 \pm 4^{\mathrm{b}}$ & $0,65 \pm 0,01^{\mathrm{A}^{*}}$ \\
\hline
\end{tabular}

FT: fenoles totales (mg GAE/100 g), Fv: flavonoides (mg CE/100 g), PA: poder antirradical $\left(\mathrm{mg}^{-1}\right)$. Los valores representan la media $(n=3) \pm S D$. Medias con una letra común por columna no son significativamente diferentes $(p \leq 0,05)$

Observando la figura IV-8 (FT, Fv y PA) y del análisis estadístico surge que luego de los 360 días de almacenamiento de la pulpa no se encontraron diferencias significativas $(p \leq 0,05)$ entre condición de luz y oscuridad para los tres parámetros.

En cuanto a la variable FT (figura IV-8.a), su concentración a lo largo del tiempo total de estudio disminuyó en un $17 \%$ (oscuridad) y del análisis de contraste de las curvas se observa tendencia asintótica (contraste lineal y cuadrático $p<0,0001$ ), es decir la concentración disminuyó hasta aproximadamente los 6 meses de almacenamiento, manteniéndose luego constante alcanzando un valor aproximado de $314 \mathrm{mg} \mathrm{GAE} / 100 \mathrm{~g}$ pulpa. 

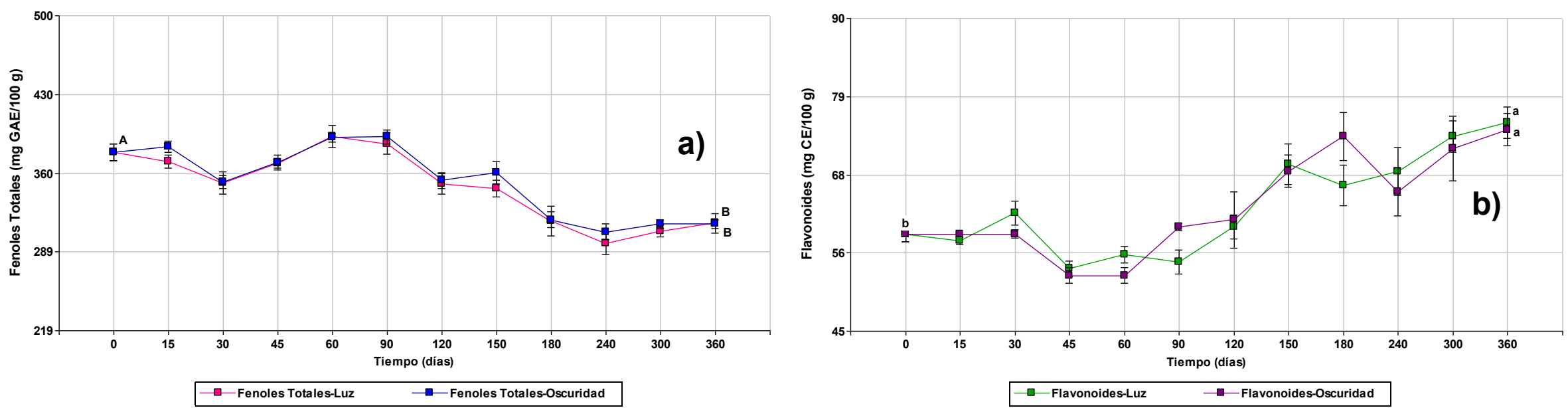

$\dot{\infty}$
$\grave{\varphi}$

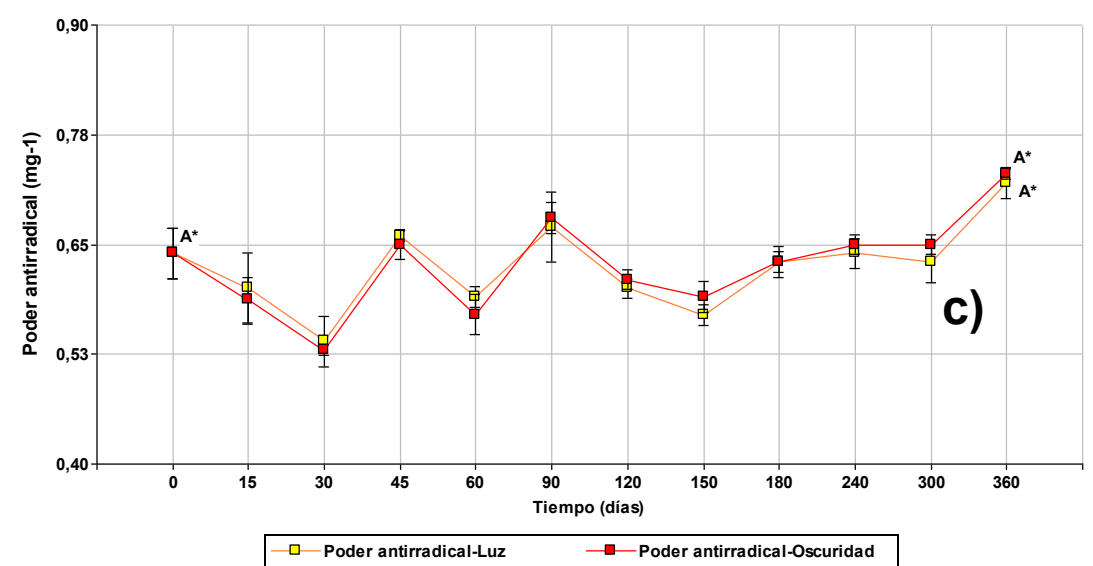

Figura IV-8. FT, Fv y PA en pulpa de zarzamora almacenada en condiciones de luz y oscuridad. Nota: la altura del punto indica el valor medio. Las barras de error expresan el error estándar. 
En Fv la tendencia observada fue lineal $(p<0,0001)$. A lo largo de los primeros 50 días de análisis la concentración se redujo, pero a los 12 se recuperó un $93 \%$ de la concentración inicial, (figura IV-8.b).

En cuanto al poder antirradicalario (figura IV-8.c), la tendencia de la nube de puntos fue asintótica ( $p<0,05$ para ambos comportamientos), lo que indicó una oscilación en los valores hasta los 180 días, a partir del cual comenzaron a aumentar, sin diferencias en el punto final respecto al valor control.

Al considerar la matriz frambuesa se observaron marcadas disminuciones para Fv y PA a lo largo del año de almacenamiento, pero un incremento de los FT (figura IV-9 a, b y c).

En la tabla IV-5, se presentan los datos correspondientes a las concentraciones de compuestos bioactivos y poder antirradicalario para tiempo cero y luego de 12 meses en las condiciones estudiadas.

Tabla IV-5. Valores de los FT, Fv y PA en pulpa de frambuesa en las condiciones ensayadas

\begin{tabular}{|c|c|ccc|}
\hline $\begin{array}{c}\text { Meses de } \\
\text { almacenamiento }\end{array}$ & Tratamiento & FT & Fv & PA \\
\hline $\mathbf{0}$ & Control & $165 \pm 6^{\mathrm{B}}$ & $37 \pm 1^{\mathrm{a}}$ & $0,76 \pm 0,04^{\mathrm{A}}$ \\
$\mathbf{1 2}$ & Luz & $173 \pm 4^{\mathrm{A}}$ & $18 \pm 1^{\mathrm{C}}$ & $0,27 \pm 0,01^{\mathrm{B}^{*}}$ \\
$\mathbf{1 2}$ & Oscuridad & $185 \pm 10^{\mathrm{A}}$ & $24 \pm 3^{\mathrm{b}}$ & $0,29 \pm 0,01^{\mathrm{B}^{*}}$ \\
\hline
\end{tabular}

FT: fenoles totales (mg GAE/100 g), Fv: flavonoides (mg CE/100 g), PA: poder antirradical $\left(\mathrm{mg}^{-1}\right)$. Los valores representan la media $(n=3) \pm S D$. Medias con una letra común por columna no son significativamente diferentes $(p \leq 0,05)$ 

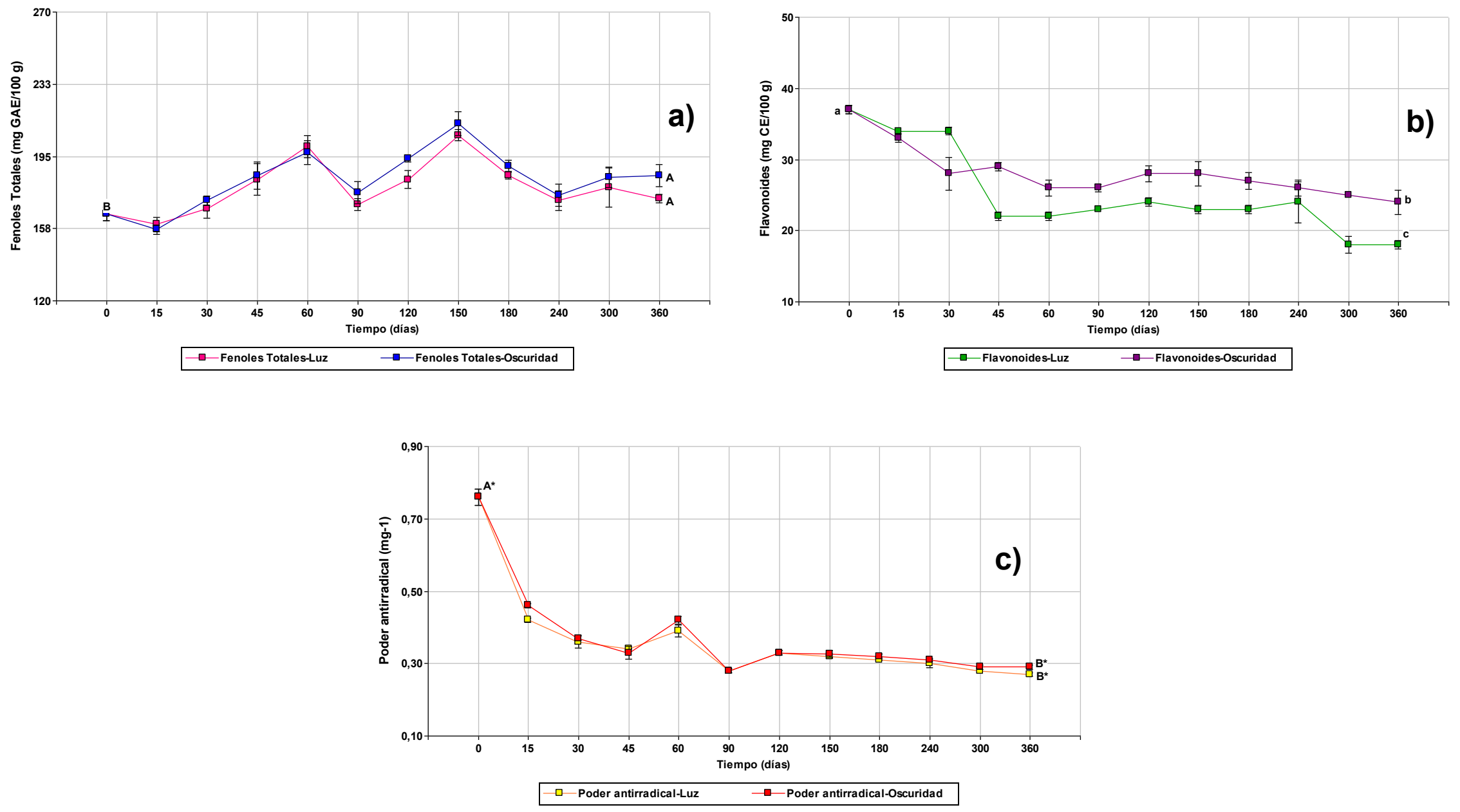

Figura IV-9. FT, Fv y PA en pulpa de frambuesa almacenada en condiciones de luz y oscuridad. Nota: la altura del punto indica el valor medio. Las barras de error expresan el error estándar. 
La tendencia presentada por los FT fue asintótica (contraste lineal y cuadrático, $p<0,0001$ ), aumentando luego de 360 días un $12 \%$ su concentración inicial (figura IV-9.a). Se observaron en ambas curvas oscilaciones, con una tendencia de los valores a mantenerse constantes luego de los 8 meses. No se hallaron diferencias significativas $(p \leq 0,05)$ para las condiciones de luz y oscuridad en el punto final.

Para flavonoides la curva presentó tendencia lineal $(p<0,0001)$, registrando a los 45 días una marcada disminución sobre todo para la condición de anaquel (40\% para luz y $22 \%$ para oscuridad), la cual se mantuvo hasta los 8 meses donde nuevamente vuelvió a decaer hasta alcanzar una retención de $65 \%$ en oscuridad y $49 \%$ en luz (figura IV-9.b). El efecto sobre las muestras de la exposición a la luz fue significativo $(p \leq 0,05)$.

El poder antirradicalario (figura IV-9.c) presenta una tendencia lineal $(p<0,0001)$ de disminución, mostrando pérdidas del $40 \%$ en solo 15 días, que continúan hasta alcanzar un $65 \%$ total al final del almacenamiento. No se registraron diferencias significativas $(p \leq 0,05)$ entre las condiciones de luz y oscuridad.

La matriz arándano se comportó de manera más estable que las anteriores, ya que solo se detectaron diferencias en la concentración de FT a lo largo del año de conservación (figura IV-10) y en los puntos finales, no se hallaron diferencias significativas $(p \leq 0,05)$ por la exposición a la luz (tabla IV-6). 

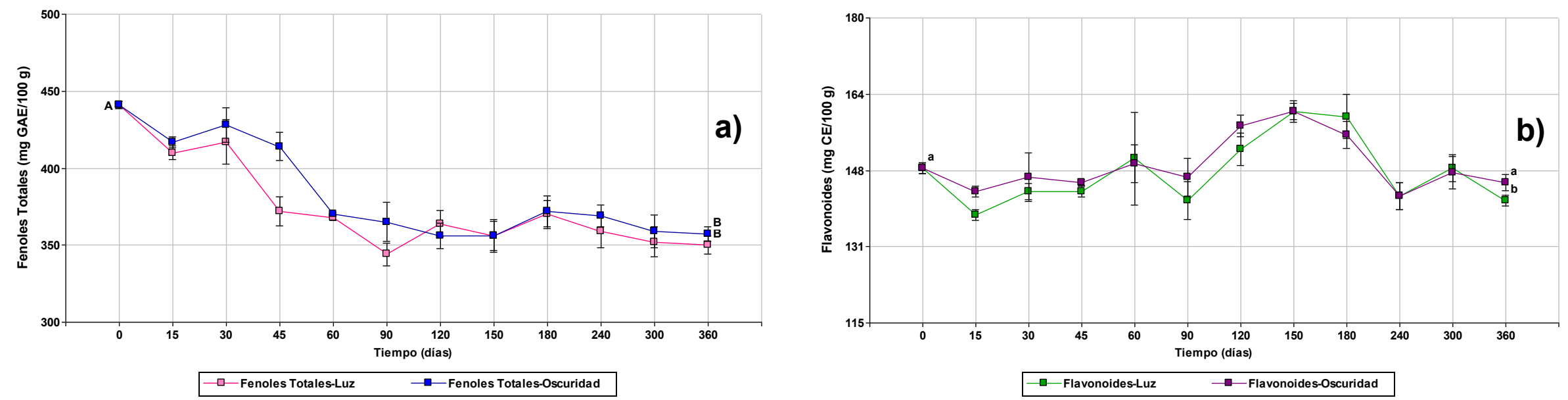

$\stackrel{\dot{0}}{\dot{\varphi}}$

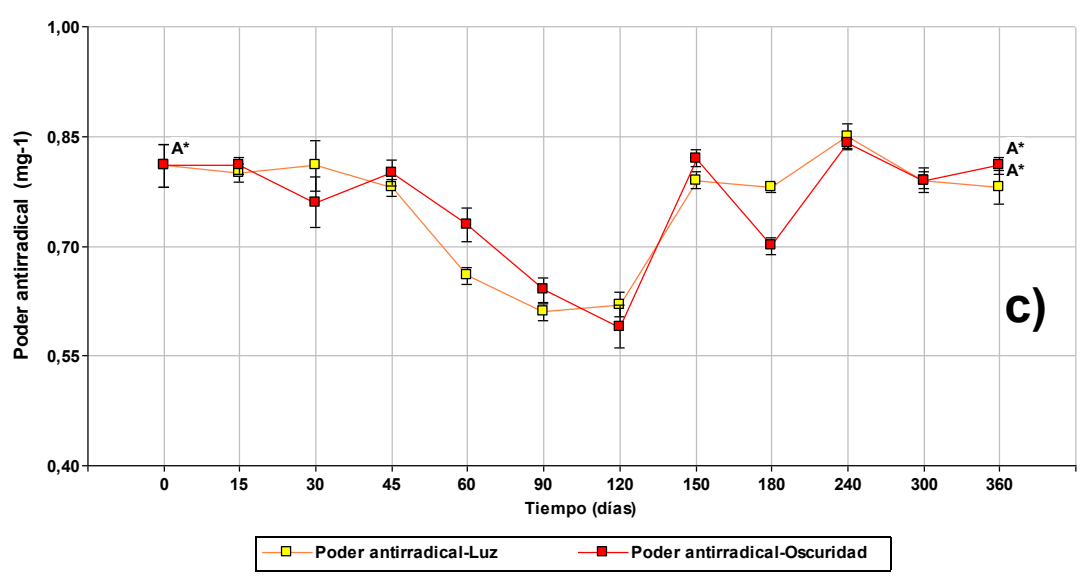

Figura IV-10. FT, Fv y PA en pulpa de arándano almacenada en condiciones de luz y oscuridad. Nota: la altura del punto indica el valor medio. Las barras de error expresan el error estándar. 
Tabla IV-6. Valores de los FT, Fv y PA en pulpa de arándano en las condiciones ensayadas

\begin{tabular}{|c|c|ccc|}
\hline $\begin{array}{c}\text { Meses de } \\
\text { almacenamiento }\end{array}$ & Tratamiento & FT & Fv & PA \\
\hline $\mathbf{0}$ & Control & $441 \pm 4^{\mathrm{A}}$ & $148 \pm 2^{\mathrm{a}}$ & $0,81 \pm 0,05^{\mathrm{A}^{*}}$ \\
$\mathbf{1 2}$ & Luz & $350 \pm 10^{\mathrm{B}}$ & $141 \pm 2^{\mathrm{b}}$ & $0,78 \pm 0,04^{\mathrm{A}^{*}}$ \\
$\mathbf{1 2}$ & Oscuridad & $358 \pm 7^{\mathrm{B}}$ & $145 \pm 3^{\mathrm{a}}$ & $0,81 \pm 0,02^{\mathrm{A}^{*}}$ \\
\hline
\end{tabular}

FT: fenoles totales (mg GAE/100 g), Fv: flavonoides (mg CE/100 g), PA: poder antirradical $\left(\mathrm{mg}^{-1}\right)$. Los valores representan la media $(n=3) \pm S D$. Medias con una letra común por columna no son significativamente diferentes $(p \leq 0,05)$

En fenoles totales, el contraste de tendencia resultó lineal $(p<0,0001)$, la concentración disminuyó a lo largo del almacenamiento (figura IV-10.a), se registró una mayor pendiente luego de los 30 días y no se hallaron diferencias significativas $(p \leq 0,05)$ entre luz y oscuridad (tabla IV-6). La retención final fue del $80 \%$.

Para flavonoides la tendencia registrada en la curva fue cuadrática $(p<0,0001)$; la concentración se mantuvo estable hasta los 3 meses donde comenzó a aumentar por un lapso de 90 días, para luego recuperar su valor inicial (figura IV-10.b). No se registraron modificaciones por efecto del almacenamiento en luz y oscuridad $(p \leq 0,05)$.

El poder antirradicalario también mostró una tendencia cuadrática ( $p<0,0001$ ); disminuyó a partir de los 45 días hasta los 4 meses luego recuperó su valor inicial, sin registrar efecto por exposición a la luz (figura IV-10.c).

En la figura IV-11 se presenta el contenido de FT, Fv y PA en pulpa de guinda almacenada bajo las condiciones de estudio. 

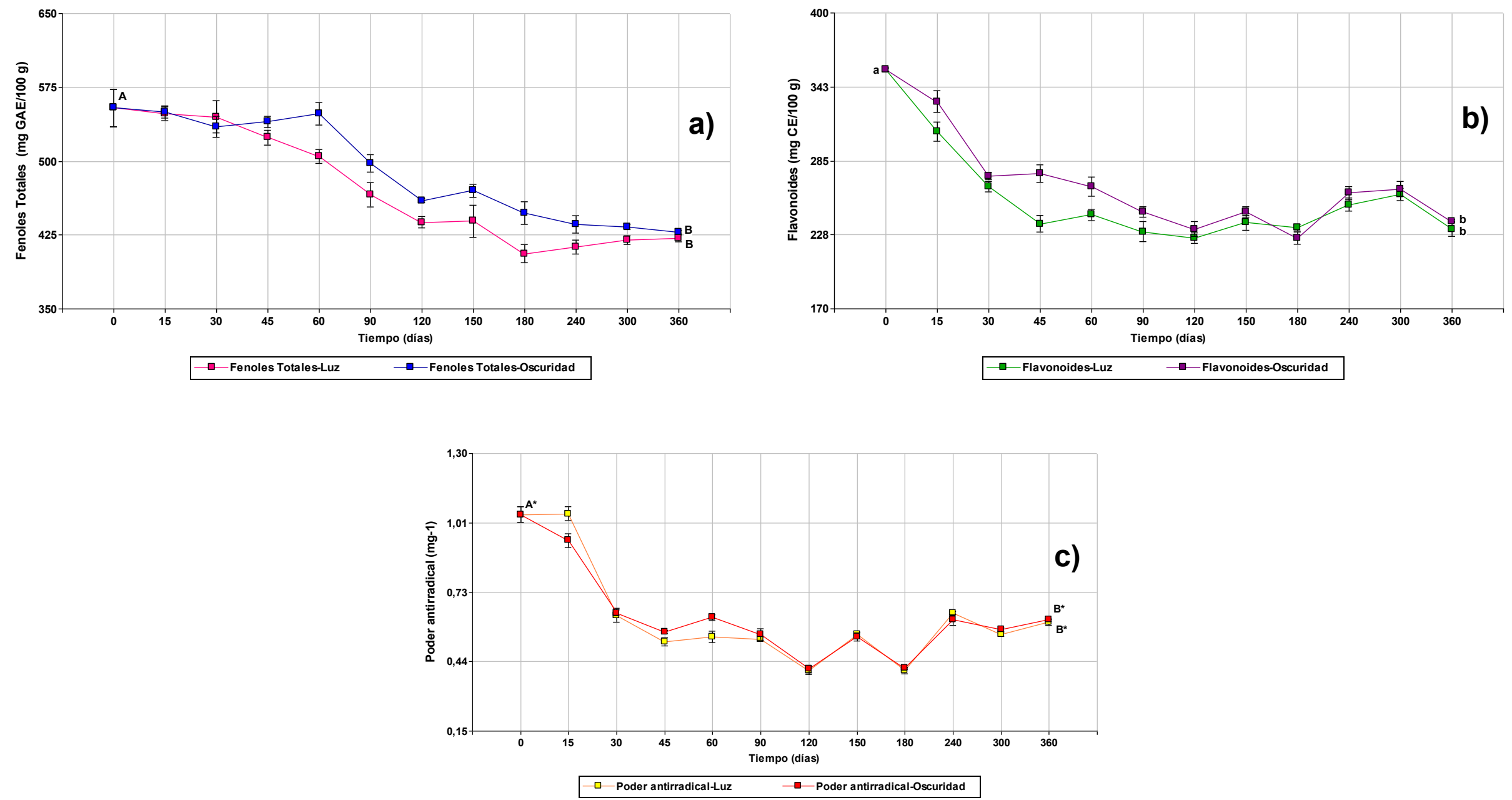

Figura IV-11. FT, Fv y PA en pulpa de guinda almacenada en condiciones de luz y oscuridad. Nota: la altura del punto indica el valor medio. Las barras de error expresan el error estándar. 
En la tabla IV-7 se observan los valores correspondientes a los compuestos bioactivos y el poder antirradicalario de pulpa de guinda almacenada en condiciones de anaquel y oscuridad por 12 meses.

Tabla IV-7. Valores de los FT, Fv y PA en pulpa de guinda en las condiciones ensayadas

\begin{tabular}{|c|c|ccc|}
\hline $\begin{array}{c}\text { Meses de } \\
\text { almacenamiento }\end{array}$ & Tratamiento & FT & Fv & PA \\
\hline $\mathbf{0}$ & Control & $554 \pm 33^{\mathrm{A}}$ & $356 \pm 2^{\mathrm{a}}$ & $1,05 \pm 0,06^{\mathrm{A}^{*}}$ \\
12 & Luz & $422 \pm 6^{\mathrm{B}}$ & $232 \pm 10^{\mathrm{b}}$ & $0,60 \pm 0,02^{\mathrm{B}^{*}}$ \\
12 & Oscuridad & $428 \pm 3^{\mathrm{B}}$ & $238 \pm 2^{\mathrm{b}}$ & $0,61 \pm 0,01^{\mathrm{B}^{*}}$ \\
\hline
\end{tabular}

FT: fenoles totales (mg GAE/100 g), Fv: flavonoides (mg CE/100 g), PA: poder antirradical $\left(\mathrm{mg}^{-1}\right)$. Los valores representan la media $(n=3) \pm S D$. Medias con una letra común por columna no son significativamente diferentes $(p \leq 0,05)$

El contraste de tendencias para fenoles totales indicó un comportamiento lineal $(p<0,0001)$ en el tiempo (figura IV-11.a), siendo muy significativo el descenso de la concentración entre los 2 y 4 meses de almacenamiento $(21 \%$ de pérdida en la condición de luz) y estabilizándose a partir de los 6 meses para alcanzar una retención total del $76 \%$. No se hallaron diferencias significativas por exposición a la luz $(p \leq 0,05)$.

Los flavonoides también disminuyeron de forma lineal $(p<0,0001)$, con un marcado descenso en los primeros 45 días de almacenamiento (34\% en condición de anaquel) y a partir de allí las concentraciones oscilaron en una zona de retención del $65-75 \%$ (figura IV-11.b). Nuevamente no se detectaron diferencias por el almacenamiento en condición de luz y oscuridad $(p \leq 0,05)$.

El poder antirradical registró una disminución significativa (40\%) luego de los primeros 15 días y luego se estabilizó alcanzando un porcentaje final de retención del $57 \%$ (figura IV-11.c). No se registró efecto significativo de la exposición a la luz $(p \leq 0,05)$.

En general, la matriz menos afectada por el almacenamiento fue la pulpa pasteurizada de arándano, seguida por zarzamora. En guinda y frambuesa se detectaron las mayores variaciones en los compuestos bioactivos y PA. 
En zarzamora, arándano y guinda se registraron disminuciones en la concentración de FT entre el 17 y $24 \%$. Varios autores informaron pérdidas de estos compuestos durante el almacenamiento, a temperatura ambiente, de productos de berries y cherries, incluidas pulpas (Häkkinen y col., 2000; Chaovanalitik y Wrolstad, 2004; Šavikin y col., 2009; Aaby y col., 2007; Hager y col., 2010; Gancel y col., 2011). En el caso de frambuesa, el valor se elevó un $12 \%$, lo cual coincide con lo hallado por Zafrilla y col. (2001) para la misma matriz almacenada en oscuridad a $20^{\circ} \mathrm{C}$. Los autores cuantificaron taninos hidrolizables y registran una disminución de los mismos que se traduciría en un aumento de ácido elágico por despolimerización de los primeros.

De acuerdo a Gancel y col. (2011) el comportamiento variable en el contenido de fenoles totales se puede deber a aumentos en la concentración de ácido elágico (ácido fenólico) por ser un subproducto de la degradación de elagitaninos y disminuciones, porque es susceptible de degradación y precipitación.

Dentro del término genérico "fenoles totales", se incluyen sustancias de diversas familias químicas entre las que se encuentran los flavonoides, que a su vez contienen, entre otros compuestos a las antocianinas (Gonzalo Rivas y García Alonso, 2002). Las disminuciones en los flavonoides podrían ser consecuencia de la polimerización de pigmentos antociánicos (sección IV3.2.2). Varios autores reportaron que los flavonoides son altamente sensibles a la degradación en presencia de luz visible y UV (Jackman y Smith, 1996; Klein y Kurilich, 2000), aunque en la presente investigación sólo se detectó ese efecto en la matriz frambuesa.

El poder antirradicalario presentó comportamientos diversos, ya que disminuyó en dos matrices y permaneció sin alteraciones en las demás. Esto sugiere que hay múltiples factores que influyen en el PA, entre los que se puede mencionar las pérdidas significativas en las antocianinas, la influencia de otros compuestos fenólicos que se mantienen estables y las antocianinas poliméricas que se forman a lo largo del almacenamiento (sección IV-3.2.2). 


\section{IV-3.2.2 Contenido de pigmentos}

En la tabla IV-8 se presentan los valores para el contenido de ACY, \% CP e IDA en las muestras de pulpas de zarzamora almacenadas a temperatura ambiente en condiciones de anaquel y oscuridad.

Tabla IV-8. Contenido de de ACY, IDA y \% CP en pulpa pasteurizada de zarzamora.

\begin{tabular}{|c|c|ccc|}
\hline $\begin{array}{c}\text { Meses de } \\
\text { almacenamiento }\end{array}$ & Tratamiento & ACY & $\%$ CP & IDA \\
\hline $\mathbf{0}$ & Control & $133 \pm 4^{\mathrm{A}}$ & $16 \pm 1^{\mathrm{C}}$ & $1,21 \pm 0,01^{\mathrm{C}^{*}}$ \\
$\mathbf{1 2}$ & Luz & $19 \pm 0^{\mathrm{C}}$ & $61 \pm 1^{\mathrm{a}}$ & $2,08 \pm 0,02^{\mathrm{A}^{*}}$ \\
12 & Oscuridad & $26 \pm 0^{\mathrm{B}}$ & $54 \pm 0^{\mathrm{b}}$ & $1,82 \pm 0,01^{\mathrm{B}^{*}}$ \\
\hline
\end{tabular}

ACY: antocianinas monoméricas (mg cianidina-3-glu/100g ms), \%CP: porcentaje de color polimérico IDA: índice de degradación de antocianinas. Los valores representan la media $(n=3) \pm S D$. Medias con una letra común por columna no son significativamente diferentes $(p \leq 0,05)$

Durante el año de almacenamiento la pérdida de ACY fue significativa $(p \leq 0,05)$ siendo notorio el impacto de la exposición a la luz. Se logró una retención del $20 \%$ en oscuridad y del $14 \%$ en luz (figura IV-12). La tendencia de las curvas obtenida a través del contraste fue lineal $(p<0,0001)$.

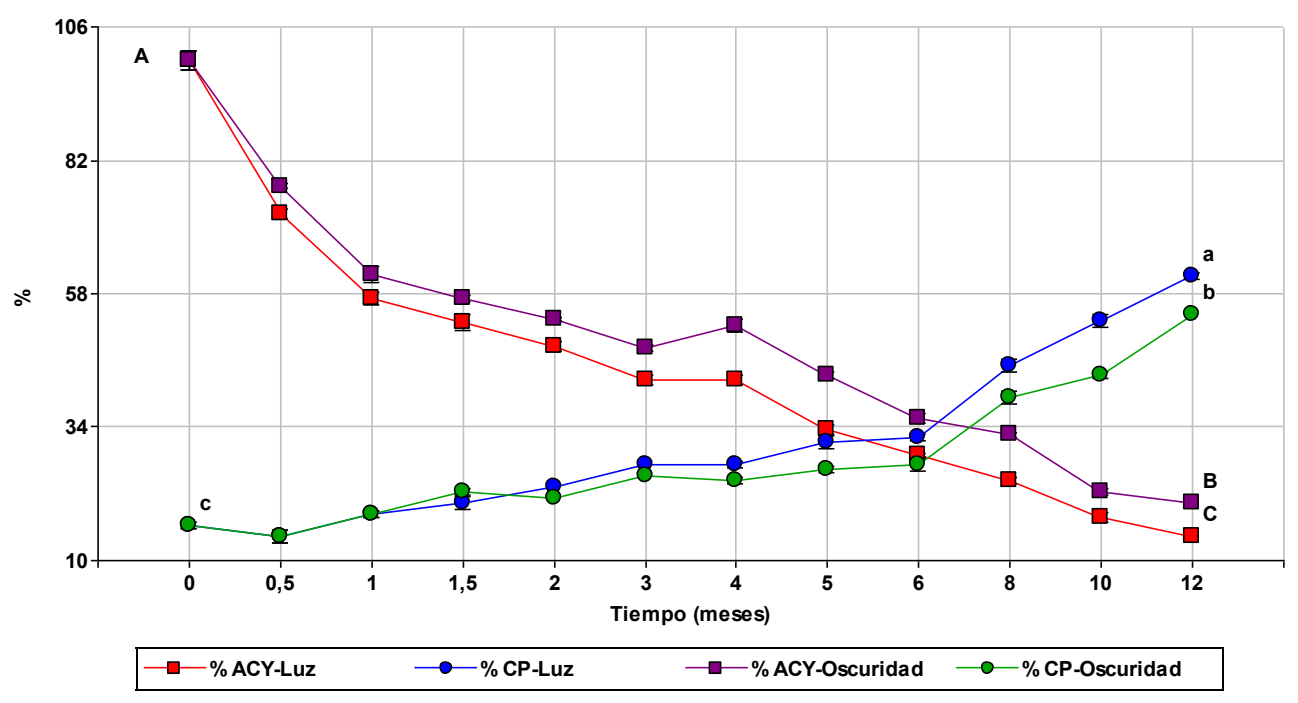

Figura IV-12. Porcentaje de ACY y CP en pulpas pasteurizadas de zarzamora bajo las condiciones de estudio. Nota: la altura del punto indica el valor medio. Las barras de error expresan el error estándar. 
El porcentaje de color polimérico se incrementa a medida que las antocianinas monoméricas se degradan, indicando su polimerización (Wrolstad, 2005). Nuevamente se observó el efecto de la exposición a la luz.

El IDA también presentó diferencias significativas $(p \leq 0,05)$ por el tiempo de almacenamiento y la exposición a la luz, incrementándose un $72 \%$ en luz y $50 \%$ en oscuridad.

Las ACY de la pulpa pasteurizada de frambuesa sufrieron un mayor impacto por el almacenamiento a temperatura ambiente, los valores correspondientes se presentan en la tabla IV-9.

Tabla IV-9. Contenido de de ACY, IDA y \% CP en pulpa pasteurizada de frambuesa.

\begin{tabular}{|c|c|ccc|}
\hline $\begin{array}{c}\text { Meses de } \\
\text { almacenamiento }\end{array}$ & Tratamiento & ACY & $\%$ CP & IDA \\
\hline $\mathbf{0}$ & Control & $34 \pm 1^{\mathrm{A}}$ & $36 \pm 2^{\mathrm{C}}$ & $1,38 \pm 0,02^{\mathrm{C}^{*}}$ \\
$\mathbf{1 2}$ & Luz & $0,34 \pm 0,03^{\mathrm{C}}$ & $94 \pm 3^{\mathrm{a}}$ & $8,24 \pm 0,03^{\mathrm{A}^{*}}$ \\
$\mathbf{1 2}$ & Oscuridad & $1 \pm 0^{\mathrm{B}}$ & $86 \pm 2^{\mathrm{b}}$ & $5,36 \pm 0,35^{\mathrm{B}^{*}}$ \\
\hline
\end{tabular}

ACY: antocianinas monoméricas ( $\mathrm{mg}$ cianidina-3-glu/100g ms), \%CP: porcentaje de color polimérico, IDA: índice de degradación de antocianinas. Los valores representan la media $(n=3) \pm S D$. Medias con una letra común por columna no son significativamente diferentes $(p \leq 0,05)$

Las antocianinas monoméricas decrecieron de forma lineal $(p \leq 0,0001)$ y, acompañando ese comportamiento, el color polimérico se incrementó (figura IV-13). La disminución de ACY impacta directamente sobre el IDA que además se ve influenciado por la condición de anaquel ya que sextuplicó su valor en presencia de luz, mientras que lo cuadriplicó en oscuridad. 


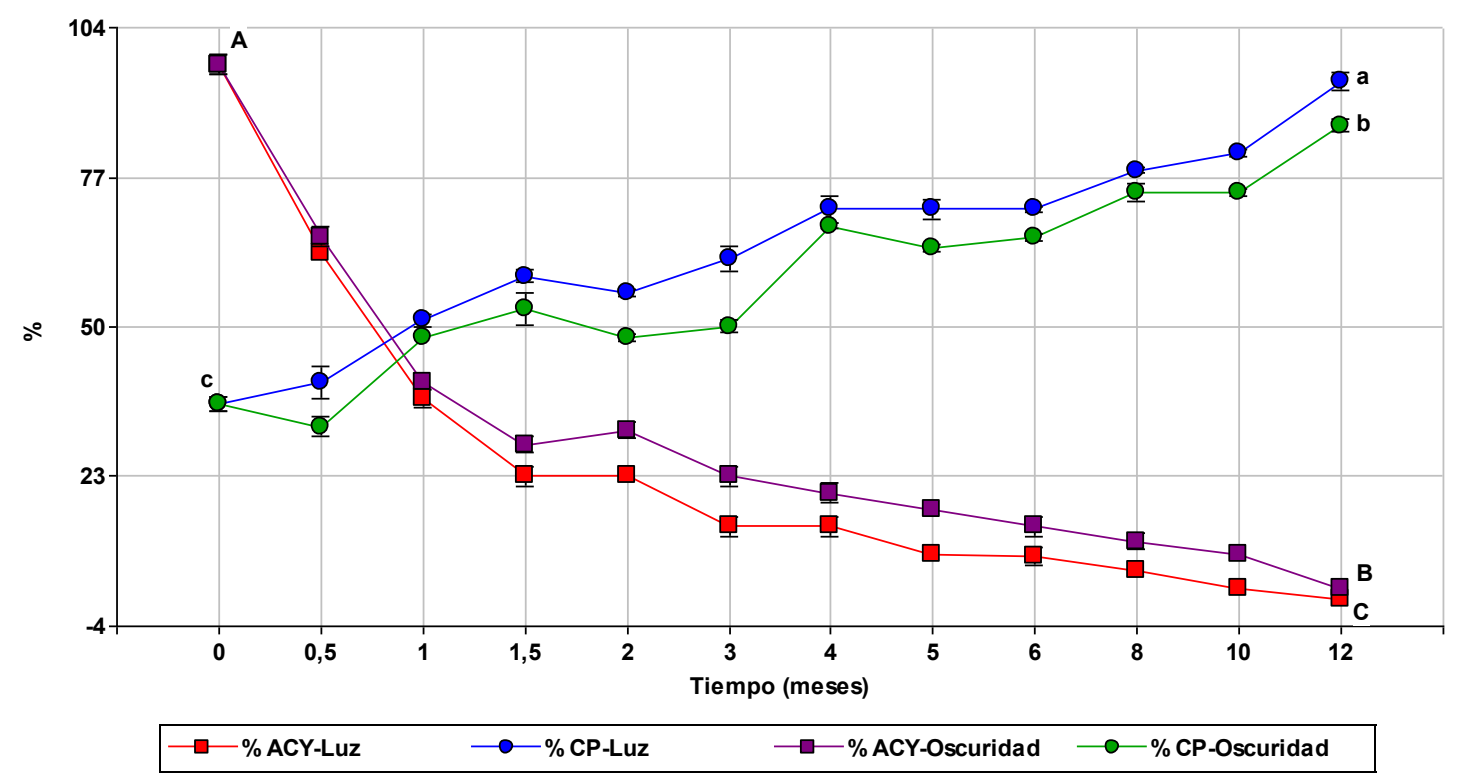

Figura IV-13. Porcentaje de ACY y CP en pulpas pasteurizadas de

frambuesa bajo las condiciones de estudio. Nota: la altura del punto indica el valor medio. Las barras de error expresan el error estándar.

En arándano el efecto del almacenamiento fue similar al hallado para zarzamora, con retención de ACY del $26 \%$ en oscuridad y $20 \%$ en luz luego del año (tabla IV-10). El \% CP se incrementó a medida que la concentración de ACY decaía, arrojando significancia para tendencia lineal en ambos casos ( $p \leq 0,0001)$, lo cual puede observarse en la figura IV-14.

Tabla IV-10. Contenido de de ACY, IDA y \% CP en pulpa pasteurizada de arándano.

\begin{tabular}{|c|c|ccc|}
\hline $\begin{array}{c}\text { Meses de } \\
\text { almacenamiento }\end{array}$ & Tratamiento & ACY & \% CP & IDA \\
\hline $\mathbf{0}$ & Control & $147 \pm 4^{\mathrm{A}}$ & $11 \pm 1^{\mathrm{C}}$ & $1,12 \pm 0,00^{\mathrm{C}^{*}}$ \\
$\mathbf{1 2}$ & Luz & $30 \pm 1^{\mathrm{C}}$ & $54 \pm 2^{\mathrm{a}}$ & $1,46 \pm 0,02 \mathrm{~A}^{\mathrm{A}^{*}}$ \\
$\mathbf{1 2}$ & Oscuridad & $39 \pm 1^{\mathrm{B}}$ & $39 \pm 3^{\mathrm{b}}$ & $1,39 \pm 0,04^{\mathrm{B}^{*}}$ \\
\hline
\end{tabular}

ACY: antocianinas monoméricas ( $\mathrm{mg}$ cianidina-3-glu/100g $\mathrm{ms}$ ), \%CP: porcentaje de color polimérico IDA: índice de degradación de antocianinas. Los valores representan la media $(n=3) \pm S D$. Medias con una letra común por columna no son significativamente diferentes $(p \leq 0,05)$

En cuanto al IDA, se destaca el pequeño incremento en comparación con las otras matrices ( $30 \%$ en condición de anaquel y $24 \%$ en oscuridad), lo que 
estaría indicando una baja proporción de pigmentos pardos al final del tiempo de almacenamiento.

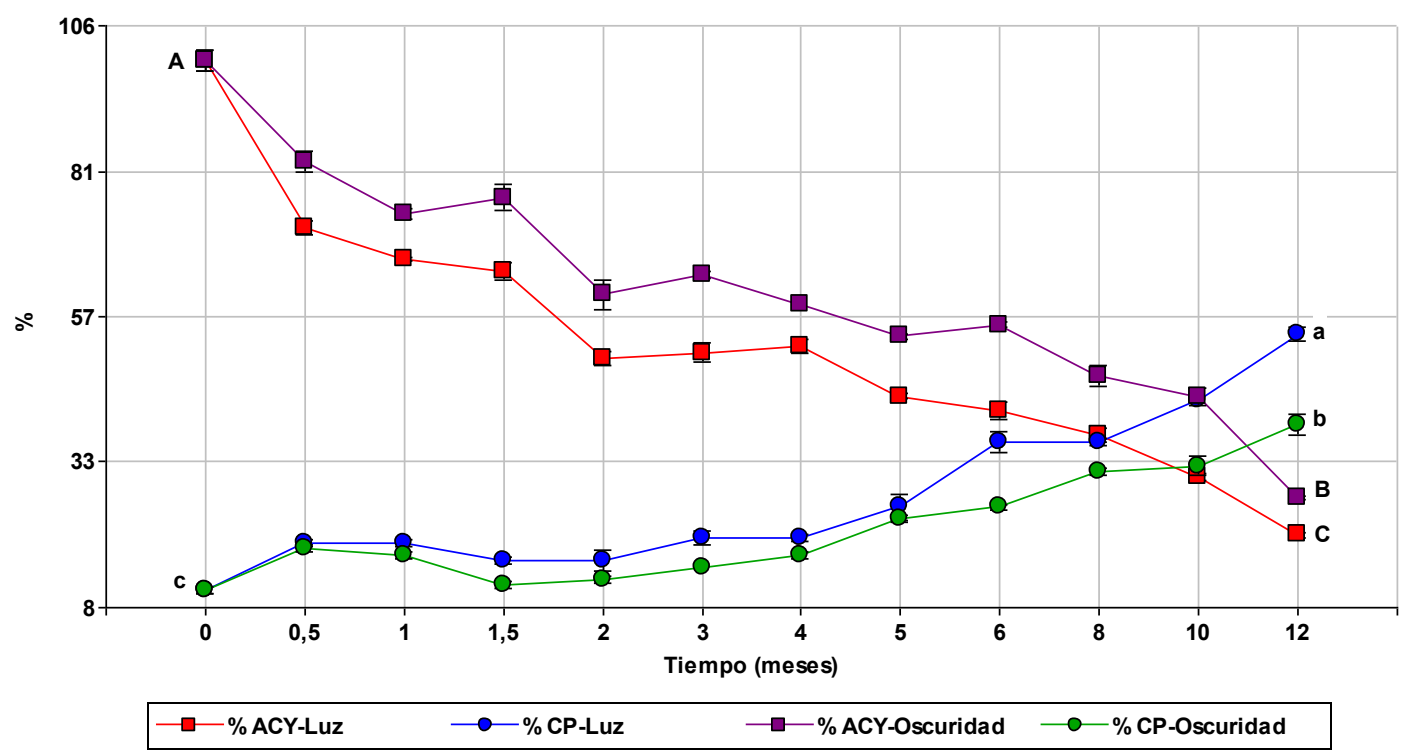

Figura IV-14. Porcentaje de ACY y CP en pulpas pasteurizadas de arándano bajo las condiciones de estudio Nota: la altura del punto indica el valor medio. Las barras de error expresan el error estándar.

Las ACY en pulpa pasteurizada de guinda prácticamente desaparecieron luego de un año de almacenamiento, reteniendo un $6 \%$ en condición de oscuridad y $3,5 \%$ en luz (Tabla IV-11). Nuevamente los valores se acompañaron con un alto \% CP, que superó el 90 \%, e índices de degradación que se incrementó entre cuatro y seis veces por encima del valor inicial.

Tabla IV-11. Contenido de ACY, IDA y \% CP en pulpa pasteurizada de guinda.

\begin{tabular}{|c|c|ccc|}
\hline $\begin{array}{c}\text { Meses de } \\
\text { almacenamiento }\end{array}$ & Tratamiento & ACY & \% CP & IDA \\
\hline $\mathbf{0}$ & Control & $17 \pm 1^{\mathrm{A}}$ & $49 \pm 4^{\mathrm{C}}$ & $1,48 \pm 0,07^{\mathrm{C}^{*}}$ \\
$\mathbf{1 2}$ & Luz & $0,60 \pm 0,05^{\mathrm{C}}$ & $94 \pm 1^{\mathrm{a}}$ & $8,62 \pm 0,05^{\mathrm{A}^{*}}$ \\
$\mathbf{1 2}$ & Oscuridad & $1 \pm 0^{\mathrm{B}}$ & $90 \pm 1^{\mathrm{b}}$ & $6,35 \pm 0,07^{\mathrm{B}^{*}}$ \\
\hline
\end{tabular}

$\mathrm{ACY}$ : antocianinas monoméricas ( $\mathrm{mg}$ cianidina-3-glu/100g ms), \%CP: porcentaje de color polimérico, IDA: índice de degradación de antocianinas. Los valores representan la media $(n=3) \pm S D$. Medias con una letra común por columna no son significativamente diferentes $(p \leq 0,05)$ 
Las tendencias de aumento y disminución se correspondieron significativamente $(p \leq 0,0001)$ con un contraste lineal (figura IV-15).

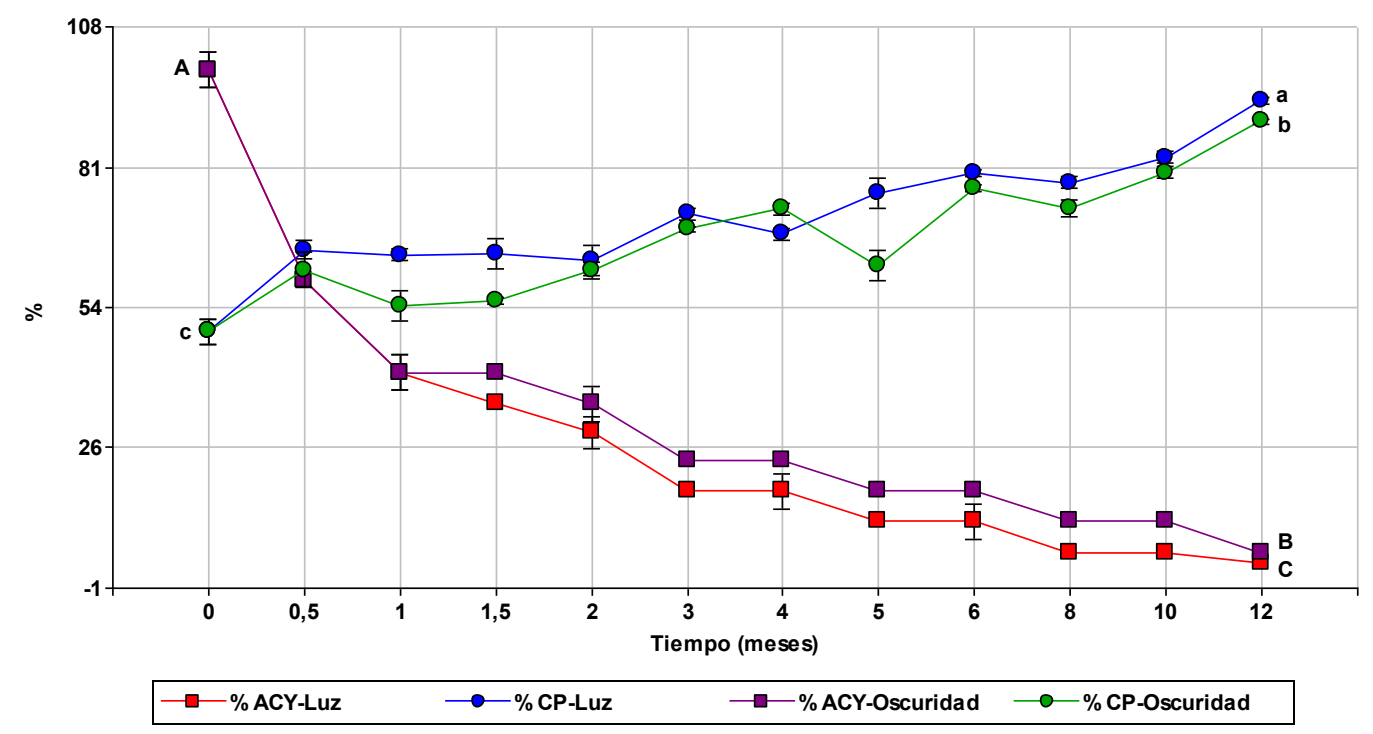

Figura IV-15. Porcentaje de ACY y CP en pulpas pasteurizadas de guinda bajo las condiciones de estudio. Nota: la altura del punto indica el valor medio. Las barras de error expresan el error estándar.

Del análisis de los resultados obtenidos durante el almacenamiento de las pulpas a temperatura ambiente se pudo observar que, guinda y frambuesa presentaron mayores \% CP e IDA que los obtenidos para arándano y zarzamora en condiciones similares de degradación de ACY (mayores al 80\%). Se cree que la causa de ello radica en la formación de un grupo de pigmentos llamados piranoantocianinas (Rentzsch y col., 2007).

Las piranoantocianinas son pigmentos de color naranja que originalmente no están presentes en frutas y vegetales, sino que se forman durante el procesamiento y el envejecimiento de los jugos y los vinos (Rentzsch y col., 2007) a través de una reacción, en la posición C-4, entre antocianinas y compuestos genuinos que contienen un doble enlace polarizable, como el ácido pirúvico y otros ácidos fenólicos para formar productos de adición. Estos pigmentos no se blanquean con bisulfito ya que la posición C-4 está bloqueada; por lo que contribuyen a incrementan los valores de \% CP (Wrolstad, 2005).

Se ha informado la presencia de piranoantocianinas en jugo de guinda (Rentzsch y col., 2007), frutilla y frambuesa (Rein y col., 2005) y, por otro lado, 
Howard y col. (2012) no han logrado hallarlas en arándano, zarzamora y frambuesa negra, lo cual permitiría concluir que las diferencias antes mencionadas y los cambios observados en el color superficial (sección IV3.2.3) podrían deberse a la formación de estos nuevos compuestos.

\section{IV-3.2.3 Color superficial}

Se midió color superficial en las cuatro pulpas almacenadas a temperatura ambiente en condición de anaquel y oscuridad. En la figura IV-16 se muestra el cambio global de color $(\Delta \mathrm{E})$, destacándose que frambuesa y guinda fueron las más afectadas; mientras que zarzamora y arándano las más estables. En todos los casos fue significativo $(p \leq 0,05)$ el efecto de luz sobre el $\Delta E$.

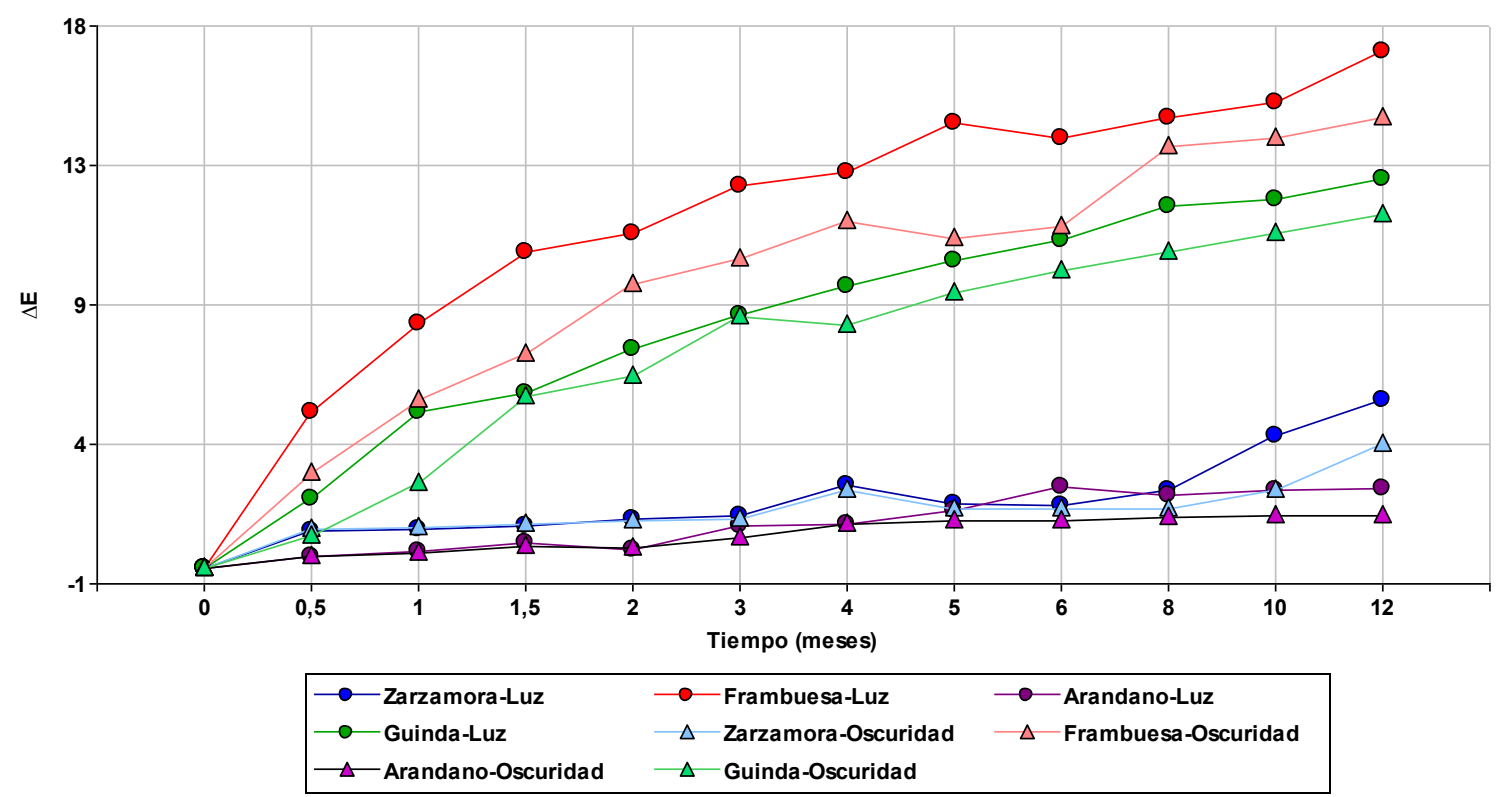

Figura IV-16. Cambio global de color en el almacenamiento a temperatura ambiente de pulpas pasteurizadas. Nota: la altura del punto indica el valor medio. Las barras de error expresan el error estándar.

La pulpa pasteurizada de zarzamora presentó inicialmente un color púrpura rojizo, el cual se fue desplazando, en el tiempo, disminuyendo la componente roja $\left(a^{*}{ }_{\text {control }}=9,88 \pm 0,42 ; a^{*}{ }_{\text {anual } L U z}=5,30 \pm 0,28 ; a^{*}{ }_{\text {anual OSC }}=6,64 \pm 0,30\right)$ y en menor medida la amarilla $\left(b^{*}{ }_{\text {control }}=2,80 \pm 0,18 ; b^{*}{ }_{\text {anual LUZ }}=1,03 \pm 0,30 ; b^{*}\right.$ anual osc $=1,02 \pm 0,10$ ), girando hacia los púrpuras en las muestras (tabla IV-12). 
Tabla IV-12. Funciones de color en pulpa pasteurizada de zarzamora durante el almacenamiento a temperatura ambiente

\begin{tabular}{|c|c|cccc|}
\hline Meses & Tratamiento & $\mathbf{L}^{*}$ & hue & Chroma & $\Delta \mathbf{E}$ \\
\hline $\mathbf{0}$ & Control & $21,13 \pm 0,39^{\mathrm{A}}$ & $15,81 \pm 0,50^{\mathrm{a}}$ & $10,27 \pm 0,45^{\mathrm{A}^{*}}$ & ----- \\
$\mathbf{1 2}$ & Luz & $20,75 \pm 0,53^{\mathrm{B}}$ & $11,00 \pm 0,32^{\mathrm{b}}$ & $5,40 \pm 0,47^{\mathrm{C}^{*}}$ & $5,50 \pm 0,35^{\mathrm{a}^{*}}$ \\
$\mathbf{1 2}$ & Oscuridad & $22,81 \pm 0,98^{\mathrm{A}}$ & $8,75 \pm 1,02^{\mathrm{C}}$ & $6,72 \pm 0,29^{\mathrm{B}^{*}}$ & $4,06 \pm 0,22^{\mathrm{b}^{*}}$ \\
\hline
\end{tabular}

$L^{*}$ : luminosidad, hue: ángulo de tono, Chroma: saturación, $\Delta \mathrm{E}$ : cambio global de color. Los valores representan la media $(n=6) \pm S D$. Medias con una letra común por columna no son significativamente diferentes $(p \leq 0,05)$

Las pulpas resguardadas de la luz no presentaron cambios significativos $(p \leq 0,05)$ en la luminosidad con respecto al control aunque si en la saturación y en el tono del color final. Los viales expuestos en anaquel presentaron menor luminosidad e intensidad que las muestras control. A los fines de realizar una comparación visual se presentan las fotografías de las pulpas y los extractos obtenidos (fotografía IV-6). 

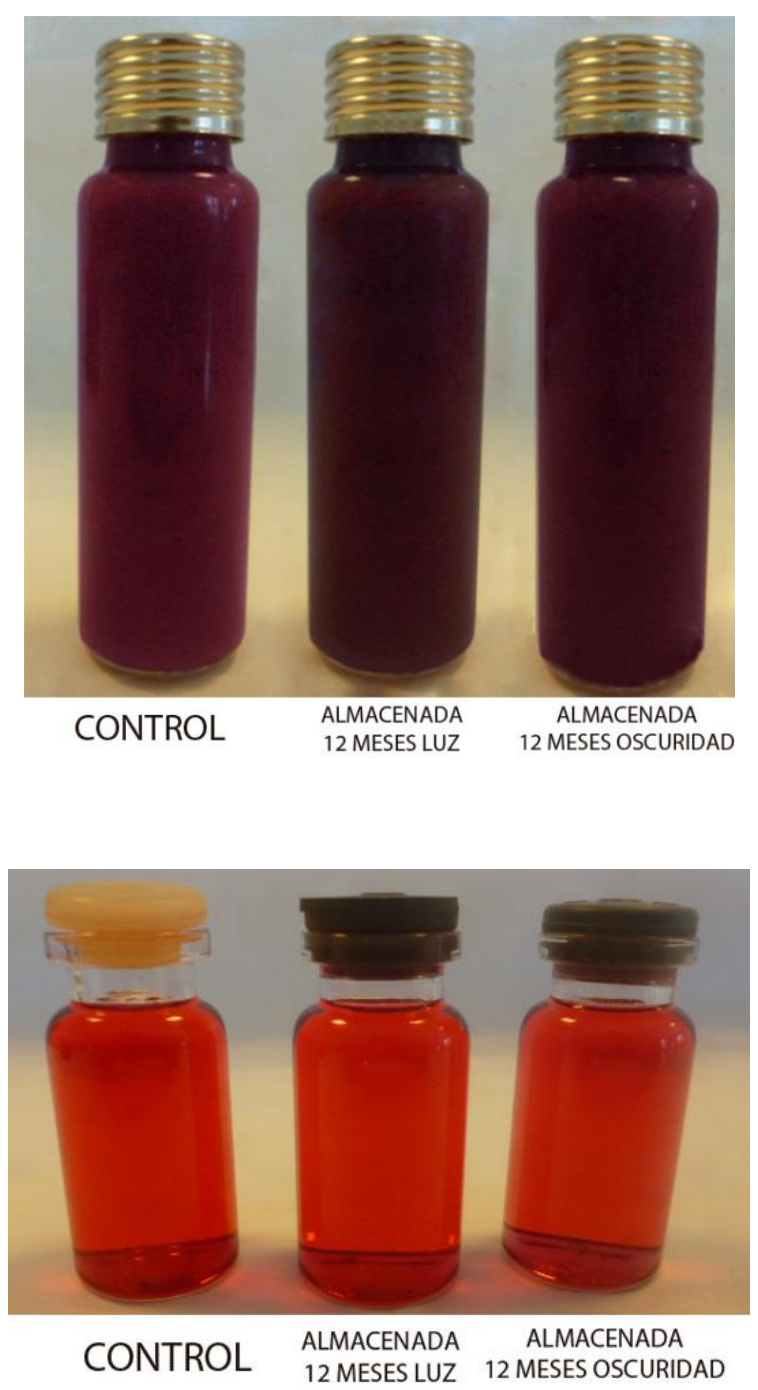

Fotografía IV-6. Pulpas pasteurizadas de zarzamora y sus extractos almacenamiento a temperatura ambiente

En la pulpa pasteurizada de frambuesa el almacenamiento a temperatura ambiente causó detrimento de los rojos $\left(a^{*}{ }_{\text {control }}=27,00 \pm 1,31 ; a^{*}\right.$ anual LUz $=$ $11,60 \pm 0,37 ; a^{*}$ anual osc $\left.=13,83 \pm 1,01\right)$ y amarillos $\left(b^{*}{ }_{\text {control }}=12,64 \pm 1,16\right.$; $b^{*}$ anual LUz $=5,86 \pm 0,25 ; \quad b^{*}$ anual osc $\left.=6,42 \pm 0,72\right)$, generando un importante cambio global de color para cada condición (tabla IV-13). 
Tabla IV-13. Funciones de color en pulpa pasteurizada de frambuesa durante el almacenamiento a temperatura ambiente

\begin{tabular}{|c|c|cccc|}
\hline Meses & Tratamiento & $\mathbf{L}^{*}$ & hue & Chroma & $\Delta \mathbf{E}$ \\
\hline $\mathbf{0}$ & Control & $31,14 \pm 1,01^{\mathrm{A}}$ & $25,04 \pm 1,09^{\mathrm{a}}$ & $29,82 \pm 1,66^{\mathrm{A}^{*}}$ & ----- \\
$\mathbf{1 2}$ & Luz & $30,12 \pm 0,69^{\mathrm{A}}$ & $26,81 \pm 0,72^{\mathrm{a}}$ & $13,00 \pm 0,45^{\mathrm{C}^{*}}$ & $16,85 \pm 0,27^{\mathrm{a}^{*}}$ \\
$\mathbf{1 2}$ & Oscuridad & $29,27 \pm 2,03^{\mathrm{A}}$ & $24,85 \pm 0,94^{\mathrm{a}}$ & $15,24 \pm 1,22^{\mathrm{B}^{*}}$ & $14,96 \pm 0,19^{\mathrm{b}^{*}}$ \\
\hline
\end{tabular}

L*: luminosidad, hue: ángulo de tono, Chroma: saturación, $\Delta \mathrm{E}$ : cambio global de color. Los valores representan la media $(n=6) \pm S D$. Medias con una letra común por columna no son significativamente diferentes $(p \leq 0,05)$

Si bien no se hallaron diferencias significativas $(p \leq 0,05)$ para la luminosidad y el ángulo hue, que ubica las muestra en la zona correspondiente a los rojos, la marcada variación de la saturación originó cambios muy notorios en el color superficial, que tendió a "apagarse", perdiendo el atractivo característico, condición que se trasladó a los extractos (fotografía IV-7). 

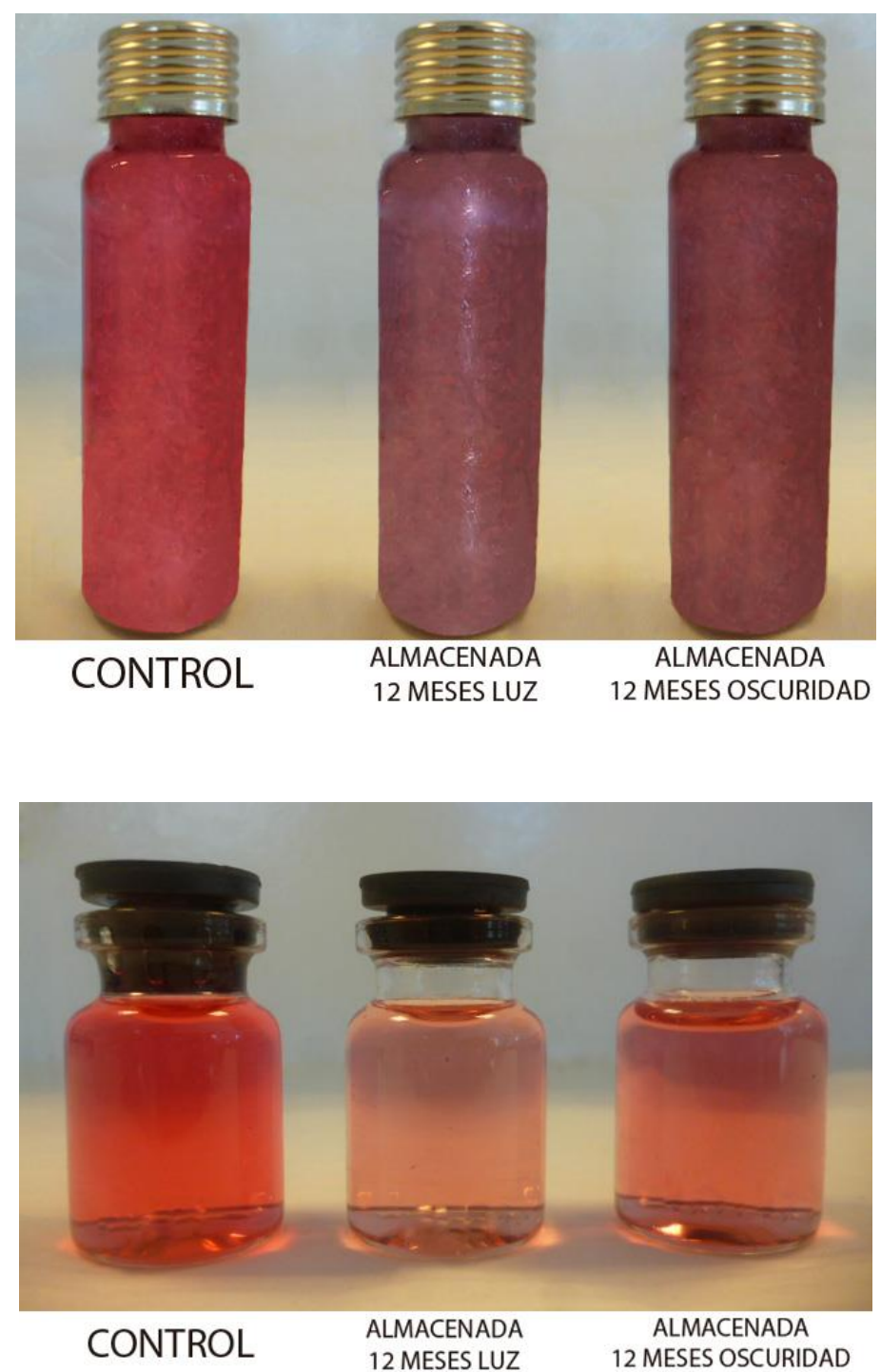

Fotografía IV-7. Pulpas pasteurizadas de frambuesa y sus extractos almacenamiento a temperatura ambiente

El color en las pulpas pasteurizadas de arándano presentó la mayor estabilidad, con pequeños $\Delta \mathrm{E}$ (tabla IV-14). Se divisó un aumento de rojos $\left(a^{*}{ }_{\text {control }}=7,94 \pm 0,30 ; a^{*}{ }_{\text {anual LUz }}=9,89 \pm 0,47 ; a^{*}{ }_{\text {anual OSC }}=9,39 \pm 0,69\right) \quad y$ disminución de amarillos ( $b^{*}$ control $=1,44 \pm 0,11 ; b^{*}$ anual LUz $=0,91 \pm 0,05 ; b^{*}$ anual osc $=0,89 \pm 0,08$ ), lo que se traduce en una disminución del ángulo hue hacia tonos violáceos. No se hallaron diferencias significativas luego de un año entre ambas condiciones de almacenamiento $(p \leq 0,05)$ 
Tabla IV-14. Funciones de color en pulpa pasteurizada de arándano durante el almacenamiento a temperatura ambiente

\begin{tabular}{|c|c|cccc|}
\hline Meses & Tratamiento & $\mathbf{L}^{*}$ & hue & Chroma & $\Delta \mathbf{E}$ \\
\hline $\mathbf{0}$ & Control & $20,92 \pm 0,58^{\mathrm{A}}$ & $10,27 \pm 0,58^{\mathrm{a}}$ & $8,07 \pm 0,31^{\mathrm{A}^{*}}$ & ---- \\
$\mathbf{1 2}$ & Luz & $19,26 \pm 0,43^{\mathrm{A}}$ & $5,24 \pm 0,50^{\mathrm{b}}$ & $9,43 \pm 0,18^{\mathrm{A}^{*}}$ & $2,62 \pm 0,31^{\mathrm{a}^{*}}$ \\
$\mathbf{1 2}$ & Oscuridad & $20,19 \pm 0,31^{\mathrm{A}}$ & $5,41 \pm 0,10^{\mathrm{b}}$ & $9,43 \pm 0,69^{\mathrm{A}^{*}}$ & $1,72 \pm 0,52^{\mathrm{a}^{*}}$ \\
\hline
\end{tabular}

L*: luminosidad, hue: ángulo de tono, Chroma: saturación, $\Delta \mathrm{E}$ : cambio global de color. Los valores representan la media $(n=6) \pm S D$. Medias con una letra común por columna no son significativamente diferentes $(p \leq 0,05)$

Las pulpas de arándano conservadas durante un año presentan un color atractivo con la ventaja de que no necesitan almacenarse al abrigo de la luz. En la fotografía IV-8 se observan los viales que representan cada situación y los extractos correspondientes. 

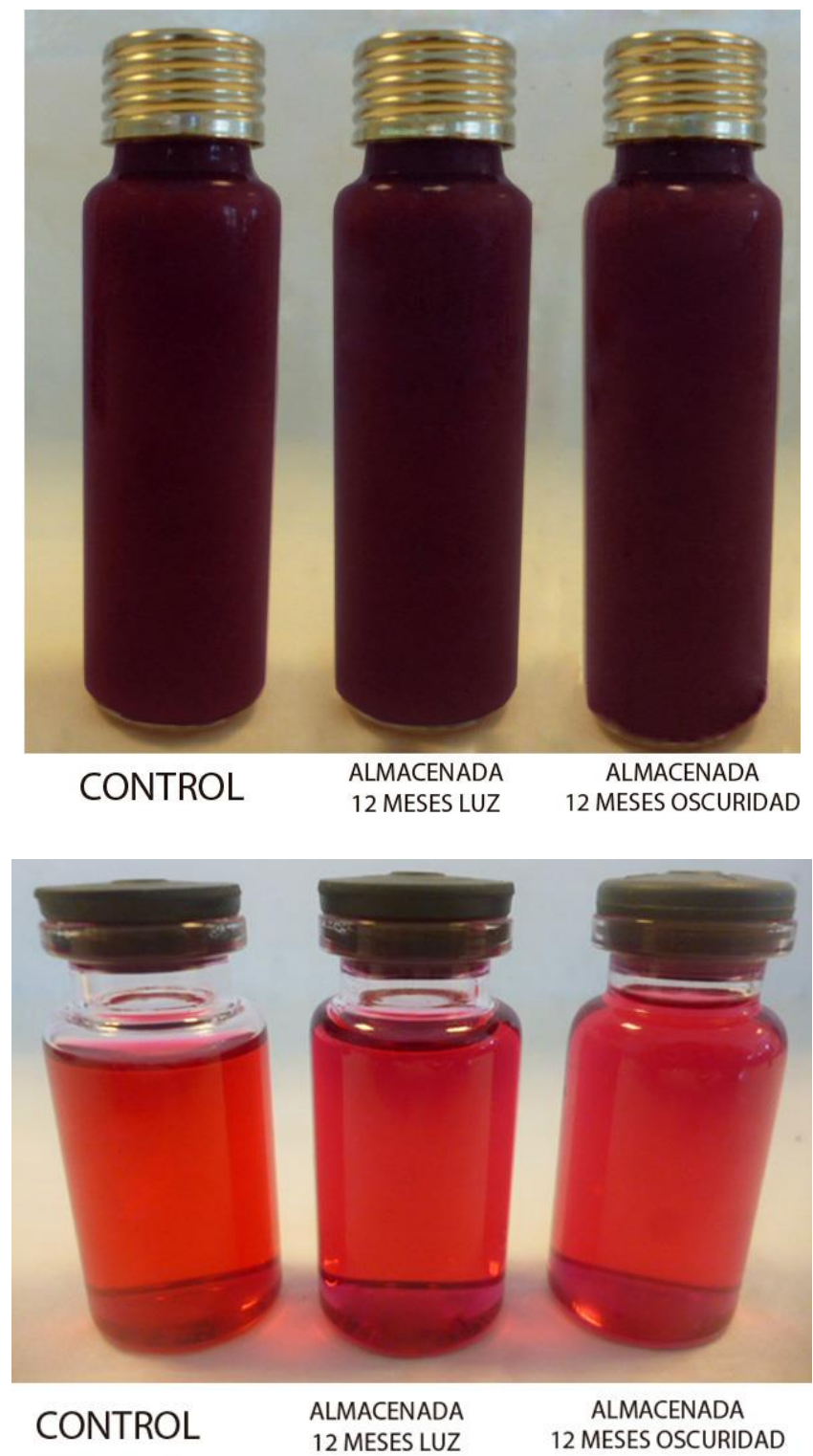

Fotografía IV-8. Pulpas pasteurizadas de arándano y sus extractos almacenamiento a temperatura ambiente

En la tabla IV-15 se presentan las funciones de color para la pulpa pasteurizada de guinda almacenada a temperatura ambiente. Si bien los $\Delta \mathrm{E}$ fueron menores que los alcanzados por frambuesa, sufrieron un mayor impacto en el color superficial debido al aumento del $15 \%$ en la luminosidad, la alta saturación y el corrimiento del ángulo hue hacia tonos anaranjados probablemente debido a la formación de piranoantocianinas lo que se manifestó en una pérdida de rojos ( $a^{*}{ }_{\text {control }}=24,43 \pm 0,49 ; a^{*}{ }_{\text {anual LUZ }}=13,27 \pm$ 0,$34 ; a^{*}$ anual osc $\left.=14,15 \pm 0,19\right)$ y un aumento de amarillos $\left(b^{*}{ }_{\text {control }}=11,47 \pm\right.$ 0,$54 ; b^{*}$ anual LUz $=14,89 \pm 0,80 ; b^{*}$ anual OSC $\left.=14,39 \pm 0,35\right)$. 
Tabla IV-15. Funciones de color en pulpa pasteurizada de guinda durante el almacenamiento a temperatura ambiente

\begin{tabular}{|c|c|cccc|}
\hline Meses & Tratamiento & $\mathbf{L}^{*}$ & hue & Chroma & $\Delta \mathbf{E}$ \\
\hline $\mathbf{0}$ & Control & $33,00 \pm 1,06^{\mathrm{B}}$ & $25,13 \pm 0,64^{\mathrm{C}}$ & $26,98 \pm 0,66^{\mathrm{A}^{*}}$ & ----- \\
$\mathbf{1 2}$ & Luz & $37,99 \pm 1,05^{\mathrm{A}}$ & $48,26 \pm 0,79^{\mathrm{a}}$ & $19,94 \pm 0,82^{\mathrm{B}^{*}}$ & $12,69 \pm 0,29^{\mathrm{a}^{*}}$ \\
$\mathbf{1 2}$ & Oscuridad & $37,37 \pm 0,69^{\mathrm{A}}$ & $45,46 \pm 0,36^{\mathrm{b}}$ & $20,18 \pm 0,37^{\mathrm{B}^{*}}$ & $11,54 \pm 0,12^{\mathrm{b}^{*}}$ \\
\hline
\end{tabular}

L*: luminosidad, hue: ángulo de tono, Chroma: saturación, $\Delta \mathrm{E}$ : cambio global de color. Los valores representan la media $(n=6) \pm S D$. Medias con una letra común por columna no son significativamente diferentes $(p \leq 0,05)$

Los productos resultaron pálidos y poco atractivos en general (fotografía IV-9), independientemente de la exposición a la luz. Nuevamente estas características se hicieron extensivas a los extractos. 

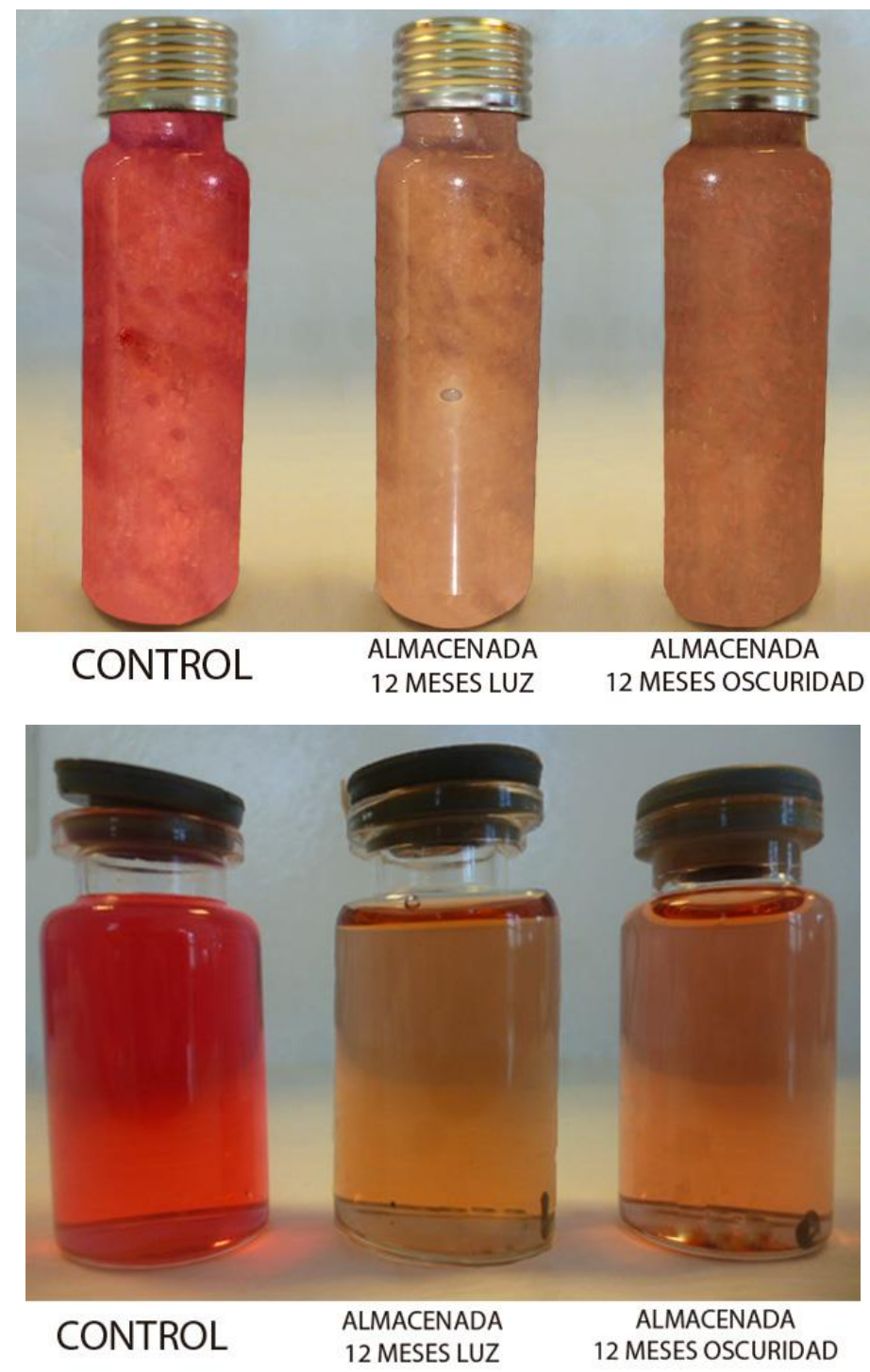

Fotografía IV-9. Pulpas pasteurizadas de guindas y sus extractos almacenamiento a temperatura ambiente

\section{IV-4. CONCLUSIONES}

\section{En cuanto a fenoles totales:}

- Durante el almacenamiento en freezer a $-18^{\circ} \mathrm{C}$, las pérdidas de FT en pulpa de zarzamora (30\%) fueron mayores a las halladas en la pulpa pasteurizada (17\%).

- La concentración en pulpa de frambuesa aumentó un $12 \%$ durante el almacenamiento de pulpas pasteurizadas, mientras que a $-18^{\circ} \mathrm{C}$ disminuyó un $23 \%$. 
- En pulpa de arándano, el efecto del almacenamiento tanto en congelado como de las pulpas pasteurizadas fue similar: 22 y $20 \%$ de pérdida respectivamente.

- En pulpa de guinda pasteurizada, la concentración decayó un $24 \%$, mientras que a $-18^{\circ} \mathrm{C}$ el porcentaje de pérdida alcanzó el $17 \%$.

- En ninguna de las pulpas pasteurizadas se registraron diferencias significativas $(p \leq 0,05)$ en la concentración por efecto de la luz.

\section{En cuanto a flavonoides:}

- Las mayores pérdidas se registraron en pulpa de frambuesa pasteurizada expuesta a la luz (40\%), mientras que la misma fruta a $-18^{\circ} \mathrm{C}$ no presentó diferencias significativas $(p \leq 0,05)$ con el control.

- En el caso de pulpa pasteurizada de zarzamora, el almacenamiento a temperatura ambiente ocasionó una pequeña disminución de Fv $(7 \%)$ sin manifestar efectos por exposición a la luz, mientras que en la pulpa congelada no se hallaron diferencias significativas $(p \leq 0,05)$ con el valor inicial.

- En la pulpa pasteurizada de arándano no se observaron variaciones $(p \leq 0,05)$ durante el almacenamiento a temperatura ambiente (en ninguna de las condiciones), mientras que en la pulpa congelada este parámetro disminuyó un $21 \%$.

- En pulpa de guinda este parámetro disminuyó para todas las condiciones de almacenamiento, siendo más notorio el deterioro sufrido en pulpa pasteurizada conservada a temperatura ambiente (33\%). No se detectaron diferencias significativas entre luz/oscuridad $(p \leq 0,05)$.

\section{En cuanto a poder antirradicalario:}

- En pulpa de zarzamora, tanto la pulpa pasteurizada almacenada a temperatura ambiente (luz/oscuridad) como la pulpa congelada no presentaron variaciones con el control.

- En pulpa congelada de frambuesa la disminución fue muy marcada, reduciéndose un $58 \%$, al igual que en pulpa pasteurizada a temperatura ambiente, donde las pérdidas fueron del $65 \%$, sin diferencias significativas por exposición a la luz, $(p \leq 0,05)$. 
- El almacenamiento a temperatura ambiente de la pulpa pasteurizada de arándano no mostró cambios respecto al control (en ninguna de las dos condiciones de exposición); mientras que durante el congelado disminuyó un $21 \%$.

- En pulpa de guinda pasteurizada, el parámetro disminuyó un $57 \%$ y no se registró diferencias significativas por exposición a la luz $(p \leq 0,05)$, mientras que en pulpa congelada el porcentaje de pérdida fu de un $26 \%$.

\section{En cuanto a contenido de pigmentos:}

- Durante el almacenamiento de pulpas congeladas se obtuvieron altos porcentajes de retención de ACY: $86 \%$ para zarzamora y guinda y 100\% para arándano y frambuesa. En contraposición, en las pulpas pasteurizadas almacenadas a temperatura ambiente el impacto fue mucho más significativo. En las pulpas más oscuras (zarzamora y arándano) la retención se ubicó entre un 14-26\%, mientras que en las más claras (frambuesa y guinda) sólo un 1-6\% de las ACY se retuvieron. Se hallaron diferencias significativas $(p \leq 0,05)$ debidas al efecto de la luz sobre la degradación de los pigmentos, en todas las pulpas pasteurizadas.

- La estabilidad de las ACY en las pulpas congeladas, se manifestó en valores pequeños de IDA y \%CP. Por el contrario, en las pulpas pasteurizadas almacenadas a temperatura ambiente la marcada disminución de ACY elevó ambos parámetros, siendo las frutas oscuras las menos afectadas. Se hallaron diferencias significativas en estos parámetros por la exposición de las pulpas pasteurizadas a la luz $(p \leq 0,05)$.

- En pulpas pasteurizadas, el almacenamiento a temperatura ambiente y en oscuridad brindaría un efecto protector sobre los pigmentos antociánicos para todas las frutas estudiadas.

\section{En cuanto a evaluación del color:}

- Las pulpas congeladas luego de un año de almacenamiento presentaron, en general, pequeños cambios globales de color. La matriz más afectada fue la pulpa de guinda, con pérdidas significativas $(p \leq 0,05)$ de 
luminosidad, de rojos y amarillos, lo que se manifestó en un producto rosa pálido.

- El color de las pulpas pasteurizadas almacenadas a temperatura ambiente fue fuertemente afectado en todas las matrices, especialmente en las más claras (guinda y frambuesa) que perdieron sus rojos característicos virando hacia un naranja amarronado. Las matrices más oscuras (arándano y zarzamora) exhibieron colores aún aceptables al ojo del consumidor. El efecto de la exposición a la luz fue significativo para todas las pulpas estudiadas.

\section{Conclusión general}

Los datos obtenidos durante el almacenamiento de las pulpas brindan herramientas fundamentales a tener en cuenta al momento de utilizarlas $y / o$ comercializarlas, no sólo en cuanto a los niveles de fitoquímicos alcanzados sino también desde el punto de vista del color que, en la mayoría de los casos, constituye uno de los atributos más importantes del producto.

En pulpas congeladas, en general, las pérdidas de los compuestos bioactivos estudiados no superan el $30 \%$, además de mantener un nivel alto de pigmentos y un color atractivo. El PA se conserva mucho mejor en las frutas oscuras (zarzamora y arándano).

En pulpas pasteurizadas almacenadas a temperatura ambiente en condiciones de luz y oscuridad, frambuesa y guinda fueron las matrices con mayores pérdidas de compuestos bioactivos y PA, siendo al mismo tiempo las que presentaron pérdidas de ACY mayores al 95\%, lo que se refleja en altos IDA. El color de estas pulpas fue significativamente afectado en todos los casos por el tiempo de conservación y las condiciones de exposición, con un efecto marcado de la luz sobre todo en las frutas más claras.

Analizado el efecto del procesado y conservación de las distintas matrices, se podría concluir que las pulpas de arándano (congelada y pasteurizada) presentaron y conservaron los mayores niveles de compuestos bioactivos, poder antirradicalario y estabilidad del color, justificando su elección para la formulación de nuevos alimentos. De las tres matrices restantes, las pulpas de zarzamora serían una muy buena elección por su alto nivel de ACY, PA y estabilidad del color. 


\section{IV-5. REFERENCIAS}

- Aaby, K.; Wrolstad, R.; Ekeberg, D. y Skrede, G. 2007. Polyphenol composition and antioxidant activity in strawberry purees; impact of achene level and storage. Journal of Agricultural and Food Chemistry. Vol. 55, $n^{\circ} 13, p$. 5156-5166.

- Brownmiller, C.; Howard, L. y Prior R. 2008 Processing and storage effects on monomeric anthocyanins, percent polymeric colour, and antioxidant capacity of processed blueberry products. Journal of Food Science. Vol. 73, n5, p. $72-79$.

- Bunea, A.; Andjelkovic, M.; Socaciu, C.; Bobis, O.; Neacsu, M.; Verhé, R. y Van Camp, J. 2008. Total and individual carotenoids and phenolic acids content in fresh, refrigerated and processed spinach (Spinacia oleracea L.). Journal of Food Chemistry. Vol. 108, n² 2, p. 649-656.

- Camacho, G. y Sanabria, G. 2005. Alternativas de procesamiento y transformación para la uchuva. En: Avances en cultivo, poscosecha y exportación de la uchuva Physalis peruviana L. en Colombia. Universidad Nacional de Colombia con el Auspicio del Ministerio de Agricultura y Desarrollo Rural. Bogotá, p 191-203.

- Carlsen, C. y Stapelfeldt, H. 1997. Light sensitivity of elderberry extract. Quantum yields for photodegradation on aqueous solution. Journal of Food Chemistry. Vol. 60, n 383, p. 265.

- Chandler, L. y Schwartz, S. 1987. HPLC separation of cis-trans carotene isomers in fresh and processed fruits and vegetables, Journal of Food Science. Vol. 52, p. 669.

- Chaovanalikit, A. y Wrolstad, R. 2004. Total anthocyanins and total phenolics of fresh and processed cherries and their antioxidant properties. Journal of food science. Vol. $69, \mathrm{n}^{0} 1$.

- Cheftel, J.; López, F.; Desnuelle, P. y Cheftel, H. 1980. Introducción a la bioquímica y tecnología de los alimentos. Acribia. España.

- De Ancos, B.; González, E. y Cano, M. 2000. Ellagic acid, vitamin C, and total phenolic contents and radical scavenging capacity affected by freezing and frozen storage in raspberry fruit. Journal of Agricultural and Food Chemistry. Vol. 48, nº 10, p. 4565-4570. 
- Di Rienzo, J.; Casanoves, F.; Balzarini, M.; González, L.; Tablada, M. y Robledo, C. 2012. Software InfoStat versión 2012. Argentina: Grupo InfoStat, FCA, U.N.C., Argentina

- Gancel, A.; Feneuil, A.; Acosta, O.; Pérez, A. y Vaillant, F. 2011. Impact of industrial processing and storage on major polyphenols and the antioxidant capacity of tropical highland blackberry (Rubus adenotrichus). Food Research International. Vol. 44, $n^{\circ} 7$, p. 2243-2251.

- Gradziel, P. 1988. The effects of frozen storage time, temperature and packaging on the quality of the tomato cultivars Pink-red and Nova. Dissertation Abstr. International B. Vol. 8, no 9, p. 2609.

- Gómez-Sánchez, A.; Cerón-Carrillo, T.; Rodríguez-Martínez, V. y Vázquez-Aguilar, M. 2007. Aspectos tecnológicos de la congelación en alimentos. Temas Selectos de Ingeniería de Alimentos. Vol. 1, p. 80-96.

- Gonzales Walter. 2011. Compuestos bioactivos en frambuesa, zarzamora y sus pulpas: efecto del proceso y almacenamiento. Memoria para optar por el título de Técnico en Control e Higiene de los Alimentos de la Facultad de Ciencias y Tecnología de los Alimentos, Universidad Nacional del Comahue. Argentina

- Gonzalo Rivas, J. y Garcia Alonso, M. 2002. Flavonoides en alimentos vegetales: estructura y actividad antioxidante. Alimentación Nutrición y Salud. Vol. 9, $n^{\circ}$ 2, p. 31-38.

- Hager, T.; Howard, L. y Prior, R. 2010. Processing and storage effects on the ellagitannin composition of processed blackberry products. Journal of agricultural and food chemistry. Vol. 58, nº 22, p. 11749-11754.

- Häkkinen, S.; Heinonen, M.; Kärenlampi, S.; Mykkänen, H.; Ruuskanen, J. y Törrönen, R. 1999a. Screening of selected flavonoids and phenolic acids in 19 berries. Food Research International. Vol. 32, n 5, p. 345-353.

- Häkkinen, S.; Kärenlampi, S.; Heinonen, I.; Mykkänen, H. y Törrönen, A. 1999b. Content of the flavonols quercetin, myricetin, and kaempferol in 25 edible berries. Journal of Agricultural and Food Chemistry. Vol. 47, $n^{\circ} 6, p$. 2274-2279. 
- Häkkinen, S.; Kärenlampi, S.; Mykkänen, H.; Heinonen, I. y Törrönen, A. 2000. Ellagic acid content in berries: Influence of domestic processing and storage. European Food Research and Technology. Vol. 212, no 1, p. 75-80.

- Howard, L.; Prior, R.; Liyanage, R. y Lay, J. O. 2012. Processing and storage effect on berry polyphenols: challenges and implications for bioactive properties. Journal of agricultural and food chemistry. Vol. $60, n^{\circ} 27$, p. 66786693.

- Inami, O.; Tamura, I.; Kikuzaki, H. y Nakatani, N. 1996. Stability of anthocyanins of Sambucus sanadensis and Sambucus nigra. Journal of Agricultural and Food Chemistry. Vol. 44, n³090, p. 266.

- International Institute of Refrigeration (IIR). 1986. Recommendations for the Processing and Handling of Frozen Foods. 3a.ed. Paris.

- Jackman, R. y Smith, J. 1996. Anthocyanins and betalains, in Natural Food Colorants, 2nd ed., Hendry, G.A.F. and Houghton, J.D., Eds., Blackie Academic \& Professional, Glasgow. Pp. 244.

- Kallio, H., Pallasaho, S., Kärppä, J., and Linko, R. 1986. Stability of anthocyanins in crowberry juice, in The Shelf Life of Food and Beverages, Charalambous, G., Ed., Elseveier, Amsterdam, p. 285.

- Kalt, W.; Prange, R. y Lidster, P. 1993. Postharvest color development of strawberries: influence of maturity, temperature and light. Canadian Journal of Plant Science. Vol. 73, $n^{\circ}$ 2, p. 541-548.

- Klein, B. y Kurilich, A. 2000. Processing effects on dietary antioxidants from plant foods. HortScience. Vol. 35, no 4, p. 580-584.

- Kobs, L. 1997. Designing frozen foods. Food product design. Vol. 6, $\mathrm{n}^{\circ}$ 10, p. $27-43$.

- Mafart, P. 1994. Procesos físicos de conservación. Volumen 1. Ed. Acribia. p. 254-259.

- Ngo, T.; Wrolstad, R.; Zhao, Y. 2007. Color Quality of Oregon Strawberries- Impact of Genotype, Composition, and Processing. Journal of Food Science, Vol. 72, no 1, p. 25-32.

- Ochoa, M.; Kesseler, A.; Vullioud, M.; Lozano, J. 1999. Physical and Chemical Characteristics of Raspberry Pulp: Storage Effect on Composition and Color. LWT- Food Science and Technology. Vol. 32, n 3, p. 149-153. 
- Ordónez, J.; Cambero, M; García, M.; Garcia de Fernando, G.; De la Hoz, L. y Selgas, M. 1998. Componentes de los Alimentos y Procesos. Volumen I. Ed. Ordóñez. p. 284-289

- Osorio Mora, O. 2008. Influencia de tratamientos térmicos en la calidad y estabilidad del puré de fresa (Fragaria $x$ ananassa, cv Camarosa). Memoria para optar al grado de Doctor por la Universidad Politécnica de Valencia. España

- Parada, J. y Aguilera, J. 2007. Food microstructure affects the bioavailability of several nutrients. Journal of Food Science. Vol. $72, n^{\circ} 2, p$. R21-R32.

- Poiana, M.; Moigradean, D.; Raba, D.; Alda, L. y Popa, M. 2010. The effect of long-term frozen storage on the nutraceutical compounds, antioxidant properties and color indices of different kinds of berries. Journal of Food Agriculture and Environment. Vol. 8, nº 1, p. 54-58.

- Rein, M.; Ollilainen, V.; Vahermo, M.; Yli-Kauhaluoma, J. y Heinonen, M. 2005. Identification of novel pyranoanthocyanins in berry juices. European Food Research and Technology. Vol. 220, n 3-4, p. 239-244.

- Rentzsch, M.; Schwarz, M. y Winterhalter, P. 2007. Pyranoanthocyanins-an overview on structures, occurrence, and pathways of formation. Trends in food science \& technology. Vol. 18, n 10, p. 526-534.

- Rommel, A. y Wrolstad, R. 1993. Ellagic acid content of red raspberry juice as influenced by cultivar, processing and environmental factors. Journal of Agricultural and Food Chemistry. Vol. 41, n 11, p. 1951-1960.

- Šavikin, K.; Zdunić, G.; Janković, T.; Tasić, S.; Menković, N.; Stević, T., y Đorđević, B. 2009. Phenolic content and radical scavenging capacity of berries and related jams from certificated area in Serbia. Plant foods for human nutrition. Vol. $64, n^{\circ} 3$, p. 212-217.

- Ścibisz, I. y Mitek, M. 2007. The changes of antioxidant properties in highbush blueberries (Vaccinium corymbosum L.) during freezing and long-term frozen storage. Acta Scientiarum Polonorum Technologia Alimentaria. Vol. 6, $n^{\circ} 4$, p. ${ }^{\circ} 75-81$. 
- Türkben, C.; Sarıburun, E.; Demir, C. y Uylaşer, V. 2010. Effect of freezing and frozen storage on phenolic compounds of raspberry and blackberry cultivars. Food Analytical Methods. Vol. 3, no 3, p. 144-153.

- Venning, J.; Burns, D.; Hoskin, K.; Nguyen, T. y Stec, M. 1989. Factors influencing the stability of frozen kiwifruit pulp. Journal of Food Science. Vol. 54, p. 396- 400.

- Wrolstad, R.; Durst, R.; Lee, J. 2005. Tracking color and pigment changes in anthocyanin products. Trends in Food Science \& Technology. Vol. 16, p. $423-428$.

- Zafrilla, P.; Ferreres, F. y Tomás-Barberán, F. 2001. Effect of processing and storage on the antioxidant ellagic acid derivatives and flavonoids of red raspberry (Rubus idaeus) jams. Journal of Agricultural and Food Chemistry, Vol. 49, n 8, p. 3651-3655.

- Zhao, Y. 2007. Berry fruit: value-added products for health promotion. CRC press. 


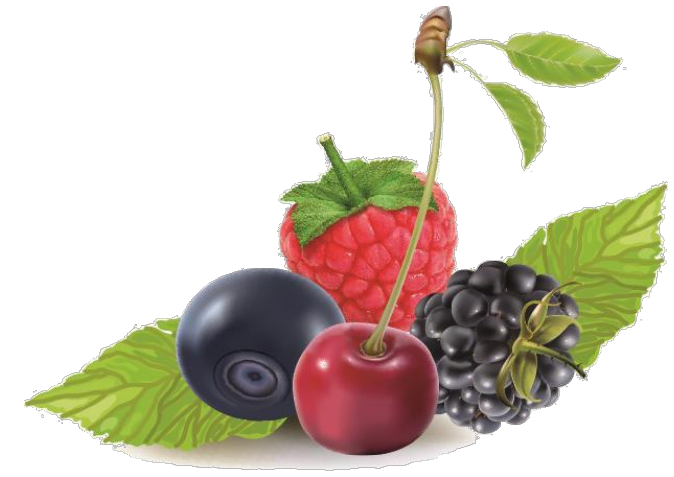

CAPITULO V

Desarrollo de alimentos funcionales 


\section{V-1. INTRODUCCION}

En la Argentina la producción de frutas finas (berries y cherries) se ha convertido en una actividad agroindustrial de suma importancia, debido a los variados productos de alta demanda que ofrece, a la generación de empleos y, asimismo, al fuerte impacto económico que esta clase de cultivos produce en las economías regionales donde tienen lugar. Tanto los productores de frutas finas como la mayor parte de los especialistas de la industria agroalimentaria, suelen brindar una opinión concordante en el sentido de que se trata de una actividad todavía en moderada expansión (Argentina 2020, 2012).

Por otro lado, la inexistencia de problemas de fungosis y bacteriosis permite una producción prácticamente libre de agroquímicos, que va a tono con la fuerte solicitud de productos orgánicos en el mercado. Si se agrega a este panorama una demanda que prácticamente no tiene techo, a pesar de su marcada elasticidad, la producción de fruta fina se presenta como una interesante oportunidad de diversificación productiva para los valles cordilleranos (De Bernardi, 2011).

Salvo para el caso de los arándanos, en que el $90 \%$ de la producción se exporta en fresco, el resto de los berries son consumidos principalmente en el mercado local, que demanda fruta congelada y en conserva para transformarlas luego en confituras, salsas, jugos concentrados, deshidratados, licores y aguardientes, entre los productos más importantes.

Según el Ing. Martinez (2007) del INTA El Bolsón: "la comercialización en fresco se está llevando a cabo en los mercados cercanos de cada localidad de la región. No hay todavía logística ni cadena de frío adecuada para llegar bien a mercados más lejanos. El grueso de la producción se vende congelada, IQF o a granel, y no presenta mayores dificultades".

Por tanto, estas cuestiones de calidad y perecibilidad hacen que exista un volumen considerable de fruta no comercializable en fresco, por el cual surge la necesidad de desarrollar nuevos productos industrializados en base a estas frutas. A esto se le suma además problemas climáticos (daño de heladas tardías, precipitaciones en cosecha) o bien de logística y comercialización (como los subrayados por el Ing. Martínez), lo que conlleva a que no toda la 
producción potencial llegue a ser levantada y en muchos casos se presenten quintas con una cantidad importante de fruta en planta sin cosechar.

La elaboración de pulpas preparadas a partir de frutas finas ha alcanzado una gran importancia económica en la industria alimentaria actual, mostrando un gran futuro comercial, ya que son la base a partir de la cual se elaboran una amplia gama de productos finales como los jugos de frutas con pulpa, néctares, mermeladas, salsas, helados, yogures y alimentos infantiles.

Es por ello que el desarrollo de este trabajo de investigación tiene como uno de sus objetivos la generación de herramientas que permitan el agregado de valor a la producción de berries y cherries, a través de la incorporación de conocimientos científico-tecnológicos, puestos a disposición de los productores, emprendedores e industriales, focalizando en la elaboración de productos que permitan conseguir efectos beneficiosos que van más allá de los requerimientos nutricionales tradicionales, es decir alimentos funcionales.

\section{V-1.1 Diseño de alimentos funcionales}

Aunque la definición de los alimentos funcionales y su marco normativo vigente admite variantes, según los criterios y los países, estos productos son una realidad comercial creciente. Se sabe que el tamaño del mercado global de este tipo de alimentos ha venido creciendo en forma sostenida con una proyección al 2017 a superar los 862 billones de dólares.

Existe una creciente tendencia de asociación de la alimentación con el estado de salud de la persona; si bien la función principal de la dieta es aportar los nutrientes para satisfacer las necesidades nutricionales del organismo, cada vez hay más pruebas científicas que apoyan la hipótesis de que algunos alimentos tienen el efecto de mejorar las condiciones físicas y mentales, así como de reducir el riesgo de contraer ciertas enfermedades.

Según cifras entregadas por FAO y la ONU, para el 2050, la población mundial alcanzará los 9,1 mil millones de personas, de los cuales el 22\% serán mayores de 60 años (1,9 mil millones). En este segmento etario, aumentará la demanda por alimentos que contribuyan a la prevención de enfermedades, es decir, los llamados alimentos funcionales; aquéllos que contienen ingredientes activos, que tienen un efecto fisiológico más allá del tradicional. 
De los productos de diseño que se encuentran actualmente en el mercado, el mayor porcentaje responde a la siguiente clasificación:

- Producto Fortificado: Alimento fortificado con adición de nutrientes.

- Producto Enriquecido: Alimento con adición de nuevos nutrientes o componentes normalmente no encontrados de manera natural en el producto.

- Producto Alterado: Alimento en el cual un componente no beneficioso es removido, reducido o sustituido por otra sustancia con efectos benéficos.

- Alimentos Mejorados: Alimentos en en los cuales uno o varios de los componentes ha sido naturalmente mejorado a través de condiciones de crecimiento especial, manipulación genética u otro medio.

El Código Alimentario Argentino define en su artículo 1363 (Resolución Conjunta SPyRS N 118/2008 y SAGPyA $N^{\circ}$ 474/2008) a los alimentos fortificados como aquellos en los cuales la proporción de proteínas, aminoácidos, vitaminas, substancias minerales o ácidos grasos esenciales es superior a la del contenido natural medio del alimento corriente, por haber sido suplementado significativamente. Puntualmente, en el caso de vitaminas hidrosolubles se exige que la porción del mismo aporte entre un 20 \% y 50 \% de los valores de ingesta diaria recomendada de nutrientes (IDR) mencionadas por la Res. GMC 46/03 (capítulo 5). Para el caso de ácido ascórbico la IDR es de 45 mg/día para varones y mujeres mayores de 19 años (Código Alimentario Argentino, 2016).

El objetivo de este capítulo fue obtener pulpas mezclas fortificadas y estudiar la evolución de los compuestos bioactivos, el poder antirradicalario y el color superficial durante el almacenamiento pasteurizado (en ausencia y presencia de luz a temperatura ambiente) y la preparación de mermeladas puras y fortificadas con polvos de rosa mosqueta y cassis.

\section{V-2. MATERIALES Y MÉTODOS}

Las frutas fueron cosechadas por productores de la zona de la Comarca Andina del Paralelo 42 en su punto de madurez óptimo y enviadas inmediatamente a Villa Regina, donde se conservaron en heladera a $5^{\circ} \mathrm{C}$ hasta su utilización. 
Se realizó un muestreo aleatorio simple, se descartaron aquellos frutos que presentaban síntomas de avanzado estado de madurez.

Las variedades utilizadas fueron: frambuesa var. Tulameen, zarzamora var. Thornfree, guindas var. Montmorency, arándanos var. Elliot, rosa mosqueta silvestre var. Rosa eglanteria y cassis var. Silvergrietten. Los extractos y las determinaciones se realizaron por triplicado

\section{V-2.1 Procesos}

Las frutas fueron sometidas a los procesos establecidos en el capítulo III: pulpado (zarzamora y frambuesa) y escaldado-pulpado (arándano y guinda).

A continuación se prepararon diez productos: dos pulpas mezcla fortificadas con polvo de rosa mosqueta deshidratada (RMD) y doce mermeladas: cuatro de pulpas puras, cuatro con agregado de polvo de RMD y cuatro con agregado de polvo de cassis.

El agregado del polvo de RMD se realizó con la finalidad de aumentar la funcionalidad del producto resultante por incorporación significativa de ácido ascórbico, lo cual convertiría a estos nuevos alimentos en fuentes no tradicionales de este compuesto bioactivo. Además se potenciaría la concentración de FT, Fv y PA.

En el caso de polvo de cassis, si bien este aditivo también presenta una concentración de ascórbico importante y superior a las matrices utilizadas como base para la elaboración de los productos, la incorporación en la formulación persigue un aumento en la concentración y estabilidad de los pigmentos antociánicos, considerando que el color es uno de los atributos más relevantes en estos productos alimenticios, ya que el consumidor juzga los alimentos principalmente por su apariencia y los relaciona directamente con su calidad.

\section{V-2.1.1 Preparación de Pulpa mezcla fortificada}

Se prepararon mezclas al $50 \%$ de pulpa de arándano/frambuesa y guinda/zarzamora y se les agregó un $8 \%$ de polvo de RMD. Las combinaciones se seleccionaron en función de los resultados obtenidos durante el almacenamiento (presentados en el capítulo IV), la opinión de un 
panel sensorial interno realizado sobre las pulpas y a los fines de cumplir con el artículo 1363 del CAA para fortificados.

Luego de homogeneizar manualmente la mezcla y de unos minutos de reposo, se procedió al envasado en viales de vidrio sellados con precintos metálicos. Se pasteurizó el producto repitiendo la técnica llevada a cabo para las pulpas puras en el capítulo IV.

\section{V-2.2.2 Preparación de mermeladas}

Las pulpas puras de frambuesa, arándano, guinda y zarzamora se pesaron y se mezclaron con azúcar, en proporción uno a uno. Se calentó hasta ebullición, con fuego directo, en recipientes de acero inoxidable expuestos al ambiente. Durante la cocción se agitó la mezcla constantemente y se monitorearon los sólidos solubles. Los productos finales alcanzaron los 66 ${ }^{\circ}$ Brix. Se envasaron en frascos de vidrio de 50 gramos esterilizados. El tiempo aproximado de obtención para un kilogramo de pulpa fue de 30 minutos.

En el caso de las mermeladas con RMD o cassis deshidratado, el procedimiento fue idéntico al anterior solo que se adicionó a la mezcla, antes de la ebullición, $8 \%$ de RMD ० $5 \%$ de polvo de cassis según correspondiese. La determinación de los porcentajes se realizó en función de un panel sensorial interno. Un mayor porcentaje de polvo de cassis le confería alta acidez a las pulpas.

\section{V-2.2 Condiciones de almacenamiento}

Las pulpas mezcla pasteurizadas envasadas en viales de vidrio se almacenaron a temperatura ambiente $\left(25^{\circ} \mathrm{C}\right.$ ) en condiciones de anaquel (luz) y en oscuridad durante 6 meses, tomándose muestras al azar para llevar a cabo el seguimiento en la concentración de los compuestos estudiados. Los tiempos establecidos para extracción de muestras fueron (en días): 15, 30, 45, 60, 90, 120, 150, 180. 


\section{V-2.3 Determinaciones}

- Extracción de compuestos bioactivos. Se realizó según la metodología explicada en el Capítulo I, sección I-2.1; utilizando como solvente de extracción solución al $1 \%$ de $\mathrm{HCl}$ en etanol y temperatura de $37^{\circ} \mathrm{C}$.

- Fenoles totales (FT). Se realizó según la metodología explicada en el Capítulo III, sección III-2.2, por Fast blue BB debido al elevado contenido de ácido ascórbico de algunas matrices.

- Flavonoides (Fv). Se realizó según la metodología explicada en el Capítulo I, sección I-2.1.

- Poder Antirradical (PA). Se realizó según la metodología explicada en el Capítulo I, sección I-2.1.

- Antocianinas (ACY). Se realizó según la metodología explicada en el Capítulo I, sección I-2.1.

- Porcentaje de Color Polimérico (\% CP). Se realizó según la metodología explicada en el Capítulo III, sección III-2.2.

- Índice de degradación de antocianinas (IDA). Se realizó según la metodología explicada en el Capítulo III, sección III-2.2.

- Ácido Ascórbico Total (AA). Se realizó según la metodología explicada en el Capítulo II, sección II-2.1.

- Color superficial. Se realizó según la metodología explicada en el Capítulo II, sección II-2.1.

\section{V-2.4 Análisis estadístico}

\section{V-2.4.1 Proceso de elaboración de mermelada}

Para evaluar el efecto del proceso de elaboración de mermelada sobre los compuestos bioactivos, poder antirradicalario y color superficial, se aplicó un diseño completamente aleatorizado. Los resultados se analizaron mediante análisis de varianza (ANOVA) para un nivel de significancia $\alpha=0,05$ y se empleó la prueba de DGC (Di Rienzo, Guzmán, Casanoves) para la comparación de medias. Se utilizó el programa estadístico Infostat v. 2012. (Di Rienzo y col., 2012). 


\section{V-2.4.2 Almacenamiento Luz/Oscuridad de pulpas mezclas fortificadas}

A los efectos de evaluar el tratamiento (luz/oscuridad) se consideró el último punto de medición con un nivel de significancia del $\alpha=0,05$.

A los efectos de evaluar el tiempo de conservación y para todos los tratamientos se realizó un análisis de varianza (ANOVA) acompañado de contraste de tendencias (lineal y cuadrática) con un nivel de significancia $\alpha=$ 0,05. Se empleó la prueba de DGC (Di Rienzo, Guzmán, Casanoves) para la comparación de medias. Se utilizó el programa estadístico Infostat v. 2012. (Di Rienzo y col., 2012).

\section{V-3. RESULTADOS Y DISCUSIÓN}

\section{V-3.1. Pulpas mezclas fortificadas}

\section{V-3.1.1 Elaboración de pulpas mezcla fortificadas}

\section{V-3.1.1.1 Fenoles totales, flavonoides, ácido ascórbico y poder antirradicalario}

En la tabla V-1 se presentan los valores de compuestos bioactivos, poder antirradicalario y ácido ascórbico en las materias primas y en la pulpa mezcla arándano/frambuesa (AF) fortificada.

Tabla V-1. FT, Fv, AA y PA en rosa mosqueta deshidratada, pulpas de arándano y frambuesa y su mezcla fortificada.

\begin{tabular}{|l|cccc|}
\hline & FT & Fv & PA & AA \\
\hline Polvo RMD & $8063 \pm 412^{\mathrm{A}}$ & $1227 \pm 27^{\mathrm{a}}$ & $14,38 \pm 0,39^{\mathrm{A}^{*}}$ & $7000 \pm 125^{\mathrm{a}^{\prime \prime}}$ \\
P. Arándano & $1778 \pm 84^{\mathrm{C}}$ & $134 \pm 9^{\mathrm{c}}$ & $0,81 \pm 0,05^{\mathrm{C}^{*}}$ & $260 \pm 10^{\mathrm{d}}$ \\
P. Frambuesa & $317 \pm 3^{\mathrm{D}}$ & $38 \pm 3^{\mathrm{d}}$ & $0,48 \pm 0,03^{\mathrm{D}^{*}}$ & $467 \pm 3^{\mathrm{b}}$ \\
P. mezcla A/F & $3253 \pm 98^{\mathrm{B}}$ & $366 \pm 9^{\mathrm{b}}$ & $0,96 \pm 0,04^{\mathrm{B}^{*}}$ & $316 \pm 0^{\mathrm{c}}$ \\
\hline
\end{tabular}

FT: fenoles totales (mg GAE/100 g), Fv: flavonoides (mg CE/100 g), PA: poder antirradical $\left(\mathrm{mg}^{-}\right.$ $\left.{ }^{1}\right)$, AA: ácido ascórbico (mg/kg). RMD: rosa mosqueta deshidratada. A/F: arándano/frambuesa. Los valores representan la media $(n=3) \pm S D$. Medias con una letra común por columna no son significativamente diferentes $(p \leq 0,05)$ 
A los fines de analizar el proceso de elaboración de la pulpa mezcla se calcularon los valores "teóricos" de cada variable, considerando la adición matemática de las materias primas, los cuales se compararon con los obtenidos (figura V-1).

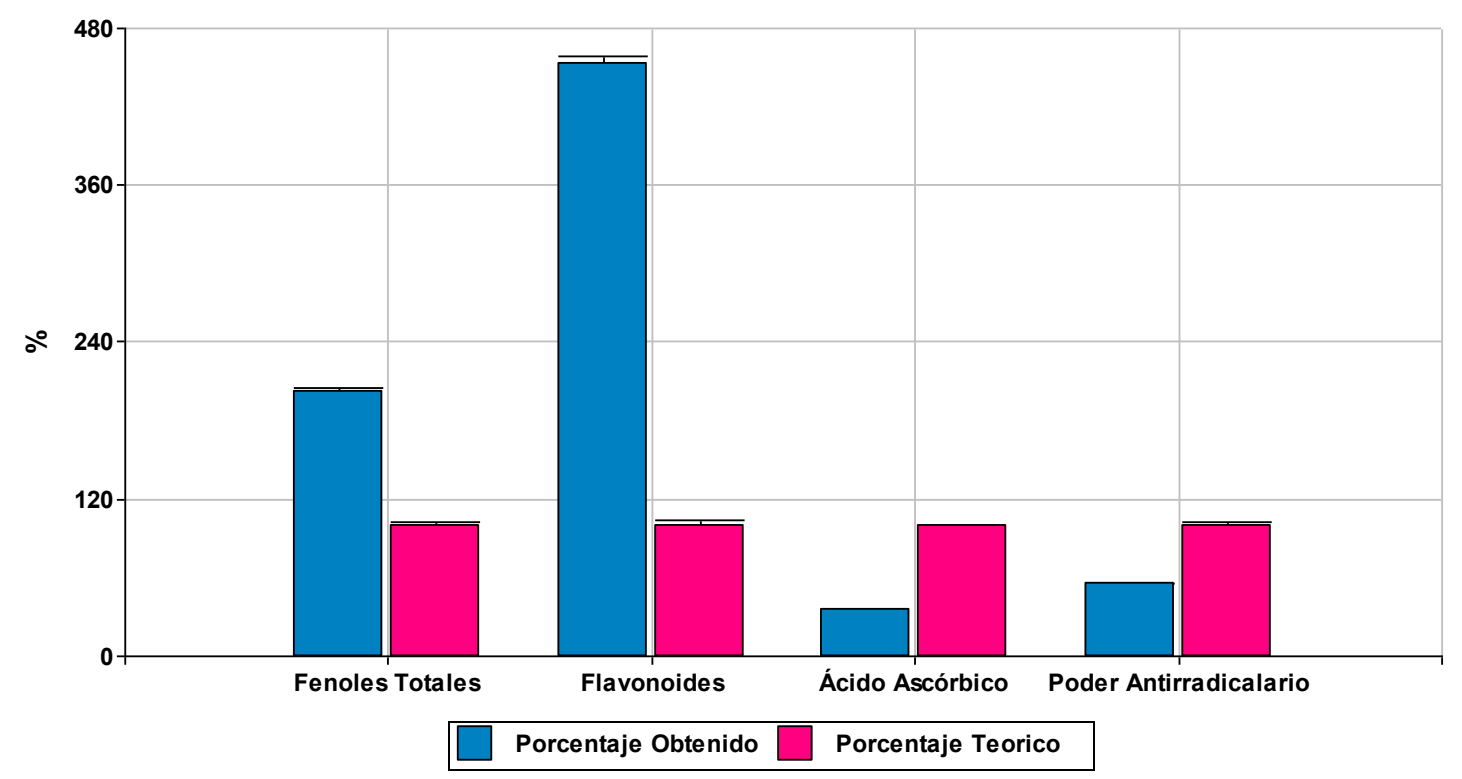

Figura V-1. Comparación entre la pulpa mezcla A/F formulada y los valores obtenidos. Nota: la altura de la barra indica el valor medio. Las barras de error expresan el error estándar.

El contenido de FT cuantificados en la pulpa mezcla fue el doble del obtenido por cálculo matemático en función de las materias primas. Los Fv cuadriplican el valor teórico, mientras que el PA y el contenido de ácido ascórbico alcanzaron sólo el 50 y $35 \%$ respectivamente de la concentración calculada.

Los comportamientos de FT y $\mathrm{Fv}$ respondieron a un aumento en la extractabilidad debido al factor temperatura (en la pasteurización) y a la inhibición de las enzimas oxidativas nativas de las matrices (Peleg y col., 1991; Nicoli y col., 2004; Kalt y col. 2000; Dewanto y col., 2002; Jeong y col. 2004). Como ya se discutió en el Capítulo III, el ácido ascórbico es un nutriente muy sensible a la temperatura, oxigeno, pH y luz (Peinado Pardo, 2011), factores que tienden a disminuir su concentración y cuyo impacto se observa en el valor final cuantificado. Además se registra un efecto negativo resultante de la 
interacción entre las antocianinas y el ácido ascórbico que produciría la disminución de ambos compuestos, probablemente por la formación de peróxido de hidrógeno durante la oxidación del ácido ascórbico (Poei - Langton y Wrolstad, 1981; Garzón, 1998; Garzón y Wrolstad, 2002; De Rosso y Mercadante, 2007; Fennema, 2010). Las tres variables tienen repercusión directa sobre el poder antirradicalario que si bien no alcanzó el valor esperado, superó el porcentaje que presentó el AA, quizás por la contribución de los compuestos bioactivos.

La tabla V-2 presenta los datos correspondientes a la pulpa mezcla guinda/zarzamora $(G / Z)$ fortificada y las materias primas utilizadas en su formulación.

Tabla V-2. FT, Fv, AA y PA en rosa mosqueta deshidratada, pulpas de guinda y zarzamora y su mezcla fortificada

\begin{tabular}{|c|cccc|}
\hline & FT & Fv & PA & AA \\
\hline Polvo RMD & $8063 \pm 412^{\mathrm{A}}$ & $1227 \pm 27^{\mathrm{a}}$ & $14,38 \pm 0,39^{\mathrm{A}^{*}}$ & $7000 \pm 125^{\mathrm{a}^{\prime \prime}}$ \\
P. Guinda & $1816 \pm 6^{\mathrm{C}}$ & $350 \pm 10^{\mathrm{c}}$ & $1,03 \pm 0,01^{\mathrm{C}^{*}}$ & $136 \pm 15^{\mathrm{d}^{\prime \prime}}$ \\
P. Zarzamora & $1118 \pm 5^{\mathrm{D}}$ & $57 \pm 4^{\mathrm{d}}$ & $0,63 \pm 0,02^{\mathrm{D}^{*}}$ & $444 \pm 12^{\mathrm{b}^{\prime \prime}}$ \\
P. mezcla G/Z & $4057 \pm 51^{\mathrm{B}}$ & $483 \pm 22^{\mathrm{b}}$ & $1,10 \pm 0,01^{\mathrm{B}^{*}}$ & $316 \pm 5^{\mathrm{c}^{\prime \prime}}$ \\
\hline
\end{tabular}

FT: fenoles totales (mg GAE/100 g), Fv: flavonoides (mg CE/100 g), PA: poder antirradical (mg$\left.{ }^{1}\right)$, AA: ácido ascórbico (mg/kg). RMD: rosa mosqueta deshidratada. G/Z: guinda/zarzamora. Los valores representan la media $(n=3) \pm S D$. Medias con una letra común por columna no son significativamente diferentes $(p \leq 0,05)$

De igual forma que en la pulpa anterior A los fines de analizar el proceso de elaboración de la pulpa mezcla se calcularon los valores "teóricos" de cada variable, considerando la adición matemática de las materias primas, los cuales se compararon con los obtenidos (figura V-2). 


\section{CAPÍTULO V}

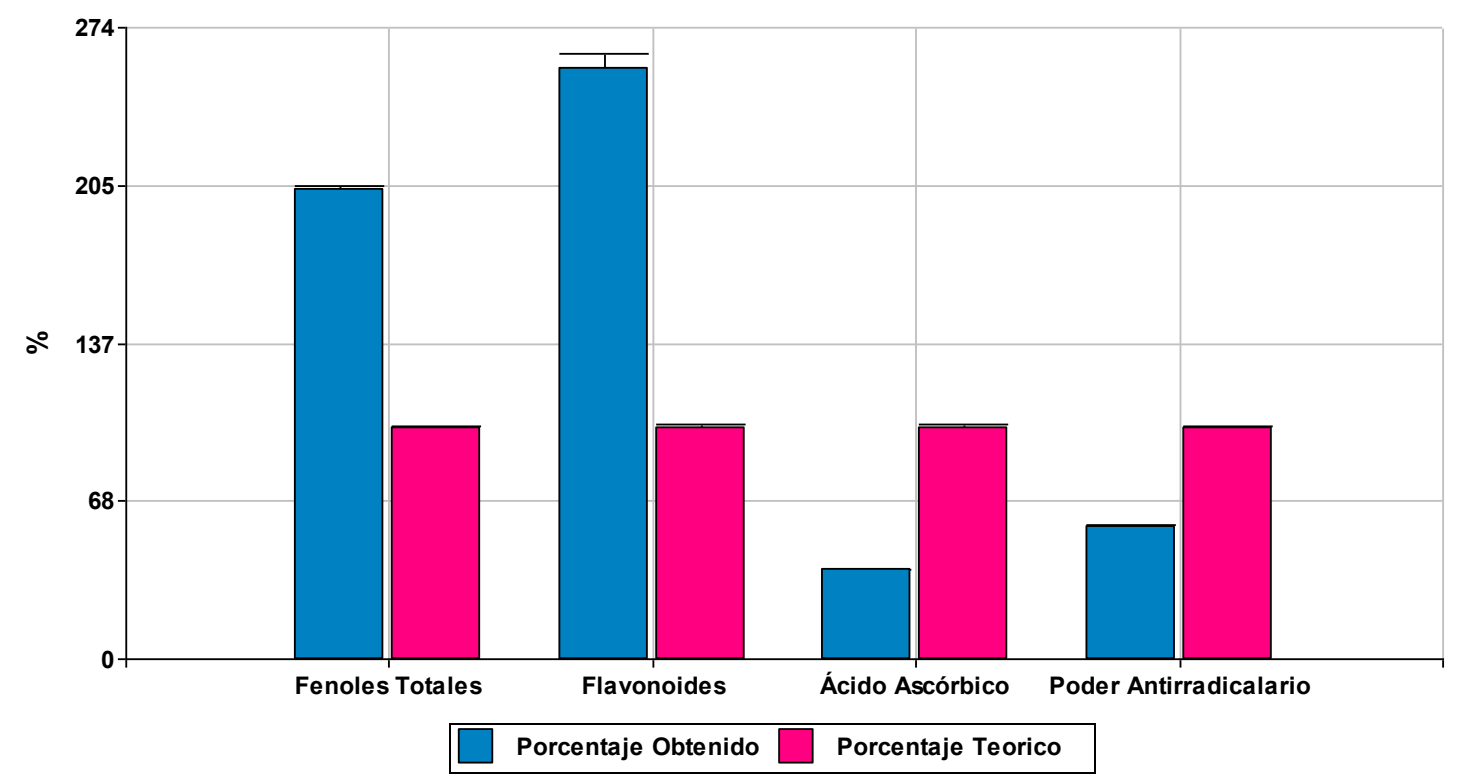

Figura V-2. Comparación entre la pulpa mezcla G/Z formulada y los valores obtenidos. Nota: la altura de la barra indica el valor medio. Las barras de error expresan el error estándar.

El comportamiento de este mezcla fue similar a la anterior: FT y Fv aumentaron en función de lo esperado (aunque Fv lo hizo en menor medida que en el caso anterior), mientras que PA y AA no alcanzaron los valores calculados.

Se puede destacar el elevado contenido de fenoles totales, flavonoides, ácido ascórbico y poder antirradicalario que presentó el polvo de rosa mosqueta lo cual lo convierte en un excelente aditivo para aumentar la funcionalidad de diversos alimentos de base frutihortícola.

\section{V-3.1.1.2 Contenido de pigmentos}

La concentración de ACY y \% CP en las materias primas utilizadas para elaborar la pulpa mezcla A/F se presenta en la tabla V-3. 
Tabla V-3. Concentración de antocianinas monoméricas y \% de color polimérico en rosa mosqueta deshidratada, pulpa de arándano, frambuesa y su mezcla

\begin{tabular}{|l|cc|}
\hline & ACY & $\%$ CP \\
\hline Polvo RMD & $3 \pm 1^{\mathrm{C}}$ & $6 \pm 1^{\mathrm{C}}$ \\
P. Arándano & $147 \pm 4^{\mathrm{A}}$ & $11 \pm 1^{\mathrm{b}}$ \\
P. Frambuesa & $40 \pm 1^{\mathrm{B}}$ & $22 \pm 3^{\mathrm{a}}$ \\
P. mezcla A/F & $40 \pm 1^{\mathrm{B}}$ & $44 \pm 3^{\mathrm{a}}$ \\
\hline
\end{tabular}

ACY: antocianinas monoméricas (mg cianidina-3-glu/100 g), \%CP: porcentaje de color polimérico. RMD: rosa mosqueta deshidratada. A/F: arándano/frambuesa. Los valores representan la media $(n=3) \pm S D$. Medias con una letra común por columna no son significativamente diferentes $(p \leq 0,05)$

La concentración de ACY obtenida en la pulpa mezcla representó un $46 \%$ del valor esperado, probablemente debido al efecto de la temperatura de pasteurización y a la interacción de estos compuestos con el ácido ascórbico presente. Esta interacción también conduciría a un aumento en la formación de polímeros y decoloración de las tonalidades rojizas (Poei - Langton y Wrolstad, 1981), lo cual se traduce en el valor elevado obtenido en el \% CP.

Para la pulpa mezcla $G / Z$ el comportamiento registrado en las variables fue similar, las ACY alcanzaron el $64 \%$ del valor esperado y nuevamente el \%CP obtenido fue elevado (tabla V-4). 
Tabla V-4. Concentración de antocianinas monoméricas y \% de color polimérico en rosa mosqueta deshidratada, pulpa de guinda, zarzamora y su mezcla.

\begin{tabular}{|l|cc|}
\hline & ACY & $\%$ CP \\
\hline Polvo RMD & $3 \pm 1^{\mathrm{D}}$ & $6 \pm 1^{\mathrm{b}}$ \\
P. Guinda & $23 \pm 2^{\mathrm{C}}$ & $40 \pm 2^{\mathrm{a}}$ \\
P. Zarzamora & $160 \pm 3^{\mathrm{A}}$ & $5 \pm 1^{\mathrm{b}}$ \\
P. mezcla G/Z & $54 \pm 1^{\mathrm{B}}$ & $44 \pm 1^{\mathrm{a}}$ \\
\hline
\end{tabular}

ACY: antocianinas monoméricas (mg cianidina-3-glu/100 g), \%CP: porcentaje de color polimérico. RMD: rosa mosqueta deshidratada. G/Z: guinda/zarzamora. Los valores representan la media $(n=3) \pm S D$. Medias con una letra común por columna no son significativamente diferentes $(p \leq 0,05)$

\section{V-3.1.1.3 Color superficial}

En la tabla V-5 se presentan los datos de las coordenadas cromáticas para las materias primas y las pulpas mezclas obtenidas.

Tabla V-5. Funciones de color: luminosidad, ángulo de tono y saturación en las materias primas y pulpas mezcla $A / F-G / Z$

\begin{tabular}{|l|ccc|}
\hline & L $^{*}$ & hue & Chroma \\
\hline Polvo RMD & $49,47 \pm 0,55^{\mathrm{A}}$ & $66,70 \pm 0,23^{\mathrm{a}}$ & $27,44 \pm 1,03^{\mathrm{A}^{*}}$ \\
P. Arándano & $19,19 \pm 2,03^{\mathrm{C}}$ & $12,50 \pm 0,89^{\mathrm{d}}$ & $8,41 \pm 1,87^{\mathrm{C}^{*}}$ \\
P. Frambuesa & $28,06 \pm 2,83^{\mathrm{B}}$ & $24,88 \pm 2,50^{\mathrm{b}}$ & $29,04 \pm 0,84^{\mathrm{A}^{*}}$ \\
P. mezcla A/F & $22,03 \pm 1,53^{\mathrm{C}}$ & $18,56 \pm 0,65^{\mathrm{C}}$ & $16,34 \pm 1,64^{\mathrm{B}^{*}}$ \\
P. Guinda & $33,69 \pm 0,29^{\mathrm{B}}$ & $25,66 \pm 0,55^{\mathrm{b}}$ & $29,46 \pm 0,26^{\mathrm{A}^{*}}$ \\
P. Zarzamora & $18,68 \pm 2,26^{\mathrm{C}}$ & $1,51 \pm 3,55^{\mathrm{e}}$ & $1,65 \pm 0,40^{\mathrm{D}^{*}}$ \\
P. mezcla G/Z & $21,75 \pm 0,52^{\mathrm{C}}$ & $19,22 \pm 0,43^{\mathrm{C}}$ & $17,36 \pm 0,52^{\mathrm{B}^{*}}$ \\
\hline
\end{tabular}

L*: luminosidad, hue: ángulo de tono, Chroma: saturación. A/F: arándano/frambuesa. G/Z: guinda/frambuesa. P: pulpa. Los valores representan la media $(n=6) \pm S D$. Medias con una letra común por columna no son significativamente diferentes $(p \leq 0,05)$ 
La combinación de las materias primas permitió obtener dos pulpas sin diferencias significativas entre sí $(p \leq 0,05)$ de color rojo atractivo y buena luminosidad (fotografía V-1). En ambos casos se logra compensar la baja saturación de una de las pulpas puras (arándano y zarzamora en cada producto) y la alta luminosidad del polvo de RMD.

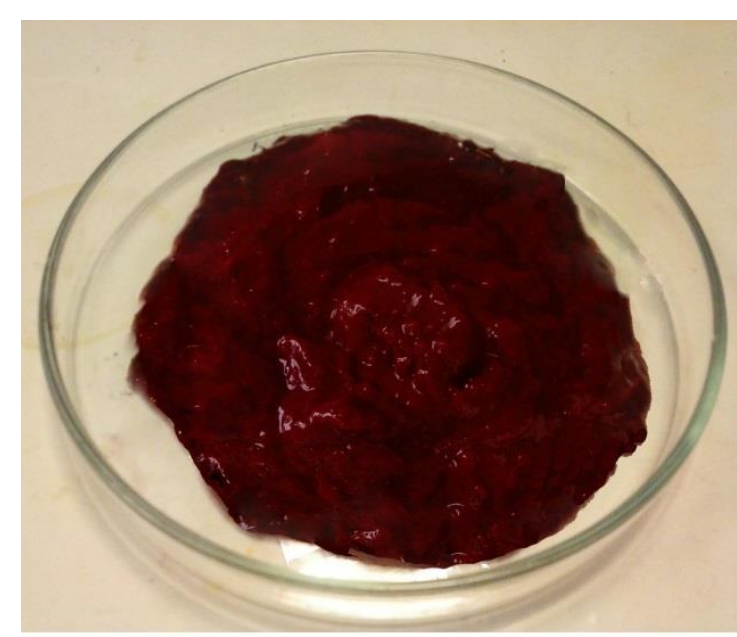

GUINDA/ZARZAMORA

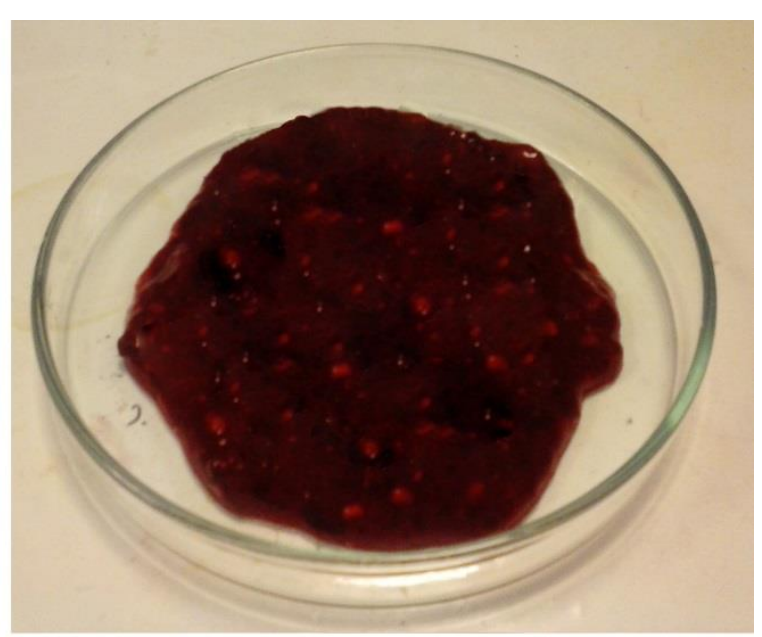

ARÁNDANO/FRAMBUESA

Fotografía V-1. Pulpas mezcla obtenidas

\section{V-3.1.2 Almacenamiento de pulpas mezcla fortificadas}

\section{V-3.1.2.1 Fenoles totales, flavonoides, ácido ascórbico y poder antirradicalario}

Se ensayó la estabilidad en el tiempo de las pulpas mezclas, a temperatura ambiente y en condición de luz y oscuridad

En la tabla V-6 se presentan los datos de fenoles totales, flavonoides, ácido ascórbico y poder antirradicalario para la pulpa mezcla $A / F$ control y luego de seis meses de almacenamiento en condiciones de luz y oscuridad. 
Tabla V-6. Valores de FT, Fv, PA y AA en pulpa mezcla de arándano y frambuesa en las condiciones ensayadas

\begin{tabular}{|c|c|cccc|}
\hline $\begin{array}{c}\text { Meses de } \\
\text { almacen. }\end{array}$ & Tratamiento & FT & Fv & PA & AA \\
\hline $\mathbf{0}$ & Control & $3253 \pm 98^{\mathrm{A}}$ & $366 \pm 9^{\mathrm{a}}$ & $0,96 \pm 0,04^{\mathrm{A}^{*}}$ & $316 \pm 0^{\mathrm{a}^{*}}$ \\
$\mathbf{6}$ & Luz & $2343 \pm 104^{\mathrm{B}}$ & $252 \pm 6^{\mathrm{b}}$ & $0,67 \pm 0,03^{\mathrm{B}^{*}}$ & $106 \pm 3^{\mathrm{c}^{*}}$ \\
$\mathbf{6}$ & Oscuridad & $2314 \pm 76^{\mathrm{B}}$ & $254 \pm 9^{\mathrm{b}}$ & $0,72 \pm 0,01^{\mathrm{B}^{*}}$ & $117 \pm 8^{\mathrm{b}^{*}}$ \\
\hline
\end{tabular}

FT: fenoles totales (mg GAE/100 g), Fv: flavonoides (mg CE/100 g), PA: poder antirradical $\left(\mathrm{mg}^{-1}\right), A A$ : ácido ascórbico $(\mathrm{mg} / \mathrm{kg})$. Los valores representan la media $(\mathrm{n}=3) \pm \mathrm{SD}$. Medias con una letra común por columna no son significativamente diferentes $(p \leq 0,05)$

Observando la tabla V-6 y del análisis estadístico surge que luego de los seis meses de almacenamiento de la pulpa sólo se detectaron diferencias significativas $(p \leq 0,05)$ entre condición de luz y oscuridad para la concentración de AA, siendo más marcada la pérdida en condición de anaquel, coincidente con lo informado por varios autores sobre el efecto negativo de la luz sobre este parámetro (Dergal, 2006; Fennema, 2010; Peinado Pardo, 2011; Ruiz Rodriguez, 2014). Además, retomando lo explicado en la elaboración de la pulpa mezcla, la interacción entre las antocianinas y el ácido ascórbico produciría la destrucción de ambos compuestos (Poei - Langton \& Wrolstad, 1981; Garzón, 1998; Garzón y Wrolstad, 2002; De Rosso y Mercadante, 2007; Fennema, 2010).

La figura V-3 muestra el contenido de FT, Fv, PA y AA para la mezcla A/F durante el almacenamiento en luz y oscuridad. 

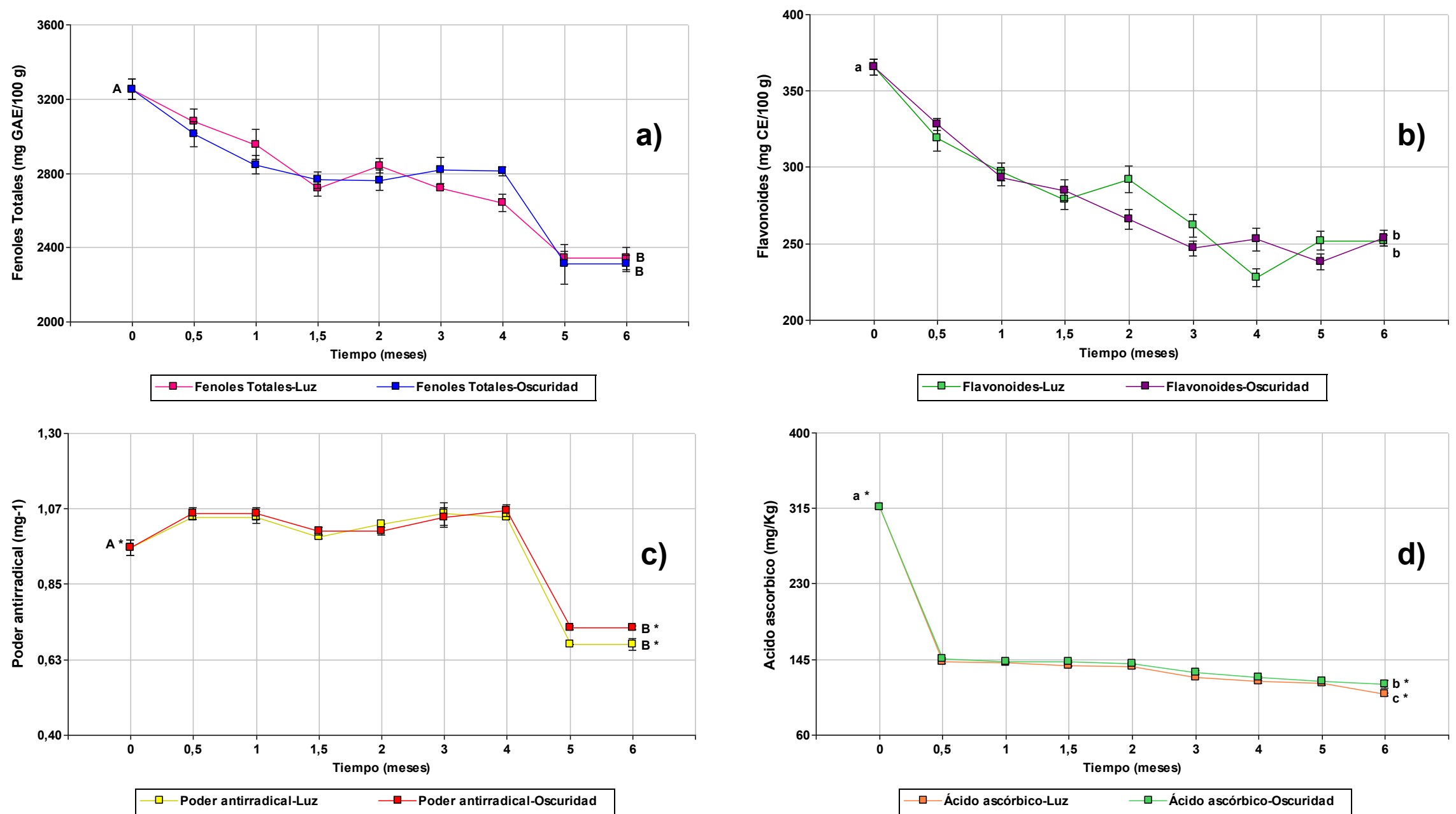

Figura V-3. FT, Fv, PA y AA en pulpa mezcla de arándano/frambuesa almacenada en condiciones de luz y oscuridad. Nota: la altura del punto indica el valor medio. Las barras de error expresan el error estándar. 
La concentración de FT (figura V-3.a) disminuyó a lo largo del tiempo de estudio, alcanzando una retención del $72 \%$. La tendencia de la curva fue lineal ( $p$ $\leq 0,0001$ ), con un marcado decaimiento a los 120 días para ambas condiciones.

En la figura V-3.b se presenta la variación en el contenido de flavonoides, que disminuyeron un $31 \%$ siguiendo una tendencia lineal $(p \leq 0,0001)$.

El análisis de tendencia para el poder antirradicalario resultó significativo para ambos comportamientos ( $p \leq 0,05)$, los primeros cuatro meses el valor se mantuvo en intervalos que rondaban el $10 \%$ de incremento y luego disminuyeron hasta alcanzar el $25 \%$ de pérdida final (figura V-3.c)

Para el ácido ascórbico se registró una marcada degradación (55 \%) con sólo 15 días de almacenamiento. La tendencia de la curva fue lineal $(p \leq 0,0001)$ y los mejores resultados, se obtuvieron con la mezcla conservada en oscuridad, donde la retención fue del $37 \%$ respecto al valor inicial (figura V-3.d).

Los datos de las concentraciones de FT, Fv, PA y AA en pulpa de G/Z se presentan en la tabla V-7.

Tabla V-7. Valores de los FT, Fv, PA y AA en pulpa mezcla de guinda y zarzamora en las condiciones ensayadas

\begin{tabular}{|c|c|cccc|}
\hline $\begin{array}{c}\text { Meses de } \\
\text { almacen. }\end{array}$ & Tratamiento & FT & Fv & PA & AA \\
\hline $\mathbf{0}$ & Control & $4057 \pm 51^{\mathrm{A}}$ & $483 \pm 22^{\mathrm{a}}$ & $1,10 \pm 0,01^{\mathrm{A}^{*}}$ & $316 \pm 5^{\mathrm{a}^{*}}$ \\
$\mathbf{6}$ & Luz & $2836 \pm 43^{\mathrm{B}}$ & $362 \pm 15^{\mathrm{b}}$ & $0,87 \pm 0,01^{\mathrm{B}^{*}}$ & $103 \pm 4^{\mathrm{C}^{*}}$ \\
$\mathbf{6}$ & Oscuridad & $2788 \pm 64^{\mathrm{B}}$ & $356 \pm 10^{\mathrm{b}}$ & $0,89 \pm 0,02^{\mathrm{B}^{*}}$ & $113 \pm 2^{\mathrm{b}^{*}}$ \\
\hline
\end{tabular}

FT: fenoles totales (mg GAE/100 g), Fv: flavonoides (mg CE/100 g), PA: poder antirradical $\left(\mathrm{mg}^{-1}\right)$, AA: ácido ascórbico $(\mathrm{mg} / \mathrm{kg})$. Los valores representan la media $(\mathrm{n}=3) \pm S \mathrm{SD}$. Medias con una letra común por columna no son significativamente diferentes $(p \leq 0,05)$

Las tendencias generales de cada variable en el almacenamiento se presentan en la figura V-4. 

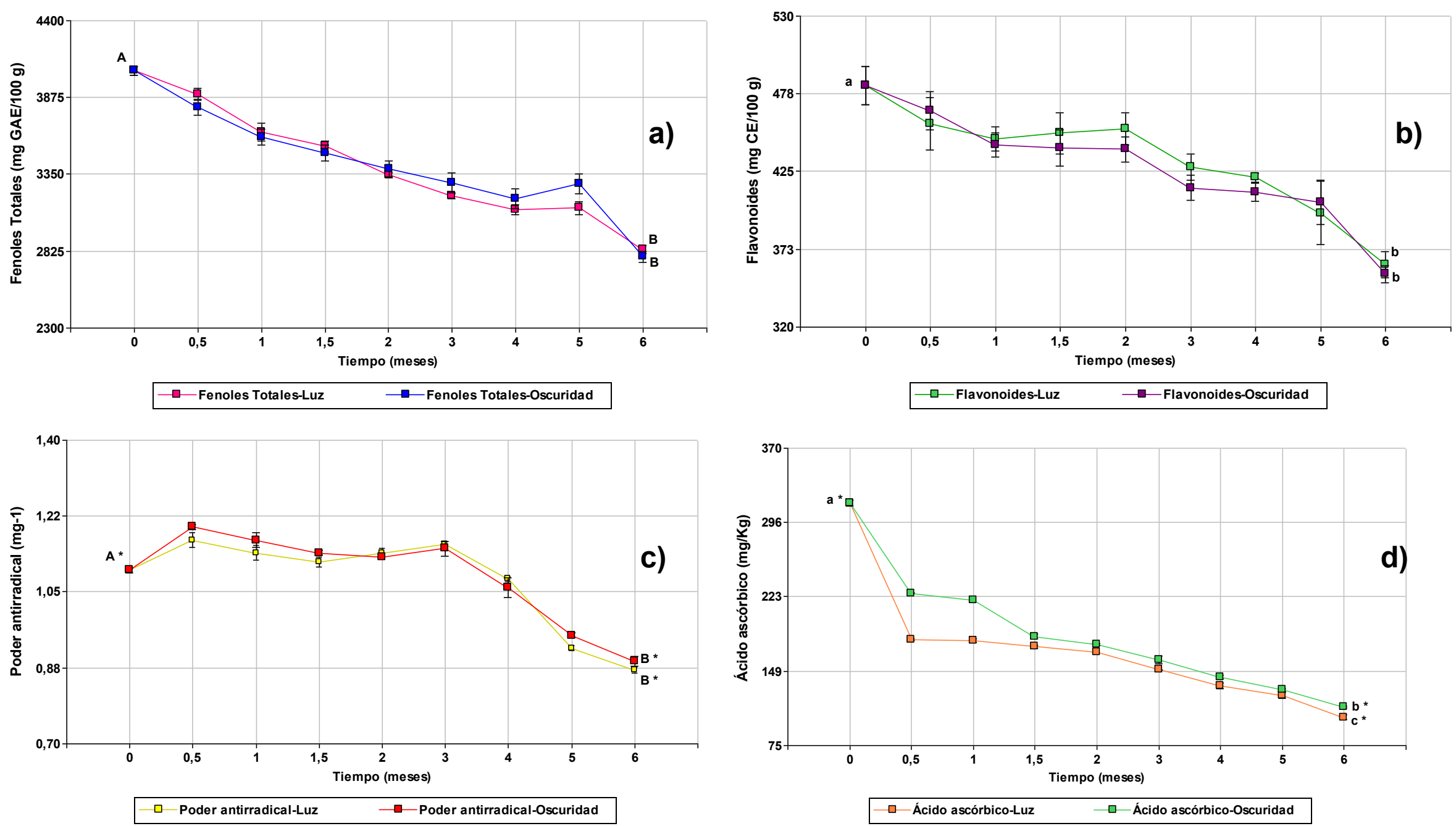

Figura V-4. FT, Fv, PA y AA en pulpa mezcla de guinda/zarzamora almacenada en condiciones de luz y oscuridad. Nota: la altura del punto indica el valor medio. Las barras de error expresan el error estándar. 
La concentración fenoles totales de la pulpa mezcla $G / Z$ disminuyó a lo largo de los seis meses de manera lineal ( $p \leq 0,0001$ ), consiguiendo un $70 \%$ de retención final (figura V-4.a).

En flavonoides, la tendencia también fue lineal ( $p \leq 0,0001)$, aunque el descenso mostró una menor pendiente. Luego de los seis meses la concentración se redujo un $25 \%$ (figura V-4.b).

El comportamiento del poder antirradicalario resultó asintótico $(p \leq 0,05$ para ambos contrastes): permaneció prácticamente invariable los primeros 90 días para luego decaer un $19 \%$ (figura V-4.c).

Para las tres variables antes mencionadas no se detectaron diferencias significativas $(p \leq 0,05)$ entre muestras expuestas y resguardadas de la luz, pero si para el ácido ascórbico, cuya concentración decayó siguiendo una tendencia lineal $(p \leq 0,0001)$, quedando luego de los 6 meses de almacenamiento en oscuridad un $37 \%$ remanente (figura V-4.d).

Cabe destacar, que las cantidades remanentes de fenoles totales, flavonoides, poder antirradicalario y ácido ascórbico en ambas pulpas mezclas, luego de 180 días de almacenamiento, fueron importantes.

Se calcula que la ingesta diaria de flavonoides provenientes de la dieta es de entre 50 - $800 \mathrm{mg} / \mathrm{día}$ (Martino, 2000), aunque algunos autores (Middleton y Kandaswami, 1994) informan hasta $1 \mathrm{~g}$. Una taza de té negro o un vaso de vino puede proporcionar hasta $200 \mathrm{mg}$ de flavonoides totales, una manzana entre 6 y $10 \mathrm{mg}$, una naranja $10 \mathrm{mg}$, una cebolla $40 \mathrm{mg}$ (Martino, 2000). Considerando $50 \mathrm{~g}$ de pulpa mezcla que podrían añadirse a un yogurt, un helado o postre individual el aporte aproximado de flavonoides seria de $125 \mathrm{mg}$ para A/F y 175 mg para G/Z.

En cuanto a fenoles totales, aún no hay valores oficiales de ingesta recomendada. En $100 \mathrm{~g}$ de pulpa mezcla quedaron $2343 \mathrm{mg}(\mathrm{A} / \mathrm{F})$ y $2836 \mathrm{mg}$ ( $G / Z)$ de ácido gálico equivalente luego de 6 meses de almacenamiento en luz, lo cual es un valor elevado si se compara con 100 gramos de: guinda (1816 $\mathrm{mg}$ ), zarzamora (118 mg), pera (95 mg), manzana (213 mg), uva (953 mg), durazno (183 mg), higo (130 mg) y ciruela (436 mg) (ver anexo); o con $100 \mathrm{ml}$ de: café (389 mg), té verde (152 mg) y jugo de naranja (20 mg) (Medina, 2011). 
Si bien luego de los seis meses de almacenamiento quedó en ambas pulpas un remanente de vitamina $\mathrm{C}$ de un $37 \%$ (oscuridad), 100 gramos de pulpa mezcla aportarían el $27 \%$ de la ingesta recomendada por el Código Alimentario Argentino (Res. GMC Nº46/03, Cap. 5).

\section{V-3.1.2.2 Contenido de pigmentos}

Las antocianinas monoméricas resultaron significativamente afectadas $(p \leq$ $0,05)$ por el almacenamiento en condiciones de luz y oscuridad de ambas pulpas mezcla.

En la tabla V-8 se presentan los valores para las ACY, el \% CP y el IDA durante los 180 días de almacenamiento para la pulpa mezcla A/F, considerando la exposición o resguardo de las muestras a la luz.

Tabla V-8. Contenido de antocianinas monoméricas, índice de degradación de antocianinas y porcentaje de color polimérico en pulpa mezcla A/F

\begin{tabular}{|c|c|ccc|}
\hline $\begin{array}{c}\text { Meses de } \\
\text { almacenamiento }\end{array}$ & Tratamiento & ACY & $\%$ CP & IDA \\
\hline $\mathbf{0}$ & Control & $40 \pm 1^{\mathrm{A}}$ & $44 \pm 1^{\mathrm{B}}$ & $1,43 \pm 0,01^{\mathrm{B}^{*}}$ \\
$\mathbf{6}$ & Luz & $3 \pm 0^{\mathrm{B}}$ & $98 \pm 1^{\mathrm{a}}$ & $5,00 \pm 0,32^{\mathrm{A}^{*}}$ \\
$\mathbf{6}$ & Oscuridad & $3 \pm 1^{\mathrm{B}}$ & $95 \pm 3^{\mathrm{a}}$ & $4,67 \pm 0,51^{\mathrm{A}^{*}}$ \\
\hline
\end{tabular}

ACY: antocianinas monoméricas (mg cianidina-3-glu/100g), \%CP: porcentaje de color polimérico, IDA: índice de degradación de antocianinas. A/F: arándano/frambuesa Los valores representan la media ( $\mathrm{n}$ $=3) \pm S D$. Medias con una letra común por columna no son significativamente diferentes $(p \leq 0,05)$

A lo largo de los seis meses de almacenamiento la concentración de ACY decae significativamente $(p \leq 0,05)$, hasta casi desaparecer $(7,5 \%$ de retención, ver Figura V-5). El efecto de la exposición o resguardo de la luz sobre este parámetro no registro diferencias significativas $(p \leq 0,05)$. Concomitante a este comportamiento, el IDA se incrementa a lo largo del tiempo. 


\section{CAPÍTULO V}

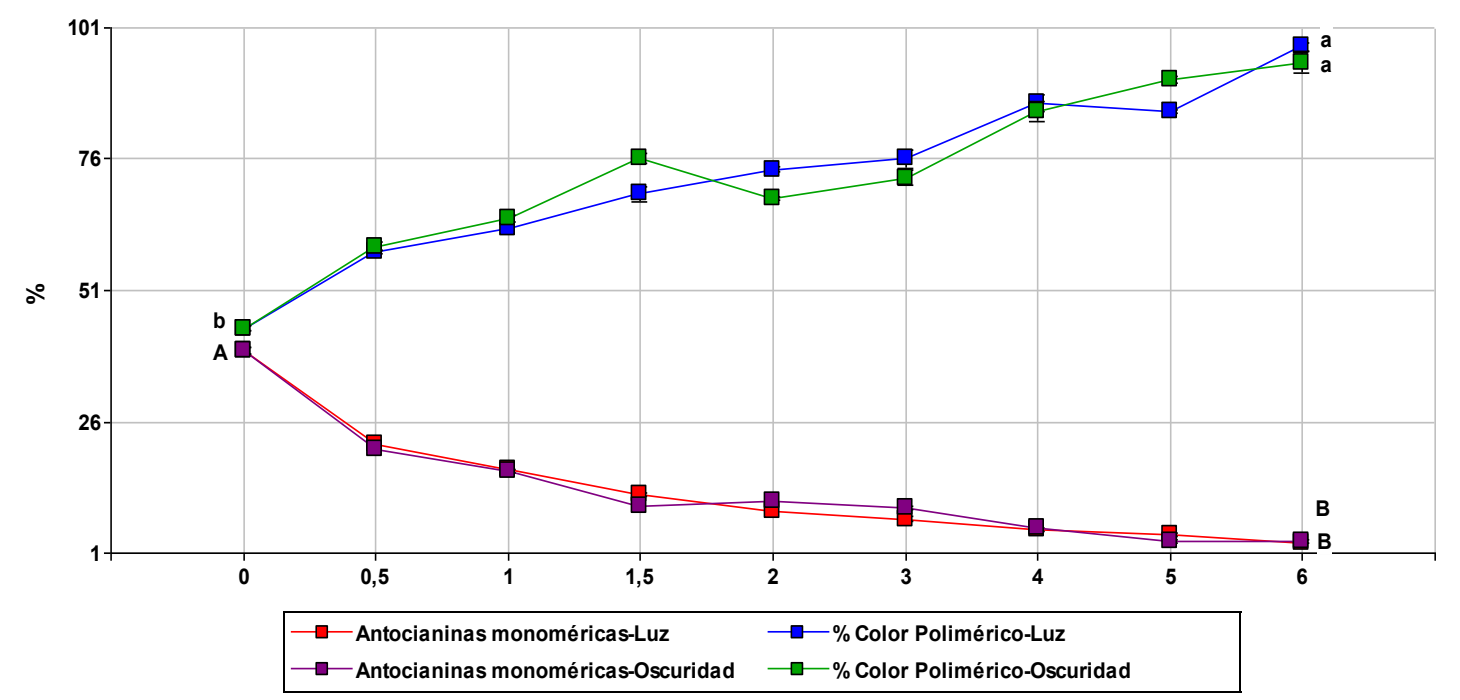

Figura V-5. Evolución del porcentaje de ACY y CP en pulpa mezcla de A/F

durante el almacenamiento. Nota: la altura del punto indica el valor medio. Las barras de error expresan el error estándar.

El color polimérico se incrementa hasta alcanzar valores máximos finalizado el tiempo de almacenamiento, sin detectar nuevamente $(p \leq 0,05)$ efecto de la condición luz/oscuridad (figura V-5).

En la pulpa mezcla $G / Z$, el comportamiento de las variables fue muy similar y los valores se presentan en la tabla V-9.

Tabla V-9. Contenido de antocianinas monoméricas, índice de degradación de antocianinas y porcentaje de color polimérico en pulpa mezcla $G / Z$

\begin{tabular}{|c|c|ccc|}
\hline $\begin{array}{c}\text { Meses de } \\
\text { almacenamiento }\end{array}$ & Tratamiento & ACY & $\%$ CP & IDA \\
\hline $\mathbf{0}$ & Control & $54 \pm 1^{\mathrm{A}}$ & $44 \pm 1^{\mathrm{C}}$ & $1,33 \pm 0,01^{\mathrm{B}^{*}}$ \\
$\mathbf{6}$ & Luz & $5 \pm 1^{\mathrm{B}}$ & $96 \pm 2^{\mathrm{a}}$ & $4,42 \pm 0,40^{\mathrm{A}^{*}}$ \\
$\mathbf{6}$ & Oscuridad & $6 \pm 0^{\mathrm{B}}$ & $93 \pm 4^{\mathrm{a}}$ & $3,93 \pm 0,20 \mathrm{~A}^{*}$ \\
\hline
\end{tabular}

ACY: antocianinas monoméricas (mg cianidina-3-glu/100g), \%CP: porcentaje de color polimérico, IDA: índice de degradación de antocianinas. G/Z: guinda/zarzamora. Los valores representan la media ( $n=$ $3) \pm S D$. Medias con una letra común por columna no son significativamente diferentes $(p \leq 0,05)$

Las ACY disminuyen un $91 \%$, mientras que el IDA y \% CP se incrementan (figura V-6), sin denotar diferencias significativas entre la condición de luz y oscuridad. 


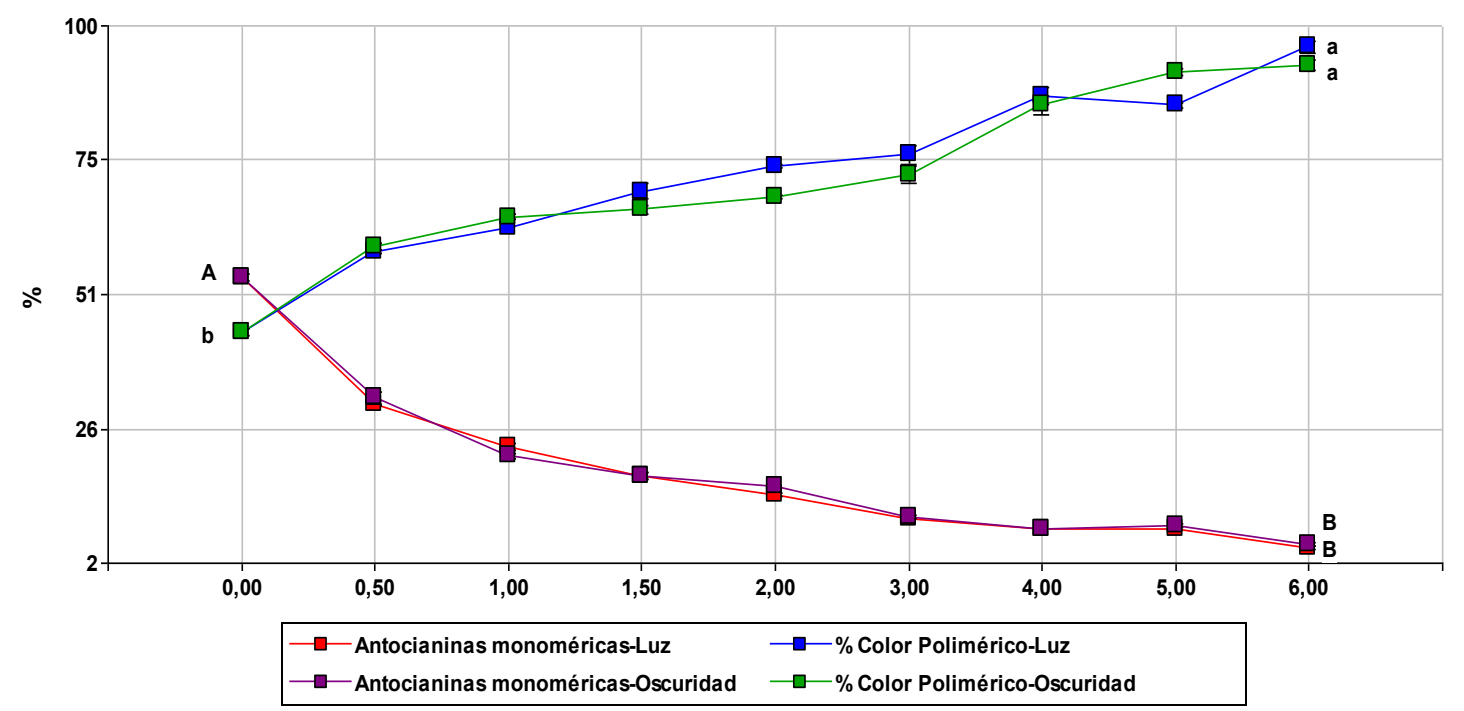

Figura V-6. Evolución del porcentaje de ACY y CP en pulpa mezcla de G/Z durante el almacenamiento. Nota: la altura del punto indica el valor medio. Las barras de error expresan el error estándar.

En ambas pulpas mezcla, si bien el ácido ascórbico, incorporado a través del polvo de RMD, acelera el proceso de degradación de las antocianinas monoméricas, el alto porcentaje de color polimérico indica que pueden haberse condensado con otros compuestos fenólicos para formar pigmentos poliméricos, es decir se alteraría su estructura química pero continuarían aportando a la funcionalidad general del producto, en términos de ingesta de compuestos bioactivos.

\section{V-3.1.2.3 Color superficial}

Las pulpas mezclas se almacenaron durante 6 meses en condiciones de luz y oscuridad a temperatura ambiente. En la tabla $\mathbf{V}-\mathbf{1 0}$ se presentan los datos correspondientes a las coordenadas cromáticas en el tiempo cero (control) y luego del período de almacenamiento para la pulpa arándano/frambuesa. 
Tabla V-10. Funciones de color en pulpa mezcla A/F durante el almacenamiento a temperatura ambiente

\begin{tabular}{|c|c|cccc|}
\hline Meses & Tratamiento & $\mathbf{L}^{*}$ & hue & Chroma & $\Delta \mathrm{E}$ \\
\hline $\mathbf{0}$ & Control & $24,54 \pm 1,33^{\mathrm{A}}$ & $18,52 \pm 0,62^{\mathrm{b}}$ & $17,82 \pm 0,53^{\mathrm{A}^{*}}$ & ----- \\
$\mathbf{6}$ & Luz & $25,94 \pm 0,77^{\mathrm{A}}$ & $35,92 \pm 0,94^{\mathrm{a}}$ & $17,04 \pm 0,63^{\mathrm{A}^{*}}$ & $5,52 \pm 0,26^{\mathrm{a}^{*}}$ \\
$\mathbf{6}$ & Oscuridad & $26,73 \pm 0,82^{\mathrm{A}}$ & $35,11 \pm 0,88^{\mathrm{a}}$ & $14,64 \pm 0,83^{\mathrm{B}^{*}}$ & $6,14 \pm 0,43^{\mathrm{a}^{*}}$ \\
\hline
\end{tabular}

$\mathrm{L}^{*}$ : luminosidad, hue: ángulo de tono, Chroma: saturación, $\Delta \mathrm{E}$ : cambio global de color. $\mathrm{A} / \mathrm{F}$ : arándano/frambuesa. Los valores representan la media $(n=6) \pm S D$. Medias con una letra común por columna y por fruta no son significativamente diferentes $(p \leq 0,05)$

No se hallaron diferencias significativas en el color superficial por la exposición o resguardo a la luz. Ambas muestras presentaron un corrimiento del ángulo hue hacia tonalidades amarronadas, consistente con el aumento del pardeamiento y la degradación de pigmentos (fotografía V-2). El cambio global de color fue significativo con respecto a la muestra control.

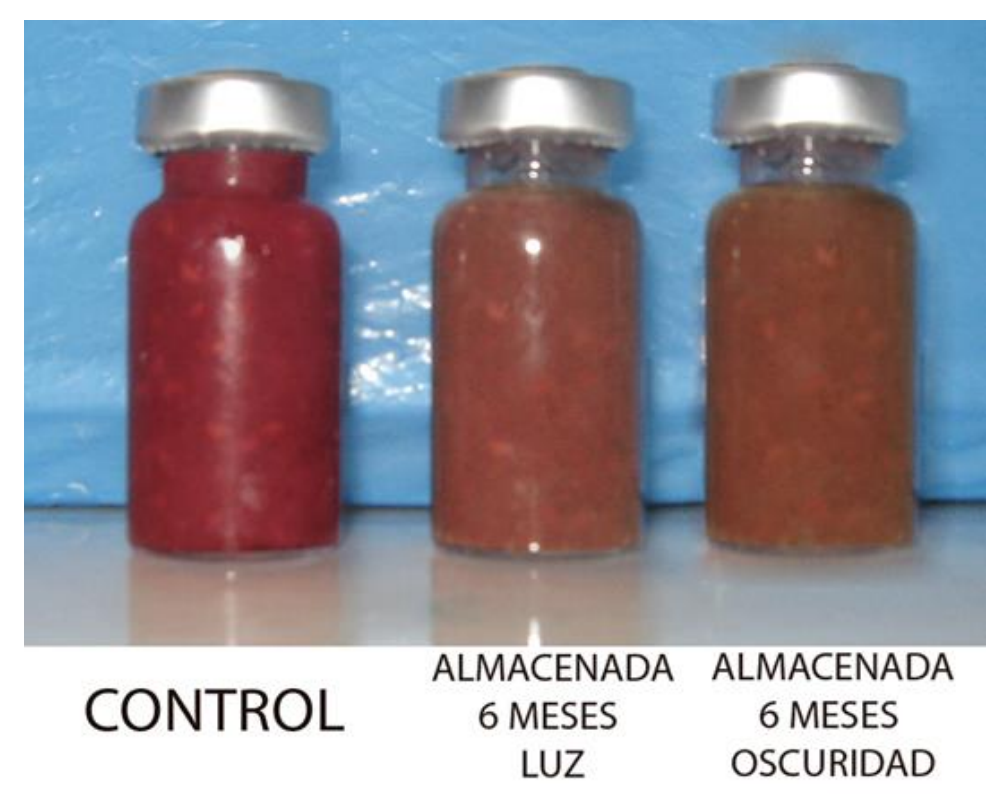

Fotografía V-2. Pulpa mezcla A/F almacenada en distintas condiciones

El comportamiento de la pulpa mezcla $G / Z$ durante el almacenamiento a temperatura ambiente fue similar al anterior, los datos se muestran en la tabla V-11. 
Tabla V-11. Funciones de color en pulpa mezcla G/Z durante el almacenamiento a temperatura ambiente

\begin{tabular}{|c|c|cccc|}
\hline Meses & Tratamiento & $\mathbf{L}^{*}$ & hue & Chroma & $\Delta \mathbf{E}$ \\
\hline $\mathbf{0}$ & Control & $25,84 \pm 0,58^{\mathrm{A}}$ & $20,68 \pm 0,63^{\mathrm{b}}$ & $15,98 \pm 0,40^{\mathrm{A}^{*}}$ & ---- \\
$\mathbf{6}$ & Luz & $24,35 \pm 0,96^{\mathrm{A}}$ & $38,33 \pm 0,68^{\mathrm{a}}$ & $16,37 \pm 0,74^{\mathrm{A}^{*}}$ & $5,28 \pm 0,51^{\mathrm{a}^{*}}$ \\
$\mathbf{6}$ & Oscuridad & $25,70 \pm 0,56^{\mathrm{A}}$ & $37,82 \pm 0,50^{\mathrm{a}}$ & $15,47 \pm 0,68^{\mathrm{A}^{*}}$ & $4,78 \pm 0,17^{\mathrm{a}^{*}}$ \\
\hline
\end{tabular}

$L^{*}$ : luminosidad, hue: ángulo de tono, Chroma: saturación, $\Delta \mathrm{E}$ : cambio global de color. $\mathrm{G} / \mathrm{Z}$ : guinda/zarzamora. Los valores representan la media $(n=6) \pm S D$. Medias con una letra común por columna y por fruta no son significativamente diferentes $(p \leq 0,05)$

Nuevamente no se detectó efecto de la luz sobre el color superficial $(p \leq$ $0,05)$, pero el ángulo de tono se modificó hacia valores superiores. Las pulpas cambiaron su color rojo atractivo por un tono marrón poco atrayente (fotografía V-3).

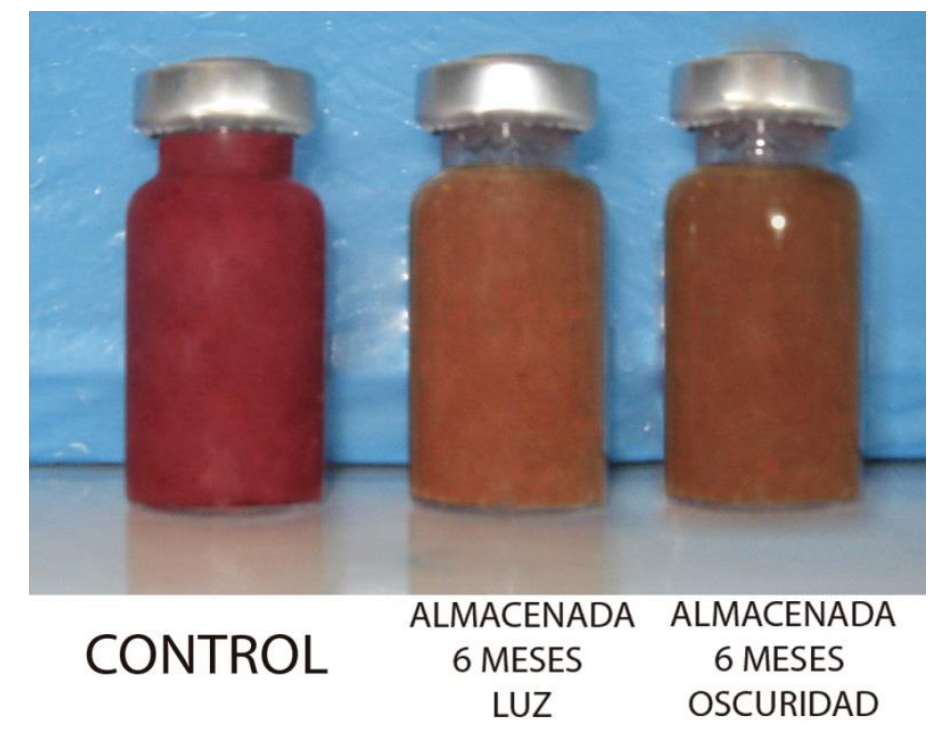

Fotografía V-3. Pulpa mezcla G/Z almacenada en distintas condiciones

\section{V-3.2 Mermeladas}

\section{V-3.2.1 Mermeladas puras}

\section{V-3.2.1.1 Fenoles totales, flavonoides, ácido ascórbico y poder antirradicalario}

Como primera instancia se procedió a la comparación de las variables cuantificadas en la pulpa pura (en los gráficos se la denomina "FRESCA") y en 
las mermeladas, incluyendo dos maneras de expresar la concentración en el producto final: cada 100 gramos de pulpa o de mermelada (producto listo para consumir) a los fines de detectar el comportamiento real de los compuestos bioactivos y el poder antirradicalario.

En la figura V-7 se muestra el contenido de fenoles totales para las pulpas y las mermeladas puras de las cuatro matrices.

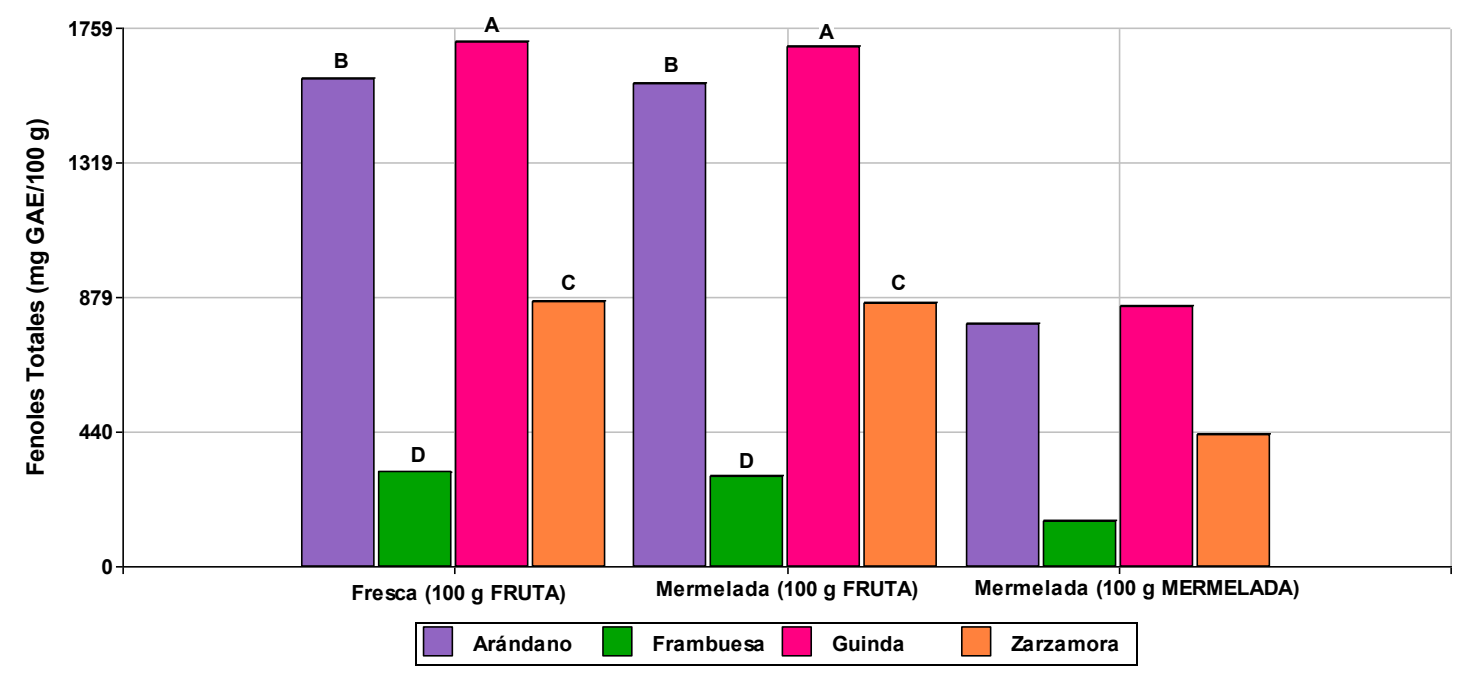

Figura V-7. Contenido de fenoles totales en la materia prima y mermeladas puras. Nota: la altura de la barra indica el valor medio. Las barras de error expresan el error estándar.

Los fenoles totales no sufrieron cambios debido al proceso de elaboración de mermelada $(p \leq 0,05)$ en ninguna de las cuatro matrices.

En la bibliografía disponible los resultados del contenido de FT en mermeladas en base a berries presentan un amplio abanico que incluye múltiples alternativas. Kim y Padilla-Zakour (2004) reportaron pérdidas muy importantes (50 - $100 \%$ ) para mermeladas de guinda y frambuesas; Poiana y col. (2011) cuantificaron disminuciones en torno al $24 \%$ nuevamente en guinda; Tamer (2012) informó disminuciones por calentamiento en FT de productos de frambuesa y zarzamora; Zafrilla y col. (2001) han concluido que esta variable no es muy afectada por los procesos al obtener mermeladas de frambuesa e incluso observaron que el ácido elágico libre aumentó 2,5 veces luego del proceso, Häkkinnen y col. (2000) y Da Silva Pintos y col. (2007) informaron pérdidas en mermeladas de frutilla de entre $15-25 \%$, Howard y 
col. (2010) no encontraron variaciones para el contenido de flavonoles pero si disminuciones de ácido clorogénico en mermeladas de arándano y Amakura y col. (2000) no observaron cambios para este mismo proceso en nueve tipos de berries.

Se observa claramente que tanto la matriz, como la variedad y las condiciones de proceso (temperatura, tiempo, agregado de aditivos, etc.) tienen una importancia y un impacto altamente significativo sobre los compuestos bioactivos y el PA.

En la figura V-8 se presentan el contenido de flavonoides para las materias primas y las mermeladas obtenidas.

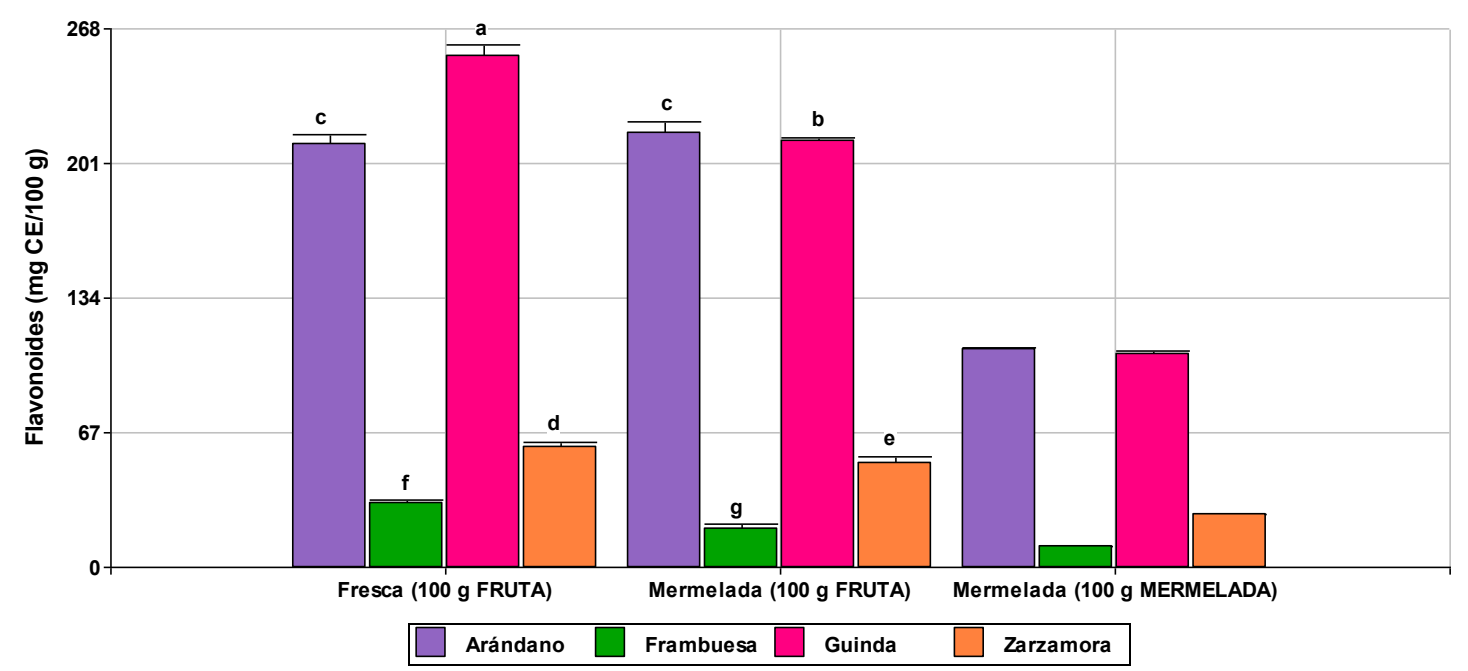

Figura V-8. Contenido de flavonoides en la materia prima y mermeladas puras. Nota: la altura de la barra indica el valor medio. Las barras de error expresan el error estándar.

En general, los flavonoides disminuyeron su concentración luego de la elaboración de mermelada: $13 \%$ en zarzamora, $16 \%$ en guinda y $40 \%$ en frambuesa. Para arándano no se hallaron diferencias significativas $(p \leq 0,05)$. El impacto del proceso de elaboración sobre la concentración podría explicarse a través de la disminución de pigmentos antociánicos (sección V-3.2.1.2), cuantificados dentro de los flavonoides.

En cuanto al poder antirradicalario, en la figura V-9 se presentan los valores obtenidos para las pulpas y mermeladas puras. 


\section{CAPÍTULO V}

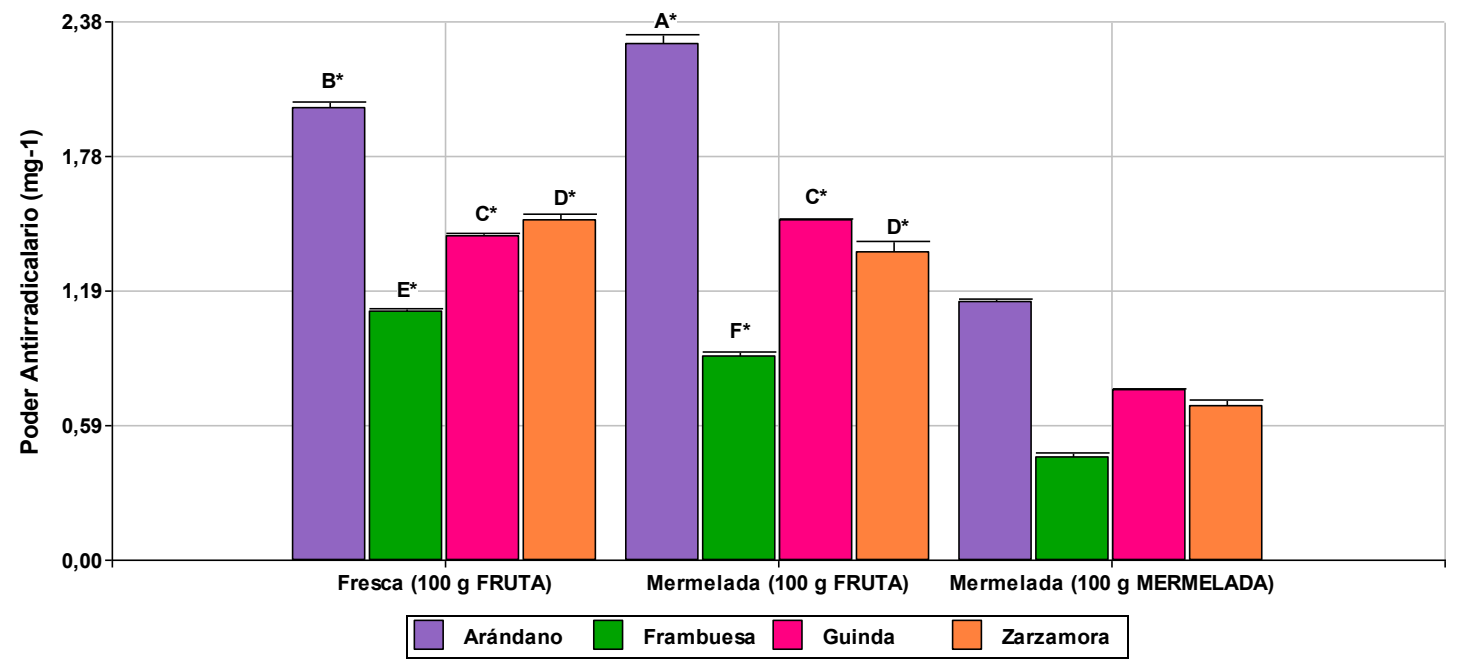

Figura V-9. Poder antirradicalario en la materia prima y mermeladas puras.

Nota: la altura de la barra indica el valor medio. Las barras de error expresan el error estándar.

En frambuesa el PA disminuyó un $9 \%$ acompañando la marcada pérdida de FV. En guinda y zarzamora no se hallaron diferencias significativas ( $p \leq$ $0,05)$, mientras que arándano elevó levemente su PA un $4 \%$.

El contenido de ácido ascórbico, como se preveía, fue la variable más afectada por el proceso de elaboración de mermelada (figura V-10).

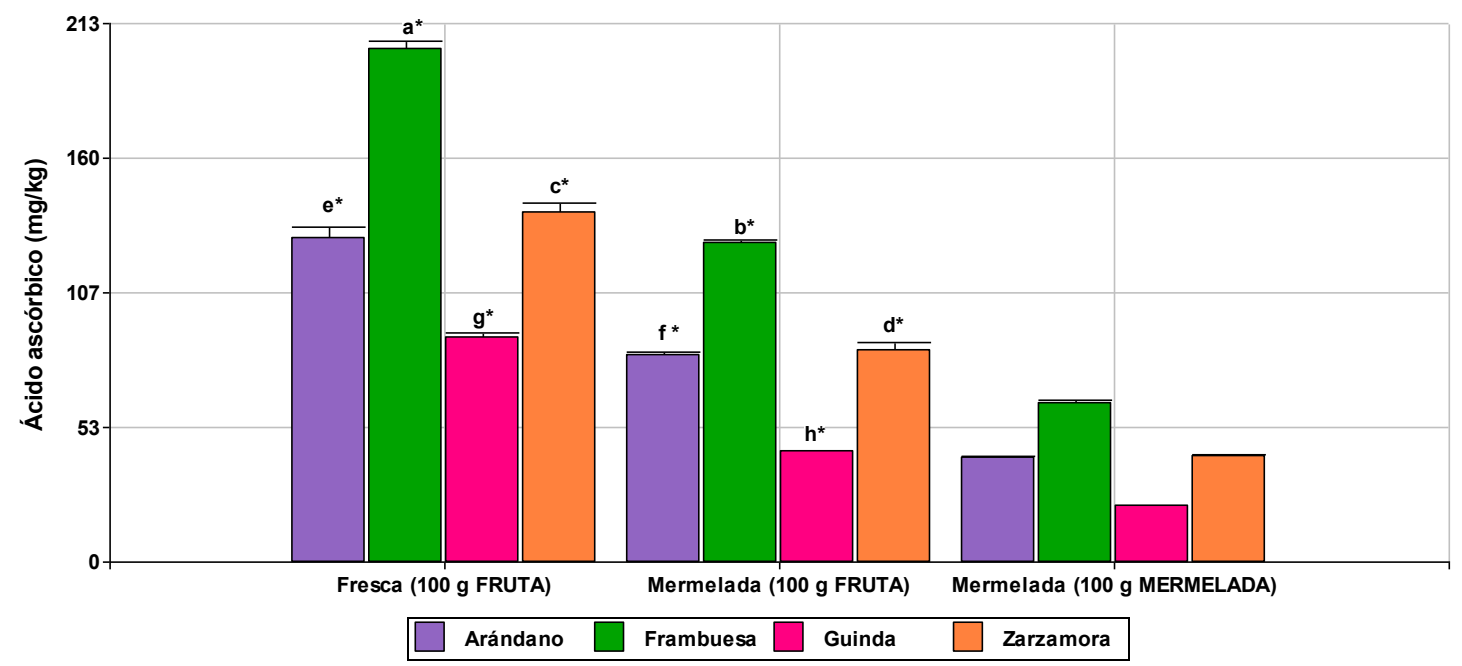

Figura V-10. Contenido de ácido ascórbico en la materia prima y mermeladas

puras. Nota: la altura de la barra indica el valor medio. Las barras de error expresan el error estándar.

Todas las matrices disminuyeron la concentración de ácido ascórbico luego de la elaboración de la mermelada, siendo la más afectada guinda (50\%), 
seguida por zarzamora (39\%), frambuesa (38 \%) y arándano (36 \%). Tamer (2012) ha reportado el efecto de la temperatura sobre la degradación del ácido ascórbico en la elaboración de mermeladas de frambuesa y zarzamora con pérdidas entre 12 y $83 \%$ según la variedad estudiada.

\section{V-3.2.1.2 Contenido de pigmentos}

Se comparó, en la figura V-11, el contenido de ACY en la pulpa pura y en las mermeladas, incluyendo dos maneras de expresar la concentración en el producto final: cada 100 gramos de pulpa o de mermelada (producto listo para consumir). En el caso del \% CP (figura V-11) se comparó la pulpa pura y la mermelada, ya que esta variable es independiente del peso de muestra.

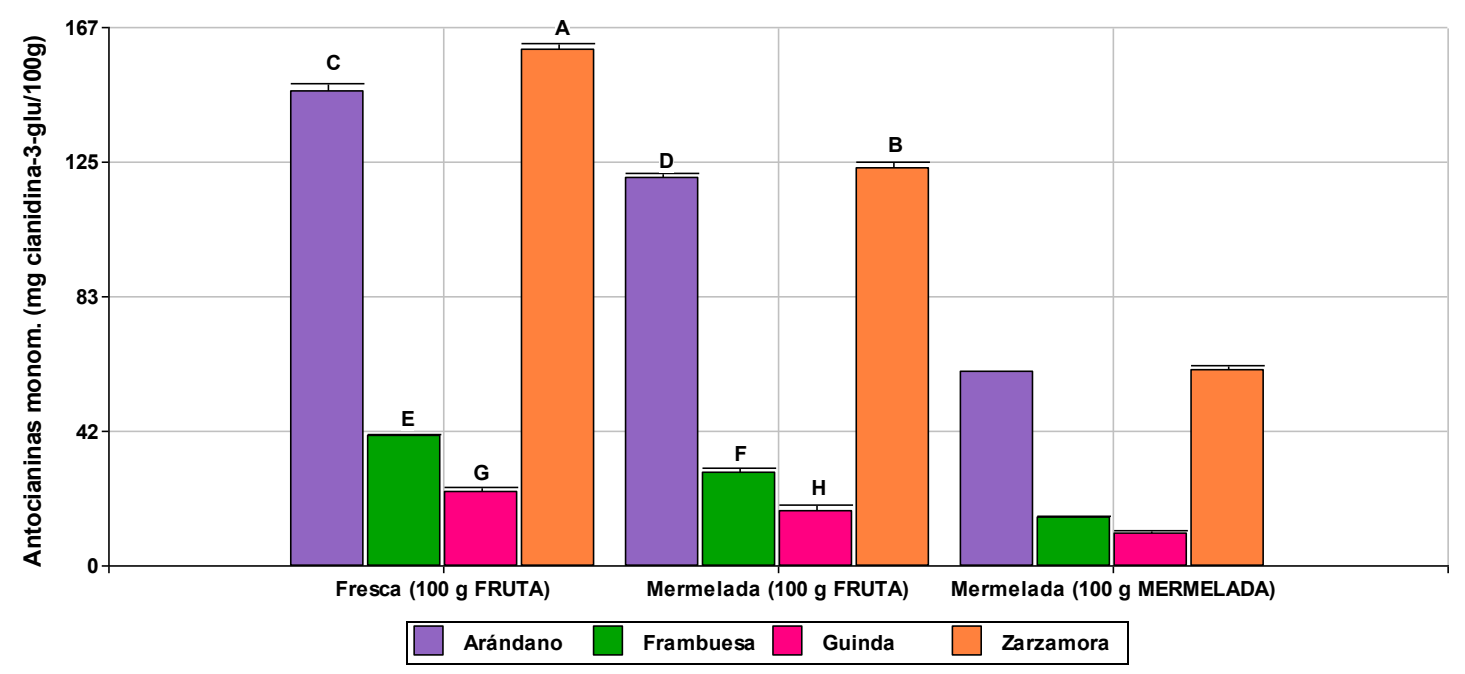

Figura V-11. Contenido de antocianinas monoméricas en la materia prima y mermeladas puras. Nota: la altura de la barra indica el valor medio. Las barras de error expresan el error estándar.

Las cuatro matrices presentaron disminución del contenido de ACY durante la elaboración de las mermeladas puras, lo que nuevamente confirma que varios factores afectan la estabilidad durante la preparación, procesamiento y almacenamiento, incluyendo $\mathrm{pH}$, temperatura, luz, oxígeno, iones metálicos, enzimas y azúcares (Rhim, 2002). Para la fabricación de mermelada, los principales efectos se deben a la temperatura de cocción, $\mathrm{pH}$ y concentración de azúcar. Durante el procesamiento de la mermelada, los frutos pulpados fueron sometidos a un intenso tratamiento térmico, previo mezclado con 
cantidades iguales de azúcar. La temperatura elevada durante el procesamiento de mermelada desplaza el equilibrio de las antocianinas hacia las chalconas incoloras, que son inestables, especialmente si carecen de azúcares (Clifford, 2000).

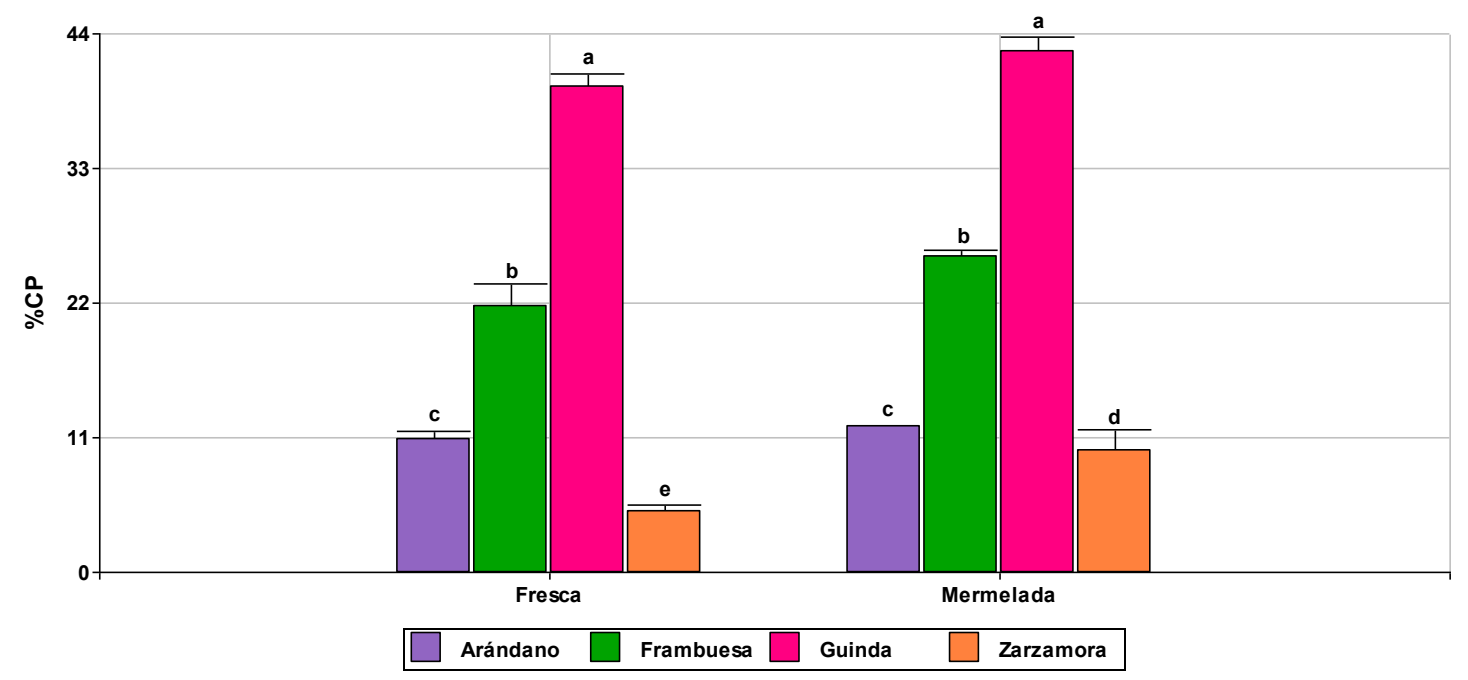

Figura V-12. Porcentaje de color polimérico en la materia prima y mermeladas puras. Nota: la altura de la barra indica el valor medio. Las barras de error expresan el error estándar.

En cuanto al color polimérico, no se detectaron diferencias significativas ( $p$ $\leq 0,05)$ para frambuesa, arándano y guinda; mientras que en zarzamora se elevó un 5 \% su valor.

\section{V-3.2.1.3 Color superficial}

La tabla V-12 presenta los valores de las coordenadas cromáticas para las pulpas utilizadas como materia prima y las mermeladas puras resultantes. En general en todos los casos se registró una disminución de la luminosidad por efecto del proceso de elaboración de mermelada y un aumento visual del brillo, como consecuencia del agregado de azúcar. 
Tabla V-12. Funciones de color: luminosidad, ángulo de tono y saturación en las mermeladas formuladas

\begin{tabular}{|l|ccc|}
\hline & $\mathbf{L}^{*}$ & hue & Chroma \\
\hline Zarzamora Pulpa & $18,68 \pm 2,26^{\mathrm{C}}$ & $1,51 \pm 3,55^{\mathrm{e}}$ & $1,65 \pm 0,40^{\mathrm{D}^{*}}$ \\
Zarzamora Mermelada & $10,76 \pm 0,42^{\mathrm{E}}$ & $30,76 \pm 2,02^{\mathrm{b}}$ & $1,52 \pm 0,09^{\mathrm{D}^{*}}$ \\
Frambuesa Pulpa & $28,06 \pm 0,83^{\mathrm{B}}$ & $24,88 \pm 2,50^{\mathrm{C}}$ & $29,04 \pm 0,84^{\mathrm{A}^{*}}$ \\
Frambuesa Mermelada & $22,70 \pm 3,5^{\mathrm{C}}$ & $30,93 \pm 2,34^{\mathrm{b}}$ & $15,14 \pm 0,81^{\mathrm{B}^{*}}$ \\
Arándano Pulpa & $19,19 \pm 2,03^{\mathrm{C}}$ & $12,50 \pm 0,89^{\mathrm{d}}$ & $8,41 \pm 1,87^{\mathrm{C}^{*}}$ \\
Arándano Mermelada & $15,91 \pm 2,23^{\mathrm{D}}$ & $41,89 \pm 6,46^{\mathrm{a}}$ & $0,89 \pm 0,21^{\mathrm{D}^{*}}$ \\
Guinda Pulpa & $33,69 \pm 0,29^{\mathrm{A}}$ & $25,66 \pm 0,55^{\mathrm{C}}$ & $29,46 \pm 0,26^{\mathrm{A}^{*}}$ \\
Guinda Mermelada & $16,70 \pm 0,31^{\mathrm{D}}$ & $27,55 \pm 0,65^{\mathrm{C}}$ & $15,98 \pm 0,71^{\mathrm{B}^{*}}$ \\
\hline
\end{tabular}

L*: luminosidad, hue: ángulo de tono, Chroma: saturación. Los valores representan la media $(n=6) \pm S D$. Medias con una letra común por columna no son significativamente diferentes $(p \leq$ $0,05)$

La mermelada de zarzamora, si bien incrementó notablemente el ángulo de tono, no presentó diferencias significativas en Chroma, lo que resultó en un color oscuro poco saturado. En frambuesa la mermelada mantiene el tono rojo característico con una disminución de la intensidad. En el caso de la mermelada de arándano, al igual que en zarzamora, el corrimiento del ángulo de tono fue muy importante, pero nuevamente acompañado de una saturación muy baja, lo que se traduce en un producto oscuro en la gama de los púrpura (bajos valores de los parámetros $a^{*}$ y $b^{*}$ ). Finalmente la mermelada de guinda no presentó diferencias significativas en hue, pero si una disminución marcada de luminosidad e intensidad, aunque el color final siguió siendo atractivo (fotografía V-4).

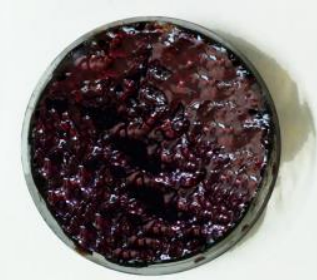

ZARZAMORA

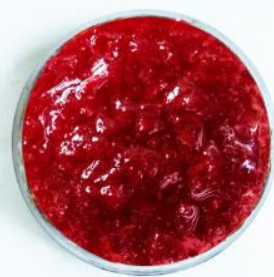

GUINDA
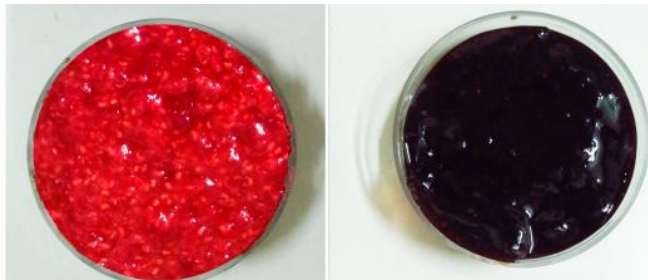

FRAMBUESA ARÁNDANO

Fotografía V-4. Mermeladas puras obtenidas 


\section{V-3.2.2 Mermeladas fortificadas}

\section{V-3.2.2.1 Fenoles totales, flavonoides, ácido ascórbico y poder antirradicalario}

En la tabla V-13 se presentan los valores de FT, Fv, PA y AA en los polvos de RMD y cassis utilizados para fortificar y en las mermeladas obtenidas en cada caso. Las mermeladas con polvo de RMD fueron las que mayor contenido de FT mostraron.

Tabla V-13. Valores de FT, Fv, PA y AA en los polvos de RMD y cassis utilizados para fortificar y en las mermeladas obtenidas

\begin{tabular}{|c|c|c|c|c|}
\hline Producto & FT & Fv & PA & AA \\
\hline Polvo RMD & $8063 \pm 412$ & $1227 \pm 27$ & $14,38 \pm 0,39$ & $7000 \pm 125$ \\
\hline Polvo C & $2934 \pm 110$ & $2197 \pm 64$ & $9,76 \pm 0,29$ & $900 \pm 45$ \\
\hline Zarzamora + RMD & $1811 \pm 211^{B}$ & $193 \pm 20^{c}$ & $0,79 \pm 0,06^{B^{*}}$ & $380 \pm 4^{b^{*}}$ \\
\hline Zarzamora + C & $911 \pm 33^{C}$ & $38 \pm 4^{f}$ & $0,74 \pm 0,08^{B^{*}}$ & $140 \pm 9^{f^{*}}$ \\
\hline Frambuesa + RMD & $1564 \pm 22^{B}$ & $165 \pm 1^{d}$ & $0,74 \pm 0,03^{B^{*}}$ & $365 \pm 5^{\mathrm{c}^{*}}$ \\
\hline Frambuesa + C & $447 \pm 8^{D}$ & $31 \pm 1^{f}$ & $0,68 \pm 0,05^{\mathrm{B}^{*}}$ & $163 \pm 7^{\mathrm{e}^{*}}$ \\
\hline Arándano + RMD & $2312 \pm 50^{A}$ & $237 \pm 3^{b}$ & $0,94 \pm 0,06 A^{A^{*}}$ & $392 \pm 7^{a^{*}}$ \\
\hline Arándano + C & $1413 \pm 23^{C}$ & $130 \pm 1^{e}$ & $0,86 \pm 0,03 \mathrm{~A}^{*}$ & $135 \pm 4^{f^{*}}$ \\
\hline Guinda + RMD & $2557 \pm 30^{A}$ & $349 \pm 14^{a}$ & $0,89 \pm 0,05^{A^{*}}$ & $323 \pm 4^{\mathrm{d}^{*}}$ \\
\hline Guinda + C & $1561 \pm 52^{B}$ & $187 \pm 5^{c}$ & $0,82 \pm 0,04^{B^{*}}$ & $98 \pm 2^{9^{*}}$ \\
\hline
\end{tabular}

FT: fenoles totales (mg GAE/100 g), Fv: flavonoides (mg CE/100 g), PA: poder antirradical $\left(\mathrm{mg}^{-1}\right), \mathrm{AA}$ : ácido ascórbico $(\mathrm{mg} / \mathrm{kg})$. RMD: rosa mosqueta deshidratada, C: cassis. Los valores representan la media $(n=3) \pm S D$. Medias con una letra común por columna no son significativamente diferentes $(p \leq 0,05)$

Teniendo en cuenta los valores esperados, en función de la constitución de las materias primas, las mermeladas obtenidas recuperaron entre un $78-100$ $\%$ del contenido de FT. 
En las matrices con RMD el valor de Fv se acercó al $100 \%$ del esperado en función de las materias primas originales. En las mermeladas con polvo de cassis los porcentajes obtenidos fueron menores, ubicándose entre el 40 y 80 $\%$ del valor esperado.

Si retomamos la comparación realizada para pulpas mezcla fortificadas en la sección V-3.1.2.1, una porción de $25 \mathrm{~g}$ de mermelada (que podrían añadirse a un postre o preparación) podría suministrar los mismos fenoles totales proporcionados por $100 \mathrm{ml}$ de té verde (en el caso de frambuesa $+\mathrm{C}$ ) y los mismos que los obtenidos por consumo de una taza de café negro (guinda + RMD y arándano + RMD). El consumo de $25 \mathrm{~g}$ de mermelada guinda + RMD aportaría además el $45 \%$ de los Fv de un vaso de vino tinto o una taza de té negro.

El poder antirradicalario también se elevó correlacionándose con el contenido de Fv y FT (coeficientes de correlación de Pearson 0,85 y 0,91 respectivamente).

Nuevamente, en la comparación dentro de cada matriz, las mermeladas con polvo de RMD presentaron valores superiores a las fortificadas con polvo de cassis. En el poder antirradicalario la respuesta obtenida en cuanto a diferencias significativas $(p \leq 0,05)$ fue la más homogénea, detectando sólo dos grupos.

El agregado de polvo de RMD y cassis a las mermeladas permitió el aumento significativo del PA en zarzamora (22 y $14 \%$ ), frambuesa (37 y $26 \%$ ) y en guinda (19 y $9 \%$ ). En arándano se registraron disminuciones del 17 en el primer caso y $25 \%$ con el agregado de polvo de cassis.

Las matrices con mayor contenido de ácido ascórbico fueron aquellas donde se agregó polvo de RMD. El impacto del proceso de elaboración de las mermeladas sobre esta variable fue significativo $(p \leq 0,05)$, ya que se obtuvieron concentraciones entre el 61-76 \% de los valores esperados.

Estas mermeladas podrían considerarse fuentes no tradicionales de ácido ascórbico. Las que contienen RMD permitirían incorporar en una porción (25 gramos): $95 \mathrm{mg}$ (zarzamora + RMD), $92 \mathrm{mg}$ (frambuesa + RMD), $98 \mathrm{mg}$ (arándano + RMD) y $81 \mathrm{mg}$ (guinda + RMD) de ácido ascórbico; mientras que en aquellas que se añadió polvo de cassis los valores son un poco más bajos 
pero igualmente interesantes: $35 \mathrm{mg}$ (zarzamora $+\mathrm{C}$ ), $41 \mathrm{mg}$ (frambuesa $+\mathrm{C}$ ), $34 \mathrm{mg}$ (arándano $+\mathrm{C}$ ) y $25 \mathrm{mg}$ (guinda $+\mathrm{C}$ ). En la fotografía V-5 se muestra, a los fines de establecer comparaciones, el contenido de ácido ascórbico en matrices reconocidas por ser fuente de este compuesto.

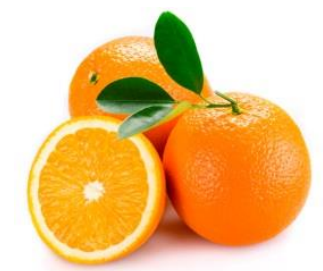

NARANJA

$50 \mathrm{mg} / 100 \mathrm{~g}$

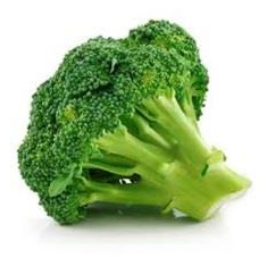

BROCOLI

$89 \mathrm{mg} / 100 \mathrm{~g}$

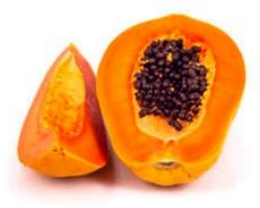

PAPAYA

$62 \mathrm{mg} / 100 \mathrm{~g}$

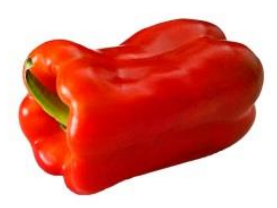

PIMIENTO ROJO $140 \mathrm{mg} / 100 \mathrm{~g}$

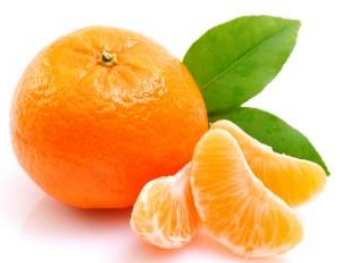

MANDARINA $49 \mathrm{mg} / 100 \mathrm{~g}$

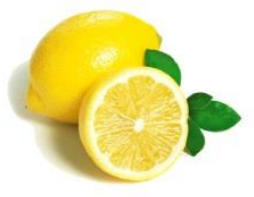

LIMON $40 \mathrm{mg} / 100 \mathrm{~g}$

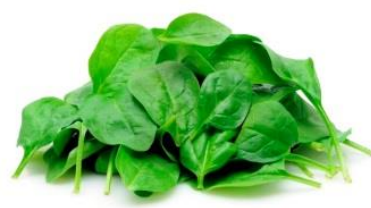

ESPINACA

$51 \mathrm{mg} / 100 \mathrm{~g}$

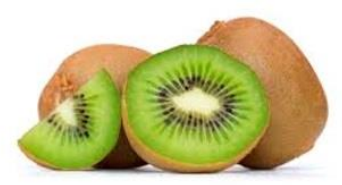

KIWI $49 \mathrm{mg} / 100 \mathrm{~g}$

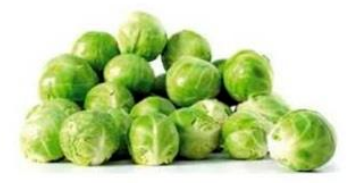

REPOLLITOS DE BRUSELA

$75 \mathrm{mg} / 100 \mathrm{~g}$

Fotografía V-5. Contenido de ácido ascórbico en matrices conocidas (fuente de datos bibliográficos: Dergal, 2006)

\section{V-3.2.2.2 Contenido de pigmentos}

El polvo de cassis presentó un elevado contenido de ACY (392 $\pm 20 \mathrm{mg}$ cianidina-3-glu/100g) y un bajo \%CP $(6 \pm 1)$, lo cual impacta elevando las concentraciones en los productos derivados, si se los compara con el aporte del polvo de RMD (3 $\pm 1 \mathrm{mg}$ cianidina-3-glu/100g y \%CP $6 \pm 1$ ). Sumando a esto, zarzamora y arándano fueron las matrices con mayor aporte de ACY 
desde la pulpa pura, haciendo que esas mermeladas (zarzamora $+\mathrm{C} y$ arándano $+\mathrm{C}$ ) fueran las de contenido mayoritario de ACY.

En la figura V-13 se presenta el contenido de ACY en las mermeladas puras y con agregado de polvo de RMD y cassis. En todos los casos el valor esperado (en función del porcentaje añadido) no se alcanzó, infiriéndose que factores tales como la temperatura de proceso, la concentración de azúcar y la presencia de ácido ascórbico afectaron notablemente la concentración de ACY. Si bien la ingesta diaria no está formalmente establecida, se manejan valores de consumo de antocianinas que podrían superar los $200 \mathrm{mg} / \mathrm{día}$ (Robards y col., 1999; Delgado-Vargas y col., 2000), siendo mayores para los consumidores regulares de vino tinto (Clifford, 2000). Por tanto, las mermeladas formuladas podrían considerarse una fuente alternativa de estos compuestos, considerando que por ejemplo, una porción $(25 \mathrm{~g})$ de mermelada de arándano con cassis aportaría $25 \mathrm{mg}$.

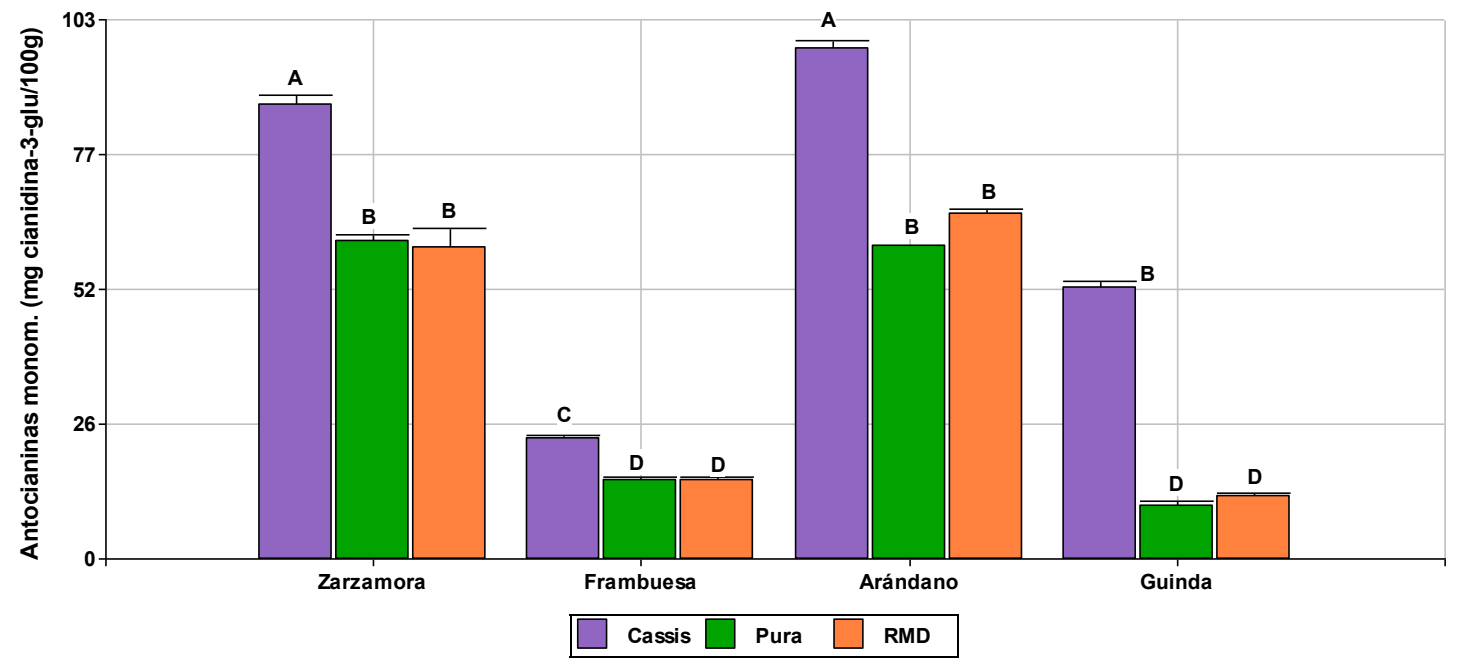

Figura V-13. Contenido de $\mathrm{ACY}$ en mermeladas puras y fortificadas con polvo de RMD y cassis. Nota: la altura de la barra indica el valor medio. Las barras de error expresan el error estándar.

En cuanto al porcentaje de color polimérico (figura V-14) las fortificaciones con polvo de cassis permitieron obtener productos donde se observó una menor polimerización de pigmentos en comparación con RMD y además no se hallaron diferencias significativas $(p \leq 0,05)$ con los valores de las mermeladas puras en cada fruta. 


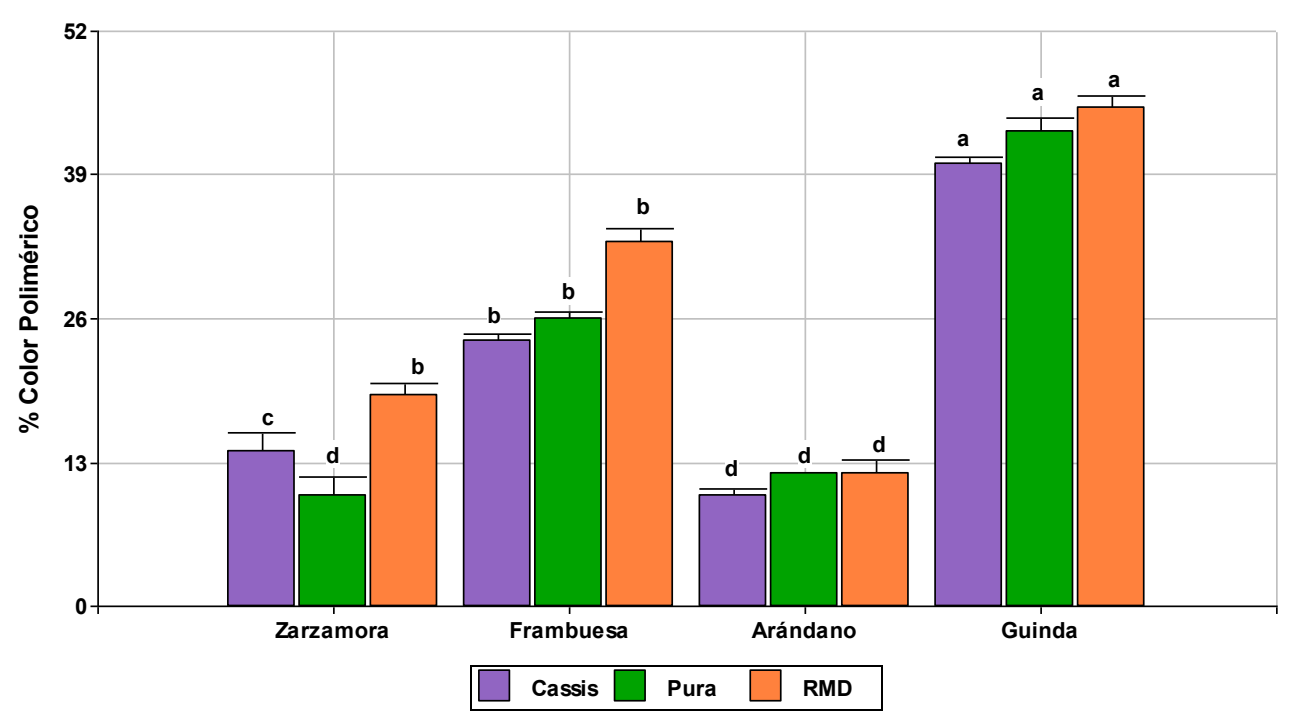

Figura V-14. Porcentaje de color polimérico en mermeladas puras y fortificadas con polvo de RMD y cassis. Nota: la altura de la barra indica el valor medio. Las barras de error expresan el error estándar.

\section{V-3.2.2.3 Color superficial}

En las mermeladas fortificadas con cassis y RMD, nuevamente se observó una disminución de la luminosidad con respecto a la pulpa pura. Los valores de las coordenadas cromáticas se presentan en la tabla V-14.

Tabla V-14. Funciones de color: luminosidad, ángulo de tono y saturación en las mermeladas formuladas

\begin{tabular}{|l|ccc|}
\hline & $\mathrm{L}^{*}$ & hue & Chroma \\
\hline Zarzamora Pura & $10,76 \pm 0,42^{\mathrm{C}}$ & $30,76 \pm 2,02^{\mathrm{C}}$ & $1,52 \pm 0,09^{\mathrm{F}^{*}}$ \\
Zarzamora + RMD & $10,02 \pm 0,65^{\mathrm{C}}$ & $34,52 \pm 5,00^{\mathrm{b}}$ & $4,74 \pm 0,34^{\mathrm{E}^{*}}$ \\
Zarzamora + C & $9,84 \pm 0,42^{\mathrm{C}}$ & $29,18 \pm 1,47^{\mathrm{C}}$ & $2,14 \pm 0,09^{\mathrm{F}^{*}}$ \\
Frambuesa Pura & $22,70 \pm 3,54^{\mathrm{A}}$ & $30,93 \pm 2,34^{\mathrm{C}}$ & $15,14 \pm 0,81^{\mathrm{B}^{*}}$ \\
Frambuesa + RMD & $20,67 \pm 3,02^{\mathrm{A}}$ & $32,06 \pm 0,79^{\mathrm{C}}$ & $10,24 \pm 1,47^{\mathrm{D}^{*}}$ \\
Frambuesa + C & $21,78 \pm 3,54^{\mathrm{A}}$ & $30,71 \pm 2,25^{\mathrm{C}}$ & $15,77 \pm 0,81^{\mathrm{B}^{*}}$ \\
Arándano Pura & $15,91 \pm 2,23^{\mathrm{B}}$ & $41,89 \pm 6,46^{\mathrm{a}}$ & $0,89 \pm 0,21^{\mathrm{F}^{*}}$ \\
Arándano + RMD & $14,71 \pm 2,80^{\mathrm{B}}$ & $22,29 \pm 3,32^{\mathrm{d}}$ & $4,03 \pm 0,49^{\mathrm{E}^{*}}$ \\
Arándano + C & $14,99 \pm 2,23^{\mathrm{B}}$ & $34,76 \pm 3,33^{\mathrm{b}}$ & $1,51 \pm 0,22^{\mathrm{F}^{*}}$ \\
Guinda Pura & $16,70 \pm 0,31^{\mathrm{B}}$ & $27,55 \pm 0,65^{\mathrm{C}}$ & $15,98 \pm 0,71^{\mathrm{B}^{*}}$
\end{tabular}




$$
\begin{array}{|l|lll}
\text { Guinda + RMD } & 15,35 \pm 0,86^{\mathrm{B}} & 30,84 \pm 1,09^{\mathrm{C}} & 12,61 \pm 0,62^{\mathrm{C}^{*}} \\
\text { Guinda + C } & 15,78 \pm 0,31^{\mathrm{B}} & 27,47 \pm 0,62^{\mathrm{C}} & 16,61 \pm 0,71^{\mathrm{A}^{*}} \\
\hline
\end{array}
$$

L*: luminosidad, hue: ángulo de tono, Chroma: saturación. RMD: rosa mosqueta deshidratada. Los valores representan la media $(n=6) \pm S D$. Medias con una letra común por columna no son significativamente diferentes $(p \leq 0,05)$

En zarzamora, las mermeladas pura y con cassis no presentaron diferencias significativas en ninguno de los parámetros cromáticos, mientras que en aquella adicionada de RMD se elevó el ángulo de tono y la saturación, aumentando la componente roja en el producto final, debido al agregado de un polvo claro (fotografía V-6).

Para las mermeladas de frambuesa, el efecto fue similar: no se hallaron diferencias significativas entre el producto control y con adición de polvo de cassis. En este caso el polvo de RMD solamente tuvo influencia en la saturación del color final, prácticamente imperceptible a la vista (fotografía V6).

Las mermeladas de arándano con cassis resultaron más oscuras que aquellas con agregado de RMD, probablemente debido a las tonalidades propias de cada polvo (fotografía V-6).

En guinda, los tres productos no presentaron diferencias significativas en el ángulo de tono, aunque si en el parámetro Chroma, lo que se reflejó en un color menos intenso para la adicionada con RMD (fotografía V-6). 


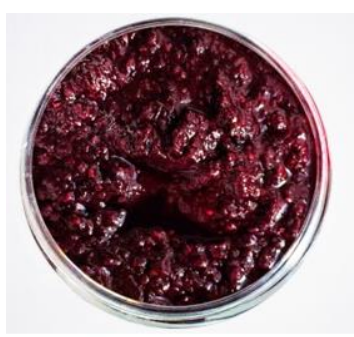

ZARZAMORA + RMD

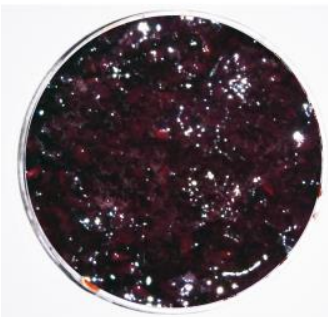

ZARZAMORA + CASSIS

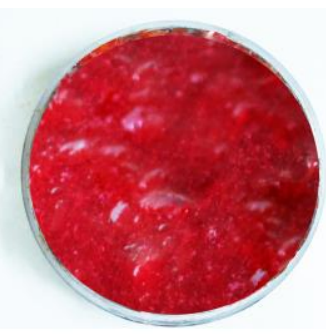

GUINDA + RMD

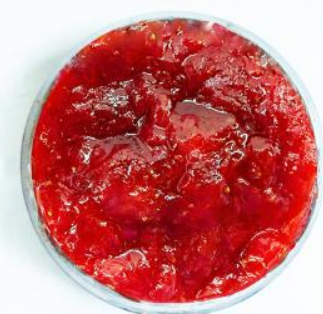

GUINDA + CASSIS

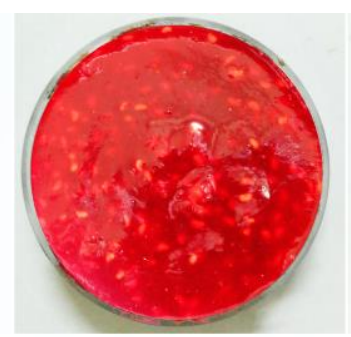

FRAMBUESA + RMD

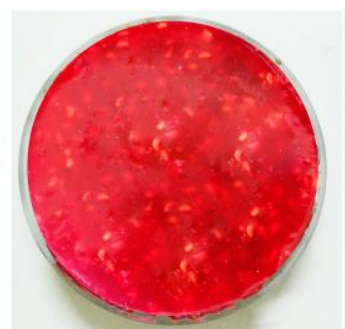

FRAMBUESA + CASSIS

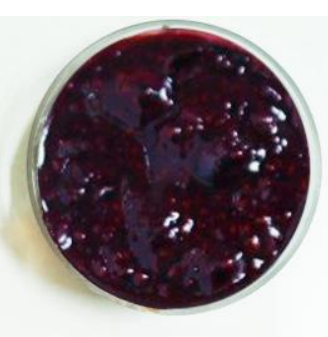

ARÁNDANO + RMD

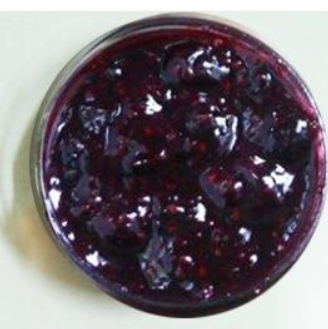

ARÁNDANO + CASSIS

Fotografía V-6. Mermeladas fortificadas con RMD y cassis

\section{V-4. CONCLUSIONES}

\section{Pulpas mezcla fortificadas}

- En las pulpas mezclas, si bien no se alcanzaron los valores esperados en función de las proporciones agregadas, se puede destacar el elevado contenido de fenoles totales, flavonoides, ácido ascórbico y poder antirradicalario que presentaron los productos finales.

- Durante el almacenamiento de las pulpas mezclas el porcentaje de retención de FT, Fv y PA fue superior al $70 \%$, sin denotar diferencias entre la condición de luz y oscuridad.

- La concentración de ácido ascórbico fue muy afectada por el tiempo de conservación y por la exposición a la luz, alcanzando (en ambos casos) un 37 $\%$ de retención luego de seis meses de almacenamiento.

- Las pulpas mezclas recién preparadas tienen un color muy atractivo que se va perdiendo y virando hacia los pardos durante el almacenamiento debido a la pérdida de ACY y aumento de la polimerización. No se detectaron diferencias por exposición a la luz.

\section{Mermeladas puras y fortificadas}

- Durante la elaboración de mermeladas puras, la concentración de FT no se vio afectada por el proceso en ninguna de las cuatro matrices, mientras que 
los Fv disminuyeron como consecuencia del efecto de la temperatura y la concentración de azúcares sobre las ACY. EI PA de las mermeladas puras sufrió pequeñas modificaciones en comparación con las materias primas.

- La concentración de ácido ascórbico en las mermeladas puras fue la variable más afectada por el proceso con pérdidas entre 36-50 \%.

- En las mermeladas puras, la concentración de ACY disminuye (acompañado de un aumento de \% CP) debido al proceso térmico.

- El agregado de polvo de cassis a las mermeladas eleva el valor de ACY cuantificado. El elevado valor de ácido ascórbico del polvo de RMD sumado a su baja concentración de ACY, impactan negativamente en la concentración de esta variable en las mermeladas fortificadas.

- Las mermeladas fortificadas no presentan grandes cambios en el color superficial, en general el polvo de RMD tiende a aclararlas mientras que el de cassis las oscurece.

\section{Conclusión general}

- El agregado de RMD o Cassis para mejorar el contenido de ácido ascórbico en los productos (pulpas mezcla y mermeladas) fue satisfactorio ya que, si bien los procesos aplicados disminuyeron su concentración debido a las condiciones propias del tratamiento, la adición realizada permitió mantener una concentración importante del compuesto en los productos finales. A su vez, esta adición fue favorable para mantener los compuestos bioactivos y el PA en valores altos.

En conjunto, nuestros resultados indican que el empleo de las pulpas mezcla o las mermeladas (puras o fortificadas) constituyen una estrategia adecuada para el desarrollo de alimento ricos en antioxidantes, cuyas propiedades bioactivas se mantengan estables durante el almacenamiento, Además, los productos obtenidos podrían considerase como una fuente no tradicional de ácido ascórbico. 


\section{V-5. REFERENCIAS}

- Amakura, Y.; Umino, Y.; Tsuji, S. y Tonogai, Y. 2000. Influence of jam processing on the radical scavenging activity and phenolic content in berries. Journal of Agricultural and Food Chemistry. Vol. 48, n 12, p. 6292-6297.

- Argentina Innovadora 2020. 2012. Núcleo socio-productivo estratégico. Procesamiento de alimentos. Documento de referencia. Plan Nacional de Ciencia, Tecnología e Innovación Productiva. Ministerio de Ciencia, Tecnología e Innovación Productiva. Presidencia de la Nación Argentina.

- Clifford, M. 2000. Anthocyanins-nature, occurrence and dietary burden. Journal of the Science of Food and Agriculture. Vol. 80, nº 7, p. 1063-1072.

- Código Alimentario Argentino. 2016. Resolución GMC №46/03, Capítulo 5. http://www.anmat.gov.ar/alimentos/normativas_alimentos_caa.asp.Fecha de acceso: noviembre de 2016.

- Da Silva Pinto, M.; Lajolo, F. y Genovese, M. 2007. Bioactive compounds and antioxidant capacity of strawberry jams. Plant foods for human nutrition. Vol. 62, n 3, p. 127-131.

- De Bernardi, B. 2011. Recursos tecnológicos para la cosecha y el packaging de frutas finas). Memoria para optar por el título de Diseñador Industrial. Universidad Nacional de Palermo, Buenos Aires, Argentina.

- Delgado-Vargas, F.; Jiménez, A. y Paredes-López, O. 2000. Natural pigments: carotenoids, anthocyanins, and betalains-characteristics, biosynthesis, processing, and stability. Critical reviews in food science and nutrition. Vol. 40, n 3, p. 173-289.

- Dergal, S. 2006. Capítulo 7. Química de los alimentos. Cuarta edición. Ed. Pearson Educación, Mexico.

- De Rosso, V. y Mercadante, A. 2007. The high ascorbic acid content is the main cause of the low stability of anthocyanin extracts from acerola. Food Chemistry. Vol. 103, n 3, p. 935-943.

- Dewanto, V.; Wu, X.; Adom, K. y Liu, R. 2002. Thermal processing enhances the nutritional value of tomatoes by increasing total antioxidant activities. Journal Agricultural Food Chemistry. Vol. 50, p. 3010. 
- Di Rienzo, J.; Casanoves, F.; Balzarini, M.; González, L.; Tablada, M. y Robledo, C. 2012. Software InfoStat versión 2012. Argentina: Grupo InfoStat, FCA, U.N.C., Argentina.

- Fennema, O. 2010. Química de los Alimentos (3ra ed.) Zaragoza (España). Editorial Acribia, S.A

- Garzón, G. 1998. The Stability of Pelargonidin-based Anthocyanins in Natural and Model Systems. Memoria para optar por el título de Doctor en Filosofía en Ciencia y Tecnología de los Alimentos de la Universidad Estatal de Oregon. Estados Unidos.

- Garzón, G. y Wrolstad, R. 2002. Comparison of the Stability of Pelargonidin-based Anthocyanins in Strawberry Juice and Concentrate. Journal of Food Science. Vol. 67, nº 4, p. 1288-1299.

- Häkkinen, S.; Kärenlampi, S.; Mykkänen, H.; Heinonen, I. y Törrönen, A. 2000. Ellagic acid content in berries: Influence of domestic processing and storage. European Food Research and Technology. Vol. 212, nº 1, p. 75-80.

- Howard, L.; Castrodale, C.; Brownmiller, C. y Mauromoustakos, A. 2010. Jam processing and storage effects on blueberry polyphenolics and antioxidant capacity. Journal of Agricultural and Food Chemistry. Vol. 58, n 7, p. 40224029.

- Jeong, S.; Kim, S.; Kim, D.; Jo, S.; Nam, K.; Ahn, D. y Lee, S. 2004. Effect of heat treatment on the antioxidant activity of extracts from citrus peels. Journal of agricultural and food chemistry, Vol. 52, n 11, p. 3389-3393.

- Kalt, W.; McDonald, J. y Donner, H. 2000. Anthocyanins, phenolics, and antioxidant capacity of processed lowbush blueberry products, Journal of Food Science. Vol. 65, p. 390.

- Kim, D. y Padilla-Zakour, O. 2004. Jam Processing Effect on Phenolics and Antioxidant Capacity in Anthocyanin-rich Fruits: Cherry, Plum, and Raspberry. Journal of food science. Vol. 69, n 9, p. S395-S400.

- Martinez, E. 2007. Frutas finas en la Región Andina Patagónica. Entrevista para el sitio web Fruticultura Sur. Recuperado el 25/09/2010. Disponible en: http://fruticulturasur.com/fichaNota.php?articulold= 475

- Martino, V. 2000. Los flavonoides como promisorios agentes preventivos y terapéuticos. Acta Farmacéutica Bonaerense. Vol. 19, nº 4, p. 303-308. 
- Medina, M. 2011. Simple and rapid method for the analysis of phenolic compounds in beverages and grains. Journal of Agricultural and Food Chemistry. Vol. 59, n 5 , p. 1565-1571.

- Middleton, E. y Kandaswami, C. 1994. The impact of plant flavonoids on mammalian biology: implications for immunity, inflammation and cancer. The flavonoids. Ed. J.B. Harborne, p. 619-652. London: Chapman and Hall.

- Nicoli, M.; Anese, M. y Parpinel, M. 2004. Influence of processing on the antioxidant properties of fruit and vegetables. Trends Food Science Technology. Vol. 10, n 94 , p. 94-100.

- Peinado Pardo, I. 2011. Influencia de las condiciones de deshidratación en los niveles de compuestos con actividad antioxidante del tomate cherry. Memoria para optar por el título de Máster Universitario en Ciencia e Ingeniería de los Alimentos de la Universidad Politécnica de Valencia. España.

- Peleg, H.; Naim, M.; Rouseff, R. y Zehavi, U. 1991. Distribution of bound and free polyphenolic acids in oranges (Citrus sinensis) and grapefruit (Citrus paradise). Journal of the Sciencie Food and Agriculture. Vol. 57, p. 417-426.

- Poei-Langston, M. y Wrolstad, R. 1981. Color degradation in an ascorbic acid-anthocyanin-flavonol model system. Journal of Food Science. Vol. 46, $n^{\circ} 4$, p. 1218-1222.

- Poiana, M.; Moigradean, D.; Raba, D.; Alda, L. y Popa, M. 2010. The effect of long-term frozen storage on the nutraceutical compounds, antioxidant properties and color indices of different kinds of berries. Journal of Food Agriculture and Environment. Vol. 8, no 1, p. 54-58.

- Rhim, J. W. 2002. Kinetics of thermal degradation of anthocyanin pigment solutions driven from red flower cabbage. Food Science and Biotechnology. Vol. 11, nº 4, p. 361-364.

- Robards, K.; Prenzler, P.; Tucker, G.; Swatsitang, P. y Glover, W. 1999. Phenolic compounds and their role in oxidative processes in fruits. Food chemistry. Vol. 66, nº 4, p. 401-436.

- Ruiz Rodríguez, B. 2014. Frutos silvestres de uso tradicional en la alimentación: Evaluación de su valor nutricional, compuestos bioactivos y capacidad antioxidante. Memoria para optar por el título de Doctor de la Universidad Complutense de Madrid. España. 
- Scalbert, A. y Williamson, G. 2000. Dietary intake and bioavailability of polyphenols. The Journal of nutrition. Vol. 130, n8, p. 2073S-2085S.

- Tamer, C. 2012. A research on raspberry and blackberry marmalades produced from different cultivars. Journal of Food Processing and Preservation. Vol. $36, n^{\circ} 1$, p. $74-80$.

- Zafrilla, P.; Ferreres, F. y Tomás-Barberán, F. 2001. Effect of processing and storage on the antioxidant ellagic acid derivatives and flavonoids of red raspberry (Rubus idaeus) jams. Journal of Agricultural and Food Chemistry, Vol. 49, nº 8, p. 3651-3655. 


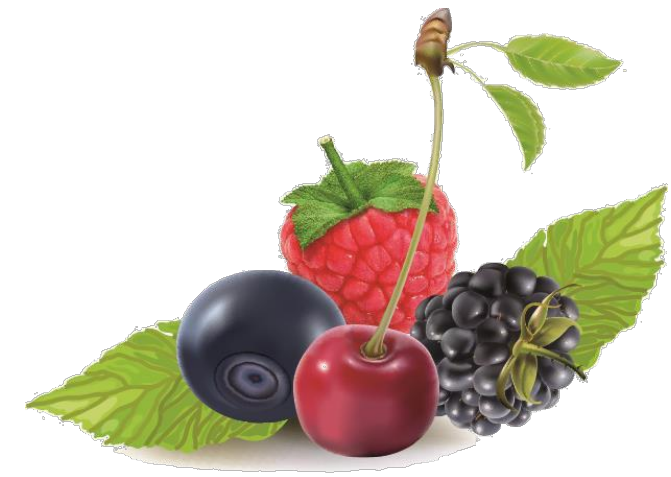

CONCLUSIONES GENERALES 


\section{CONCLUSIONES GENERALES}

- Las pulpas de frutas estudiadas se diferencian en general por su atractivo color, bajo contenido graso y el aporte de fibra alimentaria, principalmente de frambuesa y zarzamora. Todas exhibieron importantes valores de compuestos bioactivos y poder antirradicalario aunque se destacaron guinda y arándano. Zarzamora y arándano contribuyeron además con un elevado contenido de antocianinas monoméricas, lo que impactará directamente en el color superficial.

- El proceso de escaldado de arándano y guinda aumenta significativamente la concentración de compuestos bioactivos y PA de las pulpas respecto a fruta fresca; denotando el efecto beneficioso de la aplicación del pretratamiento. Además, las Antocianinas se mantuvieron estables.

- El proceso de pasteurizado de las pulpas aumentó significativamente los valores de compuestos bioactivos en frambuesa y zarzamora mientras que no generó cambios en arándano y guinda previamente escaldados.

- Las matrices sometidas a los procesos de pulpado y pasteurizado tuvieron un significativo cambio global de color, pero conservaron sus tonalidades dentro de los púrpuras-rojizos (el ángulo de saturación varió entre 270 y $25^{\circ}$ ), es decir, colores atractivos que facilitan la aceptación por parte de los consumidores.

- La deshidratación de rosa mosqueta y cassis, aumentó significativamente la concentración de los compuestos bioactivos y PA salvo la concentración de ácido ascórbico que disminuyó levemente. La concentración de carotenos de rosa mosqueta no fue significativamente afectada por la aplicación de aire caliente mientras que en cassis, se registró una pérdida de ACY muy marcada.

- Se puede destacar que el elevado contenido de fenoles totales, flavonoides, ácido ascórbico y poder antirradicalario que presentan los polvos de rosa mosqueta y cassis los convierten en excelentes aditivos para aumentar la funcionalidad de diversos alimentos.

- En pulpas congeladas, en general, las pérdidas de los compuestos bioactivos estudiados no superaron el $30 \%$, además de mantener un nivel alto 
de pigmentos y un color atractivo. El PA se conservó mucho mejor en las frutas oscuras (zarzamora y arándano).

- En pulpas pasteurizadas almacenadas a temperatura ambiente en condiciones de luz y oscuridad, frambuesa y guinda fueron las matrices con menor retención de compuestos bioactivos y PA, siendo al mismo tiempo las que presentaron pérdidas de $A C Y$ mayores al $95 \%$, lo que se reflejó en sus altos IDA. El color de estas pulpas fue significativamente afectado en todos los casos por el tiempo de conservación y las condiciones de exposición, con un efecto marcado de la luz sobre todo en las frutas más claras.

- Analizado el efecto del procesado y conservación de las distintas matrices, se podría concluir que la pulpa de arándano (congelada y pasteurizada) presentó y conservó los mayores niveles de compuestos bioactivos, poder antirradicalario y estabilidad del color, justificando su elección para la formulación de nuevos alimentos. De las tres matrices restantes, la pulpa de zarzamora sería una muy buena elección por su alto nivel de ACY, PA y estabilidad del color.

- Durante el almacenamiento de las pulpas mezclas A-F y G-Z pasteurizadas, el porcentaje de retención de FT, Fv y PA fue superior al $70 \%$, sin mostrar diferencias entre la condición de luz y oscuridad. La concentración de ácido ascórbico fue muy afectada por el tiempo de conservación y por la exposición a la luz, alcanzando (en ambos casos) un 37 \% de retención luego de seis meses de almacenamiento.

- Las pulpas mezclas recién preparadas tienen un color muy atractivo que se va perdiendo y virando hacia los pardos durante el almacenamiento debido a la pérdida de ACY y aumento de la polimerización. No se detectaron diferencias por exposición a la luz.

- Durante la elaboración de mermeladas puras, la concentración de FT no se vio afectada por el proceso en ninguna de las cuatro matrices, mientras que los Fv, ACY y ácido ascórbico disminuyeron como consecuencia del efecto de la temperatura, siendo este último el más afectado. El PA sufrió pequeñas modificaciones en comparación con las materias primas. 
- Las mermeladas fortificadas no presentaron grandes cambios en el color superficial, en general el polvo de RMD tiende a aclararlas mientras que el de cassis las oscurece.

- El agregado de RMD o Cassis para mejorar el contenido de ácido ascórbico en los productos (pulpas mezcla y mermeladas) fue satisfactorio ya que, si bien los procesos aplicados disminuyeron su concentración debido a las condiciones propias del tratamiento, la adición realizada permitió mantener una concentración importante del compuesto, como así también un buen nivel de ACY en los productos adicionados con Cassis

- En conjunto, nuestros resultados indican que el empleo de las pulpas mezcla fortificadas o las mermeladas (puras o fortificadas) constituyen una estrategia adecuada para el desarrollo de alimento ricos en antioxidantes, cuyas propiedades bioactivas se mantengan estables durante el almacenamiento, y que los productos obtenidos puedan considerase como una fuente no tradicional de ácido ascórbico. Además, el hecho de ser elaborados de forma natural a partir de frutas de colores atractivos favorecerá la aceptación del producto por parte del consumidor.

- Actualmente en el mercado argentino no se encuentran disponibles productos de características similares, existe entonces una oportunidad de agregar valor a la producción de berries y cherries, cuya perecibilidad y cortos períodos de cosecha generan importantes volúmenes de fruta de descarte, elaborando alimentos funcionales que permitan conseguir efectos beneficiosos en la salud de los consumidores que van más allá de los requerimientos nutricionales tradicionales, además de ampliar la gama de productos disponibles durante todo el año.

En futuras investigaciones sería necesario abarcar o profundizar los siguientes aspectos:

> Estudiar la estabilidad de compuestos bioactivos y color en mermeladas durante el almacenamiento en condiciones de anaquel

> Estudiar alternativas que permitan la estabilización del color en niveles aceptables en las pulpas puras y mezclas, a los fines de mejorar el 
almacenamiento a temperatura ambiente en condiciones de anaquel, que es el canal más importante de comercialización actual.

> Preparación de mermeladas con endulzantes menos calóricos, lo cual permitiría obtener alternativas saludables y ampliaría el rango de consumidores.

> Realización de un panel sensorial para evaluar la aceptabilidad de los productos elaborados. 


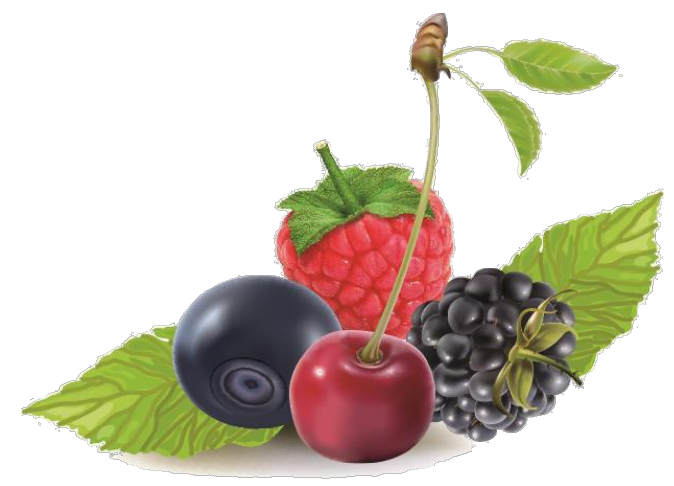

ANEXO

Interferencia del ácido ascórbico en la cuantificación de fenoles totales: Folin Ciocalteu vs. Fast Blue BB 


\section{A-1. INTRODUCCION}

El reino vegetal es fuente de gran variedad de sustancias fitoquímicas con potencial actividad antioxidante, que al ser incorporadas a través de la dieta podrían ayudar a evitar el estrés oxidativo y disminuir el daño producido por el exceso de radicales libres. En base a esta potencial actividad biológica, se han desarrollado numerosos estudios para determinar las propiedades de estas sustancias, destacándose los estudios realizados con el subgrupo de los fenoles. El hombre no es capaz de sintetizar este tipo de compuestos, así que depende fundamentalmente de la ingesta de productos de origen vegetal para incorporar estas sustancias al organismo.

Las frutas, incluidos los berries, constituyen una de las principales fuentes de compuestos fenólicos en la dieta. En ellas es frecuente encontrar derivados de los ácidos hidroxibenzoicos e hidroxicinámicos, antocianinas, flavonoles, catequinas, y taninos condensados e hidrolizables (Macheix y col., 1990). La mayoría de estos compuestos permanecen en productos elaborados a base de frutas y berries (Heinonen y col., 1998), como por ejemplo jugos, pulpas, mermeladas, jaleas, gelatinas, etc. (Häkkinen y col., 2000; Zafrilla y col., 2001).

En general los metabolitos de los fenoles son rápidamente eliminados del plasma lo que indica que es necesario un consumo diario de productos vegetales para mantener altas concentraciones de éstos en la sangre (Manach y col., 2004).

La concentración de fenoles puede determinarse a través de diferentes métodos. Para propósitos de cuantificación aproximada el más utilizado, por su fácil aplicación y bajo costo, es el método espectrofotométrico denominado Folin-Ciocolteau ( $F C$ ), el cual utiliza un reactivo que contiene tungsteno y molibdato de sodio, ácido fosfórico y sulfato de litio. El reactivo permanece amarillo sin reaccionar y cuando los compuestos de molibdeno se reducen, la estructura cambia y la solución se torna azul. El método FC se utiliza principalmente en jugos, vinos, tejidos vegetales, aguas contaminadas y proteínas. Durante el análisis la muestra se coloca en una cubeta, se añade el reactivo, agua y $\mathrm{Na}_{2} \mathrm{CO}_{3}$ (Singleton y col., 1999).

El reactivo de FC, si bien no es especifico, permite estimar los fenoles totales en la muestra. Prior y col. (2005) ha informado que en el ensayo de FC 
interfieren un gran número de sustancias, en particular ácido ascórbico, azúcares (fructosa y sacarosa), aminas aromáticas, dióxido de azufre, ácidos orgánicos y $\mathrm{Fe}$ (II), y destaca que mientras se use el método FC para cuantificar fenoles totales, siguiendo el ensayo modificado por Singlenton y Rossi (1965) se deben realizar las correcciones debidas a las sustancias interferentes y sólo utilizar ácido gálico como patrón de referencia.

En contraposición, existe en la actualidad otro método espectrofotométrico que no sufre las interferencias presentes en el ensayo de FC (Medina, 2011a); que utiliza la sal de diazonio Fast Blue BB (FBBB), donde el grupo diazonio ($+\mathrm{N}=\mathrm{N}-$ ) específicamente se acopla con el grupo hidroxilo fenólico, bajo condiciones alcalinas, para formar un azo complejo estable que presenta un máximo de absorbancia a $420 \mathrm{~nm}$. Los valores obtenidos por el método FBBB son mayores que los reportados por el ensayo FC salvo en muestras fortificadas con ácido ascórbico o jarabe de alta fructosa, donde las concentraciones son inferiores (Medina, 2011b).

El objetivo de este anexo fue comparar el método de FC con el método Fast Blue BB (FBBB) en la cuantificación de fenoles totales en frutas de la región y su respuesta ante la presencia de ácido ascórbico.

\section{A-2. MATERIALES Y MÉTODOS}

Las matrices guinda, arándano, zarzamora, frambuesa, rosa mosqueta y cassis fueron cosechadas por productores de la zona de la Comarca Andina del Paralelo 42 (Río Negro, Argentina) en su punto de madurez óptimo y enviadas inmediatamente a Villa Regina, donde se conservaron en heladera a $5{ }^{\circ} \mathrm{C}$ hasta su utilización. El resto de las frutas (ciruela, pera, manzana, durazno, higo y uva), se obtuvieron de diversos comercios de la zona. Se realizó un muestreo aleatorio simple, se descartaron aquellos frutos que presentaban síntomas de avanzado estado de madurez y/o podredumbre.

La rosa mosqueta y el cassis deshidratado, se obtuvieron por secado en las condiciones detalladas en el capitulo III, sección III-2.1.4

En cuanto a los patrones, se utilizó ácido gálico p.a. Biopack y ácido ascórbico p.a. Merck. 


\section{A-2.1. Métodos}

- Extracción de compuestos bioactivos. Se realizó según la metodología explicada en el Capítulo I, sección I-2.1; utilizando como solvente de extracción solución al $1 \%$ de $\mathrm{HCl}$ en etanol y temperatura de $37^{\circ} \mathrm{C}$.

- Fenoles totales por Folin-Ciocolteau (FT). Se realizó según la metodología explicada en el Capítulo I, sección I-2.1.

- Fenoles totales por Fast Blue BB (FT). Se realizó según la metodología explicada en el Capítulo III, sección III-2.2, por Fast blue BB debido al elevado contenido de ácido ascórbico de algunas matrices

\section{A-2.2 Análisis estadístico}

Los datos fueron analizados estadísticamente determinando la media y la desviación estándar. En primera instancia, se aplicó un diseño factorial completamente aleatorizado a dos vías, donde los factores analizados fueron fruta y método de determinación. Se chequearon los supuestos de homocedasticidad de varianza, normalidad y aleatoriedad de los residuales. El análisis se desestimó ya que la interacción resultó significativa, para un nivel de significancia $\alpha=0,05$, lo que opaca los efectos principales, invalidando el análisis. Por esta razón se procedió a aplicar un diseño completamente aleatorizado para cada fruta siendo la variable respuesta: contenido de fenoles totales. Los resultados obtenidos se analizaron mediante un análisis de varianza para un nivel de significancia $\alpha=0,05$ y se empleó la prueba de DGC (Di Rienzo, Guzmán, Casanoves) para la comparación de medias, ya que la misma permite crear grupos homogéneos excluyentes. En el caso de la variable ácido ascórbico no se realiza un análisis de varianza ya que el objetivo era evaluar el método de determinación de fenoles totales. Se utilizó el programa estadístico Infostat v. 2012 (Di Rienzo y col., 2012).

\section{A-3. RESULTADOS Y DISCUSIÓN}

La tabla 1 indica la concentración de fenoles totales en las matrices frescas y deshidratadas, determinada por ambos métodos, y la concentración de ácido ascórbico total. Aunque la concentración de fenoles halladas por FC fue similar a las obtenidas por varios autores para las mismas matrices (Marinova y col., 2005; Heinonen y col., 1998; Szajdek y Borowska, 2008; Medina, 2011b), estos 
valores resultaron muy inferiores a los detectados por el ensayo FBBB a excepción de aquellas muestras donde el contenido de ácido ascórbico era elevado (rosa mosqueta y cassis) confirmando la interferencia de este analito en la determinación (Prior y col., 2005)

En las figuras 1 y 2 se observa el comportamiento de dos patrones, ácido gálico y ascórbico, frente a ambos métodos de detección. FC presenta alta respuesta a las concentraciones de ambos patrones, mientras que FBBB solo responde a las concentraciones de ácido gálico; superando, en cada punto, los valores de absorbancia obtenidos por la metodología de FC.

El ácido ascórbico es un antioxidante no fenólico, constituyente natural de la mayoría de las frutas y reacciona frente al reactivo $\mathrm{FC}$, haciéndose notoria dicha interferencia en bajas concentraciones como se observa en la figura 2. Como se muestra en la tabla 1, en nuestras matrices la interferencia se puso en evidencia en cassis y rosa mosqueta (900 y 7000 ppm respectivamente). Resultados similares fueron hallados por Lester y col. (2012) para frutillas.

Tabla 1. Fenoles Totales (mg GAE/100 g) en frutas frescas y deshidratadas por los métodos Fast Blue BB (FBBB) y Folin-Ciocalteu (FC) y Ácido ascórbico total (mg AA/Kg)

\begin{tabular}{|lccc|}
\hline \multicolumn{1}{|c}{ Muestras } & FC & FBBB & AA \\
\hline \multicolumn{1}{c}{ Frescas } & $172 \pm 1^{\mathrm{A} 1}$ & $317 \pm 3^{\mathrm{B} 1}$ & $213 \pm 2$ \\
Frambuesa & $610 \pm 4^{\mathrm{A} 2}$ & $1816 \pm 6^{\mathrm{B} 2}$ & $94 \pm 5$ \\
Guinda & $329 \pm 2^{\mathrm{A} 3}$ & $1118 \pm 5^{\mathrm{B} 3}$ & $148 \pm 15$ \\
Zarzamora & $492 \pm 1^{\mathrm{A} 4}$ & $1778 \pm 4^{\mathrm{B} 4}$ & $130 \pm 8$ \\
Arándano & $69 \pm 9^{\mathrm{A} 5}$ & $95 \pm 5^{\mathrm{B} 5}$ & $43 \pm 5$ \\
Pera & $91 \pm 7^{\mathrm{A} 6}$ & $213 \pm 2^{\mathrm{B} 6}$ & $46 \pm 3$ \\
Manzana & $383 \pm 2^{\mathrm{A} 7}$ & $953 \pm 34^{\mathrm{B} 7}$ & $30 \pm 14$ \\
Uva & $80 \pm 1^{\mathrm{A} 8}$ & $183 \pm 4^{\mathrm{B} 8}$ & $190 \pm 4$ \\
Durazno & $41 \pm 3^{\mathrm{A} 9}$ & $130 \pm 4^{\mathrm{B} 9}$ & $20 \pm 2$ \\
Higo & $250 \pm 2^{\mathrm{A} 10}$ & $436 \pm 1^{\mathrm{B} 10}$ & $95 \pm 10$ \\
Ciruela & & & \\
\multicolumn{1}{c}{ Deshidratadas } & & &
\end{tabular}




$\begin{array}{|lllc|}\text { Rosa Mosqueta } & 10841 \pm 36^{\mathrm{A} 11} & 8063 \pm 412^{\mathrm{B} 11} & 7000 \pm 125 \\ \text { Cassis } & 3705 \pm 122^{\mathrm{A} 12} & 2934 \pm 110^{\mathrm{B} 12} & 900 \pm 45\end{array}$

Los valores representan la media $(n=3) \pm S D$. Medias con una letra común por fila no son significativamente diferentes ( $p<=0,05$ ). FC: Folin-Ciocalteu (mg GAE/100 g). FBBB: Fast Blue BB (mg GAE/100 g). AA: Ácido ascórbico total (mg AA/Kg).

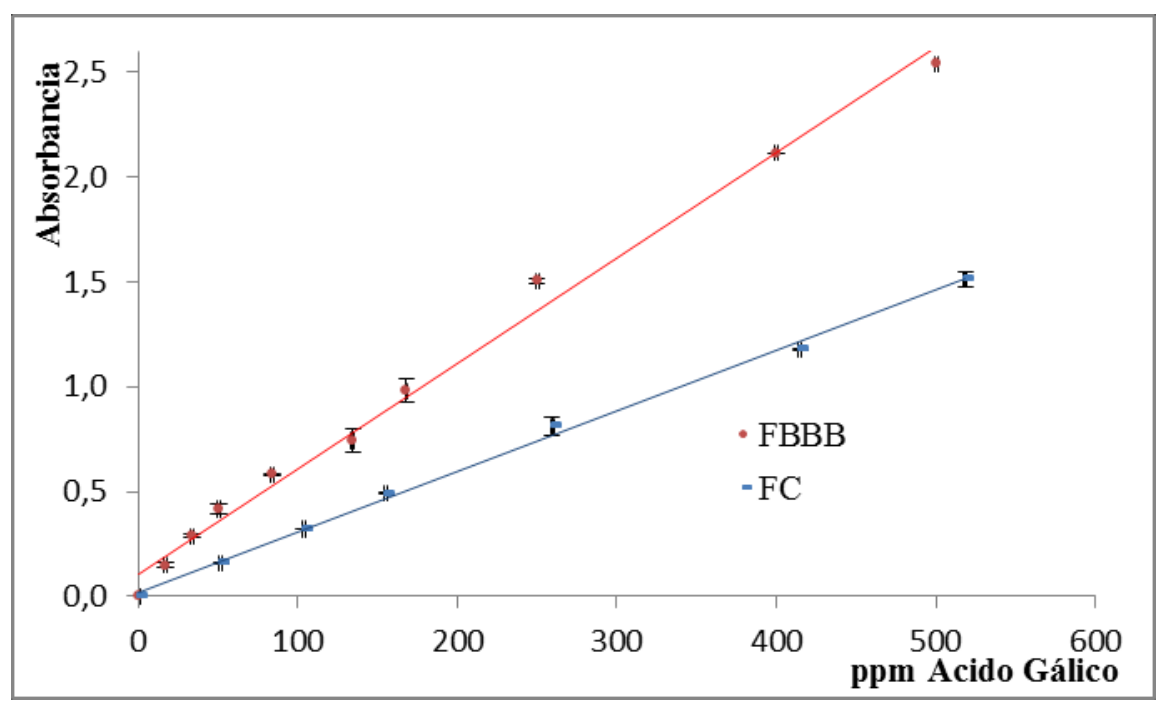

Figura 1. Curvas de ácido gálico frente a dos métodos de determinación de fenoles totales: Folin-Cicolteau (FC) y Fast Blue BB (FBBB)

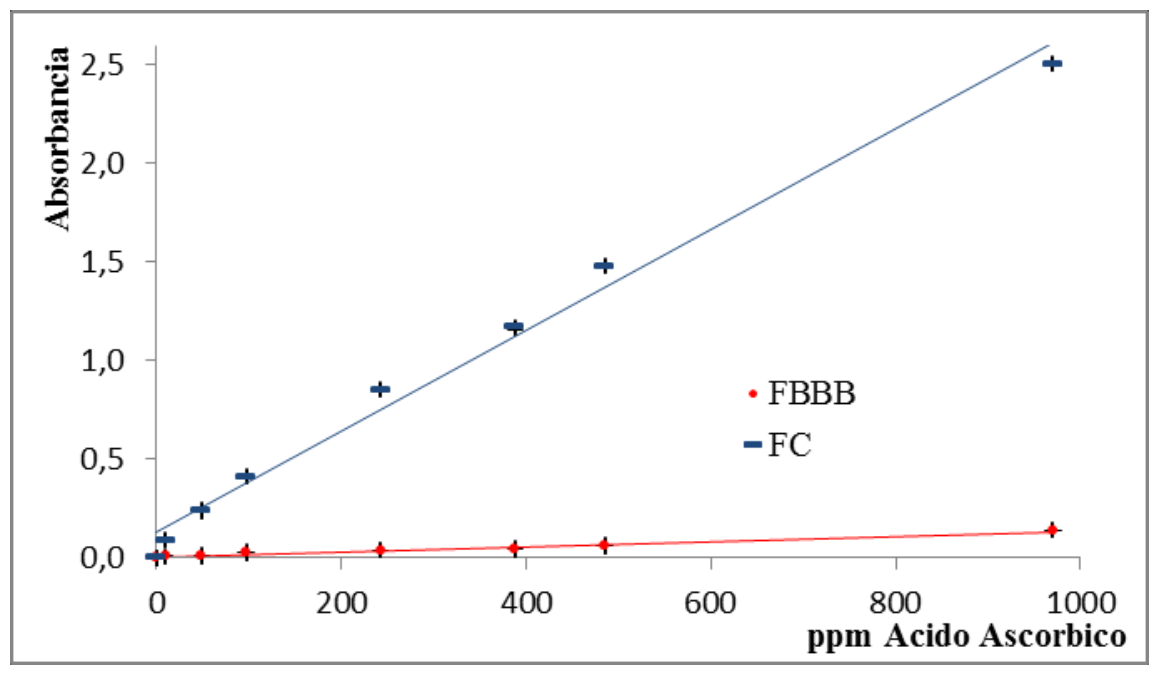

Figura 2. Curvas de ácido ascórbico frente a dos métodos de determinación de fenoles totales: Folin-Cicolteau (FC) y Fast Blue BB (FBBB) 


\section{A-4. CONCLUSIONES}

Los resultados indican que el ensayo FBBB brinda una evaluación más exacta de los fenoles totales presentes en frutas y no muestra interferencia por presencia de ácido ascórbico en las matrices. En aquellos alimentos que se sabe contienen altas concentraciones de este antioxidante, se recomienda utilizar el método Fast Blue BB.

\section{A-5. REFERENCIAS}

- Di Rienzo, J.; Casanoves, F.; Balzarini, M.; González, L.; Tablada, M. y Robledo, C. 2012. Software InfoStat versión 2015. Argentina: Grupo InfoStat, FCA, U.N.C., Arg.

- Häkkinen S, Kärenlampi S, Mykkänen H, Törrönen A. 2000. Influence of domestic processing and storage on flavonol contents in berries. Journal of Agricultural and Food Chemistry. Vol. 48, p. 2960-2965

- Heinonen, I.; Meyer, A. y Frankel, E. 1998. Antioxidant activity of berry Phenolics on human low-density Lipoprotein and Liposome Oxidation. Journal of Agricultural and Food Chemistry. Vol. 46, no. 10, p. 4107-4112.

- Lester, G.; Lewers K.; Medina M.; Saftner R. 2012. "Comparative analysis of strawberry total phenolics via Fast Blue BB vs. Folin-Ciocalteu: Assay interference by ascorbic acid. Journal of Food Composition and Analysis. Vol. 27, p. 102-107.

- Macheix J, Fleuriet A, Billot J. 1990. Fruit phenolics. Boca Raton, FL, USA: CRC Press. $378 \mathrm{p}$.

- Manach C., Scalbert A., Morand C. 2004. Polyphenols: food sources and bioavailability. American Journal of Clinical Nutrition. Vol. 79, p. 727-747.

- Marinova, D.; Ribarova, F., Atanassova M. 2005. Total phenolics and total flavonoids in Bulgarian fruits and vegetables. Journal of the University of Chemical Technology and Metallurgy. Vol. 40, n 3, p. 255-260.

- Medina, M.B., 2011a. Simple and rapid method for the analysis of phenolic compounds in beverages and grains. Journal of Agricultural and Food Chemistry. Vol. 59, p. 1565-1571. 
- Medina, M.B., 2011b. Determination of the total phenolics in juices and superfruits by a novel chemical method. Journal of Functional Foods. Vol. 3, p. 79-87.

- Prior, R.., Wu, X., Schaich, K. 2005. Standardized methods for the determination of antioxidant capacity and phenolics in foods and dietary supplements. Journal of Agricultural and Food Chemistry. Vol. 53, p. 42904302.

- Singleton, V., Rossi Jr., J. 1965. Colorimentry of total phenolics with phosphomolybdic- phosphotungstic acid reagents. American Journal of Enology and Viticulture. Vol. 16, p. 144-158.

- Singleton, V., Orthofer, R., Lamuela-Ravento's, R. 1999. Analysis of total phenols and other oxidation substances and antioxidants by means of Folin-Ciocalteu reagent. Methods in Enzymology. Vol. 299, p. 152-178.

- Szajdek, A. y Borowska, E. 2008. Bioactive compounds and healthpromoting properties of berry fruits: A review. Plant Foods for Human Nutrition. Vol. 63, no. 4, p. 147-156.

- Zafrilla P, Ferreres F, Tomás -Barberán FA. 2001. Effect of processing and storage on the antioxidant ellagic acid derivatives and flavonoids of red raspberry Rubus idaeus jams. J Agric Food Chem. 49:3651-3655 